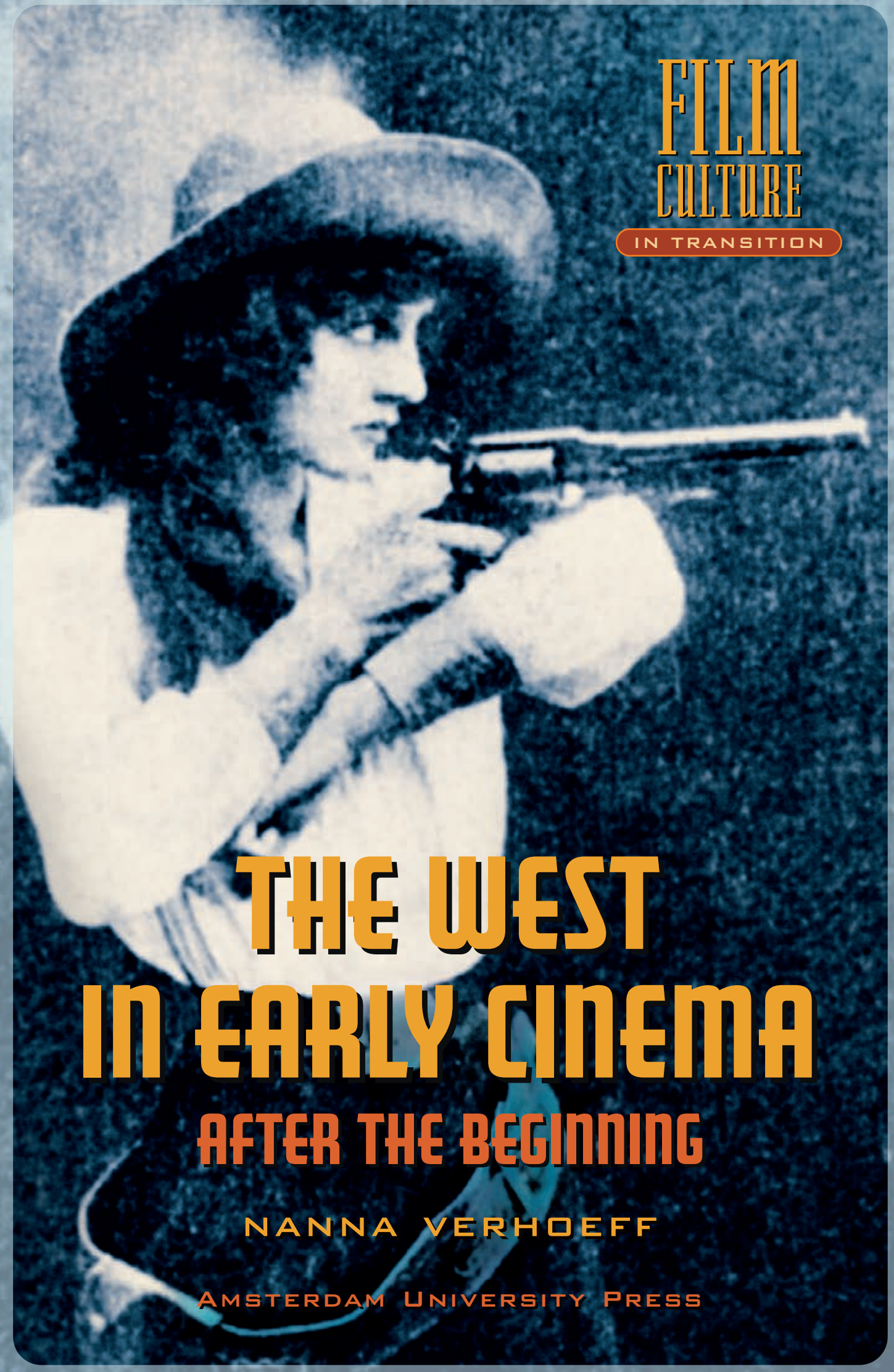


The West in Early Cinema 



\section{The West in Early Cinema}

\section{After the Beginning}

Nanna Verhoeff

Amsterdam University Press 
Cover illustration: Gertrude McCoy, Motography VII, 6 (June 1912): 251

Cover design: Kok Korpershoek, Amsterdam

Lay-out: JAPES, Amsterdam

ISBN $905356831 X$ (paperback)

ISBN 9053568328 (hardcover)

NUR 674

(C) Amsterdam University Press, Amsterdam 2006

All rights reserved. Without limiting the rights under copyright reserved above, no part of this book may be reproduced, stored in or introduced into a retrieval system, or transmitted, in any form or by any means (electronic, mechanical, photocopying, recording or otherwise) without the written permission of both the copyright owner and the author of the book. 
The experiments, the failures and the successes of the past twelve years have been stepping stones which have led to the production of the modern masterpieces in motography. The evolution of the pictures play began in 1896, when an amazed public marveled at the seeming witchcraft which reproduced upon a sheet living and moving people, animals, and scenes. [...] Today it is the subject that interests, not the novelty of the invention. Complete plays are enacted upon the curtain with specially written music that sometimes ranks with the classics. Reliable statistics show that 3,000 millions of admissions to motion picture theaters are sold to the people of the United States annually. Who can estimate the enormous power for good of this post modern factor in the entertainment and education of the masses? The library of the future will contain a file of motion picture films to demonstrate, better than books, the life of a people, their political, social and economic status.

“Motion Pictures." The Sun (February 23, 1909)

"What Next?"

As for the future of this remarkable business, with its Alladdin-like growth, it is impossible to predict. Growing at first from simple pictures which moved naturally and without dramatic possibility, it reached the pictures of constructed movement. Then came pictures more rapidly moving, but always outside pictures. Then came that baneful fashion of the chase, upon which followed the little drama's in little studios - dramas which ran to from 50 to 80 feet of film, and which possessed all the earmarks of blood and thunder. Now we have come to the film of eighteen to twenty minutes, to the period of the constructed play, to the period almost of epigram in subtitles. The cowboy is waning by the side of a declining Indian maid, to be succeeded by - ? Can anybody tell the picture men? - "Quick Fashion Changes: Public Demands New Subjects Constantly." New York Times (August 4, 1912)

The train robbery film seemed to prove pretty conclusively that in the balmy days when it was made, jerkiness, exaggerated posturing, and creeping backdrops to make trains "speed" were all part of the infant industry. No villain would dream of dying without spinning around thrice; and in general, the audience, comprised largely of men and women who daily pick the best of modern films apart, had to agree that the cinema had progressed. 



\section{Contents}

After the Beginning I I

I. After-effects 23

$\begin{array}{lr}\text { Bits \& Pieces } & 25\end{array}$

City Limits $\quad 45$

Deconstructing the Other $\quad 55$

$\begin{array}{ll}\text { Easterns } & \mathbf{7 7}\end{array}$

$\begin{array}{ll}\text { Facts and Fictions } & 96\end{array}$

$\begin{array}{ll}\text { Genre } & 108\end{array}$

$\begin{array}{ll}\text { 2. Coincidences } & 127\end{array}$

$\begin{array}{lr}\text { History Lessons } & 129\end{array}$

$\begin{array}{ll}\text { Instant Nostalgia } & \text { I48 }\end{array}$

$\begin{array}{ll}\text { Jeopardy } & 157\end{array}$

$\begin{array}{ll}\text { Kaleidoscopic Worlds } & 175\end{array}$

$\begin{array}{ll}\text { Landscapes } & 188\end{array}$

$\begin{array}{ll}\text { Modernities } & 207\end{array}$

3. Strategies 22I

$\begin{array}{ll}\text { Narrativity } & 223\end{array}$

$\begin{array}{ll}\text { Old Timers } & 236\end{array}$

$\begin{array}{lr}\text { Picture Postcards } & \mathbf{2 5 0}\end{array}$

$\begin{array}{ll}\text { Questioning Categories } & \mathbf{2 7 0}\end{array}$

$\begin{array}{ll}\text { Riding the Wilderness } & 282\end{array}$

$\begin{array}{lr}\text { Spectacle } & 296\end{array}$

$\begin{array}{ll}\text { Time Travel } & 308\end{array}$ 
4. Practices

Universal Ambition

Virtual Museums

Wild West Show

X-Rated

376

Young Wild Women 390

Zooming In, Zapping, Zooming Out 404

List of illustrations 413

Filmography 415

Bibliography 427

Index 455 


\section{Note}

The subtitle of this book has a number of different meanings, which will be outlined in an introductory chapter. The succeeding chapters each concentrate on a single topic. Topics shift between theoretical and historical emphases, always in dialogue with the archival material. With this format I wish to convey not only the sense that we understand film culture better through specific foci of attention, but also, conversely, that our thinking about general issues can benefit from a confrontation with the objects.

The organizational principle is inspired by the hypertext model. The chapters congeal into clusters because the order in which they are presented follows a recognizable logic. At the same time, they remain based on the idea that they can be linked together in a variety of ways, through cross-references in the manner of hyperlinks (marked with icons: $\mathbf{A}-\mathbf{Z}$ ), to form not a body of singular objects, but precisely the kind of kaleidoscopic whole that I consider most characteristic for early cinema as a cultural phenomenon. The short texts between the clusters will serve as guides and summaries for the linear reader, explaining the route followed in both preceding and succeeding clusters of chapters. 


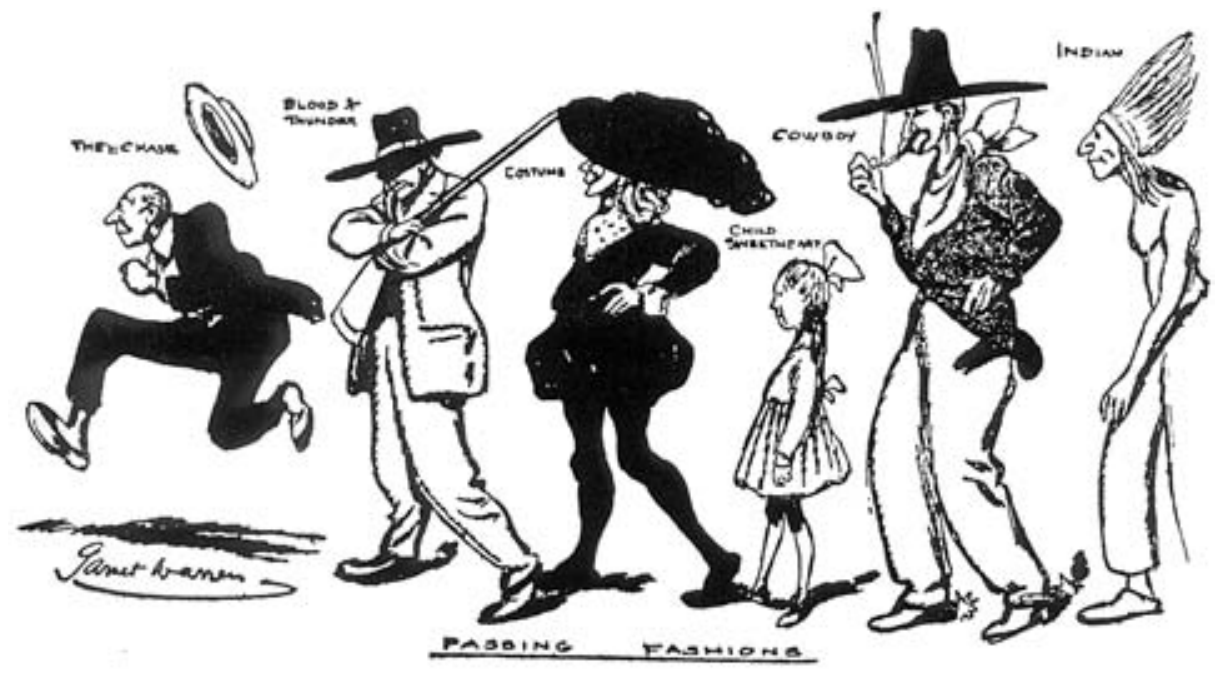

New York Times (August 4, 1912) 


\section{After the Beginning}

Do you remember the Western film, and its sister, the Indian film, now so liberally supplied? Know, then, that these, the latest of fashions, are disap-

pearing.

- New York Times, $1912^{1}$

What is found at the historical beginning of things is not the inviolable identity of their origin; it is the dissension of other things. It is disparity.

- Foucault, $1977^{2}$

Do you remember those films with cowboys and Indians, captures and chases, mountains and rivers, guns and arrows, that we call "the Western"? In contrast to the passage quoted in the first epigraph, which calls these films "the latest of fashions," for us, today, the Western is old, yet far from disappearing. The genre so firmly associated with early America has in fact, according to some critics, been enjoying a postmodern comeback. ${ }^{3}$ These mirrored situations across a century call into question common-sense historical linearity. If this book is devoted to the early Western, it is in order to understand how such an "early" genre, so early that it does not yet go by its later name, can be going out of style while still being a "latest fashion." The coincidence between "early" - here phrased through the word "latest"! - and "late" in the same historical moment raises questions about the retrospective nature of history writing. This book is about the first two decades of films about the American West, made between 1895 and 1915, written a century later, looking back in an attempt to discover and describe the uniqueness of this pre-Classical era of Westerns.

This book is the result of a voyage of discovery through film archives. An archive is a place replete with three things: objects from the past, the mission to preserve these from disappearance, and the categorizations that make them accessible. The first engage the question of materiality, in the face of the fugitive nature of current screen culture. ${ }^{4}$ The second is sometimes articulated in terms of cultural memory, an urgently felt preoccupation of our time. ${ }^{5}$ The third concerns the discursivity of even the most rudimentary of classifications. The connection between these three strands underlies the current fascination with "the archive." 
I aim to explore how we can be loyal to "history" as an endeavor and a mode of inquiry, as well as to our cultural habitat, which is the present. This is where we are steeped in the culture of new media, and deal with the textual form of hypertext: a present in which we can see, and experience, a dual fascination, with new organizations and functions of images, and with archives. Hence, the motivating question of this book is: how does the current interest in the hypertextual organization of visual experience - produced and promoted by the development of digital media and technologies such as Internet, DVDs, or digital games - relate to the historicity of visual culture? This question touches upon cultural philosophy, which can guide us in an enterprise of construction: of articulating what an "archival poetics" can be, and what it can do for such a bitemporal history.

I posit an unstable relationship between the real archive, as the starting point of this work, discovery, and understanding, and the conceptual metaphor of "the archive" - or "archival" - as a cultural model. In the first cluster of chapters, the model of the archive helps to delineate a corpus without defining it. These six chapters about after-effects reflect on the traps of seemingly clear categories applied to as yet unclear, "floating" objects from the past.

Because the archive is not only a material place holding material leftovers from the past, but also has become metaphoric and conceptual, I will term this relationship "archival poetics." B I coined this term in analogy to such poetics based on, for example, semiotic systems - narrative poetics; foci of attention - a poetics of gender; periods - Renaissance poetics; or conceptual metaphors such as mine - e.g. a poetics of place. "The Western" pertains to a poetics of place. Poetics is derived from the Greek word for making, poiesis, and thus underscores the constructed nature of historical knowledge. By mobilizing this slightly dated term "poetics" I aim to reflect on the connections between objects, discursive systems within which they can be understood, and the cultural life in the present within which such "readability" functions, in terms of poetics' etymological sense of making. ${ }^{6}$ The current interest in hypertextual discursive organization will serve as a heuristic metaphor that will help articulate an archival poetics useful for actual analysis of early screen culture, in other words, for screening the past. ${ }^{7}$

In using the archive in this way, as both material place and conceptual metaphor, I am taking up what Jacques Derrida, a philosopher with a post-structuralist philological mindset, sets out to do in an altogether different context and with different aims, when he opened his book Archive Fever:

Let us not begin at the beginning, nor even at the archive. But rather at the word "archive" - and with the archive of so familiar a word. Arkhé, we recall, names at once the commencement and the commandment. (1995: 1; emphasis in text) 
A beginning that is already subject to commandment, in other words, to law and order - to the discursive nature of categorization - cannot be an origin. This is a first of many reasons that will be exposed in the course of this book, why the earliest "Westerns" should be situated not as the origin, by definition mythical, but after the beginning. This book aims to focus on the tension between history's search for beginnings and the vertiginous sensation of looking back from a present towards elsewhen: another moment that was, then, also a present. My hypothesis is that getting the closest we can get requires a constant awareness that we are not, as historians, ever going to be in that elsewhen. Only the awareness of difference makes understanding possible. For a start, there is no way in which the contemporary modern subject who experienced the novelty of film could see the films in question as "early."

When I call this different moment "elsewhen" the analogy with the more common word "elsewhere" is a guideline. This analogy also begins to explain why I consider "Western" cinema - still called, with an adjective and in a plurality of kinds, "the Western film, and its sister, the Indian film" in the epigraph - as more than just a genre of film at the early stages of its existence. "Elsewhen" defines the films most typically. The West, wild, is itself disappearing, and below I will have more to say on what that means for the cultural status of my corpus. The West is not just a place, but the "other" place where the urban viewers of my films were, emphatically, not. C The elsewhere that characterizes the films is, therefore, a convenient place to situate these viewers' "other," the subjects of wildness that are receding into the past, West of the urban centers. D Time and place, or chronotopos, are always bound together, but in the films I am discussing here, this bond is both more intense, more emphatic than in other films of the period, and thematized in the stories told. So much so, that "the West" can be situated in the East as long as the past is firmly enough established as "elsewhen" to warrant locating the elsewhere right here. $\mathbf{E}$

A new medium, especially one that has such great appeal to the larger population, has something revolutionary about it. When critics write excited prose about it, a sense of novelty - "the latest of fashions" - is inherent in the cultural event that is happening. But this event happens in a culture that is not an origin. On the contrary, it is because the novelty comes after the beginning - of the conquest of the West, of the cultural representations of it in painting, novels, and popular press - that it can be absorbed, talked about, and experienced as new. The beginning of a new medium responds to and transforms a visual culture already in existence. Early cinema should therefore be cut loose from later film history and, in an anti-teleological view, be positioned within its own period: in its synchronicity. ${ }^{8}$

The moment that this study explores synchronically is best characterized as a constellation of coincidences. The most crucial coincidence is that between the 
end of the Wild West and the beginning of its representation in moving images. This coincidence of loss and innovation produced a compensatory public excitement. Such excitement is an event of visual culture. But how can we know that this excitement happened? No analysis can ignore the material culture from which bits and pieces - but always already subjected to the law of ordering are stubbornly present in the archive. Visual culture studies, therefore, must merge with material culture studies. ${ }^{9}$

Although the talk of novelty and the sense of loss of what no longer exists is an ongoing phenomenon that characterizes the modern sentiment, the archival material - especially the trade press - shows, here again, an intensification. I The historian aims to understand the culture of the past through the changes that occur at the end of each retrospectively constructed "period." In this second sense, "after" the beginning acknowledges the belatedness of any historical endeavor; its nature of looking back. The materiality of the archive is a great force to be reckoned with, a force that prevents fantasy from taking over in such a way that the backwards look threatens to become a projection. Changes leave scars, legible as inscriptions of the way social relationships establish marks of their power and engrave memories on things (Foucault 1977a: 160). But in order to see those marks, plain looking, with an illusion of perceptual objectivity, just will not do; we cannot but read the scars and for that, again, we need the archive, its order, while also suspending that order as law (Davey 1999: 14). Material culture studies glean the documents that constitute the scars. Visual culture studies develop methods for such readings both with and against the grain of the order already established.

In a project that is situated between material and visual culture, what does such a period label as "early" mean? Even the first two decades of cinema consist of multiple periods. Hence, "early cinema" as a term is under pressure. There are several arguments for periodization of the early period (pre-WWI) based on developments and changes in such aspects as film form, production contexts, and modes of exhibition, relevant for different historical approaches and research questions. For example, historians who are mainly concerned with the formal aspects of film, such as the development of narration and montage, tend to consider the truly "early" period as ending with the Nickelodeon boom in 1907. Some even argue that the transition to multi-shot films around 1903 is an important one. Historians whose focus is more on the cultural functioning of cinema, the relationship between text, reader, production context, and historical context, tend to investigate a longer period, including the first half of the 1910s, the so-called Nickelodeon, or transitional period.

This period of transition between the "early" period and the post-WWI rise of Hollywood had its own specific historical shifts and developments and was ended roughly by the outbreak of World War I. Before the years of war that 
more or less halted the further development in the international film industry and market, films became longer and increasingly self-contained, relying less on exhibition formats with live performances such as stage acts and lecturers, a transitional phase between the fragmented film program of short films and acts towards the later feature film. The division used for the different volumes of The History of the American Cinema is also telling: the first volume, The Emergence of Cinema: The American Screen to 1907 by Charles Musser (1990) discusses this pre1907 period, and the second volume by Eileen Bowser (1990), The Transformation of Cinema: 1907-1915 comprises the next eight years, up to WW $\mathrm{I}^{10}$

This book deals with the filmic period 1894-1915. Recognizing the different periods that these years comprise, the different stages of development within these brackets, I propose to look at this pre-World War I period precisely because it contains so much development and change, before the hegemony of the American film industry within the international market, and before the multi-reel feature film had become the norm. The specific exhibition format of the early years and the rapid changes during this period make it an intriguing period of filmmaking, challenging the film historian. Because the Westerns that were made before the feature films have not received much study and have been ignored in genre studies of the Western, this period provides a rich source for rethinking old categories, periods, and histories.

But, in line with visual culture studies, the medium is not isolated from its own cultural contexts. Instead, the films are positioned within the intertextual realm in which film plays a part. This realm consists of media and art forms that are older than cinema. Cinema itself, then, is conceived not only as novelty but also as situated - within its visual culture, - after the beginning. Not that the visual part of turn-of-the-century culture can be isolated. Key elements of the culture of the time, epitomized as "modernity", are immigration, travel, and urbanization, and the closing of the frontier. $\mathbf{G} \mathbf{M}$ These cultural themes are extremely significant for the Western as genre in the making. They all concern the intersection of time and place.

The title of this book is programmatic of a number of principles that underlie the study. Firstly, I will not be looking for the "origin" of the representation of the West in early cinema. This would be in contradiction with the premise that cinema is best considered as a cultural phenomenon. Instead, I focus on the way the films and the showing of films are embedded in a larger cultural framework which needs to be considered in its historical specificity, itself grounded in its own past. Consequently, attempts to search for origins always end up in the phases preceding the "beginning" and will break down into multiple beginnings. More importantly, the beginning of the medium coincides with the end of the "beginning" of constituting and uniting the states of America: the closing of the frontier. In this sense, film history can only take off after the beginning(s). 
Nevertheless, as the title indicates, I will be "after" something, searching for it. My search concerns the place of films representing the idea of the West in its own contemporary culture. I will be "after" the symptoms of the mutual translation of time and space into each other. This moment can be defined as a temporal frontier between on the one hand, a past that is closed off and therefore instantaneously becomes the object of idealization and mythification, and, on the other hand, the uncertain future that is imposing itself under the various meanings of the term "modernity." That sense of standing at a frontier in time, about to be cut off from the rapidly receding "elsewhen," is translated into the spatial frontier on the other side of which "the other" moves about in the elsewhere. The frontier was declared dead in political discourse, and hence, in need of revitalizing by cultural compensation. Yet, although the geographical frontier was closed in the 1890 , the frontier as metaphor was very much alive in political discourse in this period.

Theodore Roosevelt, for example, clearly cashed in on the rhetoric of the frontier in his political speeches and essays. His historiographic insights were also closely bound-up with his political philosophy. One of his most famous lectures, "History As Literature," was given before the American Historical Association in 1912. His closing remarks invoke the historians of the future who will tell the history of the frontier:

Some day historians will tell us of these things. Some day, too, they will tell our children of the age and the land in which we now live. They will portray the conquest of the continent. They will show the slow beginnings of settlement, the growth of the fishing and trading towns on the seacoast, the hesitating early ventures into the Indian-haunted forest. Then they will show the backwoodsmen, with their long rifles and their light axes, making their way with labor and peril through the wooded wilderness to the Mississippi; and then the endless march of the white-topped wagontrains across plain and mountain to the coast of the greatest of the five great oceans. They will show how the land which the pioneers won slowly and with incredible hardship was filled in two generations by the overflow from the countries of western and central Europe. The portentous growth of the cities will be shown, and the change from a nation of farmers to a nation of business men and artisans, and all the far-reaching consequences of the rise of the new industrialism. The formation of a new ethnic type in this melting-pot of the nations will be told. The hard materialism of our age will appear, and also the strange capacity for lofty idealism and the American character. (reprinted 1987: 137-138)

For Roosevelt, historians look a lot like filmmakers. But whereas the diverse elements of the "portrait" of America for him converge in a "lofty idealism," in this study convergence will be held at bay. 
What I am after, instead of such spiritual unity, is something like a thick description (Geertz 1973) of a "beginning" that is inflected by what Freud would have called, in a different context, Nachträchlichkeit, or deferred action. Nachträglichkeit is a term frequently used by Freud in connection with his view of psychical temporality and causality; experiences, impressions, and memory-traces may be revised at a later date to fit in with fresh experiences or with the attainment of a new stage of development. In that event they may be endowed not only with a new meaning but also with psychical effectiveness. ${ }^{11}$

Anthropologist Clifford Geertz discusses the role of the ethnographer, whose aim it is to observe, record, and analyze a culture. According to Geertz, she must interpret signs or cultural phenomena to ascertain their meaning within the culture itself. This interpretation must be based on a "thick description" in order to see all the possible meanings. ${ }^{12}$ Signs or symbols must be described, analyzed, and interpreted in their historically transient, cultural context. In this view, ethnographers are cultural analysts, and cultural analysts are ethnographers. As Geertz puts it:

The aim is to draw large conclusions from small, but very densely textured facts; to support broad assertions about the role of culture in the construction of collective life by engaging them exactly with complex specificities. (28)

This is a synchronic version of what Carlo Ginzburg (1980) calls micro-history. In this study I foreground the historical dimension of these specificities. Hence the focus is on the archive. What the field is for an ethnographer, the archive is for the cultural historian. With the archive as model, we focus on the non-linearity of the historical endeavor.

The first, ethnographic principle starts from the premise that cultural phenomena should be interpreted as part of a specific culture in its synchronicity. In historical terms this means that early films should be put in the context of early cinema. The second, historiographic principle hints that what we call "early" cinema is an after-effect of cultural transformation. The recent past, declared dead, is vividly present in a time when it is remembered first-hand. I This present-ness permeates the culture with what I call a sense of history. This sense of history is worked out and worked on in the films. This is why the early films are incommensurably different from the later Western as a filmic genre, conceived as rigorously fictional. $\mathbf{F}$ Here, my goal is to present this cultural moment in a way that speaks to our own contemporary culture, where history is present as a cultural bone of contention, and representations are measured by standards bound up with artistic genres of which some, more than others, seem to ask for evaluation in terms of historical "truth." In this sense, a term of comparison would not be so much the later Western but rather the historical film, 
most actively discussed today à propos of problematic representations of past tragedies such as the Holocaust.

Finally, in spite of my caution against genealogy as a search for (singular) origin, I do wish to take into account the problematic yet intuitively adequate notion that my corpus consists of "early" films. I am after something that is not an "origin" but can still be termed "early" as long as that qualification is taken to indicate a relative position in a time frame that is more or less arbitrarily delimited. Instead of a genealogy grounded in chronology, then, I will be going after those aspects of the cinematic representation of the American West that our own present culture can connect to its own image of its early days.

Thus, the historical moment generates aspects that congeal into a "genre." $\mathbf{G}$ Yet, the notion of genre already points to a retrospective look, performed after the change that makes groupings visible among the heterogeneous mess that is any present moment. The Western makes a good case study for the problematic of genre studies in early cinema. Although the (classical) Western is such a recognizable, famous, and emblematic genre, the early Western is a very different matter. To establish a lineage, a genealogy from pre-cinematic intertexts such as highbrow paintings or the popular literary tradition, to film, is highly problematic, but ignoring these traditions would equally distort the history of cinema. Clearly, whereas a relation to these precedents cannot and need not be denied, the problem is the idea of lineage itself. Early cinema studies' project to problematize ways of defining and historicizing cinema is confronted with those issues that seem crucial for genre theory as well.

Hybridity, breaks in genre history, stylistic plurality, and generic overlap in the film program - to name but a few elements - all problematize the project of tracing genres back to their origins. As a first intervention, then, positioning the early Western within the specific "early" cinematic context is more appropriate than isolating the genre in film history and tracing it in a linear fashion, from its "birth" to its "adolescence" and even speculations on its "death." The plurality, heterogeneity, and dissimilarities as part of early cinema's genres that were in the process of developing, fundamentally reposition existing models of writing genre history. The paradigmatic difference of early cinema from even its closest "descendants" in later cinema challenges familiar modes of writing genre history that are based on the organizing principles of description and definition. Instead, new aspects are relevant such as seriality, plurality, and the contiguity between films within the film program.

In short, the first cluster of the book is concerned with all these ways in which "early" and "Western" are both flags of anachronism, of a retrospective look that must be foregrounded and examined along with the material, lest it become an unacknowledged projection. These chapters, then, discuss different ways in which "early Western" cannot be defined other than by what it is not, 
by default, by negatives. These negatives I take as history lessons. They help me avoid the pitfalls of linear thinking, of anachronistic projection, and of categorical thinking in the face of material that received its categorical order only after it became buried in the archive from which we now wish to revive it.

In order to indicate how we best approach early Westerns as genre films, let me end this introductory chapter with an example of the approach I will follow in the rest of the book. Suspending the effort to pin down features, I foreground quite simply what these films have in common: something that looks like "the West." On the basis of geography alone we can begin by giving them a place in (film) history, the history of film practice, and the surrounding visual culture. Thus, I tentatively place the cultural object in its context and see how the context is affected by the object and vice versa. I analyze the films in terms of their mutual and dynamic characterization. What is most special about the early Western - its use of landscape and the relationship between the recent past and the recent present - shows a particular negotiation between proximity and distance both in time and space, a negotiation the need for which was felt in the upheavals of the transitional era of early modernity. Landscape as a seminal element of these films can be put in context: in the filmic context and in the broader context of visual culture. $\mathbf{L}$ Then the films can be analyzed, for example, in terms of a nonfiction dimension that undercuts our doxic belief that fiction and nonfiction are opposed or at least rigorously distinguished, or in terms of their "picturesque aesthetics." $\mathbf{E} \mathbf{P}$ These two examples of approaches to the landscape do not take landscape as a defining feature that ontologically determines the genre, but as a nodal point in a discursive network of issues and questions.

The four clusters reflect the multiplicity of levels on which I analyze the Western. The landscape, to continue the same example, recurs in all four. In the first cluster it is used to define the Western by negatives, as the elsewhere of urban culture and the other side of the frontier that itself has vanished. $\mathbf{O}$ In the second cluster, it is the focus of the ambiguities of setting and location. $\mathbf{\square}$ In the third cluster, devoted to strategies, it is the object of visual fascination. $\mathbf{P} \mathbf{R}$ In the last cluster, on practices, it is the object of display. $\mathbf{U ~} \mathbf{V}$ Like landscape, many other topics have a particular relevance within each context. This is why I organized my book in loyalty to the kind of culture that it aims, not to grasp or reconstruct, but to construct and "touch" - by staying in touch with its material leftovers. These leftovers, as Crary among others has reminded us, are not "raw data" but sites at which discursive formations intersect with material properties (1990: 31). I characterize the constellation of intersections that we call "early Westerns" in terms of the culture they constitute and partake of, as kaleidoscopic. $\mathbf{K}$ This kaleidoscopic object is brought into visibility by means 
of a kaleidoscopic approach. In this way I hope to propose how we can understand early Westerns better, that is, as cultural expressions in their own right, rather than as a precedent out of which grew something else, something so utterly different than them: the glorious Classics of Hollywood.

\section{Notes}

1. In: "Quick Fashion Changes:' Public Demands New Subjects Constantly." New York Times (August 4, 1912).

2. Foucault, Language, Counter-Memories, Practice (1977a: 142).

3. Some postmodern or neo-Western titles are: Unforgiven (1992, Clint Eastwood); The Ballad of Little Jo (1993, Maggie Greenwald); Dead Man (1995, Jim Jarmusch); The Quick and the Dead, (1995, Sam Raimi); Lone Star (1996, John Sayles); the SF Western WiLd WiLd West (1999, Barry Sonnenfeld); or the trilogy EL Mariachi (1992, Roberto Rodriguez), Desperado (1995, Roberto Rodriguez) and Once Upon A Time in Mexico (2003, Roberto Rodriguez).

4. "Fugitive," not in the material sense, although the material status of electronic information is fundamentally different from paper and celluloid; but in the sense that too much comes in to bother preserving it and that trends in today's screen culture are changing extremely rapidly and disappearing from the scene.

5. Of the many recent publications on cultural memory, Andreas Huyssen's Twilight Memory (1995) is a good starting point. His perspective is critical of the fetishism with old things. Pierre Nora's multi-volume Les Lieux de Mémoire (1984-1992, translated as Realms of Memory) examines cultural memory in relation to the changing nation state. For a concise discussion of his concept of "lieux de mémoire" see Nora (1989). Geoffrey Hartman's The Longest Shadow (1996) takes Holocaust memorialization as his starting point. In different ways, these studies cast a relevant light on the knot of preservation, nationalism, and the history of violence that informs the Western, as we later began to call the films.

6. Although poetics as a term is obviously dated, it has by no means lost its currency or relevance for cinema or media studies. David Bordwell (1989) has convincingly argued this in his perspectives on a "Historical Poetics of Cinema."

7. Screening the Past is the title of an electronic journal published in Australia, to which I contributed a programmatic essay from which some parts of this and the following chapter are taken (2002).

8. About this synchronic positioning of early cinema in film history, see Gunning (1991b).

9. The integration of material culture studies and visual culture studies is necessary to trace "the social life of things" that defines the object of cultural history. For this phrase, see Appadurai (1986). For the program of material culture studies, see Tilley (1991) and (1993) for the "poetics of the past" this approach entails. Visual culture studies has been developing for some time, and has been thematized after its beginning by Jenks, who defines it as working towards a social theory of visuality (1995: 1-25). 
10. About the periodization of early cinema and different approaches within early cinema studies, see Thompson and Bordwell (1983); Bordwell, Staiger, and Thompson, eds. (1985); Allen and Gomery (1985); Elsaesser, ed. (1990); Pearson (1996); Dupré la Tour, Gaudreault, and Pearson, eds. (1999).

11. See Laplanche and Pontalis, Language of Psychoanalysis (1973: 111).

12. Geertz describes his notion of thick description, a term he borrows from Gilbert Rye, in his essay "Thick Description: Toward an Interpretive Theory of Culture" published in The Interpretation of Cultures (1973: 3-30). 



\section{After-effects}

Each chapter in this first cluster presents aspects of features that characterize the films of my corpus by default, in their difference, that is, by today's standards, which tend to consider them "awkward," aspects that seem incomplete, inauthentic, and ambiguous. Since matters of alterity demand cautious questioning of the "self" in relation to whom the other is different, it is this difference that is the starting point for the questions I will raise in the following chapters. Historical difference is, on the one hand, an anachronistic projection because of the reversed perspective inherent in looking back at the past. On the other hand, it is precisely this backward glance that makes possible the recognition of historicity.

In these chapters I investigate how this doubly historical perspective calls for specific approaches. I characterize these as defining the early Western through five "negatives": 1) no wholeness; 2) no positive location, but an oppositional structure: the West as non-city; 3 ) no strictly positive or negative character types because character representations self-deconstruct; 4) no positive setting but time-place; 5) no clear-cut definition of fabula because fact and fiction merge.

The first chapter of this cluster deals with fragmentation. B This fragmentation operates on multiple levels: fragmented visual culture, fragmented genres, and fragmented materiality of the archival heritage that we find today in the film archives. In the first chapter of this cluster I focus on the relationship between the fragmented film form and the archival reality. In the second chapter I offer a reading of "cowboys in the city" or "city slickers in the West." $\mathbf{C}$ The displacement of characters activates a discursive triad of race, gender, and class in terms of location. This is a persistent theme throughout the study. Both as time and as place the West is the Eastern / urban's other. The East is where we find the creation of the West. Defining otherness becomes a tool for self-definition.

Due to this displacement of the self, the characteristic representation of Indians, Westerners, women, and other "others" is inherently self-deconstructive, as I argue in $\mathbf{D}$. Something similar happens on the level of the wavering positioning of the stories in space and time. In $\mathbf{G}$ I discuss this mechanism through films that are set in the East, although they are recognizably about the wildness on the other side of the Frontier. Here, the East is not the opposite of the West, but an earlier version of it. Thus, they are doubly historical films. In distinction from these "Easterns," straight Western films are contemporary or of a more 
recent past. And since the genre concepts we use today were not in place at the time, these films did not systematically tell fictional stories. The balance between reality and fiction that is required to understand any work of fiction is therefore different in my corpus. In the chapter on Facts and Fictions I analyze the contemporary sensibilities about this mixture. $\mathbf{F}$

The lines sketched in these chapters come together in the final chapter of the cluster where I set the historical corpus up as teacher for our historiographic position when we are tempted to use genre concepts in unwittingly anachronistic definitiveness. We can learn from the after-effects, or "negatives," of this corpus to consider genre, not as a category with fixed properties and boundaries, but as process and relations. The negatives do, after all, characterize, albeit not in any direct way, what kind of films were conceived, made, and enjoyed at the turn of the 2oth century. This is the subject of the final chapter of this cluster. $\mathbf{G}$ 


\section{Bits \& Pieces}

In many film archives [...] fragments are disappearing in the trash. They are difficult to catalogue, and who will ever want to look at them if there is so little knowledge about them? "But they are often so beautiful...," we regretfully sighed again and again in our weekly meetings. Eventually, the solution turned out to be to make a small collection of the most beautiful fragments. Eric de Kuyper came up with the name of bits \& pieces. [...] Now these snippets are preserved, each with its own number, and more importantly, they are used, that is: shown. Because all those scraps appear to have been invented to play with, to mix and match them and to transform them into new film experiences.

- Peter Delpeut, $1997^{1}$

How, then, to write the history of this corpus? In this chapter I discuss this key question of method. In the Archive of the Filmmuseum in Amsterdam, Bits $\mathcal{E}$ Pieces is the term used in the catalogue to refer to fragments rather than allegedly complete films. This notion of bits \& pieces can serve to set up the conceptualization of cinema as a representation of the other seen through the eyes of a self - modern urban culture - subjected to fragmentation due to modernity. In other words, the name used today - Bits \& Pieces - becomes a metaphor for the most typical feature of the cinematic culture of the time.

First of all, I will read the name to characterize the films of my corpus. I take the name of that small section of leftovers, and the archival reality it covers, as an indication that fragmentation might also characterize the "complete" films, whose traces, leftovers, ruins, or antiquities, the archive holds. Second, the aspect of narrative in the Bits \& Pieces could be extended to the entire corpus. $\mathbf{N}$ Narrativity is not at all obvious in the bits and pieces we find in the archive. Since narrative is a primary feature of the Western as we now see it, I will focus the analysis on this question of narrativity. Third, concerning cinematic culture, in this study I examine bits and pieces of what later became "the Western," evoking and invoking the fantasies and myths freshly forged about the wilderness past that was, at that very moment, becoming obsolete. Fourth, methodologically speaking the becoming-obsolete also characterizes the materiality of what lies dormant in archives in an age of screen culture where the standard state of being is a certain fugitivity of reception. ${ }^{2}$

Finally, the meaning of Bits \& Pieces is more than the title for what has neither name nor identity in the cinematic archive: unclassifiable leftovers, too good to throw away, not good enough to be archived, catalogued, identified, and stored for future use. Unwittingly, the Filmmuseum bestowed on these humble strips 
of celluloid the honorable function of embodying and emblematizing the secret of a culture no longer alive. To uncover that secret, they must be decoded, made readable. This meaning, then, concerns the bond between material, archival work performed today and the historical material subject to interpretation. Intertwining material and interpretive historical work, the small, barely appreciated treasures of the Filmmuseum become the bearers of an archival poetics. In this chapter, this term will be probed as a possible guideline for the chapters to follow.

For us to understand the current fascination with the archive, archival poetics as a code for readability must enable us to "translate" the meanings of the Bits $\&$ Pieces into interests, anxieties, and desires that run through the beginning of the 21st century and its culture of novelty. Novelty and the anxiety over loss of what is also rejected characterize both the early- and the late-2oth century. This ambivalence underlies current "archivalism."

There is a purely practical, material reason for the relevance of an archival poetics for the historical project undertaken here. The bits and pieces that form the Bits \& Pieces are material leftovers of objects irremediably lost in the present. The phrase is therefore, rather, a metaphor for the lacunary access we have, in our time, to the past we wish to recover as part of our sense of self. This gives pause to the historian. For, this material deficit is a symptom not of the historical material itself, but of cultural history and our (historical) epistemic limitations. Moreover, the fragmentation that I claim to be characteristic of the films is often self-conscious and self-reflective, as it was an accepted part of contemporary production and exhibition practice. This speaks to preoccupations of our own time. ${ }^{3}$

But the phrase Bits \& Pieces can also lend itself to misunderstanding. The sense of fragmentation it entails should not be seen as a metaphor of the historical position of my material as "early" in the sense of immature, primitive. On the contrary, I contend that the fragmentation is not at all a symptom of immaturity of the medium, nor of the genre of the Western, even if my material stems from an early stage. There are three reasons why this would be a misconception - and one that strikes at the heart of my project.

First, there is a material reason. As I mentioned, the bits and pieces that form the Bits \& Pieces are material leftovers of objects irremediably lost over time. The phrase is therefore, rather, a metaphor for the access or lack thereof in our present, to the past we wish to recover, know, and understand. Hence, this material lack is a symptom, not of the historical material - "early" as in immature but of our epistemic limitations. This is perhaps something we may wish to lament, but I am not sure the situation is different in any other historical discipline. Completeness of our knowledge is an ideal of the 19th century, the great era of collecting. At the present time, understanding is not necessarily bound up 
with overview, but rather with insight - a knowledge that is fragmentary in itself, but thrives on the possibility to interpret what is lost through a close scrutiny of what is found.

The second reason why such an interpretation would be a threat to our understanding lies in the way it might blind us to a keen self-awareness that characterizes the films. The fragmentation that I claim to be inherent in the films is often self-conscious and self-reflective, as I will demonstrate later. W There, I will take the fragmented status of the films and of the cinema culture of the period as the starting point of the analysis, as a given. Here, I aim to establish that status as given, and establish once and for all that fragmentation is a relative notion; that the fragmented objects are neither "broken" and thereby irreparably handicapped, nor artistically inferior to films that we are in the habit of considering as "whole."

In this respect, a useful cautionary analogy with the status of fragments might be the status of the ethnographic object as presented by Barbara KirshenblattGimblett in her study Destination Culture. She writes: "The artfulness of the ethnographic object is an art of excision, of detachment, an art of the excerpt." The author says this in answer to her own question: "Where does the object begin, and where does it end?" She states that the ethnographic object is by definition a fragment, an object excised not from a larger object - that, precisely, we often cannot know - but of the culture from which it was taken. Just as the Parthenon in its current state stands for classical Greek culture, although no ancient Greek ever saw it in its current colorless and ruined shape, the object is, not by accident but by definition, not-whole. Kishenblatt-Gimblett writes: "Like the ruin, the ethnographic fragment is informed by a poetics of detachment" (1998: 18). The analogy leads to the notion that, like the ethnographic object, every object found in a film archive is a fragment of an irretrievable, ever-widening whole: the "complete" film, the "genre," the program, the cultural habits of watching films, the culture. And, the last quotation suggests, there is a poetics to this fragmented state, which asks to be constructed.

A third reason why such an "immaturity" interpretation of fragmentation would undermine my project lies in the value it bestows upon completeness itself. For this misunderstanding I invoke another parallel, this one even more unexpected than the ethnographic one, since it concerns the value bestowed on completeness as a psychic structure. As Kaja Silverman has argued in a different context, the valorization of unity at the cost of fragmentation is not in itself beyond scrutiny. Indeed, only a culture that anxiously places primacy on unity in order to hold off the risk of an inherent fragmentation, will cast the fragmented out as its own object of abjection. ${ }^{4}$ Responding to the anxiety concerning the impossible wholeness of the body in self-perception, she writes: 
[I]t seems important to note that the body in bits and pieces is only one way of apprehending the heterogeneity of the corporeal ego, and one which is inextricably tied to the aspiration toward "wholeness" and "unity." Lacan suggests that it is "organic disturbance and discord" which prompts the child to seek out the form of the "whole body-image." However, it seems to me that the reverse is actually true; it is the cultural premium placed on the notion of a coherent bodily ego which results in such a dystopic apprehension of corporeal multiplicity. (1996: 21)

Something similar can be said to inform collecting. Indeed, the desire to create collections that are, or claim to be, "complete" - representative, holding works from all categories or genres, periods or areas of provenance involved, and the like - partakes of this cultural fetishism of wholeness. Today, there is a growing awareness that such ideals may have deeply problematic aspects, most notably the (cultural) imperialism, but also the epistemic over-ambition, that motivate them. Current dis-ease with that anxiety and a desire to establish more nourishing, as well as less utopian, connections with the past, inform the interest in the archival in today's culture.

If we consider the four meanings of the notion of Bits \& Pieces together - the specific narrativity of the films, cinematic culture's particular investment in the past, the broken materiality of archival objects, and the conditions of readability of material leftovers in historical interpretation - the phrase also helps to explain the advantages as well as the drawbacks of what seems to be an archaeology of early screen culture, here, the Western. The notion of the archaeological needs further analysis in this respect.

In this study I am not attempting to fully develop the archaeological metaphor. On the contrary, the "archival" qualifies the archaeological. There is no project of digging into the depths of a lost culture; cinema is rather often considered the most "superficial" form of cultural self-expression. There is no attempt to unify fragments in order to rebuild "structures" or "shapes"; this is not always possible, and given the amount of glue required, the restoration process risks rendering the historical object all but invisible. As is well known from archaeology, and as Kirshenblatt-Gimblett reminded us, sometimes the choice between either restoring beyond recognition, or celebrating ruins as if they were once authentic, is better avoided altogether. Thus, in our case, the fragments are not considered as fragments of anything "complete," but are valuable in themselves; it is only from the unreflective anachronistic vantage point of the present in which the ideal film requires causality, coherence, and (often) approximately 90 minutes projection time, that we can decide that the short bits that take only seconds or minutes are not-whole. Instead, fragmentation characterizes the films as they were made and watched in their own time. Hence, conserving the bits and pieces as such comes as close to making their "nature" visible as at- 
tempts at physically restoring them, if not, in some cases, as hyperbolic instances, even closer. After a long-standing fascination with depth and digging, the archaeological metaphor is currently being superceded by the archival. What Kirshenblatt-Gimblett calls "a poetics of detachment," then, I would qualify for our purposes, and in some sense "thicken," and speak of an archival poetics. $^{5}$

Therefore, I approach the archival material called "early Western" with this notion of archival poetics. In order to circumscribe, if not define, what could be an archival poetics, I explore the consequences of the fragmentation that is, perhaps, the most conspicuous characteristic of my corpus. As I announced above, given the cultural status of narrative - still predominant in film, television, and written text, but under siege in the unstable structure of hypertextuality and hypermedia - I will do that through the question of narrative, a question that will be more extensively developed later. $\mathbf{N}^{6}$ What I found in the archives were primarily pieces of nitrate that are somehow - a "how" to be further elaborated throughout this study - associated with "the Western." Nothing remotely "whole," "coherent," self-enclosed can be detected. Yet, what we see today, as "the Western" is a film genre in which certain typical plots are conventionalized, hence, "naturalized" to a high degree. We expect fights, chases, abductions, and rescues - in other words, violent and exciting narratives. These are narrative bits, elements of what, we assume, might have been a "complete" narrative as we know it from later films. Between that expectation and what we find, the link is neither logical nor completely arbitrary. Clearly, we can hardly pretend there is nothing happening that would make us expect narrative.

A film catalogued in "Record 12669", an incomplete rescue scene which was initially catalogued as such and provided with the appropriate title "The Rescue," ends up in a collection of Bits \& Pieces, where it loses its title and receives a number (\#429) instead. I propose to resurrect it from its anonymity as number and elevate it to the status of guideline for history writing. Indeed, what we see when we look at the collection of Bits \& Pieces is something that works like a motor, that generates in our minds a sense of narrative. That uncertain state between material objects and modern viewers is the kind of narrativity I wish to put forward as characteristic of the archival material. The bits and pieces are not whole, by a long shot, but somehow, in relation to the visitor to the archive, they strive towards wholeness.

This striving toward wholeness is, of course, an effect, not an inherent quality of the object. But the effect is to be taken seriously if we wish to understand what cinema culture looked like as well as how we, today, can make sense of it. The narrativity that emerges from this inquiry, then, is the direct product of the archival poetics considered as such, so that it can become a model, not for the 
retrieval of the past, but for a future understanding of the past in terms of the encounter staged by the archival discourse of Bits \& Pieces.

My hypothesis, here and subsequently, is the following: although for our corpus of early films this expectation of narrative inflected as narratives of chases, rescues, fighting, and the like, does not necessarily hold, neither is it foolish to entertain such an expectation. The presence and the place of chases in the examples to be discussed vary, and expecting them to furnish the basic narrativity of the films is an anachronistic projection. Hence, a cultural history of this corpus that avoids as much as possible the kind of anachronistic projection that promotes evolutionistic arrogance in any encounter with something "old," should start from this clash between what we expect and what we see. Through that confrontation the historian's archive can yield an "archival poetics" for our time.

To see archival poetics at work, let me give you a taste of Bits \& Pieces. BITs \& PIEcES \#66 is listed in the catalogue with a description that is also the subtitle of the unidentified film that lacks an original title: "Woman and children are assaulted by gang of criminals."7 The fragment runs approximately 2 minutes (on video). ${ }^{8}$ The opening shot shows the woman and the frightened children in a room with a window. Through the window we can see a painted view of a tree and a telegraph pole. The room is on the second floor. The woman, whom we, as narrativizing cultural agents, "appoint" as the mother of the two girls, looks out the window. The next shot shows what is happening downstairs. Three robbers are holding down a man while they are busy robbing the place. Back to the upstairs room. The woman closes the window, opens it again, and waves her handkerchief out the window. The next shot shows the waving from an opposite perspective. Seeing the outside view of the house, we can deduce that the house is, in fact, a train station. We see her waving from the perspective of the possible viewer whose attention the woman is trying to get. A train is approaching. The bandits enter the room and pull the woman and children out of the room. Crosscutting to the outside perspective, we see that, at the same time, the train continues to approach. Tension mounts. The three are taken downstairs. A long shot shows the train arriving. A few men exit the train and hurry towards the station. They capture the bad guys. The woman and children hug one of the men: a family reunited?

Here, the fragment stops. The narrative is closed. This is an almost complete narrative, which leaves few questions unanswered. Is this really a fragment, or is it a concise summary, bringing a more elaborate narrative back to the essential course of events? It seems to be "complete," for it looks like any number of short old films in the archive, containing the most elementary part of a last-minute rescue. The generic recognition of suspense and closure in the form of a 
happy ending leaves nothing unsolved. Like The Lonedale Operator (1911, $A M \& B)$ the story concerns a train-station hold-up and the suspense of the approaching rescue is shown in similar style, by crosscutting between the assaulted woman and the rescue by train. As a summary, only lacking the exposition, the film may be more effective than in complete form, for it literally cuts right to the chase.

On the basis of this sample, archival poetics already demonstrates its relevance. The first element of that poetics is to sever the tie between narrativity and wholeness. At first sight, narrativity means movement, time, and coherence. In what is, without a doubt, the most cited and followed definition of narrative, Aristotle's Poetics, the author defines a plot as a series of actions, with a beginning, middle, and end. Not that this definition says much. But for this inquiry, it has unexpected relevance if we consider that even this most general of definitions falls short of describing the artifacts of my corpus, those elements from the past. As it happens, and as I will further discuss in the concluding chapter $\mathbf{Z}$, it also fails when confronted with hypertextuality and its logic of association and collage, structured by hyperlinks, the organization of text in the present. For Aristotle's definition takes for granted a wholeness that my corpus de-naturalizes. By clearing away this age-old narrative poetics caught between early and late cinema, I aim to make visible what the archive, as such, offers as a poetics of bits and pieces. Narrativity remains, but wholeness is no longer its primary defining feature. This is the first and most characteristic aspect through which I discuss both this corpus and the most acute problem of writing its history. 9

Further, a fundamental ambiguity, replete with practical consequences for the historian, resides in the site of those things: either in the film's fabula, as we are accustomed to think, or in the viewer's need to construct them. Reader-oriented criticism has made us aware of the indispensable input of the latter. Reception study is not limited to counting visitors; it also accounts for what visitors do. But there are no records of our films other than reviews, and the archive's Bits $\&$ Pieces do not get reviewed. Hence, your own viewing experience is the only means to get access, even indirectly. But here is the catch - which is also the way out of the dilemma of cultural history. The archival material only becomes "cultural" if it is viewed. Remarkably, the viewing experience itself makes up for the lack of narrative wholeness. This casts a new light on narrativity itself. For, the viewing of bits one after another transforms whatever you are seeing into actions, simply because the images succeed each other. This turns narrativity from a text-immanent, structuralist concept to a reader-based cultural mode, questioned by new media and the dis-unified, fugitive, and user-dependent status of narrativity therein. Even if there is no clear fabula that structures an internal logic, a sense of narrative emerges and captures you. This entails a displace- 
ment of focus in my approach, from plot structure to visual rhetoric and from text to reading, even if the efficacy of the latter is tied to the former.

This approach recognizes effect as meaningful without taking its motor to be written in stone. Between Bits \& Pieces - archival dust - and a sense of film, genre, or culture, narrative emerges out of the time-travel of the encounter that cannot be situated firmly either in the past or in the present, but that momentarily, if without illusion, fulfills the deep desire for unity. Illusion-based as it is, that fulfillment is the central element of the attraction of film at this early moment. At the same time, it informs the appeal of archival work. Therefore, I submit, this dynamic of fragmentation and provisional, subject-made - and hence fundamentally diverse wholeness through narrativity - constitutes the attraction of the archival in present-day culture. It consoles both the early film viewer and the archival researcher for loss of unity by empowering the cultural participant to reclaim what is lost, to make a composition, or bricolage, out of material pieces from the past. And since, as I claim, this is precisely what "culture" means - this activity people perform within the context in which it makes sense to do so - the archival poetics of this bricolage is not a pis-aller, but a significant, indeed paradigmatic, cultural form of behavior.

In order to liberate this view, and the subsequent approach, from a narrow phenomenological focus, let us now return to two key metaphors that have been current in historical work for quite some time. Above I cited, and then qualified, the metaphor of archaeology, which I take seriously without adopting it completely. In the introduction to Le Western: Archéologie d'un genre (1987) Jean-Louis Leutrat proposes an archaeology of the Western genre. The Western, he argues, does not exist as a "natural object" ("objet naturel"). Archaeology, as a process of reconstruction, is needed to replace a history of natural objects:

Il faut substituer à l'histoire d'un objet naturel celle des objectivations qui ont reconstruit ce domaine où les connexions, les rencontres, les alliances, les jeux de force, les stratégies, ont, à un moment donné, formé ce qui a pu fonctionner presque immédiatement parfois comme évidence.

[It is necessary to substitute for the history of a natural object, the history of the objectifications through which we have constructed that domain where connections, encounters, alliances, the play of forces and strategies have at some point shaped what was then able to function, almost instantly, as self-evident.] (1987: 5; my translation)

Leutrat suggests that it is precisely the multiple origins that constituted the generic shape of the Western that create a need for an archaeological endeavor when the investigation of the "origin" of the Western is at stake.

The structure of this argument has become famous through the work of Michel Foucault, who tied archaeology to the other key metaphor, genealogy, the source and essence of the impulse to search for origins. Foucault's great contri- 
bution has been to unfix the idea of origin from singularity, and he deployed genealogy precisely to that effect. Leutrat quotes Foucault when he points out how genealogy has as its mission the preservation of a sense of disparity that belongs to the object from the past ("maintenir ce qui s'est passé dans la dispersion qui lui est propre"; "to maintain passing events in their inherent dispersion"). In other words, genealogy, as "method" that goes with the archaeological enterprise, must lay bare the multiplicity of origins, or originary diversity, of the object of investigation, thereby maintaining this diversity. As Foucault wrote:

La généalogie ne prétend pas remonter le temps pour rétablir une grande continuité par-delà la dispersion d'oubli; sa tâche n'est pas de montrer que le passé est encore là, bien vivant dans le présent, l'animant encore en secret, après avoir imposé à toutes les traverses du parcours une forme dessinée dès le départ. [...] Suivre la filière complexe de la provenance, c'est au contraire maintenir ce qui s'est passé dans la dispersion qui lui est propre.

[Genealogy does not pretend to go back in time to restore an unbroken continuity that operated beyond the dispersion of forgotten things; its duty is not to demonstrate that the past actively exists in the present, that it continues secretly to animate the present, having imposed a predetermined form to all its vicissitudes. [...] On the contrary, to follow the complex course of descent is to maintain passing events in their proper dispersion.] (1971: 152; translation 1977a: 146)

In view of this insight, historical methodology undergoes a shift. It becomes necessary to adopt a post-archaeological attitude, inflecting it into an archival one that endorses fragmentation rather than attempting to overcome it. Instead of permanent glue, it uses a type of glue that is easily undone. And this endorsement of fragmentation is necessary not only on the level of generic categories such as "Western." Nor is this "archivalism" merely a way out of preservation problems in the archive. Although classification and cataloguing determine accessibility, it is not only on that level that fragmentation manifests itself. Rather, fragmentation is, here, a metaphor for the three-dimensional fragmentation of the object of this study: the broken body of early Westerns.

This broken body is also multi-dimensional. I see its fragmentation on three levels simultaneously: a physical fragmentation (the often unidentified fragmented film strips in the archive), a generic fragmentation, as a result of the fragmentation of an historical screen culture, and the resulting archival fragmentation. Hence the inadequacy of generic classification for these films, a procedure that has proven particularly unsuitable due to the inherent fragmentation of the texts of early cinema. One symptom of this fragmented state is manifest as soon as we endorse an encompassing view of cinema, one that includes practices of screening. Like the changing shapes of the snippets of glass 
in a kaleidoscope these fragmented texts are reconfigured in the ever-changing programming format in which the films were exhibited. This metaphor of the kaleidoscope squares well with the fragmentation principle of archival poetics. $\mathbf{K}$

Leutrat and other historians of early cinema have proposed a history of their object in terms borrowed from Foucault. They invoke archaeology as a metaphor for an historical investigation that preserves the multiplicity of origin, that avoids linear thought, and that proposes a new perspective on chronology. Early-cinema historiography is infused with these thoughts. For example, in his introduction to Early Cinema: Space, Frame, Narrative (1990), Thomas Elsaesser refers to Walter Benjamin's often-quoted text "The Work of Art in the Age of Mechanical Reproduction" (1992: 211-244) in which Benjamin argues how, in Elsaesser's words, "the very existence of cinema necessitated a new archaeology of the artwork, because of the fundamental change film had brought to the notion of time, space and material culture" (1990: 1). Elsaesser uses the term "archeology" - a term Benjamin himself did not use - to offer a common positioning of the approaches to early cinema as paradigmatically different from film history on the whole. I situate my project within this paradigm and propose analyses that are integrated in this theoretical positioning of the historian, so that this position can model and shape a connection between the present of hypertextuality and the fragmented past, a connection that also integrates a textual, structural analysis with a cultural one. ${ }^{10}$

This integration is part of my agenda here. For, if formal analysis fails to account for the cultural meanings of its objects, a cultural-historical one tends to fail to probe, and learn from, those objects' specificity. The Filmmuseum's act of preserving these shreds under the title of Bits \& Pieces is a significant and stimulating move on the part of an institution that is, by all accounts, an archive. In a Foucauldian view, an archive is not just a place, but also the whole of discursive practices that enable "utterances" by and on the objects preserved there, so that they can constitute a "field." This view implies that the archive is discursive. It also implies that all those who use the archive and search the material preserved there "speak" its discourse and contribute to that discourse's further extension and deployment. The mechanisms of selection are part of the archive's discourse. Preserving only what seems whole to our eyes would be to "speak" an anachronistic discourse about the material, thus constituting the object rather than merely preserving it. Such decisions determine the legitimacy of the objects stored, categorized, catalogued, and studied - or not.

Here lies another element of archival poetics. Objects are not oeuvres in the sense in which we now speak of the oeuvres of John Ford or Sam Peckinpah, or, to stay with early cinema, D.W. Griffith or C.B. DeMille. In this sense, the fragments-objects also stand for a change in our perception of things from the past 
in a culture where authorship is becoming collective, anonymous, and dynamic. ${ }^{11}$ In order to drive that point home, the Filmmuseum chose to preserve also the unidentified, seemingly useless fragments - only made meaningful if viewers act upon them. But the notion of the fragment itself questions the status of the result of this archival gesture. For, fragments are by definition bits of larger wholes, even when these wholes are lost beyond recovery. This necessitates the move from the archaeological to the archival poetics that this chapter proposes. Below, I sketch that move through a detailed case.

The Filmmuseum has made a very simple, commonsense intervention. It has preserved these bits and pieces, and elevated their status to that of a special collection, made them accessible for researchers and film audiences. ${ }^{12}$ By doing so, the museum has done more than merely preserve the fragments. Its "poetics" - its gesture of "making" - is this: it has changed their status from fragments to details. This is where Kirshenblatt-Gimblett's concept of the poetics of detachment remains, perhaps, a bit under-theorized. She appears to mean something like this when she questions the possibility of defining the ethnographic object as an object, but her continued use of the term fragment underrates the wavering status of the object - fragment of a whole to be restored, or detail of a whole that the bits and pieces - or in her case, the objects - together constitute? This change in the fragments' status that occurs when the archivist puts bits together may be a necessary, inevitable act, but it is not neutral. Now, the shreds are parts of a new whole. This gesture is also a "speech act," an act performed within a discursive practice. The ambiguous status of the bits, as fragments of lost wholes and as details of a collective collection, makes them "orphans" of cinema history. ${ }^{13}$

This status reveals itself in a variety of ways. For example, the bits are numbered, roughly BITs \& PIECES \# 1 to 449, but since it remains an open category, the number will increase during the history of the archive and may even have changed while I am writing these words. While most items in the archive are categorized by content, the bits are numbered. By this emphatic presentation of the bits as fragments, yet unwittingly re-constituted as details, the archive poses us questions regarding the relationship between present and past.

Sometimes the rubric of Bits \& Pieces is used in order to be able to preserve a fragment of a larger film that is not available for preservation. Initial cataloguing categories can be replaced with the rubric Bits \& Pieces. An instructive example is a film that was initially catalogued as DE REDDING [The Rescue]. As an incomplete and unidentified film, the fragment is first catalogued as an individual film, and given a name by the archive. However, due to its incompleteness, it is then moved to the category of Bits \& Pieces. It loses its given name ("De Redding" [The Rescue]), which was based on the narrative content of the frag- 
ment, and it is given a number: Bits \& PiecEs \#429. As such, it receives a new role within the collection. This intervention entails a shift of narrativity. For, if the represented rescue clearly marks the fragment as narrative, the "becoming" of the fragment points to another narrative level, of which the archivist is the narrator. By eliminating the informative, content-based title as well as depriving the Bit of its earlier assumed wholeness, turning it into an anonymous "detail" of a larger "whole" constructed in the late-2oth century, the archival narrator becomes more prominent. If I may use narrative theory to provide yet another conceptual metaphor, the narrator has turned from the invisible "third-person" voice into a self-assertive "first-person" yet extra-diegetic narrator, pulling the strings for all to see, and casting the "characters" as puppets whose strings the archive pulls.

This new role of the archive projects the role of this fragment/film as a new "character," as a potential hero in the narrative produced by the archival poetics. As a fragment the bit is now a whole, as whole as fragments can possibly be; as an individual title, it remained incomplete. The labor of cataloguing such small bits might seem futile to the amateur as well as to the historian looking for mute things willing to yield to historiographic pressure. But it is, in fact, crucially important that the museum has decided to take them so seriously. For one of the most relevant criteria for selection by the researcher is the accessibility of material in the archive, and the key that unlocks this treasury is its catalogue.

The "promotion" of fragments to details is an act of great consequence. ${ }^{14}$ Emphatically, details are not fragments. Each kind of "bit" has a different function, a different relationship to wholeness and unity. For the historian, a fragment points to a whole; it can be a clue in identification of the whole that lies behind it. The Bit as detail, in contrast, only points to the anachronistic whole of the video tape. The decision to consider something a fragment assumes an epistemological attitude. The motivation of looking at objects as fragments is the dream of the whole behind it. The detail, in contrast, is a snippet that is a point of analysis. It is not broken off, but considered as if through a magnifying glass. Its status as detail makes analysis possible. In this sense, a detail is in fact "larger" than the whole. This can be put in another way. A fragment poses questions, a detail answers them. Thus the fragment poses the question of the whole from which it was broken; the detail answers by showing its blown-up version of itself as a pointer towards an historical cinema culture as a whole. It answers, that is, by shifting the question.

This is why the decision of the Filmmuseum not only to preserve the bits, but to keep them together, to mount them together on videotapes for accessibility, has consequences in two directions. Together, these consequences define what I suggest here to be an archival poetics. It puts forward the double status of this 
old material: by offering the fragments as documents - for example, to reconstitute the history of ideas - the Filmmuseum has simultaneously elevated them into monuments through the act of embedding them within, and hence, making them part of, a discourse, and has positioned them in the present. ${ }^{15}$

It is a major contention of my study that fragmentation is the "originary" status of the early Western and that this is what makes the archival a suitable, and therefore, appealing model for the present. It is because of that state that this (not-)genre can model our sense of culture in the age of electronic media. The two image cultures are not structurally similar on the level of artifacts, but they are similar in the structure of their cultural functioning. It is in this sense that the archival poetics I am developing offers a conceptual metaphor that serves as a guideline or searchlight for an understanding of the strong bond between the early Western and contemporary media culture. This contention requires, in the first place, a serious engagement with the bits and pieces, in order to at least be able to characterize the "genre" including its three dimensions - provisionally, if only metaphorically, or rather, synecdochically. If metaphor - the transport or translation of a vehicle onto a tenor - characterizes the relationship between the archive and contemporary fragmented culture, then synecdoche - the extension of meaning from bit to whole - is the logic that underlies the deployment of the Western for an understanding of the presentday fascination with the archival. As their shift from fragment to detail and the subsequent shift of the whole indicated, the bits and pieces stand for the whole, not of the "parent" films of which they were fragments and that may never have existed, but of the culture of which they are details.

As fragments of that culture, they were broken off when they ended up in the archive. As details of it, they can provide a glimpse of it, as an aggrandized section. Synecdoche, after all, is the figure where the part stands for the whole. Even if, we can now see, the whole does not exist and may never have existed as a film, the fragment does not exist as a leftover of the whole, but means "whole," albeit it a different whole, no longer an object or text (a film) but a culture, dynamic, historical, replete with practices and experiences. Meaning is located at the level at which the former fragment, now detail, operates: as a cultural intervention. For, as a culture, a visual subculture including the specific exhibition practices for the amazement and delight of urban people, the whole did exist. How can we write the history of early Westerns on the basis of such fragments aka details? This question poses the methodological issue that any attempt to define a genre, such as the Western, also poses.

I will argue later that genealogical decisions are just that: decisions, not divisions inherent in the objects, but epistemological decisions performed by the historian. G There, I deploy the Wittgensteinian concept of "family resemblance" to foreground the indecisive, provisional status of such decisions. This 
is necessary in order to protect the objects, of which, after all, we know so little, from reifying denominations. Now, if fragmentation is a constitutive feature of the objects in the four respects mentioned - their material status, their narrativity, their "pastness" and their viewing culture - then this should enable me to establish a status for the fragments in terms of details. In other words, the family resemblance between fragments turns them into details, that is, small elements provided with "family features" that may be points of recognition that do not rigidify the details themselves that, after all, are inherently only a small part of the whole.

Even if no complete and satisfying narrative can be distilled from the bits, narrativity is one such feature that serves to identify members of the Western "family." In my presentation of Bits \& Pieces \#66, we saw how deceptive the sense of narrative wholeness can be if this is sought at the structural level of the text only. Shortly, I will continue this small exercise in grouping in order to demonstrate the productivity of archival poetics as a bridge between a structural analysis that ignores cultural practice and a cultural study that ignores the objects on which that practice acts. And if my arbitrarily selected Bits \& Pieces begin to move, move you, the case will have been made for their status as actants, characters, perhaps even heroes, in a new narrative told by old things, directed - as in "mise-en-scène," or filmmaking - by the archive. It will have consoled us today for the loss of unity by providing us with a new sense of narrative, at long last, post-Aristotelian. Beginning, middle, and end are no longer in the text, but are of our making, of our own poiesis. The archival poetics, then, will have emerged.

Another fragment, Bits \& PiEces \#21, seems to stop where \#66 began. According to the summary title in the catalogue, it shows a hunting expedition in an open landscape. ${ }^{16}$ This suggests a non-fiction film. We see, however, four men in costume, riding horses. In the front, two men are dressed as colonial hunters, with white helmets and white clothing. Two men behind them are dressed as cowboys. The relationship between the four men is immediately established. The two men in white riding in front are superior; the two men anonymously in the back are positioned as their subordinates. The two men in white dismount their horses and walk through the Western-like landscape with guns and lassos. Suddenly they stop. One man kneels and points to something off-screen. Excitement. They start to prepare for something to happen. Here the fragment stops. At this moment of suspense, the abrupt ending of the fragment emphasizes the structure of narrative. With the tension that has been created in these few seconds, the lack of resolve and the open ending foreground the missing part of the film.

Like the previous fragment, \#66, about the robbers and the train, this fragment poses the question of what is complete, by showing what is missing pre- 
cisely by not showing that which is missing. The productivity of incompleteness, its performance as poiesis or making, is thus established. Also, the question of selection is left dangling in this absence. Why are these two examples possibly relevant for my corpus - or my otherwise motivated eagerness as a viewer in the present - and how does the archival act help put that relevance on the table?

Taken together, \#21 and \#66 are relevant as a group. The following example establishes this group. Bits \& Pieces \#104, described as "Cowboy hangs enemy on a rope above abyss. Under the rope he burns a candle. United States," shows a fragment of an exciting adventure story. ${ }^{17}$ The part of the narrative that is shown here is almost a focused, blown-up detail of the first robbery example, which could follow (temporally) the second example. This snippet shows the climax, following a suspenseful event. A cowboy in a cabin ties a man to a rope, and leaves him dangling from a rock just outside the cabin. A medium shot, functioning as a close-up would, shows the made-up face of the victim. He looks like the conventional representation of a Mexican. The cowboy in the cabin positions a candle under the rope that has been pulled through the window. Here the fragment stops. We know that something awful is about to happen, but we do not know if there will be a last-minute rescue. Because of the tragedy that could happen, the fall of the victim into the ravine, we can deduce that the cowboy in the cabin is probably a criminal. The victim has to be "good." But this becomes uncertain if we consider the fact that the victim is made-up as a Mexican and that usually - according to conventions of the Western - Mexicans are the bad guys. Generic conventions instruct us here to position the fragment into a specific type of narrative. The prologue to this fragment that we mentally add to the remaining images has built up the tension that these images ultimately take to a climax. The climax itself, the "answer" to the question of whether or not the Mexican is, in fact, a victim, is never given. But in the archival poetics I am proposing, the question, not the answer, builds the narrative. What makes the story is that we ask ourselves, will the rope snap?

Another example further elaborates this archival poetics and its attraction for the present. This appeal arises from its emphasis on vision, for it poses less the question of completion and narrativity, but more of spectacle. BITs \& PIEcEs \#319, "Een fantastisch duel," shows the visually spectacular collision of two trains, in front of a stadium full of spectators. The inter-title that opens the fragment announces and describes this spectacle: "A fantastic duel. Two locomotives crash into each other at a speed of 100 kilometers in the presence of the inhabitants of Indianapolis." ${ }^{18}$ The two trains and the spectators are shown. "Conductors and stokers jump off the locomotives a moment before the collision."19 A train is shown moving through the frame. Next shot: the collision. For quite some time, several seconds of the two-minute fragment, the explosion 
and the burning remains are shown, prolonging the moment of collision. Here the fragment ends. This is not so much a fragment of a narrative, but a pure and self-contained act of a play: spectacle in its essence. But here, too, we find a build-up in tension. The inter-titles lead to a very literal climax. The shot of the burning trains functions as a close-up avant la lettre of the result of the collision.
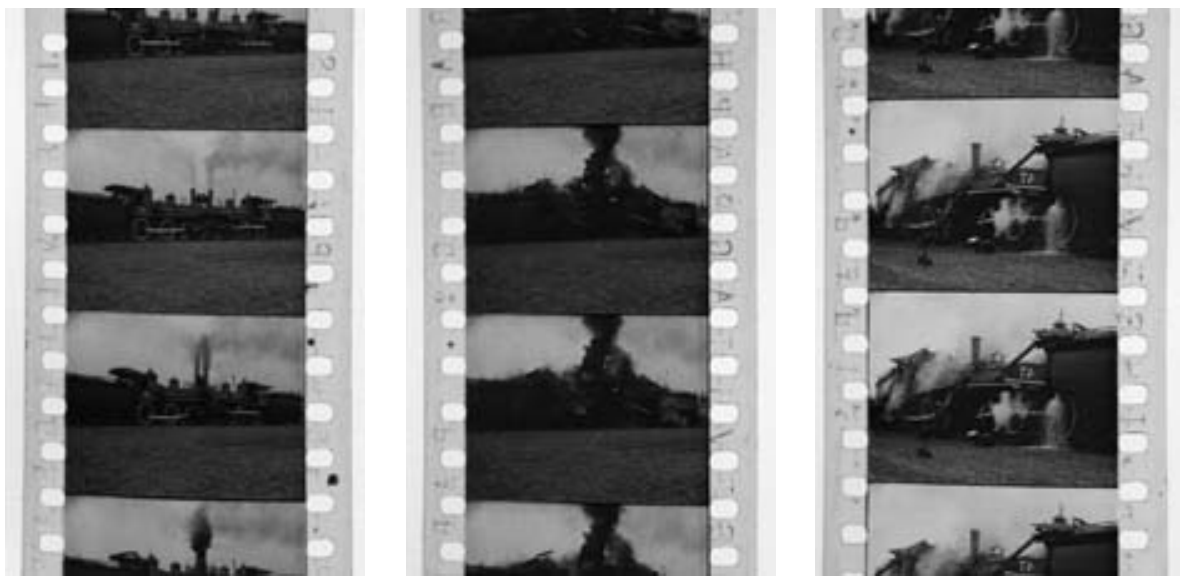

B Bits \& Pieces \#319: Three stages of collision

One way to explain the ambiguity of this short piece, which hovers undecided between fragment and complete film - a possibility that is acceptable once we unlearn to expect a set length - without explaining that same ambiguity away, is to look at it as, also, generically ambiguous. For all its spectacularity, this sort of footage belongs to a form of nonfiction. $\mathbf{S}$ Documentary footage is often editedin within scenes of a more fictional (i.e. narrative) kind. This is also the case in films we consider complete. An example is THE HoLd-Up of THE Rocky MounTAIN EXPRESS (1906, AM\&B), a phantom ride film with an added narrative. I will later discuss this film for its fragmented narrativity. $\mathbf{N}$ Here, symmetrically, I am interested in the narrativity of fragmentation - in how Bits \& Pieces tell a story.

Keeping this generic wavering in mind while viewing our Bits \& Pieces in the archive, I wish to suggest that such insertion footage has a similar function in the spectacle of the colliding trains in Bits \& Pieces \#319. Thus, like the allegedly complete, reviewed films of the time, this bit offers a glimpse into the aesthetic of early cinema. The similarity of the inter-titles between this piece and many longer films in which documentary footage is inserted is striking. For example, the numbers of miles and the speed of the trains are specified. Similarly, in the case of an oil find, the numbers of gallons would be spelled out. 
In order to grasp the significance of such insertions for the characterization of the Western of the period as fundamentally heterogeneous, as well as, in that heterogeneity, congruent with the present state of culture, it is crucial to pay special attention to ruptures, disjunctions, to the absence of attempts to make the documentary footage blend in harmoniously with the rest of the film. Attention to abrupt endings also makes fragmentation as an aesthetic principle visible, and is this kind of attention that results from archival poetics, for it belongs to the double-edged story emerging from the archival act of "preserving" bits and pieces by grouping and naming them Bits \& Pieces. A story of history, and a story in history. In other words, the story of the encounter between present and past uniquely brought to light by the archive's humble labor. To further probe the fruit of this labor as well as to honor it, I will continue on the track it projects for the historian desiring to understand the visual culture of a century ago and the cultural analyst who wants to mobilize this understanding to illuminate another moment of intense intertwinement of cultural and technological innovation.

The act of considering these bits in terms of archival poetics can now be taken to function as a meta-poetics: as a model for the understanding of a more extended corpus of films, for the historical position and motivation for the search for this understanding, and for the sense of culture in the present that demands such understandings. As we have seen, narrativity is not to be taken for granted in these films. But when considered not as structure per se, but as solicitation, the tension between narrative promise and unfulfilled desire suspends the naturalizing viewing habit by putting forward the aim of narrative's strategy - that blending of structure and projection - so that it becomes denaturalized and can be seen as one among several possible strategies, not the only "natural" one.

This is one way in which an archival poetics can help the historian while, at the same time, also explain the current fascination with the archival. On the basis of the narrativity emerging from the coincidences of pure sequential presentation of Bits \& Pieces, this poetics has enabled me to establish a connection between narrative as a textual feature and its reading function, its effect in captivating and activating the viewer. This archival narrativity, then, sustains the desire to know and understand, in fact, to have a past: preserved, available, and riveting in its unreadability, in the archive.

Ultimately, archival poetics is both narratively propelling and anti-narratively frustrating; therein lay its specificity and its significance. Taking it as a metapoetics helpful in modeling ways of understanding the more extended corpus including allegedly "whole" films, I understand the subject of this fragmentation-informed narration as concerning the semiotic mode as well as content. But what, precisely, is archival about this? Time - slow emergence, not ready-made presence - and dispersal; conservationism and reconstructionism superceded 
by solicitation and engagement. This model cannot be established suddenly, but has to be retrieved from various reiterated bits. After the beginning - after seeing the Bits \& Pieces in the archive of the Filmmuseum - we know that this is a skill that is not natural, but can be learned, culturally acquired. The making turns this view into a poetics; the effect targets the present; the diachronic perspective makes it historical, not just structural; and the work that makes sense of all this, is archival.

To make my case for an archival poetics as truly poetical - as making, forging what it presumably only stores - I put forward the following claim, hyperbolic as it may sound. The act of making the tapes Bits \& Pieces is a creative act of discursivity, specifically of narrative discursivity, making visible, and hence, speakable, something that only later could become "the Western." That later Western is now firmly a thing of the past. But as such we need it in the present. The archive's bits, in contrast, are meaningful as models of a retrospective hold on the past that sustains us in a present that is just as confusing, exciting, and yielding on the condition of being, constantly, made: that of the new media. Therefore, I end this chapter with a speculation on some general features of narrativity in films that explain why their archival status itself would be attractive as a model for current screen culture.

This is so because the paradoxes and tensions around narrativity turn the archivally-produced "early Western" into both an emblem of archival poetics and a model for a history of the present. This Western speaks to a culture where "the archive" fascinates that culture suffering from amnesia and caught up in new narrativities. These, no more than this emerging and unstable genre, have pre-existing plots, forms, and structures. Instead, this closure can only be produced by the viewer, the cultural agent in charge of the making, as is the case with present cultural modes and practices as well.

The nostalgic element in our looking back at the past is also invested in the materiality of the bits that testify to a time now gone, when "behind" the screen were things. This, finally, makes the current fascination with the archive understandable. For the obsoleteness of that object status turns the archive into a place of worship, and the fragmentary state that reigns there, "objectively," reassures us about the fragmented state of present screen culture. There is loss, to be sure; but the object of longing and mourning resists absolute loss if it can be integrated in a similarity with today. This also explains why narrativity has such a key role to play in this consoling integration. For, the task of reintegration is attributed to the de-authorized narrativity that binds archivalism to hypertextuality. The example presented in the introductory chapter, landscape, illustrates this. In the dialectic between the force of narrative, the motor that propels the film, and the viewing of it, a dialectic where narrativity is the counter-force of display, landscape may serve as a metaphor and narrative as a con- 
nector. Hence, then, the exemplary role played in my story by the genre that integrates landscape and narrative: the Western - genre of the future, narrating the past.

\section{Notes}

1. "In menig filmarchief verdwijnen [...] fragmenten in de afvalbak. Ze zijn lastig te catalogiseren, en wie zal er ooit nog een blik op willen slaan als er zo weinig over bekend is? "Maar ze zijn vaak zo mooi...." verzuchtten we steeds weer in ons wekelijks overleg. Uiteindelijk bleek de oplossing om van de mooiste fragmenten een kleine collectie te maken. Eric de Kuyper bedacht dat ze bits $\mathcal{E}$ pieces moesten heten. [...] Nu worden deze snippers, elk met een eigen nummer, bewaard en vooral gebruikt, dat wil zeggen: vertoond. Want al die flarden film lijken uitgevonden om ermee te spelen, ze door elkaar te husselen en om te zetten in nieuwe filmervaringen" (my translation). Delpeut (1997: 82).

2. Although digital storage on computers and access through Internet do permit images to be "saved," the speed and overload of information makes the act of accessing and processing overwhelmingly more important than storage.

3. Incidentally, the title Bits \& Pieces will later become linked to a notion that will otherwise remain a bit marginal in my project: the Lacanian notion of "the body in bits and pieces" indicating the perception of the infant of its own body as notwhole, during the pre-symbolic, imaginary stage. $\mathbf{S}$

4. On this particular argument, in relation to the Lacanian fantasy of the body in bits and pieces, the reader is best referred to Kaja Silverman's study The Threshold of the Visible World (1996: esp. 20-27).

5. There is another reason for this acute interest in archives in the present time. If anachronism is inevitable, if it is even necessary, in order to exist in a fugitive present through a vested interest in our self-constructed past, the cultural state that informs the interest in the archival might well be the digital revolution with the prominence of Internet and its new sense of "text," that differs so fundamentally from the task we now know to be hopeless, that of restoring. For truly historical reasons concerning the history of the present, then, I propose to replace the archaeological metaphor with the archival.

6. I use the definition of hypertext and hypermedia as analyzed and defined by George P. Landow. See especially his Hypertext 2.0 (1997). I take standard narrative theory, mostly in the structuralist tradition, as a starting point and not an end point. See Mieke Bal (1997) for terminology.

7. "Vrouw en kinderen worden belaagd door boevenbende." Production information is also given: c.1910, Edison.

8. Of course, since video tapes are viewed according to a standardized speed, the length on video tape does not match the actual length of the archival copy, but I provide this information just to indicate the short duration of the fragment.

9. Aristotle's Poetics already shows an awareness of this, as its author demonstrated in his theorization of catharsis as the wholesome effect of tragedy on its viewers. For an 
excellent edition and commentary of Aristotle's Poetics, see Dupond-Roc and Lallot (1980).

10. As a study that successfully integrates historiographic principles within the analysis of media texts I want to mention here Zielinski's Audiovisions (1999) which offers a true archaeology - or: "anarchaeology" as Zielinski calls it in his preface - of film and television within the broader history of audiovisual media.

11. I take my cue from Landow's analysis of the way hypertext blurs the distinction between author and reader. (1997: esp. chapter 4 "Reconfiguring the Author") About the authorship of interactive, digital texts, see also Janet Murray's excellent Hamlet on the Holodeck: The Future of Narrative in Cyberspace (1997).

12. A sample of the Bits \& Pieces collection is presented on a 2003 DVD presentation of Highlights From the Collections 1896-1996, produced by the Filmmuseum.

13. I borrow this name from the Orphan Film Symposium, first held in 1999 with the name "Orphans of the Storm: Saving 'Orphan Films' in the Digital Age," at the University of South Carolina, Columbia, SC.

14. For an extensive analysis of the question of details, including their differentiation from fragments, see Naomi Schor, Reading in Detail (1987).

15. For this distinction of monumental importance, see Foucault (1972: esp. 138-140).

16. "Expeditie in weids landschap, Verenigde Staten."

17. "Cowboy hangt vijand aan een touw boven afgrond. Onder het touw laat hij een kaarsje branden. Verenigde Staten."

18. "Een fantastisch duel. Twee locomotieven loopen tegen elkander met een snelheid van 100 kilometer in tegenwoordigheid der bevolking van Indianapolis."

19. "Machinisten en stokers springen van de locomotieven een oogenblik voor de samenstoot." 


\section{City Limits}

It is the effete Easterner who demands crude hand-to-hand melodrama: he loves it for its tingling novelty. But knowing how incongruous such drama is with the conditions of his own tepid and well-policed existence, he must needs turn to the West where he fondly supposes anything may happen.

- Nickelodeon, $1911^{1}$

Let us now turn to yet another, paradoxical, characteristic of early Westerns: their roots in urban life. My argument in this chapter is that the Western was the creation of the West's opposite: not the East as a geographical location, but the city as the discursive location of "us" which produces the myth of its Other, "them." This discourse of opposition may be clearly seen in reviews of films, whether on the level of their content (stories about the West as opposite of East) or of reception (the alleged reasons for judgments). Reports about Eastern, urban "naïveté" in the evaluation of realism and authenticity of the films alternate with pieces that explain how filmmakers "fake" Western locations and with anecdotes of how the "city dwellers" confuse movie actors with real bandits or Indians. $^{2}$

Such anecdotes in fact promote the realism of the movies, an agenda that shines through in the Motography article "Crazed by Indian Actors," which describes how a New Yorker, recently arrived in California and believing in the image of the Wild West, is frightened by actors:

"This is a fine country you have out here," he said. "I am just in from New York. Thought it was wild and wooly out here." He seemed sane and intelligent and conversed along rational lines. At Garvanza Inn a troop of moving picture actors swarmed aboard the car. They were dressed in vivid wild west style and guns and knives protruded from their belts. One of them emitted a war whoop to amuse a crowd of children gathered about the car to witness their departure. The New Yorker, who had been looking at them wild eyed, clenching the sides of his seat with his hands, suddenly leaped to his feet as the "Indian" yelled. With a cry of terror he ran to the end of the car and began emptying his pockets of money.

This strange behavior is explained by the fellow's Eastern background. The writer's condescension is conveyed through his opposition of the Eastern adult and the Western children. The adult is scared, the children amused. The man's East- 
ern identity is the cause of his acceptance of the movie version of the West as reality, and his urban lifestyle accounts for his high-strung nerves:

"This is the most peculiar case which has ever come to our notice," said Police Surgeon C.A. Wright in the receiving hospital. "The man has literally been scared out of his wits. We will give him the best of care and with plenty of sleep he may recover from his shock. It is doubtful, however, as his nervous system appears to have been run down by overwork. He is evidently a tourist who has come here for a rest." 3

The word "shock" is significant. The noun begins to occur regularly in contemporary accounts of modern life. It is a key word in Baudelaire and will become a key concept characterizing modernity for Walter Benjamin. ${ }^{4}$ Typically, here, shock is explained in relation to the strain of urban life, although it is precisely this causality that makes the police surgeon doubt that the shock can be cured. This rather grim view of tourism as medically motivated suggests that the Easterner would be better off just watching movies instead of the set. This particular text suggests, though, that one motivation for going West was precisely to taste some of the adventure the man had seen on the screen. ("I I am just in from New York. Thought it was wild and wooly out here.'") He had not foreseen that he would be so scared. Yet the shock occurs because his expectations were met. This story ironically makes fun of silly Easterners, while at the same time reassuring moviegoers that maybe they can experience some adventures in the West without going as far as this fragile urban dweller in search of a cure.

Clearly, then, the West is the product of life in the modern city, whose innovations that had transformed daily life continued to shock its inhabitants. The city is the location where the writers, the production houses, the readership are located. It is the site of production and consumption of the culture of the West. Recycling and deployment of images in poems, song, and dime novels occurred as frequently as the other way around, i.e. when literary texts were adapted in images. 0 This mundane level, the commercial and industrial situations, is continuous with a more ideological level. These two levels are entwined, and if we aim to understand the latter the former cannot be ignored.

Although this situation - the "West" being the product of the modern city holds for the Western of the period in general, the emblematic representation of this paradox is a stock figure that occurs in some films in which the paradox of old and new, archaic and modern, West and East, is a central theme. The figure of the "Cowboy in the city" is both the clearest embodiment of this idea and the symmetrical counterpart of our unfortunate Eastern tourist. His appearance, as well as that of related figures such as the "Indian in the city," or the more familiar "Rube in the city," achieves effects that demonstrate how deeply the impact of this reversal affects the films. 
I present this figure as a carrier of one or more three major effects. A most obvious effect is the comical one based on contrast. This can be seen in THE Cowboy Millionaire (1909, Selig) and in An Up-TO-Date SouAw (1911, American Kinema), films about Westerners going to the city, as well as in the reversal of this principle in LosT AND WoN (1911, Selig) about an Eastern office clerk going West to become a wealthy oil magnate. These films are generic comedies. The figure of the displaced person is a device that comedy has long deployed. The figure displaced between wild and urban, or between "nature" and "culture," has been the motor of comedy ever since the Enlightenment's confrontation between a self-confident Europe and its "others." Comedy works through a contrast between the figures and their cultural identity, a contrast that has a long tradition of generating ingénue views of worn-out knowledge. ${ }^{5}$

But a second altogether different effect can be detected, where harmony is invoked to reassure urbanites that the country can ultimately come to terms with its founding opposition between wilderness and civilization. THE Cowbor MiLLIONAIRE, for example, demonstrates this, as I will show below. A third effect feeds the nostalgic longing for the recent past. Examples of this effect are the temporal shifts made in films between modern urban environments and a "notyet"-archaic life beyond the city limits. Different lives, places, and characters are temporally coeval, but geographically separate. Examples include [DE ConcurRenten] The Competitors (c.1912), The Eleventh Hour (1914, Bison), Across the Great Divide (1915, Edison), and the Italian Westerns Nel VORTICE DEL DEstino [In the Vortex of Destiny] (1913, Savoia Film) and Nel PAESE DELL'oro [In the Land of Gold] (1914, Cines). In these films, the fleeting past is still present somewhere, as an after-effect of a pre-modern state. But rather than a strict separation of the conflicting oppositions we find in later Westerns, in these cases the early Western is a meeting ground of modernity and pre-modernity.

In most films different characters embody this split, but in some cases these oppositions are united in a single character, thus symbolizing the characteristics of nostalgia that suggest closeness-through-separation. This narrativization of city limits is an instance of myth-making by means of erecting contrasts. And that this is not at all a "cultural unconscious," but a common preoccupation, cannot be more persuasively demonstrated than through the following comment in the New York Times from 1911:

What kind of plays do the different parts of the country prefer? Well, the East makes a strong and steady demand on plays of the wild West. The West, which knows better, will have none of them. A Denver man who wears a dinner coat at the proper time of day can't be convinced of the reality of a play that shows him wearing a sombrero and chaps. But the east side of New York, which believes that Wild Bill is still doing business and that Calamity Jane roams the prairies to this day, eats such plays up. They are exported to Europe, where they find a steady popularity and a strong de- 
mand, although, say the moving picture men, Europe takes just as kindly to a scene of life on the Atlantic coast as it does to a Buffalo Bill or Jesse James show. ${ }^{6}$

The cowboy in the city, then, triggers effects of comedy, of harmony, or of nostalgia, three moods that share a common engagement with the West as "other."

If it has become clear that the cowboy in the city can indeed be taken as an embodiment of a significant feature of the early Westerns - their roots in urban life - I would like to explore a few other, specific features of this principle of myth-making through contrast. One is the absence of any specific form of dwelling. These films are set on unspecified pathways and roads that preclude identification as "typically Western." The action and dress carry the burden of framing the film as Western, but the feature that is allegedly the most characteristic, geographical location and landscape, leaves room for an ambiguity that facilitates harmonizing the Eastern longing for the West with its other. This lack empties out the geographical specificity on which the genre otherwise thrives, and makes the question of setting moot.

The occurrence of another kind of setting, which shows the uneasiness with the othering of the West, confirms this interpretation. I am referring to a setting that is ambiguous in a different way, where a village represents an intermediate space that is neither "wild" nor urban. Here, it is less the lack of specificity than an overdetermined specificity that produces the ambiguity. This is so because the ambiguity is not geographical but ideological.

In this context, I must also mention the relation to landscape, although I will discuss this further in other chapters, most notably in the chapter on landscapes. $\mathbf{L}$ Here, it is important to include a feature that characterizes many films, and that points to the uncertainty of location in yet another manner: the phenomenon of interior shooting. In interior settings, social class and its attendant ideologies are often played out. High society, represented as urban, is portrayed as corrupt, and is, in that sense, opposed to the honesty, the simplicity, and the sobriety of life in the West, where the Westerner is sometimes rewarded, for example, by an oil strike or a love interest. A review of THE RusTLER (1911, Selig) points out the grandeur of the scenes set outdoors:

The pictures showing the horse round-up are magnificent in their sweep and largeness of motion. How much finer is this than a narrow room with painted settings and Jack making love to Gladys on the sofa! It is this element of the big out-of-doors with its sweep and freedom, that makes Western subjects so attractive to the city shut-ins. Melodrama has no thrill to compare with the thrill of big old nature. ${ }^{7}$

Nature as a thrilling and exotic site for escapism for the urban population is a feature in different film genres. Travelogues, for example, make possible vicarious travel to all corners of the world. Adventure mixed with far-away locations is a powerful blend and Westerns provide both attractions. Through the con- 
trasts set up in these "East-versus-West" plots, however, the world of the Western is more explicitly related to the urban perspective that produces it. Films that are about the West, the city, and their limits illustrate this most emphatically. $^{8}$

In 1909 Selig, the Chicago-based film company that was famous for its Westerns, released the film The Cowboy Millionaire. Selig first sent a crew to California in 1907, established a studio in Los Angeles in 1909, and filmed Westerns "on location" in their branch studio in Colorado in 1912 and 1913. ${ }^{9}$ This film tells the story of a cowboy who lives in the West, but moves to the city, where he has problems adapting to his new life. Contrast is the motor of the film's plot.

The opening of the film presents a typical Western scene: the main character is a cowboy who plays around with lassoes and horses, performing rodeo tricks with his friends. After this scene, which takes up several minutes, a transition from the West to the East is staged when the cowboy inherits a fortune and moves to Chicago where he starts his new life. He meets a girl, gets married, and moves into a huge mansion. After some time, he becomes homesick and invites his Western friends to visit him. When they arrive they ride their horses through the city streets, shooting in the air and scaring passers-by. This scene confirms precisely those anecdotes, like the one about the New Yorker quoted above, that stage tourists who are frightened when they encounter acting cowboys. It cashes in on popular accounts of cowboys' rough lifestyle and the cultivated Easterner who is shocked at this behavior. Conversely, the cowboys visit a theater where they mistake the Western play being performed there for the real thing and shoot at the bandit on stage. After this, the cowboys re-

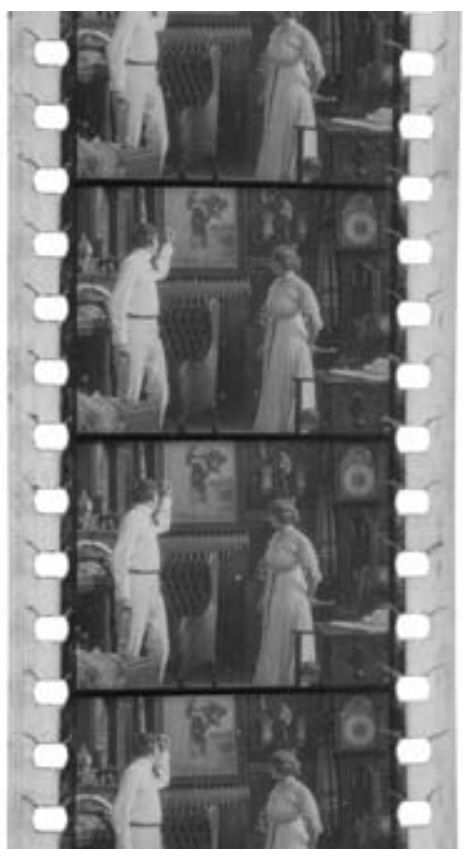

C1 A Cowboy Millionaire (1909, Selig) turn to their homes in the West. Although he had been dreaming about the life of his friends in the West, the cowboy millionaire now decides it is time to break with his past. Symbolically, he flips over the Frederic Remington painting of a cowboy on a horse that he had kept in his living room.

Many key elements of what we can consider "typically Western" are condensed in this film. The story is a comedy, based on a parody of the Western with the emphasis on such elements as riding and shooting, naïve beliefs in the 
reality of representation, and a childish cheerfulness. These parodic elements substantiate my claim, underlying this study's title, that even the "beginning" of the Western flaunts its Nachträglichkeit. These Western elements are displayed in a spectacular way at the beginning of the film, as a main attraction, but are later the basis of some comical scenes when the Westerners are literally taken to the East. The clash of these Western elements with the city environment turns this film into a self-conscious reference to the genre. Almost half the film consists of rodeo stunts like the performances in Wild West Shows, displaying action scenes in a way that is very similar to earlier films

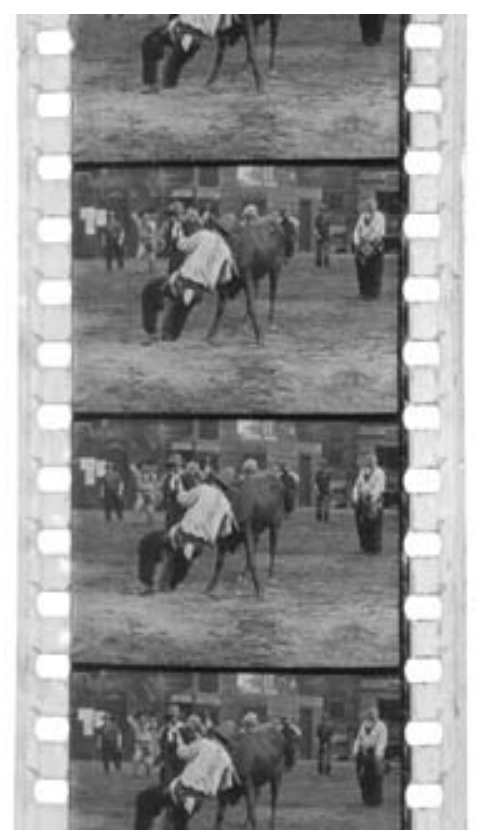

C2 A Cowboy Millionaire (1909, Selig) that are composed of single shots of recorded tricks. In its treatment of this theme of transition from the old life of the cowboy to his new life as a city millionaire, the film seems to comment on various conventions of the Western. Thus, it parodies such elements as the typical behavior of cowboys, the rough innocence of the Western lifestyle, and the sophistication of the cities in the East. ${ }^{10}$

However, the film alludes to many different types of film in addition to the Western. Therefore, it seems too limited to say it is only a parody or commentary on the Western genre. Tag Gallagher points out the "hyperconsciousness" of the genre in the pre-WW I Western. He makes this claim in objection to evolutionary schemes that are projected on the Western, so as to suggest that over the decades it evolved from "classic" treatments to "parody" (1986: 202-206). He situates the early phase of Western filmmaking, in which the genre was self-consciously parodied, as early as the 1909-1914 period. Although I certainly share his objections to evolutionary genre histories that ignore the early years of cinema, I would like to examine these "parodies" here for a different purpose than genre criticism alone. In $\mathbf{Q}$ I take up the matter of humor and parody from the perspective of generic hybridity within early film culture. Here, however, the focus is on the broader Western discourse throughout the visual culture of the time.

Upon closer inspection, this particular film plays with characteristics of older film traditions (e.g. the single shot films) that are incorporated in new ones, repeating and reforming these, as well as with conventions of other media. The film recycles images and stories (theater, painting, the rodeo and Wild West Shows), not merely referring to these forms, but also repeating them in a "new" form and adding to them. It adds to these older conventions and techniques the 
visual spectacle of the film medium, it plays with the possibilities of incorporating an elaborate narrative, it condenses time and space by visualizing travel, the passage of time, and dream images. This elaborate mixture speaks of more than hyperconscious parody; it also speaks of exuberant enthusiasm for the new possibilities that allow the adoption of conventions in altogether new wholes.

Hence, it is important to realize that this film did not stand alone in its time. Parodies, when defined as stemming from "hyperconsciousness," work when they are, more or less, singular moments of rather unexpected reversals, or other kinds of commentary on conventions. In fact, this film is not so singular, but one example among many films of this period that feature the theme of cowboys or other country dwellers in the city. For example, in Nickelodeon the film The Education of Elisabeth (1910, Kalem) was reviewed and criticized for basing its humor on facile East/West stereotypes:

Here the producers have tried to contrast the effete culture of the East with the rough vitality of the West, all to the advantage of the latter, of course. But the piece fails to prove much, for the Easterners, though effete, are not cultured, and the Westerners are not so much rough as rough-house. The treatment of both sides is farcical, and consequently the argument is sacrificed to a few laughs. ${ }^{11}$

What this reviewer objects to is, precisely, the kind of simplistic parody that we ought not to project on the films in general ("farcical", "a few laughs"). The writer makes a claim for a more serious treatment of the theme ("the argument," "sacrificed") of contrasting cultures. Like this critic who objects to the treatment of this contrast as comical, I want to argue here that the comedies about the West-versus-East involve more serious ideas and emotions than mere laughs. So let us set aside for a moment the question of whether or not we can call these films parodies, and examine their humor more closely in terms of a critical commentary on displacement.

Some examples of "situation" comedies about displacement, like Cowbors' DAY OfF (1912, Broncho Films), a film about cowboys at the Coney Island amusement park, The Taming of Wild Bill (1910, Lubin, 1910), and The Call of THE West (1912, Champion), can make this critical commentary clear. In THE CALl of THE West the cowboy Bill Smith settles in New York when he inherits a fortune. After some time he becomes homesick for his Western home and when he meets a girl who is traveling West for the sake of her health, he gives up his inheritance and jumps on a train with her back to the West. This story is very similar to The Cowboy Millionaire, but has the opposite outcome. It is remarkable that the protagonist of Cowbor MillionaIRE gives up his Western past while the film shows elaborate scenes of Western rodeo tricks. THE CALL OF THE WEST not only ends differently (the cowboy goes back to the West rather than breaking with his past), but the perspective in the film is different as well. 
Instead of the cowboy's character development, here, nostalgia informs the action. The cowboy misses his home, hence, he goes back to the West, an outcome foreshadowed in the title of the film. In the film there are scenes where he shows a friend the sights in New York. These sightseeing shots are the structural opposite of the Western scenes in Cowboy Millionaire. The city is seen through the eyes of the nostalgic cowboy in CALL OF THE WEST, while the cowboys are shown to the city in Cowboy Millionaire. ${ }^{12}$

The scenes that hold these films together in their similarities, take the Western-urban point of view a step beyond the level of character. The film not only shows cowboys in the city, but also adopts their point of view, or rather, focalization. ${ }^{13}$ This narrative situation is only apparently in contradiction with my earlier contention that the cowboy in the city embodies the myth of the West through Eastern eyes. In fact, the Westerner desiring to return to his own world feeds the nostalgia for the recent, disappearing past from which the city dweller has been cut off. I see an interesting circular movement from showing a cowboy in a "wrong" context, to holding up a mirror to him by showing his colleagues on their visit to the city, providing him the same viewpoint as the movie spectator, to offering vistas of the West and of the city. These films not only comment on the idea of the West versus an idea of the East, but through their supposed contrast they give a tour of the places identified by certain conventional oppositions, such as old-modern, honest-corrupt, labor-industrial, primitive-cultured, and like the self-consciousness that speaks from the urban-West contrasts also implies a vision of the other, which I will explore further in the next chapter.

\section{Notes}

1. From: "The Passing of the Western Subject." Nickelodeon V, 7 (February 18, 1911): 181-182; emphasis in text.

2. To avoid a political anachronism and conform to early-2oth century usage, I refer to aboriginal or First Nations people as "Indians." I use quotation marks when I speak from the present, looking back, and I use the term without quotation marks when rendering contemporary sensibilities.

3. Motography V, 5 (May 1911): 92.

4. For a lucid introduction to Benjamin and other major philosophers of modernity see Frisby (1985). The classic study of Benjamin's philosophy of modern life in his arcades project is that of Susan Buck-Morse (1991). For relevant discussions of shock in relation to the (early) cinema see, for example, Charney and Schwartz, eds. (1995), Friedberg (1993), and Singer (2001). See also the chapter on modernity. $\mathbf{M}$

5. This trope was particularly popular during the Enlightenment, which as it happens, was a similar period of discovery and conquest. See, for example, Montesquieu's Lettres persanes (1721), a fictional correspondence between two Persian gentlemen 
traveling in Europe and their friends and servants in Asia; and Voltaire's Candide (1759), a tale of an ingénue European traveling in foreign countries. The comical effect serves the higher purpose of social criticism in these works.

6. "Is The Moving Picture to be the Play of the Future?" New York Times (August 20, 1911).

7. Nickelodeon V, I (January 7, 1911): 23.

8. Studies about the classical Western that analyze the Western myth as based on fundamental oppositions such as the one between the city/civilization and the West/ wilderness are those by Jim Kitses (1969), John Cawelti (1971) and (1999), and Will Wright (1975). Wright, for example, states in his preface that the "Western, like any myth, stands between individual human consciousness and society. If a myth is popular, it must somehow appeal to or reinforce the individuals who view it by communicating a symbolic meaning to them. This meaning must, in turn, reflect the particular social institutions and attitudes that have created and continue to nourish the myth. Thus, a myth must tell its viewers about themselves and their society." (2) At the 1997 conference on early Westerns, Back in the Saddle Again, which was held at Utrecht University, Deniz Göktürk introduced an intriguing case of films about, precisely, city limits. She defined a German hybrid genre of the 1910s, the globe-trotting adventure film, in which "Western" episodes may feature as individual segments of a longer chase. These episode films usually start in a city environment where a chase begins that quickly moves out of the city, into the "wild" and exotic, but clearly "shrinking" world. Her examples clearly demonstrate how these films play on a dichotomy between the city and the "rest of the world." Different film genres such as the travelogue, chase film, melodramas, and Westerns are combined in these episodic films, and the different locations invoke the different filmic tropes associated with each genre.

9. For a short history of the Selig Polyscope Company, see Fernett (1988: 207-213). A contemporary article on the Selig company entitled "Wonders of the 'Diamond-S' Plant" by Eugene Dengler was published in Motography I, 1 (July 1911): 7-19. Musser (1990: 474-478) gives a short history of the company in $1906-1907$, the years before the Nickelodeon boom. David Emrich (1997) gives a history of the film industry's "pit stop" in Colorado on their way to Hollywood and specifically the Selig production of films in this region. He frames the production of films about the West by this company with the (similar) migration West of the industry.

10. This structure of recorded stunts is reminiscent of the Kinetoscope films (including one of Annie Oakley), but also of later films such as Broncho Busting ScenEs, Championship of the World (1902, Edison), A Bucking Broncho (1903, AM\&B), BuCKING BRONCOS (1904, Edison), or the parade of the same characters in PARADE OF Buffalo Bill's Wild West Show, 1 and 2 (1898, Edison) or Buffalo Bill's Wild West PARAde (1902, AM\&B). It also displays similarities with the documentary-like Herd of CATtLe (1901, AM\&B). More contemporary examples are A Round-UP IN Oкцанома (1908, Oklahoma Natural Mutoscene Co.), and The Wolf Hunt (1908, Oklahoma Natural Mutoscene). These filmic "attractions" are discussed in later chapters.

11. Nickelodeon IV, 10 (November 15, 1910): 280.

12. At the above-mentioned 1997 conference Back in the Saddle Again, Peter Stanfield offered an excellent reading of Cowboys' DAy OfF and pointed out how the cowboy 
can be seen as a mobile figure who questions the authority of the "Establishment", thereby appealing to the urban working classes. See also his recent Hollywood, Westerns, and the 1930s (2001). For a review of The TAming of WiLd BiLl, see Variety (November 19, 1910). The Call of the West is reviewed in Universal Weekly I, 6 (July 27, 1912): 30.

13. Focalization is the center of attention that is the direct object of narration. I wish to make a distinction between this and the more strictly visual "point of view" in the sense of "landscape view." See Bal (1997) who developed this concept. 


\section{Deconstructing the Other}

"The Trapper and the Redskin" is the conventional border drama as shown in moving pictures, except that in this case the Indians are something like the real thing in dress and appearance and the acting both of the aborigines and white people convincing. - Variety, $1910^{1}$

Lest we take a condescending view of this early form of the othering, a view that so plagues our present cultural moment, the other side of the coin needs exploration. For, if the us/them discourse may betray an impulse that runs counter to the documentary ambition to represent the West, this does not mean that it is completely successful in its compulsion to othering. Within many films there is a kind of internal, self-defeating logic at play, which undermines its own othering. In this chapter, I will look at the way this self-deconstruction operates by looking at the integration of four related phenomena. The first two integrate the Wild West within (urban) cultural life; the second two question the very possibility of its representation in ethnography, museification, transvestitism, and the theme of assimilation.

To avoid participating in the current loose usage of the term deconstruction to the detriment of conceptual clarity, let me risk, rather, rehearsing the obvious, focusing a position in the philosophy of language on a cultural phenomenon that is essentially visual. As has been explained by Jonathan Culler (1983) among others, deconstruction is a perspective from within the utterance that critiques its inherent contradictions. The presence of contradiction within utterances is neither new nor surprising. Utterances, or statements, expressions, works, images, or films are bound to be inherently contradictory. This is so, because they are structured and hence, made understandable, by means of a binary logic that is logically untenable. The unpacking of the untenability of the logic that nevertheless underlies the utterance is the activity called deconstruction. Deconstruction, then, is not the opposite of "construction," although constructions, by virtue of the poverty of their building blocks, lend themselves to deconstruction. But since deconstruction militates against binary opposition, "opposite" would hardly be the appropriate term at all.

What, then, can self-deconstruction be? This question will be answered by the analyses in this chapter. Basically, three positions can be distinguished in relation to the activity of deconstruction and its alleged agent. First, the usual view 
is that the critic deconstructs the text. The critic, that is, "unpacks" the contradictions "hidden" in the text's apparently logical smoothness. Without the intervention of the critic, the contradictions and tensions might easily pass unnoticed, precisely because they confirm the ideology the text constructs. Alternatively, the text or object demonstrates and foregrounds its own logical tensions. In that case, we are facing a self-deconstructive utterance. But, thirdly, the demonstration can also go both ways. The critic, then, further unpacks the object's tentative, imaginative, or implicit unpacking. Here, we may assume a division of labor between artwork and critical text, although, according to deconstruction, such division of labor by no means implies an essential difference between the two types of texts. On the contrary, the porous distinction between a "primary" or "literary " text - here, the film text - and the critical commentary about it, is best exemplified by this third situation, where the utterance self-deconstructs, but requires the commentary to make that self-deconstruction visible. It is this third position, then, that this chapter demonstrates.

The object of deconstruction, in this chapter, is othering: the representation of the assumed public's other, here, the Indians. Othering Indians posits the audience as White, which connotes "civilized" and "modern." Deconstructing that othering would, then, imply an uncertainty concerning the self-evidence of the audience's whiteness. It shows its hand in four modes of display of the other as such. First, conventional othering happens in the well-known ethnographic elements in (early) films, already studied by others such as Alison Griffiths (2002) and Jennifer Peterson (1999). Some of the many dance titles such as Sioux Ghost Dance (Edison, 1894), Buffalo Dance (Edison, 1894), Hopi Indians Dance for Theodore Roosevelt at [Walpi, Arizona] (1913) suffice to evoke this phenomenon. Second, display as a cinematic rhetoric of representing otherness can be seen, for example, in the relation between Westerns and the World Fairs of the time. Cinematic recordings of exhibitions at fairs such as EsQUIMAUX Leap-Frog, Esquimaux Village, Esquimaux Game of Snap-The-Whip filmed by Edison at the Pan-American Exposition in Buffalo, NY in 1901 demonstrate this relationship between film and exhibition. $\mathbf{V}$

The othering of Indians is by no means automatic. On the contrary, specific, quite sophisticated devices are put to work to accomplish the effect. For example, quotes from paintings and photographs serve - paradoxically, since they use "stillness" in the moving image - to put an emphasis on the "vanishing" of the Indian. This leads to a second site of self-deconstruction. The conventional ante-text - the still image - thus becomes an active force in a representational strategy. From medium, painting and photography are transformed into interdiscourses, accruing metaphorical status and meaning. But this metaphor for stagnation and the ensuing imminent disappearance also undermines the very possibility of representing the other, of "capturing" them. I would like to pro- 
pose this tension as the moment where film begins to deconstruct the project of representing the West. Museification shows its hand as a form of mummification. The still image evoked, cited, or even incorporated within the moving image thus undermines the transparent representation of vitality that is one of - if not the - primary ambitions of film. Similarly, borrowings and influences from natural history show similarities between display in film and dioramas in museums. This comparison betrays the notion that vanishing equals killing, equals preservation for eternal presence, the killer being the museification that pins culture up in dead display, like a rare butterfly. ${ }^{2}$

A third mode of display as deconstructive practice is the odd phenomenon of white actors playing Indians, which cannot be explained away by professionalism only. For this trans-racial transvestitism may be a familiar film practice, but as a cultural practice it needs some attention. ${ }^{3}$ The "re"-construction of the other is thus foregrounded as the construction of Indian-ness that is avowedly fictitious. This can be considered a deconstruction of the other on the other body itself, not in the rhetoric of the representation of the other.

The fourth and final phenomenon is thematic, when assimilation is foregrounded in the theme of the narrative. I will take this phenomenon as standing in for all four in an analysis of a sequence of film clips, which I present here as a filmic "Museum of the American Indian."

Note that the representations that appear as objectifying forms of othering were made at a time when, after the closing of the frontier, Indians were "officially" involved in assimilation. As a contemporary observer noted in 1900:

Transition, the passing from one state to another; that is the present condition of the American Indian. He has passed from savagery toward civilization through the intermediary stages of rebellion, defeat, ignorance, helplessness, despair, and sullen stolidity; he has been betrayed, put upon, ignored, ground down. ${ }^{4}$

It may need spelling out that obviously, in assimilation all kinds of forms of othering are going on. The Vanishing American is conquered once again; assimilation is a way of disarming, and through assimilation Indians become invisible as such. But here, again, the project deconstructs itself. For undermining differences between Self - white, urban - and Other - Indians of the plains - by putting the latter in the life world of the former and having them assimilate, also casts the Indian within white culture, which becomes mixed as a result. Invisible as assimilation makes them in one sense, however, the presence of Indians as others within white culture stimulates the flourishing industry of imagery of them as other. For example, the drama His LAst GAME (1909, Imp.) is about assimilation of Indians and their difficult life in the city.

A film that exploits the comical effect of this problematic, AN Up-To-DATE SouAw (1911, Pathé: American Kinema), is a comedy about an Indian woman 
who goes into town to buy "white" clothes, which infuriates her traditional husband. ${ }^{5}$ A Romance of the Western Hills (1910, AM\&B) is an exceptional story about an Indian girl who is adopted by white tourists. Initially her assimilation goes well, and she is fascinated by the lifestyle of her new family. However, when her white suitor drops her for a woman of his own race she decides to return to her Indian lover.

Representation of others in a kind of microscopic analysis turns them into a measurable (and decorative) object. The attention in the films to crafts, dances, and other elements of the foreign culture authenticates the representation through a documentary flavor, but it also quite explicitly takes the life out of this culture. If this life is taken out of the people, they are conquered once again. If, however, within the film the life is taken out of the white representation of Indians, we are justifiably talking about a self-deconstruction in the films. My point, here, is not so much ethical - I am not commending such self-deconstructive films for their progressive politics - but primarily theoretical and historical. The self-deconstructions I will point out demonstrate the logical untenability of race relations as they were fantasized, historically, by the culture that produced the films.

These general points are best demonstrated through a series of fragments I have collected - my own Bits \& Pieces - selected for the variety of ways in which Indians are represented. The fragments were taken from the following films, all held by the Filmmuseum:

[Het Nationaal Park in Amerika] National Park in America (c.1918)

The Cheyenne's Bride (1911, Pathé: American Kinema)

The Lieutenant's Last Fight (1912, Bison)

The Witch of the Everglades (1911, Selig)

Rose O'Salem-Town (1910, AM\&B)

A Midnight Fantasy (1899, AM\&B)

[INDIAAN GRIJPT KIDNAPPER] Indian Seizes Kidnapper (c.1910, Pathé Frères)

In what follows, I offer a reading of these fragments in order to show how different visual strategies work to foreground different visions of otherness, different ideologies, fears and anxieties, and, most importantly for this study, different conceptions of the medium about itself. Different gazes, different rhetoric. $^{6}$

Het Nationaal Park in Amerika. The intertitle reads: "Typen van Indianen in het National Park" [Indian Types in the National Park] The camera glides over a river with tepees set up along its banks. The tracking shot taken from a boat lingers over the landscape, as if to establish an environmental context for the inhabitants of this location. Although the intertitle stresses the contained and 
preserved nature of this environment ("National Park"), the natural landscape is used to authenticate the Indians as natural people. Also, because the title announces types as "species," the emphasis on the landscape seems a bit odd. It illustrates, however, the identification of the people with their (endangered) living environment, like the animals in documentaries on the National Geographic Channel.

The shot cuts to a diagonal line-up of eight men, sitting on the ground. One after another, as if on cue, they turn their heads, from looking sideways out of the frame to looking directly into the camera. The ripple of this movement resembles the tracking shot that followed the stream of the river. A formal continuity between the stream, the people, and the camera is thus established. This continuity offers insight into the profound and effective way the medium, through its specific feature of visuality-plus-moving, is able to produce and naturalize a particular representation. Here, by means of a metonymically motivated metaphor, the other is represented as a stream of water, hence, as "pure" and natural, playing on the underlying opposition to "us" as cultural. Moreover, the streaming nature of the vision presents the people as void of individuality. ${ }^{7}$

The next cut modifies this last aspect. It is a little more abrupt. The close-up of an Indian's stern visage in profile, looking out of the frame, brings the object of the image very close. He turns towards the camera, slowly, his face breaking into a smile when he looks straight at the camera. He talks and smiles, his voice unheard in the silent images. More close-ups follow. Five individuals, but announced and thus framed as "types," from the line-up take turns, showing both sides of their profiles, smiling, talking, frowning, looking expectantly at the camera, and nodding in acknowledgment at the spectator. Then they look up focusing on something in the distance while glancing back at the camera as if checking if they are doing what they were asked to do. Their poses resemble at once turn-of-the-century ethnographic portraits within the paradigm of anthropometric classification, tourist postcards, and nostalgic images of the Vanishing American at once.

Looking to a romantic past in the distance they resemble, in particular, the photographs by Edward S. Curtis. At the same time they look like men, getting instructions and smiling and talking to the person behind the camera giving them the instructions. An interesting mix of objectification and a foregrounding of the figures' subject position results. The shot both gives an impression of sympathetic amateurism, smiled at by the participants themselves, and arouses a quite uneasy feeling of looking at these grown men performing tricks on command. The amateurism seduces, the anthropometry objectifies. As a result of this combination, I speculate that the former seduces us into acceptance of the latter. $^{8}$ 
The next shot shows two men and a child looking out through the opening of a tepee. One of them picks up the child and pushes it gently out of the tent; the other is laughing at the camera. The shots produce a playful and domestic image that is also reminiscent of the popular ethnographic images of one of the allegedly universal characteristics of mankind, namely the nuclear family. However, the nuclear family would be a man, woman, and child, not two men and a child. This combination of two men and a child seems to make a point about a different kind of family - a tribal version of it - without violating the allegedly 'universal' characteristic of domesticity. Interestingly, the sympathetic togetherness and the ethnographic othering clearly collaborate very well in a universalistic humanism. ${ }^{9}$

The intertitle reads: "Een Indiaan doet een verhaal met gebaren" [An Indian tells/performs a story in gestures]. A small group is gathered around the Indian who is positioned in the middle of the frame. He tells them, or the camera, a story. Abruptly the scene stops. A long shot shows the encampment. In front of some tepees a circle of people are sitting. A man with a feather headdress gets up and starts dancing. In the background two children can be seen imitating the dance. Four women accompany him on a drum. He turns and, while dancing, looks at the camera. All the grown-ups then dance in a tight circle, looking toward the center, thus allowing the camera to film their backs.

The self-deconstructive effect in this film is produced by the invocation of the first-person narrator. Although many pseudo-ethnographic traditions can be observed in this film, a strong sense of interaction between the object of the image (the Indians) and the subject making the image (the white cameraman) is conveyed as well. ${ }^{10}$ The insistent looking (and laughing) at the camera will become a taboo in later films. Here, there is no pretense of a closed-off (diegetic) reality, something that will become essential for classical fiction film narration ("Hollywood" narration) and of some documentary styles that emphasize an independent reality rather than the construction of the image. Also, the intertitles clearly refer to the location as contemporary and accessible ("National Park"). A combination of these elements conveys the notion that Indians are not vanishing, but kept in a special place in order to prevent them from vanishing. There they can be visited and watched, and if asked nicely, they might do some tricks. This touristic tone is very strong in the film. As the previous shots showed the collaboration of subjectivizing sympathy and ethnographic objectification in favor of a universalism that justifies the latter, so here, objectifying and confining go hand in hand with tourism. ${ }^{11}$

The film was probably made around 1918 (date estimated by the Filmmuseum), which is later than the period I investigate here. However, nonfiction films such as ethnographic films and travelogues did not change as rapidly in their mode of representation or their subject matter as did fiction films. For this 
reason I consider this film relevant for my corpus, in spite of the slight temporal discrepancy. Contrary to the demands made on narrative film, the nonfiction trope seemed to have had a long-term appeal. The basic attraction lies in showing far away places and their inhabitants. In fact, one can question whether in this respect, film culture has really significantly changed. In the commercials, travel films, and ethnographic films of today we can find striking similarities with the images of early nonfiction. ${ }^{12}$

The very early documentary shots that are echoed in Het NATIONAAL PARK IN AMERIKA have established the symbols of Indian-ness in this film. The conventions of landscape films and phantom rides are taken up by the opening panoramic shot. The dancing and the storytelling in sign language bring to mind ethnographic films such as Buffalo DANCE or Esquimeaux GAME of SNAP-THE-WHIP (1901, Edison). The quasi-anthropological interest in the physical features of the Indians is given conventional form in the turning of the heads. As I pointed out above, this trope espouses the discourse of photography and other ethnographic genres. The performances of Indians in Buffalo Bill's Wild West Show that were filmed by the Edison Company had already set the tone for this kind of nonfiction film. ${ }^{13}$

The next fragment is at the other end of the generic scope. THE CHEYenne's BRIDE is a romantic story of the love between the daughter of a Sioux chief and the son of a Cheyenne chief, and the inevitable problems between the two tribes. The opening image shows the two in romantic pose, arms around each other and, again, looking into the distance. The camera, taking the shot from a low angle, emphasizes the picturesque pose, freezing it for a few seconds. The effect of this opening image is to establish this romantic and exotic discourse as the appropriate frame for the story; it has no narrative function. The freezing of the pose echoes the images of the film discussed above, establishing coded, recognizable images rather than telling a story. The costumes of the two figures are elaborate in ethnographic detail. Since costume is one of the stock classes of artifacts displayed in ethnographic shows, this feature gives the film an additional documentary meaning. ${ }^{14}$

It should be noted that the two actors, Red Wing and James Young Deer, are aboriginal Americans (Indians), as distinguished from the often-used made-up white actors. This remark is not to suggest that Indian actors playing Indians roles were exceptional in the early period. Actors such as William Eagleshirt, Mona Darkfeather, Chief Dark Cloud (Elijah Tahamont), and Dove Eye Dark Cloud were famous for their acting talents. Young Deer (who later called himself Youngdeer) also directed films for Pathé's American branch studio, American Kinema. ${ }^{15}$ Also, often performers from Wild West Shows as well as many other anonymous actors played as extras, like the Inceville Sioux or the Indians from Miller Brothers 101 Ranch, lending the films authenticity. ${ }^{16}$ 
However, this type of authenticity was sometimes contested in the press, where, paradoxically, white actors were considered more skilled in producing a better sense of authenticity as desired effect. The preference for using white actors rather than Indian actors for the parts is evidenced in criticisms like the following about AN INDIAN GIRL's AwAKENING (1910, Essanay):

The keynote is one of pathos, and the little Indian maiden makes it ring true with her sincere and capable performance. The rôle is so well-assumed that one is left wondering if the actress is not really Indian. One knows, however, that no Indian could have done it. Only a high degree of histrionic proficiency could have created so well the illusion of naturalness and simplicity. ${ }^{17}$

This striking argument that the "illusion of naturalness" is to be preferred to a sense of "ethnic authenticity" recurs in many similar reviews in the trade press. Since ethnicity is a discursive construction, this practice of made-up whites playing Indians is not so strange in itself for this period. However, the seemingly contradictory practice of using both "real" Indians and "fake Indians" is noteworthy. Perhaps this is why we can see evidence of - sometimes contradictory - criticism of the practice of "red-facing" in film reviews. Phrases like "A good deal of interest is lost through the obvious fact that the 'Indians' are badly made up 'supers'" in a review of Edison's 1907 Pioneer Days (Variety June 1, 1907) offer criticism of the practice, and indicate that "red-facing", unlike "black-facing," is evaluated in terms of realism and authenticity. In a review of Biograph's The Indian RunNeR's RomAnCe (1909) the critic mentions how redfacing is sometimes ridiculous ("a travesty") and sometimes effective in realism ("natural"):

The Biograph actors have done themselves proud in this week's early release. They have actually managed to play a western drama in a convincing way. Particular honors go to the pantomimist who plays the Indian. "Made-up" Indians are usually a travesty, but in this case both in appearance and action the redskin is natural. ${ }^{18}$

Hence, perhaps the combination of both casting strategies within a single film, like THE CHEYENNE's BRIDE, in which a white actor plays the evil character of the rival lover opposite the "good Indian" played by Young Deer, is more significant. ${ }^{19}$

THE CheYenNe's Bride presents the story of two Indian tribes at war with each other and two youngsters in love. The film is violent, and the violence occurs among the Indians. When the two chiefs of different tribes, one Cheyenne and the other Sioux, learn that their children are in love, they challenge each other, and a duel is inevitable, following the same logic as classical tragedies. ${ }^{20}$ There was no need to explain this logic, since it was culturally well known. The plot simply draws a direct causal trajectory from fact to fact, fol- 
lowing a line of fate rather than choice, thus engaging the discourse of tragedy, but without the internal conflict. The two chiefs fight on horseback, barechested and with full headdress, looking quite spectacular. With a knife, the girl's father kills the boy's father. The boy plots revenge, but when he and the girl are caught, the girl is punished by her father. When the father feels remorse for sending his daughter off, strapped on a wild horse, and the boy saves the girl, the conflict is resolved. The boy is freed from the obligation to avenge his father because now he has saved the girl, which puts her father in his debt. Thus, equality is restored.

The theme of the film, rivalry among Indian tribes, is itself rather unusual; more often, in films from this period, Indians were constructed in opposition to whites, and no acknowledgement was made of the fact that there is no homogeneous "race" or Indian-ness as undifferentiated other. ${ }^{21}$ The actor Young Deer, who was responsible for a number of films that are about distinguishable tribes, was one of the stars who countered this homogenizing othering. ${ }^{22}$ In the literary tradition of Fenimore Cooper, Karl May, and in sensational magazines and dime novels, war among Indian tribes is indeed a recurring topic. In fact, stories were often told of Indians fighting amongst each other and the white man solving the conflict, playing the dubious part of the parent breaking up squabbling children. This trope is continued in the theme of good-versus-bad Indians in relation to white characters. Cruelty and nobility can co-exist among Indians (even within the same tribe) and are played out through the exploits and adventures of the white man. I will discuss this in more detail below.

I selected this fragment for analysis to make a specific point. The juxtaposition of this film and the previous one argues a point I will discuss in a later chapter concerning the porous distinction between fiction and nonfiction. $\mathbf{F}$ Both films are about Indians and feature no white characters. The main attraction of both is the visual spectacle and the exoticist representation of the Indians. Both are about "typical" Indian behavior, and both feature the same indicators of "race": outdoor living, the camp and the tepees, the details of costumes, the performances such as dance, the telling of a story in sign language, the frozen poses and the stern gazing into the distance. The difference lies in the way this ethnographic content is constructed. The first film shows a collage-based narrative. The authenticity does not have to be asserted, and the contemporaneity need not be "hidden." The second film is a fiction film, a traditional, classical story about love and conflict and generations that seems to be set in a sort of eternal, a-temporal past. ${ }^{23}$ For the first film, the people are given orders to perform their tricks. In the second film, the story is structured so that the conventional Indian themes stand out: war between tribes, romance, the sense of justice, and the illustration of lifestyle by ethnographic detail. 


\section{KALEM FILMS} (THE NEW LINE)

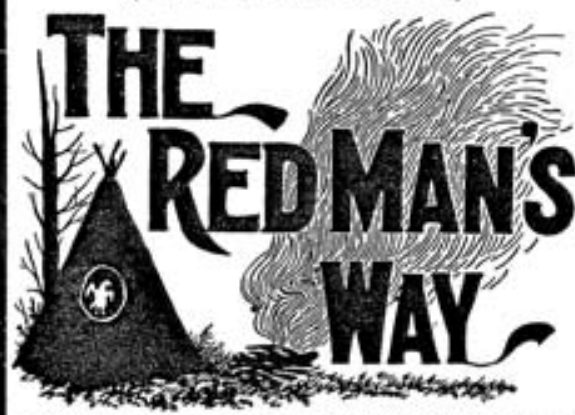

Positively the Most Perfect Picture Ever Made in Motion Photography.

\section{$=$ ELength, 680 Feot.}

IIIt may be sald that we are pattiog it a little strosg whes we claim for "The Red Man"s Way" that it is "the most perfeet pietare ever made." We make the clain however, An good faits and with coefidence that a largo majority of exhibitors will bear us out, Certalinly it thas nover bees exhiblors will bear us out, artistic potograpbic quality equalied in artiastic pbotograpbic quality its standard in sustalned faterest. It tells a story which runs the full gamut of ladian story which runs the full gamsut of lacin. entotion, - how a young squaw, Dove Bye. is belowed of two braves, Raglo Penther and Young Bear. The latter is fawored asd wins his maid in typical indian fastion. Eagle Feather, bowever, demands of the tribe at a coabcil fire that the matter be put to a test of streagth. Yousg Bear accepts the chalienge and defeats Eagle Feather both at foot-racing and wrestisg. Ragle Feather, beaten and disgraced, seeks fevengo, and coming upon Young Bear and Dove Eyes at their woolpg attacks Yoang Betr. A remarkably thrilling doel witb kaives follows and Eagle Featber meets his desth.

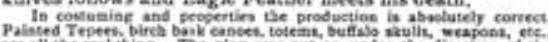

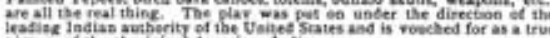

GREAT 1. Dove-Eyes' Lovers.

SCENES 2. Over Laughins Waters.

WITH 3. Young Bear at Bay.

4. At the Council Fire.

CARTOON 5. Young Bear Wins His Bride.

TITLES 6. Death of Eagle Feather.

THE SPRING GUN $160 \mathrm{ft}$.

A ratuliag good short comedy to complete the reel, showing how a farmer aet a trap for chicken thieves and got into it himself.

Next Out: NATHAN HALE RECENT KALEM SUCCESSES CHINESE SUAVE SMLGGING $650 \mathrm{ft}$. Amateur Detective $232 \mathrm{Ft}$ Nature Falirs. $490 \mathrm{ft}$ Wooing of Miles Standist 720 * Regry's Camping Party 705 . Dot Leedle German fland 555 \% A Obe Night Stand - 760 . Who"ll Do the Weshieg? 595 "t The Sea Wolf * . 655 .

KALEM COMPANY, Inc.

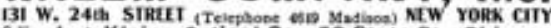
Stling Asmt, Kieine Optleal Co., 02 State $8 t .$, Chicago

D1 Kalem ad for The Red MAN's WAy. Moving Picture World 1, 32

(October 12, 1907): 155
The close relationship between fiction and nonfiction, brought about by the authenticating purpose of the use of Indian actors and a close attention to ethnographic detail in the use of "real" props, was clearly under discussion in the contemporary reception, as we see from an ad for the 1907 Kalem film The Red MaN's WAY:

In costuming and properties the production is absolutely correct, painted Tepees, birch bark canoes, totems, buffalo skulls, weapons, etc., are all the real thing. The play was put under the direction of the leading Indian authority of the United States and is vouched for as a true picture of the aboriginal American Indian. ${ }^{24}$

These words underline the nonfiction quality of the film. The use of the exotic "real thing" for entertainment as well as for educational purposes is highlighted for the purpose of promoting this fictional story about rival lovers and the physical competition that climaxes in the killing of one of the two rivals. No doubt, the conventions of nonfiction films, such as the above example of NATIONAAL PARK IN AMERIKA, set the standards for realism in fiction film. But probably the conventions of fiction films such as THE Cheyenne's Bride or The Red MAN'S WAY, in turn, define 
the ethnographic elements of non-fiction films, make them recognizable, and hence, acceptable. ${ }^{25}$

THE CHEYENNE's BRIDE raises the question whether the generic difference between fiction and nonfiction could be related to geographical and cultural differences among the audiences. This film is an example of a number of Indian films made by the French company Pathé in the United States, using American actors and filmmakers. ${ }^{26}$ These films were distributed widely in Europe. Some films were made in Europe as well. A French Indian film that is preserved today is Coeur Ardent (1912, Gaumont), a love story about two Indians from different tribes, shot in the Camargue. Although a strict difference doesn't hold, it is my impression from the many films I have seen in the archives that Europeans were especially interested in the romantic and exotic variant of fiction films about Indians. If that intuition were proven justified, the generic difference can hardly be objectified in an immanent typology of film genres, but can only be understood in relation to the contemporary audiences and local production practices.

In other words, if my selection here is any indication, films with a European signature are different from American ones, but far from being due to any inherent opposition between nonfiction and fiction, the differences result from the geographical difference of the making and the viewing of the films. These Europe-based films put none or very little emphasis on the oppositional relationship between civilization/whites and wilderness/Indians. ${ }^{27}$ This is not to say that Europeans did not base their representation of the other on the oppositional imagination that underlies the production of "the Indian." Of course, opposition is still implied in these romantic and nostalgic portraits of the "Vanishing Indian." But the opposition is not literally woven into the narrative in the form of conflict. The opposition is merely implied in the sense that the Indians do not exist in the same temporal dimension. Indians in conflict with each other is a safer image of the Indian, less confrontational than images of the Indian as savage attacker, or on the opposite end of the polarization, as victim of the white oppressor who kills off the Indian race and culture. A superior position of white civilization is implied in both cases, but the articulation of that relative position takes a different logical route. ${ }^{28}$

In The Lieutenant's LAst Fight the oppositional logic is worked out in an entirely different mode. In this film the opposition between the two worlds is, in fact, the topic of the film. The film tells the story of Buffalo Big, the son of an Indian chief who goes to a military academy. There he meets the (white) daughter of a colonel and falls in love. Because he is not accepted by the other cadets, they pick a fight with him, and he is sent away, back to the Indian village. His father is furious and plans to attack the soldiers and their women when they 
travel past the village. Buffalo Big is torn between his loyalty to his family and his love for the white girl. He changes into his old soldier's uniform and comes to the rescue. The women are saved, but Buffalo Big meets a tragic death.

In this film the topic of oppositional worlds is foregrounded by contemporaneity: contemporaneity results in contact, which causes conflict. Conflict is thus presented as a "natural" consequence, an ineluctable effect of historical beingtogether in time, of what anthropologist Fabian called coevalness (1983: 30-31). The inability to successfully move between the two worlds is a tragic truth, and the only way to preserve one's sense of justice and uphold a moral equilibrium is to sacrifice one's life for the good of others. There is no possibility of success in this life and therefore, an inevitable choice has to be made between the Indian recent past and the white imminent future.

In the first shot, the actor who plays the part of the hero Buffalo Big is an Indian. But later, when the character Buffalo Big goes to the academy, as if to underline this "travesty" on the level of the story, the actor who plays the part in this sequence is white. He is obviously much taller, and made up as an Indianmade-up-as-white. This undisguised and double travesty echoes the time element of the story. Temporal incompatibility, or the denial of coevalness, is literalized in terms of shedding skin in the changing of clothes to symbolize the movement between the two worlds and the two senses of justice. The figure seems to be undecided about which colors he should wear. At the end of the film he finds his calling and changes wardrobe for the final time. He then wears the "white" army uniform that will later be his shroud.

As far as taking sides is concerned, the film is rather complex. The Indian is the hero, but he has to betray his background to achieve his heroism, a form of self-sacrifice that implies more than just the life of this one individual. Also, the morality of the white army is dubious. The hero is treated badly, discriminated against, lied about, set up. The white women symbolize (feminine) purity and white (Christian) morality. The Indian is allowed to save them, although earlier in the film he had to be punished for his friendship with a white woman. Selfsacrifice is allowed; a mutual friendship based on equality is not. The sexual investment and the risk of miscegenation are too dangerous. Of course, this is a gender issue as well, as we will see later. $\mathbf{Y}$

These heavily invested moral issues suggest that the film concerns the dubious position of an Indian who makes an attempt at assimilation. He ends up in a cultural and social void. He is not accepted in the white world, nor does he feel he belongs in the Indian world any longer. Resenting the wrongdoings of his former colleagues in the army he changes back into an Indian, motivated by revenge. When his (white) sense of justice returns, he will change back into a white man. But assimilation remains a form of contamination, with all its dangers. ${ }^{29}$ Although morally successful, in the end he must die. 
Stories about the impossibility of assimilation and, at the extreme end, miscegenation, have had a long history since Mary Rowlandson wrote the first captivity narrative in 1682, a best-selling autobiographical novel The Sovereignty and Goodness of God, or The Narrative of the Captivity and Restoration of Mrs. Mary Rowlandson. ${ }^{30}$ Fear of the capture of (white) women by Indians was expressed in an excessive fear of becoming an Indian, strongly symbolized by the literally taking over (penetrating) by the Indian of the white body through captivity and/or rape. This fear can be soothed by stories that emphasize the lack of success of this endeavor. In the end the white woman or child will be rescued and brought back to her origins, white civilization.

The Witch of the Everglades is such a story. The film is set in the historical frontier of the $17^{\text {th }}$ century in Florida. ${ }^{31}$ Indians savagely attack a pioneer community. This massacre leaves only two survivors, a mother and her child. An Indian mother in mourning, who wants this child as a substitute for her own dead baby, saves the child from death. The white mother is left for dead among the bodies of her family and friends. She finds her daughter's clothing and, as she has gone mad, she thinks that she has found her child alive and well.

The scene is very powerful, and a strong emphasis is put on the acting of Kathlyn Williams who plays the role of the "witch." She crawls on the floor, laughing madly into the camera, stretching her arms in agony and despair. Despite the acting style based on conventions of 19th-century stage melodrama, further enhanced by the over-acting needed to compensate for the absence of speech in silent film, this scene is still very moving and emotional. A contemporary critic applauds Williams' acting:

An excellent bit of emotional acting executed by Kathryn Williams is the most memorable feature of this film. In the part of a demented woman with witchlike characteristics she put across a conception that was well-defined and dramatically effective. ${ }^{32}$

Indeed, the acting remains convincing, and it clearly demonstrates the move from 19th-century "histrionic" acting style to psychological and verisimilar performance of the period of transformation. ${ }^{33}$ This demonstration, therefore, can be taken as a discursive feature, foregrounding the historical moment of the film, rather than a simple material necessity. For, in spite of this hyperbolic acting, we are made to identify with this mother whose child is not dead, but has been taken by Indians. The politics of acting, here, signifies that being taken by Indians is a fate that, as the mother's visualized madness suggests, may be worse than death. The moving image is moving, then, not only because it moves bodies, but also because it moves emotions in order to move ideologies.

True, some identification with the mourning Indian mother could be solicited as well. For, in the opening scene of the film the death and the funeral of her child are pictured. But the emphasis on the depiction of emotions that we find 
in Williams' acting is absent in this part of the film. Comparing the two scenes, however, it seems that the more important aspect of this first loss of a child is the exotic spectacle of a traditional Indian burial. This would appeal to the audience's lust for exotica; rituals are always very appealing as exotic images of the culture of the other: marriages, funerals, rites of passage, and dances figure prominently in films, museums, paintings, and photographs. Thus, the exotic appeal obscures the human aspect of the scene. This is quite literally a form of othering, where the objectified other has her subjectivity removed.

But costume is not innocuously exoticizing either. The cruelty and savagery of the Indians is underscored by their way of dressing. In the massacre scene they are half-naked, with painted bodies and faces. Regardless of the specific meanings of body painting, I expect that the painting was exaggerated for the dramatic effect rather than correctness of ethnographic detail. For, later in the film, when the child has become a grown woman, the Indian parents are distinguished from the other members of the tribe by the "civilized" clothing they wear. There is no narrative reason for this distinction. Instead, it signifies moral contrast. Being substitute parents, they are morally distinct as well. They cannot remain savages in the story. That would be too frightening and morally dangerous for the film.

When the Indians take Lieutenant Hardy captive, and the white Indian woman (Williams' daughter) saves him from the stake, he recognizes her as being from his race. In reminiscence of Penelope's servant recognizing Ulysses by his scar, the recognition is signified in the film by the comparing of the skin color of their arms. She is able to save Hardy because the Indians believe the gods protect the person wearing her amulet. This prop is, in fact, a medallion from her mother, which she has been wearing since she was a baby. It is a symbol of her background. She does not know she is white when the soldier points out their similarities, an innocence that is put in contrast to the sophistication and, in effect, the supposed cultural and moral superiority of the white race. Hardy then plots to rescue her, restoring the gender balance according to which men save women rather than the other way around. I wish to note here that in the case of films that feature heroines that rescue their fathers, husbands, or children, the enemy is almost never a racial other. Somehow, the danger of a Mexican, Chinese, or Indian adversary is too much for women to handle. Part of the reason for this is the sexual meaning of the rescue of a woman from the savage "other." 34

As an example of a captivity narrative, this film appeals to strong emotions such as fear and danger, as well as a more diffuse anxiety, emotions that are resolved by the happy ending. At first sight, this is a bit ambivalent, since often the captives in these stories do not know they are cultural - say, racial - prisoners. But this logical oddity serves to demonstrate that the target of the aroused 
emotions is the viewer, not the character. The viewer experiences the fear based on identification so that he or she, like the spectator of classical tragedy, can "cleanse" himself of it, in a true catharsis. At the same time, the character's lack of awareness of her imprisonment mitigates the horror of the depicted situation. The situation of a child who was fully conscious of her captivity might be too frightening an idea for a viewer whose primary wish is to be entertained. ${ }^{35}$

The Rose O' SALEM-Town reverses the traditional captivity situation. Here, it is not the Indian other who takes a white victim captive. In this film, the captors are white. The Puritans are supposedly "good" Christians, but as the intertitle announces the bad guy, this figure is called a "hypocritical Puritan." The Puritans imprison a girl who is not charmed by the advances of one of the leaders of the community. She is more interested in a trapper who lives in the woods, halfway between wilderness and civilization. In the first scenes we see her in a Greek dress at the seaside, a poetic girl who is a bit different from the others. The woodsman can relate to her, and they fall in love. He is a friend of a tribe of Mohawk Indians who live in the hills, and they save the girl just before she is about to be burnt at the stake by the Puritans.

The good/bad positions are distributed a bit differently in this film compared to the previous films. The Indians are good, the Puritans bad, and the people that belong in a liminal realm halfway between wilderness and civilization, the girl and the trapper, are best. ${ }^{36}$ This ambiguity that suspends the clear-cut distinction according to which ethnic and moral oppositions neatly and reassuringly overlap, may well be taken to signify the medium's "bad consciousness" about its power to visually impose the "reality" of racial ideology. The superior position of the figures situated between worlds invested with moral value appears an almost overt confession of ambivalence about white culture's campaign for a self-serving, apologetic superiority. The fact that this ambivalence is found in a film set in a more distant past may not be a coincidence. The temporal distance alleviates

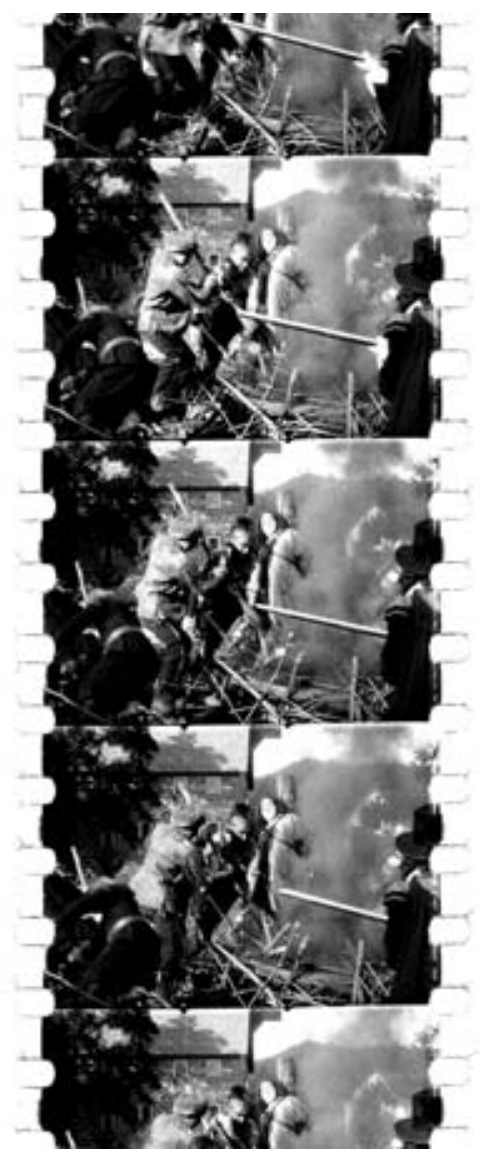

D2 Rose O'SALEM-Town (1910, AM\&B) the anxiety that such a self-deconstruction of the White-Indian opposition cannot but entail. 
The fear of Indians can also be put in a comic guise. Then, the humor easily turns to an inclusive irony, at the expense of the "speaker." A Midnight FANTASY is a kind of short filmic joke and surrealistic fantasy of an almost postmodern flavor. ${ }^{37}$ The film shows a drunken man walking down a street past a poster with a ballet dancer on it. The girl comes to life, and she steps out of the poster frame. He takes her hand, and they are about to leave together. Then, the conventional wooden Indian in front of the cigar store comes to life as well, and attacks the man with a tomahawk and scalps him. He kneels down and offers the scalp to the girl, as a token of his love for her. In this humorous film a romantic bond between Indian man and white woman is allowed. Although the attack of the Indian - the scalping - is rather brutal, it is comical precisely because of the exaggeration and the emphatic lack of realism. Whereas in the previous film temporal distance mitigated the shock of dangerous ambivalence, here humor and implausibility filter the anxiety. Because the frightening event is cast in a dream-like reality, it is less frightening. But the tropes through which this mitigated dream world is created are far from otherworldly. The Indian is a wooden Indian, a common statue that functions as marker for stores selling tobacco, just like the image of the beautiful girl is used to sell the theatrical show that is announced on the poster. Both Indian and woman are fixed, eternalized and objectified fetishes, used as literal signs and exploited for capitalist gain. Their coming-to-life signifies the return of the - ineffectively - repressed of modern culture.

But humor is time-bound and easily loses its readability. Whereas this film is clearly deploying humor as a strategy to perform its ideological work of dealing with ambivalence, [INDIAAN GRIJPT KIDNAPPER] may not have been intended as humorous, however funny the crudeness of the chase in this film may seem a century later. This is a physically spectacular Indian-rescues-girl film that consists mainly of a long and elaborate chase. ${ }^{38}$ The Indian is first unjustly accused of kidnapping a young girl. Thanks to the extraordinary ability to read tracks and marks on the ground that is so often attributed to Indians, he finds the girl and apprehends the kidnapper.

The film was made in France, by Pathé, the French company that would soon set up a branch in the United States and make Indian Westerns in the Eastern regions of the country. The Indian is dressed in a kind of animal fur, looking more like a travesty of a cave man from the Stone Age, a Fred Flintstone avant et après la lettre. Travesty, indeed, belongs to the visual strategies of this film. The other characters, supposedly pioneers living in the West, look like stereotypical gypsies with bandanas, broad-rimmed hats, and golden earrings. The hero's Indian-ness is underlined by his ability to read tracks, to ride his horse, to climb trees and rocks, to chase and capture the bandit, finally dragging him tied-up 
behind his horse. In short, he displays the idealized image of the other that is the vilifying image's counterpart.

This European film does not resemble the quasi-ethnographic nonfiction portraits of my first example, Het NationaAl PARK IN AmeriKa, nor does it look like the fiction films that emphasize ethnographic detail, such as THE CHEYENNE's BRIDE. This film, instead, looks primitive and unsubtle. However, it helps my analysis to come full circle and assess the way the films contained in this selection are all expressions as well as underminings of a whole array of cultural perceptions of the American Indian. The emphatic travesty counters the naturalization of the white-informed image of the other that is the overt thrust of such exoticizing garb. Thus, it exemplifies the effect of self-deconstruction that the imagination of the other owes to the medium of film in its early days.

At first sight, the films may look more explicitly racist than the "New" Westerns, such as DANCES With Wolves or the Disney film Pocahontas, films that demonstrate an attempt at political correctness. But I contend that the transparency, not of their representations of the other as convincingly realistic, but of the construction as such - of the constructedness - deconstructs (the image of) the other. To be sure, this is, in effect, quite totalizing - any reification is inherently a deforming - but this also leaves us, should we seek to avoid the deforming indication - or even the deforming gaze - speechless and sightless. Nevertheless, as a side-effect of the proud self-display of the new medium, the great variety of visual effects and strategies these examples have demonstrated deconstructs the white man's Indian. For in the end, they show not who

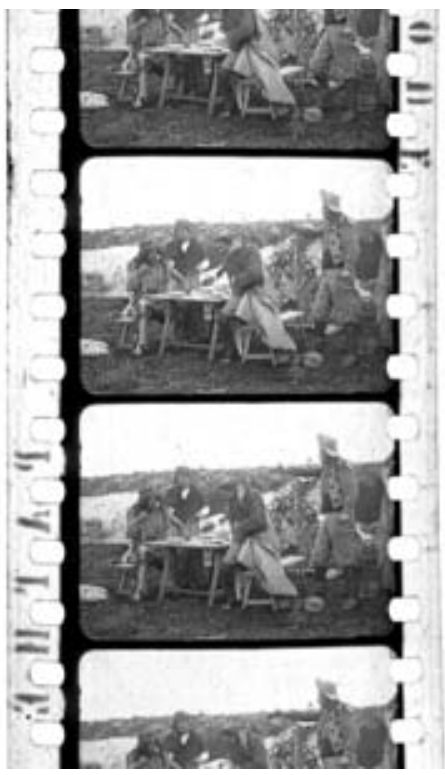

D3 [INDIAAN GRIJPT KIDNAPPER] Indian Seizes Kidnapper (c.1910, Pathé Frères) the other is, but that, unknowable, the object of othering remains ontologically elusive.

\section{Notes}

1. Review of The Trapper ANd the Redskin (1910, Kalem) in Variety (February 16, 1910).

2. See Alison Griffiths (1996a), (1996b), and (2002) for accounts of the relationship between early cinema, museum culture, and ethnographic display. 
3. This phenomenon can be usefully compared to practices of "black-facing" on the one hand, and humorous travesty on the other. Alison McMahan has worked on cross-dressing in early cinema and has given papers on this topic in relation to early Westerns, in 1997 (International Conference Back in the Saddle Again: Critical Approaches to the Early Western Film, Utrecht University) and 1998 (Society for Cinema Studies Conference, San Diego). See also her book (2002) about Alice Guy. I will take up the cases of trans-racial and gendered cross-dressing again in $\mathbf{J}$ and $\mathbf{Y}$, respectively.

4. Mary Alice Harriman, "The Indian in Transition." Overland Monthly and Out West Magazine XXXV, 205 (January 1900): 33-39.

5. For an analysis of this film see $\mathbf{J}$.

6. I composed this small corpus for a discussion of these fragments in a public lecture that I presented under the title "Movies en Moccasins. Indianen gefilmd (18941915)" (1999), in connection with the exhibition Indianenverhalen at the Museum of Ethnography in Leiden. I chose this example because of the conjunction of museum display and a presentation of old films. In this sense, I present a "program," a bit in the way the variety programs were presented at the time.

7. A metaphor whose resemblance between vehicle - here the stream - and tenor - the row of Indians - is established through contiguity is metonymically motivated. See Genette's article "Metonymy in Proust" in Figures I-III (1982).

8. Jennifer Peterson discusses the filmic "inheritance" of conventions of 19th-century anthropometric photography by ethnographic travelogues in her chapter on the "picturesque" and the "ethnographic" in travelogues. (1998). See also Tom Gunning (1995a) who discusses photography as an ambiguously emblematic technology of modernity. It stands for "grasp," control, as well as for innovation and a new system of knowledge. Photography is used for (modern) systems of classification, offering methods of identification. In the tradition of John Tagg (1988), he analyses police photographs, mug shots, and the way these portraits are considered as evidence of crime, the (photographed) body being an icon-index of the crime it had allegedly perpetrated.

9. This ethnographic othering is reminiscent of Edward Steichen's famous photo exhibition, The Family of Man that opened in New York's Museum of Modern Art in 1955. Although obviously in the different cultural context of post-World War II America, the concept of the exhibition was to present a "mirror of the essential oneness of mankind throughout the world," a goal that is similar to the ethnographic treatments of early cinema. $\mathbf{U}$

10. I coined the term "pseudo-ethnography" in analogy to Alison Griffiths' use of the term "quasi-ethnographic" in order to "distinguish such works by non-anthropologists with varying degrees of ethnographic insight from the more narrowly defined applications of film as a tool of field research by professional anthropologists" (1996b: 79-80). The prefix "pseudo" foregrounds the fake quality of the representation.

11. In the final cluster of chapters, $\mathbf{U}$ and $\mathbf{V}$, I will focus more on the practices of virtual tourism, display, and exoticism.

12. Gunning has pointed out how, as a generic style, early nonfiction was much more consistent and stable than fictional styles. Although his focus is on early nonfiction, his words certainly apply to a long-term nonfiction "mode" of filming that we can 
see in the contemporary examples mentioned here. See, for example, his remarks in Hertogs and De Klerk, eds. (1997: 35).

13. For example, Sioux Ghost Dance (1894, Edison) and Buffalo Dance (1894, Edison). Other dance films were Wand Dance, Pueblo Indians (1898, Edison), Buck Dance (1898, Edison), Eagle Dance, Pueblo Indians (1898, Edison). See also my essay on the actuality dimension of early Westerns (2001a).

14. Today, this continues to be the case in many museums where "vanished" cultures are shown through, mainly, artistic products as part of their art collection, whereas "live" (or "vanishing") cultures are exhibited through tools, crops, and costumes. This was clear, for example, in the context of the exhibition Indianenverhalen in 1999 in the Museum of Ethnography in Leiden, the Netherlands that exhibited mainly costumes and household attributes. In this exhibition some attention was paid to the historical cultural construction of Indian-ness, but the old collection of the museum was used without commentary as an illustration of ethnography, and no attention was paid to chronological mistakes or how the collection was established. The exhibition was a mixture of efforts at being politically correct and falling back on older tropes of ethnographic display, literally using the old collection that is colored by older visions of ethnography.

15. Kevin Brownlow (1979) mentions some titles of films that Young Deer directed for American Kinema: The Cheyenne Brave, The Yaqui Girl, Lieutenant Scott's NARrow Escape, and Red DeER's Devotion (331).

16. For a photograph of the cast of the 101 Ranch Wild West Show, see $\mathbf{W}$. In 1894, actors from Buffalo Bill's Wild West Show visited the Edison studio in New Jersey. The films that were shot include some Indian dances, acts from the show: Sioux Ghost Dance (1894, Edison) and Buffalo Dance (1894, Edison). These films can be regarded as both fiction and nonfiction. They are different from the fiction films that feature actors from Wild West Shows in that actual excerpts from the show were recorded in the mode of nonfiction. The (re)staging of these acts of ethnographic display can also be seen as satisfying a curiosity for the exotic. See also $\mathbf{G}, \mathbf{K}$, and $\mathbf{W}$.

17. "Recent Films Reviewed." Nickelodeon IV, 7 (October 1, 1910): 199.

18. Variety (August 29, 1909).

19. Abel (1999: 285n174).

20. A famous case is Corneille's play Le Cid (1636). In this story Rodrigue has to avenge an insult to his father by the father of his lover, Chimène. He is torn between his feelings of honor and of love. His dilemma is solved when he confronts Chimène after killing her father. He explains he had to protect his honor because of his love for her. In the film under scrutiny here, however, the conflict between the two tribes is not really a dilemma for the two lovers that has to be solved for their reunion. The boy's hands are kept clean, and, when the girl is punished by her father for seeing the enemy, he is in a position to save her from this victim position. I wish to thank Han Verhoeff for pointing out the similarities and differences between this classical play and the story of the film. See also Verhoeff (1982). In his essay "The Western: or the American Film Par Excellence," Bazin also compares the typical Western plot with the plays of Corneille, in particular Le Cid, in his discussion of the epic and the tragic in classical Westerns (1971: 147). 
21. But there were other films on this topic. Films that are about Indian tribes in conflict are: [Indianenliefde] Indian Love (c. 1913, Pathé: American Kinema), The Battle of the Red Men (1912, Bison), Hiawatha (1913, Fort Defiance Film Co.), Coeur Ardent (1912, Gaumont) and The Redskin Duel [re-issued as The Death Mask] (1914, Kay-Bee).

22. Abel (1999: 285n174).

23. The denial of temporality is a major feature of othering. See Johannes Fabian, 1983. Griffiths analyzes the tension in popular and anthropological portrayals of Indians between the co-present, or coeval Indian and the "timeless (allochronic) existence suggested in the familiar White image of the Noble Savage" (1996b): 80. Although I will discuss time and what I call time travel in $\mathbf{H}$ and $\mathbf{T}$ respectively, this is a specific issue in the case of the image of the "Vanishing Indian." This topic will recur in later chapters, including $\mathbf{G}$ and $\mathbf{L}$.

24. Moving Picture World I, 32 (October 12, 1907): 155. See figure D1.

25. The ethnographic realism of THE RED MAN's WAY was to be (literally) underscored by indigenous music to accompany the scenes with Indian rituals. Billboard (October 19, 1907): 20, quoted in Abel (1999: 164). Music was sometimes used to heighten the (ethnographic) realism of films, for instance at the screening of HiawathA in 1913. See below. In "The Picture Musicians' Page" in The Cinema (April 9, 1913): 37, a paragraph is devoted to music "for the Indian subject." Here it is clear that what counts as realistic Indian music to be used to accompany the images and heighten their realism, is not necessarily authentic Indian music: "Genuine American Indian songs are, with few exceptions, of little value as instrumental numbers, especially for the piano. There are characteristic 'Indian' numbers, however, written by modern composers which have come to be recognized as Indian music."

26. Examples of other Indian films include The REdMAN's VIEW (1909, AM\&B); Song of the Wildwood Flute (1910, AM\& B); Romance of the Cliff Dwellers (1911, Edison); The Battle of the Red Men (1912, Bison); The Bear Hunter (1913, Pathé: American Kinema); [Indianenliefde] Indian Love (c.1913); The DeAth Mask (1914, Kay Bee). Eileen Bowser (1990) recognizes the Indian film as a genre separate from Westerns. See also Abel 1998b.

27. There is a specifically European literary tradition as well that is focused on portraying Indian life rather than cowboy life. Karl May, of course, is an exemplary author in this tradition. I would suspect the American tradition is different because of the geographical, historical, as well as symbolical proximity to the Indians. Karl May, after all, had never been to America when he wrote his famous books about Old Shatterhand and Winnetou.

28. For a discussion of the Westerns that were made by Pathé's branch in the United States, American Kinema, see my essay (2001b) and J here.

29. On the fundamental fear of contamination and its relation to urban life (here, evoked by implication through binary logic) see Stallybrass and White (1986).

30. Mary Rowlandson spent three months as a prisoner of Indian tribes that were allied against the English during King Philip's War in 1675-1676 in New England. Her account, the first "captivity narrative" published in America, became a bestseller: four editions were issued in the first year of publication alone, and nineteen more by 1828 . 
31. According to Edward Countryman, this period is "the historical basis from which the literary genre and the filmic sub-genre [of captivity narratives] developed." Edward Buscombe, ed. (1988: 79). There are other stories of captivity set in Florida, such as TANGLed Lives (1911, Kalem).

32. Motography V, 5 (May 1911): 99.

33. Roberta Pearson (1992) has analyzed this transition in the Biograph films between 1908 and 1913. Ben Brewster and Lea Jacobs (1998) argue, however, that, what they call, the "pictorial style" was much more persistent than Pearson's account of the transformation from histrionic to verisimilar acting styles suggests.

34. For stories about women saving men, see $\mathbf{Y}$. Examples of films about women taken captive by Indians, Mexicans, or Chinese include L'Indienne Blanche (1911, Pathé: American Kinema); The Winning Hand (1913, Vitagraph); and The FAtaL Hour (1908, AM\&B). In the French film Mong Fu Tong (1913, Éclipse) a cowgirl and her boyfriend are prisoners of a group of Chinese gangsters. When the boss tries to rape her, she stabs him and frees herself and the cowboy. Variants of these stories are films about white women falling in love with Indians who turn out to be whites who were taken captive in their youth, a discovery which legitimizes the love between them, in a fashion similar to the romance between the daughter and the soldier in Witch of the Everglades. Examples of such films include Tangled Lives (1911, Kalem) and White Dove's Sacrifice (1914, Sawyer). In the film LA MARQUe RÉVÉLATRICE [French release title] (c.1912, Pathé: American Kinema) the love between a captive white woman and her Indian adoptive brother ends tragically when he is killed. When she finds his murderer, she discovers that she is white and that the man who is framed for his murder is, in fact, her real brother. In THE CAll of THE Wild (1908, AM\&B) the Indian, who kidnaps the woman he loves, releases her himself and is left with a broken heart. This is a combination of an Indian-self-sacrifice theme and a captivity story. ORPHANs OF THE PlaINs (1912, Pathé: American Kinema) is a positive story about captivity in which Indians adopt a daughter of pioneers when another tribe has killed her parents. When, in turn, the two Indian parents are killed by cowboys, the young son of the Indians decides to take care of the little girl. Other titles of films about Indians stealing white children are the scene "Rescue of Child from Indians" in The Pioneers (1903, AM\&B), ORPhans of The Wild (1914, Pathé: American Kinema), LA flÊCHE empoisonnée (1912, Pathé: American Kinema), and The Redemption of Red Rube (1912, Vitagraph). A variant of this theme is The Zulu's HeARt (1908, AM\&B) in which the Indians are replaced by Zulus and the Western wilderness is here the African wilderness. In this film the "good" Zulu saves a little girl from the other, "bad" Zulus. The theme, plot, and visual aspects of this film are strikingly similar to the Western films.

35. I want to note here that the historical proximity or distance makes an important difference in the reception. The literary (17th-, 18th-, or 19th-century) captivity narratives often told stories of contemporary events, sometimes based on true stories, written by women who experienced captivity as is the case of Mary Rowlandson's novel (1682). Although the captivity stories have held their (sensational) appeal for centuries, an important difference in viewer/reader experience must be made be-

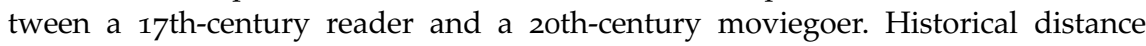
makes a difference in the sense that Indian-white relations have changed dramati- 
cally during these three centuries of white expansion and oppression. Still, stories about women in captivity were extremely popular in cinema. Another type of captivity film deals with white slavery. As the opposite of "frontier captivity," these were stories that sprang from the anxieties aroused by the urban underground world. The Fatal Hour (1908, AM\&B) features these characteristics of "film noir" avant la lettre. A hybrid film about Chinese white slave traders and cowboys in France is The Mong Fu Tong (1913, Éclipse).

36. To illustrate the flexibility of these positions: in MARriage or Death (1912, Pathé: American Kinema), a different group of religious extremists, Mormons in this case, kidnap a girl to force her to marry one of their men. The Indians in this film are on the side of the Mormons and, although they play a very small role in the film, they help with the kidnapping of the girl. Liminality or in-betweenness - mostly spatial signifies the transition celebrated in rites of passage as theorized by Arnold van Gennep (1960), later structurally analyzed by Victor W. Turner (1967) and (1969). Within this conception, the negotiations of assimilation also imply a development narrative, according to which Indians are children. This squares with primitivist fantasies such as those described by Freud, among others. On primitivism in Freud, see Torgovnick (1990).

37. According to Brian McHale (1987) the defining feature of postmodernism is the questioning of ontological certainty. Modernism, in contrast, is defined by an epistemological uncertainty. The modernist question of epistemic access - how can we know? - yields, when radicalized, to ontological doubt: if we cannot know what is, how can we know that it exists at all? I will take up the matter of comedy and humor in $\mathbf{Q}$.

38. The copy in the collection of the Filmmuseum is not complete. The end of the film is missing, and therefore the film lacks narrative closure. Judging from the first part of the film, however, the exposition of the story that shows the cause (excuse) for the chase is very short, and it gives the strong impression that this is really the main structure of the film. This film echoes the many (comical) chase films that were so popular around 1902-1908. For a discussion of the chase film as comic genre, see Abel (1998a: 109-117). Gunning analyses the narrative format of the chase film in $D$. W. Griffith and the Origins of the American Narrative Film (1991a). See also Bowser's Transformation of Cinema (1990). 


\section{Easterns}

In a recent bulletin of the Superintendent of the Census for 1890 appear these significant words appear: "'Up to and including 1880 the country had a frontier of settlement, but at present the unsettled area has been so broken

into by isolated bodies of settlement that there can hardly be said to be a frontier line. In the discussion of its extent, its westward movement, etc., it can not, therefore, any longer have a place in the census reports." This brief official statement marks the closing of a great historic movement. Up to our

own day American history has been in a large degree the history of the colonization of the Great West. The existence of an area of free land, its continuous recession, and the advance of American settlement westward, explain American development. - Frederick Jackson Turner, $1893^{1}$

Main Entry: fron • tier

Pronunciation: "fr\&n-'tir, 'fr\&n-", frän-', 'frän-" Function: noun Etymology: Middle English fronter, from Middle French frontiere, from front Date: $15^{\text {th }}$ century

$\mathbf{I} \mathbf{a}$ : a border between two countries $\mathbf{b}$ obsolete : a stronghold on a frontier $\mathbf{2} \mathbf{a}$ : a region that forms the margin of settled or developed territory $\mathbf{b}$ : the farthermost limits of knowledge or achievement in a particular subject $\mathbf{c}: \mathbf{a}$ line of division between different or opposed things $\mathbf{d}$ : a new field for exploitative or developmental activity - Merriam-Webster's Online Dictionary, 2005

In addition to the cultural and racial othering we have witnessed in previous chapters, there is a third, less obvious, but perhaps even more crucial element in the tension inherent in representation of the West. This tension concerns the Western's nature as an historical representation. What will become central in this chapter is a conflation of "far" and "long ago," two forms of remoteness that underlie the representation of the past as metaphorically embodied in the idea of the West. Concretely, I am referring to the paradoxical phenomenon of the historical Western. The histories of the $17^{\text {th }}$ and 18th centuries that these films portray are more remote than the recent history of the late-19th century, the stuff of many Westerns. I call these films Easterns, to underline their alle- 
giance to the Western on a basis other than their geographical setting. For these films are set in an East that was once the West. ${ }^{2}$

Precisely because the "Eastern" is not predicated on the form of othering that we have learned, today, to regard with a hermeneutic of suspicion, the oppositional structure that informs its possibility as a genre - tentative and provisional - provides insight into the corpus of the early Western beyond the well-known thematic of cowboys fighting Indians on the plains of the Trans-Mississippi West. For, much more characteristically than its recurrent themes, the Western is grounded in the idea - and reality! - of the frontier. And that imaginary and real line, that demarcation between civilization and wilderness and hallmark of progress of which I will have more to say in chapters $\mathbf{H}$ and $\mathbf{I}$ is more than a demarcation between areas or even levels and kinds of civilization. It is also a semiotic tool, the bar that separates and links signifier to signified. ${ }^{3}$ Thus, it is not a semantic unit, but a tool that shapes meaning. The frontier as a cultural phenomenon is neither situated below the bar that separates signifier from signified, nor is it simply a signifier, although it is also just that. Instead, I speculate here that it is (also) the ground, in Peirce's sense, that links the two: the ground on which the making of meaning is based.

Before further analyzing the concept of the frontier as sign, it seems worthwhile to quote Peirce's definition of the sign in full. For, beyond the point I am attempting to make in this chapter, the semiotic perspective of this American philosopher, who was also a contemporary of the films I am discussing, will be important in articulating my take on several other phenomena as well. ${ }^{4}$ Peirce wrote:

A sign, or representamen, is something which stands to somebody for something in some respect or capacity. It addresses somebody, that is, creates in the mind of that person an equivalent sign, or perhaps a more developed sign. That sign which it creates I call the interpretant of the first sign. The sign stands for something, its object. It stands for that object, not in all respects, but in reference to a sort of idea, which I have sometimes called the ground of the representamen. (1984: 13; emphasis added)

This definition will be invoked in other contexts below, but here I wish to foreground its communicative ("it addresses somebody") and dynamic conceptualization of signification. The final clause of this definition concerns me here. It stipulates that meaning emerges not as a full definition of the sign but as a limited, oblique take on it: "in reference to a sort of idea, which I have sometimes called the ground of the representamen." This "sort of idea" that determines how, at a given moment in time, for a particular person ("somebody") a sign produces meaning ("That sign which it created I call the interpretant of the first sign") that Peirce calls the "ground" and later semioticians have streamlined under the concept of "code," is, in my considerations in this chapter, the frontier. 
Parading now as a sign, then as meaning, the frontier is primarily a structure that makes the connection of sign to meaning possible. The point, here, is to examine the notion of the frontier as itself mobile. Its filmic representation started at the moment of the "official" closing (or dissolving) of the historical frontier in the 1890 , when the census announced its closure due to population density in the West. In the epigraph to this chapter we have read the famous words of Frederick Jackson Turner who proclaimed the importance of this moment. ${ }^{5}$ Yet, as a conceptual term it is inherently mobile. In this sense, reality reinforces the imagination and its semiotic elaborations of collective myths and fantasies. For it is well known that the frontier was always on the move just like the people who made it, as settlers went further and further in the Western direction. If, so far, the geographical opposition between East and West had been over-determined as the opposition between wild and civilized, or in practice, urban, this opposition would lend itself to become a tool in the service of meaning-making based on "primitivism." ${ }^{6}$ Primitivism is a dichotomy of the us/them kind, where the term referring to the other is grounded in space as well as time, the latter often serving as a metaphorical substitute for the former. Hence, the opposition between East and West is here deconstructed as temporal. On this metaphorical level, the West is now not a geographical unit, but an historical one.

This conflation of space and time is inherent in the colonial endeavor. In the beginning of this endeavor, all of America was the Wild West; civilization was conceived as modern, wildness as a-temporal, and hence, through the oppositional structure, as old. ${ }^{7}$ As the frontier moved westward due to the colonial expansion that was legitimized by the doctrine of "Manifest Destiny," this traditional form of othering - also an old habit in Europe, known from the Greeks and Romans - could be released from its temporal axis and made emphatically geographical. ${ }^{8}$ But the mechanism that sustained the evolutionist imagination remained, underground as it were. The "genre" of the historical Western, set in the East, makes visible what geography-based Westerns repressed.

The historical "Easterns" are set, then, in a relatively remote past. Their couleur locale makes their setting visible not in landscape, but in costume. Rose O'SALEM-Town (1910, AM\&B) cited in the previous chapter is an example, to be discussed below. Note that the issues raised by this "sub-genre" are different, then, from those (on which more later) that arise in Westerns not set in the East, but that use Eastern locations as a convenient place to shoot. Here, in contrast, the features that make the films relatives of the Western are diegetic. For example, while they are openly set in the East, they use the Indian characters, the trapper who befriends them, the theme of wilderness versus civilization and other elements that often characterize the Western. The tensions reside not in the actual shooting location - East standing in for West - but in the fictional 
setting itself - East representing itself, with fictional elements standing for, through the genre affiliation, "Western."

One element in the genealogy of "Easterns" is their rooting in a literary tradition. Many of these films were adaptations of literary works of great popularity, so that, in an integrated view of film-within-culture, these films emerge, in yet another sense, "after" the beginning. I am referring to such films as those based on Cooper's Leatherstocking Tales, mountain films, and the many captivity narratives. The Conspiracy of Pontiac (1910, Kalem) is based on Francis Parkman's 1851 history of the Pontiac rebellion of $1763-66$. Among the films of the trapper period, those recounting the exploits of Daniel Boone and Kit Carson deserve mention in the present context, as they depict specific events or people and are often adaptations of well-known texts, which are often themselves historical. These films will be examined for their historicist thrust in $\mathbf{H}$, and I will discuss the phenomenon of filmic adaptation of literary works more thoroughly later. 0 Here, I wish to draw some attention to the fact that it is precisely the "Eastern" that drew on older traditions such as literature and other historical writings. For this recycling of cultural material that was bound to be recognized as "old" is part of their historical makeup.

The translation of geographical difference into historical difference (and back again) seems to be motivated by a temporal relation similar to that underlying the nostalgia for the recent past. This nostalgia, as Kristen Whissel (1999) argues, taking her cue from Renato Rosaldo (1989), is inherent to the imperialist project:

Relevant to early cinema's encounter with empire is Rosaldo's argument that modern imperialism's drive for "ongoing progressive change" provokes an impulse to look back in time for a more stable world that seems to precede the tumultuous change of contemporary society. Irretrievably lost to the past, these nostalgic formations are referenced through narratives that articulate a longing either for another culture's more "primitive" way of life (prior to its transformation by colonialism) or for a simpler way of life located in the nation's own past. (390)

Whissel's "imperialist nostalgia" is the mourning for what one's own self has destroyed. This nostalgia is the mediating trope between the spatial, temporal, and cultural meanings of the sign "frontier." $\mathbf{I}$

The frontier is a line of conquest, a wedge rather than a segue, or smooth transition between now and then, us and them. It is bi-polar but inherently "final." This finality has a temporal flavor to it. In its temporal guise it propels nostalgia for the "other side" of the divide, because it is founded on the conception of before and after. The present is situated "after" and thereby cut off from its past. The turmoil of the present turns longing for what is conceived as more stable into a form of rest, relaxation, in and of itself. The resulting nostalgia 
hinders, even precludes, the clear vision of what it is that the frontier separates and to which it thus gives meaning.

This cultural function of the frontier as a mobile and shifting ground for meaning production is an historical phenomenon that students of American history ought to analyze instead of endorsing it. Yet endorsing it, unreflectively, is precisely what historians of the American West appear to have been doing for a long time. In the introduction of her influential book The Legacy of Conquest: The Unbroken Past of the American West (1987), Patricia Limerick analyzes the historiography of the region in terms of a crisis, or possible demise of the field of the History of the American West in the wake of more recent insights. She also proposes a way out. Central to her critique are some of the assumptions about what the object of study would be. Limerick claims that the influence of Turner's Frontier Thesis had a negative after-effect on the field. This thesis promoted the unifying concept of the frontier and its supposed "closing," a concept that became immensely influential. For a long time it seemed so "natural" that the idea of contradicting it would not even have occurred to historians because such an objection would imply contradicting the field of Western history as such, and, following Turner's thesis, of (North) American history in general.

Through this naturalized status, the frontier has become an axiom in the conception of the history of the West. Limerick rightly suggests that this strong effectivity of the thesis was due, in particular, to what I would call a binary form of periodization, organized in terms of before and after. I see the strong, culturally potent version of this temporal logic as a central factor in the success and significance of the Western. The phrase "After the Beginning" foregrounds the temporality according to which the present is marked by its position "after" in a temporal dichotomy, an "after" that posits what it fears, longs for, and focuses on, as rigorously "before." Before, that is, out of reach, surpassed and lost, object of condescendence and even contempt when one is immersed in a utopian excitement about modern life; an object of longing, in contrast, when the drab reality of everyday life in the crowded city threatens one's sense of wellbeing. This feeling for the time of the "beginning" in relation to which modernity is melancholically belated, needs an idea like the frontier to hold on to, as, precisely, a ground in more senses than one. This interpretation squares with my suggestion above that the frontier can be considered as a semiotic tool for meaning-making in general, connecting, precisely, geographical with temporal oppositions through the dichotomy of values and their repressed messiness - civilization being the primary value, wildness the nostalgically longed-for and simultaneously dangerous other.

This becomes clear once we realize that the frontier is a metaphorical model, transferring a feature of one concept, the comparant or vehicle, onto another, the compared, or tenor. 9 The metaphor is based on a geographical delineation as the 
vehicle, and social, cultural, and economic meanings as the tenor that becomes "colored" or even understandable by the features from the vehicle that are conferred upon them. This metaphor facilitates an extension of its domains of application. As a result, it became equally "natural" to conflate different kinds of frontiers, separating different domains: different times, areas, but also different registers (geographical, social, cultural). Temporal distinctions and the subsequent representations of "slices" of time are infused with considerations of space. This problem in the historiography of the American West fits into a more general concern that occupies historians of the longue durée (the French Annales School) and micro-historians (such as Carlo Ginzburg), as much as it does anthropologists involved in "thick" description. Current debates offer an interesting and relevant insight into the problems of (inter-)disciplinarity involved, so that we can say that the disciplines themselves are products of a conflation we are now painstakingly trying to disentangle. ${ }^{10}$

That cultural mechanisms work in this way is clear from the cultural products that constitute the historical legacy. But, in addition to helpful interdisciplinary debates, a rhetorical analysis of history writing itself is indispensable if we are to grasp such key elements of cultural history, for this cultural operation becomes invisible when history itself, the scholarship that writes and analyzes these occurrences, borrows its metaphors from its object domain. The critique that Limerick and others offer regarding the failure of the Frontier Thesis as an organizing principle for the historical study of the West is therefore extremely timely ${ }^{11}{ }^{1}$ contend that, with necessary emendations, this critique is also significant for the representation of history in film. A detail of timing gives a first clue: Turner announced the ending of the frontier at the moment film began to prolong its life on nitrate. This seems to me an historical coincidence of great allure. As long as the idea of the frontier remains simplified, however, this Turnerbased idea of closure misses the point of the frontier as a cultural artifact and semiotic tool.

First of all, it is quite impossible to determine when it was closed, for that depends on how you define the frontier. As Limerick explains in her introduction, conflicting definitions of the closure of the frontier originate in different definitions of the frontier itself. Strategies for definition can be based on population density - both scarcity and density can be markers of a frontier state - or symbolic events such as land acquisitions or markers of conquest, or - yet another marker - on the popularization of the region as tourist spectacle, preferred by Limerick herself (1987: 23-25). Not only do these different definitions result in different types of closures, but they also lead us to focus on different moments, while some frontiers are not yet closed.

Secondly, paradoxically, by arguing from within the logical string: America = frontier $=$ closed, one implicitly dismisses the relevance of everything in the 
West after this point in history, say, after the 1890s, for (Western) history. For my purposes, therefore, Limerick's insights in the shifting and diverse meanings of "the frontier" are most relevant if we are to understand the consequences for the early Westerns and, consequently, the "Easterns." Rightly dismissing the frontier as organizing principle for historical periodization and delineation, Limerick recognizes the concept as an "historical artifact," worthy of study and analysis as such. Hence, the films about fictions set at the (different) frontiers in U.S. history reveal contemporary ideas about "the" frontier, and thus provide evidence of the way it functioned as a cultural concept, with all the ideological implications such mobile concepts carry. Considering "Easterns" as relatives of Westerns, then, substantiates the consequences for representation of the intricacies pertaining to the frontier as meaning-maker. The films do in fact appear to confirm some of Turner's ideas, but do they also reveal a broader sense of the term? This is the central question in this chapter.

As we have seen, in Rose O'SALEM-Town (1910, AM\&B) the plot revolves around an "Eastern" situation in a "Western" mode. The Puritans imprison a girl who resists what we would now call sexual harassment. She rejects the leader of the community. The imprisonment is an element of a traditional "Western" captivity narrative. However, the prison guards are not Indians, but Christian extremists. Moreover, the girl is more interested in a trapper, a character that embodies what is most typical of the Western: life in the wilderness. At the beginning of the film we see the heroine in a Greek dress at the seaside, a characterization of her as poetic that sets her apart from the others. The difference, here, is as yet suspended between literary and cinematic references, and "Eastern" rather than "Western" in kind. But our semi-wild woodsman is attracted to this girl because of that difference, and thus they can fall in love, which wins the girl for the wild side of things. And as the woodsman is friendly with some Mohawks who live in the hills, the plot turns "Western." The Indians rescue her just before this Eastern, literary girl turned wild/Western, is about to be burnt at the stake for having elected life beyond the frontier. Abandoning civilization does not go unpunished. To be burnt at the stake, the historical penalty for those accused of witchcraft or heresy, signifies the gravity of her transgression. If the point needed making at this stage of the plot, the girl is treated by the Eastern Puritans as a dangerous pagan, just as dangerous, strange, and wild as the Indians from the other side of the frontier.

The Christian (Puritan) theme returns in An Acadian Elopement (1907, $\mathrm{AM} \& \mathrm{~B})$, as discussed below, in which Quakers figure as quintessentially "Eastern." When we compare these Easterns with a film like THE PioneERs (1903, $A M \& B)$, we see a different frontier, with different dangers, inhabited by different Indians, but a similar historization of the frontier, the same development of 
"Western" stock figures and plot elements, the same development towards estrangement of an originally Eastern figure turned wild.

Some years before RoSE O'SALEM-TOWN came out, and in the same year as the Great Train Robbery (1903, Edison), Biograph produced The Pioneers. It tells a story about the early days of settlement: "The Pioneers: A story of the early settlers told in motion pictures. A series of five splendid scenes taken in the Adirondack wilderness." And as the Biograph Bulletin continues: "All of the scenes in this great production were made amidst the wildest and most beautiful scenery of the Adirondack Mountains, and the subject is one which will appeal strongly to all classes of people." ${ }^{12}$ The film comprises five extremely short tableaux-like scenes, which are listed in the Biograph Bulletin as: "The Log House," "An Indian Massacre," "The Oath," "The Mountain Trail," and "Vengeance." These scenes were probably recognizable to the audience, who needed little information to "get the picture." Langman summarizes the scenes: "This early film depicts an Indian attack upon a pioneer family's remote cabin - a popular theme during this period. The raiders kill the parents and carry away their daughter. Local trappers rescue the captive after a battle in which the Indians are slain" (1992: 334). ${ }^{13}$

In 1913, in a short story based on the film DANIEL BOONE's BRAVERY by Kalem, the setting of the early frontier is described in poetic, if not sublime and even religious terms, in the exposition of the story:

In a park-like forest, mostly of moss-covered monarchs, many parts of rare flowering trees, mingling with honey-locusts, paw-paws and sugartrees, a little clearing, the first made by white men in Kentucky, lay open to the warming sun. The scattered cabins, and stumpy fields waving with new corn, seemed a toy invasion of the unbroken wilderness. On every side of the cleared space, like walls of a shallow well, dim shadows under brilliant foliage hemmed them in. To a Cavalier or Quaker, or even to a psalm-singing Puritan, the unbroken forest would have seemed a horrid trackless jungle; but to the woodsmen - such is their craft - its reaches and streams, its bogs and tangle, were set out like the fine traceries on a hand. And to them the impenetrable solitudes had their arteries, too, narrow trails, winding vein-like beneath the laces of trees, worn hard by noiseless, moccasined feet.

Such was the Scioto Trail, the war-path thru the mountains even to the Gap of the Cumberland; there, overlooking civilization below, in a watered valley, it halted, as if weary of its turns and twists. Boone, coming up to it, from the Yadkin lowlands, had gazed prophet-like from the summit over the wilderness which reached to the setting sun. Reports had drifted down the slopes from wandering trappers, of this new country, teeming with buffalo, elk, bear, and small game. Now he could see its first reaches with his own eyes. "Truly," he had acclaimed, "there is a country where the beasts attain their full size and where the spirit of man is free." ${ }^{14}$ 
In view of such films, the frontier is a helpful concept for our purposes after all, but on the condition that it is properly defined, namely in its dynamism and multiplicity. It can break open the geographical and temporal definition of the "West" and therefore also a problematic generic conception of the Western that defines the films as being about a specific historical period in a specific geographical location. As I will argue in chapter $\boldsymbol{F}$ the notion of the "Eastern" as the historicizing cousin of the Western has methodological implications beyond the more nuanced historical accounts that Limerick advocated. My point is that the corpus itself can be methodologically productive. In this case, the sheer acknowledgment of a category of films I call "Easterns" - and their presence in early cinema is undeniable - makes the heuristic productivity of the Wittgensteinian idea of family resemblance as a basis for genre definition convincing, not only epistemologically - as producing knowledge - but also analytically as making the corpus more accessible for subtle analysis. Hence, the flexible genre concept I am advocating on the basis of, among other reasons, this category of "Easterns," stands out for our corpus with particular acuity. $\mathbf{G}$

As I mentioned, Limerick's methodological caution against unwarranted endorsement of historically specific conflations is one of many recent attempts to take the notion of the frontier out of its naturalizing limelight. A few decades ago, in a study of the frontier, Ray Billington traced the different meanings of the "frontier" throughout history and demonstrated how the denotation of this word has changed (1966: 23-46). The frontier in its different historical stages is represented in the variety of early films, before it becomes more narrowly codified in the classical Hollywood cinema. These representations are worth considering in their various embeddings in other frames, notably aesthetic ones. For example, in chapter $\mathbf{L}$ I discuss the implications of this unspecific nature inherent in the concept of the frontier, for the landscapes represented in these "Westerns." Here, I wish to foreground another aspect of the same phenomenon, namely its use of - unspecific - nature which in and of itself constitutes "the West" in order to "locate" historical otherness that is not Western but similarly "other" in the developmental sense in which "West" and "Past" can be conflated.

This raises further fundamental questions of genre definition. I submit that using a specific time - the past - in a specific place - the West - as a generic prerequisite, would be in a profound sense, anachronistic. Anachronism is a grievous sin for a historian, yet it is extremely difficult to avoid if we take our theoretical concepts too much for granted. This fact of method alone makes the traditional division between historical and theoretical approaches to cultural material, altogether obsolete. In the case at hand, if we are to account for the cultural imagination that became newly embodied in the films that represented it, it is not the separate representation of the place called the West as belonging 
to the past, but this conflation of past and West through the common feature of otherness in opposition to urban, or Eastern, or modern civilization, that must be considered the crucial feature of the genre. This requires that we define the corpus through an awareness of what identified the films at the time as everything that the notion of "Western" stood for. The subsidiary question we must pose, then, is: how are the different frontiers marked as frontiers?

This question requires taking contemporary characterizations as a starting point. In the press, for example, often a specific "frontier spirit" is mentioned. The word "spirit" is to be taken in the double sense derived from mentality as in "team spirit," and as spirituality, which attributes moral goodness to it. Such mentions provide evidence of an idealization of the primitive and the moral goodness of simplicity - by implication in contrast to the corruption of sophistication and complexity of the modern. Given the importance of contrast as a tool to shape representations, this semantic of the frontier propels implications of its opposite, so that we need to ask how the contrasting characteristics of the modern, the urban, and the East are integrated into these visions.

Although in Easterns it is related to location, this pioneer spirit is attributed to character and not to place - and in this case, the noun "character" denotes personality rather than the figurative representation that embodies it. ${ }^{15}$ According to such mentions, location serves as a metaphor, a precondition for human behavior. That Nickelodeon valued the moral lessons these historical films could teach - lessons that are different from those concerning historicity itself, of which more in chapter $\mathbf{H}$ - is clear in the review of A Kentucky PIONEeR (Selig) in 1910:

A Kentucky Pioneer - Selig, is a spirited frontier drama, exceptionally well costumed. [...] The plot is not very original, but it is adequate; the scenery and acting are very good. The film gives quite a rounded view of pioneer life, showing some of the pleasant features as well as the hardships. The co-operative spirit of the pioneers, whether in joy or trouble, is well suggested. ${ }^{16}$

The last sentence foregrounds the moral superiority attributed to life on the other side of the frontier - both past and West of the modern city. This moral superiority is clearly put in terms of robust, American masculinity in the following review of THE SPOILERs (1914, Selig):

William Farnum appears exceedingly well as Glenister, his first venture in photodramatic art. It is a well studied part; for his headstrong miner, permeated, as he is, with elemental Americanism and not overburdened with the refining influences of polite society, is a mighty hard character to portray, if one views him from the appealing point. He is force personified; a man who takes what he wants - yet is honest withal. ${ }^{17}$ 
According to Richard Dyer (1997: 30-40), the very notion of "spirit" is loaded with moral, and even, implicitly, racial connotations. Dyer examines the notion of spirit in relation to whiteness. In this context, other ideological implications connect "spirit" through "pioneer spirit" more specifically to the Western.

The family is a nuclear point in the frontier zone - growth of population is only possible in family setting. ${ }^{18}$ Therefore, this foregrounding of an ideology of a familial "pioneer spirit" is necessary for the colonial enterprise. If we consider Dyer's analysis, then the phenomenon of the "Eastern" becomes even more significant, pregnant with cultural sentiment:

[The frontier] is both a temporal and a spatial concept, not only in the sense of being the period and the place of establishing presence, but also in suggesting a dynamic that enables progress, the onward and upward march of the human spirit through time, that keeps pressing ahead into new territory.

This spirit is part of what he calls an "historical imagination":

The Western is set at a point in history when the project of the creation and settlement of a new society was underway but had been neither completed not abandoned. When exactly that is, whether it ever was, is not the issue, what matters is the possibility of imagining that moment on the brink of making a society. It is carried by signs of pastness and a geographical location, whose imprecision in no way diminishes the mobilization of an historical imagination. (33)

"Making a society" requires historical imagination. The urgent need of the pioneers to conquer the land is inherent, according to Dyer, to a sense of self as white. The pioneer spirit's bond with Christianity is part of that sense of self. Combining these two elements of "whiteness" (Dyer's term for white racial identity), namely, the Christian way of life and the conquest of the land generates a specific plot structure we see at work in Easterns.

The feature affiliating the Eastern films with the Westerns from my corpus is, then, also and importantly located in the treatment of the family. The films feature families and specifically their test of moral viability, a test that consists of being under attack. For an imperialist enterprise expanding westward and attacking everything encountered on its way, this plot element is, of course, highly significant. For example, figure E1 announced a film about pioneers under attack and the dangers of a divided family. 


\section{A TALE \\ OF THE WILDERNESS}

In the Pleneer Days of Kentucky

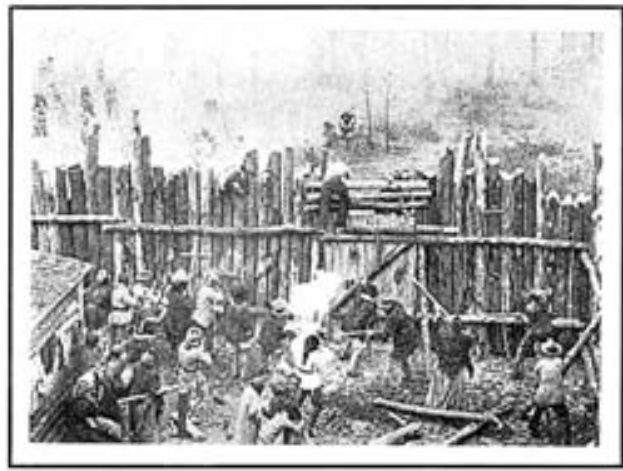

TN THE WILDS of the Kentucky hin two beotherk the elder an outiaw, view from a dintance the apsesech of a party of settien moving forward to a new home in the vast whidnes. The

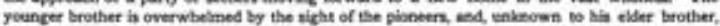

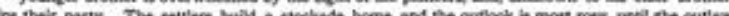

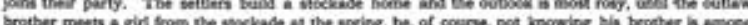

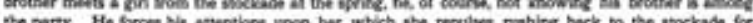

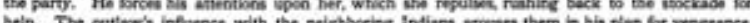

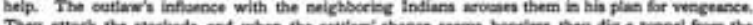

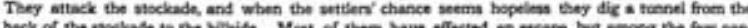

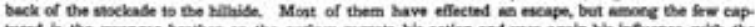

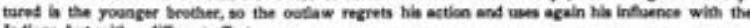
Intiasse, but with a different effoet.

\section{(B) BIOGRAPH (B) \\ Ralanes Jos 2. miz}

E1 Biograph Bulletin for A TALE OF THE WiLDERNESS, release date January 8, 1912

An example of such a plot can be found in Billy's Stratagem (1912, AM\&B):

Billy's Stratagem. A Vivid Portrayal of the Early Days on the Frontier. The little frontier family, in their stockade home, is enjoying the simple life such an existence induces. The father goes off to a distant woods to work, and while the mother is there with his lunch, good-natured grand-dad, who is left in charge of the two young children, allows them to go outside of the stockade to play. In another section of the woods is a peaceful tribe of Indians, but an unscrupulous trader lets them have in exchange for skins, a quantity of whiskey. On this "firewater" they become drunk, and, in search of more, attack the stockade home, killing grand-dad and driving the youngsters in terror into the cabin. The children, concerned, upset a keg of powder in 
the kitchen and put a slow fuse to it, escaping through a back window. The Indians enter the kitchen just as the powder explodes. The details of this picture make it one of the most thrilling ever produced. ${ }^{19}$

In this film the family is threatened from within as well as from without. The temporary absence of the parents and the heroism of the children left on their own, emphasize how family members actually need each other. The primary danger comes from the outside, the Indians. The inside-outside opposition selfdeconstructs, however, once we realize that the Indians turn savage not before, but after contact, i.e. after being given whiskey. After the beginning, in yet another sense (see figure E2 ).

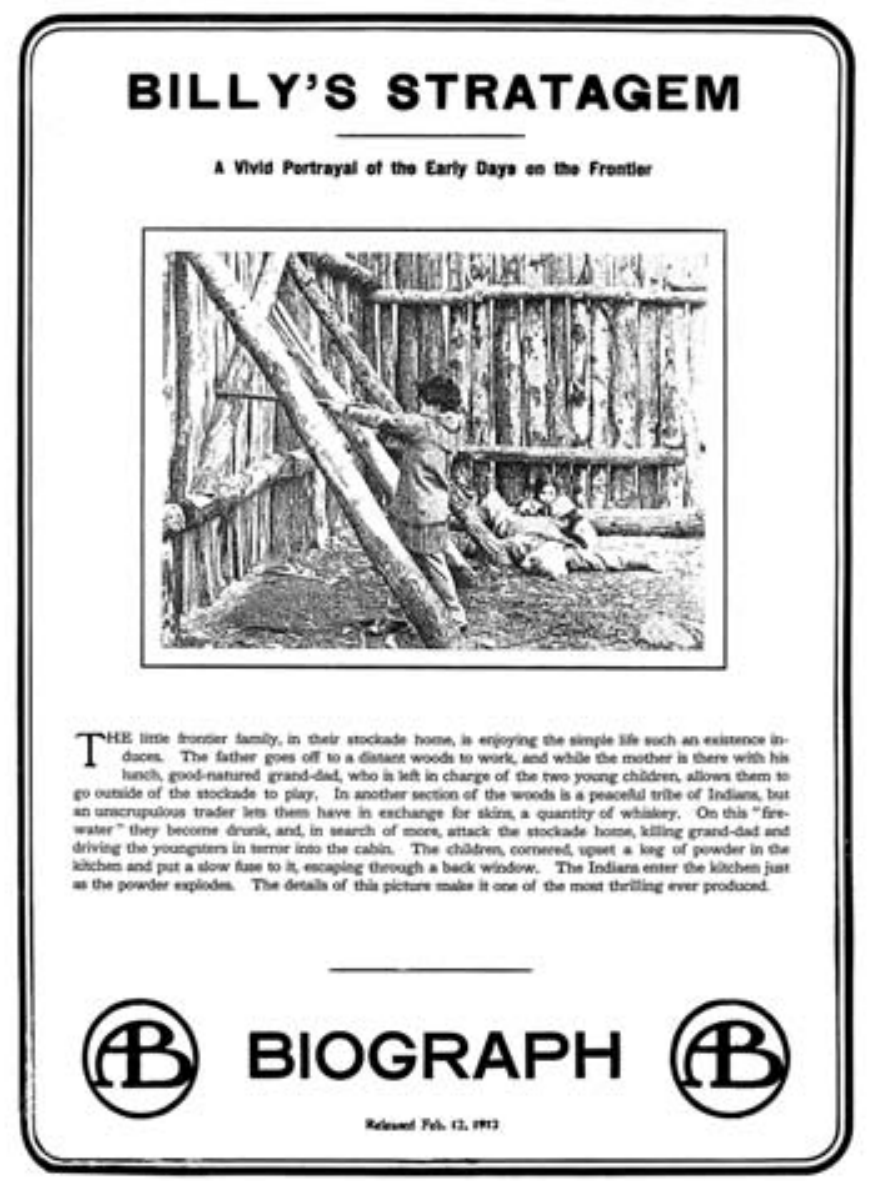

E2 Biograph Bulletin for Billy's StratAGEM, release date February 12, 1912 
Within the framework of the present chapter, the example derives its relevance from the way it represents how the family is central to the early frontier experience. This is especially visible in the films about the late 18th and the early 19th centuries. The historical distance attempts to position the family and the threats to it early, in other words, in an unspecific before, but the clearly Eastern setting makes such historical innocence untenable.

The conflation of time and place to which the "Easterns" bear testimony, is more than this ground - in the semiotic sense - in duality alone. Not only was unspecific nature, connoted "Western," strongly enough semanticized to place events into the past, but, in turn, the spatial discovery of wildness was projected onto a past that otherwise would not be past at all, so that the primitivism based on the ideology of progress could retrospectively confirm its own reality in the past. Thus, touristic visions of the early 2oth century are sometimes imposed on the historical imagery. From the Biograph Bulletin of THE Horse-THIEF (1905, $\mathrm{AM} \& \mathrm{~B})$ :

The scene is laid before a vine-clad hovel, a most picturesque ruin over 150 years old, situated on a hillside overlooking one of the loveliest valleys in Westchester County, New York, and in the immediate vicinity of the great estate of John D. Rockefeller and other well-known magnates. The house is practically a ruin, but it is the hang-out of a family of disreputable characters who pretend to make a living by farming in a small way, but who, as a matter of fact, would sooner steal a horse than hoe a hill of potatoes. $^{20}$

The rhetoric of this fragment is rich in its sophistication of a modern overlayering of ideas in which high stakes were invested. The attraction of poverty witnessed by tourists and beautified, made attractive, by an aesthetic of the picturesque, turns a desolate view into a postcard-perfect image. In the same move, the poverty that must have been striking for the well-to-do tourist who saw this view, as much as for the cinema viewer who enjoyed its spectacle in the film, is narratively "explained" by fictional facts that erase potential guilt and provide the seed for a good story. The rhetoric betrays itself by overdoing its truth claim with the phrase that sets up the story and the primitivist contrast: "as a matter of fact."

And of The Moonshiners (1904, AM\&B) the Biograph Bulletin says:

In "The Moonshiners" we have a film in which the romance and tragedy of primitive life in the Kentucky mountains are portrayed in a most powerful manner. The moonshiners, as everyone knows, are simple mountain folk who regard it no crime against laws or morals to convert the corn which they raise into whiskey. ${ }^{21}$ 
Again, primitivist projection comes with the attribution of moral depravity to the "wild" people allegedly living in the past. About the later film A KENTUCKY FEud (1905, AM\&B):

The enormous success of "The Moonshiners," now the most widely known and most popular film ever made, has led us to produce another similar subject; and in the "Kentucky Feud" we believe we have equalled and, in some respects, excelled "The Moonshiners." The scenes of the feud are laid, as before, in the picturesque Kentucky mountains, and in each section of the film the background is a picture in itself. The old mountain houses are in the same condition they were a hundred years ago, and every costume and property is absolutely the real thing. ${ }^{22}$

The picturesque quality of the scenery depicted - postcard-perfect, as the phrase "a picture in itself" boasts - serves to set the clock back by a hundred years. Historical realism, foregrounded in the words "absolutely the real thing," makes the historical meaning of the Kentucky Mountains just as convincing as the Rocky Mountains are in authenticating the scene of any Western. ${ }^{23}$

One last example of this play with frontier connotations concerns a film advertised as inspired by a literary pre-text, An AcAdian Elopement:

Lovers of Longfellow are here transported to the beautiful scenes so dear to him, the Normandy of the New World, with its blossomy fields, and lanes shaded with masses of pendulous foliage, colored with ephemeral clusters of wild flowers. To this spot comes a New Yorker to spend his vacation. In the little Acadian village dwells a pretty Quaker maiden whose heart he wins $[\ldots] .^{24}$

Again, the natural scenery is unspecific but clearly Eastern and of old. In relation to this scenery, we can take into account these significant facts about the region portrayed in the film. Acadia National Park was the first Eastern National Park, established in 1919 under the name Lafayette National Park, and renamed Acadia National Park in 1929 to reinstate the historical name for the region. Maine as a constituent state of the United States is, historically as well as geographically, a mirror image of the West that was reached by westward expansion. It is a symbol for the initial colonization of North America by European empires as well as of its independence reached in the American Revolution and the formation of the United States. Also, Maine is the most sparsely populated state East of the Mississippi river, a demarcation line between the West and the East, an Eastern frontier in its own right. Thus, a film about this region resonates with strong symbols for the historical status of Easterns. Through an historically reversed glance, the later designation of the area as a national park also gives the place a connection with Western national parks such as Yellowstone or the Grand Canyon. ${ }^{25}$ 
The typically Eastern phenomenon of Quaker villages in AN ACADIAN ELOPEMENT benefits from the historical effect of unspecific nature. Such scenery becomes by definition part of the past that accommodates moral values the urban cinemagoer appreciates just as much as does the film's tourist from New York.

These examples make clear that the films are set somewhere and sometime other than in the West. Or at least they demonstrate the diversity of the films' locations and times. But they also reveal a sense of the picturesque aesthetics that binds them to the Western. Obviously, this aesthetic is part and parcel of the historical thematic of the films and their specific (historical) locations. Hence, on its own, this aesthetic would not quite substantiate my claim of affiliation with the Western. But the point is, this setting supports the moral values projected on the past. Moreover, it accommodates the nostalgia that infuses the past as much as the primitivist logic that also, in turn, facilitates projection of moral values onto that past. Thus, the proximity of the Western is "thicker" - in Clifford Geertz's sense of "thick description" - than setting alone would suggest.

These meaning-producing conflations can be made even more convincing if we compare them to films that do not deploy the same cluster of meanings around the frontier. At the opposite end of this mobile frontier stands, for example, a film like Blade O' Grass (1915, Edison). In this film, a disappointed father whose wife has left him moves to the Eastern woods of Maine to live a simple but honest life with his daughter. When she grows up her father sends her to her aunt in the city to learn about "civilization." She has trouble adapting to the modern life style and moves back to live with her father. She is followed and abducted by a villain, but rescued by another young man in collaboration with her father. She falls in love, and the father, who knows, after all, about true love, gives the young couple his blessing.

This version of the East is not historical, but modern. It substantiates the temporal point I will be making in the chapter on time travel. T Why is this "Eastern-ness" not an instance of the historicizing of the frontier I dubbed "Easterns"? The movement in the film is from the city to the woods of Maine. The mode of travel is overtly touristic rather than that of exploration, conquest, and settlement. However, this film does echo some of the attractions of the other direction: the Eastern "West." The woods signify several themes also present in the Eastern Westerns. We notice the wild-girl-of-the-woods theme, for example, that we can compare to the modern example of the Jodie Foster character in NeLl (1994) and which is utterly romantic in its primitivism. Eastern woods are the location where civilization meets its other, nature. Nonfiction footage inserts foreground and to a certain extent, specifies the scenery, while also emphasizing the realism. However, the overall tone is touristic rather than historicizing. Hence, the time-place conflation that characterizes the deployment of the fron- 
tier as sign is here less pronounced than in the other examples of Easterns I have invoked.

Yet, this difference is relative rather than qualitatively absolute. For, viewed from the vantage point of the "Eastern," as I have argued we must, the Western is always already an Eastern because of the Eastern perspective. The focalization shifts from historical Eastern to "modern" Eastern. An example of the latter is the above-mentioned BLADE O'GRASs. In the following chapter I discuss films whose primary thrust is not quite the primitivist conflation of time and place discussed here, but a more clearly thematized reflection on the new medium's play with the reality it so proudly proclaims to be able to represent.

The "frontier" - rather than a line between savagery and civilization, as in Turner's thesis based on dichotomy, then, can be seen as a "zone of exchange and conflict among many civilizations," as the Oxford History of the American West has it (Milner, O'Connor and Sandweiss, eds. 1997: 116). And this book continues: the frontier was "a region of extraordinarily dynamic changes, transformations, a competitive arena of a few dozen powers whose varying strengths were ebbing and surging" (116). Events represented from the perspective of a history with a strong cultural resonance, can only confirm that this conflictual nature of the frontier was important enough to explain the cultural desire to pacify the past by distancing.

\section{Notes}

1. From "The Significance of the Frontier in American History," reprinted in Turner (1921).

2. In Buscombe, ed. (1988) the sub-genre of the Colonial Western is described: "The historical core of the Western genre is white America's conquest of its continent, and that process took almost three centuries to complete. [...] The classic questions of the Western - expansion, cultural contact, racial war, economic development, community formation - were being posed from the very beginning." The author notes that, in the classical period, the "early period, from original colonization to independence, has been of negligible interest to film-makers" (93). However, archival study has shown that this is not true for the pre-WWI film period. I wish to use a different label for the early historical films because their term "colonial," although commonly used for this period in North American history, connotes hierarchical relationships and meanings attached to colonialism that I do not wish to invoke here. To distinguish "colonial" from "about the Colonial period" I think it is wiser to use a completely different term, Easterns, which has multiple meanings that I want to put to use as I will explain below.

3. "For the bar separating the two symbols is itself more than a symbol: it is the pictorial enactment of a necessary and irremovable cleavage between them" Malcolm Bowie (1987: 110). 
4. Thus, the landscape will be considered as the sign of an historical division between the aesthetics of the Sublime and that of the Picturesque. $\mathbf{P}$

5. For more about his "frontier thesis," see below, and for more about the coincidence of historical facts and myth-making fictions see chapters $\mathbf{I}$ and $\mathbf{K}$.

6. The conflations between high and low, civilization and wildness, mature and young, that underlie primitivism are clearly exposed by Marianna Torgovnick (1990).

7. This may seem paradoxical, since another opposition sets America as the "new world," or "virgin land," off against Europe, the "old world." The coexistence of these two oppositions confirms my point about meaning production through opposition. For this point, see $\mathbf{\square}$.

8. The term "Manifest Destiny" was coined by the journalist John L. Sullivan in 1845, who wrote in a newspaper editorial about America's "manifest destiny to overspread the continent allotted by Providence for the free development of our yearly multiplying millions." Quoted in Buscombe, ed. (1988: 180-181).

9. The terms come from Genette's article "Restricted Rhetoric" (1982) and Max Black (1962) respectively.

10. For a clear and helpful general analysis of this time-space conflation, and the respective tasks for historians and anthropologists, see Marc Augé's “Anthropology's Historical Space, History's Anthropological Time" (1999: 1-16).

11. Other important revisionists in the field of Western history are Richard White (1991), William Cronon (1991), and David Worster (1992). For a good overview of the evolution of the "New Western History" and reworkings of Turner's frontier thesis, see Gerald D. Nash (1991).

12. Biograph Bulletin 26 (August 5, 1904); emphasis added.

13. A discussion of this film and Kit CARson (AM\&B, 1903) is given in $\mathbf{H}$. Below, I will give a summary of a similar interpretation of the frontier as portrayed in BILLY'S Stratagem (AM\&B, 1912).

14. Motion Picture Story Magazine II (November 10, 1913): 73.

15. For an analysis different from mine, it would be interesting to further examine such ambiguous concepts as character in these films from, for example, a psychological perspective. See Christopher Bollas (1993).

16. "Recent Films Reviewed." Nickelodeon IV, 7 (October 1, 1910): 199.

17. Moving Picture World (April 3, 1914): 186-187.

18. I realize that population growth on the frontier was initially maybe more from migration than from demography. However, this initial growth can only be sustained by demographic "results."

19. Biograph Bulletin (February 12, 1912).

20. Biograph Bulletin 49 (September 9, 1905).

21. Biograph Bulletin 25 (July 28, 1904).

22. Biograph Bulletin 56 (November 13, 1905).

23. Let me mention some more films set in Kentucky, some with historical and others with contemporary stories: The Kentuckian (1908, AM\&B), The Feud And the Turkey (1908, AM\&B), In Old Kentucky (1909, AM\&B), The Rose of Kentucky (1911, AM\&B), The Revenue Man and the Girl (1911, AM\&B), A Tale of the Wilderness (1912, AM\&B), and A Feud in the Kentucky Hills (1912, AM\&B). The "Kentucky period" in American history is the period of the trans-Appalachian 
migration of (self-supporting) farmers. The frontier of trans-Appalachia "ends" or moves on by 1820 . From then on this frontier can be regarded as "Eastern." "By 1820 the frontier had left its mark on Trans-Appalachia. As an historical condition it had moved on. Its defining traits now prevailed in the country beyond the Mississippi." Milner, O'Connor, and Sandweiss, eds. (1994: 130-137; 146).

24. Biograph Bulletin 108 (September 16, 1907).

25. Let me acknowledge that I have not been able to verify if the setting is indeed the part of Acadia located in Maine, not the Canadian region of Acadia. However, even if the latter is the case the geographical opposition between (South) West and (North) East remains the same. 


\title{
Facts and Fictions
}

\begin{abstract}
Poetic conception is an excellent assistant in the concoction of plots and the construction of romances. But the poetic conception which has embodied so many impossibilities in good film under the name of West deserves some pruning or some other operation which will at least curb, or in some degree control, its altogether exuberant fancy. Closer attention to historic fact would add to the interest, even though it might reduce the sensation. Fierce rides do not make a cowboy, nor do fine feathers make an Indian. - Moving Picture News, $1912^{1}$
\end{abstract}

Is there any hope for the survival of the Western subject? There is a little, but not much. The Western subject may gain a renewed lease of life if it made a change of base. It might drop the old melodramatic conventions and really attempt to portray the West.

- Nickelodeon, $1911^{2}$

By 1912 the press had demonstrated a keen and sophisticated awareness of the meaning of "the West" in American modern culture. Read, for example, the following almost philosophical musing:

There was a West worth knowing. There is a West better worth knowing. Those who were there thirty years ago understand what this means. Those who have been there recently understand full well that the present is quite as seriously misunderstood as the time long since passed. The West is a state of mind which requires adjustment, no matter whether the author is indulging in reminiscence or is reproducing facts which belong to the present. The real result, misleading and untrue to life, is almost invariably the same. ${ }^{3}$

As this quotation makes clear, the West is both history and present, and the films are judged on the adequacy of their depiction of both past and present. Then as now, criticism of the realism of the films was based on inconsistent arguments, precisely because of this double function. Some critiques are based on arguments about the medium's specific (photographic) properties, particularly in terms of the relationship with authenticity. Other arguments are founded on a cultural conception of the West, grounded in the coincidence of the closure of the frontier and its mythography. This foundation of the genre will be at the core of the next cluster of chapters. Here, working toward a cau- 
tious circumscription of the (suspended) genre by default, through "negatives," I will focus on how contemporary judgments on realism reveal that realism was conceived of in relation to the meaning of the medium, film: the medium as a reality machine. Facts and fictions are told as one and the same by this machine.

Richard Slotkin describes what he calls the "dilemma of authenticity" in the case of Westerns. This dilemma stems from cultural tradition, the time/place nexus of the West:

Cultural tradition defined "the West" as both an actual place with a real history and as a mythic space populated by projective fantasies. Expectations about Western stories were therefore contradictory: they had to seem in some way realistic or "authentic" while at the same time conforming to ideas of setting, costume, and heroic behavior derived from literary fantasy. The cultural tradition the movies inherited was based on successful resolutions of this problem, in the forms of the historical romance, the dime novel, and the Wild West. But one of the unique appeals of early cinema was its claim (derived from photography) to be a direct and true representation of "the real thing." (1992: 234-235)

The mission of cinema as reality machine is to smooth away the tension in the cultural moment. In this chapter, I argue that this dilemma was felt at the time of these films. I take stock of those features discussed so far that have in common an uncertain historical status.

Underlying the features of the films under discussion are questions predicated upon general, diffuse cultural assumptions, as substantiated by the standards of judgment in contemporary reviews, about cinema's mission to represent some level of "truth." In the case of the fiction film, this "truth" may be psychological, philosophical, diagnostic, or descriptive, but is located elsewhere than in the factual reality of what is represented. In historical films, balancing between fiction and nonfiction, the story, the characters, the events, are held up to standards of truth and - something altogether different - authenticity. $\mathbf{H}$ These standards may appear naïve, but are persistent throughout film history. For example, more recent Holocaust films such as Steven Spielberg's ScHINDLER'S List (1993) or his World War II film SAVING PRIVATE Ryan (1998), are most hotly debated in these terms. ${ }^{4}$ Clearly, the facts represented are emotionally charged for the films' viewers.

But such debates are by no means confined to these sensitive historical topics. Topics less subject to contestation and more remote historical subjects such as intrigues and politics at the court of Elizabeth I - ELIZABETH, by Shekhar Kapur (1998) - or the recent "sword-and-sandal" epics Gladiator (2000, Ridley Scott), Troy (2004, Wolfgang Petersen), and Alexander (2004, Oliver Stone) are also evaluated in terms of historical truth. More specifically, I contend that in the old films as in the more recent ones the historical caliber of the films also bleeds 
over into their alleged moral or ethical "truth." This conflation of cultural issues makes a closer examination of the Western's truth claim important for a cultural history that includes a good look at its own logic.

The Western, as we have come to know it from classical Hollywood, would fall into the category of the historical fiction film. No one would question the appropriateness of representing the conquest of the American West in obviously fictitiously epic narratives, such as How the WeSt WAS Won (1962). The project to understand the films of the corpus under consideration, the Westerns made before WWI, on their own cultural terms, in contrast, requires that we endorse the starting point that the films were frequently seen, discussed, and reviewed as contemporary rather than historical, and that within this framework their "truth" or "authenticity" was a hotly debated issue. Filmic strategies of representation were perceived to sustain the truth of the films' contents. Let us trace some of these strategies that, together, or in varying combinations, contribute to characterizing the genre by default.

In the early years of cinema, the rhetoric of realism operated differently when compared to today's "age of digital manipulation," to invoke Walter Benjamin's seminal essay on the loss of aura in the age of mechanical reproduction. Images were less thoroughly, less fundamentally, and more visibly manipulated than today, and may, for that reason, appear to us to be more awkward but honest, than present-day cinema. Yet, no matter how "clumsy" the depictions, the landscapes that served as background looked real enough to authenticate the narrative. In the culture of the turn of the 2oth century, the medium of photography itself authenticated the representations it offered as real. This is, of course, a prevalent view of photography, but not the only one. There were artists who used photography and film for explicit and spectacular (science-)fictional constructions, like Georges Méliès who created a magical world of fairies and fantastic voyages to the moon. ${ }^{5}$ But popular belief clung to the idea of the reliability of photographs as documents, even if different paradigms of realism - here, magical realism next to historical realism - could operate right next to each other within the variegated film program. In debates in the press about the cultural value of the new medium, we can recognize arguments that build on this popular belief. For example, in a series of articles on "Practical Moving-Picture Making" in Bioscope the author reflects on film's educational value that originates precisely from the possibility of "substituting" photography in motion for the "real thing":

With the moving picture, however, you are enabled to show the thing itself, as it is commonly said, like life. [...] if it is desired to illustrate the manners and customs of a foreign country, or the growth of plants, or travel; if it be required to demonstrate the physiology of a living object; if it be desired to teach history by showing moving pictures of historical scenes; then the moving picture camera will be found to do all 
this far more effectively than it can be done by stationary photographic or other graphic representation. Indeed, in this respect the moving picture camera is a perfect substitute for the real thing itself, whatever that real thing may be. ${ }^{6}$

This chapter focuses on those elements of filmic presentation that authenticate or establish realism as discussed in the press. To this end, it is helpful to look at promotional advertisements as well as criticism and see what arguments are used. One important distinction that I discuss here is that between the arguments made for historical in the broad meaning of "of time" - historical here refers to both present and past - and those made for poetic, or for ethnographic or exotic realism. These different forms of realism will be broached in greater detail in later chapters, including $\mathbf{H}$ and $\mathbf{O}$. The criteria deployed for evaluation in the contemporary press can be handily divided into iconographic consistency, poetic authenticity, and moral truth. The first concerns elements such as the costumes and make-up of characters, or the use of either fake or real locations. The second is couched in terms of weak or strong plots, and hence, addresses the diegetic level. The third criterion judges the accuracy of depiction of life in the West. This criterion merges moral with ethnographic truth. For example, moral outrage about lack of ethnographic realism is expressed in a letter from the Indian Red Eagle who protests against the "average Indian Pictures." He writes: "The finer sensibilities of an Indian rise futilely at the grossly exaggerated and falsely represented position to which his race is subjected. I know, for I am a full-blooded Milicete." Tellingly, the reporter cannot help once more exoticizing Red Eagle's ethnicity when introducing Red Eagle's letter to the readers: "His language is dignified, graphic, picturesque."7 Figure F shows a cartoon that parodies protests by Indian audiences to their stereotyped portrayal in films.

The most suitable corpus through which to study these criteria consists of films that explicitly hover between fiction and nonfiction, as well as reviews thereof. Such films are, for example, (re)staged nonfiction films such as DRIVING Cattle to Pasture (1904, Edison), or A Round-up in OKLahoma (1908, Oklahoma Natural Mutoscene). Some examples of phantom rides with "inserted" subject positions also belong to this category. These I will discuss more fully in terms of landscape $\mathbf{L}$, narrativity $\mathbf{N}$, and train travel $\mathbf{R}$. Here, the temporal aspect of these films is of prime importance. These films demonstrate how films about the West in this period are not so much about the past; nor are they strictly about a present. Rather, they reflect the passage of time. Discussions of realism and authenticity are grounded in this temporal flux between past and present.

Complaints about the transition from actuality to fiction in Westerns are heard loud and clear, indeed, hyperbolically, in the press: 
24. THE NICKELODEON. Val. V. No. 9.

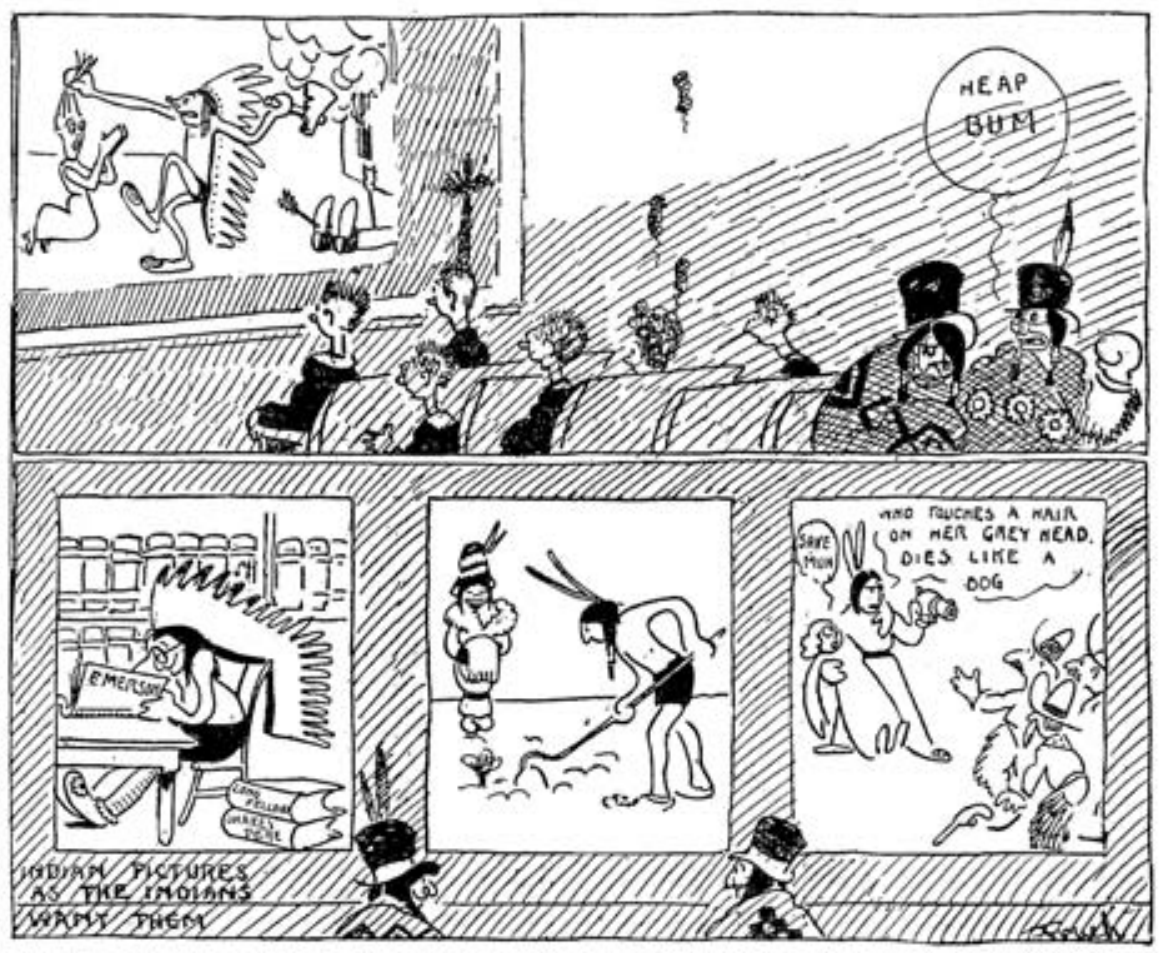

F "Indian Pictures as the Indians Want Them." Nickelodeon V, 9 (March 4, 1911): 246

The public is getting utterly sick and tired, utterly disgusted with the bad photography, the illogical stories, the poor acting, the general shooting and hold-up, that is being illustrated in these Wild West pictures, and, with the exhibitors, we feel the time has come when some stay should be made in thrusting these subjects before the public. Not only are the Wild West pictures absolutely incongruous, but they offend the better taste of the Western people, the settlers in Western towns. ${ }^{8}$

The offended party, here, is the public, whose "taste" is not exactly satisfied ("utterly disgusted"). The claim on behalf of the public is sustained by value judgments, which are, at first sight, of a more or less aesthetic nature: "bad photography, the illogical stories, the poor acting." The judgments do concern, however, those techniques by means of which historical representation is performed: photography, story, and acting. Were these done better, the implication seems to be, then the product would be more plausible, believable, in short, authentic. 
In other cases, such as evidenced in Red Eagle's letter, the offended party is not the viewing public, but the represented population. In the article, "Some Inconsistencies of the Moving Picture Cowboy" in Moving Picture News, arguments for authenticity are made explicitly. These arguments point out that contemporary Westerners would be offended by these inconsistencies. This article sums up the kind of mistakes that filmmakers generally make in the costuming of cowboys. The moving picture cowboy is held up against a reality of life and (hard) work in the West. The writers conclude that a "real cowboy" would never look and behave in the way in which these pictures present them. Therefore, the movie versions of that life are considered rather silly. This judgment concerns the iconographic consistency of the representation. ${ }^{9}$

These criticisms exemplify the way reviews specify the kind of realism that is at stake. Realism in Westerns is considered necessary to do justice to the West, and its adequacy measured by the standard of contemporaneity. In other words, the reviews claim contemporaneity, not historical truth. Praise goes to films with a documentary feel to them, such as The LAND of Promise (1912, Imp.) in which the actuality of the story is said to underscore its realism:

The picture gives the opportunity for the portrayal of graphic scenes of Western life to-day - not the Western life of a decade ago, the wild Western life that is rapidly becoming forgotten, but natural incidents associated with the agricultural and cattle raising in the far Western States of to-day. ${ }^{10}$

According to these reviewers the standards for good Westerns are set by the reality of life in the West at that moment. For the one film, it is the lack of authenticity that is criticized; for the other, it is precisely its documentary (read: contemporary) value that is praised. Although consistent between themselves, these opinions are examples of only one standard. But critics evaluating Westerns reveal different conditions these films have to meet. For example, they have to be either exciting, educational, based on history, or based on "quality" source texts such as canonical literature; they have to be based on the reality of the contemporary West, and more contradictory conditions.

Of course, the varying standards respond to each film's specific ambition and, at the same time, reflect production trends. In some films, an explicit documentary vision of the West is presented. Films like Cattle Fording Stream (1898, Edison), Lassoing Steer (1898, Edison), Cattle Leaving the Corral (1898, Edison), Calf Branding (1898, Edison), Rocking Gold in the KLONdike (1901, Edison), Packers on the Trail (1901, Edison), Herd of Cattle (1901, AM\&B), Herding Horses Across a River (1904, Edison) show moments in the working life of the West. These early films contain mostly single-shot views of men working, performing their activities in front of the camera. Some are more staged, or rather, more explicitly performative than others. 
Some of these films allow me to speculate on their reception in the press as based on the criteria I have pointed out. I am particularly interested in the way the first criterion - adequacy - merges with the second - plot - that is so blatantly of a different order. Sometimes a mix of staged nonfiction and explicit narrative strategies are incorporated into the films. In DRIVING CATTLE TO PAsture (1904, Edison) for example, the filmed cowboys take pains to make as exciting a picture as possible. They wave their hats and kick their horses so that they will cavort for a "rodeo-effect." Although it does not build a proper story line, this short film does feature some visually spectacular effects that are hardly "documentary." These effects would fall under the criticism of a lack of authenticity in the plot. In another Edison film of that same year, CowBors AND INDIANS FoRDING RIVER IN A WAGON, the costuming of the Indians seems odd. The cowboys look like the men in the other Edison films, very plain; maybe, by virtue of that plainness they appear to be "authentic." The Indians in the wagon look awkward, very elaborately dressed, holding some kind of spears decorated with ribbons. In fact, they look more like actors from a Wild West Show performing than like Westerners-at-work. ${ }^{11}$

But the attempt to evaluate contemporary criticism immediately hits the limits of our present competence to do so. For it is hard to decipher these images in terms of authenticity a century later. What we now perceive as the crudeness of the camerawork, or the poverty of costuming, can just as well strike us as a lack of manipulation, and hence, as a sign of authenticity. But on the same basis we could consider the films ostensibly "fake." This confrontation between cultural products from the past and our present attempts to evaluate them, foregrounds a methodological problem. It confronts us, that is, with the cultural embeddedness of such criteria themselves. For these films, for all their (semi-) documentary ambition, were not meant to be real slices of life, cut out from a setting the knowledge of which permits a viewer to sketch an overview against which to evaluate their authenticity. Re-staging, performance, posing, and substitution of "real life": these are accepted strategies to convey a sense of reality.

Realism is a general label for effects that can be produced by very different strategies. It is the concern - realism, or perhaps better, the realism effect that establishes the sense of reality - that remains the same. As a consequence of the pervasiveness of this concern, criteria for realism tend to operate in concert. If one aspect is constructed according to the standard of realism, then those that are not become more conspicuous. The serial aspect of these concerns - causing something like a ripple effect - stands out in a literary text, Jean of the Lazy A, which I read here as a fictionalized version of contemporary film criticism. The sheer existence of such a novel testifies to the lively cultural preoccupation with realism in Westerns. In this book a concern for landscape leads to a paradoxical "sensational" kind of realism. This 1915 novel by B.M. Bower, pseudonym for 
Bertha Sinclair, offers an interesting case of the intimate intertwinement of setting and plot to produce realism effects on all levels.

In the chapter "A New Kind of Picture," this novel presents a film director shooting films in the West to make his productions more authentic. This director calls for more "punch" in the films, for more spectacle and stunts. They already had actual Western locations, but now a local woman named Jean proposes that the director use real Westerners like herself as actors and real Western stories for the film plots. She advocates contemporary adventures, events set in the actual West of that moment, and writes the scenario herself:

"Hello, Lite! I've got a job for you with the movies," Jean announced, as soon as she was within speaking distance. "You can come right back with me and begin. It's going to be great. We're going to make a real Western picture, Lite, you and I. Lee and Gil and all the rest will be in it, of course; but we're going to put in the real West. And we're going to put in the ranch - the real Lazy A, Lite. Not these dinky little sets that Burns has toggled up with bits of the bluff showing for background, but the ranch just as it-it used to be." Jean's eyes grew wistful while she looked at him and told him her plans.

"I'm writing the scenario myself," she explained, "and that's why you have to be in it. I've written in stuff that the other boys can't do to save their lives. Real stuff, Lite! You and I are going to run the ranch and punch the cows - Lazy A cattle, what there are left of them - and hunt down a bunch of rustlers that have their hangout somewhere down in the breaks; we don't know just where, yet. The places we'll ride, they'll need an airship to follow with the camera! I haven't got it all planned yet, but the first reel is about done; we're going to begin on it this afternoon." (1915: 231-232)

These adventures are alleged to be more plausible than the predictable plots of the standard Western. Therefore, they will fit these real locations better. In this case, authenticity of location - the first criterion - accelerates the authenticity of character and plot - the second criterion. Like a stone thrown in a pond, it produces ripples of authenticity.

Jean's appeal to authenticity as a ripple-effect alludes to an aspect inherent in shooting outdoors. Clearly, authentic natural scenery had an appeal of its own, not only for its beauty and for the action it allows, but because of its authenticity per se. The feature of spectacle is perceived as a trigger of a specific mode of looking - with thrill, and hence, as an aesthetic. Thus the integration of the first and the second criteria logically, instead of merely incidentally, leads to the fulfillment of the third criterion.

But authenticity cuts both ways. On the one hand, the authentic landscape literally gives space to the characters and makes the representation of the events possible as well as plausible. On the other hand, in some films the action seems to authenticate a less-than-plausible landscape. In both cases the function of the 
landscape is tied to what Roland Barthes dubbed an "effect of the real." This term (effet de réel) indicates that the primary, denotative meaning of the specific setting is superceded by the secondary, connotative meaning attached to it, "this is real." Thus the connotation takes over, and the two, denotation and connotation, become the new denotation "authenticity." ${ }^{12}$

On a negative note, a lack of realism in Westerns due to Eastern innocence is criticized in an article in Nickelodeon, "The Passing of the Western Subject":

It is melodrama that the film makers are seeking. When they went West, it was with no sympathetic, high-minded intention of portraying real Western conditions, of interpreting its life and spirit. The filmmakers went West to find a stamping ground for melodrama. And they were attracted thither for two reasons: first, because certain phases of life in the West, where passions had been strong and the will unchecked by law, gave a plausible basis for melodrama; and second, because the West was not the East. The strangeness and unfamiliarity of the life out there, as seen from the East, cast a glamor of plausibility around lurid, impossible themes, giving room at least for the benefit of the doubt. Thus the West served the photoplay-producers as a convenient peg to hang either crude melodrama or crude farce upon, not because these were essentially characteristic of the West, but because the East could easily be fooled into thinking so. ${ }^{13}$

Clearly, the oppositional structure East-West, discussed à propos of Easterns, works here to shift attention from the insufficient strength of the plot - the second criterion - to the advantages of that failure for satisfying criterion three, that of moral truth. ${ }^{14}$

In a 1911 essay about realism in film, James B. Clippen makes a distinction between correct detail and suggestion. He prefers the latter, even though in the case of Westerns a lot of criticism is devoted to pointing out the mistakes in the former:

How far is realism to be carried? Must a film be absolutely impeccable in regard to detail before it can receive the stamp of approval? Obviously not, because a state of absolute impeccability never was or will be. There is no film so perfect but that a sharp eye could pick out some material flaw. The photoplay producer is not another Creator, omniscient and omnipotent, molding a world that is new and perfect; he can only combine old forms in his own fallible way, and inaccuracies are bound to creep in. And after all it is not the producer's purpose to create reality, but the illusion of reality. Art is not presentation but representation; it only assumes the form of reality in order to convey thought. Realistic details are thrown in simply as an aid to the imagination.

This is a philosophical point of view that resonates strongly with Barthes' discussion of the reality effect half a century later. But this critic is more concrete 
when comparing these higher goals of (dramatic) art and the realistic codes of the new medium. Like Barthes' discussion of diegetically irrelevant details in Flaubert, the article links a concern with details to the successful production of an effect of the real:

Along with the drama, whose concerns are essentially ideal and spiritual, there has grown up a subsidiary art of production, mounting, staging whose aid and standard is quite properly realistic. Whatsoever details enter into a picture must be accurate. The material vehicle of the drama must be perfect in its realism - or detailism, as it might be called. ${ }^{15}$

The concern with strategies that produce a reality effect has a temporal aspect as well. In an extreme form, the contemporaneity and the attraction of reality are taken as simultaneity between event and recording, similar to newsreel footage. I refer here to a use of the term simultaneity different from Uricchio's to designate the ambitions to invent a "live" medium, rather than the canned version such as film. Uricchio refers to the (close) temporal relationship between shooting and viewing that will become the initial hallmark of television. (Uricchio 1997a and1998a) In contrast, I am speaking here about the temporal distance between the occurrence of an event and the shooting of this event, taking into account the contemporary usage of the terms re-staging and re-creation as accepted stand-in for the real thing. Here, this simultaneity-of-event is, of course, impossible.

This becomes clear in the following case. A very exceptional deal was made between Pancho Villa and the Mutual Film Company, a deal worthy of CNN's involvement in the Gulf War of 1991. The New York Times announced this spectacular arrangement:

Pancho Villa, General in command of the Constitutionalist Army in Northern Mexico, will in future carry on his warfare against President Huerta as a full partner in a moving-picture venture with Harry E. Aitken of 130 West Fifty-seventh Street, in this city. The business of Gen. Villa will be to provide moving picture thrillers in any way that is consistent with his plans to dispose and drive Huerta out of Mexico, and the business of Mr. Aitken, the other partner, will be to distribute the resulting films throughout the peaceable sections of Mexico and the United States and Canada. ${ }^{16}$

Here, the use of real locations, real events, and real people came together in a perfect mix of strategies for, and aspects of, realism. But this deal was not made for the purpose of making anything like a news bulletin. Instead, as if to demonstrate the impossibility of a harmony between realism and reality, two totally unrelated needs were satisfied: real political ends on the one hand, and a spectacular action film on the other. Not surprisingly, this turned out to be a fiasco. The footage showed no battle scenes. ${ }^{17}$ 
The relationship between facts and fictions, then, cannot be reduced to historicizing claims for truthful representation. The realism most eagerly sought is anchored in the opposite of historicizing: simultaneity, or at least, the maximum reduction of the temporal gap between event and re-staging. In this respect, the concern for iconographic, diegetic or poetic, and ethnographic or moral adequacy of representation as evidenced by the press clippings quoted, is of an order that is altogether different from the concern, discussed in the previous chapter, to hold the spatial other (side) at arm's length by means of temporal distancing. But, whereas Easterns showed a marked family resemblance with Westerns set in the West, the criteria for the successful, persuasive merging of facts and fictions contribute to deepening our understanding of how the nearobsessive interest in the West was an aesthetic and moral issue of the culture in which the films had their impact. Both the (sub-)genre of the Eastern and the rhetoric of realism help us to further understand what was at stake in this flourishing, indeed booming, genre that accompanied, emblematized, and implemented the new medium. Together with the lack of wholeness of the Bits and Pieces that constitute large segments of my corpus, the urban background, and the self-deconstructive inconsistency of the representations of the alleged other who most essentially substantiated the difference of "the West," the negatives discussed so far constitute the provisional elements of the genre.

\section{Notes}

1. “The Wild West.” Moving Picture News V, 8 (February 24, 1912): 21.

2. "The Passing of the Western Subject." Nickelodeon V, 7 (February 18, 1911): 182.

3. "The Wild West." Moving Picture News V, 8 (February 24, 1912): 21.

4. SCHINDLER's List has triggered a vast amount of discussion about the representation of the Holocaust. To mention a few works: Thomas Elsaesser (1996), Miriam Hansen (1996), and Yosefa Loshitzky, ed. (1997).

5. On the film genre of the Féeries, see Frank Kessler (1999) and (2000). Some of the fantastic films by Méliès are Le voYage dans LA Lune [A TRIP TO THE MoON] (1902), Voyage À travers L'impossible [Voyage Across the Impossible] (1904), Le Dirigeable fantastique [INventor Crazy Brains ANd his Wonderful Airship] (1906), and La FÉe CARABOSSE (1906).

6. Bioscope I, 162 (November 18, 1909): 29.

7. Moving Picture News IV, 50 (December 16, 1911): 32.

8. Moving Picture News IV, 46 (November 18, 1911): 6.

9. Moving Picture News IV, 49 (December 9, 1911): 27.

10. Moving Picture News V, 17 (April 27, 1912): 20.

11. A nonfiction film about cowboys at work, HeT LEVEN DER Cowboys [The Life of Cowboys] is mentioned in the Dutch trade paper De Kinematograaf I, 10 (28 March 1913): 59, in a listing of nonfiction films ("Natuur- en Wetenschappelijke Films" 
[Nature and scientific films]) in an advertisement of a distribution company (Het Algemeen Internationaal Filmbureau, Amsterdam). The list includes films depicting labor, animals, and countries such as ZwAVELINDUSTRIE op SiciLië [Sulfur Industry in Sicily], Hoe gloeilampen worden gemaAKt [How Light Bulbs are Made], RijSTPLANTAGE IN JAPAN [Rice Plantations in Japan], IN HET LAND DER APEN EN SLANGEN [In the Land of Apes and Snakes], and ONDERZOEKING VAN DEN MAAG DOOR RÖNTGENSTRALEN [Exploration of the Stomach by X-Ray]. This list of titles is significant in itself: without seeing the actual films we can get a sense of the programming and generic stratification of the time.

12. Barthes (1986: 141-154). For a discussion of this term in relation to landscapes in Westerns, see my essay "'Where the Real Thing Runs Rampant': Landscapes in Early Westerns" (1999). This topic is also discussed in $\mathbf{L}$.

13. Nickelodeon V, 7 (February 18, 1911): 182.

14. In this argument, the site of reception determines the assessment of the site of production. In the press this was often stressed as if to emphasize the widespread distribution of film as a medium. For the European reception of the use of "fake" locations and "fake" Westerners (including made-up Indians), see "Exporting an Imaginary America to Make Money." New York Times (30 July, 1911). This article is partly reprinted as "Exporting the American Film." Motography VI, 2 (August 1911): 90-91.

15. "Realism and the Photoplay." Motography V, 4 (April 1911): 15; emphasis in text.

16. "Villa at the Front; 'Movies' Sign Him Up." New York Times (January 7, 1914); emphasis added.

17. For more details about this case, see Brownlow (1978: 87-105) and De Los Reyes (1995). 


\section{Genre}

It is the expectation of the company that about the first of November it will be able to release one 101 Bison and one Broncho feature every week in a variety of subjects, Civil War, historic, Indian military, straight military, pioneer, early days of the West and cowboy pictures.

- Motography, $1912^{1}$

[We] see a complicated network of similarities overlapping and criss-cross-

ing: sometimes overall similarities, sometimes similarities of detail. I can think of no better expression to characterize these similarities than "family resemblances"; for the various resemblances between members of a family: build, features, colour of eyes, gait, temperament, etc. etc. overlap and crisscross in the same way. - Ludwig Wittgenstein, $1953^{2}$

It has become clear enough, in the five different challenges to the long-held notion that the Western equals the classical Hollywood genre, that, when searching in film archives for Westerns made before World War I, the variety of films found demonstrates that many different readings of what we now call Westerns are possible and that different markers of the West are variably activated by different films. As a consequence, it is not so obvious which films we would classify as Westerns and why we see them as belonging to this genre.

In the collection of the Filmmuseum, for example, a thorough search will uncover a wide variety of films that in many different ways treat the subject of the history of the American frontier. A film like How States ARE MAde (1912, Vitagraph), whose title suggests an epic story about a transitional phase in the history of the American West, is reminiscent of the classical Western. It is a film about a famous historical land rush and the adventures of a family racing to stake their claim. Broncho Billy's Christmas Dinner (1911, Essanay) is also a story about life in the American West, but this is a romantic, domestic melodrama of a bad man's redemption at the Christmas dinner table. ${ }^{3}$ In standard genealogies, e.g. of literary genres, these two films would be classified in different categories: one as adventure, the other as melodrama. Why do we see them both as "Westerns," and hence, as belonging to the same genre?

Other films are not clearly recognizable as Westerns, but after viewing them and comparing them with other films provisionally labeled early Westerns, si- 
milarities pop up that are nevertheless striking. We have already seen that RosE O'SALEm-Town (1910, AM\&B), for example, is obviously set in the East in the 17th century. The film deals with Puritans and witch-hunts, not with gold rushes or hold-ups. This film is, in turn, very different from MExicAN FILIBusTERERS (1911, Kalem), which is set in the West, and refers to the specifically contemporary context of the 1911-1919 Mexican Revolution. In that sense it is set in the simultaneous reality. The plots of both films are very different from the well-known "Cowboys and Indians" stories. An historical "Eastern" and a contemporary "Western" - why do they seem related?

There are good reasons for that impression. For one, the spectacular aspects of the films, such as the last-minute rescue in the former and the chasing of a train transporting contrabands by the border police in the latter, put both in the category of action films that many Westerns are at heart. In the latter film the setting, the Western regions of the United States, along the border with Mexico is, of course, typically "Western." In contrast, Rose O'SALEM-Town deals with an entirely different period in history than most Westerns, and therefore can only be set in the East. But as we have seen, the film is still set at the frontier. Only, this frontier lies much closer to the East as is consistent with the temporal aspect of Western expansion.

Moreover, we have also seen that this film features Indians within a binary opposition between a "pure" state of wilderness and a corrupt Christian civilization at the frontier where these oppositions clash. Then, there is the historically relevant aspect of the cultural appearance of the films in actual programs. The Eastern film is related to MexicAN FILIBUsterers when shown together within the context of a film program, as is Cupid THrough PAdLocks (1912, Imp.), a romantic comedy in a rural setting that features two young lovers dressed in cowboy gear. Here, the story itself is not a specifically Western story, but it is the setting and the costumes which give the film a specific flavor, making it distinctly different from love stories set in the city.

Finally, to offer an even more diffuse yet pertinent cultural historical reason, the films were promoted and perceived as Westerns. In Nickelodeon, a review of Rose O'SALEM-Town describes the film as an historical film about Puritans in Massachusetts. The role of Indians, however, is compared to "the traditional role" of Indians in other films. This comparison relates this film to other, more clearly "Western" films:

The film compensates for this injustice to the Puritans, however, by treating the Indians with unusual fairness. For once they go out on the warpath in the cause of justice and right, frustrating the wicked purpose of the white settlers. This is a complete reversal of the traditional roles. Motion pictures have villainized the Indian for so long that they have thereby added another burden to the load of injustice already borne by that unfortunate race. ${ }^{4}$ 
I wish to demonstrate with this quote the reference the film makes to other stories with "Indians." Thereby, I am making a triple point.

My point is, first, to justify a sense of a genre of the Western on the basis of rather fragile and volatile immanent resemblances. Second, I would like to insist on the existence of such generic allegiances in the historical reception, and hence, implicitly arguing against anachronistic projection as well as immanent formalism, so that both these limiting approaches can be opened up to - not necessarily replaced by - a cultural historical (reception-) genealogy. Third, I will demonstrate that such an historical consideration of reception is itself already invested in a generic perspective that serves a purpose beyond simple categorization. For, the last quotation shows how the critic uses this film as a commentary on other films as a group, clearly showing that genre is a critical concept. It helps the reviewer to articulate not only the film's critical relationship to other films of, precisely, its "genre," but also its cultural-critical importance at a time when the relations between whites and Indians were a matter of immediate social importance. These three claims gain in relief when set off against the complaint about injustice to which film has "so long" contributed. More emphatically than ever, early films are here positioned after the beginning.

I refer here to genre criticism as historical object: the less theoretical and authoritative, but all the more active form of criticism of the historically specific culture within which the films were made and shown. ${ }^{5}$ This aspect of historical reception is a rich source of genre discourse that, together with the films, can tell us a lot about the cultural functioning of genres, and thus about the relevance of historical genre studies. These films are all story films that in one way or another deal with a period in the history of the United States. The historical framing of the story determines the region in which the story is set and determines the characters that move around in that setting as well as their adventures. This appears to be enough of a basis for generic affiliation. But, lest the simple and more or less intuitive concept of this genre be closed off right away, another complicating "type" shows its face. Whereas the films I just mentioned can feature different times, a consistently contemporary type of film, the travelogue, seems to be relevant for our search as well. Here, the ambiguity is not in the region, nor the time, but in the role of action in relation to nonfiction.

Many titles are ambiguous as to whether the films are story films, travel films, or maybe "documentaries" avant la lettre: [NATIONAAL PARK IN AMERIKA] National Park in America (c.1918), Montana State FaIr (1914, Vitagraph), BucKing Bronchos (1904, Edison), Parade of Buffalo Bill's Wild West Show (1898, Edison), or Grand Hotel to Big Indian (1906, AM\&B). These films may well be classified as nonfiction, but although they are very different from the fiction films, they are very explicitly about "Western" subjects - more so than many less problematic members of the emerging "genre." They display 
the Western landscape with cowboys and Indians against this setting as if to authenticate the landscape. Meanwhile, they also show how these vistas of the Wild West have come to resemble a national park, but in such romantic shots that a strong resemblance to fictional Westerns is invoked. In that respect they "touch" the Western: they point to them indexically. ${ }^{6}$

Some films emphasize their Western-ness more than others. The frontier stage of the West becomes a theme in the story for some, while for other films the location is merely used as a backdrop, as a kind of coloring of the story. "The West" can mean a specific geographic location; it may refer to the frontier as west of Europe, or in a later phase of history, as west of the Eastern United States. The West can be a marker of savage, but honest, lives in the wilderness, or it can be a setting for contemporary stories about a political reality, or a coloring for romantic comedies.

Hence, the question arises: what criteria do we deploy when we establish a corpus of films, whether for historical research, for critical analysis, or for archival practice, almost a century after the films were made? How do we make choices about what films are relevant for our topic of study, and what corpus is relevant for that topic but does not beg the topic's question? How do we decide which films to preserve and restore and how to categorize them for catalogues that make the treasures in the film archives accessible for researchers of today and of the future; how do we program these films, bringing them back from the archives into the theater?

Here is the predicament of the historical study of a "genre." On the one hand, we need to have some sense of genre as a tool to delimit a corpus in order to be able to study the past, to create order in the archives and to take decisions about restoration, preservation, and programming. On the other hand, the notion of genre poses problems that can hamper rather than help those three activities. Therefore, reflection on this necessary and impossible subject is important. This reflection is indispensable prior to those decisions, however casually and hastily we might be forced to make them - or precisely because of that practical necessity. The following is meant as a contribution to that reflection.

Genre definitions based on essential, positive characteristics such as certain iconographic markers, stock characters - Cowboys, Indians, Sheriffs, Virgins and Prostitutes, familiar locations - the Sheriff's Office, a Saloon, Hotel, or Ranch or the typical Western landscapes of prairies, mountains, and deserts, have been pointed out either for defining films in terms of that specific genre, or for defining the genre itself. For a self-conscious cartoon about this type of categorization, see $\mathrm{G}$. 


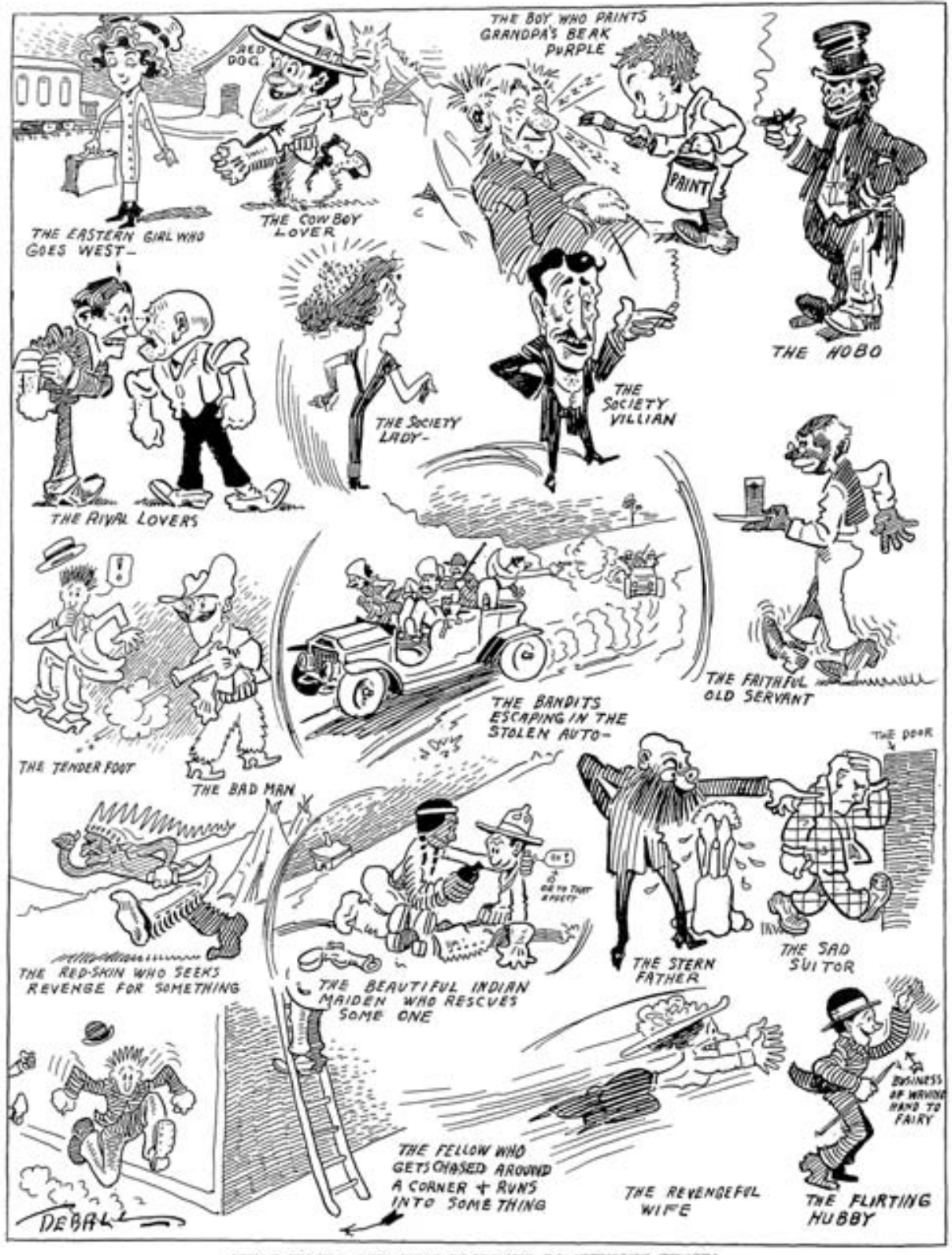

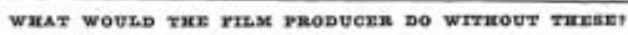

G “What Would the Film Producer do Without These?" Nickelodeon V, 19 (March 11, 1911): 278 
An immanent textual approach would focus on attributes or iconography, considering defining elements such as guns and horses or cowboys and Indians. A contextual approach is more reception-based and suggests looking at contemporary discourses, such as film descriptions in the trade press and in programs. A structural analysis focuses on other levels of meaning pertaining to the films, such as ideologically encoded myths about the wilderness versus civilization, the struggles of the individual or other layers of "frontier" myths coated with imperialism and exoticism, or plot elements such as chases and hold-ups.

The limitations of the pioneering studies of the 1970s and early '80s based on such approaches, like those by André Bazin (1971), John G. Cawelti (1971), Thomas Schatz (1981), and Will Wright (1975), have been evaluated, for example by Rick Altman (1999), Tag Gallagher (1986), and Steve Neale (1980, 1990). Toby Reed and R.J. Thompson (1996) analyze what they call "essentialist models of the Western as genre" and restrictive definitions that operate by exclusion and the myth of the origin or pure form of the genre (52-53). They evaluate Bazin's work on the "essence" of the Western and Wright's structural definition of the Western. In their criticism they propose a more dynamic analysis of the genre, following Deleuze's thoughts on the simulacrum. ${ }^{7}$ They stress that "[the] generic text is created through a complex relationship that accentuated [...] difference in a product that has the image of sameness." Rather than following models based on inclusion and exclusion and of origin and development, they argue that genre is "subject to the same vertigo as the simulacrum: it is inherently decentered while giving the impression of origin and center; it has the impression of sameness but in fact conceals difference $[\ldots]^{\prime \prime}(62){ }^{8}$

These approaches are based on a model or formula that is defined in terms of conventions and generic markers that are recognized in the films or the generic discourse around them. Genre definitions are based on just such conventions. Such definitions seem to fall easily into a trap of circularity. Films are defined in terms of a genre that is, in turn, defined by films. This is a circularity of deduction and induction. The question is, what comes first, the category or the films? Or, as Altman asks: "Where do genres come from?" In his study on film genres he formulates the following hypothesis:

Before they are fully constituted through the junction of persistent material and consistent use of that material, nascent genres traverse a period when their only unity derives from shared surface characteristics deployed within other generic contexts perceived as dominant. (1999: 36)

It is in the early period of cinema, before 1910, that the genre historian can see traces of this dynamic. This period provides us with new facts, new films that constitute an as yet un-canonized corpus. There is much that does not fit in any kind of category, and there is a lot of stylistic and iconographic instability in this 
period. Therefore, it seems fitting to include in a study on the early Western an inquiry into the basic, underlying premises of the very categorization on which the delineated corpus is based.

It is my contention that any genre definition is subject to an inevitable, yet problematic, anachronism. In an article on genre, Steve Neale (1990: 46) raises the point that genres are "not simply bodies of work or groups of films" but that "they consist also, and equally, of specific systems of expectation and hypothesis" on the part of the spectator. When searching the archives today, the scholar-as-spectator necessarily has more or less anachronistic expectations because the perspective cannot but be retro-spective. The qualifier "early" to name what contemporaries called "latest," that delimits my corpus is symptomatic of this retrospectivity. This dilemma can neither be avoided nor endorsed as if it were "natural." Therefore, I would like to raise some questions concerning "time" and "genre" as implied in "early" and "Westerns." The qualifier "early" is necessary as well as being filled with implications that need probing. It is necessary, because the noun "Western" is not specific enough. "Early Westerns" are distinct from the larger category of "Westerns," for which the classical period of the genre has been so exemplary. At the time of the "early Western" there had not been, and hence, there was not, in the cultural imagination, a "classical Western," and that obvious situation changes everything.

"Early," in fact, suggests a preliminary or preparatory status for the films; not yet "mature," they do not as yet quite fit the genre. The notion of "early," therefore, already carries a condescendence that all but obliterates the films from visibility in terms of films, as culturally functional objects in their own right, not yet burdened by an after. For this reason - that is as simple and obvious as it is devastating for our normalized sense of the historical - we have an interest in reconsidering the early period if we seek to gain insight into the development of the Western genre throughout its history. Development, however, also already predicates the goal of the analysis upon a later state.

In order to counter these naturalized drawbacks of our historical consciousness, then, it is helpful to look at Westerns within the synchronic state of their own time: early cinema as a whole, as a cultural practice occurring at a specific moment. This "synchronism" helps us to gain insights into the genre dynamics of the period. In this respect, it is a good starting point to realize that, at the time, no simple genre label such as "Westerns" was in use for films. "Western" was used mostly as an adjective to specify a certain kind of melodrama, comedy, or romance, giving dominance to these larger categories. The phrases: "Romance of the West," "Western Comedy," "Western Melodrama,"9 or "Dramatic story of the Wild and Woolly West" are such qualifying usages of the label in the trade press. But in a different view, the films could also be called "Frontier Drama,"10 "Village Drama," "Mining story,"11 "“Early Settler' Subject,"12 "In- 
dian Romance,"13 "Military drama," or "Civil War picture," scenic film," or plain "Melodrama" with no Western adjective. The following review of A Dutch Gold Mine (1911, AM\&B) uses the adjective "Western" to differentiate between Western comedy and Western drama in order to underscore the company's rich and varied offerings:

This, if memory serves, is Biograph's first "Western" comedy of the season, and one observes that Biograph's idea of Western comedy is quite as distinctive and "different" as is Biograph's idea of Western drama. ${ }^{14}$

But this qualifying usage with its implications for generic instability was only one indicator of the floating life of the "genre." Neale (1990: 52-53) also refers to the use of the term as other than adjective and in reference to film (the first mention of which in the Oxford English Dictionary dates from 1912 according to Neale), illustrating the anachronism of the genre label for THE GREAT TRAIN RobBery. He mentions Musser (1984) who argued that this film was considered part of a crime genre, and that it was the mixture of this genre with elements from railroad films, melodrama, and the chase film that made the film successful (54). According to Musser, The Great Train Robbery was therefore not a "blueprint" for Westerns, but was a combination of already popular film forms in its time: “One reason for The Great Train RobBery's popularity was its ability to incorporate so many trends, genres, and strategies fundamental to the institution of cinema at that time." (Musser 1984: 56-57) Similarly, in 1905 when Biograph released THE HoRse THIEF it described the film in the Biograph Bulletins as a chase film with as extra feature the novelty that "all of the chases in this film take place on horseback."

Even studios that specialized in films about the West used a variety of genre labels to emphasize the richness of their film output, as in the announcement in Motography about the New York Motion Picture Company, quoted as epigraph to this chapter. ${ }^{15}$ Sometimes, however, no label would be used at all, and the generic status of the film would be ignored. ${ }^{16}$ All of this evidence points to the considerable inconsistency in the use of genre labels. We should note that such inconsistency is not a sign of a lack of theoretical clarity, but of the emerging, and hence, not yet crystallized notion of genre itself. What we are facing is not, as we tend to think, something old, but on the contrary, something new.

This wavering brings us back to my initial question about research, cataloguing, or programming of films for which a genre label is the organizing principle. It is helpful to realize that it was not the "early" - then, simply, contemporary practice of naming that causes the problematic mismatch between label and films, but our own, retrospective projections of later rigidified genre concepts. This realization opens up the corpus to a renewed "newness," a fresh look at 
how we can study a genre that had no separate name while avoiding projection of the later film genre that did have the label of "Western."

A new corpus calls for new approaches, and film historians have recognized that a new historiography is needed for a newly-discovered corpus of early cinema. For example, new methodologies challenge the textuality of early films. These methodologies mark a shift in attention from film as text to film as practice. This shift recognizes the "actuality," or "contemporaneity" of the films, which in turn entails a central position for spectatorship. Methodological strategies within these approaches include the study of intertextuality, which results in analyses of a variety of texts and discourses, but also the study of conditions of production, distribution, and exhibition of these texts. This approach underlies research on the exhibition practice of the "variety format" of film exhibition and the contextual effect of the film program, for example. Below, I will return to the implications of this shift from the singular text to the film as part of a larger film program.

As a consequence of these new approaches for the period before classical Hollywood cinema, a theoretical take on periodization is necessary. In terms of this "early cinema" and its stages of development, periodization with its double allegiance to the object of study and the history of its study becomes an issue in itself. To begin addressing this issue, let us heed Miriam Hansen when she writes: "More than a chronological distinction, the concept of 'early cinema' implies a paradigmatic other-ness" (1991a: 16). ${ }^{17}$ Taking Hansen up on her use of the word paradigm, here, I contend that periodization may best be understood as related to the notion of paradigm.

This notion has been much abused by scholars desiring to claim more innovation for their work than is warranted, and it has been criticized for its malleability. But here, the concept can serve a different purpose, a more programmatic one that does not claim results but endorses an obligation. For here, this terminological shift indicates a desire to emphasize that early cinema is not merely a phase in a development, but a fundamentally different phenomenon and practice than the classical period after the teens. Therefore, placing early cinema in its own time liberates it from developmental models. This liberation leaves firmly in place the obligation to understand that synchronically-situated otherness on its own terms. In other words, invoking the concept of paradigm to define and delimit historical periods increases the homework rather than validating the work that has already been done. My study aims to make a small contribution to that work ahead of us.

This view entails a periodization based on the historiographic premise of synchronic slices, assuming breaks and discontinuities in history rather than the continuities between historical periods. ${ }^{18}$ For example, when historians speak about a paradigm shift that occurs between 1907-1917, from early to classical 
cinema, I argue that this period is not a shift between paradigms, but a paradigm in itself. It is not merely a transition period from early to classical, marked by instability and changes due to this transition, but a paradigm because of its fundamental instability; a paradigm that is defined by it. The instability, which was symptomatically indicated by the great variety of genre labels cited above, is a feature of this paradigm, not the sign of a shift. As such, it is to be taken seriously and positively.

Thus, the notion of paradigm can help in conceptualizing differences within, instead of from: a take on radical and plural differences without the evolutionist comparison that leads to value judgments. ${ }^{19}$ The first two decades of the medium embrace transformations, changes, and breaks as well as changing relationships between film and other media and art forms. These transformations were not experienced as a rush to what came after, but as a situation of the present. This cultural environment constitutes the films' intertextual and interdiscursive framework.

When we consider these changes, transitions, and plurality of the period, both conventions and innovations matter, and neither is more important, characteristic, or aesthetically valuable than the other. Early cinema is marked by instability, but also by continuity. Once we consider it in its own time, we notice both a movement towards standardization and a space of possibilities for different styles, narrative modes, types of plots, and iconographies. A diachronic history of this period shows continuity as well as breaks; a synchronic overview shows similarities as well as differences.

Therefore, the perspective of plurality as a heuristic strategy that the deployment of the concept of paradigm entails opens up a lot of insights. I contend it to be a methodological necessity. The perspective of plurality becomes part of the project of genre studies and in our case, of the study of the Western. "Paradigm" bridges the discrepancy between the "period" and the "genre" aspect of our category "early Westerns.", putting us in a near-aporia. It is all but impossible to approach instability and even map early cinema's forms of heterogeneity through a defining, but also confining, and an inherently periodicized term such as genre. Yet, open networks or groupings, open categories, seem to be contradictions in terms. To resolve this dilemma I approach it as a productive problem. Therefore, the problematic of the early Western as genre requires a reconceptualization of the idea of genre in early cinema itself, but with the understanding that the historicizing element is just as inherent in the "genre" - and hence, undermining it from within - as the defining features we may wish to attribute to it.

When we seek concepts that would be amenable to such a conception of genre, intertextuality offers itself. Intertextuality has become a keyword for studying the distinctive mode of reception of early cinema as it gives us insight 
into the way films would fall into pre-established cultural expectations. Intertextual analysis yields knowledge of the spectators' frame of reference. For this, a focus on textual relations between films and, for example, paintings, literature, dime novels, as well as Wild West Shows and dioramas in museums or fairs can be helpful. But we can also focus on discursive relations - ideologically specific representational modes, such as exoticism, cultural imperialism, or a nostalgia for a recent past, which can be seen at work in different texts.

In this respect, the films' historical positions are doubly embedded. On the one hand, previous traditions continue to resonate, on the other, contemporary (synchronic) intertextuality is actualized. Here lies the relation of one medium with others within its cultural context. Examples of very direct references between media are visible in some of the films, such as The Cowbor Millionaire (1909, Selig). The story of this film plays with a stereotypical image of the "Westerner," referring to different media. A Remington painting on the wall of the protagonist's living room has literally become a substitute for the "real" West. Extended rodeo scenes that frame the narrative exoticize the main character. A scene of misunderstandings in a theater is based on an idea of the boyish, naive Westerner who does not understand the codes of this "Eastern" form of art. These allusions to other genres and media can be considered part of what defined the "genre" of the Western. They contribute, also, to the sense of belatedness that positions these films always-already after the beginning. ${ }^{20}$

In addition to this kind of immanent intertextuality, yet another contemporary context can be considered to have a bearing on the intertextual effect of the single filmic text as "Western" and thus to be an indicator of the "genre." I am referring to the context created by the exhibition practice of the film program, as mentioned above, one of the most characteristic elements in the cultural practice of early cinema. This context provided a format for programming that is characterized by an emphasis on diversity. Not only could a program contain different media or theatrical elements, such as vaudeville acts, narrators, lectures, magic lantern slides, or even entire acts from Wild West Shows (Hansen 1991a: 29-30). But the reverse could also be the case, with films incorporated into other media.

Films could be a part of a larger show such as a Wild West Show. The Nickelodeon reported that:

Fred. H. McMillan is preparing to put another Indian show upon the road.[...] Moving picture managers have taken to the Indian show with great enthusiasm. It takes the place of vaudeville and is of a higher class than the usual vaudeville seen in moving picture theaters. [...] The show consists of Cherokee Blanch and her shooting specialty, and other Indian dances and singers, and 2,00o feet of film showing scenes of Western and Indian life. ${ }^{21}$ 
According to this announcement the function of film within the program consisting of acts and tricks seems to be the "educational" aspect of the show, referring to an ethnographic interest in "scenes of Western and Indian life." This is an example of how the exhibition context determines the variable reception depending on the site (and situation) of the exhibition. ${ }^{22}$

Moreover, the films as components of such programs could be selected on the basis of the differences between them, their shifting modes and styles of representation. As a result of this exhibition practice, a striking degree of heterogeneity among genres or types of film prevailed. Therefore, this heterogeneity is inherent in the genre, if we can call it that, of the turn-of-the-century Western. The program itself is based on diversity as well as coherence and balance, showing different films but presenting them in the coherence of a show and in a specific order or sequence. In fact, the presentation of separate films in the totality of a program can break down the borders between genres, while that production of permeability between genres defined them.

This relationship between programming, media, and genres illustrates how plurality works on different levels, on the level of the individual film, on genres, and within the film program. To understand these films closely, the relationship of each film to its surrounding films is important because of the context-effects, prompted by the exhibitor. This is less strange and unmanageable than it may appear if we consider that in the present, the programs of conferences and festivals, or screenings in cinemas or film archives, can be seen as an analogy with this practice. Showing diverse films in the context of a program about Westerns emphasized their "Western-ness" or at least created coherence while also highlighting differences within the genre. Differences between films were emphasized by their similarities and, conversely, their similarities are clear because of their differences.

Not only did every film have a place within a variety program, that place could be different within each new program, hence, for each new viewing of the film. Genres had specific places as well, as we can deduce from trade-press discourse and the few program charts or booklets we can still find. It may well be that the first reason for distinguishing genres was the balancing of film programs. Genre, then, does not stand "above" the films as historical objects, but is part of them, as a discourse as well as an object of reference. Films refer to a rich diversity of genres inherent in programming, instead of referring to a canon of other films within the "same" genre as it emerged later. In short, rather than a group of individual films, the historical object of the "Western" consists of cross-genre relations between films rather than generic coherence. Here is a basic pragmatic historical difference between classical and early Westerns - an instance of a difference of paradigms. 
Films, then, are not put into a genre like into a box in which they fit, but are put in a dialectic position with a theoretical concept of genre. This is not a pregiven definition based on a selection of films, in itself based on previously established criteria in which the films have to fit. The circularity inherent in using a concept to delimit the corpus to be analyzed through it, makes it evident that it is not just a new genre concept for Westerns that is called for, but a new conception of "genre" in general. One way of attributing a different meaning to genre is to bring it back to the function of searchlight, instead of a method of labeling and categorizing. As a searchlight, genre can provide ways to find films, to program them, and to make films visible in their relation to others. But by foregrounding the participation of the historian in the manipulation of that searchlight, this heuristic tool emphasizes that such decisions are by definition provisional, valid only as long as the searchlight shines to illuminate the objects there, then, and thus.

With a provisional genre concept modeled after the metaphor of a searchlight, it becomes easier to allow for a great deal of openness in definition. This is not simply a matter of labeling, but a truly epistemological shift. For, in such a conception, genre becomes a means for provisional description, allowing for historical change and fluctuation, instead of a procrustean means for listing determining features and cutting off works that do not appear to fit. Therefore, my proposition is not another concept of genre, another model that will be applied to the films. Instead I propose genre as a method: as a way of looking at films that may activate the dynamics between the films and some ways of defining genre. It opens up a flexibility, a mobility of what the markers of the Western are, which in turn may revise the corpus of films we study when working on "the Western."

What would such a genre concept, or practice, look like? As can be surmised from the second epigraph to this chapter, I find Wittgenstein's notion of "family resemblance," another conceptual metaphor, useful here. As I mentioned above, within the film program as exhibition of generic mixes a stylistic heterogeneity is visible. Miriam Hansen suggests the following about the films:

In preserving a stylistic heterogeneity of their component parts they invoke a larger field of intertextual bricolage of which the individual film is only a segment, as is the particular program in which it is shown. (1991a: 47-48)

Hansen claims that, unlike in classical genre films, the generic hybridity of early films "mobilize[s] intertextual awareness across genre boundaries" (48). However, when we seek to map out different genres in this period, to stop at heterogeneity and bricolage is not enough. To make this view of stylistic heterogeneity operational for genre in both the senses I have just distinguished, I propose a 
concept of genre inspired by Wittgenstein's metaphor. ${ }^{23}$ I wish to emphasize the second word of his phrase family resemblance. The family metaphor is here used in opposition to the closure that tends to be associated with the idea of family. Here, it is deployed to de-emphasize a singular identity and foreground plurality and difference within affiliation. Resemblance based on difference within, then.

Wittgenstein introduces the notion of family resemblances when he attempts to explain the metaphorical relationship between language and games as a way of understanding the former. The idea of family resemblance is useful to understand these generic terms - "language" or "games" - as being essentially variegated and defined by flexible criteria. Like a family, the genre of games consists of multiple elements that do not share any essential, exclusive feature, but is held together by a network of overlapping traits. Similarly, "Westerns" as variegated texts devoid of single, or even multiple, essential features, can be grouped together through their overlapping traits, none of which is required, defining, or delimiting in itself.

Western "family traits" can occur on different levels; they can be iconographic or situated on the level of structure, setting, character, story, or mood. The rule of the game is that each member of the "family" has at least one feature in common with at least one of the others, but 1) this may not be the same feature; and 2) this single member may have nothing in common with one or more of the other members, as long as it has some feature in common with some of the other members. The network of features that they share, pair by pair, is what constitutes the family resemblance. ${ }^{24}$

In this view, NATIONAAL PARK IN AMERIKA with its foregrounding of touristic travel and picturesque landscapes shows resemblances to ROMANCE OF THE RAILs (1903, Edison), whereas the latter shares features with LE RAILWAY DE LA MorT (Gaumont, 1912), with its train motif and its mobile display of landscape. ${ }^{25}$ While The Cowbor Millionaire, featuring similar rodeo scenes to those shown in Montana State FaIR, also has the kind of references to other media that is an important motif in LosT AND WoN (1911, Selig), with its selfreference to film. All three show the same contemporary dimension, as they are set in modern times. Thus conceived, these films can form a group on the basis of family resemblances. ${ }^{26}$ This concept allows for flexible switches between subgenres. It is not a taxonomy, for there is no hierarchy between genres such as: the Indian genre is part of the Western genre and the captivity narratives are a cross between Indian films and Westerns. Through inter-generic relations, a kind of "intertextual bricolage" occurs indeed; these films are composite genre films. At the heart of these different compositions are shared themes, subjects, elements that hold them together as a "family." Behind this lies no core element, 
no shared essence, but rather an idea of partial overlap. The remaining question is, how does such a concept of genre help work in, for example, the archive?

Against the background of the negatives - the five challenges to genre definition - that constitute the bulk of this cluster, it is now time to take stock of what is opened up by this conception of the early Western as a generic paradigm based on family resemblances. Most importantly, as I suggested, the diversity of the period's film practice can be captured by a system of family resemblances as open categories. But there could be a danger in taking heterogeneity as an end point of this mapping of the period films - a danger of disempowerment and an invitation to "anything goes." Hence, it is imperative to articulate an access to shifts and diversity that is possible without losing all form of grasp. For such a loss would make the corpus elusive and, ultimately and paradoxically, invisible again. Instead, my proposal does allow the use of genre as a heuristic tool, not an essential characterization, but heuristic nevertheless, conducive to the practical work that is the task of the historian, archivist, and analyst. In these terms, the relationship between subject matter and modes of representation remains complicated. When we look at these elements simultaneously, there are no grounds for application of such simple oppositions as fiction-nonfiction, past-present, nostalgia-celebration of modernity. Instead, we find grounds for a piece-by-piece, open characterization, that makes the films under scrutiny understandable in their own time and cultural practice, through comparison and assessment of differences.

For example, first of all, the traditional opposition between fiction and nonfiction becomes problematic. Within films the narrative fiction can be intercut with non-narrative sequences of display and non-narrative spectacle, such as the view of the landscape seen from the moving train in A ROMANCE OF THE RAIL or the rodeo scenes in The Cowboy MillionAIRE. This makes fiction films relatives of nonfiction. Also, the opposite is apparent when nonfiction is coated with a sense of narrative, e.g. NationaAl PARK in Amerika and Los Angeles (1912, Imp.). Compared to other films, such as some of the period's "Indian romances," NATIONAAL PARK IN AMERIKA contains shots that are just as artificially staged as shots in these fiction films. Moreover, the cartoons in this film would definitely reposition any romantic "Indian picture" that would be seen in the same film program.

Juxtaposed to A ROMANCE OF THE RAILs, these films make a convincing case for the argument of context or contiguity effects of film programming. Shown next to travelogues, the nonfiction "traits" of a hybrid film like RoMANCE OF THE RAILs are foregrounded. If we imagine a film like THE GREAT TRAIN RoBBERY next to ROMANCE OF THE RAILS, this allegedly "first" Western seems to display a strong inheritance of some characteristics of the travelogue side of the "family." In this sense, it comes after the beginning. In fact, when we compare it 
to Parade of Buffalo Bill's Wild West, this 1898 one-reeler could be considered an earlier "Western" than The GreAt TrAin RobBery. The nonfiction film features a pageant of actors from Buffalo Bill's Wild West Show passing in front of the camera. Following my argument, it is an early Western, not in spite of its nonfictional recording of this pageant, but because of its paradigm-specific use of display and the contemporary element of the West instantly put in the context of a Wild West Show. Through a concept of family resemblance based on paradigm, this film is related to other "surrounding" films on Western subjects. What makes this film particularly interesting is that it is, in fact, an exhibition of another, older Western tradition within the new medium of film.

This feature also sheds a different light on the Cowbor Millionaire with its opening and closing extended scenes of cowboys. These men perform tricks before the narrative takes over and after it closes. The film is not so much late in shifting to narrative, being based on out-dated, primitive, and incoherent modes of narration, but rather it shows a strong relationship between this film and others of its "family." Films that are related in this way are grounded in a mode of display that fits within the same paradigm.

In a conception of the film archive that would do justice to this genre concept as historically relevant, then, one imagines clusters of films that reconstruct, not necessarily programs as they actually occurred - documentation is insufficient for that as a systematic mode of archiving - but, on the basis of the documentation that we do have, programs that, in turn, "resemble" the few reconstructable programs. Clusters, that is, which convey an historically specific sense of film as a cultural practice. Thus, the archive would be a place for conservation - but with current orderings and divisions, it is also much more than that. Rather, it would endorse its own intervention in its treasures, account for the mode and rationale of this intervention, and enable all kinds of research and teaching activities that would convey historical experience as well as understanding. Last but not least, a catalogue based on a hypertextual organization of descriptions of films along the lines of the many features involved would supplement, and give access to, the objects stored.

The searchlight function served by the concept of family resemblance as a basis for genre is especially relevant for the early Westerns with their varieties of representations of the West. The "West" is, indeed, a shifting marker. It is used differently in many films: as mere background of a narrative (CUPID THROUGH THE PADlocks), as visual spectacle (Brother BILl 1913 Vitagraph; Romance of THE RAILS), as site of adventure or drama (THE SACRIFICE 1912, Vitagraph; THE TRIUMPH OF RIGHT 1912, Vitagraph), the West as historical frontier, as redeeming environment, as backward opposition to the civilized and future-oriented East, or as object of nostalgic longing for a recent past. The mixed moods of 
these films parallel the different meanings of the West. These films clearly illustrate how the West or the frontier is transient, both as time and as place.

Because of the proximity of the actual West, in time and in place, it is important to acknowledge a contemporary dimension to Westerns that are set in modern times. Through contemporaneity, a film like Mexican Filibusters can be considered part of the Western family, just like THE Colonel's EsCAPE (1912, Kalem). Also, the contemporary stories of A Cowbor Millionaire and Lost AND WoN are typical for the early Western, even compared to more historical stories of How States were Made and Brother Bill. Some films show a temporary mix of modern and historical layers, playing with the moment of transition between the past and future (A Cowboy MillionAIRE or LosT AND Found), and are still related to a film set in the days "When States were Made" or the days the witches were burnt at the stake (ROSE O'SALEM-Town). Different notions of Western-realism are at work because generic conventions are not set. Hence, there are no rules for the genre such as "a Western has to have horses in it," or "has to be set west of the Mississippi."

The issues discussed in this chapter come close to what Norman Bryson, in a similar spirit, writes about the genre of still life in painting:

If the word "genre" has too many negative connotations (of the trans-historical study of art, of formalism, of idealism), the word series may be more useful here: still life paintings were made to enter the still life series. That series has no essence, only a variety of family resemblances. And it is not a linear series, like successive generations of computers or atomic reactors; rather the series (plural) regroup themselves around the individual work, the boundaries of the series fluctuate around each new case. It is a category, in other words, not only within reception and criticism, but within the historical production of pictures. (1989: 11; emphasis in text)

Significantly, all the terms I have suggested concur in this passage. Moreover, the concept of the series proposed here can be borne in mind as the relationship between the texts that are connected by properties to form family resemblances.

The notion of family resemblance gives us a label to talk about films that are related but different, and therefore can do justice to the many sides that the idea, and the image, of the West have in this period. In turn, it also makes a good case study of early cinema's paradigmatic difference, because it is open to difference and unpredictability. This concept can help overcome the problem of inadequate language, and of our need to map, to categorize. When we re-appreciate the plurality of early cinema, this appreciation bears consequences for the study of genres. With a double focus and a good searchlight we can see differences as well as similarities while still being sensitive to surprises, following the progress of history, as well as its breaks. 


\section{Notes}

1. “To Add '101 Ranch Wild West'." Motography VIII, 8 (October 12, 1912): 299.

2. [66] “Wir sehen ein kompliziertes Netz von Ähnlichkeiten, die einander übergreifen und kreuzen. Ähnlichkeiten im Großen und Kleinen. [67] Ich kann diese Ähnlichkeiten nich besser charakterisieren, als durch das Wort "Familienähnlichkeiten"; denn so ubergreifen und kreuzen sich die verschiedenen Ähnlichkeiten, die zwischen den Gliedern einer Familie bestehen: Wuchs, Gesichtszüge, Augenfarbe, Gang, Temperament, etc. etc." Philosophical Investigations (1963 [1953], §66/67: 32).

3. For a review of this film, see "Essanay Pictures for the Holidays" by Franklin Pierce, in Motography VI, 6 (December 1911): 269-271.

4. Nickelodeon IV, 7 (October 1910): 201.

5. Obviously, with this form of criticism I do not mean something like the academic approach to genre as a theoretical concept that is called "genre criticism." Gunning articulates a definition of this critical discourse as follows: "In this mode of discussion the authority rests with a critic who tries to articulate the underlying patterns and to interpret the significance of established genres" (1995b: 50).

6. "Index" is used here in the sense in which Peircean semiotics defines it: "An index is a sign which would, at once, lose the character which makes it a sign if its object were removed, but would not lose that character if there were no interpretant. Such, for instance, is a piece of mould with a bullet-hole in it as a sign of a shot; for without the shot there would have been no hole; but there is a hole there, whether anybody has the sense to attribute it to a shot or not" (1984): 10-11.

7. Gilles Deleuze (1990). On the simulacrum see also Jean Baudrillard (1987), who gave the term currency. A lucid critique and deployment of the concept is offered by Scott Durham (1998).

8. I wish to thank William D. Routt for bringing this essay to my attention.

9. For example, in a review of The Fatal Gold Nugget (1910, Bison) in The Nickelodeon IV, 10 (November 15, 1910): 281.

10. See the review of A Kentucky Pioneer in The Nickelodeon IV, 7 (October 1, 1910): 199.

11. In Universal Weekly I, 9 (August 17, 1912): 5, the film The Widow's' Claim (1912, Bison) was called "a mining story."

12. As in the description of IN THE WiLderness (1910, Selig) in The Nickelodeon V, I (January 7, 1911): 21.

13. The Tribal Law (1912, Bison), for example, was called "Indian Drama" in Universal Weekly I, 21 (November 9, 1912): 4.

14. Motography V, 6 (June 1911): 148.

15. Broncho Films, the company mentioned in this ad along with Bison, announced its films in Moving Picture News VI, 8 (August 24, 1912): 4 as being "Frontier - Indian Military and Pioneer Subjects."

16. In Variety (January 19, 1907) The Life of A Cowboy (1906, Edison) is qualified as "melodramatic" and called "a long and interesting moving picture" which "covers a wide range of subjects and the locale seems to be really the Western Plains." The location is mentioned as a coloring of the story. 
17. Hansen locates the differences "on the level of textual conventions of representation and address and on the level of exhibition practices, which are embedded in the public sphere of late-19th century popular, commercial entertainments." (1991a: 16)

18. Foucault (1977a).

19. For a theorization of the productivity of the concept of "difference within" as selfnon-identical, see Barbara Johnson (1987).

20. In conformation with current critical practice I use the term intertextuality here, even though the play on other genres and media is more precisely termed interdiscursivity to distinguish it from the specific and traceable quotation of other texts. For this distinction, see Walter Moser (1988).

21. Nickelodeon II, 4 (October 1909): 131.

22. In the same vein, Musser (1984: 56-57) argues how the exhibition could stress different generic traits in individual films, using the example of how the reception of THE Great Train Robbery (1903, Edison) can vary.

23. Wittgenstein 1953. For a useful discussion of Wittgenstein, see Allen Thiher (1984: esp. 19-20) on Wittgenstein's Philosophical Investigations.

24. Carl Plantinga (1987) uses the concept of family resemblances in relation to documentary film. Rather than defining documentary as a genre by listing its "necessary and sufficient properties" he takes a cue from Morris Weitz (1956), who draws on Wittgenstein's notion of family resemblances for his argument that, rather than defining art, art theory should call attention to salient aspects of art. Plantinga uses this concept for describing, instead of defining, what are considered salient aspects of documentary, putting it to use for description of the historicity of conventions of the oppositions "fiction" and "nonfiction." In my use of the term I stress the dynamics of genre history, so as to have a methodological tool to enable an investigation on all levels: on production, reception, and exhibition. This method would also make possible reflection on the historiography of genres by crossing the borders of history between synchrony and diachrony (accounting for similarities as well as differences within and between the slices of history) as a tool to grasp the process and the practice of genre.

25. In Photoplay Magazine III, I (August 1912): 23-29, the plot of the film is re-told as a short story with the English title "Their Lives For Gold." The film in the Nederlands Filmmuseum under the Dutch title WEG DEs Doods is clearly the same as the film on which "Their Lives For Gold" is based, judging from the story and the photographs. The French (original) title is probably Le RAILwAY DE LA MORT (1912) as the description of the film in the collection of the Cinémathèque Gaumont suggests. The film stars Joë Hamman, Max Dhartingy, and Ernest Bourbon. See also $\mathbf{O}$.

26. Clearly, this idea is helpful, if I may judge from Jim Kitses' acceptance of it. See Kitses and Rickman, eds. (1998: 19). 


\section{Coincidences}

In the following chapters, I discuss what characterizes the films in my corpus not so much in terms of their paradoxical features or non-features, but in terms of the underlying philosophical ambiance, which I see as a result of the moment in history marked by the coincidence of the disappearance of the wild West and the invention of the Wild West. This moment generates a phase in film history in which the invention of moving pictures as a technology leads to the birth of the medium of cinema.

Historiography is becoming increasingly uncomfortable with the ambition to "reconstruct" the past "as it was." On the one hand, the simultaneous occurrence of the invention of the medium - a beginning - and the closing of the frontier - an end - would make a case for such a traditional view of history based on events. On the other hand, though, neither can be taken at face value. Culturally, the medium did not arise out of the blue; it was related to photography, which had been around for decades, and the frontier was kept alive by powerful cultural sentiments, such as nostalgia.

In the first cluster I analyzed the material against the retrospective projection of what followed. Here, I investigate the material as witness to a key moment in cultural history. This moment was viewed as the state of the world poised between "wild" and "civilized." Moreover, this moment also can be seen as the state of the moving image between machine (for any use, that is, as "wild" and "rough") and cinema (as institution, cultural practice, "civilized").

In the chapter on History Lessons $\mathbf{H}$ I analyze the transformation of film as a clever technology into cinema as a medium suitable for working through the negotiation of the discontinuities between past and present. A philosophy of history is at issue here, articulated visually rather than in argumentative texts, yet philosophical nonetheless. The groping, tentative philosophy of history was necessary to counter the effects of the inevitable mythification of the West as national myth. The workings of the myth of the West were inadequate as history, but serve a different cultural productivity: The myth was a narrativity machine. The first chapter of this cluster probes the ways in which films about the West, exploiting the myth's potential as a narrativity machine, were at the same time testing their stories' relationship to history.

A chapter on Instant Nostalgia \ follows. This highly specific cultural sentiment emerged at the unique moment where novelty and pastness are both actively present in the present. It was a moment when loss and innovation coin- 
cided. But as I foregrounded in the first cluster, the notion of "early" is problematic for its tie to development and to the ideology of progress. Polemically, I would put forward the argument that the notion of "early" is itself anachronistic. It is fed by that other kind of nostalgia that stimulates not only an escape from the present, an escapism that idealizes the past, but also an escape from engagement with the past. In the historiographic intermezzo Jeopardy $\mathbf{J}$ the case of "nation" as a feature of films at the time serves to de-naturalize the concepts regarding time ("early") and place ("nation") that underlie so much of historical thought. I distinguish four different meanings of "national" as cultural belonging, only some of which are recognizably present in the later Westerns, and even then, not in ways that warrant placing these two types of Westerns within one development narrative.

What did the world look like as it surrounded people with celluloid? Visual, fractured, and attractive. These features of the world as it was experienced in American modernity coincided with the major characteristics of cinema practice. The chapter on Kaleidoscopic Worlds $\mathbf{K}$ is devoted to that coincidence. But there was also one stable element that recurred in the films. As it happens, this element, the landscape, is the unifying feature of the Western. $\mathbf{\square}$ But, as per the negativity of binary opposition as representation "without substance," through differentiation or negative dialectic, landscape's unifying capacity depended on its opposition to urbanity. I will discuss the conflation of setting and location as signification. This conflation was possible because of the coincidence of urban innovations with the innovative medium.

Summing up the coincidences that so characterize my corpus (in the extended sense), the chapter on Modernities $\mathbf{M}$ focuses on both fragments and the representation of fragmentation. The modern sense of excitement was embodied in the moving image - in more senses than one - and most typically in those films that required breathtaking stunts. The moving image moved the body as the train moved it in travel. And what more typical destination for travel than the West - no longer "wild" in modern reality, but still capable of thrilling the body with motion and emotion. 


\section{History Lessons}

But there is presented to the modern world a further chronicle of achievement. History has a new means of accurate record. What would we not give for a moving picture of the famous charge of the 600 at Balaklava; or of the tragedy of Julius Caesar at the base of Pompey's statue in the Forum. These things are perpetuated in imagination upon painted canvas. But what if the same had told the true story? - Motography, $1911^{1}$

No one goes to a Western for a history lesson, so to charge most Westerns with inaccuracy is pointless. In any case, the history of the West is as plagued by myth as the history of the cinema, and to untwine the barbed wire of legend is all but hopeless.

- Kevin Brownlow, $1979^{2}$

Is it true that no one goes to a Western for a history lesson? Perhaps one should. It might be a good idea, if only to ponder how the relationship between past and present changes over time. Historical distance seems to have transformed the historical West into a mythical West. This mythification as an after-effect of time happens to occur in parallel to the process of development of the genre's own representation of the West. But, like cinematic genres and forms, myth is an unstable, as well as fictionalizing structure. One could see myth as a continuous process of negotiating the relationship between past and present, rather than as a fixed, rigid unit of narrative meaning. The meaning of the "West" for the different synchronic slices or moments, the different "presents" of history, has continuously shifted. In terms of temporality alone, this meaning has been sliding from the site of a safety valve for the future, through that of a nostalgic "pure" past, to an exciting place for the present.

"No one goes to the Western for a history lesson," Kevin Brownlow asserts in the passage I quoted as an epigraph to this chapter. True, probably no one goes to the movies in general for a history lesson, or any kind of lesson. True, the lessons "taught" by the movies, if any, are probably not about history. They do not present truthful accounts of "what really happened." In fact, one may doubt that this is at all possible. ${ }^{3}$ But such lessons may very well be, rather, historiographic. With this term I mean that cinematic lessons might be informing us about the (historical) present's relationship to the past, in its variability. These 
films do not merely present a visualization of history, but also of the meaning of this history, and the positioning of an historical present in relation to this meaning. I wish to contend that the present of the films - turn-of-the-century modern, urban culture - might well have developed a fondness for films about the West precisely because of the West's semantic openness, its flexible relationship to meanings that mattered, so that the changeability of the present's relationship to the past stands out more clearly.

If this contention holds, then Brownlow's dismissal is in one respect premature. The longing for historical truth, or even for "historical experience," that transpires in my other epigraph does give us a "history lesson" in one sense of the phrase. It provides us with insight into what a given, historically remote culture - but one from which we cannot cut ourselves off completely - thought and experienced as historical. In other words, this journalistic fragment points to a philosophical sense of history as experienced and facilitated by visualization. Something, that is, which can perhaps be called the historiography of the historical. I wish to use this perhaps redundant phrasing to emphasize the fact that the history of the historical is a construction, a true historiography. In the preceding chapters I aimed to make clear how the different shapes and sizes of the West are (partly) results of the shifting meanings of the West, specifically between the West as temporal and the West as geographical entity. Here, I will look at the "historiographical" thrust of early Westerns and how this relates to these meanings of "the West."

To "untwine the barbed wire of legend" is, indeed, a hazardous job. Not merely for the reason that Brownlow suggests, the impossibility of uncovering "real" history in - as in represented by - fiction films. But this desire to know the past is not an issue here, and it is pointless as well as hopeless as a goal. It is, on the other hand, possible as well as useful to uncover structures of myth and legend and the methods used to disguise these and pass them off as history. In other words, I can analyze the ambitions and strategies undertaken by filmmakers and critically evaluated by the public, to visualize the past in moving images. The relationship between these strategies and the historical "stuff" they purport to muster may be impossible to untwine neatly into separate strands, but the ideas about this relationship are not. For the definitions of "what is history" and how this history is correctly portrayed in this period of transition are formulated very often in the contemporary press.

In the earlier chapter about Facts and Fictions I discussed contemporary evaluations of realism and authenticity. There I discussed specific measurements by which historical as well as "contemporary" realism were gauged, both as distinct from and as related to, poetic realism, ethnographic realism, and other strategies of representation. I discussed the example of the evaluation of "correct detail" as a standard for historical realism, a realism that, in practice, often 


\section{KALEM FILMS}

(THE NEW LINE)

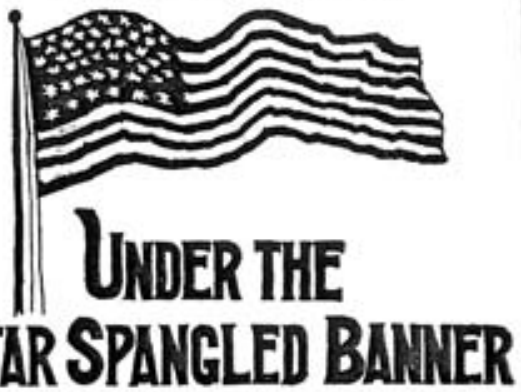
A Thrilling Historical Story of Pioneer Days on the Plains

Length, 675 feet. Ready February I.

There is no more fascinating theme in Americas his tory than that which centers in the courage atad deter mination of the ploneers of the West, the men who crossed the plains with their goods and familles in "prafrie nchoosers" and fought their way through hordes of savage Indans. Is this pleture we open with a pleture taken in a frostier fort, the always impressive ceremony of lowerlng the flag at sunset and the fring of the sunset gun. Thes we go out to the prairle, where a ploneer with his "schooner" and eatule is slowly traversing toward the promised home Evening comes and the emlerants halt and prepare for the night.

Next we see a camp of United States troops on a scout ing expedition after hostlle Sionx. They, too, go into camp for the night. Following tois we see the attack of the Indians-all os borseback-on the emirrants. The brave ploseers put up a spirited defense, but are rapldly belpg overwhelmed, when a brave youninter works his way through the Indian lises asd gets word to the soldiers, who dash to the rescue and wisd up the drama with a glorions scrimmage with the redsidns,

Throughout the flim there are wosderful opportunities for effects, and the story is one to arouse all sorts of patriotic eathuslasm,

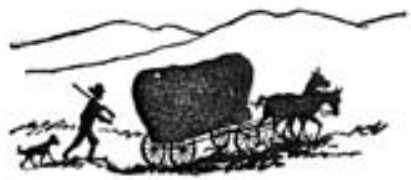

KALEM COMPANY, Inc.

131 W. 24th STRLI (Telepsose 4as Natises) NEW YORK CIrY Soling Aget, Kieine Optical Co., B2 State St., Chicago Londen Agents Urban Trading Co., 42 Rupert Street

H Kalem ad for Under the Star Spangled Banner. Moving Picture News II, 4 (January 25, 1908): 61 remained at the level of historical suggestion. This strategy did not produce an historically correct picture but what I call a "sense of history." Dismissing this sense of history as historically irrelevant would be condescending and anachronistic.

In this chapter the focus is on two issues that underlie such techniques for the production of a sense of history: How is a sense of history established, and what purpose did it serve? One question concerning the latter issue asks how the historical infusion of temporally vague stories can be considered a vehicle for education. I focus specifically on the teaching of nationalism. By the same token, the question becomes irrelevant if these discursive constructions of history engage in specific discourses of nationalism, combined with discourses of racialism and gender. These subsidiary questions are two-directional. On the one hand, then, I ask how these films are understood as a vehicle for nationalism. Film, here, serves a goal beyond entertainment. On the other hand, I ask how this nationalist purpose, in turn, serves the medium in its endeavor to conquer its place in modern (global) society. ${ }^{4}$ My conclusion will be that the lessons these historical films teach are not (just) about what happened in 
the past - the accurate picture - but clearly served another purpose, which had its own historical importance and urgency: the promotion of a sense of national identity.

The date is 1912. Evaluating the cultural, and specifically, educational task of the medium, H.F. Evers optimistically asserts in his article "Motion Pictures and History":

Moving Pictures have proved their value as an aid to the study of history for the young. As this wonderful invention is of only recent origin, it can in no way recall or picture actual events that have taken place years before and are now forever lost to the visual knowledge of mankind. The Motion Picture can, however, present enacted representations of great historical events, followed out with an accuracy only secured thru [sic] study and an earnest desire to be true to the authentic record. This feature of the art is being developed. The attention given to details, to every custom and character of the time pictured, has reached such a high standard, that the time is not long before the historical Motion Picture will be used as an invaluable aid to the instructor in history. ${ }^{5}$

Crucial terms used in this quote are aid, visual knowledge, enacted representations, and details. In a few sentences this critic formulates some widely-held ideas about the contribution of the new medium film to (visual) history: its capacity to store the present as historical record for the future. A very close and direct relationship linking past, present, and future is envisioned here with the term visual knowledge. In the face of the overwhelming predominance of written records in the study of history even today, the acknowledgment of visual expression as forms (and sources) of knowledge deserves attention. Vision requires presence. The more distant past is lost for this memory, since the camera was unfortunately not there to record this lost present and thereby extend its presence. In spite of this loss, the passage states, film offers the possibility to recreate this past by means of re-enactment. Enacted representations are close enough to the real thing to become a substitute for authenticity. The author acknowledges the instrumental role of film as educational aid. Role-playing thus becomes a serious aid, or even source, for knowledge. Details provide the reality effect necessary to establish this new type of authenticity. But this writer is not naïve. He foresees historical films as "aid" not substitute; as pedagogical instrument, to be used with insight.

For, film is not merely a mnemonic device. More importantly, it defines what history is; in fact, it establishes and thus creates the events. In the case of the West it is not only the canon of established punctual events, but that more diffuse collection of events that are made possible or thinkable by the punctual historical events: the possible past, which stands for history. The sense in which 
a contemporary, integrative cultural perspective cannot accommodate an opposition between fact and fiction in the same way as that opposition circulates in today's culture, can be emblematized precisely by those events represented in the films that have been granted "historical" status. ${ }^{6}$

An examination of this perspective begins with a discussion of the case of "real" historical events. These are most typically those punctual events whose occurrence is accepted but that were almost immediately made legendary. Examples include Custer's defeat in the battle of Little Big Horn (1876), or the Oklahoma land rush (1889). These events were given an exemplary status as history. Such events are often adopted into the ideological underpinnings of a mythical structure. Films representing such historical events like ON THE LITTLE Big Horn (also titled: Custer's Last Stand, 1909, Selig), ${ }^{7}$ Custer's Last Fight (1912, Bison) or How States ARE Made (1912, Vitagraph) tended to use these events within a nationalistic celebration of conquest or (tragic) heroism. In such an historical framework, authentication was sometimes produced by the insertion of journalistic footage that helped the realistic rhetoric through a crucial device. $\mathbf{F}$ The footage carrying the reality effect did not so much authenticate the event as punctual but as one of a kind. In other words, it helped the rhetoric to situate rather than narrate the event. The Oklahoma land rush thus provides, for example, a dramatic setting for the story of deceit and a last-minute rescue in How States are Made. Authentic locations were required for this, as can be gleaned from critics in the trade press. In more senses than one, these locations were, in the end, the grounds for historical accuracy as conducive to a sense of history. Locations superceded punctual events.

In an article in Motography about the educational possibilities of the medium, the advantages of film for teaching history were explained:

Thomas A. Edison, inventor of the moving-picture machine, contributes his mite to the present discussion of that enormously popular mechanical entertainer by pointing out its great but, so far, neglected possibilities in the educational field.

In the old days, he says, such subjects as history and geography were taught by rote. Children scarcely in their teens were expected to memorize long lists of kings, wars, counties and capitals and to learn the boundaries and shapes of the various continents, countries, oceans and inland seas and the courses of rivers in the same pollparrot manner. Now a better method is practiced; the one effort of the modern pedagogue is to make history and geography pictorial and vivid - to convert the tedious accumulation of facts and figures into a pleasant business, even into a game.

Here, a well-balanced mix of entertainment and education is proposed. Film's attributes of being "vivid" and "pictorial" are especially useful for the historical discipline. They increase the efficacy of memorizing. This is a recurring argument in the press. It echoes the nostalgia that is heard in accounts of a disap- 
pearing frontier of the West and of the Vanishing American. The text continues by pointing out what the educational topics would be, namely, (punctual) historical events:

Mr. Edison suggests that history might be taught in the same way - that is, by the representation on the screen of great historical events: the landing of William the Conqueror, the signing of the Declaration of Independence, the ride of Paul Revere, even actual battles on a large scale. ${ }^{8}$

The previous month Motography had announced a series of historical films by the Edison Company, depicting great battles and other famous historical events, up to "approximately the present day":

The Edison Company is actively working on a series of films embracing the most important incidents of United States history. This series begins with "The Minute Man," a story of the battle of Lexington [...], "The capture of Fort Ticonderoga," and [...] "The Battle of Bunker Hill."

The educational value is stressed, but also the package that sells history, "drama," if necessary brought out in fictionalized stories. This narrativization is intrinsic, both in the referred-to units of history referred to, and in history's own narrativizing enterprise.

But a little later, the use of authentic locations is presented as a reason why these films are interesting and exciting, by providing visual spectacle in addition to the dramatic interest:

In each one of the above subjects the film will be treated in the same manner as the numerous educational films released by the Edison Company. In other words, each film will be much more than a collection of dry facts. If history in itself provides sufficient drama, it will be taken literally. If not, the main historical incidents will be faithfully portrayed and a story written around each, embodying fictional characters. In other words, while the main idea of the above series is to vitally illustrate from an educational standpoint the great events of United States history, the producer realizes that no such stories would be a great success unless each film in itself were made interesting. So far as possible the films will be taken on the spots where the actual events occurred and if this is not possible, as in the "Battle of Bunker Hill," a location will be selected which will be as nearly like the original as possible. ${ }^{9}$

In this emphasis on authentic location, the historiographic interest of the journalist joins the concern, discussed earlier, for an authenticity that will neither offend the audience nor falsify the representation.

In a review of the making of The Siege of the Alamo (1911, Star Film), we can see how this concern for the use of actual locations helps the nationalistic 
agenda of historiography as such. Clearly, nationalism is served by the "truthful" representation of historical events such as heroic battles:

The Méliès Star Company is now busily engaged in reproducing "The Siege of the Alamo," and every scene will be taken at the actual spot where it took place. All the data relating to this siege has been obtained from direct ascendants of the illustrious warriors who sacrificed their lives in fighting for their country during this siege. These native Texans, who are thoroughly imbued with the intense patriotism with which their forefathers were inspired, have entered into this remarkable work of the Méliès company and are extending every help and giving their most eager interest and assistance in reconstructing this great historical event. Everywhere the company has been supplied with information and documents which will make this series of historical events unique in the annals of moving picture photography. The company has covered the ground most thoroughly to the Mexican border, and has lived over again the experiences of those who fought for the freedom of the Lone Star state. ${ }^{10}$

I have emphasized the words that apotheosized the historical events and the figures who made them happen. Less conspicuously, but for my purpose here, more relevantly, the parallel between present-day Texans and these heroes of history makes the collaborators in the film production into heroes of a lesser kind: heroes of the teaching of history. The fact that these heroes may be French, as is the director of the Méliès Star Company, George's brother Gaston Méliès, does not change much in the case quoted here. However, the problematics of this trans-national nationalism will be the topic for further discussion. J

Another example of the cinematic transformation of a punctual event into a history lesson is the above-mentioned film How States Were MAde (1912, Vitagraph) about the 1889 Oklahoma land rush. Although the title suggests an epic story about the formation of the United States, the plot of the film is restricted to the bare bones of a competition during the land rush between an honest family and a cheater who wants to steal their claim. This is an instructive example of what I mentioned earlier: the use of great historical events to situate rather than narrate historical moments of formative importance. The reduction does not diminish the historical importance of the framework within which this competition allegedly took place. Nor does it make the event less authentic. Most importantly, the modesty of the event represented does not reduce the grandiosity of its nationalism. On the contrary, by presenting the common wo$\mathrm{man} / \mathrm{man}$ engaged in struggles that are structurally parallel to the great events of the formation of the nation, the celebration of nationalism on a minor scale, in all corners of society, is shown to participate fully in that formation. This kind of "every-day nationalism" underscores the values promoted by the great mythical events. ${ }^{11}$ 
A specific form of this use of film to promote nationalist values is the "teaching" of these values to immigrants. The following passage makes this use very explicit:

The motion picture develops another very important quality in our newly naturalized citizens. It instills and develops in them the sentiment of patriotism, without which they can never become a useful part of our commonwealth. Our great heroes like Washington, Lincoln and Grant are familiarized to and made beloved by people who have hitherto heard only of Kosiusko [sic] or Garibaldi. Our history from Revolutionary times down through the days of ' 49 and the Civil War is made their history. The great crises of the nation are brought far more vividly to their minds in the film-play than ever they would be if read between the covers of even the greatest historical works of a Motley or a Gibbon. How many of us, native born or not, have not thrilled to the stirring pictures "How Washington Crossed the Delaware," "Nathan Hale," "Shenandoah," "The Battle," "The Fall of the Alamo," "Daniel Boone," "The Discovery of America by Columbus," "Barbara Frietchie," or "The Declaration of Independence?" We all have. Such films arouse in us the same spontaneous patriotism that flashes forth when the band plays "Dixie." They make us proud that we are Americans. $^{12}$

The tone of this passage indicates that the issue is of different mythical proportions, as is also the case in the story of Custer's last stand.

Telling the much-circulated legendary story, a film like CUSTER's LAst FIGHT (Bison 101, 1912) provides the moving images to illustrate the events. The film was described in an article in Universal Weekly, significantly titled "'Custer's last Fight' Will Amaze the World" as if the familiarity of the outcome of the story would not diminish the interest. On the contrary, this film narrativizes as well as visualizes the historical events which enables the director to give an "accurate account" of them - amazing "truths," especially for those already familiar with the legend:

The greatest value of this play lies in a serious attempt on the part of Director Ince to produce an accurate account of Custer's defeat on The Little Big Horn, probably the most dramatic episode of its kind and certainly the most disastrous of our Indian battles. He has delved into the inception of events and followed the narrative beyond the tragedy to the pathetic dedication of the Custer monument, an obelisk, which marks the spot where the splendid soldier fell.

I saw this three-thousand-foot reel with its hundred or more scenes before there were any explanatory subtitles inserted, but I was able to follow it without difficulty, and I especially approve of the brief, incisive pictures of action that give all that is required where prolongation might belittle the fighting. [...]

The New York Motion Picture Company's production has a final scene which contains a pretty touch of pathos. It shows the dedication of the Custer monument on 
the battlefield, and one of the last acts is that of a little girl. This tiny representative of the greatest civilization Time has painted upon the background of worldwide history steps. $^{13}$

This critic values highly not only the "actual account" of the battle, but also the reflective epilogue at the end of the film, which he finds to be an effective device for the teaching of history. More recently, Steven Spielberg has employed epilogues similarly, as an instrument of historical closure as well as a statement of historical relevance (SchindleR's List, SAving Private Ryan).

In Photoplay Magazine III, 2 (September 1912) 25-32, the story of this film is published as a richly illustrated short story, written by Alice Ward Bailey who proclaimed that the film was: "Founded upon the true story of the Battle of Little Big Horn." This is just a tiny example of the wide spread of the intertextual relay of Custer's Last Stand, in which this film and its tie-in short story participated. The circulation of Custer's legend was greatly aided by the Anheuser-Busch beer company's distribution to bars and restaurants all over the country beginning in 1896 of a lithograph of a painting of the "last stand" as promotion for the company. This became the most famous and most circulated image of the historical events, if not the most ubiquitous staple of Western Americana. This type of intertextual richness results in iconographic consistency when images are copied and imitated throughout different media. Whether the Bison film actually used this famous painting as a source for its imagery is not clear, since no copy of the film is available to us today. But it is safe to speculate that this film probably used this type of intertextually-derived imagery of Custer for its visualization of history. ${ }^{14}$

There is another dimension to these films set in historical times, at historical frontiers, that has a bearing on the question of history lessons in terms of "how" to teach history rather than "what." This dimension consists of references to well-known stories and a large intertextual field of images (paintings) and texts (literature, poetry, historical novels). As with the narrative aesthetics and its rhetoric of realism, again, aesthetics helps along the project of historiography. Elaborate costumes and histrionic acting emphasize the aesthetic conventions of historical narratives, rather than supporting the historical realism per se. In line with Uricchio and Pearson (1993: 113-130), I wish to argue here that it is the reference to established cultural conventions, already thickened with historicity, outside of film per se, that spills over and thus produces a sense of history for the films.

In their analysis of the Vitagraph historical films, Uricchio and Pearson summarized the following strategies:

Much of Vitagraph's publicity for its historicals stressed the same commitment to historical authenticity, which consisted of correct period detail, accurate key events and 
images, and iconographic consistency, all intertextually derived. Similar strategies for historical representation appear in texts circulated by a wide range of institutions of cultural reproduction, from state-mandated ones such as schools to commercially dependent ones such as the theatre. Placing the Vitagraph films within this intertextual frame illustrates how the company sought to market its films as historical texts comparable to those of legitimate cultural producers. (115-116; emphasis added)

But this intertextual field only worked so well to replace lists and dates because it could be spectacularized. A film like The Conspiracy of Pontiac (1910, Kalem), an adaptation of Parkman's History of the Conspiracy of Pontiac, and the War of the North American Tribes Against the English Colonies After the Conquest of Canada (1851), is praised for its sense of history in terms of its spectacle:

This spectacular and very interesting story is an exact reproduction of the incidents as they transpired leading up to the attack on the little settlement of Detroit in the year 1763. [...] The costuming is absolutely correct and the scenic surroundings beautiful and true to the period. ${ }^{15}$

The words "exact reproduction" state the historical claim, even if the formulation "the incidents as they transpired" begs the question of historical truth. This is a good case of the spectacularization of history, as distinct from its emplotment by narrative. The film is elaborate in its costumes and attributes, the acting style is very static and, probably due to the reference to the well-known text, the plot quickly goes over the key incidents. This film is about a punctual event, but at the same time it refers to a 19th-century literary tradition. In other words, films were not unique in their historical "taste," since the subjects were derived not only from the historical events themselves, but also from their depictions in literature and paintings. 0 It was the mode of visualization, the movement, and the possibility of shooting on location that was new and unique.

The most famous example of this literary tradition is James Fenimore Cooper's Leatherstocking Tales, from which especially the second part, Last of the Mohicans, has been adapted for the screen (as well as television) throughout film history. ${ }^{16}$ Cooper's texts were so famous that they came to have an historical effect of the real in and of themselves. As a result, even the most tangential or oblique intertextual borrowing became enough to do the trick. Early adaptations of his writings often consist of very loose, associative reference work, rather than explicit adaptations of characters and events. A film like LEATHER STOcKING (1909, AM\&B), for example, was advertised in the Biograph Bulletins as "freely adapted from the tales of James Fenimore Cooper." ${ }^{17}$ Also the film A MoHAWK's WAY (1910, AM\&B) refers to the Cooper trilogy with its "Cooper atmosphere," as it is called in the Biograph Bulletin of the film. This film bears the subtitle: "Biograph subject of the James Fenimore Cooper Type," suggesting 
a generic category of Cooper adaptations and thereby implicitly referring to the studio's other productions such as LEATHER STOCKING of a year before. ${ }^{18}$

In a Variety review, the visual attraction of moving images (in contrast to written versions, as it suggests) and the use of outdoor locations are given special attention:

In this newest release of the Biograph studios there are hair-breadth [sic] escapes enough to make up another novel of the "Leather Stocking" tales, from which it has been in more or less detail taken. One of the best things that has been shown on the animated sheet for a long time is the race and final victorious fight between the pioneer scout of friction and his pursuing Indians through raging rapids. The series is a capital example of the modern stage manager for moving pictures, whose stage is the wide stretch of nature. ${ }^{19}$

Other literary works were purveyors of historical grounding. THE LANDING OF THE PILGRIMs (1915, Edison) was based on Longfellow's poem "The Courtship of Miles Standish" (1858). This film emphasized the historical facts, its subtitle setting the tone: "A dramatic adaptation of the historical incidents surrounding the settling of Plymouth, Massachusetts." While many films bring out their literary source text by citing lines in their intertitles, the titles of this film give historical data such as exact numbers, dates, and names of people and locations, as for example: "July 21, 1620. The Mayflower sails from Leiden with 102 pilgrims. She touched Plymouth, England, and sailed from there for America on Sept. 6, 1620. She touched Cape Cod on Nov. 9, 1620." And later: "Nov 11, 1620. William Bradford and Captain Myles Standish with others go ashore at the spot which is now known as Provincetown, Massachusetts, leaving the remainder of the Pilgrims aboard the Mayflower." After these historical facts, the film becomes a love story between Miles and Priscilla, a story that represents the romantic interest of the poem. Thereafter, most of the titles are directly drawn from the poem.

These canonical literary works are themselves historical. The source-texts for filmic adaptations are not so much the historical events that transpire in the texts as the novels that are written after these, as well as the tradition associated with them. In a later chapter $\mathbf{O}$ I will discuss more thoroughly the relationship between literature and film and the use of literary references in film. But in general, it is fairly impossible to distinguish one "original" source text for films, making a sharp separation between historical events on the one hand, and poetic narratives about these events on the other. What matters here is to see how these accounts are intertwined and how the intertextual web within which these films figure is a complex combination of different texts and discourses. By the same token, punctual events are mixed with their narrativized traditions; hence, they are fictional stories about possible pasts infused with punctuality. 
The history lesson, here, tends to pass smoothly from teaching about events that took place to teaching about habits and ways of life. In other words, history and ethnography make common cause here. Biograph's Mended Lute (1909), for example, tells an Indian love story set in the early 19th century. The story does not feature white characters, and the film's description in the Biograph Bulletins explains how the ethnographic realism is built on correct details. This is followed, however, by a sketch of the historical framework of the film, based on the punctual events of white colonialism, showing a distinction - quite telling in nationalistic terms! - between the a-historical ethnicity of Indians and the historical identity of whites:

Moving Picture Stories based on the life and customs of the American aboriginals have ever been attractive, and we conscientiously doubt if there has ever been a more intensely interesting subject presented than this Biograph production which, indeed, is a masterpiece. Much thought and time were given [to] the many details, and we may claim that as to costumes, manners, and modes of living, it is more than reasonably accurate, these details having been supervised by an expert in the matter. The Dakotas, or Sioux Indians, when first visited by Jean Duluth in 1680, who claimed their country for the French, inhabited what is now North Minnesota but were driven during subsequent Indian wars as far south as the present Sioux City when in the war of 1812 they were allies of Britain. The incidents of our story are laid in the neighborhood of Spirit Lake, Iowa, just previous to the outbreak, the first of which occurred in 1854, when Lieut. Grattan and his force were killed, the failure of the government to meet stipulations in land purchases being the cause. Owing to their roving, migratory nature, they were tent or teepee dwellers, expert horsemen and canoeists. Despite general impression, they are highly emotional and poetic; yet with superlative power of dissembling, and the quaint love scenes herein depicted are unique in the extreme. $^{20}$

This piece is a history lesson in itself. By retelling the facts, it demonstrates the need to refresh the cultural memory of the time. The way in which historical details become ethnographic details has been discussed in $\mathbf{D}$. Here, it matters that the assigned roles of victim, aggressor, conqueror, hero, fraud, and criminal in narratives form a constellation that conveys a specific historical interpretation. This can be different in each new narrativization.

In the case of the 1910 Biograph film, Rose O'SALEM-Town, already presented $\mathbf{D} \mathbf{G}$, the depiction of oppositional "sides" in history is discussed in the press:

Rose O'Salem Town - Biograph, revivifies history in commendable style, showing Salem, Mass., in the old puritan days. It reveals our forefathers in no admirable light, but as they thoroughly disgraced themselves during their spells of witchcraft fanaticism, there is no reason why they should not suffer the ignominy of it. We must reg- 
ister something of a protest, however, against the fact that the Puritan leader is made an amorous old hypocrite and villain. There may have been such among the Massachusetts Puritans, but they were decidedly in the minority and in no wise typical. ${ }^{21}$

This critic objects to the merciless representation. He argues that this displays a lack of typicality, thus signifying one purpose of the historiographic project of film: to turn punctual events into typical occurrences that contribute to the larger picture. It is shaped as a 19th-century melodrama of a merciless villain and an innocent victim. This "wrong plot" disrupts its historicity. The negative representation of the Puritan leader clearly offends the reviewer. This points to a nationalistic and/or religious slant in the historiographic argumentation. Puritan religious sentiment was integral to nationalism.

As should be clear by now, I have used the term "punctual" to distinguish these historical events from their ethnographic cinematic rival or counterpart, "typical" events. Between historical and typical events an intermediate category could be composed of the representation of legendary lives of heroes or outlaws - the Dalton or James brothers, for example - within which certain events grew to become emblematic, legendary in themselves, applicable to other characters, so that they lend themselves to becoming typical. But the category of events that became so typical that the later Western has been associated with them, comprises both fictional events through which historical individuals were characterized, then typified, and documentary ethnographic events from the life in the West, such as river crossing or cattle branding. These were events that situate the films in the West by depicting Western labor as the counterpoint of urban life.

If we attempt to understand the historiographic lesson offered by my corpus, this in-between category is, perhaps, the most significant element of this particular period. It demonstrates best the myth making in progress. It also fits the generic twists and turns of the period in which the medium was subject to experimentation and visual knowledge was fresh in the making. In fact, this category of events seems to imply a comment on the key issues of historiography in these events' own constructions of the past. The deeper question raised here is the following: is historical truth located in punctual events, which would reduce its range, or can it equally be located in the typical, even at the expense of the possibility of verification due to the inherent, constructed nature of the typical? The category of events that sketch the transition from the one to the other seems to embody, at the same time, the uncertainty, the wavering, of "truth" between these two extremes, and the difficulty and, perhaps, the need, to maintain a balance. A balance, moreover, that positions teaching - history lessons - between dry fact and captivating adventures; between verbal and visual knowledge. In this sense, the category I am pointing out can even be conceived of as a 
self-deconstruction of historical representation; hence, as a historiography in the true sense of the term.

The category I am referring to is most successfully represented in films which present the lives of figures involved in punctual events, but whose actions were subsequently mythified, films about legendary people of the West such as, for example: KIT CARson (1903, AM\&B). In the Biograph Bulletins the spectacle of the documentary value of this film is underscored:

This subject is a production upon which was spent a great deal of time and money. It was taken amid scenery of the wildest natural beauty and enacted with the greatest possible fidelity to the original. The costumes, arms, log cabins, etc., are all historically correct. The story embodies the adventures of the greatest of all American scouts and pathfinders, "Kit Carson," his life in the wilderness, his hand-to-hand conflicts with the savage Indians, his hairbreadth escapes, and his safe return to his log cabin home in the clearing. ${ }^{22}$

To be sure, as the plural alone indicates, it is not any particular conflict, escape, and return home that carries the historical relevance of Carson's life, but their repetition, which turns them into an historical way of life. After an assessment of the representation's historical truthfulness, the last sentence of this quotation accumulates qualifiers that instill a sense of heroism ("greatest") combined with nationalism ("of all American scouts and pathfinders") in the figure. The heroic character of Carson is specified by a category of actions that are neither punctual nor simply typical, but can be made typical, precisely, by their representation in certain constellations. "Life in the wilderness" consists of, typically, hand-to-hand (brave) conflicts with Indians qualified as "savage" so that the events become captivating enough ("hairbreadth escapes," "safe return") to form narratives that remain with the public as both historically typical and in the fictionalized narrative, punctual. This is, precisely, the contribution of narrative to the writing - and the imaging - of history.

The character Kit Carson also played a part in another 1903 AM\&B release, the earlier mentioned The Pioneers. The name Kit Carson is mentioned only in the film description in the Biograph Bulletin, as if for marketing purposes only:

This is another frontier picture taken in the wilderness with the greatest possible care as to detail. It shows the massacre of a settler and his family by the Indians, the burning of his cabin, the captivity of a little girl and her final rescue by Kit Carson and his scouts. $^{23}$

A year before, Biograph had issued a pamphlet for this film ("The Pioneers: A story of the early Settlers told in Motion Pictures") in which the scenes were described, but the name of Kit Carson was not mentioned. My impression is that it was only after the release of KIT CARSON that it occurred to the promoters 
to group these two films together by making reference to this character. The typical events of the episodes of THE PIONEERs thereby became infused with a sense of history, anchored to an historical period by means of the reference to an historical (legendary) character. This is precisely the kind of use of historicity to strengthen the sense of history in the intermediate category of events that I have suggested above.

Something similar can be noticed in another film based on a legendary historical figure: DANIEL Boone's BRAVERY (Kalem), the plot of which was published as a short story by John Olden ("From the scenario of Phil Lang") in Motion Picture Story Magazine II, 10 (November 1911) of which I quoted a passage in $\mathbf{E .}$ In 1911 the Republic Film Company also produced a film about Daniel Boone (which was to be released on 13 and 14 January 1912). In Moving Picture News a review was published under the significant title "Ministers and Educators Review Film of Daniel Boone as Produced by Republic Film Co." that proclaimed in a rather solemn tone:

After the picture has been thrown on the screen and the guests made thoroughly acquainted with the story, all with one accord made the statement that if the film companies would only put on such historical pictures and with such accuracy moving pictures would soon become the greatest sector in the education of coming generations.

As is stressed by the reporter, this enthusiastic response to the film was based not only on its educational value. The excitement of the action scenes won over even this morally sophisticated audience:

The visitors forgot their dignity entirely when the famous battle of Fort Boonesdale was shown. They applauded enthusiastically the heroic men and women in the fort as they bravely kept up the uneven battle. One settlement worker, braver than the rest confessed that she was entirely carried away by the scene. It behooves the other producers to sit up and take notice as this picture is not alone of value to the people who have the advantage of education, but to those who have no advantages of learning other than an evening spent at the picture houses. ${ }^{24}$

This mix of education and entertainment, according to this promotional report, provides a pedagogy that is considered uplifting for lower-class audiences. The great end justifies the means, as the phrase "visitors forgot their dignity" suggests. Nationalism is a fine teaching tool: "applauded enthusiastically the heroic men and women." The belief in the benefit of such teachings for the lower classes, quite typical of the times still strongly indebted to Enlightenment ideals and steeped in utopian social reform, is unabashedly asserted ("those who have no advantages of learning other than an evening spent at the picture houses"). Respectability and cheap entertainment can indeed go hand-in-hand. As the ex- 
pression of a reformist project as well as the expression of a dated social attitude, this statement contains a history lesson in the double sense of the phrase.

In the context of this discussion of legendarization as a paradoxical tool for historical instruction, one figure must be mentioned in particular: Buffalo Bill is the most emblematic figure who represents the legend-who-lives. While I will present this figure more specifically in the context of nostalgia in the next chapter $\mathbf{I}$ and of the Wild West Show in $\mathbf{W}$, here, his status as embodiment of historiography deserves attention. Indeed, by making a spectacle of his own, very recent past, William F. Cody as "Buffalo Bill" infuses history with a thrill of presentness. Turning his shows into films, he adds to this presentness the permanency, and hence, the future, that the medium as teaching tool provided.

A specific case of this use of famous, legendary heroes for the promotion of a visual culture that could be taken seriously as a source of knowledge and instruction is presented by the life stories of outlaws. Such films as The James Boys in Missouri (1908, Essanay), The Last Stand of the Dalton Boys (1912), and its remake The Dalton Boys (c.1914) contribute to the creation of legends around those national heroes of which these bandits were the negative counterpart. ${ }^{25}$ But here, the wish to edify dangerously courts the opposite effect, as captivating narratives framed the stories of such figures with the same attraction of suspense that made the heroics so effective as history lessons. Former bank robber Al Jennings played himself in The BANK RoBbery (Oklahoma Natural Mutoscene, 1908). Thus, he became a hero twice over, as the generator of suspense and as a movie star.

It comes as no surprise, then, that the press shows a keen awareness of this fine line between instruction through uplifting examples and the danger of making evil attractive through the same kind of adventures. These stories about outlaws provoked discussions in the press about the flip side of the positive educational aspects of historical topics: the bad influences of crime in films. For example, in the court case of an exhibitor who wanted to show THE JAmes Boys From Missouri (and also the film The Night Riders) the debate remained stuck in a discussion about these bad influences. Against this charge the defendant argued that the film concerned an historical topic and was therefore morally good. ${ }^{26}$

The morally good thus became itself a bone of contention in connection with the historical truthfulness whose pedagogical usefulness provided it with an intrinsic goodness that was acknowledged but not uncontested. The moral value remained specific to the issue at hand. Thus, the moral quality of films that tell the history of settlement (and conquest) is located in their promotion of the pioneer spirit. In the earlier chapter on historical Westerns $\mathbf{O}$ I have referred to the ideological coloring of frontier stories with this "spirit." We can see this 
clearly in the following review of the film IN THE WiLderness (1911, Selig) in Nickelodeon:

One of those "early settler" subjects which Selig does so well, and of which Selig seems to have a private monopoly. Nobody else tries them, yet they are of large value and effectiveness. The beauty of them is that they offer valid excuse for conflict and turmoil - conflict with nature and with Indians. This one, like its predecessors, suggests with fine effect the communal and co-operative spirit of those early times, the plot concerning itself not with a few isolated souls, but with a whole community. This provides a bigness and breadth, a canvas of epical proportions, that is rare to photoplay subjects. ${ }^{27}$

The praise for "communal and co-operative spirit" bleeds over from the historical subject-matter into the film that represents it for the benefit of the public. The slightly nostalgic tone of "the spirit of those early times" is symptomatic of the use of history for moral education - the history lesson of the culture as we can now know it. And although the criterion for praise is ostensibly aesthetic ("canvas," "epic") the level of generality between individual and group seems to be the deeper reason for moral weight ("a whole community").

As has become clear, most numerous in this period are the literary adaptations or films only loosely based on the lives of legendary historical figures, films about "possible pasts." It is now understandable why this category would be particularly suitable to the historiographic project of the time. Although they may show similarities to canonical events, they rely more on a general referencing to the historical West, and further, on a more geographical West that stands for the former. In other words, the specifics of region are more important than the specifics of time, although the temporal infusion of space is implied. This is evidenced in subtitles like, for example, Pioneer or Indian given to stories in promotional advertisements. Consider, for example, these 1908 Biograph releases that are announced in the Biograph Bulletins: "A Night of Terror: Thrilling Experiences of a Little girl Alone in a Mountain Wilderness"; "A Woman's WAy: Romance of the Canadian Woods"; "The Fight For Freedom: A Story of the Arid Southwest." Replete with edifying possibilities, such subtitles also promise that particular integration of historical truth and captivating narrative that is emblematic for the history lessons firmly believed to be both possible and important for the epistemic revolution the new medium was in the process of bringing about.

Between historically "real events" and typifying "reel events" the process of mythification is ongoing, so that emblematic events are constantly in development rather than being a given. Only retrospectively - after the beginning - do they seem to be stock events. My interpretation of this constant sliding from 
history into fiction and from documentary situating into fictional narrating brings in the concept of myth making. Myths are variably attractive according to the ideologies dominant at a specific time and place. In the case of turn-ofthe-2oth-century America, that is to say, in the early stage of a young nation, myths of wildness and civilization needed anchoring in the history of the nation. Myths are carriers of medium-term ideologies, but also of short-term nationalistic projects. Films such as How States are Made and Mexican FILIBUSTERS appealed to the urges of the socio-political moment. The events anchored the myth; but the audience was required to share the knowledge to which these films appealed in order to turn them into stories. This aesthetic principle of what we would now call audience participation, calling for a view of the films that can properly be called "performative," was effective because the films both solicited and nourished an historical sentiment that I call "instant nostalgia."

\section{Notes}

1. "Films as Historical Documents." Article from the Boston Post reprinted in Motography V, 5 (May 1911): 66.

2. Brownlow (1979: 223).

3. The fundamental doubt about a clear, recoverable, and singular historical "truth," shapes the historiographic principles of the New Historicism. For introductions to the New Historicism, see Veeser, ed. (1989) and Thomas (1991).

4. See for these questions, respectively, Abel (1999) and Uricchio and Pearson (1993).

5. Motion Picture Story Magazine III, 2 (March 1912): 124; emphasis added.

6. About cultural memory and the intricate relationship between the (camera) image and the (historical) event, see for example Marita Sturken's Tangled Memories (1997). For the distinction between punctual and durative events, see Bal (1997: 93).

7. See Abel (1999: 161, 278n85 and 278n89).

8. "Education by Films." Motography VI, 2 (August 1911): 57.

9. H. Kent Webster, "Reproduction of American History." Motography VI, I (July 1911): 23; emphasis added. H.F. Evers also mentions the filming of The Battle of BunKer Hill in "Motion Pictures and History" in Motion Picture Story Magazine III, 2 (1912): 124.

10. "An Alamo Picture Coming." Nickelodeon V, 4 (January 28, 1911): 114; emphasis added.

11. For the multiple meanings of "nation" and "nationalism" see my article on the American films made by Pathé (2001b) and below $\mathbf{J}$.

12. DeLysle F. Cass, "Higher Education and the Motion Picture." Motography VIII, 3 (August 3, 1912): 97-101 (99).

13. Universal Weekly I, 2 (June 29, 1912): 5-7; Originally published in Moving Picture World. 
14. About the depiction of Custer's Last Stand throughout film history, see Pearson (1995) and (1998).

15. Moving Picture World VII, 13 (September 24, 1910): 701, 704.

16. Cooper's five books of his Leatherstocking Tales included: The Pioneers (1823), The Last of the Mohicans (1826), The Prairie (1827), The Pathfinder (1840), and The Deerslayer (1841). For more information about literary works about the West from this period, see The Western Literature Association's A Literary History of the American West (1987). Some filmic adaptations of Cooper's books are LEATHERSTOCKING (1924, George B. Seitz), Last of the Mohicans (1932, Ford Beebe and B. Reeves Eason), Last of the Mohicans (1936, George B. Seitz) The Deerslayer (1957, Kurt Neumann), and the most recent version: LAST OF THE MoHicans (1992, Michael Mann).

17. Biograph Bulletins 278 (September 1909).

18. Biograph Bulletins (September 12, 1910). Incidentally, this phrase bears witness to the relevance of the conception of genre I proposed above $\mathbf{G}$. Today, a "James Fenimore Cooper type" would clearly be no longer visible as a genre, but the meaning of such a label made perfect sense at the time, specifically within the discussion of history lessons.

19. Variety (September, 1909).

20. Biograph Bulletins 163 (1909).

21. Nickelodeon IV, 7 (October 1, 1910): 201.

22. Biograph Bulletins 2610 (1905).

23. Biograph Bulletins 2611 (1905).

24. Moving Picture News IV, 51 (December 23, 1911): 19.

25. The Australian counterpart of the Western outlaw, the bushranger, was immortalized in several "bushranger films." William D. Routt presented this relative of the Western genre in the earlier mentioned 1997 conference Back in the Saddle Again (Utrecht University).

26. Lee Grieveson (1999: 295) mentions the arguments used in this case. For a more detailed discussion of this case and the concerns about outlaws in, and the morals of, early cinema, see $\mathbf{X}$.

27. Nickelodeon V, I (January 7, 1911): 21. 


\title{
Instant Nostalgia
}

\author{
I have rode upon the prairie, \\ $\mathrm{An}^{\prime}$ the hills so bright and green, \\ But those days would all be hist'ry \\ Only for the picture screen. \\ For I kin live them wild days over, \\ As when we, on Ol'Percell, \\ Was together punchin' cattle \\ Down along the Musselshell \\ - H. Webb, $1912^{1}$
}

The sentiment discussed in this chapter was born from the interweaving of three pairs of simultaneously occurring cultural happenings that bear on the meaning of Westerns.

First, there is a sense of simultaneity between the present-future and the recent past, or to be more precise, the present-future and the present-past. Modernity, the present but experienced as inherently future-oriented, is on its way in. The past, the recent past in particular, is still around - in the present - but is on its way out, officially declared dead at the closure of the frontier in 1890, but possibly, hopefully, recoupable in the "elsewhere" evoked in the imagery of the West.

Second, this simultaneity is experienced with an intense, if conflicting, sentiment. The invention of the modern medium par excellence, film, coincides with the vanishing of the world of the Wild West betokened by the closing of the frontier. This conflicting sense of temporality is conducive to a cinematic culture that explores how the tension between advent and disappearance is both exciting and frightening. Cinematic culture thus helps us to cope with loss while enjoying novelty. The medium enabled the culture to record the West while it was still somehow "there," available for recording. But through the urge to do so, the medium, at the same time, demonstrated the frontier's death. In its attempt to capture life, film, like a museum, cannot but preserve its object as dead.

Third, as a consequence of both the first - a conflicting sentiment about the present's two, opposed directions - and the second - the historical coincidence of innovation and loss - conditions, the greatest excitement came from the realization of the dual possibility the moment offered. The primary source of the 
medium's success came from the simultaneity of (the last stage of) the happening of the conquest and settlement of the West, and the act of recording it. While happening implies mobility, recording means fixation. What is happening escapes, and proceeds toward an ending. What is recorded, even in moving images, is fixed forever and, therefore, loses the very mobility that motivated the recording in the first place.

What I call here instant nostalgia emerges from, and informs, the flourishing film industry representing the Vanishing West. I offer this term with some emphasis because it accounts for something that, fleeting and transient as all sentiments are, is perhaps the most characteristic feature of early Westerns when considered, as I here propose we do, as a cultural-historical phenomenon. The term captures, that is, what made films set in or about the West so specifically attractive in their time that they came to stand for so much of American mythology, and for so much of American cinema. ${ }^{2}$

The sentiment is much more specific than the general term "nostalgia" suggests. I would like to discuss it here as specific to, and characteristic of, the films of my corpus. Instead of a romantic longing for a distant past, and an escape from the present, we are dealing with a longing, not in order to escape, but to deal with, the present. Where the present is in crisis, the recent past whose loss partly accounts for that crisis can be invoked, absorbed, and integrated within the present. Thus the break that modernity threatened to cause in the temporal continuum, without which no culture can be at ease, could be remedied by this particular kind of nostalgia. What is so often called the shock of modernity is cushioned and made more bearable by the cultural production that facilitates endorsement through recuperation. ${ }^{3}$

In a passage that all but names the sentiment to which this chapter is devoted, Leo Charney refers to Simmel's characterization in "The Metropolis and Mental Life" (1903) of a yearning that is triggered by modernity, a desire to really capture, to "experience," the moment:

The post-1870 transformation of modernity generated a perceptual climate of overstimulation, distraction, and sensation, characterized by Georg Simmel in 1903 as "the rapid crowding of changing images, the sharp discontinuity in the grasp of a single glance, and the unexpectedness of on-rushing impressions." In the midst of this environment of fleeting sensations and ephemeral distractions, critics and philosophers sought to identify the possibility of experiencing a moment. Experiencing a moment in these contexts meant feeling the presence of the moment, fully inhabiting it. (1995: 279)

Both temporal registers, the present - "moment" - and the past are unified in instant nostalgia, which thus functions as an investment of the past in the present. Instead of dismissing nostalgia as sentimental and escapist, we should un- 
derstand that sentiment as historically relevant and culturally helpful. I make this case through a look at three bodies of evidence. First, there is, of course, the corpus of films that deal with "modern" visions of the West with an investment in the past, stories about Vanishing Westerners and changing presents. Assimilation stories are good examples: His LAst GAME (1909, Imp.) or STRONGHEART (1914, Klaw and Erlanger), both set on an Eastern college campus. Second, the many stories, songs, poems, and even cartoons that evidence a kind of generic nostalgia are also relevant for this analysis. The poem of the epigraph above is a case in point. Last but not least, the reception of films about the West supports my case for the felt importance of this particular kind of nostalgia. Reviews offer this support on more than a merely intellectual level. Significantly, the reception apparently triggered personal memories. While we cannot trace individual reception of the films, the popularity of the "genre" of nostalgic songs and poems about the filmic experience of the West, suggests the medium's investment in instant nostalgia. ${ }^{4}$

Instant nostalgia, as the term "instant" also suggests, is closely bound up with popular aesthetics, specifically the aesthetic of the picturesque that is characteristic of modern culture. P "Instant" as in coffee or dessert, suggests a commercial, "easy-to-take," and "ready-made" presentation of the world. It suggests that the world represented is always-already in existence, and hence, that the object offered in "instant" form is inherently of the past. Yet, in its commercial, modern handiness this object obviously belongs also to what is present - or "moment" - oriented. Two simultaneous developments demonstrate this dual temporality. On the one hand, we notice that the West is becoming a tourist attraction; on the other, and surely related, there is a preservationist movement, which led to the creation of the National Park system. ${ }^{5}$ Clearly, a concern for authenticity and the preservation thereof accompanies the exploitation and mystification of the West. This makes sense if we realize the contemporary cultural agents were well aware of the contribution to vanishing that tourism, settlement, and other forms of exploitation entailed. As Jonathan Culler puts it in his analysis of tourism: "One of the characteristics of modernity is the belief that authenticity has been lost and exists only in the past - whose signs we preserve (antiques, restored buildings, imitations of old interiors) - or else in other regions or countries." (1988: 160)

As I have argued before, there is a strong bond between the West as place and the west as time, and the cultural signification of the West is located at the intersection of these meanings. This makes the West an ideal focus for the kind of sentiment I am exploring. For, different places, accessible by new means of travel as well as visible by new means of recording, also stand for different levels of development. It is precisely to the extent that feelings about modernity were 
not simply - or not only - positive, that the areas considered "backward," or at least less developed than the urban culture of the East held an appeal to those who enjoyed the new phenomenal world and the possibilities it offered. The notion of "pre-modern," basically temporal, is still in use today to characterize areas of the world termed, with a thinly disguised euphemism, "developing."

Something of this ambivalence is visible in cinematic culture in the early period. Repetition as a form of continuation of recent history is the strategy of the Selig production Tracked by Bloodhounds; or a LynCHING AT CRIPPLE CREeK (1904, Selig):

The scene of the attack and hold-up, as well as the actual stage coach and driver, were the identical ones where twenty-five years ago robberies of gold dust from the state were almost daily occurrences. Colonel William F. Cody - Buffalo Bill - was also one of the leading spirits in these chases that always ended in the death of several persons. Robbers and pursuers knew not at what instant a leaden messenger of death would come and life be extinct even before the sound of the report reached the ears. It was indeed the strenuous life and this picture perpetuates the thrilling scenes. ${ }^{6}$

The advertisement stresses the historicity of the film through the use of period details ("actual stage coach") and faithful plots ("identical" scenes of an attack and hold-up), as well as by the reference to the historical and mythical figure of Buffalo Bill, who had nothing to do with the film, but authenticates the fabula nonetheless.

Travel films may show parts of the world where an old, pre-modern lifestyle is still present. Westerns, however, are not exactly travel films, nor are they merely story films situated in the West. Instead, in order to fulfill the desire captured by the term "instant nostalgia," Westerns employ some characteristics of travel films and some characteristics of "exotic" story films, in a particular blend designed to offer the present-ness of the past as a consolation for its loss. Instant nostalgia is the underlying sentiment, containing within itself the visual and spectacular aspect of this modern form of nostalgia. I do not argue, however, that this is a defining and exclusive trait of Westerns. Instead, I contend that this is inevitably a sentiment that is present in a culture undergoing change. The urban modernizing culture of the American East was such a culture, and it was precisely this culture, which found Westerns so appealing.

But the phenomenon is certainly more widespread. To what extent is this sentiment specifically relevant for our understanding of the Western as cinema? In 1907, in "The Dime Novel in American Life" Charles M. Harvey explains how dime novels trade in images of the recent past, a disappearing lifestyle that is on the verge of being transformed from current event into a fact of national history: 
The aim of the original dime novel was to give, in cheap and wholesome form, a picture of American wild life. At the time when it began to be published, 1860, less than fifteen years had passed since the country's boundary had been pushed from the Sabine, the Red, and the Arkansas rivers, and the Rocky Mountains, onward to the Pacific. In that decade and a half we had gained Texas, Oregon, New Mexico, and California, and had enlarged the national area to an extent equal to that of the entire territory east of the Mississippi. A real frontier in 1860 along the line of the Missouri and the Arkansas, with thousands of fighting Indians beyond that line, and some of them east of it, gave the reader an ardent concern in the adventures in Malaeska, Seth Jones, Massasoit, and other tales which told of life when the frontier was in New York, Massachusetts, and Pennsylvania. These tales had both contemporaneousness and vitality. ${ }^{7}$

This text makes clear how the past is read into the present. This comment gives a clue of how film inherited a form of nostalgia that is bound to the subjectmatter of the passing West characteristic of the older, yet also relatively new and modern medium of the popular press. In order to avoid a naïve isolation of film, this quote cautions against both temporal and medium-wise separatism. Yet, paradoxically, this comment also offers an addition to the understanding of instant nostalgia satisfied by the medium itself. For it foregrounds the idea of the picture - a picture of life in the West, adventurous and contemporary. While acknowledging this older and literary form, I would still submit that something more specific, more deeply satisfying and also, more short-lived, is going on with the Western films.

The nostalgia operating in dime novels of the 1860 s is apparently still vital a few decades later with the advent of the cinematic form; some continuity must be posited here. This implies that, although film may have been a good medium for this specific ambivalent longing for the past, the sentiment is also, and perhaps foremost, subject-specific, focusing on the West in particular. This is precisely why, I argue here, the visual form that film uses had a particularly keen appeal that makes the sentiment also medium-specific. The appeal of readymade imagery, loved because recognized, cherished because available, made the picturesque aesthetic of Westerns a particularly gratifying form of cultural nourishment. This gratification has to do with visuality. It also has to do with present-ness.

One reason for this privileging of film as satisfying instant nostalgia is, paradoxically, the representation of current events on films. As a predecessor of newsreels, the genre of actualities displayed a recognizable reality, events experienced as part of the present, in a form that also allowed the representation of that near-present that just eluded visual grasp. In a subsequent chapter $\mathbf{K}$ I discuss a case where the two coincide almost perfectly: the Buffalo Bill parade 
films which serve as a presentation of actualities - in fact a commercial - while their subject matter belonged to precisely that recent past that lay just beyond actual visual grasp. The visuality of the medium slowly accustomed people to conflate what they saw with what they remembered as one and the same. No dime novel or poem, song, or slogan could offer that experience with the same level of intensity.

Hence, instant nostalgia can be a medium-specific form of nostalgia in the following sense. Cinema emblematized a more widely rampant sentiment because it was so fully visual and gave off evidence of the real, and hence, recent quality of its object. This reality appealed to memory - whether personal or diffusely cultural. But this does not make Harvey's comments redundant. Images, no more than other representations, cannot thrive without being cushioned by memories shared by the members of a culture - cultural memories. The fame and popularity of the cowboy films cash in on other forms of representation that were in circulation such as novels, paintings, songs, and poetry. This cultural frame further facilitated the efficacy of films in their appeal to instant nostalgia.

The connection was explicit. In the promotional article "Cowboy Pictures" in Moving Picture News the American Film Manufacturing Company advertised their Westerns by sketching an image of the disappearing West and the Vanishing Cowboy who is accompanied by the Moving Picture Cowboy. The article, rather tongue-in-cheek, uses the present tense to promote the desire for depiction:

The romantic West of the early days lives mainly in story and song. The bog ranches of the West are now being cut up into small farms. The farmer has come and come to stay. Gone are the buffalo, the Indian war whoop, the free grass of the open plain. Save in some of the secluded valleys of Southern New Mexico and California, the maverick steer and the regal longhorn have been supplanted by their more profitable Durham and Herford [sic] cousins from across the seas.

In the secluded valleys of Southern California the last of the fast vanishing type of American cowboy sits his horse easily, riding through the wide valley enclosed by mountains, with his face turned steadily down the long, long, road - "the road that the sun goes down." [...] And here with him, the last of his type, is the stock company of the American Film Manufacturing Company, with their producers and expert camera men recording, into film classics, the romantic stories of the West amid the original scenery and backgrounds of the Range Country. ${ }^{8}$

In visual terms this text describes an image of memory. That image is fastened onto the one that the public knew through repeated watching: the image of the cowboy on his horse, the background of the landscape that surrounds him. Even the time dimension is incorporated stylistically by the repetition of a 
word: "the long, long road." But the songs and stories that are referred to would not have the same impact as the kind of film that is also evoked. For, in the case of film, a collapse of the vanishing real cowboy would visually certify a direct lineage between the object of desire (the past) and the instant surrogate (the filmic "present"). The fact that this combination of historicity, visuality, and medium specificity is used in this form of advertising underscores the commercial aspect of the popular variant that instant nostalgia is of more highbrow forms of nostalgia found in other arts, such as painting and literature.

There is yet another reason why the sentiment under discussion is bound up specifically with the Western as filmic genre. Nostalgia has a special relationship with progress. Paradoxically, since it aims to preserve, nostalgia is a phenomenon that transforms over time. It is an active response to a changing world, but this changing world also transforms the shapes, sizes, forms, and intensities of nostalgia. The instant variant fed by Westerns is typical of a specific moment in time. ${ }^{9}$ It is only at the particular moment I am describing that it has the sentimental value that distinguishes it from other forms of nostalgia. Although nostalgia can be considered a form of protest against or resentment of change, instant nostalgia is a positive, because satisfying, sentiment. It is a celebration rather than a refusal to proceed; it is a positive means to come to terms with a changing present.

One more feature distinguishes this form of nostalgia from other forms. The possibility of coevalness of the presence of the historical object of nostalgic desire with its presence in nostalgic celebration, is essential for instant nostalgia. As a result, this form of instant nostalgia for the West changes into a form of generic nostalgia over time, as the object of nostalgia shifts from history to myth. Discussing Buffalo Bill's cycle of "Farewell Performances" which ended in 1917, Richard Slotkin points out how these performances:

[...] reveal the extent to which the Myth of the Frontier had become independent of the historical reality that produced it. In Cody's farewell tours, that nostalgia for the "Old West" that had been the basis for his first success gave way to a new form of the sentiment: a nostalgia not for the reality, but for the myth - not for the frontier itself, but for the lost glamour of Buffalo Bill's Wild West. (1992: 87)

Slotkin identifies a division of time, between the period in which retrieval of a past still connected to the present, if only in the imagination as fed by representations, remains possible, and the past that is irrecoverably lost, that can only be conjured up as myth. This further developed form of nostalgia, so to speak, is radically different from the instant variant, because the object of loss is not as closely related to the subject of nostalgia as is the case with instant nostalgia. It is precisely the closeness in time, and the attempt to prolong history by, literally, canning it on film that gives the instant nostalgia its distinct identity. When 
compared to the more heavily codified nostalgia that is based more on myth than on the immediate past and present, instant nostalgia is more open or flexible. One final distinction should be noted here, lest I appear to be idealizing a politically troubled sentiment: the distinction between instant nostalgia and imperialist nostalgia as described in $\mathbf{E}$. Where imperialist nostalgia mourns the destructive side of imperialistic progress, it is instant nostalgia, with all the features attributed to it here, that characterizes the cultural welcome awarded to the films of my corpus.

\section{Notes}

1. First stanza of the lyric "The Motion Picture Cowboy" by H. Webb in Motion Picture Story Magazine IV , 7 (August 1912): 136. Many songs and poems about motion picture cowboys were published in this magazine. These texts articulate a desire to prolong the history of the West by keeping the cowboy alive in the theaters. Some examples are: "Cowboys Up-to-date" by Mary Carolyn Davies in Motion Picture Story Magazine III, 4 (May 1912): 88, and "Making Western History" by Harry E. Loomes in Motion Picture Story Magazine IV, 7 (August 1912): 121.

2. For a discussion of the different shades and shapes of nostalgia see Malcolm Chase and Christopher Shaw's contribution "The Dimensions of Nostalgia" in Shaw \& Chase, eds. (1989: 1-17). In his contribution to that volume, "Nostalgia Tells it Like it Wasn't" (18-32), David Lowenthal traces the sliding meaning of the term from its medical origins in the $17^{\text {th }}$ century, to the modern, metaphorical meaning of the 2oth century. He accentuates the modern form of nostalgia that is based on a very short time between the event and the nostalgic processing of this event: "As obsolescence conferred instant bygone status, 'history was being recycled as nostalgia almost as soon as it happened.'” (19) For a further discussion of Lowenthal's analysis of nostalgia see his The Past is a Foreign Country (1985).

3. For Baudelaire's and Benjamin's conceptions of distraction or "shock," see Armstrong (1998: esp. 216-219) and Kevin Newmark (1995).

4. See the opening anecdote of "Bounding Billy of the West" in Uricchio (1998b). The myths about different types of moviegoers - old men, young women, country "rubes," or other categories of "naïve" spectators" - and their typical audience responses as they are constructed in the trade press, are similar in their treatments of the movie experience. See, for example, Nico de Klerk (2000). In his plea for more attention for the film program - and exhibition - as object of historical study, de Klerk refers to the often fictionalized accounts of screaming and fainting audiences, frightened by the images of fast-approaching trains that the new entertainment film thrusts onto the naïve and unsuspecting spectator. When he quotes these cases of film-historical mythography de Klerk refers to Mark Sandberg (1995) who points out how "crossover spectating" might have triggered audience responses to film that are similar to experiences of visitors to amusement parks, for example. For more on this mode of looking at and experiencing film, see $\mathbf{R}$ and $\mathbf{S}$. 
5. These factors are literally related, as railroad companies not only promoted travel to the West (through sponsoring railroad films, among other strategies), but also played a role in the establishment of preservationist parks. For example, The Northern Pacific Railroad supported an 1871 Yellowstone survey that included the painter Thomas Moran and photographer William Henry Jackson, whose pictorial "reports" helped to persuade Congress to establish the first national park. See Barry Mackintosh (2000).

6. Selig Special Supplement (1904); emphasis added. Reprinted in Emrich (1997: 18).

7. Atlantic Monthly 100 (1907): 42; emphasis added.

8. Moving Picture News IV, 22 (June 3, 1911): 11.

9. Michael S. Roth writes about the links between nostalgia and modernity as they are explained in 19th-century medical writings. He concludes: "For psychoanalysis, desire is, in a sense, nothing but nostalgic. Thus, if by the end of the 19th century nostalgia becomes almost invisible as a medical pathology, it soon reappears as an essential aspect of normal desire. Nineteenth-century French medicine came to see historical progress as the cure for nostalgia and the conditions which gave rise to it. Ironically enough, psychoanalysis would come to regard progress itself as a symptom of nostalgic desire." See his article "Returning to Nostalgia" (1993). 


\section{Jeopardy}

A remarkable Kleine-Éclipse Indian drama in two reels to be released December 16, 1912, "The Red Man's Honor," is of universal interest, because it is unique in the history of moving-picture business; being the first time that a typical Indian and wild west picture, practically perfect in every detail, has been produced in Europe to be submitted to the American public. There have been other films released in the past, showing Indians and cowboys portrayed by European actors, but in every case glaring inconsistencies in the plot, characterization, or costuming made the subject appear ridiculous. Exhibitors and exchange men who were in business as far back as 1905 and 1906, will recall with amusement a film of this character which, although very successful at the time, called forth a great deal of ridicule, because the

horses ridden by the "Indians," instead of being the customary lean and undersized "snakes" of the plains, were beautiful animals with bob-tails such as were used in the French cavalry regiments.

But one can find none of these faults in "The Red Man's Honor," for many reasons, probably mainly because, as it is announced, the principle roles are

taken by Mr. and Mrs. Joe Hamman, Americans who have spent several years on our own wild west, thus being well fitted to portray Indian characters in a subject of this kind and at the same time able to direct others in the details regarding settings, costumes and manners of the American red-

skin. - Motography, $1912^{1}$

Main Entry: jeop•ar•dy Etymology: Middle English jeopardie, from Anglo-French juparti, from Old French jeu parti alternative, literally, divided game Date: 14th century $\mathbf{I}$ : exposure to or imminence of death, loss, or injury : DANGER 2 : the danger that an accused person is subjected to when on trial for a criminal offense - Merriam-Webster's Online Dictionary, 2005

We have seen that my speculations in the opening chapter have turned out to be relevant not only in theory, but also in the practice of analyzing early cinema: as in the popular American television game show Jeopardy!, in which contestants 
have to ask the questions that correspond with answers provided (instead of the other way around), historians have to pose their questions after the "answers," the historical bits \& pieces, have been found. The consequences of this situation are many and varied. At this point, therefore, a historiographic intermezzo seems called for. The problem of "early" can now be addressed more fully, as in "Early Western Challenges Cinema History." The discussion of historical events as another, more specific, entrance into the problematic of historicity and factuality, which yielded the notion of instant nostalgia, has by now set the stage for a confrontation with a major problem of writing history.

In this chapter, I present a case study of an aspect of my corpus that the notion of "early" would not entice us to consider: the sense of "nation" that emerged in the face of the increasingly international commerce within which that tenaciously "national" product, the Western, was caught. The case in question puts the idea of nation itself in jeopardy. Through the following analysis I aim to play "early" and "nation" off against each other by way of what is "modern" about "inter-nation." The case consists of the production of a French company that produced films in America of the kind we would now call "Westerns." The production of the company, Pathé, between 1910 and 1914 makes the label "made in America" double-edged. The answer, these films, is given: the question, are they French or American? - in other words, what nationality can such a product have? - goes a long way toward understanding cinema culture of the time on terms that are its own:

There is one American article of export out of which fortunes are being coined in every corner of the world, and which, under its rightful name, does not appear upon a single steamer's manifest. This is the picturesque - what is bizarre, exciting and unusual in American life, chiefly scenes of cowboys and Indians. This picturesque, a real, definite commodity of genuine commercial importance, goes with many another moving picture film across the seas, and Britisher, Frenchman, German, Spaniard, Italian, South American, Australian and South African clap their hands with joy, or otherwise show their approval, when the exploits of the "Yankee" brothers are flashed upon the screen. ${ }^{2}$

Nation, nationality, nationalism: none of these words suffice to characterize the phenomenon I wish to speak of in this chapter. By the early years of the 2oth century, after the first fifteen years of filmmaking, cinema had found a steady place in Western culture, and film had become an international commodity. As it happens when an international patronage picks and chooses its coveted objects, "international" and "national" become each other's supplement. In the case of film, people begin to wonder about what "colors" films from different national backgrounds. Nationality and the practice of filmmaking become entangled in the public eye. National "tastes" become relevant, particularly in the 
light of international market competition. This is evident in the article on the export of American film quoted above, in which study of the tastes of audiences is seen as the key to success of movie entrepreneurs:

The filmmakers of America, like those of any other country, and like other purveyors of amusement the world over, have made it a point to study audiences everywhere. They have sent out experts to visit the nickelodeons of the various nations, with instructions to penetrate into even the smallest cities and find out what people want. When it is remembered that a few years ago it was figured out that fifteen million dollars was invested in moving picture studios for the making of films all over the world, more than a million dollars in America alone, and that these figures have since wonderfully increased, it will be seen that meeting the tastes of audiences is a matter of much importance. ${ }^{3}$

For film, national taste is intertwined with the particulars of the rapidly expanding medium that is nevertheless still perceived in terms of its "beginning" after which it is always already situated. With the international success of a young but booming "industry" in the United States, and with American-ness, Western-ness, and the nations of "Indians" playing such a predominant part in film culture at this time, the question to what nation the qualifier "national" refers, is fundamentally complex. I aim to foreground that complexity, and propose that the situation argues against, rather than for, a notion of "nation," even at the heart of this preoccupation with "the national" in the international film business. In other words, the pre-WWI years put the sense of nationhood attached to products in serious jeopardy.

In 1911, the New York Times published a long article on the state of the art and the future of cinema, already noted in $\mathbf{C}$. The matter of national (or regional) tastes is part of the author's preoccupations. The complexity of this national quality is immediately obvious. Let me quote again:

What kind of plays do the different parts of the country prefer? Well, the East makes a strong and steady demand on plays of the wild West. The West, which knows better, will have none of them. [...] They are exported to Europe, where they find a steady popularity and a strong demand, although, say the moving picture men, Europe takes just as kindly to a scene of life on the Atlantic Coast as it does to a Buffalo Bill or Jesse James show. [...] In the East, say Pathé Frères, there is a heavy demand for Western plays and not much of a demand for European importations. In the West they want "American stuff" without much regard to what part of the country it portrays. ${ }^{4}$

If this passage is any indication, the issue of what makes a film American, say, as opposed to European, is directly bound up with the thematic centrality of Western thematics. "American stuff" - today we would call it "Americana" - is 
a phrase that points to the "flavor" or "taste" that we associate with souvenir shops and postcards. The passage from the New York Times indicates that this tourist flavor is in "strong and steady demand" and has the "steady popularity" of fashionableness. This combination of taste and fashion through commerce is typical of modernity. It is essentially visual in nature. Consequently, it is particularly suited to become a stock feature of such a visual commodity as silent film, new to the international market. But for reasons I have explained in other chapters, the heightened bond between film and fashion, taste, and commerce is even more intensified when "nation-ness" of an altogether different kind comes into the picture: the acting out of American national identity through the relationship between "Indians" and white Americans.

What I wish to sketch in this chapter is a sense in which "nation" becomes a quality or aspect of a cultural product between cultural style and economic force; between aesthetic and practice; and between form and content. My goal is not to unpack these but, on the contrary, to demonstrate their inextricable braiding. The situation I will briefly indicate becomes, then, an allegory of how, in my view, early cinema is best studied in an historical perspective.

With the firmly established nation put in jeopardy by increasing internationalization, the relation to "national" thus becomes the crossroads or shifter between no fewer than four meanings of "nation." First, the nation "of origin" receives meaning from the inter-nation that is the international culture within which the film market is embedded. This I will simply indicate, according to custom, as American, European, French, and the like; and as "national" and "nationality." Second, the American film comes to be recognizably distinct from European film. A sense of belonging and of cultural ownership is involved. Without overstating this aspect, it can be indicated as "nationalist" and "nationalism." Third, "Americanness" is a bundle of features that cater to a recognizable taste that becomes fashionable, even if films are made in Europe. The reinforcement is mutual: as nationality is marketed through nationalism, those aspects in films that foreground a sense of nation become more visible, while the increasing internationalization of the market calls for a focus on what distinguishes one national product from another. This is intensified in what we now call the "genre" or rather, "proto-genre" of the (future) Western, alternatively characterized by setting, plot, and/or collective characters, "Indians."

In order to distinguish it from the first two, I will indicate this aspect as "nationish" and "nation-ness." Finally, the dynamic that paradoxically reinforces a sense of nationhood in interaction with its loss through internationalization what we call today "globalization" - is overdetermined by the centrality of inter-American nations at odds with each other, in the Western plot where aboriginals and immigrants meet as Indians and cowboys. For this aspect I will simply continue to use the contemporary terminology of Indians and whites. From 
site of production to taste to genre to national identity: what we have here is a constant interaction between nationality of films to identity in films.

Let me make this a little more concrete through the example of the French producer Pathé. How should films about America, made in America by a French company, be positioned in terms of national identity and the construction of the exotic other? Some specific questions arise due to the significant fact that the American branch that Pathé opened in 1910 specialized in Westerns. In the first place, the question arises: How European are these films about the American West, made in the American East by a French company? This question can be rephrased in terms that bind the aesthetic to considerations of content: Whose vision of what do we get to see in the films? This question is extremely important if we realize that nation-ness implies nationalism as well as nationality, in relation to internationalism. For, as soon as the culture no longer automatically defines itself within a nationality, the question of nation - that of "us" versus "them," of self and other, must come up. For our Pathé example, the question is, then: Whose other are we dealing with? The question concerns the geographical and national site of the otherness on display and the "self" implied. Most of these questions have so far remained largely unanswered, because little reception data are available and only a limited number of films can be investigated in our archives today. Due to these practical handicaps, the methodology for answering these questions is still unclear.

In addition to these practical shortcomings, historical film studies are also caught in methodological problems of a more theoretical and meta-historical kind, and it is such problems that primarily interest me here. How can we investigate such complicated concepts, or constructions, as national identity and ethnicity in the case of these short films? Perhaps the fact that Pathé specialized in a genre that explicitly deals with these issues in their stories and imagery helps us to get a clearer grip on problems of method in general. Because of their clear conditions of production and their relatively good documentation in the archives, the Pathé films are a distinct group within the larger output of Westerns and provide us with a good case study of the relationship between Europe and American in the Americanization of cinema, issues of national and ethnic identity, and genre developments in the pre-WW I (pre-1915) period. ${ }^{5}$

In the American trade press discourse about French productions in general is abundant, especially from 1910 until the outbreak of the war in 1914. These European films are mostly evaluated in the context of market competition between American and foreign products. At the same time, in the midst of the different genres that were made in these years, the Western was praised and promoted as a truly American product. ${ }^{6}$ But confronted with the Pathe films, this praise put the very idea of American nationalism - in the sense I use that 
word here - in jeopardy. With the popularity of Westerns and Indian films - let us not forget, still wavering generic categories in the early years - a form of genre criticism emerged. A qualitative distinction was made between films that were shot in the East versus films produced on location in the West. ${ }^{7}$ Note that location is a category of production as well as aesthetic, while in the case of Western content, it is also the setting for the fabula. Thus, location is triply relevant for a sense of belonging or nation-ness. The authenticity of location was a point of evaluation in the press, while production and exhibition practices show that not only Western Westerns, but also the Eastern Westerns, could pass the test of popularity. ${ }^{8}$

The American Pathe films exemplify the problem of this contradiction. It is difficult, even problematic, to position them in terms of national production are they French or American? In terms of nationalism, their marketing is contingent upon their nationality's ostentation. But since they are nationally hybrid, their nationalism is by definition artificially constructed and ambiguous to read. It is equally hard to characterize them in terms of genre. One can well wonder whether, and how, these "Westerns" are different from other Westerns? Thus, caught up as they are by the international-national dynamic, these films challenge such categories of nationality and generic identity. In our little game of jeopardy, the answer is given by the moving images of the films. The question corresponding to that answer is the key question indicated above: What visions of which West do they show? What strategies of authenticity do they deploy?

Consider the following. In April 1910 Pathé opened their American branch in Bound Brook, New Jersey. The first film released was a Western: THE GIRL From Arizona (May 1910), shot on location a few months before the studio opened. Later that year, French director Louis Gasnier came over to manage this American branch and to direct many of the movies that would be made by the company in the subsequent few years. Westerns were their specialty. Soon, American Indian actor/director James Young Deer was hired along with his wife, actress Lillian St.Cyr (also called Princess Red Wing) and was sent to open a West Coast studio in Los Angeles and direct Westerns shot on location in the West. ${ }^{9}$

These French-American films were not made for the American market only. Instead, they were produced for an international market, and, in effect, circled the globe, along with other Westerns made by specialized companies in the United States, or French Westerns shot in France, Italian films about the American West, German Westerns, and even a Dutch Western or two. The Filmmuseum holds two Dutch "Westerns": WigwaM: DE GESCHIEDENIS VAN EEN KINDERRoof in CANAdA bij NiJMEgen, made by the young Joris Ivens and his family in 1912, and Telegram uit Mexico (1914, Hollandia). Both films clearly exhibit a Dutch/European perspective. The film by Ivens was shown before an 
audience at the time, but was not made for commercial distribution. It is an amateur home movie, with the whole family participating, playing double roles of both Indian characters and white settlers in a story of captivity and the good Indian versus the bad in the vein of Karl May's Winnetou (1908). A contemporary German novel published in translation in Dutch, with the significant title of 'N PRAIRIE-FILM (c.1900), tells the story of a small boy who befriends an Indian and lives with a scout in the wilderness.

Although clearly in a different category than the commercial films, Ivens' film reveals a lot about the popularity of Western stories in Europe. It evidences a popular conception of the West, and the joy of dressing up and acting out familiar stories, free from the constraints of the commercial "rules of the game," such as realism and authenticity. TeLEGRAM UIT MEXICO is a contemporary story about immigration and the anxiety of those who stay behind in the "Old World"; a son experiences the dangers of the unrest in Mexico in 1914, while his parents back home are sick with worry because they fear he will get killed overseas. $^{10}$

To return to the Pathé films, these exemplify the methodological problems of attributing "nation," first of all, for some practical reasons. The recent restorations of the Cinématèque française, together with the unique collection of the Filmmuseum provide a wonderful source for the study of the relationship between Europe and the United States in the pre-WW I period. Made between 1910 (the opening of the Pathé studio) and 1914 (the outbreak of the war with its effect on the international film market that would change the situation in the industry again), the corpus of films is relatively small, and comprehensively available for historical analysis. ${ }^{11}$

Moreover, these films emerge at a time when the genre of the Western is just assuming shape, still open for variety and difference, but recognized by the public as a distinct category. The genre evolves through nation-ness, for Pathé cashes in on the popularity of Cowboy and Indian pictures, and contributes to the production output of this type of films. At the same time, they are able to further define the genre, and to put, so to speak, their brand on it. Emerging genre criticism in the 1910 provides an echo to film production in the form of a public debate, the traces of which enrich the historical perspective on the films today.

Secondly, in terms of filmic characteristics, the larger part of the films deals explicitly with Indians, in a manner that seems to be different from many American films, though, as always when an aspect is scrutinized from a later vantage point such as our present, it is necessary not to overstate this difference. Their difference from American films is not always very clear; nor can we say that they are part of a European "school." The impossibility of labeling them "European," "French," or even "Non-American" is in part explained by the fact that 
the Pathé Westerns are not strictly "European." They are fundamentally hybrid. But what does that mean? Do they perhaps hold an in-between position, do they have "dual nationality," or are they in a sense without national identity? Their treatment seems distinctive compared to mainstream American films from the period. But how can we approach this otherness?

In contrast to others who would label the Pathé treatment of Indians as more "sympathetic," I do not think the significance of these films lies in a binary moral of "good" or "bad" Indians. ${ }^{12}$ Sometimes the delineation of race and nationality is not only a matter of mirror images of goodness and evil. Rather, I propose to characterize the Pathé films as being open for national or racial mobility. An uncertainty in the production of "race" is more typical for the Pathe films, which cannot be pinned down in terms of sympathetic versus othering strategies of representation. I speculate that this mobility is tied up with the uncertain nationality of the films as products.

In his Red Rooster Scare (1999), Richard Abel outlined the "Americanization Project" of the years 1907-1910. Where Abel positions this Americanization in relation to European dominance, American resistance, and ultimate victory in the industry, I propose to focus here on the European response to popular demands, rather than on the American press's rejection of European products. Perhaps paradoxically, I want to look at Pathé's collusion with, or participation in, this Americanization, rather than at how they fell behind American companies like Selig, Bison, and Kalem. After all, the Pathé Westerns fit the demand for American subjects both in America and in Europe, even though the "ultimate" identity of the company was European. Maybe the European contribution to the Americanization of cinema as a whole helped to make the Western into a universal genre, rather than a national genre.

In view of the complexity of the issue of national identity, I want to take as a starting point for a historiography of film culture in terms of nationality - as distinct from, say, immanent film history - some of the issues that are raised in the contemporary press about the Western in relation to conceptions of "national cinemas." And, not surprisingly for a medium that enchanted because it appeared to be a simple recording of reality, and whose aesthetic and marketing focused on location, a major issue targeted in the press turns out to be realism. Thus, even my cursory inquiry already demonstrates that it is necessary to frame genre in terms of realism and the clustering of the two, by issues of national (and international) identity through which both "genre" and "realism" functioned. This becomes obvious as soon as one starts examining the Pathé films that the archives hold today. The analysis cannot but focus on both national identity and generic identity, for I hold these two issues to be inextricably intertwined. Some hypotheses concerning their place within the context of the genre at the time emerge from looking at the way the debates in the contempo- 
rary press on generic realism and nationality framed those identity issues. This may shed some light on the significance of the American Pathé films in relation to their hybrid nationality. Staying away from essentializing national features, I will not answer, or even pose, the question of how "French" they are, except to offset the limits of their "American-ness."

The following review of Cowboy Justice,(1910), one of the first films made by American Pathé, catches my eye because it explicitly addresses several issues relevant to the question of cultural belonging, or nationality, in an aesthetic assessment of the films:

Cowboy Justice - Pathé. Any place west of New York is the West to a New Yorker, so the Pathé producers evidently flattered themselves that they were getting the real Western atmosphere when they went as far west as New Jersey to get the scenery for this cowboy melodrama. The result is truly incongruous - cowboys chasing desperados down pretty lanes between whitewashed fences. The acting, on the whole, was spirited, one fellow making a sensational fall from a running horse, and another a daring dive into the river; but that surreptitious "hist-like" thread with which the desperadoes approached the station was enough to make one laugh. The play is scarcely drama, being without heroine or "heart" interest; but that is no objection, we merely point it out as being unusual. The piece aims to be a thriller, and it succeeds. ${ }^{13}$

First of all, the review zooms in on authenticity. It establishes an opposition between "real" versus "fake" location. This is related to the Eastern/urban spectator who is supposed to be naïve. Second, the text refers to the genre of the Western, or in more contemporary lingo "cowboy melodrama." It makes it clear that the important elements are realism (in location and acting) and action. Pathé fits the bill in this review, because the public (not the critic) is fooled. Hence, realism is acknowledged to be an effect: Roland Barthes' "effect of the real" (effet de réel) comes to mind again. $\mathbf{F}$

But then, this positive assessment was to be expected. Nickelodeon would not be too critical of Pathé as a producer of Westerns, for a few months later, they published an article on the "World Wide Activities of Pathé Frères" in which the endeavor was praised, pretty much in the same terms as the other one was criticized. ${ }^{14}$ Here, the article concerns an Indian film by Pathé, the realism and, significantly, the "class" of which are praised. "Class" is a matter of taste, invoking the kind of nationalism I have connected above to that peculiarly modern mix of marketing and visible fashion. The crucial place of nation-ness in that mix shows in the tendency to give a nationality to class itself - a word used as a synonym of quality: in terms of nation-ness, having class is being French. For, while realism remains a matter of successful tricks, or effects, class is associated with the artistic imago of French films: 
The Heart of An Indian Maid - Pathé. This Indian drama stands apart and above the usual run of its class. The Indians are really convincing and the mise en scene artistic. The costumes deserve special mention as they are rich, individual and picturesque. The facial make-up is so skillful from the principals down to the last "super" that one could easily believe the troupe to be a band of real Indians - possibly some of them were. Not a little of the artistic quality of the film is due to the film tones, which are warm and pleasing. The film is a gratifying example of what the Indian drama might be, and thanks are due to Pathé Frères for restoring one's faith in this much derided class of photoplays. It also confirms one's belief that the customary manner of producing Indian subjects is improbable and inexcusable. ${ }^{15}$

Please note the bond between realism and aesthetics, a bond which entails nation-ness: improbable, and therefore inexcusable.

The authenticating effects of which the article speaks can also be analyzed in its own rhetoric. For example, French-ness - artistry in color and tone - is signified by the addition of "Frères" to the name. The French connections of this production are here emphasized to stress its artistic qualities that suit the exoticism of the Indians. "French" stands for an aesthetic that, in its colorfulness colorful as picturesque and as racially marked - suits the task of exotic representation. This particular ground for praise sets up a contrast with American companies who claim Westerns as their unique national product. But as much as the Pathé Western is nationally hybrid, it is equally strongly furthering nation-ness, inflecting all manner of categories through Frenchness and Americanness, respectively.

This particular aesthetic judgment fit the cultural discourse of the moment, where the question of national in combination with genres had only recently become posable. Right before Pathé opened their New Jersey studio, in January of 1910, an editorial was published in Moving Picture World, on precisely the question of the possible nationality of film genres. The article bore the title: "What is an American Subject?"16 The Westerns and Indian films, it implied, are truly American subjects. As the evaluation of Pathé suggests, however, the "nationality" of subject matter is not identical to that of aesthetic success. For example, most Westerns that were made by American companies feature the white cowboys more prominently than other inhabitants of the West, such as Indians, Mexicans, and Chinese. This biased representation of national groups carved out, for Pathé, a specific assignment: to pluralize "nation." As a result, it seems the Indian films were a niche in the market available for the French company to exploit.

This pluralization of the idea of the "nationality" of stock characters, and of the films in which they appear, led to the development of a variety of forms of exoticism, which I have discussed in D. Moreover, in their treatment of exotic 
subjects, Pathé films provide evidence of what I propose to call a trope of mobility. This trope stands here simultaneously as an example of the way the four meanings of "nation" are imbricated, and as an allegory of an approach to history, or historiography by means of a fundamentally rhetorical centering. I will demonstrate that this trope characterizes the way in which "nation" is both present, even overdetermined in, and a shaping force for, early 2oth-century-cinema culture, by presenting a sample of films that differ in their representation of "the other" as nationally different. These are, successively, 1) two love affairs: miscegenation gone sour, and Indian rivalry; 2) a captivity narrative; 3) a case of ethnic transvestitism.

\section{Love Affairs}

My first example is The Souawman's Sweetheart [Jalousie de Squaw] (1912, Pathé: American Kinema). "Squawman" is the term for a white trapper who lives with an Indian woman. Often these men are also married (in the East) to white women. The story goes like this. Since his arrival in the West the white trapper Paul Wesson lives with a squaw. He receives a message from his white wife. The squaw, played by Red Wing, is saddened by this renewed contact. Paul's wife arrives in a wagon. The Indian woman is depressed. She feels rejected. Humiliated, she returns to her village. The Indians swear revenge. They approach the trappers' camp in canoes. Paul goes out on a hunting trip. Two Indians, with the help of the squaw, grab the trapper's wife while he is away. They take her with them. Then the film cuts to the trappers' camp. Paul returns to his cabin. His sister tells him that his wife has been abducted.

The intertitle reads: "Eager for revenge, the squaw decides to use Rose's hat to defy and torment Paul." And this is exactly what happens next. An Indian brings Rose's hat to the cabin. Paul takes him into custody. And then, as if to put the idea of "nation" in jeopardy, Paul takes the headdress of his captive and dresses up like an Indian. In the next scene, the trapper goes to the Indians. On his way he runs into one of them and ties him up. When it is dark he attacks the guard, sneaks into the tepee, and liberates Rose.

The captured Indian frees himself and discovers that the white woman has disappeared. He wakes the others, and in their canoes they pursue the fugitives. In a long shot we follow the progress of the Indians canoeing in the river. Meanwhile Alice, Paul's sister, has arranged the family's escape. They rush off in the wagon. The Indians set fire to the cabin. Paul embraces his wife and cracks a joke about his stolen Indian costume, and all's well that ends well.

This film is quite explicit in the way it puns on nationhood. The Indianness of the Indians is ridiculed when Paul dresses up as one, but visually, the joke is on him. While in the fabula the utility of the disguise makes obvious sense, a 
grown man dressed up in an Indian costume is quite touchingly funny, at least in the eyes of today's viewers. This would be anachronistic fun. But the disguise turned carnivalesque is also, historically, a statement about the relative nature of racial difference.

More subtle, perhaps, is the thematic use of feminine rivalry that, as such, does not put nationhood so explicitly in jeopardy. Yet, this theme undermines the ethnographic othering that underlies so much of the Western's representation of Indians, by cashing in on another form of stereotyping. The theme of jealousy between women is a stock motive in early cinema, just as it is in popular productions of boulevard comedy in theater, dime novels, and other forms of popular entertainment. This theme can be deployed in many different ways. In the film under discussion the jealousy sharpened racial contrast and problematized the sense of belonging to a nation. ${ }^{17}$ When the theme is exclusively attributed to women of the same nationality, this more general Western gender stereotype can be used to mediate between the two national identities - Indians and other Americans - by projecting a feature of one onto the other, as happens, for example, in Starlight's Necklace [La parure de Starlight] (1911, Pathé: American Kinema). Starring Joseph DeGrasse and Red Wing, this film stages a European-American style rivalry between two women in a fabula about Indians.

Indian couple Eagle Eye and his wife Red Wing live in a camp by the lake. The opening shots present the couple in a picturesque setting, standing near the water. The husband takes off on a hunting trip. The intertitle announces "a most unexpected and attractive encounter." Indeed, he runs into another Indian beauty who is drinking water from a brook. The young woman gives him water. This Biblical motive representing charity leading up to love is one of the symptoms of trans-national projection. ${ }^{18}$ "Starlight's present" says the intertitle. In fact, the stranger named Starlight gives the man a necklace. The hunter returns to the camp where he embraces his wife. When she notices the necklace, she becomes upset. They have an argument. Domestic trouble looks the same, whether in a brick house or in an Indian camp.

The following day a friend comforts Red Wing. Her husband returns to the forest. But this time, Red Wing follows him. The pursuit offers occasion for a picturesque visual trip through the forest and along the brook. Again, he encounters the same beautiful Indian woman dressed in virginal white. Red Wing witnesses the encounter from the background. When Eagle Eye and Starlight separate, Red Wing follows Starlight, and the inevitable confrontation follows.

The intertitle announces the next phase of this stereotypical plot. "Meanwhile, Eagle Eye comes back home carefree." Ignorance is bliss. When he returns to his tepee his wife is not there. Another woman indicates the direction in which she has gone. When he finds his wife, he finds her in a fight. The two 
women rivals are at knife point. The beauty has overpowered Red Wing and knifes her. Eagle Eye joins the fight and tries to stab Starlight. But Red Wing stops him. Eagle Eye returns the necklace to Starlight and chases her away. He embraces his wife and carries her back home. Reconciliation. More embraces. He looks in the distance and points with his arm. The film ends on this postcard-like image, recalling a Curtis photograph. This closing image reinserts the film into the general culture of "nationhood in jeopardy." Indians R Us, a plot of jealousy in support of a Christian-type monogamy, even if no Christian figures in the film.

\section{White Indians and Indian Whites}

Captivity narratives provide eminently suitable stories of disrupted identity. An example is L'indienne blAnche (1911, Pathé: American Kinema). In this film the protagonist, a white girl who grows up in captivity in an Indian tribe, breaks with her new "parents" when she discovers her background. As in the previous example, which stands here as an example of the "pure" Indian story, ethnographic details are emphasized. A partly Indian cast enacts the story. Lots of beads and elaborate costumes insure the exotic quality of the visual display. As a result, the film looks "authentic," and the aesthetic nation-ness that ought to help international marketing is, again, classy French. ${ }^{19}$

The plot goes as follows. A group of Indians break open a chest that they have found in a wagon, after killing a family of pioneers. Thus they discover a child who had been hiding in the chest. The chief wants to kill the child, but an Indian stops him. In the next scene a white man with a beard, who looks like a trapper, is captured and tied to a pole. The title reads: "Jim recognizes his sister who has been given the name the white Squaw by the Indians." She shows him a birthmark: evidence of identity and of racial nationalism go hand in hand.

Night falls. An Indian encampment, a silhouette of three tepees and hills are visible in the background. The White Squaw unties her brother. They flee. After a few steps they encounter a stagecoach. They tell their story to a cowboy. Meanwhile, the Indian guard wakes up. He sees the prisoner has fled and he sounds an alarm. The Indians chase the stagecoach. They capture the girl for the second time in her life. But this time the cowboys rescue her when her brother calls for their help. Overpowered by the cowboys, the Indians break up their camp and flee.

The story is about capture and recapture. The Indians move from being the enemy who kill white settlers and kidnap the little girl, to a parental position for the girl who grows up as an Indian woman, to enemy again when the girl discovers her background and flees the camp with her brother. Removal is the only possible definite solution to the problem of racial displacement. Through the 
shifting national identity of the girl, the position of Indians as "other" is defined and ultimately re-instated, even though a plot of national mobility is needed to do so.

\section{Cross-dressing: Ethnic Transvestitism as Farce}

The two themes that seem capable of undermining nationality and nationhood through an ironic deployment of nation-ness - female jealousy and cross-dressing - can also be mobilized in unison. Another case of mobile identity takes this trope to the extreme by means of just such a thematic combination. I will have more to say about this film in $\mathbf{Y}$. My example, here, is the 1911 American Pathé film An Up-To-Date-Souaw. The French title with which the film was released was L'INDIENNE Ko-To-SHO SE MODERNISE. In this film the issue of nationish identity is explicitly addressed in the themes of tourism, ethnicity, and gender, through a single, unifying trope of mobility. ${ }^{20}$

The opening scene shows a group of tourists visiting an Indian reservation. As an example of the mutual reinforcement of nationality, nationalism, and nation-ness, tourism and the nationalism this practice in and of itself implies is worked into the plot. The group of white men and (mostly) women walk around in the camp, checking out what they see. The typical tourist attractions are shown, Indian women weaving, men and women dressed up in traditional attire and selling arts and crafts to the tourists. However, as a first mobility trope, the gaze of the tourist is reversed in this scene when the women visiting the Indians become the object of the curiosity of the Indian woman in the foreground of the image. In admiration she looks at the way these white women dress, and by trying on a basket for a hat she imitates their dress code. Her husband furiously takes off her "hat" and gives her a feather instead, the proper headdress for an Indian. She cries and sulks like a child.

When the tourists leave and night sets in, the Indian woman secretly tries on the basket and admires her reflection in a cooking pot. The intertitle describes her actions: "Haunted by the memory of the marvels which charmed her, KoTo-Sho attires herself like her paleface sister." "Paleface" and "sister" constitute the verbal equivalent of the mobility trope. Happy and exhilarated, she sneaks out of the tepee and goes to the nearby city.

She walks along a street with shops and display windows. She goes into a store and comes out with a huge fashionable hat. In the meantime her husband wakes up and finds her missing. He alerts the other Indians, and they look for her, but in vain. Her husband then goes to town, looking for her in the streets. He goes into a store, but the girls working there are frightened and call a policeman. When he makes clear that he is carrying a pipe and not some kind of weapon, he is kicked out on the streets by the policeman. Meanwhile, his wife 
continues her shopping spree. She buys a fur coat and, ignorant of the shop girls laughing at her behind her back and happy as a clam, she continues. Her husband frantically runs through the streets, putting his ear to the ground, hoping for sounds or signals.

When a city gentleman notices the Indian woman, he likes her looks and follows her on her way back to the camp. In the woods, near a stream she sits down. He taps on her shoulder and is taken by surprise when she turns around, and he sees her face. He did not expect her to be an Indian woman. Her husband, in the background, sees this encounter. He throws the man in the water and angrily removes his wife's new hat. She begs for forgiveness, but he stays angry. When the man struggles out of the water and lies down on the ground, the Indian scalps him and makes a victorious dance around his victim. However, the man was wearing a wig - thus ridiculing male vanity - so he stays unharmed. As the final intertitle explains, as if commenting on the rest of the film as well, "Excessive coyness is a sin that may turn providential."

At first sight, the film is not very clear in its moral position, in spite of its heavy deployment of stereotyping in the joint domains of ethnicity and gender. It is clearly a comedy about the impossibility (or at least, the punishment) of ethnic and gender mobility, but it also comments on the unjust treatment of Indians by whites. Crudely, the Indians are made fun of, and, overdetermining nationalism and gender, the Indian woman is the particular object of ridicule. The man is the stereotypical possessive husband, the poor ill-treated Indian, and the vindictive, scalping Savage, all at the same time. This stereotyping could easily be construed as disturbing - and on the level of character figuration alone, it certainly is - if it weren't for the equally heavy-handed stereotyping on the other side, which makes an assessment of the film's ethics more complex, and its nation-ness messy.

For the white characters are also humorous stereotypes: the tourists appropriating everything with their gaze, and, at the same time, in an interesting role reversal that implies a critique of tourism as such, they become the object of the gaze of the Indian. The shop girls are giggling and hysterical adolescents, crying for help with no cause. The policeman is a bully, and the "gentleman" is a coward, vain, and a womanizer. None of these characters carry a character-plot knot that modifies these stereotypical views. ${ }^{21}$ The Indian woman, however, is the one who is partly "mobile". She takes on a subject position in the beginning of the film, and sustains this position to the very end, until her husband punishes her for it. It is not white society that is able to exclude her. She demonstrates immunity to the whites' attempts to degrade her, when she is oblivious to the smirking and laughing behind her back. Thus, she embodies the notion that discrimination depends for its effectiveness on a certain amount of collusion on the part of the object. Triumphantly, the Indian woman continues parading 
through the streets, buying the objects of her desire - as an emblem of the very market she, as a fictional product, caters to - dressing up as what she wants to be. Dress implies fashion implies visuality implies market: what a perfect icon of modernity this Indian woman ends up being! Paradoxical as this appears to us now, this is not an anachronistic view. Nor did it escape the producers, who titled the film in French L'INDIENNE Ko-To-SHo SE MODERnISE. The title sounds condescending only if interpreted literally - to become like a modern Western woman. But if we get the pun implied in the French word moderne, we hear the word mode (fashion). If this woman is doing this herself (se means just that), she receives a subjectivity at odds with the ethnographic othering that we have come to expect.

In view of the problematic of this chapter, how to analyze historical nationness while demonstrating how nation-ness is by definition in jeopardy, the site where the figure's mobility is played out is relevant. It may not be the ethnic, that is, national, mobility to which she aspires, but rather class mobility: her desire is focused on luxurious garments, she is not looking for acceptance in the white community. This mobility activates the plurality of meanings attached to "nation" in this chapter. Class is neither national nor nationalistic, but nationish nevertheless. For class, we remember, is also "classiness," especially when connected to fashion. Both "class" and fashion, in turn, are features connoted "French." Through that connotation, then, the film can be attributed a "nationality." For, although it is set in America, largely "made in U.S.A." and, moreover, caters to the taste for Americanness in both the U.S. and Europe, the aesthetic nationness is subtly, but decidedly, "French."

At the end of this exploration of the intricacies of "nation," we can see how this ambiguity is a good-enough emblem for the problem of "early." There is no point from which the mobility demonstrated can be called "early," except "after" the beginning that knows no end.

National identity is never fixed, but always in construction. In the case of the French-American Westerns this construction is perhaps never completed. As I attempted to show in the analysis of the films in this chapter, there is a sliding scale of Indianness and whiteness. Moreover, the trope of national or ethnic mobility ensures that this story of identity construction remains never ending. Rather than just passing judgment on how Indians are treated in these films, I want to argue that it is precisely the trope of mobility and "openness" that characterizes many of the Pathé Westerns. This openness is rhetorically played out in the shifting positions of Whites and Indians and the unstable relations between the two. In this sense, they foreground an unstable "nationness" that draws attention to the impossibility of pinning them down in terms of nationality. The nationalism in the sense defined above, inscribing a sense of belonging 
and of cultural ownership, is not so clear. Some features of the plot "taste" American, have an American feel about them, but the double-edged irony in the plot makes such American nationalism an object of reflection rather than a plausible, realistic feature. The setting is definitely American. But because of this openness and the trope of mobility that makes it a rhetorical strategy that overrules all attempts to fix nation, it remains impossible to define the national identity of these hybrid films. They are neither European, nor American, but the construction of identity in the films is definitely instigated by the identity of the films. Perhaps, then, we are closest to the historical meanings of the films by defining their nation-ness as "between," that is, strictly speaking, inter-national.

\section{Notes}

1. “An Indian Picture Made in Europe." Motography VIII, 12 (December 7, 1912): 421422.

2. "Exporting the American Film." Motography VI, 2 (August, 1911): 90. A longer version of this article was originally published as "Exporting an Imaginary America to Make Money." New York Times (July 30, 1911).

3. Motography VI, 2 (August, 1911): 90.

4. "Is the Moving Picture to be the Play of the Future?" New York Times (August 20, 1911).

5. When I call such theoretical problems as I am focusing on here, "meta-historical," I wish to obliquely bring into the discussion the kind of historiographic analysis initiated by Hayden White with his path-breaking book Metahistory: The Historical Imagination in Nineteenth-Century Europe (1973).

6. Robert Anderson (1979) concludes that "From 1907-1911, the conception and function of the Western underwent three distinct shifts. Undertaken initially by Selig as a way to emphasize local color and to differentiate his 1,000 foot productions from European films, by 1909 the staging of imitative Eastern Westerns became the most frequently selected means of unlicensed manufacturing to the entire film industry until by mid 1910-1911 the Western had evolved into a fully articulated genre that emphasized locale, characterization and visual spectacle to the benefit of motion picture patrons, the M.P.P.C. and the Independents alike. In this five-year span, the Western grew into a consistent money-making, distinctly American form of motion picture entertainment - a position that the genre maintained for the following six decades" (26).

7. Some vehement criticism of the average Western was published in an editorial "Wild West Pictures" in Moving Picture News IV, 46 (November 18, 1911): 6. Other examples of such criticisms are "The Passing of the Western Subject." Nickelodeon V, 7 (February 18, 1911): 181-182; “The Wild West." Moving Picture News V, 8 (February 24,1912$): 21$.

8. I will further discuss the use of "authentic" or "fake" locations in $\mathbf{\square}$. 
9. Kristin Thompson (1985: 18). See also Sadoul (1951: 67) and Abel (1999: 138-139 and 173-174).

10. I will take a closer look at this film in $\mathbf{M}$. For a discussion of the use of intertitles and written texts as narrative devices in this film, see Frank Kessler (1997). Elsewhere, Kessler points out how this film was perceived in different generic terms according to different countries and their different national contexts (1999: 230; 2001).

11. For a presentation of the films that were restored by the Cinémathèque française in 1997, see Claudine Kaufmann's “Le silence sied à l'Indien. Journal de la restauration (2)" (1997)

12. Kaufmann, for example, says that it is difficult to categorize the collection of Pathé Westerns, but that the originality of this corpus lies in the positive treatment of Indians: "L'Indien y est traité en égal des Blancs, il est même souvent paré de vertus qui font cruellement défaut à ses derniers. [...] Au début du siècle, déjà, l'Indien est le héros sans peur et sans reproche de nombre de productions populaires sans prétention" (1997: 121-122). In a recent article on D.W. Griffith's films about "Indians," Gregory S. Jay "explains how the apparently sympathetic representation of the Native American still adheres to the logic of white supremacy" (2000: 3). Although Jay complicates the "positive" portrayal of Indians, he adheres to the binary moral of positive or negative representation. This is useful in his case where he wants to draw parallels between the depiction of blacks and that of Indians in his analysis of the construction of whiteness. Although, clearly, these films often do present a black and white world view, for my question of hybridity in national identity this polarization alone is not so helpful, as I will further explain below.

13. "Recent Films Reviewed." Nickelodeon IV, 10 (November 15, 1910): 180.

14. Nickelodeon V, 1 (January 7, 1911): 17-18.

15. Motography V, 6 (June, 1911): 148.

16. Moving Picture World (January 2, 1910): 82.

17. Another American Pathé film, which could be mentioned in this context of interracial rivalry between women is Amour D'INDIENNE [F] (c.1910).

18. See in the book of Genesis, the story of Rebecca, providing water to Eliezer's camels when Eliezer is in search of a wife for his master Abraham's son Isaac. Providing water - a task of young women - is a qualification for marriage. Later, Isaac's son Jacob encounters Rachel by a well. Repeating the sequence of Rebecca and Isaac, Rachel gives water and becomes Jacob's bride.

19. By "authentic" I mean an effect brought about by repetition, not a judgment on historical ethnic fact.

20. The film is listed under "Comedy" with the release date of 20 September 1911 in "Complete Record of Current Films." Motography VI, 4 (October, 1911): 201.

21. The term "character-plot knot" will be explained in $\mathbf{Y}$. 


\section{Kaleidoscopic Worlds}

Here is a system of images which I term my perception of the universe, and which may be entirely altered by a very slight change in a certain privileged image, my body. This image occupies the centre; by it all the others are conditioned; at each of its movements everything changes, as though by a turn

of a kaleidoscope. - Henri Bergson, $1911^{1}$

The film Buffalo Bill's Wild West Parade produced by the American Mutoscope and Biograph Company (AM\&B) shows the entrance of Buffalo Bill's Wild West Show into New York, on April 1st, 1901. The parade attracts a great many spectators. On the old, black-and-white images we find almost a century later in the film archive, in the first seconds it is difficult to distinguish who belongs to the public and who to the show. The people in the street walk along with the parade, accompanying the figures from the show, a cortege of horsemen marching through the image, making their way with difficulty through the masses. Cowboys, Indians, soldiers of the cavalry, the Rough Riders, and other stock figures are welcomed like heroes in the Eastern metropolis. The cameraman stands in the middle of this crowd and records the festive happening. ${ }^{2}$

This early recording of life in the West came after the beginning. Three years earlier, a similar event had already been filmed several times. In PARADE OF Buffalo Bill's WiLd West SHOw 1 and 2, two films of approximately one minute's duration each and produced by Edison in 1898, the parade of the title is also displayed. In these two short films the images have a somewhat calmer look. People are standing on the side of the road, and the camera is between them. In the first film, the street looks like an unpaved country road; in the second this road turns out to be a street in a larger city since the presence of overhead wires indicate that streetcars circulate there.

Those who remember the newsreels shown in movie theaters before the main film up to the 1970s, can imagine something like the screening of a short film which announces a show that is soon to be performed in the city. This is a matter-of-fact, journalistic presentation of an event in actuality. People who watched this film knew that they were being addressed as co-inhabitants of the same time and place, people who liked to be kept informed of what mattered in their own, contemporaneous world. We see the parade through the eyes of the cameraman who is standing among the viewers of the parade on the side of the 
road. The film spectator is thereby placed in the actuality of what is displayed, as a spectator among eyewitnesses. At the same time, this public on the sidewalk is a potential future audience for the shows that Buffalo Bill and his group will later perform in the city. The future audience of the film can also recognize itself in these people whom, in the filmic images, they observe the parade. These various spectatorial positions indicate a number of levels in the representation. This plurality of levels demonstrates that it is not so easy to indicate what the representation, exactly, shows to whom.

A first level of representation that can be distinguished is based on what is happening on the streets of New York, in front of the camera. This layer of actuality in the representation shows the spectacle of the parade itself. Moreover, the parade is a kind of commercial for something that will soon become part of the reality of city life, and therefore, this second layer concerns an implied future. A third, more symbolic level of representation consists of Buffalo Bill's life, for he has turned his own life into a spectacle. Appealing to instant nostalgia, the recording of this announcement of a show about the recent past to be seen in the near future, is subsequently turned into the subject matter of a film screened for a paying audience seeking to be entertained in the present. This is a fourth level of representation. Hence, it is the camera that turns the actual, happening event into an event, one that matters enough to exist in recorded, already somewhat fictional, form. To direct the camera towards an object is to turn this object into a spectacle, an image, and thereby into a point in the sequence of time that can be identified as such. In this stratification of the image, the camera is the pivot on which the production of the moment turns. The camera creates, fixes, and reproduces that moment.

These four layers of representation each held its own audience in thrall. This can be explained through a closer look at the kind of films they were, and the kind of cultural event they generated. The films I just described can be considered representative of filmic actualities, which were popular in the first years of cinema. ${ }^{3}$ On the one hand, the actuality films or actualities, were a form of journalism. They showed what was happening at that moment, as a current event in and of the present. On the other hand, the cinematic event of showing the film was part of the attraction and underscored the actuality of the new possibilities of the medium to show images of public life to the larger public (Musser 1997: 77). It was not only Buffalo Bill's parade that was popular, but also the event recorded on film attracted the audience for a second time. This journalistic (and PR!) feature that appears in the non-journalistic context of cheap amusement can be said to produce an effect similar to that produced by the Pathé Weekly cinematic news bulletins, which could be seen from 1910 in France and from 1911 in the US. 
Let me show just how much this novelty was appreciated as a history lesson of the present. In 1912 Lillian Conlon, a journalist writing for Motion Picture Story Magazine, expressed amazement at the knowledge the children of that time had about current events. She discovered they had been watching the Pathé Weekly, the news bulletin shown in the theaters:

Dining at a friend's home the other evening, I was surprised at the ease and intelligence with which his two children, of grammar school age, joined in the table-talk. They were better informed on current events than most adults of my acquaintance.

The author, already familiar with the kind of films, but not with the program format that stresses the news factor, then discovers the educational value of these news bulletins:

I had seen, and enjoyed, the Pathés Weekly in various picture houses, but somehow had never realized before just what a wonderful bit of film it was for educational results. [...] Of all the marvelous achievements of the Motion Picture camera, this seems greatest. To present, weekly, the news of the whole world in a form which is intelligible and attractive to people of all ages, classes, and nationalities; to show, with such accuracy the actual places and events which are making history and the men and women who are shaping the destiny of nations, will surely bring all humanity into closer touch and deeper understanding.

She attributes the value of the films to the accuracy and realism of the depicted events, which she sees as differentiating these actuality films from staged events or fiction films:

The educational value of these films depends upon the fact that every event is taken on the actual spot which is represented in the picture, with the actual personages shown. Nothing in the Weekly is "faked" or made up.

This last remark refers to the earliest actualities that did use quite a lot of staging and faking for the rendering of current events. With the ability to show these real events in moving images, the medium had an advantage over newspapers, which had already discovered the power of images over words:

The sensational newspapers have attained enormous circulation by telling the news in pictures. That which is pictured is understood and remembered long after printed words would be forgotten. ${ }^{4}$

This early film practice in which such news became a culturally available phenomenon points to the nature of these events as actualities-cum-entertainment. The point here is not so much to emphasize the news value, nor the educational value as history lesson, but rather to foreground the phenomenon that filmic actualities were in and of themselves a form of entertainment. This form of en- 
tertainment was the incentive for the practice of creating news by recording, distributing and projecting the event. The modes of representation of the past have their own, specific representational norms of imagining the relationship between present and past, and of determining what the event really was. At a moment of heightened instant nostalgia, such a cultural form catered to a deeply felt need.

What did this virtual world look like to the people who "worked through" these images? They were fascinated by something specific that I aim to pinpoint in this chapter. The popularity of nonfictional representations of the world around the spectator demonstrated a fascination with the new medium and the possibilities of the film camera to capture contemporary reality in its flux and dynamics and to convey a sense of presence in its filmic reconstruction for the viewer. $^{5}$

This fascination has often been associated with cinema's background in the photographic experiments of Eadweard Muybridge, and the chronophotography of Ottomar Anschütz or Etienne-Jules Marey. Charles Musser emphasizes the inspiration Edison received for his invention from Muybridge's zoöpraxiscope experiments in the photographic analysis of movement. In 1888 they discussed the possibilities of adapting the invention of the phonograph for the recording of moving images. Musser cites Edison: "I am experimenting upon an instrument which does for the Eye what the phonograph does for the Ear, which is the recording and reproduction of things in motion, and in such form as to be both cheap, practical, and convenient" (1991: 129). ${ }^{6}$

The fascination with actuality has also been explained in terms of the rapid expansion of the illustrated mass press at the end of the 19th century. ${ }^{7}$ These mechanical inventions are, however, but partial explanations for the fact that actuality dominated the first years of film production and that a specific mode of representation became associated with this first cinematic genre. $\mathbf{M}$ In addition to such explanations I investigate here how films about the West are positioned in the filmic context of the period and how they fit in the vision of the world offered by the actuality genre. This vision can be characterized as kaleidoscopic.

I use the term kaleidoscopic here as a conceptual metaphor. This is a metaphor that, by producing associations between two separate domains, suggests and orders an empirical field that so far had remained heterogeneous and therefore unnoticed in terms of field. Two associations are established by the metaphor of the kaleidoscope. First, the metaphor brings to our attention a mechanical optical device - the vehicle of metaphoric meaning. Second, it brings this device - and the ideas it in turn suggests - to bear on a particular cinematic discourse the tenor or resulting meaning of the metaphor. The heterogeneous field here is the practice of film in the early period, and in particular the place of the Western 
therein. The image of the kaleidoscope thus serves as a concept, which helps my project of bringing an order to that field, an order that is neither alien to it, nor projected from the present producing anachronistic distortion. It stands for vision, for visual culture, and for fracturedness. ${ }^{8}$

The filmic context that I call here kaleidoscopic fits that conceptual metaphor on two levels. First, it fits on the level of the suffix "-scope." On the one hand, the content of the films establishes a relationship between filmic discourse and the cultural historical context. Modernity calls for a modern representation of life and world. In a sense the films reflect in their representation the relationship between the medium and the world. As Siegfried Kracauer put it:

[Film reflects back at the audience an existence] deprived of substance, empty as a tin can, a life which instead of internal connections knows nothing but isolated events forming ever new series of images in the manner of a kaleidoscope. ${ }^{9}$

Kracauer is fairly pessimistic here - more than in his later collection of essays The Mass Ornament ([1963] 1995) - about modern culture and its media. For me, it is not the distractedness and the seamless flow of the kaleidoscopic imagery that I wish to underscore, but rather the possibilities and richness of kaleidoscopic arrangements of images. This scope of film production, literally exhibited in the film program, produces a contained diversity that hooks up individual views to a larger picture of the world. $\mathbf{U}$ However, the diversity itself is continuously offered under new constellations. This aspect concerns the "kaleido-" facet of the metaphor: the ordering of elements in series produced by random changes of focus. Each new constellation is appealing, beautiful: kalos.

My double question in this chapter is: How do films about the West fit this broader kaleidoscopic project of the cinema in these first years, and how does this framework, paradoxically, influence the development of a particular, retrospectively generic segment of this kaleidoscope? The first aspect I will look at here is the element "-scope" of the kaleidoscope, namely, the kind of stories and images that are programmed to inform and entertain the audiences visually. The second aspect is the element "kaleido," pointing at the changing constellations produced by each program. Thus, I make a case for the relevance, even key role, of programming as the historical practice of the Western.

The films about Buffalo Bill's Wild West Show are good examples of the complex stratification of the representation of the American West in this context of actuality-amusements. The point of the show was to re-stage fragments of the past and to re-arrange these in the modular format of a show. W Why did films about this re-staging of the past fit so well in the actuality genre? Why is this non-fiction genre particularly appropriate to record a disappearing past, or rather, the sliding transformation from recent past into a mythical and symbolic 
past? As this cluster aims to substantiate, there was a temporal coincidence of the disappearance of the Wild West and the subsequent birth of the Myth of the Wild West (the birth of a past), on the one hand, and the advent of the modern mass media, on the other. This coincidence reinforced the sense of importance and novelty of media that provided the tools to record, and hence, to save for contemplation what was also dismissed as outdated.

Superimposed on this cultural collapse of temporalities was the political reality. As I mentioned before, the frontier, the moving border between savagery and civilization of the westward expansion, was declared closed in 1890 because the population had become so dense that the West was no longer Wild. At precisely that moment, William F. Cody was performing as Buffalo Bill, an incarnation of the reality now doomed by the progress of time. Without a blink, lived reality became a show. Emblematic of this complex simultaneity is the presence of Buffalo Bill's Wild West Show at the World's Columbian Exposition in Chicago in 1893, where Frederick Jackson Turner gave his famous address, "The Significance of the Frontier in American History," for the members of the American Historical Association. Inspired by the official closing of the frontier in 1890, Turner explained how important the presence of the moving border of expansion had been for the course of American history. Note that three years down the line, the Frontier, and hence, the Wild West, was already material for a big show - the Fair - and for history - the American Historical Society. Both Turner and Cody, one the academic historian and the other the showman, explained in their own language the significance of the past of the West at this crucial moment of a closure that marked the West's disappearance. We should also note that Edison had been planning to demonstrate his invention of the Kinetoscope at the same exhibition, but this spectacularization of spectacle had to be cancelled because of a delay in the production of the machines. ${ }^{10}$

By making his own past into a show, Buffalo Bill became the example of the making through staging of myths and legends about the West. This recent past was thus embalmed, made ready to become an object of desire - of instant nostalgia. The new medium of film could then re-stage and re-vitalize this past by repetition. ${ }^{11}$ These films appealed strongly to a new feeling, a sense of the times that was part and parcel of the turn-of-the-century modernity. This feeling was further influenced and sharpened by the rapid modernization of industry, the explosive growth of the cities, and the wave of immigrants to the United States in the last decade of the 19th century. This direct and yet canned form of attempting to contain everything that is changing, transforming and disappearing is the form taken by the feeling I have described above as instant nostalgia. Here, what matters about that feeling is its compelling production of a need to record, almost randomly, what was still - but barely - available for recording. This craving to preserve explains the attraction of news as entertainment, as 
well as the constantly changing constellations of items presented in the shows of the records.

As a response to a period of change and crisis this direct ("instant") form of nostalgia is colored by the wish to be the immediate witness of history. This form of nostalgia may be seen as optimistic rather than as a desire for a closedoff past. Instant nostalgia is fed by the need to cherish the traces of the past in the present in the light of a repetitive cycle of time. The presence of the past at the moment of its disappearing offers the possibility to emphasize the co-presence, on the level of affect, of both the transient and the durable. I would like to emphasize here the instantaneousness: the direct need to stop a process of disappearance in the short term by repeating precisely this moment of transition. As I recalled above, nostalgia is not only an individual sentiment, but has a collective (cultural) meaning. The personal investment of collective needs makes it useful for this myth-making process of the national past of westward expansion. For the developing role of mass media as collective amusement in this process, the personal investment in instant nostalgia is of crucial importance.

Although it may seem paradoxical at first, I wish to point out that nonfiction films in particular exemplify the complexity of the relationship between modern past and nostalgic present in relation to the filmic stratification of genres. The examples of actualities mentioned above belong to nonfiction formats from the first decade of filmmaking, formats that are based on instant nostalgia. But the reason actualities are relevant for the present chapter is that during this same period other direct registrations of forms of entertainment were also recorded. In the fall of 1894 the Edison Manufacturing Company, the same company that filmed Parade of Buffalo Bill's Wild West Show in 1898, produced a series of films when the show visited New York. This time it was not a registration of the parade in the city as an announcement of the show, but rather, the films were recordings of show elements, acts that were re-staged in front of the camera. Here, the actuality of the show was less important than the content of the show, the stunts and spectacle of the costumes or the heroes of the show.

However, the newspapers declared that the recent visit of the troupe to the city was the motivation for making the films. They gave detailed descriptions of the troupe's visits to the Edison studio in New Jersey. ${ }^{12}$ The actuality of the film was emphasized more insistently than the novelty of the medium, or rather, the actuality of the content of the films established the attraction of the medium as conveyor of a spectacle, such as the Wild West Show.

Kinetoscope films that were recorded include Buffalo Bill, Sioux Ghost Dance, Buffalo Dance, Indian War Council, A Bucking Broncho, and AnNIE OAKLEY. A BUCKING BRONCHO is an open-air recording of Lee Martin's rodeo tricks. In the Edison catalogue the film is described as follows: "A fine ex- 
hibition of horsemanship by Lee Martin, a genuine cowboy. This particular broncho is an unusually wicked one."13 Annie Oakley performs in front of the camera against a black backdrop in the Black Maria, the Edison studio. An assistant (an Edison employee or maybe her husband Frank Butler, who had become her assistant and manager) throws discs in the air that Oakley shoots down efficiently. ${ }^{14}$ On the same stage American Indians that were part of Buffalo Bill's cast performed allegedly traditional dances in costumes for the camera in Sioux Ghost Dance and Buffalo Dance. The dancers look into the camera and return the spectator's gaze, emphasizing the performative nature of their act. $^{15}$ These films are based on a fairly direct form of (re)presentation, although they exemplify the complex layers of the kind of representation that I have analyzed in the parade films. The show elements are recorded for the future film spectator, and at the same time these films are announcements of the show. As Musser has pointed out: "With the kinetoscope [...] performers and amusement entrepreneurs quickly concluded that moving pictures were good publicity and could help their careers" (1991: 50). The commercial goals of both the filmmakers and the showmen were met, an achievement that positions the young medium among the more established forms of entertainment.

Besides this connection between film, theater, and vaudeville and the conventions of (re)presentation that were adapted for the filmic presentation of the acts, in this period other nonfiction genres were discovered as being suitable for imaging the West. The films of Buffalo Bill's Wild West Parade are related to films that feature show elements like the vaudeville and rodeo acts, but also show features of another genre of the parade films. ${ }^{16}$ Short films about travels to the West and landscape films showed the landscape and both the accessibility and the impenetrable wildness of the Western regions. Such travel films include Coaches Going to Cinnabar From Yellowstone Park (1899, Edison); Coaches Arriving at Mammoth Hot Springs (c.1899, Edison); and Tourists Going Round Yellowstone Park (c.1899, Edison). Landscape films include, for example, Canyon of the Rio Grande (1898, Edison); and Panoramic View of Moki-Land (1901, Edison). Films about every-day life of Cowboys and other Westerners - e.g. Driving Cattle to Pasture (1904, Edison); Rounding Up and Branding Cattle (1904, Edison) - were shown next to ethnographic portraits or staged performances of ceremonial dances of American Indians - Indian Day School [Isleta, New Mexico] (1898, Edison); Wash Day in Mexico (1897, Edison); Wand Dance, Pueblo Indians (1898, Edison); Hopi Indians Dance for Theodore Roosevelt at [Walpi, Arizona] (1913) - and elements of ethnographic exhibitions - e.g. Esquimaux VILlage (1901, Edison); Esquimaux GAME OF SNAP-THE-Whip (1901, Edison). This diversity of images of the West would be distributed over the scope of different filmic genres that 
filled the bill of the film programs in these years. This is the -scope element of my metaphor.

These diverse expressions of nonfiction filmmaking are part of what Tom Gunning and André Gaudreault have described as the cinema of attractions and are each elements of a kaleidoscopic vision of the world. Gunning (1986) describes the cinema of attractions as a film form that demands a specific kind of attention from the spectators, demanding from them curiosity and offering visual satisfaction for this curiosity. This form is not grounded in narration, but in presentation and demonstration. In "Before Documentary: Early Nonfiction Films and the 'View' Aesthetic" (1997), Gunning emphasizes the aesthetics of the view as part of the cinema of attractions. He describes the view as the primary form of early nonfiction, as a presentation of something that exists in front of (and independent of) the camera. By describing it as part of the cinema of attractions he, in fact, distinguishes the view from the cinema of attractions by shifting the presentative character of the presentation from the pro-filmic event to the presentation:

With this term [view] [...], I mean to highlight the way early actuality films were structured around presenting something visually, capturing and preserving a look or vantage point. In this respect the 'view' clearly forms part of what I have called the 'cinema of attractions,' the emphasis found in early cinema upon the act of display and the satisfying of visual curiosity. As an actuality, a 'view' makes a greater claim to recording an event of natural or social history, while attractions include artificially arranged scenes enacted precisely to arouse and sate the spectator's curiosity. (14)

This distinction is useful for comparing the actuality/newsflash variant and recorded vaudeville acts that I have used as examples. Both are nonfictional representations but show different relationships to the pro-filmic event. ${ }^{17}$

The kaleidoscopic vision is variegated, primarily visual and presentative rather than narrative. It assembles an exotic, tourist scope of the world. ${ }^{18}$ The presentations of the West are diverse, not so much in the image of the West they show, but in the relation to truth, reality and history they each entertain. In that sense, they can be seen as different elements of the kaleidoscopic assemblage: the West as past, as exotic region, as location for action and adventure, as a contemporary counterpart to the East. These different shapes and sizes of the West position that region on the crossroads of time and place. The different temporalities of these visions of a (geographic) place are presented in terms of vitality, both by the spectacle of fiction - the creating or re-creating of a past and by nonfictional description of the present.

The exhibition format of the film program consisting of multiple titles, arranged in an order, a flow where films were possibly alternating with live stage acts, music, recitals, lectures, and other events. This format creates a space for 
this broad variety of images while containing it in a presentable format that emphasizes (visual) attraction. The ways in which themes from nonfiction films are echoed in fiction films that play with the different ways of presenting Western life in either a dramatic or a comic format, emphasize the context-effect of the program. This arrangement allows for switches between the different modes of fiction and nonfiction, between newsflashes of current events and reconstructions of historical happenings. The different types of films about the West can be shown one after another without contradicting each other. The multiple meanings reinforce each other in this arrangement. ${ }^{19}$

The multiplicity of elements of this kaleidoscopic whole was absorbed when films became longer, and the film programs would contain fewer titles. The development of longer films can be interpreted as a process of absorbing different, primarily visual and presentational elements into one containing narrative. This is a process of bricolage, of molding different ingredients into a new form. It played an important part in the development of new genres that are distinguished differently from the earlier genres. The term "bricolage" as borrowed from Claude Lévi-Strauss, also a conceptual metaphor, is useful for pointing out the multifarious influences on both the technique and the mode of representation of early cinema. ${ }^{20}$ In this respect, Hansen points out the openness of genres in this period. She mentions how individual films refer to other films through this process of bricolage: "In preserving a stylistic heterogeneity of their component parts they invoke a larger field of bricolage of which the individual film is only a segment, as is the program in which it is shown." ${ }^{21}$

I use the concept of bricolage here to designate the cinematic embodiment of the kaleidoscopic view and the way that this view is designed to become part of a process of development of film language and the subsequent differentiation of genres. In the case of early film, the process of bricolage is visible in the configuration of the film programs that are based on variety. Hence the label, variété. In the development of narrative films in the period between 1904 and 1907 and of genres, these circulating visual elements are slowly absorbed into a new mold.

An anecdote can illustrate this transition from short attractions to longer narratives. I am referring to the confusing reception of Porter's film LIFE OF A CowвоY (1907, Edison). From the film description in Variety it becomes clear that the critic interprets the film as a series of separate scenes that form a kaleidoscopic whole. He writes: "A long and interesting moving picture is 'Life of a cowboy' shown at Pastor's. It covers a wide range of subjects and the locale seems to be really the Western Plains" (Variety January 19, 1907: 9). The critic then describes the scope of the film in an inventory of scenes that emphasizes this diversity. From the description published by the Edison Company in Film Index it becomes apparent that the company meant to present a coherent narrative, told in 
a succession of interrelated scenes that are the episodes of one long adventure. ${ }^{22}$ The interpretation of the critic places the film in the (earlier) tradition of shorts with an emphasis on (re-staged) nonfiction, rather than in the (newer) mode of representation based on narrative fiction. Only a short period of time had elapsed, but the difference is radical.

Bricolage and the variegated context of the film program shape the kaleidoscopic constellation of the image, and thereby the cultural meaning, of the West following, and produced by, the development of cinema. This process is essential for understanding the way the genre of the Western develops. It is also crucial to grasp the kaleidoscopic nature of the visual culture of the time in order to see how this first phase of filmic (re)presentation is still open and multifarious, a feature that will later become contained in the institutional mode of representation (Burch 1991) of the classical genre. As Miriam Hansen asserts:

While the classical genre film relies upon the viewer's intertextual awareness primarily within the specialized category of one and the same genre and according to preexisting standards of homogeneity, the films in question mobilize intertextual awareness across genre boundaries, playing with contiguities among formally distinct types of film. (1991a: 47-48)

For the methodology of the history of early cinema this entails the fundamental insufficiency of formal, text-immanent analysis. The kaleidoscope is a virtual container that holds filmic segments, brought together in the seemingly infinite number of possible constellations of programming. Bricolage then absorbs this into a development of longer narrative Westerns. To reiterate, with Kracauer, the most important feature of this new visual culture:

[...] deprived of substance, empty as a tin can, a life which instead of internal connections knows nothing but isolated events forming ever new series of images in the manner of a kaleidoscope.

It is no coincidence that out of that tin can sprung horses, action men, and a landscape many Eastern city dwellers only knew - but were getting to know better and better - from the movies.

\section{Notes}

1. Henri Bergson, "Of the Selection of Images For Conscious Presentation. What Our Body Means and Does." Chapter 1 in Matter and Memory (1911: 1-85; 12).

2. The name of Buffalo Bill's show was Buffalo Bill's Wild West and Congress of Rough Riders. After Theodore Roosevelt had called his troops the "Rough Riders" during the Spanish-American war in 1898 after the figures from the Wild West Show, Buf- 
falo Bill honored Roosevelt and his men by including a reconstruction of the charge on San Juan Hill in his show. A description of the cast of Buffalo Bill's shows is given by Richard Slotkin, Gunfighter Nation (1992), and by Don Russell in The Lives and Legends of Buffalo Bill (1960).

3. Early actualities are explored in KINtop. Jahrbuch zur Erforschung des frühen Films, 6 (1997). The editors give a description of this first genre of short nonfiction: "Krönungen, Paraden, Staatsbesuche, Umzüge, Einweihungsfeiern, Denkmalsenthüllungen und dergleichen mehr: Gerade in den Anfangsjahren der Kinematographie machen Ereignisse des öffentlichen Lebens einen bedeutenden Teil der Filmproduktion aus. Vor Ort gedreht oder nachgestellt -Aktualitätenfilme gestatten dem Zuschauer, sich 'ein Bild zu machen' von Ereignissen, von denen er schriftlich aus der Presse oder einfach nur mündlich vom Hörensagen erfahren hat." (7) The diversity of these films becomes apparent when looking at the different meanings of the names and labels of "actuality" in different languages. In France the term actualité was used for films about current events that were of interest to a large audience. The English name topical film is closer to this French name than actuality, which means more generally "reality." In film historiography, actuality is used to distinguish the early nonfiction shorts from the documentary, the nonfiction genre name that can only be applied after John Grierson launched and defined it in the 1920s. For a description of the different names and labels, see the contributions of William Uricchio and Sabine Lenk in KINtop 6.

4. "Newspaper vs. Newspicture." Motion Picture Story Magazine III, 2 (March 1912): 9093.

5. See Uricchio (1994) and (1997b).

6. About Muybridge, see Rebecca Solnit (2003); about Marey's chronophotography, see Mary Ann Doane (1996).

7. Michael Denning (1983) wrote a very illuminating book about the rise of the popular press in the 19th century.

8. For a discussion of conceptual metaphor, see "Cognitive Metaphors and the Dynamic of Interdisciplinary Study" in Teri Reynolds (2000: 85-113).

9. Kracauer, The Street February 3, 1924. Cited in Hansen (1991b: 49).

10. It is not clear whether Edison eventually made it to the World's Fair with his Kinetoscope. According to some sources he did exhibit his invention, according to others he did not. For example, the article "Rise of the Moving Pictures" in The New York Times (January 3, 1909) mentions as the "beginnings" of moving picture history the display of Edison's Kinetoscope in Chicago. Charles Musser gives more insight into the controversy about Edison's presence at the Fair. See his Emergence of Cinema (1990: 73-75, and 504n36).

11. Interestingly, Buffalo Bill emphasized his claims of realism more after 1893 than before, as Slotkin explains in Gunfighter Nation (1992: 81-82). Although Slotkin does not point out a connection to the advent of film around that time, the coincidence is striking.

12. "The Wild West", The New York Tribune (July 1, 1894): 14, and three weeks later in "Day With the Wild West" (July 22, 1894): 15. See Musser (1991: 500).

13. Edison Films Catalog 105 (July 1901): 49. Quoted in the Library of Congress catalogue, Inventing Entertainment. For references to the Library of Congress catalogues, see the Bibliography. 
14. See Joseph G. Rosa and Robin May (1989: 81).

15. About performance and performative aspects of bodily display see, for example, Eva Warth, "Moving Bodies" (1999) and Jennifer Barker, "Bodily Irruptions" (1995).

16. These films have a strong military and nationalistic slant. The number of parade films with Western figures is significant. This context of military parades and processions of other nationalistic groups underscore similar tendencies in the parade of Buffalo Bill's show. Parade films with Western types include President Roosevelt and the Rough Riders (1898, AM\&B); Buffalo Police on Parade (1897, Edison); Native Daughters (1898, Edison); Procession of Mounted Indians and Cowboys (1898, Edison); Convention of The Red Men (c.1904, Edison); and Parade of Chinese (1898, Edison).

17. About the cinema of attractions in relation to narrative and spectacle, see $\mathbf{N}$ and $\mathbf{S}$.

18. For a discussion of the meaning of tourism for the representation of landscape in travelogues in the 1910s, see Peterson (1997). Uricchio (1998b) connects the documentary meaning of landscape and the position of the mimetic in early fictional Westerns with the picturesque aesthetics.

19. Here are some examples of early fictional shorts: Terrible Teddy, the Grizzly King (1901, Edison); Cripple Creek Bar-Room Scene (1899, Edison); Poker at Dawson City (1899, Edison); A Western Stagecoach Hold Up (1904, Edison); and A Frontier Flirtation (1903, AM\&B).

20. For an application of Lévi-Strauss's term bricolage to early cinema, see Abel (1998a), Hansen (1991a), and Williams (1992).

21. Hansen (1991a: 47-48).

22. The whole text is necessary in order to be able to discern the coherence of the scenes, but it is too long to reproduce here. Both documents are reprinted in Musser (1991: 360-361). 


\section{Landscapes}

Out in the broad West, where nature has provided thousands and thousands of acres of natural scenery, with the ever blowing breeze to inspire life to the scene, is the place to produce the realistic pictures, under God's broad canopy, where there are no flaws in the background, foreground or

balance. - Photoplay Magazine, $1913^{1}$

The kaleidoscopic structure of both programs and films of the medium's early deployment, is especially visible in the element that, like a kaleidoscopic vision, shows itself as image, not narrative. I mean the element that most centrally characterizes the Western, so much so that the genre derives its name from it: the landscape. The Western land we see: is that really a land, or a manipulated image we are presented with on the basis of the as if structure that characterizes fiction? If the latter is the case, as inescapably we must assume, then the questions arise: what manipulations underlie this fiction? What purposes do they serve or what effects do they produce? What do images do to make us forget their fictionality? This specific rhetoric of landscape is the subject of this chapter.

One major goal towards which this rhetoric works is the production of a sense of authenticity. This is the topic of discussion in the first half of this chapter, where I offer a continuation of some of the issues of $\mathbf{F}$. After that, the tables will be turned, from effect to devices, deployed to produce this authenticity effect. In the second half, then, a few rhetorical devices will be presented. This presentation is by no means comprehensive. Instead, the devices discussed give an idea of the intricate issues - of realism, but also of narrative, the construction of space, and indeed of "the West" itself - that combine in the visual production of landscape.

We have seen that the early actualities started within a tradition of diversity in the representation of the West. A plurality of very varied images became the standard, and since authenticity was a major attraction of the new medium, this plurality was also a requirement for authenticity. I have argued that variety was very much part of the program as a whole as well as within each of the films: there is no single historical object, no single film. It follows, I contend, that you can only be an adequate historian of this period if your picture of the segment of the past that is your object is presented as kaleidoscopic. This thesis will now be brought to bear on that fundamental feature implied in the term "Western": the 
(a-filmic) landscape that allegedly constitutes the West as a geographical unit. There, at first sight, my thesis appears to clash with the referential unity of the region used as (pro-filmic) location - of which the Western as a "genre" allegedly presents a representative, plausible image. No matter how diverse the plots and characters of the innumerable stories depicted in the films, the one feature, or background, that they all have in common is a (diegetic) setting in "the West." If we can speak of "the Western" at all, then this indication rests on the construction of space, which is articulated as landscape and opposed to cityscape.

Hence, examining the landscape - of which I just posited a unity - is asking for trouble, so that exploring this backdrop first against the grain of the kaleidoscopic aesthetic I outlined becomes a good case of an attempt at falsification. Not so long ago, this was a methodological ideal; here, while still being that, it is primarily an attempt to flesh out the insights we might gain from the awareness that the culture of the early Western was fundamentally kaleidoscopic. ${ }^{2}$

True, the landscape counters the fragmented appearance by suggesting a common backdrop for its elements. Thus, this setting becomes the key to understanding the magic of representation itself. Our starting point, then, is the notion that the kaleidoscope of this Western representation is bound together by some repetitive patterns that share a common ground: the landscape of the West. Whether as background for the lives of the inhabitants of these regions, or as object of the gaze in travelogues that show panoramic views of the plains, the hills, and the valleys, or whether as stand-in locations of the East that are identified by characteristic events such as rodeo tricks, round-ups, chases of cowboys or Indians, and the like, this re/presented area is what holds the kaleidoscope together.

This is but one side of the story, however. Inevitably, this unified notion of landscape falls apart in its turn. To understand the rhetoric of landscape, we must recall that the subject matter of the Western, even when most broadly defined, is at least double-edged. On the one hand, different versions of the West are shown, ranging from the West in the geographical sense to the West as a way of life. But even the geographical definition lacks stability, for, as I have outlined in the chapter on "Easterns," some films about life on the frontier were set in Eastern or Northern regions of the US. Another kind of frontier is in play here, as these regions represented the frontiers of other phases in history. Due to the inherent movement of conquest, the systematic principle appears to be that when a story is set in an earlier time, the frontier is located much more to the East. And, still within the geographical sense, the frontier, in turn, is a double notion. It refers sometimes to the wilderness, at other times to the city limits, the frontier of urban or civilized life. 
This wavering meaning of "frontier" already implicates the landscape. Rather than a backdrop or referential place, the landscape becomes an indicator of the invisible line that separates "wild" from "civilized." Moreover, it refers to, or points to, the fact that this line is moveable, that the conquest at its heart is, precisely, the progression of a borderland, that eventually will dissolve when all is conquered. Whatever we get to see in the image is primarily a signifier for a signified that escapes this signifier. The landscape finds its meaning, in other words, through opposition to what it is not, rather than by and for itself. Although I propose to discuss the central issues of the landscape through the pairs of oppositions that signify it - nonfiction/fiction, landscape and its other, cityscape - I will not repeat the by now all too familiar deconstructions of binary oppositions, but instead explore the productiveness of these oppositions, both individually and in relation to each other. ${ }^{3}$ As each category acquires meaning through its opposition to the other, each representation is necessarily rhetorical, whereby the double sets of oppositions work in conjunction. As a result, the engineering of space is achieved by an intriguing rhetoric of fiction and nonfiction.

This principle, which turns depiction into signification, facilitates the understanding of a fact that might otherwise be interpreted retrospectively and anachronistically as a failure of representation. I am alluding to the fact that a lot of "Cowboys and Indians" pictures were not clearly set in the West at all. To the anachronistic eye at least, some of the films were quite obviously shot in Europe. As a result, clearly, shot almost comes to signify set. This semiotic of landscape goes so far that some films are even not recognizable as Westerns, but only had a title or a description in the press that referred to Western topics, which put them in the category without further ado. This is how far away from the Western landscape the signification of "landscape" can take us.

Since even the most obvious and concrete feature of a genre - its setting presents such ambiguities, I propose to examine such expatriate Westerns under the provisional suspension of the issue of genre. And since we are so accustomed to speaking of these films in terms of what really is a geographical notion, I propose to look at what underlies that label. In other words, in view of the uncertainties just mentioned regarding what West in Western means, I will now examine one particular feature that recurs through most of the films we encounter in film archives under the rubric "Western." Their authenticity effect depends on their setting outdoors, not on geography.

One implication of this feature is to make them distinctive within their context of showing, of which we have already seen the vast implications for a historiography of early cinema. For example, films about the West either stand out compared to films that mostly show interiors, which is to say, probably the larger part of fiction films, or they show a strong resemblance to other films that 
have landscape, not narrative, as their primary visual feature, such as travelogues. In terms of the rhetoric of programming, then, the setting puts the films as a category at a distance from other fiction films and close to nonfiction genres.

Context is relevant in other aspects of landscape as well. On a more discursive level, and just like the travelogue, the films are influenced by, and take part in, an existing visual culture in which the imagery of "elsewhere," "elsewhen," and the cultural "other," constitute the major appeal, a specific aesthetic. In nonfiction films, this imagery is presented in, and colored by, an aesthetic of the picturesque. This will be discussed further in the next cluster on Strategies. $\mathbf{P}$ Jennifer Peterson links the turn-of-the-century term picturesque to the landscape-oriented travelogue, as distinct from people-oriented travelogues (1997: 86). However, this aesthetic is also vital in films that are routinely categorized as fiction films. In Westerns, for example, both landscape and ethnography are present and hard to disentangle: the films are about people in their environment, switching back and forth between an emphasis on landscape, on motion and action within the landscape, and ethnographic types, whether these are cowboys, Indians, Mexicans, trappers, or pioneer families.

As I will argue in the next cluster, cinema reshapes the sublime into the picturesque, making landscape a modern commodity, turning landscape into a more transient version of the sublime. ${ }^{4}$ In addition to determining a mode of looking, the aesthetic of the picturesque also influences the object of the look, which is the subject of the present chapter, for an important aspect of this visual culture of the picturesque is an intertwinement of nature and culture in the spectacle. Most importantly for an understanding of the films in their moment of cultural history, the visual representation of landscape constitutes a shared environment. As a consequence, landscape does not stand on its own, as a geographical setting only, but rather functions as a shifter, including in the precise linguistic sense of that term, between ways of life. It stands as the point of access to the other of modern and diverse culture. In this sense it has a specific role in the representation of modernity. To put this more strongly, the representation of nature partakes of a specific representation of its negative, culture, and hence, it is an oppositional representation of the urban. The terms of the binary couple nature/culture, or wild/urban, need each other. From the vantage point of the second term of the opposition - which is that of the viewer - the first term opens up to a spatial otherness, an elsewhere. The elsewhere, just like "elsewhen" and the other, only has meaning in an oppositional structure which, as a shifter, organizes itself around the "I" /eye of the urban viewer that is its focal point. ${ }^{5}$

As will become clear in the next chapter, the particular way in which these oppositions are played out in the films is central to the discourse of modernity. They work as a discursive practice that establishes specific perspectives in its 
attempt to make sense of a changing world by mapping it. This cinematic effort to map the world hinges on geographical metaphors, on the articulation of temporal and spatial coordinates that create perspective, meaning, and a position for the viewer. What matters, then, is not what the landscape looks like in itself, but how it relates to the modern city and the modern way of life, as well as to the position of the viewing "I." This is why the outdoor setting, with its embedded narrative capacity is in and of itself a feature that matters. In terms of our oppositions, this re-articulation of the world as an image both annihilates and creates the notions of fiction and nonfiction (as filmic genres), of cityscape and landscape (as mutually constructed object), and of the known and the unknown (as cognitively relevant acquisitions). While these oppositions must be suspended in terms of their ontological aspects, they acquire importance in terms of their discursive function. In my approach to these categories as rhetorical strategies, the landscape acquires meaning in a different sense than is often assumed, since I approach the notion of evidence not in terms of epistemology but discourse, e.g. not as image of the pro-filmic, but of the filmic itself. Furthermore, the meaning of setting is specifically produced by the relation to the narrative it hosts.

The concatenation of an aesthetics of the picturesque, as a viewing posture, with this oppositional structure positing the desirability of an elsewhere, can be observed in the contemporary press. For example, the article, "A Chat with Mr. David Horsley," explicitly mentions how the film White Cloud's SEcret (1912, Nestor)

[...] holds the interest of the onlooker not only in the working out of the plot but also in the splendid choice of scenes, the novelty of which thrills the Easterner, and all those unaccustomed to the Western desert scenery. ${ }^{6}$

This review demonstrates how, in the trade press, the scenery is emphasized as much as the "thrilling action" of the plot. The "splendor" of the Western desert scenery - the spectacle - "thrills" the viewer, not only because of its inherent qualities but because it is elsewhere to the Easterner, who is urban, by implication. The use of the noun "novelty" is almost unwittingly ironic, if we consider the flavor of pastness of these films that cater to instant nostalgia in an urban culture shocked, precisely, by its own novelty.

This concatenation of aesthetic issues in the quotation from 1912, is overlayered with another conflation concerning the landscape's satisfying authenticity, that between setting and action. Although a different emphasis can be put on, respectively, landscape and narrative, it is also hard to separate them. Of course, one can make a distinction between films that have landscape as primary subject, such as travelogues, and films that have landscape as background for action. Although, as we have seen, the programming might put Westerns 
closer to travelogues than to other kinds of action films. Charles Musser (1984), for example, traced a lineage from a preoccupation with the attraction of the display of landscape in travel films to fictional films, based on narrative integration. Yet, substitution is not integration, and therefore, I propose to examine how this integration works. For it is on the level of this integration that we can speak of manipulation of the landscape to serve a purpose beyond mere depiction. With the programming context and the visual culture in mind, it is useful to look at the function of this outdoor setting for the construction of the narrative, that is to say, the landscape's discursive status within the films themselves.

The use of landscape can be marked by the exploitation of the possibilities of shooting films outdoors and the subsequent emphasis on the specific relationship between landscape and narrative. Let me give some examples of the specific characteristics of such relationships. In the Bronco Billy episode BRONCo BILly's CHRISTMAs Dinner (1911, Essanay), an extremely short but rather spectacular display of the possibilities offered by outdoor shooting can be seen when Billy, in order to rescue the damsel in distress, attempts to calm down the horses of a runaway stagecoach. The camera is mounted on top of the stagecoach. The landscape in itself is not at all spectacular, but the filming is, and explicitly so. It spices an otherwise rather dull and sentimental Christmas story. A review of this film was published in Motography. There, a concise description of the plot of the film was given as well as an elaborate account of the production and the adventures that happened on the set during the shooting of the film, including a "real" accident, as if to underscore the realism of the fiction:

There is a thrilling episode connected with the making of this film, which, however, will not be seen by those who view the picture. It was a narrow escape for Miss Edna Fisher, the girl in the stagecoach. During the supposed runaway, the horses became unmanageable and a real "sure-enough" runaway resulted. A thrilling ride followed which resulted in the overthrowing of the coach. The fair driver was thrown about twenty feet. Seemingly unhurt she sprang to her feet and asked excitedly: 'Did the camera get it? Won't it be great?'

But the camera did not get it.

Anderson on horseback dashed up and inquired if she had sustained any injuries. The girl, taking a step forward, winced. Examination of her foot revealed a broken ankle. Anderson called off the picture for the day, but Miss Fisher would not hear of it and insisted on working in the three remaining scenes in order that the picture could be released before Christmas. She then mounted the coach which had been set upright again and drove the horses in the following scenes of the runaway, which will be seen in the picture. After the film was completed, Miss Fisher was forced to go to the hospital to recover from her injuries. ${ }^{7}$ 


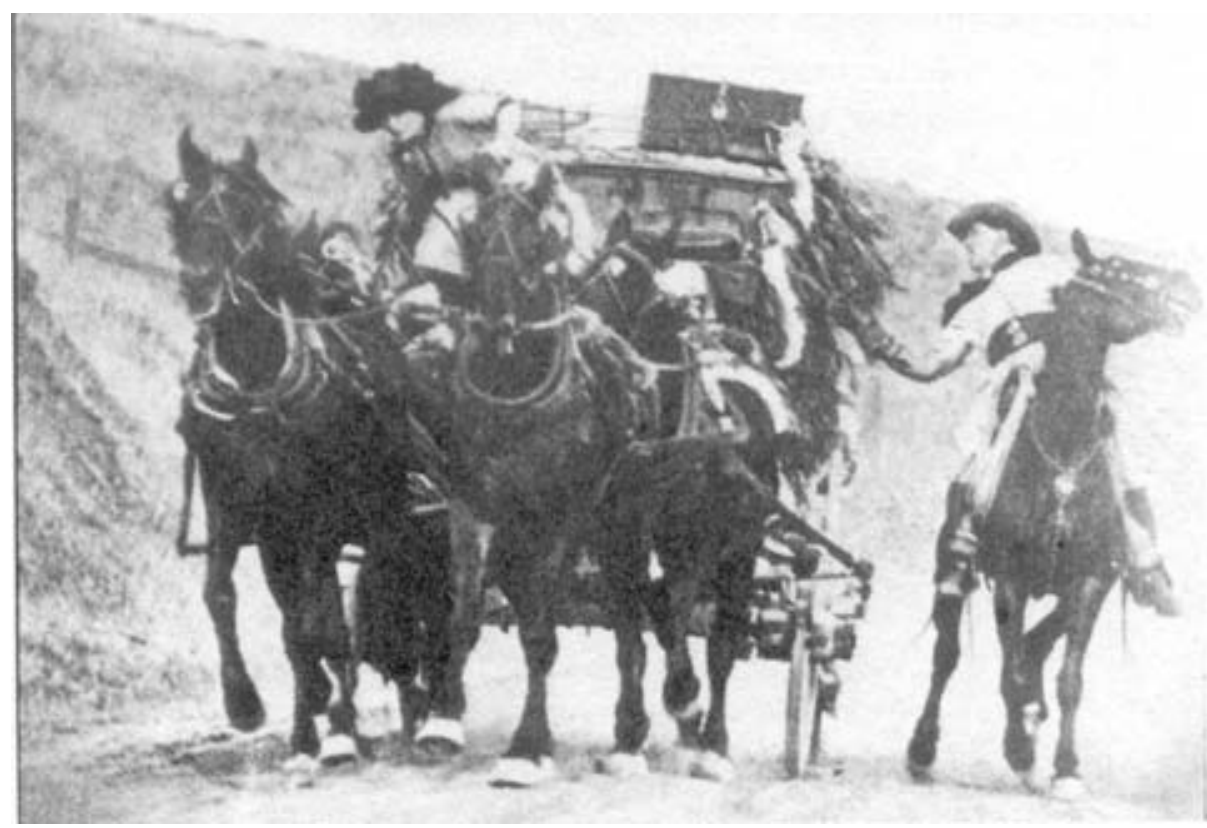

L The shooting of Broncho BiLly's Christmas DinNer (1911, Essanay)

This is a completely different situation from that of CoEUR ARDENT (1912, Gaumont), a film set in the American West but shot on location in the South of France. Here, the beauty of the landscape is explicitly foregrounded for its own sake. Unlike in BRONCO BILLY, the long shots emphasize the beauty first, almost exploiting the action in order to sustain these shots rather than the other way around. The use of long shots and vertical movement through the frame from the horizon to the camera, emphasizing the depth of the image, creates an impression of scenic grandeur, the setting reminiscent of the paintings of, for example, Frederic Remington. But this technique of shooting still offers the possibility of showing a lot of action against this background. ${ }^{8}$

Action, however, is itself a double-edged notion. The fact that filming outdoors is bound to specific conditions and allows for specific stunts involves the risk that the setting may come to dominate and even overrule the narrative action. A predominance of the one or the other is likely to occur precisely because visuality and narrativity are bound up together. The tense but inevitable merging of landscape and narrative can even be "literalized" when a film represents landscape as an obstacle rather than background, creating a suspense-producing tension in the narrative. The chase on foot in the partly-unidentified 1910 Pathé film [INDIAAN GRIJPT KIDNAPPER] Indian Seizes Kidnapper is an example 
of how the struggle through the landscape gives form to the chase as an extremely physical experience of nature.

The intimate intertwinement of setting and narrative was present in other media as well, but in cinema it achieved, perhaps, its most potent form. An interesting case where film and literature met in this intertwinement can be found in the 1915 novel Jean of the Lazy A, already quoted in $\mathbf{F}$. In this novel, the use of authentic landscapes for film locations necessitated authentic plots: contemporary adventures, events set in the actual West. These adventures were to be more plausible than the predictable plots of the standard Western. In this case, authenticity of location reinforces the authenticity of character and plot.

This appeal to authenticity as a kind of ripple-effect brings me to a fourth aspect of the outdoors. Clearly, authentic natural scenery had an appeal of its own, not for its beauty nor for the action it allows, but because of its authenticity per se. To recall the review of The RustLeR (1910, Selig) quoted earlier $\mathbf{C}$ :

The pictures showing the horse round-up are magnificent in their sweep and largeness of motion. How much finer is this than a narrow room with painted settings and Jack making love to Gladys on the sofa! It is this element of the big out-of-doors with its sweep and freedom, that makes Western subjects so attractive to the city shut-ins. Melodrama has no thrill to compare with the thrill of big old nature. ${ }^{9}$

Again, the feature of the spectacle is perceived as a trigger of a specific mode of looking - with a thrill - hence, as an aesthetic.

The need for plausibility, a requirement for realism, entails a maximal conflation of location and setting. That conflation generates the specific narratives apt to occur there:

The film makers went West to find a stamping ground for melodrama. And, they were attracted thither for two reasons: first, because certain phases of life in the West, where passions had been strong and the will unchecked by law, gave a plausible basis for melodrama; and second, because the West was not the East. The strangeness and unfamiliarity of the life out there, as seen from the East, cast a glamour of plausibility around lurid, impossible themes, giving room at least for the benefit of the doubt. ${ }^{10}$

But authenticity cuts both ways. On the one hand, the authentic landscape literally gives space to the characters and makes the representation of the events possible as well as plausible. For example, in CoEur ARDENT the fact that the film is shot in France matters less than the fact that its landscape is really wild, spectacular, and beautiful. When the young Indian brave flees his tribesmen shooting at him and almost drowns in a river, the authenticity of the scenery makes the events plausible, hence, more dramatic, thrilling. On the other hand, in some films the action seems to authenticate a less-than-plausible landscape. A clearly very un-wild country road becomes sufficiently "Western" when a 
horseman chases a stagecoach down it. No natural Western landscape is needed; the horse and rider do the trick. In both cases the function of the landscape is tied to Barthes' reality effect. ${ }^{11}$

The stunts that shooting outdoors allows and necessitates are described in the trade press as entertainment. They are seen as almost as suspenseful as the fictive adventures in the films and as adding to the quality of the films. Accounts of the filmmaking process often dwell on the dangers of working on location and of performing the many physical stunts required in outdoor films. This is comparable to today's television documentaries of the genre of "The Making of...." For example, in 1911 a piece called "Realistic Filming" describes a thrilling mishap on the set of The OutLaws (1911, Selig):

In producing a film at the mouth of Grape Creek on the Arkansas river showing the pursuit of a couple of outlaws, or cattle "rustlers," at least three men narrowly escaped drowning, to say nothing of several other minor incidents that came near resulting seriously.

Then the drowning incident is described as vividly as if it were the description of a film plot, or dime novel written on the basis of it. It is worth quoting in full for the way its documentary, journalistic telling generates a suspense that emulates fiction:

The two outlaws, who were represented by Tom Mix and Charlie Farrar, rode their horses at break-neck speed down the side of the mountains on the south side of the river, some four or five hundred yards above the mouth of Grape Creek, and plunged into its current from a rock fully ten feet above the bank, creating a mighty splash. A few minutes later the sheriff and a posse followed and repeated the same performance; a regular fusillade of shots being fired by the pursued and the pursuers to give realism to the scene.

There is an unusually high stage of water in the river at present, and also in Grape Creek, and to that fact was due the danger to both horses and riders. The great volume of water pouring out of Grape Creek forces its way at right angles almost across the river and imperils any living thing that gets into it, except waterfowl. A sandbar has been created by its current for perhaps a quarter of the distance across the river on its Eastern border and it was to that haven of refuge that Mix and Farrar were swimming their horses when the latter nearly lost his life. Farrar in some manner got too far out from the bank and was swept around the end of the bar by the rushing waters, and horse and rider were repeatedly submerged in a swirling current that nothing could withstand.

Mix, and those who a few moments before had pursued him as an outlaw, hurried to Farrar's assistance and succeeded in saving him by the skillful use of their lariats; one of them throwing a rope over his shoulders as he appeared for a moment above the water. He was hauled out upon the sand more dead than alive and the efforts of his 
associates devoted to his resuscitation. He was soon all right and jocularly asked Mr. Thayer if he wanted the performance repeated. ${ }^{12}$

The adventures of scouting for suitable filming locations resembled the dangers of working on location. For example, in "The Famous 'Flying A' Cowboy Films - Popular Western Subjects," a trip of the manager of the American Film Company to El Cañon Valley is described as a hazardous adventure. While inspecting the Cañon as a possible location for a Western, the manager's horse almost made a plunge towards his death. The filmmaker barely saved his skin: "Grasping the mare's bridle, he hung on for dear life" (Moving Picture News IV, 22, June 3, 1911: 11).

These accounts of the filmmaking process serve to emphasize the authenticity and realism in the resulting films. For they, too, have their systemic oppositional other already culturally implemented. They stand in sharp contrast to the criticism of using "fake" locations and the way the cameraman can "lie" with the camera:

It requires eternal vigilance to know just where to go to get the proper setting for the thousand and one scenes that are pictured in one of these stories. Here is where much of the faking in the pictures comes in. [...]

As the spectators in the vaudeville house sit and gasp at some perilous deed pictured amid the rugged scenes of the West he [sic] never for a moment suspects that the view of that rugged mountain side was obtained somewhere in Prospect Park, or in the outskirts of Brooklyntown. ${ }^{13}$

The noun "vigilance" and the hyperbolic qualifier "eternal" give the issue a moral slant. This text equates faking with lying. This more radical opposition is also relevant, the one not between real West and nearer outdoor settings, but between the outdoors and its faking. It becomes clear just how important for authenticity the mere use of actual outdoor locations that result in a conflation of pro-filmic location and diegetic setting, is taken to be when we see it in contrast to the use of painted backdrops.

It is remarkable that the use of painted backdrops was common practice even in films that were largely shot outdoors. The sheer frequency with which this combination occurred suggests that this practice was accepted by the contemporary audience. But along with acceptance, there was also some debate in the press. This concern for authenticity shows up in reviews of particular films as well. In a review of Girls of THE RANGE (1910, Selig), the critic is sensitive to this phenomenon:

The natural scenery (much resembling the vistas of California) is as beautiful as the painted article is unsightly. Selig has just two results in the scenic line: natural and delightful and "phoney" to the rankest degree. With regret it must be recorded that of 
late he has taken to indoor monstrosities and painted landscapes, much to the undoing of his previous good reputation for photographing nature's glorious works. ${ }^{14}$

Again, a moralistic tone resonates in words like "monstrosity" and the quasireligious celebration of nature. As this quotation demonstrates, the passionate defense of "nature's glorious works," in other words, of authentic landscape, is closely bound up with issues of signification, which is why I consider landscape as a rhetorical device rather than an object depicted.

In our films signification is predicated upon detail as much as on spectacle. The shooting of outdoor locations used for outdoor filming gives authenticity, a greater sense of reality, to fiction. Two remarks are called for at this point. First, this sense of reality is a reality effect, the eclipse of the denotation of specific reference by the connotation "reality" which takes its place. More specifically, in combination with the aesthetic issue discussed earlier, the use of outdoor locations in early Westerns plays to the attraction of outdoor locations as special effect, enhancing the authenticity, but based on a realism that fits into ideas of the picturesque. Second, and to strengthen the first point while adding specification, it is striking how this exotic, nostalgic notion fits comfortably with the "backyard" quality of some of the settings. This paradox allows me to connect authenticity, the effect of the real, to modes of signification.

The conflation between location and setting, a synthesis due to a mimetic referentiality, makes clear how landscape works as a sign structure. The perfect synthesis of pro-filmic location and diegetic setting is due to two factors: contemporaneity and authenticity of setting. In addition to the authentication of setting by the reality effects produced by the location, the temporal borders between the "present" of the shooting and the "past" of the representation are crossed over. Present and past are conflated. As a result, authenticity, of both time and place, needs no confirmation. ${ }^{15}$ We can notice this, precisely, in the simultaneous occurrence of the promotion of authentic locations and of the use of backyard locations. The latter needs no more authenticity than a factual referentiality. This brings me back to the details and their rhetorical position as synecdoche.

The referential truthfulness of detail (called "facts") results from the conflation of setting and location. A review of The Squawman's Daughter (1908, Selig) argues as follows:

The increasing population of the West is causing a gradual extrication of daring adventure and makes a reproduction of actual occurrences all the more valuable. Ostensibly, it requires a production based more on facts than imagination.

"Facts" point to authenticity by a rhetoric of synecdoche, producing authenticity rather than being produced by it. This is a characteristically synecdochic mode of signification. Synecdoche is the figure of rhetoric where an element, a 
small part, stands for the whole simply by virtue of its being a part of that whole. The facts that are here opposed to imagination - generating the opposition between fiction and nonfiction - function as synecdoche for the entire "real world" they signify in their wake. This logic is indispensable for the opposition between fiction and nonfiction to make any sense. In turn, the authenticity effect thus produced by "facts" generates aesthetic value. For, about the film under review the critic says:

Not a story of Western fiction enacted in the same back yard in the East, but a worthy dramatization of a thrilling romance, which actually occurred and which was re-enacted on the same ground. ${ }^{16}$

Clearly, in this argument the authenticity of the location guarantees an authenticity of setting, in turn establishing a realism to the story ("dramatization") that makes the film more spectacular.

This aesthetic quality produced by the authenticity effect of synecdochic detail ("facts") is not only compatible with, but even a requirement for, the appreciation of a representation that would otherwise be perceived as anachronistic. The contemporaneity in relation to landscape that I mentioned before does not strike a false note but, to the contrary, infuses it with affect, a quality that is sometimes even explicitly foregrounded.

The location that is used for these Western scenes is, in fact, a flat setting that makes this possible. Something that, in a different context, would make the setting inauthentic - its "backyard" quality - makes it possible to infuse the setting with an emotional charge, a weight. Because it refers to the West through synecdoche, the action in front of it makes the flat background a signifier of the landscape, signifying opposition to the modern world, signifying a past that will not exist much longer physically but remains present as an after-effect.

Authenticity is not the only effect of landscape. Landscape is a sign contributing to signification in the larger, complex text. In the remainder of this chapter the focus will be less on effect than on strategy, and less on the image seen than on the image cast out. In other words, in order to make these general ideas more tangible, I will now discuss a few rhetorical devices through type scenes that each entertain a specific, rhetorical relationship to the landscape in its systemic relation of opposition to cityscape. ${ }^{17}$ Rhetoric develops a perspective and positions the speaker and viewer in the coordinates of time and space, defines what is then and now, what is here and there; it defines presence as well as the present. First, the most obvious "take" on landscape is represented by that curiously nonfictional, yet quite fictional "scene" - if we can call it that - of the phantom ride. 
Phantom rides are emblematic of early cinema's nonfiction that shows landscape and its (tourist) "consumption." The first film I invoke in this respect shows the passing landscape along the tracks: Going Through THE TunNeL (1898, Edison). In this film, we see simply a view as the camera-bearing train emerges from a tunnel: out of the blackness of the image "we" emerge, and the camera shows us the scenery that the train traverses. Edison advertised it as part of the "Southern Pacific Company Series":

The Southern Pacific Company ("Sunset Route") offers special inducements to winter travelers, by reason of its southern route, thereby avoiding the extreme cold of the winter months. Its course lies through a section of the country that presents a variety of beautiful and picturesque natural scenery. It is also the direct route to the popular resorts of Southern California, thereby making it a favorable route for tourists. The following subjects were taken by our artist while traveling over the very extensive lines of the Southern Pacific Railroad Co., to whom we are indebted for many courtesies, and without whose co-operation we should not have been able to bring before the public these animated photographs of interesting and novel scenes. ${ }^{18}$

The phantom ride provides a visual experience of landscape that is achieved by mounting a camera on top of a moving train. This vantage point establishes a field of vision that suggests open access to, and a perfect perspective on, the land that is traversed. The object of the look, the panoramic landscape, positions the I/eye of the look, coded in terms of the modern, by the symbol of travel and tourism by train. People jump off the track when the train approaches, as if to demonstrate for the camera how fast the train moves. But mostly, the landscape is empty of people, of characters, and defamiliarized because of the lack of personified "anchor points" of identification within the image. It is presented as a "pure" visual spectacle from one perspective (in both senses of the word).

An urban counterpart to this train ride along the Sunset Route can be found in a scene from a film from the East, which is both an extension of the phantom ride, and at the same time an opposition: Interior New York SubwaY, 14TH StREET TO 42ND STREET (1905, AM\&B) This film extends the tunnel sequence of the previous film, but it counters the panoramic experience of an "open" landscape. The visual breaks caused by tunnels in phantom rides evoke those hybrid films that integrate narratives into panoramic train rides at the point where the trains enter a tunnel, such as A Kiss IN THE TunNel (1899, G.A. Smith) or WHAT HAPPENED IN THE TuNNEL (1903, Edison). The breaks in the panoramic perception are used to insert a narrative that is generated by this momentary lapse of vision. But rather than invoking a narrative, and hence, sliding into fiction, INTERIOR New YoRK SUbway extends vision where other phantom rides suspend it. As ultimate cityscape it represents a lack of landscape. 
Released together with this film are fictional scenes that are copyrighted as Reuben [and: A Rube] IN the Subway which exhibitors could intercut with this subway footage (Musser 1990: 386). These shots are meant to frame the subway ride by a narrative about a naïve country-type who enters the subway station from the street, gets his money stolen by pickpockets, and is electrocuted by the subway rail. In this transition from fiction to nonfiction and back to fiction again, the images of the city are framed by the non-urban person's experience of this confusing, modern environment. The perspective from the train in the phantom ride footage shifts to a diegetic perspective from within the train: the experience of the narrativized traveler. By positioning him as "other," as an outof-town visitor, a moment of self-reflection is established for the urban film spectator, based on both identification and difference. Through the comic defamiliarization of city experience, the fictional framing enhances the nonfictional effect of this subway ride.

A third type of scene is the fictional beginning, set as a change of trains. In the kind of film using such scenes, it is the arrivals at, and departures from, stations, where characters may appear, where stories can begin. In the city environment everyone is a passer-by, as well as a possible character. We can see this in WHAT Happened on 23Rd StReEt, New York City (1901, Edison). Actuality footage of a New York street shifts to a narrative that almost literally "pops up" when a couple walks towards the camera and is singled out from their environment by the way they move in a straight line towards the spectator. As she walks over a subway-grate, the hot air causes the woman's skirt to billow and rise. In this scene, the nonfictional foreground is transformed into the background of a (staged) narrative, which is generated by selection.

The previous scene was emphatically urban, and my readers may wonder why it is included in a chapter on landscape. As I have suggested above, landscape is not an object, a reality, but a construction made, set up, by rhetorical strategies. In order to argue that this urban setting is rhetorically part of the discourse of landscape, I offer a final example. A RAILwAy TRAgEDY (1904, British Gaumont) opens similarly to What HAPpened on 23Rd STREeT, New York CITY: on the streets, at the arrival and departure of the train at the station, and it ends with the train's arrival at another station. In this film, both trajectories, the nonfictional display of landscape and the fiction of the characters on the train with their urban point of departure, are literally intertwined by the insertion of views of passing landscape into the frames that show the interior of the train. As if they were traveling companions of the characters on screen, spectators can see the same view from the window, and they can also take a peek in the train compartment. ${ }^{19}$

However, as we see, this "entering" of the train is not without hazard. In this film the suspension of vision in the darkness of tunnels has become the suspen- 
sion of the "public vision" by showing the danger of isolated compartments in the trains. This is what generates the story, like the moral danger in the comedy format in What Happened IN THE TunNel. At the beginning of the film a woman enters the station, boards the train, and falls asleep. The man next to her steals her wallet. The landscape enters the scene just when the man has stolen her wallet. When the woman wakes up and discovers her wallet to be missing, she confronts her fellow passenger. The culprit opens the compartment door and throws her off the train. She falls into the grass next to the tracks and is found by two men. They rescue her from being run over by another passing train, by pulling her away from the tracks.

A strong difference between interior and exterior is set up. The exterior is strongly coded as authentic, as realistic (the streets, the station, the landscape), which clashes with the fake theatrical set used as interior. The perspective shifts from inside to outside by the view through the window, and the moment of transition between fiction and nonfiction hinges on spatial difference. This can be underscored and enhanced by programming. The usual framing of the film by different types of travel films, such as the phantom rides, and the generically hybrid mode of nonfictional train panoramas of landscape with inserted fictions, reinforces this rhetoric of space.

Let me conclude by going over some specific rhetorical strategies deployed in these examples. The first one is opposition, the second perspective, the third narration, the fourth synecdoche. Opposition is the most obvious element in this construction of space as landscape and cityscape. The implied "other" (as in all binary oppositions) seems to be present in the construction of the one: the land is shown in its non-urbanness, and vice versa. This opposition can be dramatized in different ways, for example through confrontation, transition, or sequence.

In some cases, confrontation is embodied by the traveler. The figure of the traveler is either shown diegetically, as in A RAILWAY TRAgEDY, or in the inserted narrative of A RUBE IN THE SUBWAY, or in phantom rides where this figure is the structuring code of the visual. This visual code, a travel gaze, establishes a subject and an object in a specific hierarchy. The landscape is there to be "entered" by the spectator; it is open for discovery and wonder. It is thereby constructed as object.

When the city is shown, the (urban) viewer takes up a double identity that plays with both identification and distance. City films are always already selfreflexive as the familiar is shown in a defamiliarized way. The subway film does this in extreme form, but we can see this also in city panoramas that are filmed from trains, boats, or tall buildings. ${ }^{20}$ The inserted comedy about the country rube repositions the viewer. The subway ride enables the viewer to take this 
ride through the tunnels of the city; the narrative version lets the viewer laugh at the naivety of the non-urban traveler. Opposition is therefore a tool for confrontation, which yields either comedy or tragedy.

In some of these films, this can be thematized on the level of the story. In A RAILWAY TRAGEDY it is the state of isolation, the suspension of both categories of cityscape and landscape, that triggers the narrative. The city (as point of departure and arrival) frames the narrative: the non-city is where the woman is thrown into and where and from where she is rescued. The train compartment thus signifies a space of transition, resulting in transgression, which can be seen as a specific way of dealing with opposition.

Spatial difference, as we have seen, generates different emotional registers. In addition to the comic, and the tragic, a nostalgic trajectory can be the underlying tone of the film when the spatial difference is constructed as a temporal distance. As I argue in $\mathbf{T}$, opposition is staged as a sequence, in terms of "then" and "now," when landscape and cityscape are coded in the terms of the modern and the pre-modern. ${ }^{21}$

The second rhetorical strategy that is of key importance is perspective. Perspective establishes space, but it also identifies the position of the look into this space. It thus defines the object as well as the subject of vision. It points in both directions, and ultimately it plays with self-reflection when the perspective shifts from inside to outside (or the other way around) and the subject becomes the object.

As a city counterpart to the phantom rides in the country, the urban landscape can be filmed from trains or subways, cars or boats that move through the city's arteries. These films show urban panoramas that are non-landscapes, but represented in visual codes appropriate to landscape representation. These cityscapes are instantly juxtaposed by the landscape panoramas surrounding these films in the film programs. Like the landscape films, they present a variety of vantage points in their attempt to establish a "perfect" point of view. Perspective as a rhetorical strategy engineers a point of view for the spectator onto the object. It establishes positions of a subject and an object, it creates a background and a foreground, and it offers a position from which to make sense of the environment. In addition, or as a result of, making visible, perspective makes meaning. Thus "painting the picture" is not just a matter of aesthetics, but also

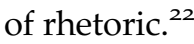

The rhetorical patterns illustrate that these strategies, especially the different forms of opposition but also perspective, are tightly interwoven with that other oppositional pair, fiction and nonfiction. Let me conclude by examining this interrelationship between the rhetoric of space and referentiality a little more closely. I will do so through two rhetorical strategies, previously evoked, by means of which landscape is engineered: Narration and synecdoche. 
In terms of a rhetoric of space, narration allows a change of perspective through character, as when traveling protagonists construct the space that is traveled, or through temporal sequence. The narrativization of space can also be the effect of encapsulation, as in the clash between a person and the environment. In A Rube on the Subway, the character is an out-of-towner, and it is through this figure of the other, displaced in the setting familiar to the viewer that the city, deprived of its naturalness, becomes more self-reflexively city-like. The rube is overwhelmed or immersed by the city, literally when he is almost run over by a train. Opposition is here enhanced through the narrative.

But this rhetorical construction of space through narrative cannot be separated from the problem of referentiality. And landscape, because of its traditional documenting value and recognizable beauty, is eminently suited to produce an illusion of referentiality. Stories authenticate location, landscape or city and the other way round: locations make stories happen and therefore render them "real." This intricate play between the construction of space and authenticity, between a rhetoric of space and ontology, of which I wrote in the earlier half of this chapter, is nicely illustrated in WhAt HAPpened on 23RD STREeT. Here, the presence of people in the street - this presence actually makes a street a street - produces the transition to fiction through selection by the camera when an anonymous passer-by becomes a character. Yet by the same token, the opening becomes authenticated in retrospect. Fictionalization and authentication go hand in hand.

Finally, a particularly interesting rhetorical figure based on the nexus of space and ontology is synecdoche, the figure in which the part stands for the whole. In numerous films, this strategy enables the articulation of an opposition in which spatial difference crafts or enhances the effect of authenticity. This is why Westerns can be shot in Central Park or New Jersey - like The Great TraiN Robbery (1903, Edison) - in England or in France, without destroying the effect of authenticity. This is the power of the effect of the real.

In my example of A RAILWAY TRAgEDY, the woman found on a grassy patch suggests the distance, which the train has traveled: from the city to the wilderness. We have seen this through the window in the corner of the frame. The references made to a generic landscape and city oppose each other in a very concentrated way by this synecdoche. We can call this a synecdochic summary of space. In films that have space as their defining feature, such synecdoches are properly called mises-en-abyme. One patch of grass, and we have traveled to the West. In contrast to classifiable nonfiction films, the geographical identity of the location is secondary to the type of location, which is here established in reference to its opposite: a patch of grass versus the pavement of a city street. The clash between the quoted wilderness (grassy patch), the implied city street, and the staged modernity (in the cardboard interior of the train) thus establishes 
a dramatized triple structure of space. This dramatization ties the perspective of the city, as personified by the woman who figures as stand-in for the urban film spectator, firmly to this fabricated space.

Synecdoche, along with the other three rhetorical figures investigated in this chapter - opposition, perspective, and narrative - is an important device for the binary construction of landscape and city through both fiction and nonfiction. Together these figures illustrate how "authenticity" is a product, and how this product is founded upon rhetorical patterns. The resulting landscape, whether principal or subordinate, beautiful or barely visible, is the visible evidence not of a Western landscape but of a fiction, a cultural projection, a fantasy called "West." This fantasy was particularly appealing in a time of rapid change. Modernity, with its shocking transformations of every aspect of social life was particularly receptive to the sense of space this contrived "West" and its primary embodiment, landscape, emanated, for delectation, thrill, and reassurance alike.

\section{Notes}

1. "Reflections of the Critic," Photoplay Magazine III, 6 (January 1913): 100-104 (102).

2. On the methodological ideal of falsification, see Popper (1959).

3. Culler (1983). See also $\mathbf{D}$, the chapter on self-deconstructive principles in the construction of the other.

4. For a discussion of the sublime in relation to the experience of the moment in modernity, see Charney (1995).

5. For the term "shifter" and its implications, see Émile Benveniste (1970). Shifters function as mobile focal points, often within an oppositional structure such as "here," implicitly opposed to "there." Such terms, also called deixis, indicate the relative meaning of the utterance, tied to situation of utterance, an "I" in the "here" and "now." They have no fixed, referential meaning. For a more detailed discussion of shifters and their operation within the rhetoric of landscape depiction, see $\mathbf{P}$.

6. Moving Picture World V, 5 (February 3, 1912): 18-19.

7. Motography VI, 6 (December, 1911): 296-271.

8. Buscombe (1984) discusses the influences of Frederic Remington and other painters on the formation of the idea of the "West" and the filmic Western. An excellent study on Remington is by Alexander Nemerov (1995) who uses art history, literary theory, and psychoanalysis for his investigation of Remington's paintings as highly complex expressions of turn-of-the-century American culture. For more about paintings see also $\mathbf{P}$.

9. Nickelodeon V, I (January 7, 1911): 23.

10. "The Passing of the Western Subject." Nickelodeon V, 7 (February 18, 1911): 182; emphasis added.

11. Barthes (1986). See also $\mathbf{F}$. I will return to this term below.

12. Motography VI, 5 (November, 1911): 243.

13. Moving Picture World I, 15 (June 15, 1907): 234. 
14. Variety (February 26, 1910); emphasis added.

15. Due to this integration, the paradox that, in Jonathan Culler's argument, inheres in the "authentic experience" in tourism (1988: 164), an experience which depends on markers of authenticity that turn the authentic into a sign, can be said to have been "resolved" in these films.

16. Moving Picture World II, 10 (March 7, 1908): 195; emphasis added.

17. What follows was presented by Eva Warth and myself at the conference Visible Evidence VIII, Utrecht, August 17, 2000, as "Rhetoric of Space: Cityscape/Landscape." See also our article (2002) with the same title.

18. Edison Films Catalog 105 (July 1901): 43. Quoted in the Library of Congress catalogue, Inventing Entertainment.

19. We can see similarities with films like A Romance of the RaIL (1903, Edison). This film about travel with inserted fictional narratives was programmed next to travel films that show locations and people inhabiting these places.

20. Elevated Railroad, New York (AM\&B, 1903); New Brooklyn to New York Via Brooklyn Bridge (1899, Edison); SKy-Scrapers of New York City, From the North RIVER (1903, Edison).

21. This distinction is established as a rhetorical effect of opposition. For example, as icon of the old, the majestic, "wild" nature of phantom ride films like GAP ENtrance to Rocky Mountains (1902, AM\&B) or Panoramic View of the Canadian Pacific R.R. Near Leauchoil B.C. (1902, Edison) clashes strongly with the subway of New York City, icon par excellence of urban modernity.

22. A rhetorical analysis of space does therefore not contradict Gunning's thesis of the view aesthetic (1997), but it illustrates how this aesthetic is coded, or enhanced by, rhetoric. 


\section{Modernities}

We are just at the dawn of the moving picture as a feature of modern life. [...] It is impossible to conjecture how great a part it may play in our civilization by, say, the dawn of the twenty-first century. - New York Times $1911^{1}$

The plural of this chapter title is, of course, programmatic. Rather than coming up with yet another philosophy of, or even just another statement on what constitutes modernity, I will sketch three areas in which a notion of modernity plays itself out in direct relation to my corpus. But the plural must be taken as programmatic in another sense as well. To foreground the emphasis in my study on the concrete, material cultural objects under scrutiny, modernities is also meant as parallel to the word antiquities, indicating not the "spirit of the times," but the objects that we cherish, today, as remnants, relics, or souvenirs of that spirit. Relics that were, at the time, considered the opposite of remnants of the past: utter novelties. Thirdly and finally, the plural indicates one aspect of the culture of which my films are elements, and which has been discussed earlier through the double sense of "bits and pieces," namely their status as representations of fragmentation as well as fragmented, short and broken representations.

Although such themes as nostalgia and landscape are central in Westerns, these are not in opposition to modernity, but through the trope of "loss" these themes are rather reflections on the effects of modernity. But it is not only in this negative sense that modernity plays a part in the filmic depiction of the West. In fact, the idea of the modern is central to the films of my corpus in three ways: in terms of materiality, of experiences, and of practices. First, there are the phenomena of modern life, of modern culture, that set in motion the urge to represent an "elsewhen" disguised as "elsewhere." This became clear, for example, in my discussion of the representation of landscape. This first area concerns material culture and its mythification in visual representations. The phenomenon perhaps most often associated with modernity in this sense is industrialization. Since we are talking here about an industry - in Hollywood parlance - this process cannot be considered redundant or beside the point. Film changed the lifestyles in the industrialized areas drastically and irreversibly.

But doubling itself up, this particular industry is an industry of the representation of industrialization. Industrialization took a great many forms and influenced cultural life in many more ways than I can account for. But specifically for 
my study, one particular industry became a privileged object of representation, an emblem of modernity in this sense: the modern machinery of the train as a favored new phenomenon. It mediates between a socio-economic force of industrialization, the cultural form of tourism, and the older, but continuing process of colonization. In this respect, the train is directly bound up, both with the conquest of the West and with the desire to travel to it and see it. Hence the popularity in that industry of seeing, from afar, under the illusion of eye-witnessing. The two elements - conquest and seeing - came together in the aesthetics of shock and trauma that the train contributed to the collective imaginary and that, in turn, informed the thematic and aesthetic elaboration of the possibility of the image in movement that was the new phenomenon. The train as deploying speed became a favorite form of the moving image as both in movement and emotionally moving, thrilling. The train thus accounts for what is often cited as the most dramatically influential cinematic experience of modernity. Furthermore, the massification of the cities is directly related to the flurry of inventions of mass media. Another important material phenomenon that affects the fate of the Western is internationalization of which I wrote in J. This facilitated the role the Western was soon to take on as a model of universal(izing) film, precisely because it integrated all these aspects. ${ }^{2}$

Second, on the level of experience, consciousness, awareness, in brief, "spiritual" culture, "modernity" is part of that culture that binds material changes to bodily experiences of them, so that people tend to think and feel differently. In the period, fragmentation is one element of such experiential changes; shock, anxiety, and the fear of catastrophe, another. One specifically relevant fear is that of the influence of film on the psyche and the ensuing social behavior. This is the subject of $\mathbf{X}$, which offers a further discussion of public debate informed by this anxiety. But, on another level, the fear of catastrophe also informs the content and form of largely fictional films, such as Le RAILWAY DE LA MORT [Their Lives For Gold] (1912, Gaumont) or A Railroad Smashup (1904, Edison), as well as filmed events that lend themselves to the peculiar integration of spectacle and narrative that I will discuss later. $\mathbf{S}$

But fear and shock are not the only sentiments that accompany modern inventions, such as the railways, cars, airplanes, subways, or trolley cars, and the ensuing acceleration of life. There is also, and primarily, a great excitement. The excitement about these inventions as well as the speed with which they came about, and the speed they made possible, are also part of the changes in consciousness they brought about. A defining feature of the emerging modern consciousness that ends up in, as well as "behind" the films is, therefore, the ambivalent combination of shock and excitement. A certain futuristic jubilation informed the celebration of Los Angeles in Los Angeles (1912, Imp.) or of San Francisco in Bird's-eye View of San Francisco, California, From a Balloon 
(1902, Edison) that I will discuss below. Films that celebrate the modern experience of the city and the joy of experiencing the thrill of the modern were, for example, shot by the Edison company at the 1901 Pan-American Exposition in Buffalo, N.Y., at one of those most extravagant celebrations of modernity, the World's Fair. Circular PANORAma of Electric Tower shows a panning view of the buildings, as well as of the strollers or flâneurs on the grounds of the exposition. PANorama of Esplanade by Night flaunts the possibility of afterdark photography and the visual splendor of electric lights mounted on the buildings, and Panoramic View of Electric Tower From a Balloon adds the attraction of simulated aerial photography. ${ }^{3}$

When I consider the notion of modernities as sketched so far, as a key to analyze the films from my corpus, then, this intensity of cultural sentiment and the ambivalence that colored it, are helpful heuristic tools. Ambivalence guides my analyses in this chapter, in my attempt to understand the films within their cultural context and effects. This focus on ambivalence is methodologically important, for ambivalence is easily overlooked when one considers only plot. For example, shock without ambivalence seems to show up in films like THE GREAT Train Robbery (Edison, 1903), with its brutal killings and its frontal shot of the outlaw shooting straight at the spectator (see figure M1), or A MiDNIGHT FANTASY (1899, AM\&B), in which a wooden Indian comes to life and with a tomahawk attacks a gentleman wearing a top hat who flirts with a ballerina.

One could easily see here only the negative aspect of shock. It must not be forgotten, however, that the sheer fact of making and showing films "about" shock betrays not only cultural shock, but also the thrill it was able to trigger. If this were not the case, the desire of the public to go and watch such films would be in dire need of explanation. Anxiety, shock, futurism, and excitement: all these modern sentiments were quite tightly bound up with cinema,

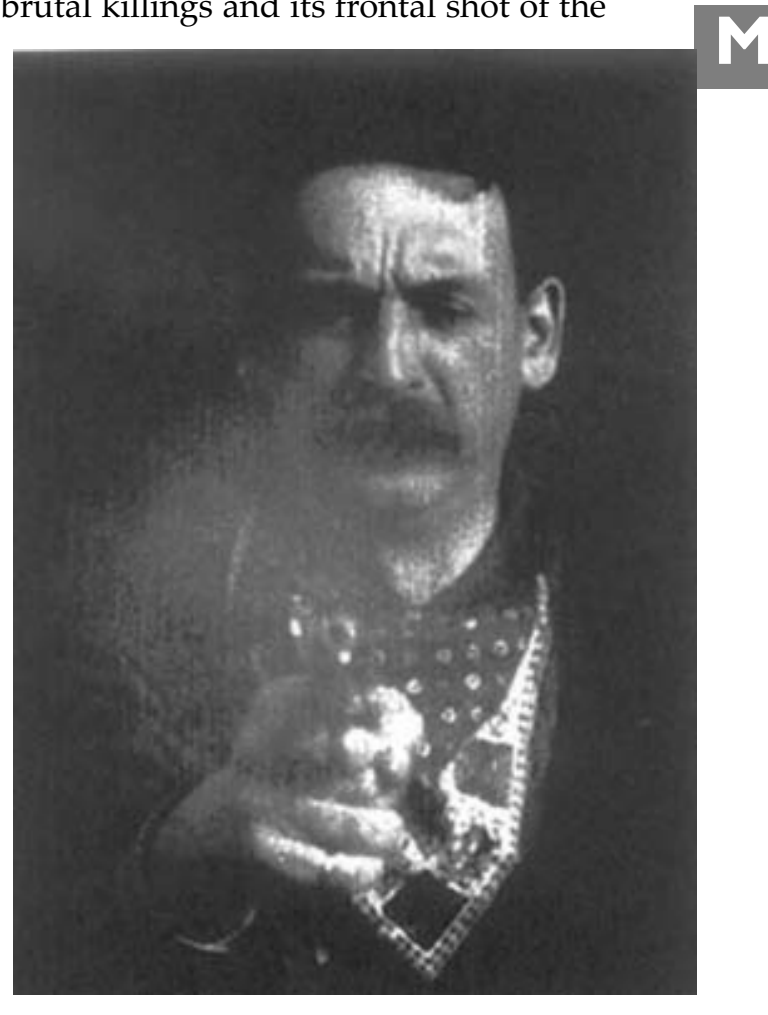

M1 The Great Train Robbery (1903, Edison) 
whose presence changed its surrounding culture drastically. But I contend that this was especially relevant in the case of Westerns.

Thematically, Westerns are particularly apt to work through such emotions because of their inherent focus on the contrast between such modern phenomena - trains, cities, speed - and their apparent opposite, the "uncultivated," or rural areas imagined as "Western." Also, the rhetoric of authenticity that subtended this contrast derived not only from the use of "real locations" and wellknown (historical) stories for their plots, but was also sustained through featuring real outlaws and heroes of the West, which enhanced the thrill of danger. These bandits literally embodied danger. Authenticity is also foregrounded through the celebration of showmanship, something I will discuss more in $\mathbf{W}$ and $\mathbf{X}$. Ambivalence becomes even more fascinating when we consider how such contrasts are often nuanced and complicated. Speedy "modern" trains speedy "old" horses: the race of the traditional riders on horseback against newly-invented trains plays on the fear of disaster, and on the excitement of novelty pitted against a sentimental nostalgia due to irreversible progress, but equally strongly, on the excitement triggered by the astonishing speed of the boys of nature. $^{4}$

This leads to the third aspect of my plural title here: in addition to being material and experiential, modernities are also practices. Travel became a significant, desired and dreamt-about possibility but also a performed practice, which had a great impact on the production and the generic diversification of films. Photography, a modern practice par excellence, was one form of recording. Film was another, and it, uniquely, allowed the paradoxical recording of movement. An important attraction of film was the possibility, finally achieved, of storing movement in legible images (Doane 1996), which an increasing awareness of the importance of memory at a time of rapid change had made desirable.

To turn this lived experience, these modern phenomena and practices, in spite of their fragmentation, into something the culture could deal with, cinema, and as I am arguing, in particular the films representing the West, employed an aesthetic strategy that enabled the films to gloss over fragmentation and produce an illusion of unity. That strategy, which consisted of the concretization of ambivalence, was narrativity. Narrativity was so important because the medium enabled for the first time the recording of movement. Movement of the body equals "real life." Recording body movement was a revolutionary new way of addressing, through representation, certain questions that had been central in cultural life, ideology, and religion for many centuries: the question of what defines humanity. The relation between spirit and body had never been more open for scrutiny than in the recording of bodies in willful movement. Thereby the centrality of the body in figurative representation could be connected to the ambivalent Christian issue of embodiment. 
Embodiment, Richard Dyer (1997) argues, is an idea that glosses over the contradictions inherent in the mind-body split:

Christianity (and the particular inflection it gives to Western dualist thought) is founded on the idea - paradoxical, unfathomable, profoundly mysterious - of incarnation, of being that is in the body yet not of it. (1997: 14; emphasis in text)

The "spirit" that is so crucial in Christianity is conceived as lodged in the body, but not "of the body." Therefore, it is able to migrate in and out of the body. But the notion of spirit is double-edged; it is far from leading to spirituality only. For it is also the spirit of entrepreneurship that propelled colonization. In most cases, and the colonization of the West is an emblematic case, the locus of this particular spirit is the white body.

As a way of dealing with, responding to, but also coming from modern life, narrative cinema provided means to re-unify but also to preserve fragmentation in a contained and harmonized form. It enabled nostalgic trips to an unbroken past, as well as futuristic kicks from the fragmented present and a virtual future. Fragmentation and nostalgia are two symptoms of a certain un-ease or even disease that I consider first and foremost as a sign that the culture was being confronted with the illusionary nature of the sense of wholeness that the subject assumes in relation to his or her own body. For this reason, in this last chapter of the cluster about coincidences between the development of what has become "the Western" and the moment in history in which this genre began to emerge, and as a prelude to the next cluster of chapters on filmic strategies, I broach these three aspects of modernity - material, experiential, and practical through the analysis of a few cases where the modern body is central. For I contend that the centrality of the cinematic body in (early) film is especially evident in the Westerns.

Of course, I am not the first scholar to link the phenomena and practices of modernity with the body. In his study of techno-culture in modernism, Tim Armstrong observes about the body in modern life:

The desire to embody and perform is an important part of the story here, a corporeal equivalent of Modernism's slogan "No ideas but in things." In the modern period, the body is re-energized, re-formed, subject to new modes of production, representation and commodification. (1998:2)

Armstrong rightly draws attention to a preference for concreteness - "no ideas but in things" - that only seemingly subordinates "spirit" to body. Rather than subordinating the former to the latter, however, this modern sense of the concrete - that takes the form of "objective correlative" in poetry - questions the severance of spirit from body in older periods. But, as Dyer (1997) has argued, it did this only partly, so that "spirit" became the property of an unmarked, self- 
evident white body. Armstrong has this to say about the filmic capacity of storage and re-instituted unity:

Even film can be seen in these terms: as a visual illusion which exploits the limits of perception, but which also offers the cinematic body as recompense for the fragmented body of technology. (1998: 5)

I contend that this inquiry into the limits of perception and the ambivalent recuperation of the body takes on a highly specific and intensified form in a genre that confronts the old conceptions of the body with the new ones that invalidate them. This can be grasped when we look at films belonging to the genre of the Western that are about modern means of transportation as cases of the "problems" or adventures of modern life.

Compare, for example, Rescued From an EAgLE's Nest (1908, Edison) with A Twentieth Century Tramp (1902, Edison). These films stand in contrast to each other as representations of archaic life in the mountains and the woods versus modern life in the city. Both are replete with powerful panoramic shots. They exploit the possibility of the medium through the deployment of trick shots. In particular, they contain panoramic shots from an emphatically "modern" point of view, flaunting the technological possibilities. They both contain shots from the sky. These shots are narratively motivated. Thus, in the former film, which foregrounds archaic life, these shots are enabled by an enormous eagle who captures a little girl. In the latter film, which celebrated urban life rather than life in the backwoods, a "tramp" is seen riding a sort of futuristic flying bicycle through the sky. The two films foreground their espousing of modern technology, but whereas the former nostalgically harks back to the past, in a privileged rejuvenated visual form, the latter enthusiastically and hyperbolically forecasts the future. They share a framing of the body in the modern technology that makes possible the unreal representations "from the sky." In spite of their differences, this form of visual presentation is itself, in both cases, both hyperbolically optimistic and ambivalent in that it dwarfs the subject framed by machinery.

The ambivalent attitude towards modernity is particularly satisfying as a code to understand RESCUED FROM AN EAGLE's NEST. In this film, we see a cabin in front of a backcloth depicting a view of the mountains. We see an eagle picking up a small child and flying up with her hanging from its claws. Below the child we see the panoramic view that is deployed as if the viewer, too, were hanging under the eagle. Although the story is set in primitive nature and portrays the (historical) life of lumberjacks in the mountains, the look that is facilitated through the cinematic portrayal of the (virtual) trip through the sky, is visually very modern. It is as if the bird is moving through the screen, but technically this effect is produced by scrolling behind it a backcloth with a land- 
scape painted on it, a technique borrowed from the theater. This look makes the bird quite dominant, an aspect that contrasts with the vulnerable position of the child. Thus the ambivalence is again balanced between fear and excitement.

In contrast, in A TwENTIETH Century Tramp we see a tramp flying through the sky on a futuristic flying bicycle that could have been invented by Leonardo da Vinci. The lower part of the frame con-

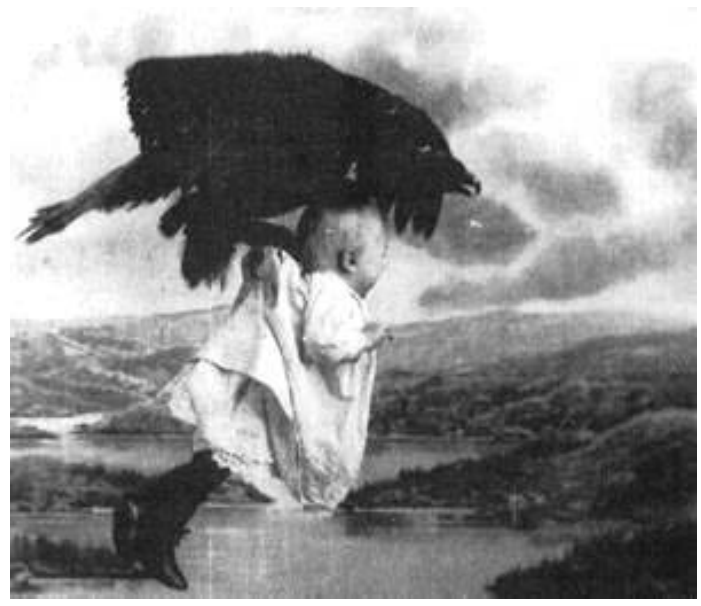

M2 Rescued From an Eagle's Nest (1908, Edison) sists of a matte shot of a moving panorama of an urban landscape. It is, in fact, footage that could have been shot from a balloon, or a pan from a tall building.

From this comparative description of the two films we can gather the way ambivalent responses to modernities - in the multiple sense of the plural outlined above - inform and even make legible, the films that establish contrastive views of the modern world. Similarly, I would like to bring BIRD's-EYE VIEW OF San Francisco, California, From a Balloon (Edison, 1902) into this comparative framework with "modernities" as the code. A nonfiction film, it shows a "real," i.e. photographic and not painted, filmic panorama shot of the new Western city from a balloon. This film is explicitly emblematic of modernity because it refers to the fascination with, and fashion of, balloon flights, and in the same sweep, to the phenomenon of (relatively) new metropolises in the West, such as San Francisco. Such cities stand for the development through which urban, Eastern modernity got established "West of the Wild West."

But like trains, balloons were embodiments of the ambivalent thrill-cum-terror that such machines induced. In the Library of Congress catalogue the cultural background of this film is sketched in the following manner:

As early as 1874, passenger balloon flights were being made over San Francisco. San Franciscans - and Americans in general - were fascinated with the thrills and dangers of flight. Although balloon technology had not advanced greatly by the turn of the century, attempts at man-powered flight were sustaining public interest. The era of powered flight arrived in 1903 with the Wright brothers' flight at Kitty Hawk, North Carolina. The balloon used in this film was owned by Professor T. S. Baldwin, who had earlier displayed it in San Francisco in 1893-94. His return to San Francisco followed an engagement at the Pan-American Exposition in Buffalo, New York (1901). 
The balloon made headlines shortly before this filmed flight, when it burst its moorings on November 2, 1901, carrying eight terrified passengers fifty miles south to Pescadero. Although nobody was hurt, the balloon was almost swept out to sea. ${ }^{5}$

This film played with the possibilities of air flight, of shooting this footage - a modern accomplishment in itself, as well as with the virtual and visual experience of shock that film viewers could enjoy while watching this film. ${ }^{6}$ The modern phenomena of newspaper headlines and popular sensationalism whetted the viewers' appetite for such experiences.

Modern technologies are systematically foregrounded in my corpus to the extent that films displaying and narrativizing modern transport are often set in modern times with cowboy figures and/or cowboy plotlines. This combination does more than simply use or celebrate modernities. Through this combination the films implicitly or explicitly raise the "philosophical" questions of modernity as progress full of danger, an enrichment that simultaneously entails a loss. As the earlier mentioned RAILWAY DE LA MORT and The GREAT TrAIN RobBERY on the one hand, and A Cowboy Millionaire (1909, Selig) and LosT AND WoN (1911, Selig) on the other, demonstrate, the effects of modernity include shock and disaster, but show other futures as well: visions of progress, promise, and fortune.

With these cases in mind, let's go back to RESCUED FROM AN EAGLE's NEST and A Twentieth Century Tramp. Beyond mere technological self-display, these films and the contrast between them raise a discussion of modernity in terms of perception, vision, and the fragmented body. The intricacies of the relations between the body and the world, as well as the question of what the body can do and what remains of it when its illusionary wholeness must be given up, are evidenced in the films. But the films are significant because this is not done on the more straightforward level of thematics and motifs. By foregrounding possibilities as well as the dangers they carry, the futuristic vision through the technological machinery this vision requires takes on programmatic, aesthetic significance. These two films, each in its own, contrasting way, enable me to move in the argument of this chapter from the levels of phenomena, experiences, and practices of modernity, through the modern, filmic "parts" of vision, visibility, and visuality, to a consideration of the characteristic aspects of motion, fragmentation, and montage, to the construction of the modern body that I consider especially typical of the Western.

Although the Western lends itself particularly well to "argumentation" through contrast, combining thrill for the new with nostalgia for the loss that the new entails, ambivalence is not necessarily represented through temporal discrepancies. The Eleventh Hour (1914, Bison), for example, is set in the present. In terms of location, however, the beginning of the film, set in the East, appears to 
contrast with the ending, set in the West. Thus, within the stretch of time that evolves between beginning and end, the historical trajectory from past to present is covered. On the level of plot, the story is about the recovering of the past as the heroine of the story tries to solve a murder, so that her falsely accused lover will be acquitted. This adventurous trajectory is set in a movement from East to West, after the beginning that is set in the East within the high society of industrial magnates that symbolizes this region. Although the film refrains from laying out an overt contrast between past and present, it does foreground the contemporaneity of both worlds. Thus, it cannot help offering "modernities" for reflection and enjoyment. When the railroad cuts through the landscape, and cars and motorbikes drive through the screen, the wildness of the West is definitely put up for ambivalence. At the same time, however, the Indians who figure in this film look very traditional.

The strategic, self-aware use of the ambivalence of sentiment focused on the opposed sides of modernities could not be more emphatically expressed than on the poster used to advertise this film. On this poster we see a car falling off a cliff: the nature of the Wild West demonstrates its power over man-made technology by punishing modern hybris in a visual representation that, at the same time, satisfies the sensationalist eagerness to see the thrill of danger to the body in the spectacle of what modern man can make to frame, enable, and extend his body.

As a form of extension of the body, setting can function to establish contrast on a basis other than East-West. Cowboy Justice (1910, Pathé: American Kinema), for example, involves the hijacking of a car, the chase of the car on horseback, as well as a modern brick house instead of an old-style wooden house, and also a train station. This is another instance of a Western in a contemporary setting. This film plays with modern transport systems and settings, but the story about the chase and capture of outlaws vigorously recalls the price to be paid for this modernity and the recent victory over wildness that brought it into existence. In particular, it refers to older times when the modern systems of law enforcement and a structured society had not yet been established, to the kind of lawless, or pre-modern, society that so many classical Westerns represent or use as a framework. ${ }^{7}$ A contemporary critique of the film in Nickelodeon - that I also employed to substantiate my take on the "Eastern" $\mathbf{G}$ - cultivated the sense of location as meaningful:

Any place west of New York is the west to a New Yorker, so the Pathé producers evidently flattered themselves that they were getting the real Western atmosphere when they went as far west as New Jersey to get the scenery for this cowboy melodrama. The result is truly incongruous - cowboys chasing desperadoes down pretty lanes between whitewashed fences. ${ }^{8}$ 
The phrase "whitewashed fences" duplicates the irony. The film, the phrase says, deprives the West of its wildness by making the representation as a whole "white." And by foregrounding the typical fences that depicted civilization in everyday, material life by embodying the delimitation of individually-owned territory, the phrase expresses the characteristic ambivalence inherent in American-Eastern-Urban modernities by pointing out how safety came at the cost of freedom - the freedom that the West, in turn, stood for, and which remained its appeal.

A Distant Relative (1912, American) is another example of this ambivalence. This film features the chasing of a car by a man on horseback in a modern environment. Here, the confrontation between one of modernity's gadgets and the traditional tool of locomotion does not seem to clash with the temporal setting of the story. For the story is about modern times in the West. It is a story about modern, rich people in a California setting, decorated with emblematic palm trees. The men are dressed as cowboys, hence the "Western" flavor that flags the genre is present. The story includes chases on horseback and in cars, over roads, and hence, not in the "wilderness." Eventually the bad men are caught by the good cowboys in their car - thanks to their modernity. This victory of good over evil, then, is also a victory of the modern over the old, and cars - then and later - often serve as extensions of the (male) body.

The point, here, is not this particular direction in which the victory goes. Modernity is foregrounded and - ambivalently - celebrated through the contrast itself. This is a general feature of the genre. In A Cowboy's Justice, for example, the good-bad divide is arranged in the opposite direction. The bandits steal a car and are chased by a posse on horseback. So, the modern means of transportation such as trains and cars are not necessarily associated with corruption and criminality or similar dangers, but they can be. The point is not in the specific valuation but in the signifying, cultural encoding that cars and other modernities facilitate. At the other end of the scope, from tragedy to suspense and a happy ending, we also find comedies. A Cowboy Millionaire features a car full of cowboys being chased for fun through the streets of Chicago by cowboys on horseback, shooting their pistols in the air.

"Modernities" as a code through which the historical coincidences of old and new are brought into connection and confrontation, also helps me to further theorize the way "genre" is a case of family resemblance more than of essences. For example, many films are relatives of the more straightforward Western through the way they share the ambivalence toward modernization and the narrativization of this ambivalence in adventure plots. One film that can be seen as a distant relative to the Western is An Outcast Among Outcasts (1912, AM\&B), an action film set in a rural environment and featuring tramps, modern-day "homeless" people, or hoboes, who ride the trains illegally and beg 
for food. They lead a life that is both an idealized life of freedom, reminiscent of the stereotypical life in the West, and a suspect life of crime and marginality. Here lies the typical ambivalence that affiliates the film to the Westerns. In this story the duality of the character of the tramp or hobo is emphasized by the character of the "good" tramp who helps "the law" catch the "bad" tramps. But the duality is also present on the level of props intersecting with plot. The means of transportation in this film are wagon and horse, train and automobile. It features trains, a post office, a hold-up, a damsel in distress who is saved by the good tramp, and a young hero.

"Modernities" - props and their narrativization, ambivalence and contrast situated in the body enabled and endangered - are also at the core of some films that appear even farther removed from what will become the classical Western, yet are also cousins of the early Westerns because of their deployment of "modernities." Take The Mong Fu Tong (1913, Éclipse), a "modern" detective story, set in Europe, made in France, about cowboys and Chinese, with a gloomy atmosphere and featuring a car. The George Kleine Catalogue lists: "Cast: Joe Hamman (Arizona Bill series) Kleine copyright: 14 August 1913. 2 reels, $651 \mathrm{ft}$., $16 \mathrm{~mm}$. Summary: Arizona Bill and his wife Betsy, Westerners who are stranded in Europe, track down a band of Oriental thieves headed by Mong Fu" (1980: 88). The word "Westerners" flags the catalogue's awareness of the family resemblance with the Western. The film includes the chase of a car full of Chinese gangsters by a car with the hero and heroine of the story, a cowboy and his girlfriend. The hero's profession seems the only element that affiliates this film with the Western. But if we take "modernities" as the code, the affiliation becomes much clearer, and then, many other elements - such as the chase, as well as the body-in-peril - also fit the genre.

Maybe this film is not explicitly about white slavers, but it clearly echoes the characters, the story and the gloomy atmosphere of a film like THE FATAL HouR (1908, AM\&B). That film is an intriguing, strange, and chaotic "thriller" about the dark and ominous side of life, about the underground of modern life, that "other world" that is in a sense similar to other early, violent Griffith films. ${ }^{9}$ The criminal in The FATAL Hour is, in fact, a serial kidnapper, rapist, and killer, and the Chinese in The Mong Fu Tong similarly personify this sinister underworld. The female heroine of THE FATAL HouR resembles the serial queen heroine that became so popular a few years later, when the girl detective tries to rescue a kidnapped woman. Unfortunately, she is also captured by the criminals and has to wait for rescue by the police. In this particular film the heroine is explicitly a rescuer of other women, as well as a potential victim. In $\mathbf{Y}$ I discuss more explicitly the theme of femininity in contrast to masculinity, and the ways in which modernity foregrounds the feminine side of that contrast. In this chapter, I mention as relevant the contrast between the public and private spheres, the 
vision of domesticity involved therein, and the idea of the New Woman, in relation to diverse threats to society that are expressed in the films. All these issues, foregrounding the body and its confinement or capacity of extension, are part and parcel of modernities as I sketch the meaning of this plural above.

There are many other ways to consider "modernities" than the few I have outlined here. We can think of the modern in terms of a European perspective, of filmmaking in Europe, and of internationalization, both of the films and of the stories of the films. For example, travel and migration and news-flow between the continents become thematized. Telegram uit Mexico (1914, Hollandia), a film mentioned earlier, is an interesting example of a European perspective in both these senses. This is a Dutch film about migration and the relationship between the Old World (Europe) and the New World (the Americas). This is symbolized by the generations that feature in the film about a young man and his elderly parents. The son has migrated to Mexico. His parents in Holland read frightening news in the papers about the revolution and the violence that is happening in Mexico at that time. He sends them a telegram saying that he will try to stand his ground for as long as possible. But following increasing violence and growing threats, he writes that he must return home for his safety. When the parents receive the second telegram they both faint because they are sure that it must be bad news. But instead, and as a moment of concentrated ambivalence, the son then arrives safely, and all ends well.

This is a story about new media as well as old (telegraph, newspapers) and means of travel, and about the subjective experience of time. Time and duration and the suspense that is generated by the physical absence of the son, the "bad news," the duration of his travel home, all conspire to make the viewer aware of temporal discrepancies in a modern world that has lost its unity. The young man's father is blind, his parents are both old, and they faint because of their anxiety; their age, and the difference between their lifestyle and that of their son are foregrounded through the body in danger.

Let me return to my earlier claim that the construction of the modern body as fragmented and destabilized is typical of the Western, albeit, of course, not at all exclusive to that genre. The special relevance of this fragmented body, foregrounded as if "naturally" by the moving image, becomes a matter of principle when we realize the many ways in which the Western more than other genres lives off the materialities - the train - the experiences - of contrast - and the practices - travel - that constitute that condition. Thus experienced, the modern body, for the first time, came forward as made, constructed. It became itself a case of modernities as our antiquities. The body and the bits and pieces that show it, in temporal transit as it were, are the relics of a time when the modern body was a novelty. Moreover, the relationship between the body and narrative 
lost its innocence. Narratives of capture emblematize the body's unmoored state. At the same time - and this is the crucial coincidence - film was able to reconnect the unsettled modern body with what was lost.

Some of this is suggested in Eva Warth's closing remarks to her discussion of the cinematic representation of the (female) body in her article "Moving Bodies":

As Benjamin has pointed out, the disabling effects of technology can only be overcome through technology and technical media can thus facilitate the recuperation of subjectivity. Film may allow us to re-experience lost experiences. One of the pleasures and fascinations of early cinema is rooted in those moments when it becomes a site in which the body is shown and experienced differently, when the body is allowed to step out of its own image. (1999: 150)

This healing function of film also appears in Armstrong's remark about what links cinema and modernity on a level beyond historical accident, namely, cinema's "prosthetic" function (note the fake-physical metaphor):

Modernity, then, brings both a fragmentation and augmentation of the body in relation to technology; it offers the body as lack, at the same time as it offers technological compensation. Increasingly, that compensation is offered as a part of capitalism's fantasy of the complete body: in the mechanisms of advertising, cosmetic surgery, and cinema; all prosthetic in the sense that they promise the perfection of the body. Indeed, in this study, cinema comes to signal the terminal point of a certain form of prosthetic thinking. (1998: 3)

And when, a bit later in his introduction, Armstrong characterizes modernity through this prosthetic function: "Modernism, then, is characterized by a desire to intervene in the body; to render it part of modernity by techniques which may be biological, mechanical, or behavioral" (6), he seems, I suggest, aware of the interconnection of materiality, experience, and practices through which I have tried to characterize the modernities that more than elsewhere appear in the Western. The ambivalences that necessarily accompany such rapid cultural changes require, for their mitigation into an acceptable and, indeed, highly attractive practice, the deployment of strategies of appeal. The primary strategy that enhances experience and forgetting, identification and distancing simultaneously, is narrative.

\section{Notes}

1. "Is the Moving Picture to be the Play of the Future?" New York Times (August 20, 1911). 
2. Let me mention here two films about the laying of the tracks in the West, adventures set at this emblematic moment of conquest and modernization: A Question of Seconds (1912, Edison) and [De Concurrenten ] The Competitors (c.1912). A "relative" of these films is Alone In THe Jungle (1913), a film made by Selig, the company that specialized in both Westerns and Jungle films. Here, the laying of a railroad track in the African "wilds" is the dramatic setting of the narrative.

3. Titles from the Edison series shot at the Pan-American Exposition in 1901 include: Esquimaux Game of Snap-The-Whip; Esquimaux Leap-Frog; Esquimaux Village; Horse Parade at the Pan-American Exposition; Japanese Village; Pan-American Exposition by Night, President McKinley Reviewing the Troops at the Exposition, President McKinley's Speech at the Pan-American Exposition, Spanish Dancers at the Pan-American Exposition, A Trip Around the PanAmerican Exposition, Opening, Pan-American Exposition, Sham Battle at THE PAN-American Exposition. I discuss some of these films in other chapters. U V

4. Films that show chases and races between different modes of transportation, old and new, include: The Hold-Up of the Rocky Mountain Express (1906, AM\&B); Le Railway de la Mort (1912, Gaumont); and Das Teufelsauge [The Devil's Eye] (1914), a German episode film with an elaborate chase. Deniz Göktürk discussed this generically hybrid type of film in her paper "From European Living Rooms to the Wild West: Cinematic Geography and Generic Hybridity in the 1910s," delivered at the 1997 conference Back in the Saddle Again in Utrecht. For a more detailed discussion of the chase, see $\mathbf{N}$ and $\mathbf{R}$.

5. Library of Congress catalogue, Inventing Entertainment.

6. Other films even extend this modern experience of virtual flights, including the science fiction films by Georges Méliès such as Voyage DANS LA LuNE (1902) and VOYAGE À TRAVERS L'IMPOSSIBLE (1904). Kessler (1999) discusses Méliès in relation to the 19th-century origins of the film genre of the féeries. All these flight films, except for the one shot from the balloon, convey a cinematic experience of flying by film tricks such as stop action, double exposition, and matte shots as well as theatrical conventions like (moving) painted backdrops.

7. Some significant examples include High Noon (1952), Rio Bravo (1959) and The Man Who Shot Liberty Vallance (1962).

8. Nickelodeon IV, 10 (November 15, 1910): 280; emphasis added.

9. I am thinking, for example, of The Red Girl, The Stage Rustler, or The VAQUERo's Vow, all from 1908 and directed by Griffith, and all of which show extremely violent behavior among or against women. Gunning discusses these early Griffith films. In his analysis of the kidnapping in The FATAL Hour, Gunning lucidly demonstrates how the suspenseful plot of this sensational melodrama relies on parallel editing for the visualization and structuring of temporality (1991a: 95106). 


\section{Strategies}

In this cluster, I further pursue the characterization of "early Westerns." Here, this inquiry is not based, as it was in cluster 1, on their paradoxical features which I have argued to be mainly an effect of anachronistic conceptions. Nor is it based, as in cluster 2, on the underlying philosophical ambiance that characterized the culture at that peculiar time when cinema began and the conquest of the West ended. In order to get a tighter grasp on how the films could be what they were and do what they did, I examine some of the major strategies of expression, or discursive, semiotic strategies, deployed to turn celluloid into culturally important artifacts that managed to further develop and convey to cinema's consumers the "signs of the time" that I have mapped out in the previous cluster. The opening chapters on Narrativity and Old Timers deal with the strategies that underlie narrativity. $\mathbf{N}$ deals with cinematic strategies of "showing" and "telling," taking the structure of the chase as paradigmatic case. $\mathbf{O}$ explores cinematic narrativity in the light of literary and theatrical adaptations.

The distinction between clusters 2 and 3 can be grasped through the different treatment of landscape. In the previous cluster, $\mathbf{L}$ is about the infusion of nostalgia in landscape, and the cultural meaning of landscape in relationship to the concept of "The West," as in: nature versus culture.

In this cluster, landscapes are discussed in terms of the pictorial attributes deployed to tell the story. Here, then, I discuss how film visualizes, picturizes the world. In $\mathbf{P}$ I discuss how film is about trying to capture the world from the best possible vantage point, making it a picture, putting it in perspective - literally and metaphorically - and opening it up again for the viewer. Here, landscape takes part in a discourse that is both aesthetic and rhetorical. In $\mathbf{Q}$, a reinvestigation is taken up of the issue of genre in the light of parody. This chapter explores the operation of irony by looking back at the play with conventions in early Western comedies. In $\mathbf{R}$ the focus is on the specifically modern way of traveling: by train. The visual deployment of the mechanization of travel (including its possibilities and its dangers) and the specific way of showing the passing landscape that is associated with this means of travel are the objects of analysis. $\mathbf{S}$ is concerned with the spectacle that results from, and is celebrated by, the mix of movement, speed, and nostalgia. In the later chapter on Time Travel $\mathbf{T}$ I examine travel more than landscape depiction, and here the temporal axis of the spatio-temporal matrix of travel is central. 



\title{
Narrativity
}

\author{
"Chase films," so called because of the opportunity they give for wide \\ scope of action, will probably never lose their fascination to the average \\ audience. The thing now is to introduce into the chase as many novel and \\ exciting elements as possible. \\ - Biograph Bulletins, $1905^{1}$
}

The larger question of narrativity in the films of my corpus raises a number of subsidiary issues. Each of the chapters in this cluster on semiotic strategies are devoted to one of them. This chapter addresses the presentation, the representation, or rather, in a specifying combination of these two, the showing and telling of the West. The tension between narrative movements in the plot and the fabula does not bear comparison with the kind of harmony between these that we take for "natural" in - or in the case of more experimental, post-modern films as a background for - present-day film. Instead, I will draw upon André Gaudreault's concept of monstration (1987) and Tom Gunning's notion of the cinema of attractions (1986) to characterize the kind of narrativity at stake. These scholars deploy their concepts in order to account for the tentative combination of strategies whose increasingly successful blending has become a standard in our perception of what cinema most essentially is. "Monstration," as act, or "attraction" as rhetoric device, then, suspends the narrative-based viewing habit by putting forward the aim of that strategy - that blending - so that it becomes denaturalized and can be seen as one among other possible strategies, not the only "natural" one.

As a complement to Gunning's study, Yuri Tsivian's discussion (1998) of the reception of narrativity in early cinema is also relevant. While the former explores the more general question of how narrativity participates, as a handmaiden, in the building of a more general attractiveness of the moving image for its fascinated early spectators, the latter probes the place of narrativity within the effects of this moving image. Both Gunning and Tsivian analyze the first transitional phases and developments in film narration, before the classical system of narrative integration emerged. Gunning (1991a) proposes an analysis of the narratorial system in the work of D.W. Griffith and his contemporaries as the next development toward the system of narrative integration. In his chapters "The Reception of Narrative Categories" and "The Reception of Narrative Devices," Tsivian highlights the role of the spectator, as I do here, thus estab- 
lishing a connection between narrative as a textual feature and its effect in captivating the viewer.

I do not intend to analyze, describe, and theorize early cinema's developments in narrative strategies. This is beyond the scope of this project, and others have already provided productive insights into this aspect of film history. ${ }^{2}$ Instead, I understand the subject of "narration" as concerning both how film "tells a story" and how film "tells a story," that is, in terms of semiotic mode as well as content. From that vantage point, I will explore two questions simultaneously. The first concerns narrative strategies invented to deploy narration as a mode of showing things, of captivating spectators, of turning the moving image into an image moving. The second, altogether different question follows the cultural process through which the object of that show, of that narration, became a story rather than an idea, or spectacle such as landscape only. I am interested above all, then, in finding a way to analyze the crossing of these two strands. For that crossing, that braiding together of these two strands ties narrativity to an idea of generic development of narration conceived not as "natural," but as something that could also have evolved in a different direction.

In other chapters some specific issues of narrativity will be discussed: the textuality of early Westerns: Its narration that relies on the relationship with older media, such as literature and pulp fiction or painting and photography. $\mathbf{P}$ Also, different forms of movement are analyzed, in terms of tourism and travel, and visual spectacle.R S T In this chapter I wish to set some of the parameters I use in these analyses. I start with the connection between narrativity and genre. As discussed before, genre as a category is impossible to define because it is at the junction of content and form, or, to use a more geographical metaphor, of context and core. Narrativity is crucial in substantiating this claim for the Western in particular. Moreover, as we have seen in the chapter on fiction, generic terms such as fiction and nonfiction are dependent on specific narrative issues. ${ }^{3}$

As a key example, then, the chase. The chase is narrativity in its most characteristic, perhaps even essential form, and although not limited to Western subjects, it is typical for my corpus. It is also quintessentially filmic. In unmediated "real life" one can only experience a chase, or witness a segment of a chase; it is only in filmic representation that an entire chase can be visualized. For one thing, the event happens too fast. For another, in "real life," a chase only happens in the body and consciousness of each one of the participants, rigorously limiting it to "being followed at high speed" and "being afraid" or "following in order to capture." Neither of these moments or elements of the chase can be visually shown. One feels fear, and one runs or rides fast, but the connection between the two is inferred, not seen. It is only when a camera cross-cuts from one to the 
other, from the figure on the run to the one following, that the narrativity of the scene can be established, that is, the theme "pursuit" conveyed as a series of small actions producing events or sub-events, together forming the string we now automatically read as "chase."4

It is only after the fact - after the habit of seeing such sequences has been established - that the chase film can be considered a narratively defined genre. Its narrative structure, in other words, becomes the structure of the message, and, at the same time, its meaning. This allows me to specify the concept of (cinema of) attractions, a concept that characterizes early film in its form and rhetoric. This principle of rhetoric in and of itself enables one to consider including films that are non-narrative but presentational. I contend, however, that the type of narrativity emblematized by the chase is also generic, bearing in mind the problematic status of the genre-avant-the-genre so to speak, of the genre that follows the invention of captivating, suspenseful effects. These effects can be achieved by cutting from one participant to the other, focusing on the dust on the road, the backward glances of the victim (or bandit), and the determined face of the pursuer, the fast-moving trees that are lined up as mute spectators of the event, all devices that, together, are saying "this is a chase." The chase, thus, is a narrative form of display.

All this can be summed up in the words with which Gunning argues that the chase format is essential for the development of narrative form:

The chase [...] plays a pivotal role in the transition from a cinema of attractions to a cinema organized around storytelling. It provided a model for narrative causality and linearity extending over several shots and established the continuity of space and time that subtended narrative action. (1991: 67)

This model is not established suddenly but has to be retrieved from various reiterated bits. The symbolic form of the chase is only semiotically possible once it is recognizable as a chase. This recognition, again, is not "natural," because technicalities have become invisible, hiding behind the predictable effects. It is the recognition that turns it into a narrative chase, as opposed to, say, a display-chase.

Properly narrative elements of the content of this symbolic form are the theme of loss-and-recovery and, of course, the last-minute rescue. And, as it happens, these themes are abundant in the Western genre. This is how, then, we can speak of specific forms of narrativity as form plus content toward effect. This particular form of narration defines the genre-to-be, or the not-yet-genre in the making.

This general speculation requires a close examination of a generically relevant type scene of the chase. I take the chase as form first of all, and probe its unfolding in films such as The Hold-Up of the Rocky Mountain Express (1906, 
AM\&B) and INDIAAN GRIJPT KIDNAPPER (Indian Seizes Kidnapper) (c.1910, Pathé), both "pure" chase films. As contrast, I take The Cowboy AND THE School-Marm (1910, Bison) as an example of an integrated chase film. Here the role of the type scene as means of constructing narrativity is important. In this film there is a noticeable narrative that is based on the chase but no longer solely structured as chase. ${ }^{5}$ The analyses of these three films serve to theorize narrativity in the chase through highlighting the narrative aspects of movement, speed, and causality, and their relationship to display. In particular, the relationship between subject and object is relevant in this respect. In this relationship, the question of what the focalized object is determines what kind of subjectivity and what objectivity is programmed in the representation. Display, view, and attraction turn out to be counter-forces to narrative.

The Hold-Up of the Rocky Mountain Express is a phantom-ride film. This type of film, essentially the display of landscape through a point-of-view shot from a train, a chase of landscape if you will, is part of the cinema of attractions. This film was shot in the same year as Into the Haunts of RIP van WinKLE, IN the Heart of the Catskills, Grand Hotel to Big Indian, to name a few members of its cohort, and is part of a collection of early Biograph films that were issued in 1906 for exhibition in the railroad car theaters of Hale's Tours. These railroad films are mentioned in the Biograph Bulletins: "Hale Tour runs attractive Railroad Pictures which have been found highly successful with tour car schemes."

The Hold-Up of the Rocky Mountain Express is printed in bold letters and stands out in this listing of forty-four titles:

This film is concededly the greatest crowd-drawer of them all. It gets the money when everything else fails, and no other film offers such opportunities for front display. Ran for five weeks continuously at the headquarters of the Brady Grossman Co. 46 east 14th Street, New York City, and still running on the issuance of this bulletin. The action shows a railroad run, an interior comedy scene, the hold-up as viewed from the inside, then on the track, finishing with a race between the train and the bandits, who first take to a hand car and then to a horse and wagon. The robbers are captured at the crossing for an exciting finish. ${ }^{6}$

Let's face it: a "railroad run," which is a phantom ride type of film, is quite suitable for Hale's Tours exhibition, which took place within a (stationary) train car to enable a virtual experience of train travel. Here, the run is combined with a simple plot, including characters, actions, motivation, building of suspense, and satisfying closure. Within the context of this chapter, I speculate that this film might have been the pride of Biograph, and the most successful with the 
public because it has such an elaborate narrative. It stands out among the titles in this list that are mostly "mere" phantom rides."

This disproportionate place of the run as a chase - from the point of view of today - in an otherwise rudimentary plot, shows that the balance between elements was very different from what we have grown accustomed to. This difference was emphatically related to the place of the chase as not simply a typical scene, but as one that produced the narrativity it was subsequently to exploit. Other films of this group also include a short digression from the phantom ride display of landscape in the form of a short narrative. This happens, for example, in IN THE Haunts of Rip VAN WinkLE. The advertisement mentions "Magnificent mountain scenery in the Catskills, introducing an amusing comedy feature of a tramp who goes to sleep on the track." Or, I can mention THE VALLEY of THE EsOPUs (1906, AM\&B), promoted as "An amusing fishing picture figures as the feature of this film, which shows a run through the site of New York's new \$161,000,000 reservoir in the Catskill Mountains."

In the summary of Hold-up of THE Rocky Mountain Express I just quoted, it is emphasized how the film is a combination of "types of scenes," a generic kaleidoscope. The piece mentions "a railroad run," "an interior comedy," "the hold-up," "a race." This enumeration does more than just provide us with a list of scenes considered typical at the time. It also demonstrates how strongly the reception of the films in terms of narrative was bound up with the string of such scenes that held them together. The importance of this list, therefore, as a ground for characterization of the place of narrativity in the establishment of generic conventions, cannot be overestimated. We need to see this establishment as process, not retrospectively, as result, but caught in the act by a contemporary witness.

Here is my own description of The Hold-up of THE Rocky MountaIn ExPRESS. I describe it in some detail because it demonstrates the strategies that narrativize the overview of the landscape by means of the chase:

It begins at a train station. Some turbulence occurs from unclear causes. Perhaps the man who comes running in is late, and his friends who were waiting to wave him goodbye, are relieved. Whatever the cause, the beginning is rather smashing. Suddenly the camera begins to move. It turns out a train was waiting, at least, there is a suggestion that this is the case. Hence, I infer, the man has barely made it to the train. People wave along the track. There follows a beautiful panning shot of a typical phantom ride, or just a train ride, while the landscape glides by. The camera is mounted high on top of the train. At first some houses can still be seen, later only the landscape: the train has left town, moving from civilization to nature. The scenery becomes more and more rocky.

Then we get the narrative part. A cardboard interior shows men and women in the wagon. A spinster-type woman is sitting by herself. Two men and two women are 
sitting next to each other. The lone woman attempts to attract attention. The men and the women pair up, however, and she remains alone. A black servant enters. The woman traveling alone beats him up. A tramp enters; the spinster tries to kiss him. (Quite a weird scene, all in all).

The film moves to the outside again. A tree trunk is lying across the track, signaling the narrative scene to come. The train stops, two men remove the trunk, but then ... Two bandits appear and keep the men under fire. One of the bandits goes inside and demands the loot. He has the looks of a cowboy. The film moves to the outside again. A handcar approaches on the same track. A little shooting occurs and the bandits take over the handcar and the people on it, holding them hostage. The train accelerates and pursues the bandits. They pass a wagon and horse. They jump from the carriage onto the wagon and hence, they take - steal - these. They continue to ride along the tracks The chase continues. There have been three consecutive relays of chasing: the bandits running, riding on the carriage, riding on the wagon, each means of transportation increasing their speed. The road ends at a railroad crossing with a house. Some people exit the house with shotguns and capture the bandits.

The End.

This film offers the mix of nonfiction display of landscape and the train, with narrative fiction of the hold-up and the chase, a mix that was more characteristic of the Western at the time than any of the harmonious blends of predominant narrative that we find in later Westerns.

Short and simple as the film may strike us to be, it is quite an ambitious film. However simple in its narrative structure, confined to the predictable sequence of one hold-up, one chase, one capture, it features a wide range of themes that can be considered typical of the emerging Western genre. In quick succession and simultaneous display we witness versions of the themes of an opposition between civilization and nature, of racism and sexism, narratively intertwined when the scorned woman is also the one who beats up the black servant and acts out her sexual frustration by assaulting the tramp. This kind of narrative economy is itself a case of non-integration, however, if we consider that there remains a clear division between the "decent couples" who are ordinary, therefore, boring, therefore simple background not narratively viable, and the group of active agents, consisting of the spinster, the black man, and the tramp. Moreover, the film plays with the mixing of genres, narrative strategies, and possible camera positions.

Landscape display is amply represented, a form of display for which the narrative offers a sufficient but in fact rather tenuous justification. Travel as theme, activity, but also, filmic genre, is the background or stage that makes the narrative possible. The dangers emanating from the opposition of civilization and nature partake of the rhetoric that builds up suspense, when the houses along the railroad become few and far between. Cutting back and forth between in- 
side and outside scenes, the filming flaunts its own technique, and the camera is itself framed as a traveler, then a thief-catcher of sorts. ${ }^{8}$ The camera mounted on top of the train inserts the discourse of landscape display and travelogue by means of a technique that is also its own display, demonstrating the capabilities of the new medium. Finally, the depiction of social life inside the train, opposing the couples comme il faut to the outrageous behavior of the spinster parodies the very stereotypes on which its readability is based. All these elements were known from other films, other short bits we would now tend to see as fragments but whose completeness cannot be automatically denied, as I have argued in $\mathbf{B}$. Their readability, even in such a short film, depended in fact on this appeal to other filmic discourses than the one evolving around the chase.

This film, then, exemplifies the thesis of this chapter. The chase as emblematically narrative scene, as the scene that operates the magic of showing what can, without cinema, in fact, only be told, and of showing simultaneously or in quick succession the experience of the two opposed parties of an event that only the public can actually see as "chase," takes the lead role in this concatenation of genres only because it is so irreducibly, captivatingly, narrative. It is thanks to the strong narrativity that the chase as type scene embodies, that it comes to epitomize the Western not for some inherent bond between them but because the chase produces the narrativity on which the chase, and by the same token the Western, thrives. This double-edged narrativity - as feature and product of the chase - will promote the centrality of the chase, of which my next example offers an instance.

This is a film that, on the level of plot, is primarily a chase. Its title already indicates this centrality, for it is called INDIAAN GRIJPT KIDNAPPER (Indian Seizes Kidnapper). It is relevant to note that in this case, it is the archive that designates the film as chase film, since the original title is lacking and the film is only partially identified. This film is instructive in the way that it differs from the previous one: it is "all" fiction, in the sense that it puts less emphasis on the generic inheritance of a nonfiction genre, and shows less ostentatious, self-reflective framing in the film itself. The previous film is framed as phantom ride within the film; this frame is emphasized in its exhibition, as well as in its distribution, as evidenced in the Biograph Bulletin. In the film itself the display of landscape through a moving camera is immediately recognizable as such. INDIAN SEIZES KIDNAPPER is more prominently and primarily a chase film.

As a result, it appears as a much simpler film. The narrative itself, that is, takes over. Here is my description of the narrative:

A bandit helps two men, one of whom an Indian, the other in a "gipsy"-type costume, to a state of alcoholic stupor. He seizes a little girl - the daughter of one of the men? and hides her, unconscious, under a heap of straw. When the men come to, the Indian 
is blamed for kidnapping the girl. Using his skills in reading tracks the latter follows footprints and finds the girl. He then chases the bandit and seizes him.

As a summary of the plot - the narrative as content - I submit that this is an adequate account. It is immediately apparent that the plot is simpler than that of the previous film: less crammed with events. This is not everything we see, however. The other side of the sign "narrativity" is amply present. This, precisely, makes narrativity a sign, a two-sided complex of expression and meaning, bound together like the two sides of a sheet of paper, to use linguist Ferdinand de Saussure's famous simile. ${ }^{9}$ For visually, and hence, in its work to establish narrativity as a cinematic strategy, the chase strikes me as a very physical one. In the course of the pursuit, the Indian climbs a tree, pulls the bandit over a rock, and performs other acrobatic feats. The men struggle through the landscape, even with it. The landscape, thus, becomes an actant, an active agent within the plot, in contrast to the more distant form of display of the phantom rides, including the one in the film I discussed above. ${ }^{10}$

In complementarity to what I wrote in $\mathbf{D}$, the narrative function of the Indian is worth considering. At first sight, his role is bound up with ethnographic representations of Indians. We "know" - rather, we are used to being told - that Indians are "good with the land." Standing for naturalness, they have kept a bond with the earth, the ground, and therefore, this Indian can serve the plot by rescuing the girl - and incidentally, saving himself from unjust punishment. But as a feature of the process - not the result - of making narrativity central in the Western, the figure of the Indian comes to stand for, to exemplify, something else, through the smart exploitation of this intertextual relation with ethnographic films.

The Indian, in his guise of self-reflexive device in this film, demonstrates that particular skill of Indians and film viewers alike, of reading the landscape. He reads it, moreover, so that it can become accessible, usable, not a backdrop but an actant, set to work within the narrative content. At first, when the girl is missing and the landscape remains complicitly mute, it is an opponent. But thanks to the work of the Indian and his stereotypical role, the landscape is an opponent that a skilled reader, knowledgeable about the forces of narrativity, can turn into an ally: it helps the Indian to find the girl, and the viewers to enjoy the movie and to travel in their armchairs, all at once.

I invoke a later film here to exemplify a third stage in this avowedly projected and speculative division of the input of the chase as narrativity incarnated, and other conventions, to produce, slowly but surely, the generic conventions called "Western." ${ }^{11}$ With a more integrated form of chase, this film is a more elaborate narrative. To be sure, the films discussed previously were also more than mere chases. But there, the chase's "others" - the different filmic discourses that framed, and were framed by, the chase, setting it off as a candidate for the main 
role - differed from the chase as type scene of narrativity, less in terms of narrative itself and more in terms of display. Although the 1906 film THE HoLD-UP OF THE Rocky MountaIn ExpREss was generically also quite elaborate, the following film contains various narrative elements of which the chase is just one. Here is my description of the plot of THE COWBoy AND THE SCHOOL-MARM:

A school day ends. The school teacher says good bye to two of her pupils. A man gets off his horse. He is a bully. He has the appearance of a rich and sophisticated city slicker with his suit and high top hat. He harasses the teacher. A cowboy - her boyfriend? - appears and the bully leaves the scene.

A Saloon. Two Indians, a man and a woman, sell strings of pearls. The bully kicks the man. The cowboy comes to the rescue once again and fights with the bully.

The bully takes revenge by kidnapping the school teacher when she happens to be out riding by herself. The Indians see this. The woman secretly chases the two and drops pearls to leave a trail for the rescuers. Meanwhile her partner notifies the cowboy. Together they trace the pearls and follow the track. The Indian woman collapses from exhaustion. She and her husband signal in sign language to the cowboy what happened to the teacher. They find the teacher and her assailant.

A gunfight among the rivals. The bully holds the woman like a human shield. In the end the cowboy almost strangles him. The fight is spectacular. As a climactic and emblematic display of what it means to defeat an enemy, the Indian leads the bully away like a slave. The woman and the cowboy start kissing. The End.

Here, I am interested in the technical integration of these various narrative episodes.

There are two chases, one of the bully followed by the Indian woman, one of the cowboy and the Indian chasing the Indian woman chasing the bully. Remarkably for the topic of narrative integration, the two chases are imaged through a single camera standpoint. In a sequentiality that signposts the temporality of narrativity, the three appear in the same frame, according to the same choreography. Entering the frame from the right, they move diagonally through the frame to the left, then they move from left to right. Then from top to bottom.

Another integrative effort is evident on the level of narrative thematic. The stock theme of the self-sacrifice of the "good Indian" is at least alluded to when the Indian woman almost dies of exhaustion, and the woman-as-brave as well as the woman-as-weak motives have also been thrown into the bargain. A scene can serve many masters at once. All this, however, is neatly integrated within the narrativity of the chase. Whereas in the first film discussed above, the chase itself was relayed between three means of transportation allowing the increasing speed needed for prolonging the viewer's captivation, here the different thematic strands are relayed as different characters of increasing competence pass 
the torch from one to another. Hence, the woman who initiated the rescue does not participate in its heroic climax. The integration of the three chases within one narrative, then, works toward the Western as a genre while rehearsing thematic emphases that were ideologically connected to the spirit of the moment.

The more levels of filming collaborate toward integration, the more effectively the latter will be "naturalized." It is important to note, therefore, that integration, finally, also occurs in terms of location. The house functions as background. The predominant location may be an open-air setting, but it is framed as if shot in an interior location. The scene in the saloon is indoors. The opening of the film, the part before the chase, is set in a very domestic environment. All this, of course, helps to put or keep women in their place, in the most literal sense. When the woman is kidnapped she was riding, by herself, outside of the city limits. There, needless to say, it is dangerous. An opposition is established again between civilization, specified through school - the very site of civilizing activity - as the domain of woman, and the saloon as the liminal site susceptible to the penetration of danger. Take note of the conventional louvre doors: half only, as well as semi-transparent, and easily opened. Social meanings are offered to naturalize narrativity, and conversely, the narrative helps the social meanings pass.

This passing is also skillfully exploited on the level of the visualization in general. The white protagonists in this story are riding on horseback, the Indians move on foot, a connotation that situates the characters in social relation to each other. Thus, differentiation of movement in the moving image also makes the image as such dynamic. Once the chase has begun, the image no longer looks like the theatrical staging of the first scenes. This is meaningful on many different levels of cultural production and process. First, the chase, still the emblem of narrativity, flaunts the medium's specific capacities in contrast to the theatricality it has both inherited and superceded. This can be seen as a selfreflexive act in which film shows its clients how much they stand to gain.

Second, within the production process, the chase not only creates suspense on the level of plot, but it enables the filmmakers to shoot more dynamic scenes, facilitating their own boasting, setting this film off against others of its kind. The reviewer praises the "novelty" of the chase in The ReDMAN AND THE CHILD (1908, AM\&B):

The robbers abduct the child and carry him off in their canoe. The Indian, after finding the old man's body, swears vengeance and gives chase, and a splendid pursuit series, through beautiful scenery and exciting incidents, begins. Every instant of the reel has a new thrill. From the canoes pursuer and pursued jump into the water and the finish is made in a swimming chase, in itself a novelty. ${ }^{12}$ 
The insistence on the thrill of the chase suggests a counter-discourse to a tradition of rather boring chases.

Third, and paradoxically, within the narrativity of the chase, the integration of the three chases within one plot ends the reign of the chase as emblem and instead "naturalizes" the narrative plot it so often continues to embody. This change of narrative regime so to speak, happens by means of the chase's ultimate success as a purveyor of narrativity. It is, precisely, to the extent that the narrativity is integrated, and this on so many levels at once, that the chase does not strike us so forcefully as emblematic. ${ }^{13}$

But lest I appear to be espousing an evolutionary model, I wish to point out that the chase in this film is very static compared to the phantom rides, including the one that shaped the chase in the earlier film. The camera stays in a frontal position. The result is a quite stage-oriented way of filming, even when the action, the chase, takes over. Also, before this moment, it takes quite some time for the action to accelerate. This seems a step backward compared to the earlier film which, the reader recalls, was helped along by the technique of the camera mounted on the train, taking its ride there, as well as by the conventions of the discourse that thrived thanks to that technique, the travelogue.

Here, another feature shows how paradoxical such assessments are bound to become as soon as they are framed in terms of evolutionary ideology. The plot of The Cowboy AND The School-Marm is allowed much time to develop. Today this produces a sense of slowness. The beginning of the earlier film was much faster, and hence, more immediately captivating. But the point is, this slow development of the plot is also a sign of the plot's integration, which enhances the narrativity of the film as a whole. For example, the plot is elaborately motivated, even psychologically. It also takes on symbolic meanings whose positing requires time-consuming elaboration. Narrativity takes on a new guise here, and if that new guise must in turn conquer its "naturalness," this only goes to show that the place of narrativity in the Western is built up in a variety of different ways, each producing its own moments of success. In this film that success is named integration.

On the basis of these analyses, I end this chapter with a speculation on some general features of narrativity in the films. In order for narrativity to be activated, a certain comprehension of continuity must be expected by the viewer an expectation that must, first, be solicited by reiterating instances of narrativity. Moreover, secondly, a plot development is required to achieve closure. Thirdly, the level of narration requires a narrativity that the medium itself already implies, but which, within the framework of narrativity, can be exploited, displayed, and integrated. 
Narrative continuity is challenged by the tension, or alternation, between elements of the fabula - events - and the display of setting and elements of show. $\mathbf{S W}$ On the other hand, narrativity is required for the mission of Westerns of the period to translate the representation of space - elsewhere - time - elsewhen - and people - the other - into a story that is moving in the two senses of the word: moving images that move their audiences.

Early cinema's narrative techniques relied heavily on intertextual knowledge and the use of conventions such as easily recognizable type characters and familiar plot structures. Commentaries in the press on these conventions reveal this, but also criticize the practice and show an increasing demand for a "new" mode of narration. In the dialectic between the force of narrative, the motor that propels the film, and the viewing of it, a dialectic where narrativity is the counterforce of display, landscape may serve as a metaphor and narrative as a connector. Intertextuality, the next chapter argues, makes both readable.

\section{Notes}

1. From the bulletin of the film The Horse-THIEF, "a cross-country chase on high-class thoroughbreds." Biograph Bulletin 49 (September 9, 1905).

2. Besides the works already mentioned, specialized works on the narratology of cinema in an historical perspective are Bordwell (1985) and (1989), Gaudreault (1988) and (2004). Elsaesser, ed. (1990) includes several contributions on narrative in early cinema. Karin Esders (1997) analyzes the development of cinematic narration through a focus on gender and the early Western.

3. In $\mathbf{B}$ narrativity was conceived of as the product of the viewer's agency; here, the emphasis is on the textual feature of narrativity. The difference, of course, is merely relative.

4. Kirby (1997: 55-56) discusses Gaudreault's analysis of The Lonedale Operator in terms of such cross-cutting.

5. The "chase-influenced trajectory film" is what Gunning (1991: 68) calls his example of The Adventures of Dollie (AM\&B, 1908).

6. Biograph Bulletins 73 (June 30, 1906).

7. In $\mathbf{R}$ I elaborate on these mixes of travel shots and narratives that showed a combination of temporal aspects of travel, landscape-realism, and the virtual experience of time and place that was a hallmark of Hale's Tours.

8. For a short, extremely efficient explanation of the relevance of the concept of framing, see Culler's preface to his Framing the Sign (1988).

9. For a concise explanation of de Saussure's ideas and their relevance for semiotics and for the humanities in general, see Culler (1976).

10. I use the term "actant" here not in the strictly Greimasian sense, but as a (shifting) narrative function of material objects, in this case "landscape" or "nature."

11. With this formulation I wish to remind the reader that we cannot speak, without anachronistic distortion caused by retrospective projection, of a "development' in 
"stages" from a non-existent to a fully-fledged narrativity of the Western, brought about by the strategy of the chase. This apparent relativism does not imply, however, that the three modes or moments of relative integration of chase and other discourses that I am foregrounding here, are the mere products of my over-heated imagination. Rather, from the stream of barely distinguished differences, I have selected and foregrounded a few cases that exemplify a diffuse process to make it readable. In this sense I have learned from the Indian reading footprints.

12. Variety (August 1, 1908).

13. The notion of narrative regime is meant to evoke Martin Jay's illuminating discussion of the notion of scopic regimes (1988). 


\section{Old Timers}

The story is a series of dissolving views told by a Western "Old Timer," a method of story exposition which calls for an immense amount of title, the only apparent value of which is that it furnishes some effective contrast. - Variety, $1914^{1}$

Narrativity has mostly been studied in narrative texts from the literary tradition. Strategies such as appeal to identification, suspense, and attraction have been considered major elements in the "literariness" of literature. At the same time, these strategies have been alleged to explain the specific popularity of non-aesthetic, mass literature called, precisely, "popular" (Cawelti 1976; Denning 1987; Bold 1987). This double agenda is no coincidence. It points to the way in which mass literature and, by extension, our films, are mediators between cultural domains that tend to be artificially separated: "high art," "popular culture." Such a trans-artistic status change is not at stake in this chapter, however. I will limit my discussion mainly to the first point, strategies of attraction, and examine how these operate when a text is turned into a sequence of moving images. Thus, I will focus on trans-media status changes, even if trans-artistic slides do occur in that process. In other words, I will consider the transfer from one medium in which different degrees of popularity and aesthetic status were achieved, into another, more generally considered popular, at least at the time. The translation of stories from one medium - literature, including dime novels and popular magazines as well as more canonical literary works and theater plays - into another medium - film - is of specific interest for my attempt to gain insight into what characterizes the film culture of my corpus.

Moreover, not only were books turned into films, feeding the new medium with content out of an extensive stock of available narratives. The reverse phenomenon - films turned into text - is perhaps less obvious but just as relevant. Whether or not their fabulas were taken from extant literature, films were also, in turn, recycled as texts. Motion Picture Story Magazine and Photoplay Magazine, for example, specialized in publishing stories of films. They did not only offer synopses or fabula outlines like other magazines from the trade press, as a way of informing their readership about ongoing film production, but more significantly, they published short stories based on film plots, illustrated with frames or production stills from the films. ${ }^{2}$ 
Of course, one purpose of such publications was to implant in the culture an ongoing incentive to go and see films - a form of advertisement that we also know today - making use of the immensely popular format of cheap short fiction in dime novels and magazines around the turn of the century. But more diffusely, they had a characteristic cultural function. The circulation of outlines made the public knowledgeable about culturally available plots. By contributing such plots to the stock of narrative frames through which people could think and imagine, the context in which the films could be understood and accepted was further built up. The magazines' revealing of denouements therefore, did not undermine suspense, but prepared and even legitimated the viewing. ${ }^{3}$

In this chapter I analyze how film is perceived as an image-making medium in this double sense: making images out of stories and stories out of images that become cultural icons. The discourse in the contemporary press about film in relation to other arts and media provides the material on which to base the analysis. In these texts evaluations of the medium's specificity and the cultural position of film in the broader intermedial network of arts and media indicate how the cinema is perceived as a new player. At the time of the emergence of mass media, the reworking of stories between media was itself, understandably, a focal point on which cultural interest was centered. As we saw in $\mathbf{I}$ in particular, this interest fit the mood of simultaneous nostalgia for the (recently) old and excitement of the (recently) new. Specifically, the ability of film to translate existing, older traditions (Old Timers) into a new and modern filmic discourse reveals how this new medium held the public riveted. But just as much interest was aroused by the ease with which the new accomplishments of film's technological possibilities yielded no less clear and plain plots, re-actualized through their new appearances.

The trade press of the 1910s provides evidence of the cultural actuality of the questions of the competition between text and image on the one hand, and "high" and popular culture on the other. Especially concerning the latter, the discourse in the trade press of the period shows an ambivalence which is inherent to the cultural moment. The former question is clear in the following quotation from the New York Times:

The present tendency, most moving picture men say, is towards the "picturization" of standard novels or classic plays, chiefly novels. That is to say, the public seems to prefer them, and of course, the caterers to public taste fall in line. As a rule, where a novel has been dramatized the moving-picture people disregard the dramatization and make their own scenario, though sometimes they take hints from what has already been done. 
In this newspaper article the journalist raises the question of the position of the new medium of film: "Inventions which will vastly increase its capabilities how these dramas are obtained and why actors give up the stage to enter this new profession." In his investigation of the new medium's strengths and weaknesses the central issue is how the movies compare with theater.

In the pursuit of a new and respectable position in the hierarchy of the arts, the key is to have good and respectable (hence, older) material and to be better than others in translating this material into a (new) visual language. More than 15 years after the first public screening of films this is still a much-debated issue. In fact, the medium's attempt to achieve respectability by changing direction had been the subject of criticism for some years already, and this criticism is fuel for basic questions about the status of the medium. Therefore the writer observes:

The sudden vogue of the motion picture leaves most of us still gasping. It came up so quickly, and so overspread the amusement horizon in a moment that we haven't got ourselves accustomed to recognizing its importance. Because we have to keep our children away from the nickelodeons that show how Big Bart robbed a bank we have failed to recognize the fact that in a few years we will be going to sublimated nickelodeons ourselves to hear Carmen and see Macbeth.

Sliding between its status as medium of violent and sensational entertainment and a new art form that can compete with opera and the classical stage, the cultural status of film is unstable. We can see this instability as the critics praise efforts of the film industry to use the classics as a source for their products. At the same time emancipation from other art forms and media was necessary if film were to gain its own cultural status.

This writer emphasizes both necessary characterizations: film is perfect for adapting novels and theater plays, and film is distinctly different from written texts and the theater. The distinction that is made in this newspaper article is that between dramatization (adaptation of stories for the stage) and picturization (adaptation for the screen). This ability - and strength - of film to bring the past back to life and create moving images of fantasies is also a responsibility of the medium:

When [Vitagraph] "dramatized" - it is the only word available, although some moving-picture men prefer the word "picturize" - the life of Moses, they got a leading clergyman of this city to superintend its staging, so that they could protect themselves against historical errors. Historical plays are the chief pitfalls. The public exercises a sterner judgment over motion-pictures than over other plays, and resents a solecism. ${ }^{4}$

Double standards in public criticism are evident in judgments of the success or failure of filmic adaptation of novels and theater plays. The historical realism 
and the medium's potential for showing the exotic elsewhere/elsewhen/other result in a curious mix of historical or ethnographic "realism" and poetic, aesthetic value. In the case of Westerns these ambitions intersect. ${ }^{5}$

One critic of "Indian and Cowboy" films scorns the impossibility of this combination:

There is little or no variety in Indian life as Fenimore Cooper depicted it, as Mayne Reid depicted it, and as it is shown on the screen. As Longfellow showed it in his poem of "Hiawatha," it probably never existed. Hiawatha is pure poetry, if not poesy. At any rate it is highly imaginative. ${ }^{6}$

This critic blames the represented reality's monotony for the failure of its (filmic) representations to achieve aes-

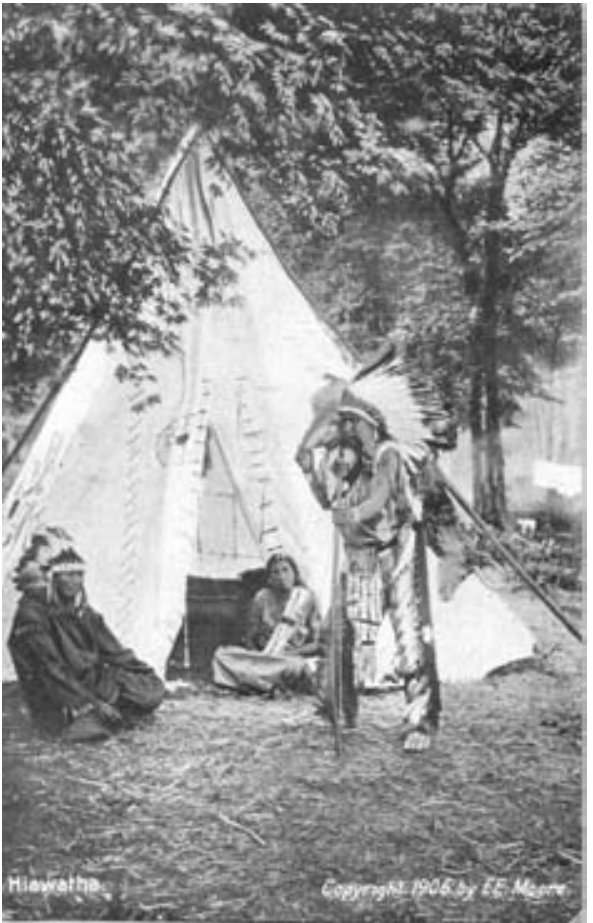

O1 Picture postcard, "Hiawatha” (1906) thetic value, and criticizes the poeticality of the source text (the poem) for lacking historical realism. But the example he chooses is very instructive for other reasons as well.

Henry Wadsworth Longfellow's famous and widely-read poem "Song of Hiawatha" (1855), a romantic and legendary story about an Indian chief, was turned into the 1913 film Hiawatha by the Fort Defiance Film Co./Gaumont. ${ }^{7}$ The long poem creates the figure of Hiawatha, the heroic but tragically vanishing aboriginal American. It celebrates the heroic deeds of the legendary Ojibway Chief sent by the Great Spirit to lead his people. The story of Hiawatha's feats and tragedies includes falling in love with and marrying the beautiful Dakota maiden Minnehaha. Eventually, with the advent of the white missionaries, the immortal Hiawatha must leave his people and join his forefathers in the Kingdom of the West Wind, leaving his people the advice to listen to the guests from overseas preach about Jesus and his god.

The original poem starts with a long introductory part that explains how the Song of Hiawatha is a legend told by Indians and how this poem re-tells this legend. These stanzas set up the description of a romantic and mythical past, with the atmosphere of eternity that is so typical for myths and legends. The references to an indigenous oral tradition that had passed on this legend give 
the poem an historical and an exotic legitimacy. Moreover, the quoted verses appear embedded in a distancing, fictionalizing frame. ${ }^{8}$

The filmic adaptation stayed very close to the text, and can be considered to integrate the text-image relation into itself. So much so, that an abstract of the poem was transcribed in the form of intertitles, a quite literal case of intertextuality. Reminiscent of Shakespeare's Hamlet, the film opens with an apparition that is witnessed by a group of warriors. This double-exposed trick shot shows the face of the Great Spirit against a rock wall. The men run downhill towards a village hidden behind some trees. Illustrated with moving images, these are the opening titles:

And they stood there near the river.

With their weapons and their war-gear.

Painted like the leaves of Autumn,

Wildly glaring at each other.

"I have given you lands to hunt in.

I have given you streams to fish in;

Why then are you not contented?

Why then will you hunt each other?"

"I will send a Prophet to you,

A deliverer of the Nations.

Wash the war-paint from your face;

Bury your war-clubs and your weapons." 9

The intertextual framing was emphasized by the producer Frank E. Moore at the first presentation of the film on February 25, 1913, of which the Moving Picture News reported that:

At the $[\ldots]$ presentation in the Berkeley Theatre Robert Stuart Pigott recited the lines of the poem as the picture play was being enacted upon the screen. An overture of Ojibway music rendered by a capable orchestra preceded the opening of the picture, which consumed from an hour and three-quarters to two hours in its projection. ${ }^{10}$

This particular exhibition of the film underscores the poetic value of the film on the one hand, and, on the other hand, it gave the film a quasi-ethnographic feel by playing indigenous music as an overture.

This film is a classic case of a film drawing for its plot on an old timer, in all senses of the word. The poem was both popular - famous, widely-read - older, and "literary." Moreover, the fabula is set in old times, in the past when only Indians inhabited America, and the advent of the White Man was still (literally) a prophecy for the future. The subject matter is particularly appropriate for ci- 
nematic reworking, because of its nostalgia-inducing potential and the spectacle of exotic detail. The 1913 production was filmed on location in the Seneca Indian reservation in New York State and had a cast of approximately 150 Native American actors. ${ }^{11}$

In some films explicit references to both historical sources and literary sources can be made. In this particular case, literature predominates. The film is clearly attempting to "render" in its own, visual medium, the mythical ambiance whose evocation constitutes the literary source's primary "high art" feature. The relation to the past remains diffuse and evocative only. Historicity is anchored in an exotic-aesthetic approach to history, not to a factual differentiation between past and present. But

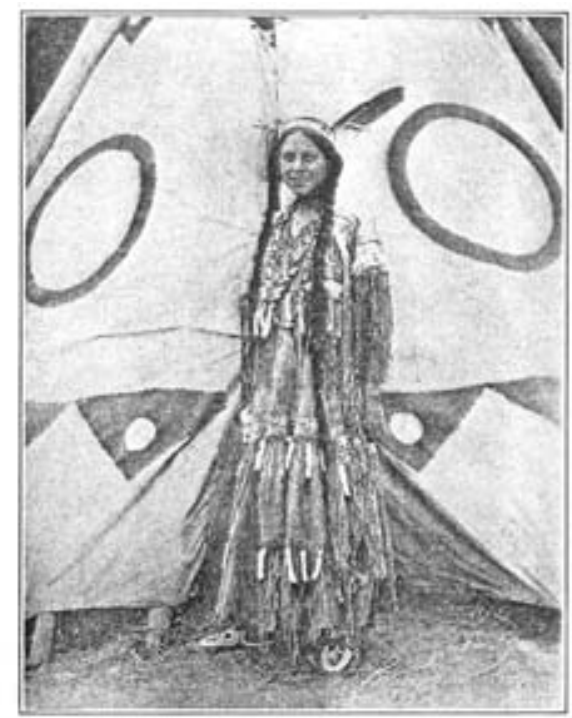

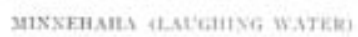

O2 Minnehaha, from Hiawatha (1913, Fort Defiance Film Co.). Moving Picture News VII, 13 (March 29, 1913): 11 the opposite occurs just as frequently. Even on the basis of a text from the same genre, even the same author, the emphasis of the film can shift from the historical to the literary aspects of the source, foregrounding either realism or poeticality. Although the emphasis on either aspect varies, in the case of these stories about the West and other frontiers, the two strategies are inextricably intertwined. This mixture entails a double task for filmic re-telling and image making: realism and poeticality. On the one hand, the technological abilities of photography-in-motion were a tool for revitalizing the past. On the other hand, legitimizing the medium as a new art form with educational value was a motivation for using classic literature such as Longfellow's poems as a source for film. This choice of source fuels the ambitions towards a more aesthetic as well as an historical-educational approach to the translation of these sources into moving images.

Let me give an example of the wavering between the two poles of this translating activity. In 1915, another poem by Longfellow was used for a film when the Edison company released THE LANDING OF THE PILGRIMS, an adaptation of his "The Courtship of Miles Standish," a film which was reissued in 1917 as THE Story of Plymouth Rock. ${ }^{12}$ The opening title says: "A dramatic adaptation of the historical incidents surrounding the settling of Plymouth, Massachusetts." From the changing of the title (twice!) alone we can infer that less emphasis was 
put on the literary source for this film than in the case of HIAwATHA, which was a much more famous, canonical, literary text. The film appears to waver between the two opposing demands of historicity and literariness. The opening title accentuates the historical source of the story, rather than the poetic background: "A dramatic adaptation of the historical incidents surrounding the settling of Plymouth, Massachusetts." In the first part of the film the historical aspect of the story is clear in the use of years and dates in the intertitles, emphasizing the historical facts.

In the course of the film the tone shifts and the historical story turns into a romantic drama, with more and more reference to the literary source in the form of quotes from the poem in the titles. This is explicitly announced in the titles:

"Into the open air John Alden, perplexed and bewildered, rushed like a man insane, and wandered along by the seaside. (The following poetical excerpts are from Longfellow's 'The courtship of Myles Standish')."

"John Alden! You have betrayed me! Me, Myles Standish, your friend! Have supplanted, defrauded, betrayed me!"

The next morning.

Then he had turned away and said: "I will not awake him; Let him sleep on, it is best; for what is the use of more talking!"

"Truly Priscilla," he said, "when I see you spinning and spinning, you are no longer Priscilla , but Bertha the beautiful Spinner."

Lo! in the midst of this scene, a breathless messenger entered, bringing in hurry and heat the terrible news from the village. Yes: Myles Standish was dead! - an Indian had brought them the tidings

"Those whom the Lord hath united, let no man put them asunder."13

But neither the historicity nor the literariness as such - neither the event nor the text - are the primary stake in this ambition. Both strategies promote cinema's greatest asset: the deployment of movement into liveliness. Reviews insist on this quality, comparing implicitly but also explicitly the film to the source, a comparison that often turns to the advantage of the new medium:

In choosing the picture version of Rex Beach's stirring novel, "The Spoilers," as the opening film feature of the new Strand theatre, Manager S. L. Rothapfel exercised excellent judgment. To the rabid movie fan - the one who revels in action, excitement and a panoramic succession of real live adventures - this picture hands him a wallop. 
[...] As a rule movies of the melodramatic sort are expected to have several thrills but this story has been so realistically told by the camera one is handed thrill upon thrill. As a movie production it beats the book. Colin Campbell is given the credit of having staged the production yet to [sic] one familiar with the book and Beach's style of description and love of adventure, can readily see that Beach had an important hand in the staging of his novel before the camera. While credit is due to Campbell for his studio and exterior work, Beach should not be forgotten in the handing out of praise for the success this picture is going to attain before the summer season is very far advanced. "The Spoilers" is a red-blooded, peppery story that will catch wide-awake, live Americans. The photoplay follows the book so closely one can forgive the author and director for having digressed the rules a little and played several incidents up a little differently. But these changes, while making the story stand out stronger in photoplay, are such that no one will register any kick about the film not sticking pretty close to the text. [...]

In staging "The Spoilers," Rex Beach had the Selig Co. re-enact the story of the Alaskan dance halls and gold fields at the California plant (Selig's) where a second Nome and surrounding country were built under the author's direction. In subtitles many phrases, word for word from the book, are employed to good advantage. ${ }^{14}$

"Beating the book" is achieved by way of (visual) thrills and realism. Yet the book already provided a "red-blooded peppery story" suitable for this "beating." The critic James S. McQuade for Moving Picture World prefers the filmic version of THE SPOILERS over the source text by Rex Beach because of the way the film adapted ("realistically visualized") the story's scenes so that they became "better" than the original, literary version. The visual effect of vitality and physicality becomes, almost, a spiritual experience:

"The Spoilers" in film form, in this sense, appeals to us even more strongly than the book of Rex Beach. We view the living scenes in which plot and counter-plot are launched, and watch the principals as they play their parts, whether behind doors or in the open. And we view finally that overpowering scene, where Glenister - man against man and not with the advantage - meets his foe in physical combat and breaks him with his bare hands. It all seems so real and so just that we whisper, between breaths, "Amen." ${ }^{15}$

As suitable as some books are, due to the lively action more than either historicity or literariness, it is clear that the key to translatability is based on the intersection between the two. Both are manifestations of liveliness, and that is what film is about. Hence, translatability is a two-way street.

For, conversely, my next example demonstrates the image-text translation. In the French production of RAILWAY DE LA MORT (1912, Gaumont), the setting of the story is a little underdetermined. ${ }^{16}$ Although shot in France, the titles of the story and, in fact, the very type of story, suggest that the fabula is set in the 
Northern regions of the American West. In the printed story, in contrast, the American setting is introduced right away:

Joe Baker and Tom Burke had been "pals" for years in the mining country, and in fact ever since their graduation from an Eastern college they had been well nigh inseparable. Both had been drawn to the northern ore fields by the lust for wealth, quickly gained, though to date they had been poorly rewarded for the months of toil. (23)

The exposition of setting, character, and plot in the film is very direct. Little background is given about characters and story. Instead, the opening shots literalize the function of background by a play with the possibility of the camera. The scene shows a farm with much simultaneous activity going on in the background and foreground of the frame, foregrounding the great possibilities of depth of frame.

The final scene of the film shows a spectacular explosion of the cabin in which the two friends are killed. In the subsequently published story, we read a succinct account of that spectacular, truly cinematic event. Although the text cannot match the spectacle, it provides, on the one hand, a causal explanation for it ("storage for the gunpowder"), and, on the other hand, a visual description of that aspect that texts are able to render visually ("Tom clutched"):

Glancing up just then, he saw Tom approaching. In a moment more the latter would have discovered him. Hesitating no longer, Joe pushed open the window. All was dark within. Fearing that it might be a drop of some little distance to the floor, Baker struck a match that he might examine quickly the conditions within. The match flickered and then burst into flame. He raised it, cautiously shielding it with his hand and lowered it within the window. A moment later there was a burst of flame, a concussion which shook the country for miles around, and then the whole structure has disappeared as cleanly as though it had been wiped off a slate with a wet sponge. The building had been the storage for the gunpowder and dynamite used about the mine and the lighted match had exploded it all.

Both Joe and Tom were found days afterwards by investigative miners, who searched the debris. Tom clutched in his hand the map he had stolen, and Joe, in death, had endeavored to also get his hand upon the document. The two had bartered their lives for gold. (29)

Whereas the written word appears here less suitable for an adequate rendering of the thrilling visual event, the more psychological aspects of the friendship between Joe and Tom are barely visualized in the film. The story, in contrast, is more explicit in its elaboration of this motif. It uses dialogue to accomplish this. For example, where the film shows a short scene of Joe confronting Tom, the printed version reads: 
“Come on across!" cried Joe.

"Across with what?" angrily replied Tom, the larger of the two.

"With the map, of course," said Joe.

"You saw me find it and then grabbed it out of my hands when you saw me busy with the stranger. It's mine! I found it, and I want it and want it quick, too!" concluded Baker.

"You do, eh?" laughed Tom. "Well, I have it and I'm going to keep it, then you'll know where it is all the time and so will I. After I find the mine and get ready to open up for business probably I'll give you a share," and sulkily he began to whittle on a stick he had picked up.

"Say, what ails you?" thundered Joe. "Ain't we partners? Didn't we agree to share and share alike in any discoveries we made? I don't want to be a hog. I don't expect to keep the whole mine for myself even if the cross on the map does happen to mean a rich strike - and that we don't either of us know yet. I expect to let you in on half of whatever we find when we get to the place indicated on the map, but I found the document in the old fellow's shirt and I want it and mean to have it, too." (24)

However, this competition between word and image does not imply essential differences between the media's abilities. The printed story also emphasizes the visually spectacular scenes of the film: Joe's sneaking away in the moonlight, the chase, the stunts on the train, the explosion, and the still image of the two dead bodies in the tragic ending.

That texts are not indifferent to the visuality of their subject matter is therefore not a matter of course. An explosion may be difficult to render in its blasting spectacularity, but a romantic lighting can be "translated" into words:

The moonlight poured in through a rough window and dimly showed the objects in the room. It revealed a soft, slow-moving figure that crept cautiously forth from one of the bunks and with shoes in hand made its way toward the door. Still more cautiously the door was opened and for a moment the room was flooded with light from without. Quickly the door closed upon the figure, however, for the man feared the sudden flash of moonlight would awaken his partner.

As he at last stepped clear of the cabin and, after donning his shoes, stood revealed in the moonlight we discover that it is Burke, who has stolen a march upon his one-time comrade and now, his brain filled with wild thoughts of a fortune in sight, he is setting out to locate the mine before his partner can awaken and follow him. (25)

In this passage, on a first level of visuality the light is rendered, but, on a second level of visuality its unfolding itself is described as well. Words that shift the passage to the visual unfolding are numerous: revealed, showed, soft, flooded with light. The spectacle itself is emphatically visualized, as becomes evident from words that denote lighting, angle, and distance, all primary devices of 
filming. Moreover, on a third level of visuality, an implied spectator is staged. The door is closed on him/her, ("quickly the door closed upon the figure"), and such a spectator is explicitly brought in at the end of the scene. The shift to the present tense ("we discover") carries the trace of the story's filmic source, while the second part of the sentence gives information that only fictional words are able to provide: "who has stolen." This triple thematization of vision - vision rendered in the fabula, foregrounded in the presentation, and reflected upon through the dramatization of the viewer - clearly demonstrates a sophisticated mode of writing that indicates the cultural presence of the discussion about the media.

On the grounds that the relative differences in aptitude cannot be taken to be absolute, even less as a basis for value judgments, competition is not the most productive framework within which to assess the new medium's relation to discourse. Evaluations of how successful film is in translating stories and plays are often couched in terms similar to those attributed to translation. Translation is therefore a better term for typifying how the dynamic between the arts and media works. Translation, as Benjamin argued in "The Task of the Translator" (1992: 70-82), is not the production of a derivative, always lesser version of the original. Translation is not a matter of faithful rendering of the original, but rather of drawing out the original's "untranslatability," its "essence" which is not dependent on a language. ${ }^{17}$ When transposed to the recycling of narratives and imagery between media, we can say that this untranslatability consists of that which makes the media handle the "same story" differently. To be "faithful" to the source, then, is to make a radically different work on the basis of it. It is this untranslatability between the media that holds the cultural interest in the relationships between written texts and moving images. In other words, translation is a matter of untranslatability.

This Benjaminian notion of translation goes a long way to explaining the efficacy of "loose," or "associative" adaptations. Rather than retelling or summarizing a well known story, films could refer to titles or characters (or authors, for that matter), and thereby cash in on the fame of the canonical works, in films that show/tell different stories. An example already mentioned in $\mathbf{H}$ is the film LeAther Stocking (AM\&B, 1909), that refers to the Leatherstocking Tales by Cooper. In its promotional bulletin, Biograph acknowledges the fact that it is loosely based on the novels by Cooper and even presents this as an advantage. Because of its relative independence from the original literary text, the filmic translation can fully benefit from the advantages of the new medium, while still using the well-known source text as promotion:

What person has not been enthralled by the beautiful and thrilling pen pictures of that greatest of novelists, James Fenimore Cooper? Living as he did, almost associated 
with that tribe of the Algonkin stock, the Mohicans, his characters were real, living people, and while we have made no attempt to follow closely his story, we present a vivid appreciation of his work, the result, we may truthfully assert, being one of the most thrilling and picturesque subjects ever produced. ${ }^{18}$

Again, Hiawatha is a good example. References are made to the poem HiaWATHA and its characters very often, in the titles or through character names, in films that tell different stories than the source text, the poem by Longfellow. Examples are the landscape film The Falls of Minnehaha (1897, Edison), the historical film Wenona (1910, Powers), the character of Winona in THE BuRNING BRAND (Broncho, 1912), and that of Hiawatha in LA MARQUE RÉvÉLATRICE [The Revealing Brand] (c.1912, Pathé: American Kinema). ${ }^{19}$ This practice relies on an intertextual network familiar to contemporary audiences in which film plays an important part, and also establishes a generic system based on canonical references.

Thus, the analysis of the translation from one medium into the other is not only a means to understand the properties of each, but also, more importantly, to understand the thickness of the historical moment's engagement with film and its paradoxical attitude towards time. Film, in this view, cannot be considered in isolation from those cultural productions with which it was in constant interaction and exchange. $\mathbf{G}$ As a strategy of representation, this cross-medium translation contributes an enlargement of the kaleidoscopic presentation that we saw at work in the presentation of the programming of the shows.

\section{Notes}

1. “The Sage Brush Girl," Variety (November 28, 1914).

2. See Ben Singer (1993) and (2001).

3. On the cultural function of stock plots, see Roland Barthes $S / Z$ (1974). Barthes distinquishes five codes through which readability is achieved, one of which is the proairetic code or stock plots.

4. "Is the Moving Picture to be the Play of the Future?" New York Times (August 20, 1911). About Vitagraph's production of literary and stage adaptations, see Uricchio and Pearson (1993).

5. The title of D.W. Griffith's Souaw's Love: An Indian Poem of Love in Pictures (1911, AM\&B) cashes in on this successful formula of Indian films of exoticism, poetry, and film. See also D. Peter Stanfield discusses the portrayal of Indians in this film in "The Western 1909-14: A Cast of Villains" (1987).

6. "The Indian and the Cowboy. (By One Who Does Not Like Them)" Moving Picture World (December 19, 1910): 1399.

7. This was not the first adaptation of Longfellow's poem. In 1909 Imp. had released a version of Hiawatha as their first film. In Nickelodeon II, 5 (November 1909): 159, 
this event is mentioned in the article "Leammle's First Film": "For the past six months there has been an insistent demand for American subjects and here was one that was as American as one could possibly imagine. The story of the love of Hiawatha and Minnehaha was a beautiful theme, but how about the picture? A positive proof that it was good lies in the congratulations received by the makers after the film was run. The photography is very good, the acting is excellent, the story was staged amid beautiful scenery, and the plot well carried out."

8. Interestingly, the publication of the poem in 1855 created quite a stir. The sale was a huge success, but Longfellow was accused of plagiarism for taking the form of the poem from the Finnish national epic Kaleva, an oral folk poetry collection published in 1835, and the content from the stories and legends collected by Henry Rowe Schoolcraft, an historian, pioneer explorer, and geologist who published them in his Algic Researches in 1839 .

9. Intertitles found on the print at the Library of Congress. In Longfellow's text the men stood "on the meadow." Since the scene which preceded this title was shot near a stream it appears the makers found it logical to change this line. The rest of the text is an abbreviated but faithful rendering of the original poem.

10. "'Hiawatha,' The Indian Passion Play in Pictures." Moving Picture News VI, 9 (May 1, 1913): 5 . Here, the subtitle explicitly refers to the other film genre that was built on intertextual and intermedial reference, the passion play. See Uricchio and Pearson (1993) for a thorough study of the filmic passion plays and their intertextual relay.

11. In "Fade Out and Slowly Fade In" American Cinematographer (December, 1923): 9 and 26, cameraman Victor Milner reminisces on the making of this film. He recalls shooting near Buffalo on the Seneca reservation in the summer and shooting the winter scenes in New York City. The film is preserved by The Library of Congress and listed in the inventory of American Indians in silent film compiled by Karin Lund. The film is credited as featuring a cast of 150 Indians from New York, Cana$\mathrm{da}$, and the Dakotas. Needless to say, these are credited anonymously.

12. An earlier adaptation of this poem was made by Kalem. In 1907 they released ThE Wooing of Miles Standish. A plot summary of the film is given in Moving Picture World I, 29 (September 19, 1907): 456-457.

13. Intertitles from the copy at the Library of Congress. The name "Myles" is spelled differently than in the poem by Longfellow ("Miles").

14. "The Spoilers." Variety (April 17, 1914); emphasis added.

15. James S. McQuade, "The Spoilers." Moving Picture World (April 3, 1914): 186-187. Reprinted in Kalton Lahue (1973: 191-193).

16. The fabula of the film soon shows up in Photoplay Magazine III, I (August 1912): 2329, as a short story entitled "Their Lives For Gold," illustrated with film stills from this Gaumont picture. On 25 June 1912, the Dutch version of the film was programmed in a film program that contained three Westerns. In the publicity leaflet the film was called "a drama from the gold fields of the 'Far West'" (Drama uit het goudland van "The far West"). The title of the film, the filmmakers (actor Joe Hamman specialized in Westerns, and also the director Jean Durand made other Westerns in the same period), the films next to it in the program, all constitute a context that determines an expectation of what the story of the film will be about. I think this is part of the reason why French and other European productions of films about America are rather easily understood and accepted in the pre-W.W.I years. The in- 
ternational heritage of early Westerns in the collection of the NFM shows evidence of this.

17. This Benjaminian view has had great influence on recent translation theory. See important studies by Lawrence Venuti $(1995 ;$ 1998). Venuti argues for the foregrounding of the "remainder" of translation, the idiosyncrasies of the source text and its context that can easily, but should not, be smoothed over in the target language.

18. Biograph Bulletin 278 (September 1909); emphasis added.

19. The film WenONA is described as "a pathetic story of the constance of a squaw taken from the Revolutionary days" in Nickelodeon IV, I (1 July, 1910): 7. 


\title{
Picture Postcards
}

\begin{abstract}
Those vast abodes of the picturesque and romantic which are included in the somber mysteries of the Rocky Mountains, the spreading plains of the ranchman and the clustering adobe dwellings of the Mexican frontier offer wonderful bits of motion to the flying film of the camera man. [...] Throughout the world the Grand Canyon of the Colorado is a byword for grandeur. Its immensity is inconceivable; its ever-changing detail seems made for more than mortal eye to grasp. Truly a big subject for the little pictures of the motograph, but the camera man has done well. - Nickelodeon, $1909^{1}$
\end{abstract}

To continue the exploration of the relations between narrative and its neighbors: On the other side of narrativity, pictorial display is a counterforce to the moving aspect of the new medium. It remains to be seen, however, if it counters both senses of that qualifier. For if display stops the movement of the narrative that so characterizes the moving image, it can move the spectator just as much as can the gripping speed, suspense, and sensation of the fabula. In an earlier chapter, I suggested how the West could be primarily represented through the landscape that characterized it in the eyes of the bemused viewers, city-dwellers who were thrilled to take a trip into the wilderness by proxy and reassured to be spared the dangers these proxies faced.

The wide panoramas that present the West as the counterpart to and shortterm liberation from the confines of the Eastern cities, invoke, and simultaneously transform, the impressive - and in a sense, oppressive - vistas of nature in the Romantic tradition of the Sublime. In this chapter such panoramas and the ensuing shift from the Romantic to the modern aesthetic will not be discussed as the counterforce to narrativity it surely is, but rather as a strategy to involve, implicating the viewer as a viewer. What becomes of the Romantic sublime, I will suggest in this chapter, is an aesthetic more suitable for the crowded and hasty world in which the films functioned: that of the picturesque.

But it does not seem meaningful to me to compare the sublime and the picturesque in a hierarchy of value. Rather, I propose to look at the transformation, through cinema, of the sublime, as experience of landscape, into the picturesque as a (pictorial) quality attributed to things seen. I will argue that the difference resides in the mode of looking. This change in the culture of looking itself is decisive enough to place it in the anthropological cultural context of modernity. 
Modernity, on the one hand, nostalgia for what modernity rendered obsolete, on the other. These, coupled with a tension between landscape and narrative, constitute the frames of the aesthetic that characterized the Western. In my comments on modernities $\mathbf{M}$, I have focused on the body as it is constituted by the landscape that, in a sense, extends it. Landscape was treated as a frame within which meaning was created. Narrative was landscape's other that helped shape the significance of what it means to see "the West." Here, I will focus instead on the figures, or figurations, that shape, in my corpus, the aesthetic in its transformation from sublime to picturesque

Within today's cultural framework, one way to grasp the fundamental transition of which the films are both a producer and a result, is to compare the paintings of Thomas Cole (1801-1848), Frederick E. Church (1826-1900), Albert Bierstadt (1830-1902), or Thomas Moran (1837-1926), for example, with the brilliant, glossy color photographs in the National Geographic magazine. If the Sublime is, in the words of Kant and Burke, an experience that threatens the subject with a loss of self as the self is overwhelmed by nature, the anxiety produced by the experience of the modern sharpens this threat to an unbearable Angst that needs reassurance. Catering to this need to reassure without depriving the modern subject of the thrill the sublime experience provided, the aesthetic of the picturesque offers a different measure according to which the landscape of elsewhere, impressive as it is, can be mastered. ${ }^{2}$

The category of the picturesque is, however, more specific than that. It is bound to what characterizes the Western most specifically: nature, and the possibility to conquer it. Nature is its main character, its figure, and the ground on which figurations suitable for picturesque aesthetic experience could be shaped. The systematic relation to the sublime is important to keep in mind. For, as we know, the sublime is neither a thing - an object, a work of art, or a landscape nor a feature of such a thing, like "beauty." It is essentially an experience. And that experience entails a desire. The experience of awe, of being almost - but importantly, not quite - overwhelmed by nature's grandiose power, incited the desire to retain or regain mastery. Mastery over the self, so that one can remain or become again, a full, rational subject. ${ }^{3}$

The key element in the passage from the sublime to the picturesque is distance. Whereas the experience of the sublime is awesome due to its threat to the subject who is part of the natural scene that threatens to engulf him, the picturesque puts the object of vision at a safe distance. As a result, the subject is involved enough to enjoy it, but remote enough to enjoy the beauty of the landscape without partaking of its often huge, almost overwhelming qualities. This is the aesthetic equivalent of armchair travel. The reassurance emanating from the distance at which the view is projected is a condition for another feature of this aesthetic. It helps the viewer feel in charge. One becomes the visual owner 
of what is on display. This aesthetic promotes a colonizing mode of looking that is a form of appropriation. In contrast to the sublime, with its powerful encapsulating of the viewer who needs the risk this entails in order to feel empowered by conquering it, the picturesque produces a viewer who hardly risks anything, but whose thrill comes from the sense of visual ownership. Needless to say, this aesthetic is the more appealing for our corpus as it naturalizes the real colonization of beautiful wilderness on which it is predicated.

Some of this problematic of mastery, distance, and appropriation lingers in the usage of the term picturesque contemporary to our films. There, this term refers to an aesthetics that is not merely based on definitions of beauty, but fits into a particular way of showing the world. The crucial feature of this mode of showing is the possibility of commodification. Commodification is a form of mastery; in fact, the strongest form of mastery that entails actual, material possession. This strikes me right away as the systemic, perhaps passionate, opposite of the sublime. The picturesque mode can, in turn, be transported all over the world as a modern commodity. $\mathbf{U}$

This meaning of the term picturesque is evident in the contemporary press. For example, in the 1911 article "Exporting the American Film" in Motography, the picturesque is defined as follows:

This is the picturesque - what is bizarre, exciting and unusual in American life, chiefly scenes of cowboys and Indians. This picturesque, a real, definite commodity of genuine commercial importance, goes with many another moving picture film across the seas. ${ }^{4}$

Clearly, the picturesque quality of the films is related to a consumable and an exportable vision of "American life." The vision itself is the "thing" to be sold. But what makes this vision commercially promising? The answer lies in the rhetorical production of landscape as backdrop for the quintessential American-ness of what is on display. This quality, or rather, this vision, is inherently nonfictional and fictional at the same time. Nonfictional, because it presents fragments, scraps, of "real" American life (or landscape). That is its primary attraction. Authenticity is, thus, a strong element in the product for sale. On the other hand, this product is fictional, because it freezes these impressions into bits that come to stand, as synecdoche, for the whole from which they were taken. $\mathbf{\square}$ Nonfictional, then, but displaying only those bits of the reality that were "bizarre, exciting and unusual." And the author qualifies these bits rather casually as "chiefly scenes of cowboys and Indians." In other words, what is both essential and exceptional in American life can become something properly commercial, and hence, picturesque.

This raises the question of the relationship between rhetoric and fiction. In argumentation, rhetoric may be suspected of manipulating the discourse to ap- 
parently enhance, but in fact, damage, the truth-value of the argument. However, in any form of cultural discourse, such as film, rhetorical structures do not in and of themselves turn the text into fiction. ${ }^{5}$ If this were so, the category of nonfiction would lose all potential analytical value. In terms of the case at hand, synecdoche as such does not entail fictionality. But its use does raise an important issue of modes of signification, which affects the traditional distinction between fiction and nonfiction. The use of rhetorical figures in early cinema - a subject that deserves a separate study - does, I contend, make that distinction problematic. For, if rhetoric does not equal fictionality, neither does it yield a straightforward, "transparent" reference to what is assumed to be "reality." Rather, rhetoric establishes realism as an effect, as a mode of signification, one that therefore cuts across the binary opposition of fiction and nonfiction. ${ }^{6}$ It is precisely because it is neither fictional nor nonfictional that the working together and mutual influences of both fiction and nonfiction in the usages of landscape are significant. By means of this figure of synecdoche, the vistas come to function as shifters between fiction and nonfiction, as well as between plot and story, or syuzhet and fabula. ${ }^{7}$

I borrow the term shifters from linguistics. There, it refers to a category of words that are not referential. They have no meaning that can be found in dictionaries, but they help set up the referential world to which the text relates. In contrast to, for example, nouns or adjectives - say, "mountains" or "yellow" shifters only have meaning in relation to the situation of utterance. Their meaning is produced through indication rather than reference. Personal pronouns of the first and second person - I, we, or you - are shifters. But "he" or "she" are not. These latter words, although also in need of identities to fill them in, do not change when the situation of utterance changes. But when " $\mathrm{I}$ " speak and "you" answer, "you" become "I," and "I," "you." "She" remains the same, since both "I" and "you" know whom we are talking about. If we don't know who is speaking, the first and second person pronouns have no meaning. Similarly, we cannot "place" the meaning of such words as "over there" or "right here" if we don't know from where the speaker is speaking. Nor can we "time" the meaning of "yesterday" without a determined time frame.

I use these examples of shifters to suggest that time, place, and person are their primary anchor. If I now establish an analogy between such a linguistic category, on the one hand, and an aesthetic and a narratological one on the other, a few questions arise. Firstly, how does this analogy shed light on the notion that, as I suggested, the figure of synecdoche makes the vistas function as shifters between nonfiction and fiction, as well as between text and fabula? Secondly, how does that notion further illuminate the aesthetic of the picturesque as an extreme form of mastery, namely commodification? 
Like a personal pronoun, the vista that constitutes a particular landscape filmed, and hence, both recorded and narratively made significant, derives its meaning from the look that fills it in as "real," "authentic," "American." It is, thus, a gateway to a whole experience of seeing reality that speaks the visual discourse of ethnography, travelogue, or postcard. The situation of utterance is inflected by that participant in it, the viewer, who is the primary "you." This "you," we can say, "speaks back" to the film, confirming its meaning as nonfiction. The vista, in this sense, suspends its meaning until the "you" processes it.

But then, the "I," say, the vista's immediate successor in the unfolding of the moving image, takes the floor back and "speaks" the discourse of fiction. For the next image shows an actor, figuring the actions our journalist called "bizarre, exciting and unusual." Now, the scenery gives up its meaning "authenticity" in favor of that of "place where these bizarre things (can) happen." In order for the fiction to work, the "you" must speak back in acceptance of the opposite meaning, namely, "fiction." For, only then can the actions retain their bizarreness without forcing thrill into fright or even trauma. Place and time are made dependent on the vista's processing from moment to moment of the filmic text as its "you" is watching it. The second mediation, not between persons and place/time but between the filmic text and the fabula that consists of the series of actions and events, operates in the wake of this function of the shifters. Depending on the direction of the analysis, the movement between film text and viewer is horizontal - with first and second person exchanging positions or vertical, with the emphasis on the sequence of images - the text - or on the reconstructed series of events that the viewer takes home.

Taking home: this is, metaphorically, what viewers do with the films' images. In this sense, a mental postcard remains in the possession of the viewer, just as much as, say, the bizarre and exciting actions that happened "in" the landscape of "the West." Instead of overcoming awe and thus feeling the satisfaction of being a rational subject who masters the words, albeit tenuously, the vista as shifter implicates the viewer in a desire to take the landscape home.

This special status sheds a particular light on the aesthetic implied and embodied in the picturesque imagery of the West. For aesthetics are just as dependent on the implied opposition that makes meaning, as other realms of signification, even if the aesthetic cannot be reduced to meaning. As I have suggested, the aesthetic of the picturesque implies as its other that gives it meaning, the aesthetic of the sublime that was so important in the period just before the advent of cinema. This temporal succession, and its embedding in the cultural transformation we call modernity, is a matter of prime historical importance for my inquiry.

In her article on early film and the American "Great Picture" tradition in painting, with Frederick Church as its most famous representative, Iris Cahn 
discusses the sublime as it occurs in the pre-cinematic painting tradition of American landscapes. Cahn argues that the sublime as pictorial quality is diminished by the shifts and reconfigurations of the modern world. Accessibility, for example through the railroad, "lessened the value" of these regions. Cahn's argument depends on a historicizing of the trope of decline. According to Cahn, with the waning of the sublime, landscape disappeared from center stage to become a mere background for stories (1996: 91-92). I would like to footnote this view a little. For, the idea of decline, an historical ideologeme of great importance and widespread application, represses the meaning of change and of the remainder of that which the novelty allegedly replaces. To put it succinctly: Maybe the sublime vanishes, yet it seems to be replaced by the picturesque. And replacement is never total. ${ }^{9}$

Cinema reshapes the sublime into the picturesque rather than replacing it wholesale. The primary change is that the picturesque, through cinema's doing - but not exclusively - makes landscape a modern commodity. And perhaps, as Cahn suggests, due to the "mobility of referent," cinema turns landscape into a more transient version of the sublime. ${ }^{10}$ But rather than comparing the sublime and the picturesque hierarchically or developmentally, I propose to look at the aesthetic transformation at stake. This is necessary, not only because such value judgments rest on an elitist view of art which is, by definition, at odds with a mass medium such as cinema. It is also necessary because the replacement thesis represses what the two aesthetics share, and hence, how the new one retains elements of the one it transforms. Finally, such a revision of Cahn's thesis is necessary because it presupposes a "thing-ness" of the aesthetic that is in contradiction with that most characteristic feature of the sublime, its nature as experience.

The latter footnote, as it turns out, underlies the transformation itself. This transformation, then, is two-fold. First, as I mentioned above, the aesthetic changes from the experience of threat to a reassuring answer to that threat, offering the formerly mighty other as a thing to be possessed. Second, the new aesthetic of the picturesque reorients aesthetics from experience to attribute. This is just as decisive a change, modifying the very thought of aesthetics itself, from a sense-based connection between viewer and object into something manageable in which representation and distance predominate, and which is, moreover, a view which we still hold. This change entailed a change in the discourse which, as aesthetician Jean-Marie Schaeffer complains, rests on the profound misconception that aesthetics and artwork are one and the same (1997: 21). Because we are still immersed in this new aesthetic, the argument goes, it is almost impossible to even see that it was a transformation in the first place. Hence, I would add, the discourse of decline is the only explanatory model available. 
These two transformations join when through cinema, the sublime as experience of landscape, is transformed into the picturesque as a (pictorial) quality attributed to things seen. The difference resides in the mode of looking: whereas the sublime is an experience of the subject being in nature, overwhelmed and thereby threatened with annihilation, the picturesque is an experience of seeing from the outside, without being immersed in it, and hence, without being at risk. This change is a change in the culture of looking itself. Such a cultural transformation is general and profound enough to place it in the anthropological cultural context of modernity (Walter Benjamin). ${ }^{11}$

An awareness of this double transformation facilitates a better understanding of what the commodification of the landscape entails. The picturesque enables the subject to appropriate, indeed, incorporate the formerly sublime landscape by consuming its threat. In three areas of modern life this strategy facilitates this absorption. Thanks to the camera, the panorama can now be reduced to a glossy surface, bought and sent home on a picture postcard. Thanks to the railway, it can be consumed on a trip. Thanks to the combined contributions of photography and travel, the otherness of nature and its inhabitants can be colonized by consumption.

In order to probe further the strategic use of nature in relation to the viewer, this chapter is also the right place to say some things about the genre of the travelogue film and the place of landscape therein. In distinction from the fiction film, travelogues, while thematizing travel, lack proper characters. As in the sublime paintings, only anonymous figures occur. Although they are anonymous, they serve the purpose of identification with the figure of the traveler. They are anonymous, small, and either on their way to, or already inside, the awesome landscape. In these capacities they serve the important role of inviting the viewer to "enter" the image through identification with the figure of the traveler. Being anonymous, they stand for Everyman, but the latter qualified as daring, adventurous, risk-taking, and rewarded with excitement. In the works of these painters the figures are tiny compared to the image of nature (see, for example, figure (P1) This representation of scale facilitated the sublime experience by proxy. It also liberates the urban viewer from the spatial confinement that is the price of progress. Finally, they are inside the wilderness, or, as in the painting Emigrants Crossing the Plains (1867) by Bierstadt, on their way to even more awesome nature. The emigrants there are crossing the plains where some trees in the left foreground still offer the reassurance of shade, water, and vegetation, but they may well have days ahead with nothing but mountains: Rocky, raw, merciless, but so beautiful and impressive that any shudder the viewer feels joins with fear to cause a thrill. 


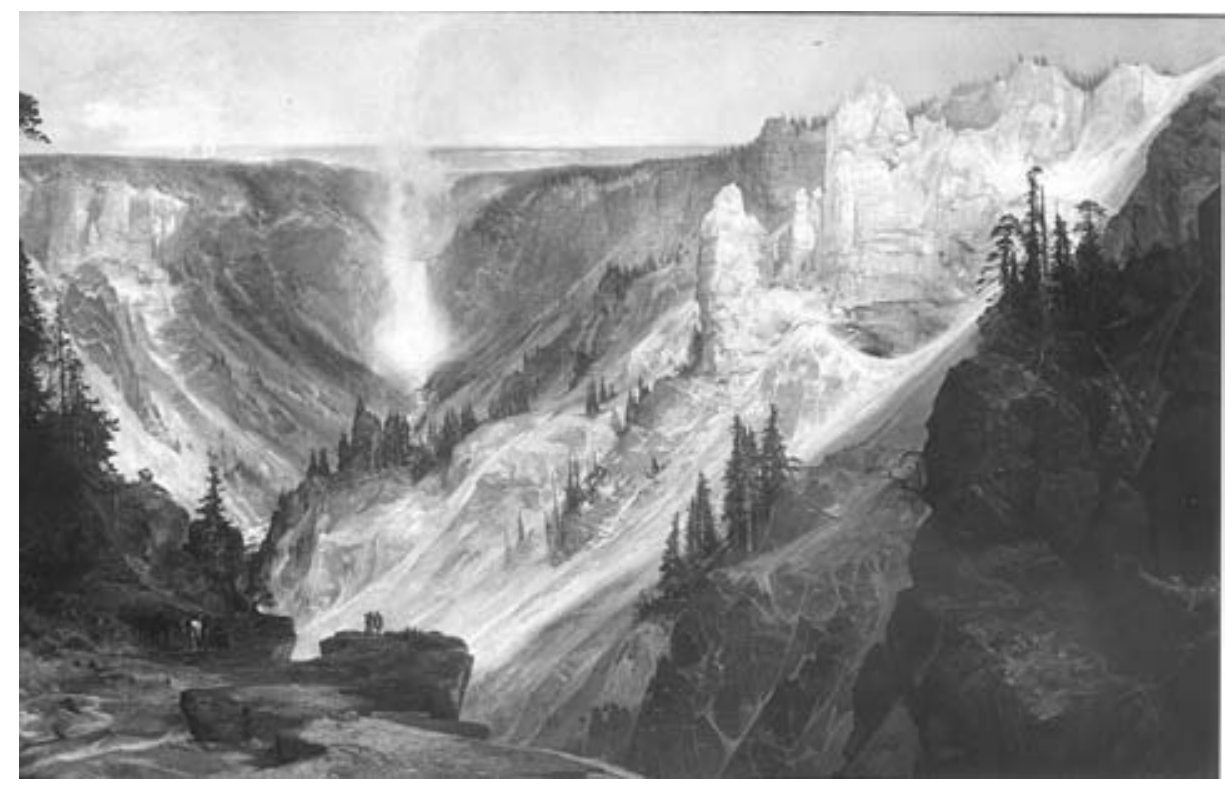

P1 Grand Canyon of the Yellowstone. Moran (1872)

In terms of the colonizing aspect so easily integrated in landscape representation - and so crucial in the aesthetic that turns sublimity into picturesque - it is noticeable that human figures in these paintings tend to be either exotic and part of the world to conquer, or they are tiny but casting their terrified look on the near-overwhelming natural world, turning their back to us in order for us to follow their gaze. Standing on the edge of the landscape - of the cliff, the lake, or the view as a whole - they literally mediate between the armchair traveler and his more adventurous counterpart.

In the 1990 catalogue of the Reynolda House Museum of American Art, the sublime in Church's landscapes is described in these terms:

The infinite botanical detail, the terrifying depths of the abyss, and the overwhelming sense of unlimited space combine to communicate a powerful sense of the sublime. As landscape became the primary vehicle for communicating this intense feeling of awe, artists became proficient in creating the illusion of infinitely receding vistas, and Church mastered the imagery more skillfully than any other American artist in midnineteenth-century America. ${ }^{12}$

Insinuating a religiosity that the concept of the sublime always appears to imply, one commentator on Church's use of figures alleged: 
Church never toys with scale, but he does alter scenes, for he often finds a vantage point where no one could really stand. The actor comes to the fore alongside the grander subject. In traditional painting, the point of view was fixed, outside the scene. Here Church subtly enters his world. In one painting, he in fact paints a Biblical revelation, Mount Sinai. There is no escaping Moses, the most privileged observer ever, as a tiny point in a larger scene. ${ }^{13}$

But these comments easily lead to a standard misconception. These relationships between small figures and great landscapes in Church's still images cannot be called sublime. At most, they help the sublime to occur. It is only if the viewer identifies with the figure that we can speak of a sublime experience, but then, by proxy. Our habit of calling the Romantic paintings of nature "sublime" makes for the tenacious misunderstanding of that concept and the aesthetics it indicates. But if sublime there is, it is not out there in the painting; it happens to the figure. Only if we identify, heteropathically - by stepping out of ourselves and letting ourselves be absorbed by the other - does sublimity become possible.

This limitation demonstrates that, far from signaling decline, the transformation that cinema ties into is already on its way in the paintings of the Romantic school. It is precisely because of their appeal to heteropathic identification due to the disproportion between nature and figures that Church's still images are, then, further "picturesqued" in the moving image. The figures are bearers of the look, which, through identification with these figures, the spectator is awarded - but now, this becomes a look into a manageable scenery. Manageable, I surmise, because visually reiterated and actually traveled. These figures stand in for "the people" of the region traveled. They walk in the landscape, caught in the act of "just being there." Clearly, the rhetoric of synecdoche is at work here. One figure, many figures; one experience, open for all.

Although the travelogue is a genre different from the fictional Westerns I am looking at, the family resemblance between the two genres - travelogue and fiction film - gives yet another slant to the kaleidoscopic view I am developing. By way of a demonstration of that continuity, I have previously mentioned films like A Romance of the RaIl (1903, Edison) or The Hold-Up of the Rocky Mountain Express (1906, AM\&B), in which the camera shoots phantom footage from a train, and where the fabula provides a sometimes rather flimsy pretext for the fictionality as attraction, sustaining a fluid boundary between fictional and nonfictional genres. $\mathbf{L}$ Grand Hotel to Big Indian (1906, AM\&B), for example, shows a rather dynamic pan shot from a train, following the twists and turns of the railroad track before it turns into a comedy. The Biograph Bulletin announces: 
Here is where Mr. Butt-In butts in. After a trip down the famous Horseshoe Loop from the Grand Hotel, on the Ulster and Delaware Railway, we show an interior comedy scene, and then a ridiculous happening on the track showing Mr. Butt-In trying to help a farmer manage a balky horse. ${ }^{14}$

Although this particular film shows a rather elaborate fictional story, the framing of this narrative through phantom ride shots is also quite explicit. In the case of this film, the interest lies in the shift of focus from outside to inside to outside again. After the opening traveling shots, the first fictional scene is set inside the train. We see a traveler picking fights with his fellow passengers. After some more phantom ride shots that intercut this narrative, we see the same character outside, next to the train tracks where a wagon and horse block the train, preventing it from moving forward. When the train conductors try to move the horse the man hinders them and picks a fight with the man on the wagon. They then remove the struggling man, move the horse from the track, and the train continues on its course.

Cases like these raise the question of whether travelogues can be said to be without narrative - or if fiction films are always narratively shaped. However flimsy the story, the figures carry whatever story there is, narratologically speaking, in the same way as in more strongly narrative films. What Church, in his still images, articulates through relative size - small figures, large vista - the moving image articulates through various relationships between figures, their visual and other acts, and the scenery in/on which these are performed. The visualization through acts entails and implies a form of taking possession - of conquest. By the same token, the aesthetic transforms intimidating sublimity into thrilling but manageable pictures.

This excerpt from the Biograph Bulletin of THE Moonshiners (1904, AM\&B) gives a taste of the tongue-in-cheek tone in which picturesque aesthetic effects were discussed in the trade press. It demonstrates that there were no secrets about what was done to cater to which taste:

In selecting the locality of this production, the greatest possible care was taken, and as a result there is a strong element of local color and picturesqueness pervading the film from beginning to end. In the opening scene we have the home of the mountaineer, typical in its rude architecture, and almost hidden by waving foliage. In front of the house stands a decrepit old horse hitched with ropes to an equally decrepit old wagon, into which the stalwart young mountaineer, Abe Smiley, the hero of the production, is loading his mugs of "mountain dew," to be taken to the "blind tiger," in town, and there exchanged for provisions and commodities. The jugs are carefully covered with straw, and a couple of children clamber in on top of the load. The mountaineer's wife, carrying his ever-ready Winchester, follows. ${ }^{15}$ 
The first scene of the film is described as a picturesque image. Even the figures, the characters of the film, are put in a pictorial place: they are positioned within the image, enhancing the couleur locale. Even the quotations ("blind tiger" and "mountain dew") are used to give the scene, as well as the review of it, a mountain flavor.

Symbolic for this type of manageability is the visual appropriator of the landscape, the traveler with the tourist gaze, within the image. Through this device the (film) viewer is literally placed within the image. The city-dwelling viewer, too busy with business to actually make the trip, is offered an attractive model, an alter ego who fulfills the film viewer's desire to travel, incited by the restlessness of modern life. In the list of titles that Biograph released for exhibition in Hale's Tour cars, from which I have quoted above, the railroad picture From Peticodiac to Elgin, New Brunswick is advertised in the following words:

A run through a Canadian wilderness on one of the most primitive roads in America. The engine and a flat car, carrying a group of sportsmen, are constantly in the picture, giving additional interest to the grand scenery. Of wonderful photographic quality. ${ }^{16}$

The inclusion of spectators in the image, as well as the quintessential symbol of tourist access, the railroad, is praised here as the additional attraction of the film, accentuating the antonyms of "the primitive" and "the modern," an opposition that is such an important constituent (and object) of tourist vision.

It is attractive to compare this structural property of the diegetic viewer with the role of the flâneur in cityscapes. Although the object of the gaze may differ, both types of "strollers," "window shoppers" or "wildlife watchers" can be said to appropriate the world visually, at leisure, while maintaining an invisible screen between the "self" and the "other."17 The film viewer is enabled to identify with the stroller engrossed in an activity so typical of modern city life. The walker in Western nature is, then, the Western incarnation of the Baudelairian/ Benjaminian flâneur in Paris, the figure formerly lost in and overwhelmed by nature, now a casual stroller in it. ${ }^{18}$ Thus, the wavering boundary between travelogue and fiction film itself argues for the aesthetic change as a facilitator of the medium's primary technology of aesthetic effect: The entrapment of the viewer. Structural devices such as focalization and perspective thereby are put in charge of a fundamental ideological mission.

Given the nature of the picturesque aesthetic as a commodity, or producer of vistas as commodities, it comes as no surprise that the new and cheap mass product of the photographic postcard became its carrier par excellence. These, in turn, informed filmic productions of vistas. Uricchio (forthcoming) writes in a similar vein:

Many early nonfiction film subjects extended a notion of documentation and temporality established in the illustrated press since the early 1880 os. Paradoxically, the still 
photograph established the dominant horizon of representational expectations. The introduction of relatively low-cost printing techniques in the last quarter of the 19th century, together with the proliferation of the illustrated newspaper and magazine, the stereograph and picture postcard, served quickly to stabilize certain representational conventions. On the production side, one can see similarities within pictorial compositions, image typologies, and markets between news photographs and moving pictures. Halftone photographic images of fires, parades, crowded city streets, disasters, and industrial processes and technology tended to dominate the new visual discourse in a process of standardization driven by producers, buyers, and audiences. The extension of these practices in the film medium may be seen among other places in American Mutoscope and Biograph's turn-of-the-century 68mm "living postcard" series attesting to the intertextual "fixing" of certain cinematic conventions not only by well-established production practices particularly evident in the press, but by the intertextually positioned expectations of viewers, again, largely informed by their exposures to the press.

While he presents the idea of a "living postcard" within the framework of temporality, I see the connection to aesthetic change as also being relevant.

Artist's Point (1903, AM\&B) is one example among innumerable instances of this kind. Its interest is obvious, for it is inserted within a film, but remains a postcard-type shot. The image of this filmic postcard consists of a very short, shaky pan over a hilly terrain. The image of the archival copy is very bad, and it looks as if it is painted or sketched, rather than photographed. This artistic imago fits the content of the image, for it shows a generic vista that is reminiscent of the landscape paintings, photographs, or the popular stereoscopic view cards.

These latter are particularly closely related to the early films. After its invention in 1861, stereoscopy became an immensely popular entertainment in the decades preceding the invention of moving pictures. People could collect the stereographic viewing cards and look at them in a stereoscope, the viewing device that allowed $3 \mathrm{D}$ vision of the double image on the cards. As a result, looking at images became a different experience from what it had been before. No longer a single-glance mastery through the window on the world, it became a more poly-sensual experience, where the viewer was immersed within the represented world. Mastery was replaced by a mode of viewing that included the sense of touch. This was a powerful trigger for the affective participation. The immersive strategy of $3 \mathrm{D}$ imagery suggest the possibility of "entering" the world of the image. Not surprisingly, travel subjects, landscapes, and exotic peoples were favorite subjects, often collected in containers that resemble the volumes of an encyclopedia.

But this change in the culture of looking had other aspects as well. On the back of the stereocards you can often find texts about the sites and sights in the 


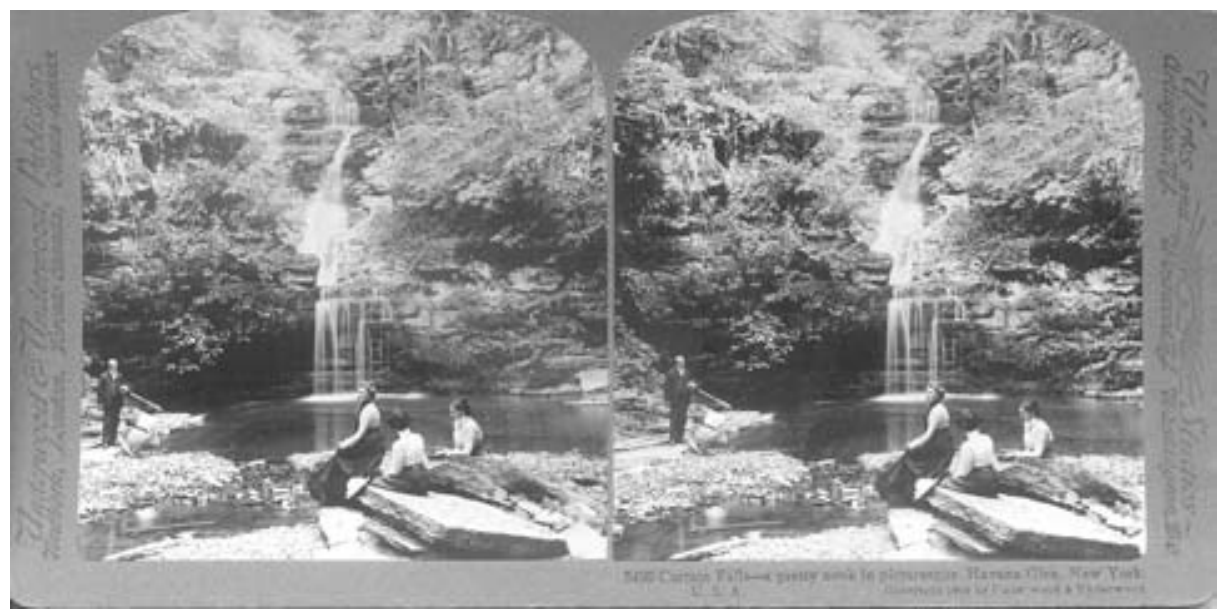

P2 Stereocard Curtain Falls (1904)

image. These are more than descriptive. The titles and subjects of the cards correspond frequently with the titles of the earliest nonfiction films. Film titles such as California Orange Groves, Panoramic View (1898, Edison) or California Oil Wells in Operation (1901, Edison), Serving Rations to the Indians (1898, Edison), and RoYAL GoRGE (1898, Edison) match generically similar card titles as, for example, At Breakfast: Typical Desert Home of Navajo Indians, Arizona (1904), Pumping Wells in the Oil Country (1903), Down the Granite Gorge (1903), or Curtain Falls (1904). For this last title, see figure P2. The text printed on the back of this last stereocard, for example, reads:

This is the town of Havana in central New York, about three miles from the famous Watkins Glen. It is a favorite resort for tourists; for more than a mile you can wander about in its picturesque gorges where there are a number of waterfalls as lovely as these. ${ }^{19}$

The tone is reminiscent of advertising. Clearly, these cards were part and parcel of the relatively recent efforts to promote travel for pleasure, as distinct from travel for migration, family visits, or business. T "Artist's Point," a prototypical image for both stereocards and early nonfiction films, is the significant emblematic name for specific locations that enable a grand outlook on the land below. For example, it is the name used for locations in Yellowstone Park (Wyoming), with a view of the Grand Canyon of the Yellowstone, in Yosemite Valley (California) with a view on the waterfalls, and in Monument Valley (Arizona), also notable for its magnificent view. 
The noun "point," indeed, had great currency for a good reason. Its ambiguity binds together the viewer and the view, the "point of view" from which nature is viewed as well as the spectacle itself. When the latter was meant, the noun received a qualifying indicator of place. There were many stereograph cards with titles such as: Glacier Point, Rowe's Point, Pyrites Point. These cards had a parallel in what we can call "filmic postcards." For the static footage of such views inserted in films were as static as the camera could be held still. The moving water falling down provided an almost still image of beauty. These images were moving only in the sense of touching the viewer: more important than showing movement in the sense of mobility, was the movement of the spectator. But "touching," in turn, retained the dual meaning of an emotional and physical, immersive touch. The immersive effect of stereoscopic cards, the ${ }_{3} \mathrm{D}$ illusion that puts the spectator "sensationally" within the image, is strived for in these static films. Observation points function thus as entry points, or rather, diving boards for the spectator to enter the image. The noun "point" in the name, then, is to be taken as little more than a metaphor.

There is more to these cards than meets the eye, however. The immersion effect is not the opposite of, or an alternative for, the conquering gaze of old. It is a further, rather daring extension of it, one that puts the viewer at risk on an emotional and sensuous level, but also extends the satisfaction that came with an awareness of the joint powers of conquest and technology. The cards were part of the logic of collecting that was an important aspect of this visual culture.

Ellen Strain (1996) analyses how tourism was part of a broader visual culture of the 19th century that was based on strategies of collecting - mapping and storing the world in visual terms - and immersion - creating a visual world that submerges, or can be virtually "entered" by, the spectator. ${ }^{20}$ She writes about stereoscopy:

In the realm of stereoscopy [...] the logic of the collection was supplemented with a concern for immersive entertainment. Like the museum display with its three-dimensional animals and curved dioramas designed to create the illusion of enclosure within an exotic space, the stereoscope filled the viewer's range of vision with three-dimensional images. (95)

"Moving," thus, receives two different embodiments. The stereocard appealed to the involvement of the senses, while the moving image appealed to the bodily movement of the viewer as target of the image that itself remained still.

Both these stereocards and filmic postcards, as you could call these moving but static films, depict geographically significant locations, meaningful for their capacity to offer a point of view, the spectacle that results, and the moving effect. Since they offer a literal, yet overdetermined "point," a puncture of the 


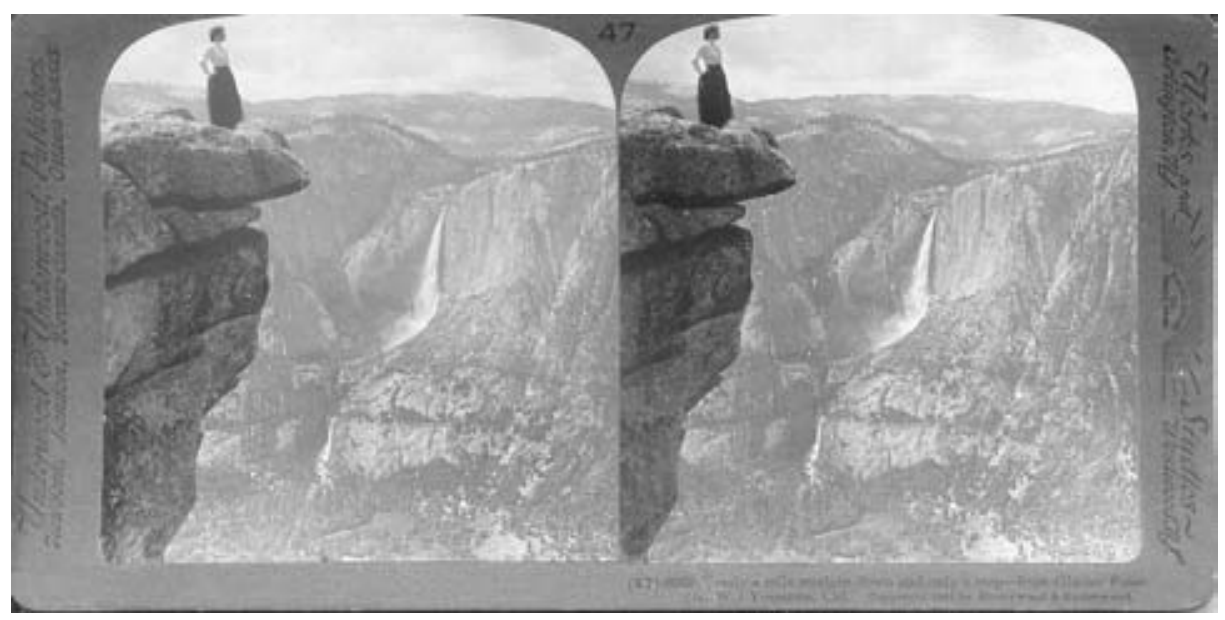

P3 Stereocard Glacier Point (NW) Yosemite, California (1903)

image that makes the border between represented world and viewer permeable, let me call these panoramic sites "punctuated" places. ${ }^{21}$ For, in images so called, the camera points at, or rather, from a specific spot that is emblematic for its vantage point. The image thus recreates the point of view of the tourist that looks at a well-known vista or point from this position. His/her stand-in, the armchair traveler who looks at famous photographs, paintings, postcards, or stereocards of these vistas, follows the same direction of the gaze, and from the vantage point that deserves its own name. Punctuated places are therefore places with a name that signifies the direction of a look to another place. It is punctuated because it is a "starting point" of a look elsewhere; moreover, the "elsewhere" is broader and therefore more vague, than the specified "point" in the landscape: the observation point that can be marked on a map. The place that is looked from becomes equal to the place that is looked at. The observation point signifies the beauty of the object of the look.

As a consequence of this logic of the sublime-turned-picturesque, the exemplary viewer is, at least implicitly, represented within the image. This is clearly and explicitly the case in the stereocards of the next illustrations. In the three additional examples I present here, this viewer receives even more meaningful representation. In all three, this representation is reassuring, but in different ways, all highlighting the fact that the figure of the viewer is representative of the intended real viewer, traveler, or consumer of images. In the first card (see figure (P3) this viewer is female. The silhouette of the woman whose light blouse and dark skirt offer the same contrast as the bright sky with the dark rock, stands dangerously close to the abyss, yet with a body language that 


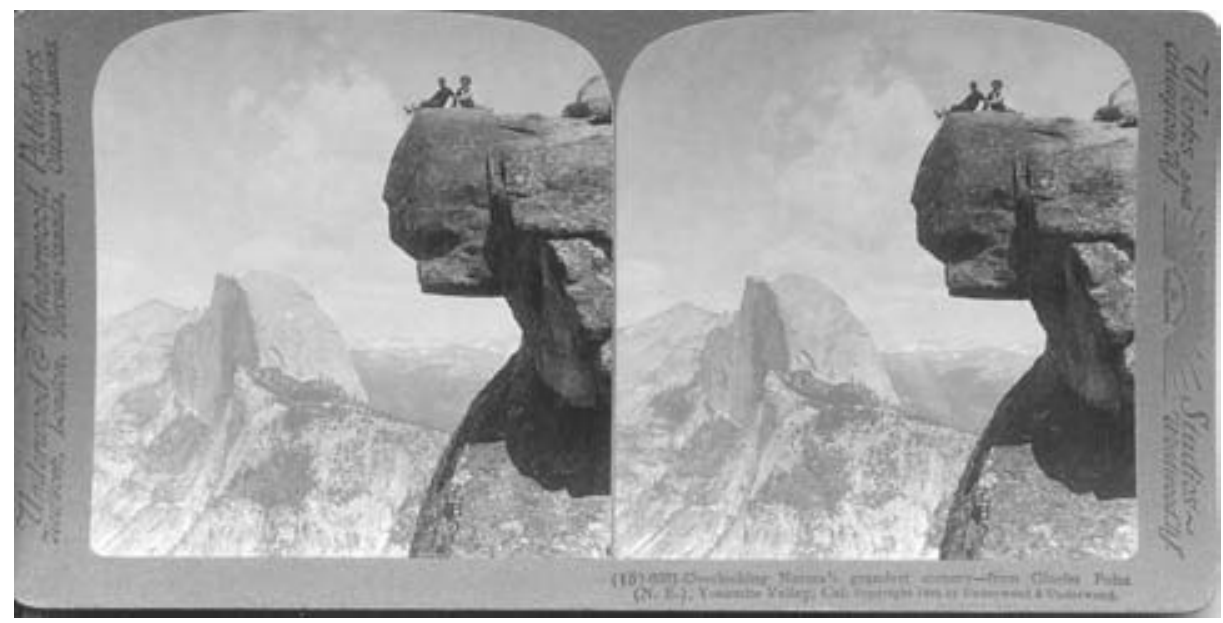

P4 Stereocard Glacier Point (NE), Yosemite Valley, California (1902)

exudes relaxation. Enjoying the vista with her arms bent at her sides, this viewer clad in feminine dress is clearly at ease, enjoying the beauty without reminding us of any of the dangers of travel.

In the next image (see figure $\mathrm{P4}$ ), the single woman is replaced by a couple. Sitting as if for a picnic, the tiny figures do not fail to signify their heterosexual unison. The man, of course, is closer to the abyss. He seems to be testing, childlike, how far he can go. The woman is turned in the opposite direction, as if she had been leaning against his sturdy back and is now holding his arm to prevent him from falling, but not at all panicking. In the third image (see figure P5), the couple is emphatically posing for the photographer, who is standing still higher up than they are. The woman is sitting at the edge, but with another ridge right below it so that no danger is indicated. She sits in an elegant pose frequently taken by female sitters at the time, whereas the man, hands in his pockets to demonstrate a relaxed holiday feeling, is towering over the small platform on which he stands. The three poses are all highly conventional, signifying, in addition to the enjoyment of nature's beauty, both safety and innocence. In none of these images is work, conquest, fighting, or colonization anywhere in view.

From this perspective, the image of the stereocard of Curtain Falls (figure P2 ) is even more complex. Here, the scene between represented viewers repeats the scene between the card viewer and the scene represented therein. The group of women, in uniform white blouses and dark skirts, are disposed on the rock with the elegant visibility of women in the tradition of the Three Graces. The man approaching them is standing still, one imagines, in order to better take in the sight of them. If one conjures up the image of a stereocard taken from the 


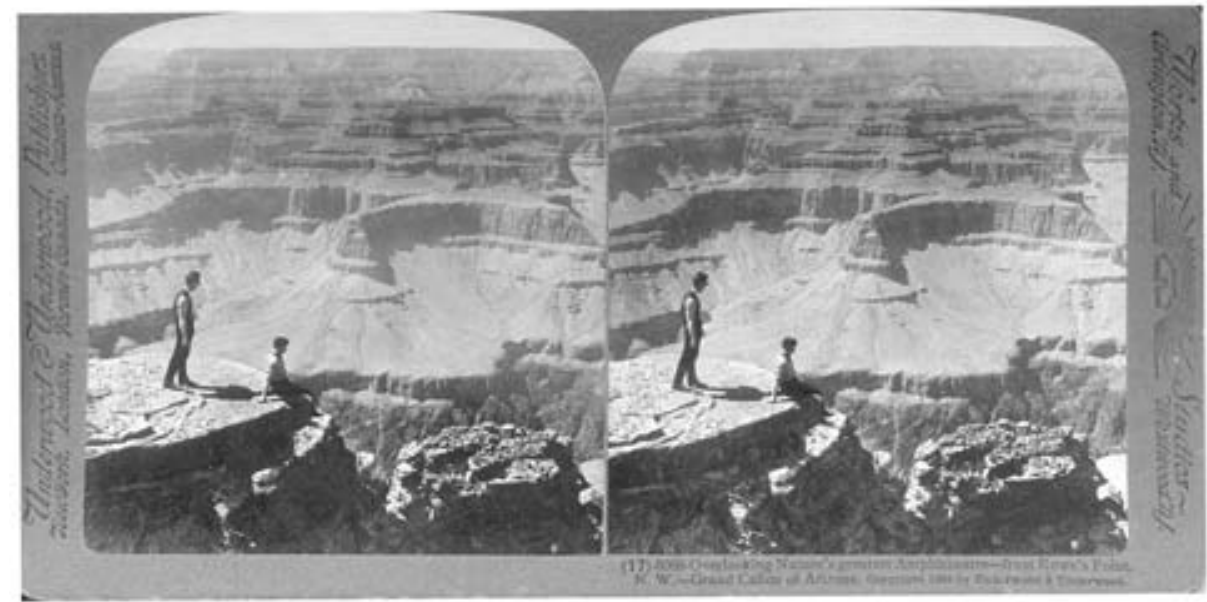

P5 Stereocard From Rowe's Point (NW) Grand Cañon of Arizona (1903)

back of this scene, the man would see the three women in the way we see the waterfall: tangibly close, three-dimensional, and forming a $3 \mathrm{D}$ triangle that sucks the eye in to its furthest point of depth. Reassurance concerns less the dangers of the scenery, virtually absent here so close to home in New York State, than the accessibility of the object of vision in this gender-wise exchange.

Similar images occur within or even as moving images or films. Films like Waterfall in the Catskills (1897, Edison) or Lower Falls, Grand Canyon, Yellowstone PARK (c.1899, Edison) are in their essence filmic postcards. They show frontal views of waterfalls. This choice of subject matter is in turn significant. It allows the film to integrate the static image so apt to induce visual rapture while retaining a reminder of the medium's wonder: the water coming down moves, but otherwise it is a static shot. This is a clear case of the double resonance of intertextual allusion. It retains the charm and immediacy of tourist snapshots, and at the same time recalls the prestige of high art. Indeed, waterfalls are painted, in such works as Falls of Kaaterskill, painted by Thomas Cole in 1826, photographed - William F. Jackson photographed Yellowstone Waterfall in $c .1871$ - and filmed by companies like Edison. ${ }^{22}$ These filmic postcards are early single shot images, but later, in longer travelogues we see compilations of this same imagery. Films such as [NATIONAAL PARK IN AMERIKA] (c.1918), A Trip Through the Yellowstone Park, USA (1906, Edison), [Yellowstone PARK] (1912, Edison) or [Het AARdsche PARAdiJs] (c.1919) can be considered the equivalent of postcard albums. 
The transformation of aesthetics from the Great Picture to the Picture Postcard is, thus, more complex than an ideology of decline would suggest. This view asks for a more in-depth discussion of the picture postcard, which functions as evidence, memorabilia, and mnemonic tool. The word that names these objects, memorabilia, resonates with both "time" and "space." Mementos of travel are precisely traces of the experience of time and place: the time when you were traveling, the duration of the experience, and the places that you visited. The dictionary meaning of the word memorabilia, "things that are remarkable and worthy of remembrance," should be taken at face value, and quite strongly, even if the things - flimsy, glossy, often kitschy postcards - have little value of their own. ${ }^{23}$ Memorabilia are also "things that stir recollection," a definition that also points to their double function. Memorabilia point to themselves, as commodities, as well as to memories of other times or places. And to other people; the people the viewers or recipients cannot be. As for postcards, perhaps the aesthetic of the picturesque can be taken most seriously if postcards may be considered as traveling souvenirs: you can write yourself in the postcard and send it home, another step on the path from sublimity towards the picturesque.

The acquisition, collecting, and sending of postcards, the acquisition, home display, and giving away of souvenirs, visiting World's Fairs, and more generally, all kinds of forms of tourism are practices that belong to the commodification of travel. As Ellen Strain poetically puts it:

The world was a quarry of sights and sounds which could be mined by the enterprising few and put on display for the middle class who attended world fairs, circulated through museums, and collected stereoscopic view cards. (1996: 75)

I will have more to say about the place of travel in this new culture. T Here I wanted to offer a brief analysis of the meanings and sign systems that link travel, as the opening up, the conquering, and the "final" domestication of the West, to the objects that constitute the large domain of memorabilia that were travel's after-effect and side-effect. ${ }^{24}$ Our films exist historically in continuity with these practices and commodities; thus, the kaleidoscopic cultural setting of the films is widened yet again.

\section{Notes}

1. Wilson Mayer, "Moving Picture Work of the Railroads," Nickelodeon I, 2 (February 1909): 41-42.

2. Church and Bierstadt were second-generation artists of the so-called Hudson River School, the first coherent school of American (sublime) landscape painting, founded by Cole in the early 19th century. 
3. For background information on the Kantian concept of the sublime, see Paul Crowther, The Kantian Sublime: From Morality to Art (1989). For the sublime in aesthetic theory, see Walter J. Hipple, The Beautiful, the Sublime, and the Picturesque in Eighteenth-Century British Aesthetic Theory (1957). A concise exposition of the concept can be found in Ernst van Alphen, Caught by History: Holocaust Effects in Contemporary Art, Literature and Theory (1997: 193-205). A classic study of the picturesque is Christopher Huyssey, The Picturesque: Studies in a Point of View (1967 [1927]).

4. Motography VI, 2 (August, 1911): 90.

5. I refer here to a distinction between fiction and nonfiction based on claims of "truth," in the sense of "mediated" or "arranged" presentation versus an aesthetic of transparency.

6. In our article "Rhetoric of Space: Landscape/Cityscape" (2002), Eva Warth and I analyze the operation of the binary oppositions of fiction and nonfiction. We argue that through rhetorical figures such as synecdoche and opposition, early nonfiction establishes reality as an effect and works together with fiction as a discursive practice. See also $\mathbf{L}$.

7. Bordwell (1985) discusses fabula and syuzhet as principles of narration in fiction film.

8. About the study of shifters within the field of theoretical linguistics, see Hengeveld (1997).

9. The term ideologeme, or minimal ideological unit, coined after the semantic term sememe, a basic unit of meaning, comes from Fredric Jameson's The Political Unconscious (1981). In essence, this ideologeme of decline operates as oppositional parallel to the ideologeme of improvement: both are applied in the historiography of sophistication that sketches the development of arts and media. $\mathbf{A}$

10. For a discussion on the sublime in relation to the experience of the moment in modernity, see Charney (1995).

11. See for an analysis of this aspect of Benjamin's work Susan Buck-Morse (1991).

12. From the on-line edition of the catalogue American Originals: Selections from Reynolda House, Museum of American Art (1990).

13. From John Haber's review of the 2000 exhibiton of Church in the Berry-Hill Gallery in New York City, published on his web site: Postmodernism and Art History: Gallery Reviews from Around New York.

14. Biograph Bulletin 73 (June 30, 1906).

15. Biograph Bulletin 25 (July 28, 1904).

16. Biograph Bulletin 73 (June 30, 1906).

17. For a comparison between the flâneur and the tourist, see Friedberg's Window Shopping (1993).

18. Livio Beloï writes on the Baudelairian flâneur in comparison to the strolling eye of the Lumière cameramen (1995).

19. For more on the place of stereocards in the transformations in the cultural experience of vision in the late 19th century I refer to the seminal study by Jonathan Crary on the historicity of vision, Techniques of the Observer (1990). The examples and illustrations of stereographic cards that I use here are from the collection America through the Stereoscope volumes I and II, published in New York by Underwood \& Underwood Publishers between 1902-1906, graciously lent to me by Marja Roholl and William Uricchio from their private collection. This representative collection is in- 
deed held in a box that looks from the outside like two volumes of a 19th-century encyclopedia.

20. This principle of stereoscopy can be considered a prelude to the digital virtual reality that was to be invented a century later. About immersion and the principles of Virtual Reality, see Jonathan Steuer (1992).

21. The inevitable reference to Roland Barthes' frequently used term "punctum" cannot be helped. It is only partially justified, however. Although "punctuated locations" punctured the viewer's separation from the image, this puncture is designed and predictable, not surprising and personal like Barthes' punctum (1981).

22. To illustrate the profusion of this theme in films, let me list some more titles by Edison and Biograph: American Falls from Above, American Side (1896, Edison); Falls of Minnehaha (1897, Edison); Passaic Falls (1896, Edison); The Upper Falls of the Yellowstone (1901, Edison); American Falls, Goat Island (1896, AM\&B), American Falls, Luna Island (1896, AM\&B); Cascade Near WAWONA, CAL. (1903, AM\&B).

23. On the deeper emotional value of picture postcards, see Naomi Schor (1992).

24. In fact, Patricia Limerick (1987: 25) proposes that it was the popularization of tourism and the museification of the Western frontier that marked its closure. The conquest of the West was complete the moment it became a tourist attraction. About the definition of the frontier and its (supposed) closing or ending see $\mathbf{E}$. 


\section{Questioning Categories}

The shock of laughter ... designates the loss of equilibrium that is always entailed by an actual fall into history, where history itself can be experienced only nonteleologically, as a constant falling.

- Kevin Newmark, $1995^{1}$

Throughout this study so far, I have been questioning the categories upon which film history, and specifically, the history of a genre such as the Western, is predicated. In that endeavor, I have systematically considered all those features of my corpus that an evolutionist concept of "the Western" inevitably, by virtue of its own logic, would compel historians to consider as flaws, imperfections: signs of "early" as a lack of sophistication and development. Hoping to counter such a logic, the remedy I have been advocating has been to take any such features as defining the emerging genre, rather than hindering it. As a result, I argued, the films of my corpus cannot be labeled through the terms of a later and altogether different genre, the one we now see as the Western. Deploying the means, visions, and cultural habits available at any given moment, to effects we are now barely able to see is not the same as naivety. So far, this reasoning seems to point to limits of what history can accomplish. But what if the films themselves use, enthusiastically and self-consciously, their own defining features as strategies to flaunt their alleged properties? In this chapter I will argue that one of the strategies that definitely undercuts any attempt to see flaws or naivety in what is, instead, a joyful endorsement of means and possibilities, is already provided in the films themselves.

To be sure, parody and comedy are also notions that have changed their meanings over time. But one elementary feature that such strategies of representation display, namely irony, is double-edged and self-reflexive. ${ }^{2}$ Difficult as it is to demonstrate irony - its subtlety and ambiguity are precisely what define it - once deployed as a reading strategy, it opens up dimensions of meaning that question the categories on which previous reactions were unwittingly based. In addition to questioning genre categories as well as the notion of "early," then, such irony-based genres as comedy and parody also question chronology. ${ }^{3}$ For, they are based on reflection on earlier productions. In other words, they flaunt their historical position after the beginning. 


\title{
"A Cowboy for a Day"
}

RELEASED FRIDAY, APRIL 21

\begin{abstract}
Clarence wants to be a cowboy and the boys have lots of fun with him. Every hazing trick known on a ranch is played on him, and he is finally made the victim of an Indian attack and captured by the made-up cowboys and preparations made to burn him alive. He is then rescued by the rest of the gang who heroically drive away the fake Indians. Later when Clarence finds out the joke he decides to play one himself. Dressed as an Indian he enters the bunk-house and begins shooting promiscuously with two big guns. The cowboys are completely routed, and when Clarence makes himself known they accept the joke on themselves and agree to leave him in peace hereafter and to help him become a real cowpuncher.
\end{abstract}

Q Bison ad for Cowboy for A DAY, Moving Picture News IV, 15 (April 15, 1911): 29

Taking my lead from such strategies, I will first return to a film I have already discussed, and probe its potential self-reflexivity, before turning to a more obvious case where this potential is actualized. As I mentioned, in CoEUR ARDENT (1912, Gaumont) the landscape plays a remarkable part. $\mathbf{L}$ And since landscape is perhaps the only defining feature, in terms of this chapter's questioning, I can now suggest that this almost reversed relationship between landscape and action might be seen as a commentary on the notion of "Western" itself. The Indians literally racing into the landscape, entering the image from the back and riding to the front underline the centrality of that one feature that defines the genre. This is the more convincing as the film was shot in the South of France, so that "Western scenery" is emphatically not a reality but an object of representation. The same can be said of the presence of the aboriginal inhabitants of "the West." This film is set in pre-contact days, so that the typical plot - hostilities, fighting, rescue - evolves within Indian communities, not between Indians and settlers or cowboys.

The plot is based on an inter-tribal love story. A father has a serious talk with his daughter, who then goes and fetches her boyfriend to meet the father. Father and fiancé smoke a pipe together. Then the father says things that make the young man protest vehemently. Clearly, the match is not an approved one. The couple devise a plan to steal cattle, suggesting that lack of possessions was the reason for paternal disapproval. The landscape of the Camargue marshes facilitates wonderful shots of cows swimming in deep water, barely holding their 
heads above water. This shot, it turns out, will be proleptic of later events. The other tribe discovers the crime. The father of the girl is clearly unhappy with the turn of events.

An Indian races into the image. The thief is captured. The tribe deliberates on the punishment. Here is the deal: all members of the disadvantaged tribe are allowed to shoot at the young man until he reaches the water. He is sentenced to be a living target. This is the fulfillment of the prophecy of the swimming cows. Struggling with his horse in the water, the young man almost drowns. Exhausted, he reaches the other bank. The girl leaves her camp on horseback, armed with a gun, to rescue him. When the fiancé proves his courage by shooting two Indians, the couple obtains permission to marry. The girl is clearly the boy's equal, but he also passes the test with ease.

If irony is the kind of self-reflexive double-talk that it is frequently taken to be, based on an unbridgeable discrepancy between what is stated and what is meant, then this sweet-ending film is not ironic in any obvious way. But irony is so hard to grasp precisely because it is not totalizing. ${ }^{4}$ I will suspend judgment, except to suggest that COEUR ARDENT, a comedy in the sense of its happy ending rather than any overt irony or laughable scenes, foregrounds three elementary features of the Western in a rather emphatic way. Perhaps there is irony there - a French wink to American popular culture? -

perhaps not. In addition to the foregrounding of landscape as an actant - the young man's near-drowning is, in fact, a fight between the landscape and the human - and the deployment of stereotypical plot elements - cattle theft, capture, and rescue - the "discussion" about the fiancé's eligibility based on his lack of possessions appears emphatically far-fetched.

Of course, this does not make the film a parody; its potential irony cannot even be demonstrated with any amount of clarity. Instead, I propose to take this film as an injunction to suspend the categories - both "Western" and its parody - on which such decisions would be based. This is also the case with the second film I wish to bring in. Destiny is Changeless (1912, Vitagraph) tells a convoluted story set among lonely trappers in the forest. A man courts a girl by forcing a bearskin upon her. A second man shows up with the same intent and purpose. He, too, forces his skin upon her. The two men fight. The first one pulls a knife. In order to stop this dangerous situation, the girl, in the manner of fairy tales, promises to marry the one who will bring her the skin of a blue fox. If nothing else, this trick will gain her some time. The second man wants to shake hands with the first, who refuses. When the second leaves, the first secretly follows him. Good guy and bad guy are thus clearly identified from the beginning. In a remarkable shot where he is directing his boat straight at the viewer, the second man arrives at the bank, and walks, again towards the viewer, to set his trap. We see a boat with four Indians. The first suitor comes 
upon the second while the latter is cooking a meal. He puts his gun aside. The Indians creep up on him - again, straight towards the viewer - and turn left when they arrive at the picture plane.

In an extraordinary demonstration of racial allegiance, the two suitors, when their fighting is interrupted by the arrival of the Indians, together fight the latter. The second suitor saves the life of the first, who still refuses to shake his hand. In the following shot, the second suitor finds the skin of the blue fox, as if ready-made. This could be the end. But then he is caught in a wolf's trap, which is clearly very painful, thus occasioning dramatic acting. The first suitor finds him but instead of repaying the favor by saving his rival, he steals the fox skin. When the victim begs him, all he does is kick and laugh at him. The victim faints, and the culprit looks at the viewer in what appears to be remorse. This is shot in extreme close-up. After some thinking he goes back to release the other man. Taking his unconscious rival on his back to the boat, they go together to the girl's house. He carries the second suitor up to the house, puts the prizewinning skin on him, knocks on the door and leaves. The girl finds the second man who doesn't know how he got there, but does give her the skin. He faints in her arms.

Again, there is no way to determine whether this film is ironic or totally, straightforwardly in earnest. If anything in this film is ironic, it might be the elaborate symmetry between the two halves of the plot. The bad guy becomes worse and worse, until he turns around and becomes more and more self-sacrificing and heroic. But I am more interested in the ironic potential of the filming itself. By making the movements so emphatically frontal, the viewer is told that this concerns her/him, but also, that this is a trick of representation. The film's narrative is no longer told "in the third person," evolving on the screen out there, but comes rather aggressively at the viewer. With the close-up of the guilt-ridden convertee as the central moment, the moralizing nature of such recognizable plots is perhaps driven home a bit too emphatically to be credible. Yet, like the previous one, there is no inherent reason to consider this film parodic.

Parody is an intertextual form. It takes a lot of knowledge of previous texts to be able to spot the quotations that identify a text as parody..$^{5}$ As Janet Staiger puts it: "One unambiguous index of a story's familiarity is its replication in parody, since parody's humor relies on an audience's intertextual knowledge" (1992: 109). For Margaret Rose, parody is primarily humorous, laughing both at and with the target. Hutcheon is more focused on critical distance than on laughter. Both these studies take the intertextual nature of irony for granted, and fail to distinguish between intertextual and interdiscursive relations. As the terms indicate, intertextuality establishes relations between specific texts, whereas interdiscursive relations connect, critically or otherwise, different dis- 
courses. ${ }^{6}$ If that distinction is brought to bear on my corpus, and if irony as an discourse or interdiscourse informs parody as a genre of response, then parody, or rather, parodic elements, can be detected even where iconographic citation is not easy to trace, at least for the modern viewer.

Following Deleuze's theory of repetition as necessarily including difference, Hutcheon describes parody as defined by the critical difference between original and parody. ${ }^{7}$ But according to this concept, parody does not need literal quotation to be effective. In a time where films were much more anonymous and embedded in larger variety shows than today, it is much more plausible that the genre, tenuously established as it was, was a visual discourse that all following specimens repeat with a difference. Hence, the idea of parody itself becomes subject to radical relativization: a category that questions itself while being subject to questioning.

By its title alone, The Hero Track Walker (1911, Kalem) is one of many repetitions-with-a-difference of THE GREAT TRAIN RoBberY, a film so often taken up that responses to it almost form a genre in itself. This film begins with cowboys "playing" (or working) on a ranch. A young man, Willie plans a train robbery. He tries to get an Indian to participate. Willie saves a girl from a bull, albeit a bit late, since she is already safely in a tree. He tries to kiss her, but she pushes him back. The tree is very close to the picture plane. The girl walks away. The Indian stands waiting with the horses while Willie walks off to the office of the superintendent of the railway. He asks when the train is due, then runs back to the Indian. The Indian betrays the plan to the girl Myrtle. She goes with him, leaving her mother behind with a worried face. Money boxes are transported from a coach into the train, in close-up. The train departs. Willie puts dynamite under the railway bridge and runs away. The train comes toward the left corner of the picture plane. The Indian and Myrtle wave to stop the train. The girl takes the burning dynamite away. The train stops and the conductor warns the passengers. They all run to catch the would-be bandit. While Willie is still waiting for the explosion, the Indian finds him. But the Indian has a gun and forces him to face the crowd. The passengers mistake Willie for their rescuer. They give Willie small gifts as a reward for saving the train and carry him on their shoulders.

The trigger of a parodic reading is, of course, the confusion of heroism and banditry. A failed bandit becomes a mistaken hero, and the "moral" of the story is that it is more rewarding to be good than bad. But this is taken so literally Willie is actually rewarded instead of becoming a better man - that comedy results. Laughter makes the earnest moral lesson ineffective. Hence, this film is much more obviously parodic than the first two I discussed. This is partly due to the more literal "quotation" of the plot of the famous predecessor. It is also due to the ridiculing moral confusion and details such as Willie's belated rescue 
of the girl, and the division between good and bad as ethnically reversed compared to tradition. Finally, the apparent stupidity of the passengers who give Willie what he intended to steal from them makes for an ironic reversal that undercuts the point of such stereotypical plots as a whole. If there is no point in robbing trains, the film suggests, then there is no point either in representing, film after film, the same plot of train robberies. In this respect, the film is interdiscursively related to more than its intertextual predecessor alone.

As a strategy to question its own categories, then, parody and its primary tool, irony, become a theoretical concept. For the modern film historian it can serve as a tool to avoid the traps of history-writing. It can serve as a searchlight, that is, to spot which features of the genre were so much part of the culture of the "Western" that they became the subject of self-reflection and ironic questioning. This ought to caution us against decisions of what is parody and what is not, decisions that can only be overly firm and deceptive in the face of what parody itself is and does. My hunch is that some films appear to us to be parodies but might well have been watched in utter earnestness, and vice versa: the contemporary parodic effect of films for which we lack the recent visual memory of their predecessors may entirely escape us. The key, of course, is viewers' expectations, a cultural context that we can never do more than approximate. The best we can do is spend a lot of time in the archive. Yet, and this is the most exciting conclusion, that time spent is best devoted to questioning the categories we find there.

I found the film titled by the archive as De RAMpspoedige Weddenschap VAN OOM SAM [A Fatal Bet] (c.1912, American Kinema) in the archive of the NFM through that retrospectively applied title that suggested a nostalgic character: "Uncle Sam." But I was surprised to find it such a clear case of comedy, indeed, of parody. Given its likely date of 1912, it is a parody made before the consolidation of the genre into the "classical" Western. But conventions must be set first in order to be overturned by parodic reversal. Clearly, we must then conclude, the expectations that were to generate conventions were sufficiently set that we can detect the later fixed conventions. Here, the film begins when a girl in an over-crowded store kisses a young man (Jack) who is hit on the nose by a ham. A barrel of potatoes falls over, and before we know it, we are in the middle of "classical comedy." The girl's father, the shop owner, throws the man out and locks the girl in her room.

Next episode. The girl has an idea: she writes a letter to Jack, her would-be fiancé. She puts it in a can and tosses it out of the window, on top of Jack's head. Buddy helps Jack. Meanwhile, we get a view of the bar in the store. Hung between the bottles of liquor, a landscape painting and a sign saying "no trust" serve as imaginative reminders of the genre. The father looks like a clown, with the typical hair, nose, and vertical slits for eyes. The bet Buddy proposes to the 
father is: say "tick tack" for half an hour, following the tail of the clock. Other customers arrive, but the old man is still carrying out the bet. The customers take advantage of his dim-witted behavior. Outside, the girl escapes from her room with sheets knotted together, and elopes with Jack. The customers steal the cash register, and also a lamp, the still-burning stove, and more. Jack and the daughter marry.

At the end of the half hour the father finds his store depleted. With a gun in his hand he runs after the thieves. The girl and Jack come back. Despair when the father turns out to be missing. They go in search of him. They are barely gone, when the father returns, and starts weeping. The young couple pursue the thieves, who are visible thanks to the burning stove, which looks just like a steam engine or a locomotive. They catch the thieves, tie them up, and retrieve the household goods. The thieves are forced to walk and push the wagon, the girl enforcing this with her gun. All ends well, of course.

Is this a parody? I laughed a lot when watching the film. What made me laugh, and were contemporary viewers amused by the same things? The excess of stupidity of the father, his clownish looks, the excess, also, of the thieves' wickedness, and the excess of the plot where the returning couple just missed the other party: all this, clearly, amuses. If anything here suggests parody, it may be these excesses. But most of all, the smoke coming out of the still-burning stove on the thieves' wagon, which beats verisimilitude by means of iconographic overdetermination. If the filmmaker had any parodic intent, he flaunted it by inserting artificial signs of Western - the landscape - and crime plot - "no trust." But potential suspense is counteracted by the excessive stupidity of the father, whose comical looks already undercut any of the questions on which suspense is based. The boyfriend is not much brighter. He is first knocked on the nose, starting the stock generator of comedy - the turned-over barrel - and then on the head by the love letter. The romance plot - girl in love, father resisting, happy ending - is thin, just enough to be evoked but not to be sustained. This, precisely, marks the film as a parodic Western comedy.

Parody deploys strategies of mobility for its double-edged, interdiscursive commentary on the discourse it engages. Not surprisingly, then, movement is central. The thieves racing around, the couple pursuing them, the hilariously funny voyage back with the still-burning stove and the thieves doing penance by pushing what looks like a mobile home, the girl being boss and the only one with her wits about her, it all points to the trope of ironic reversal. In a final example, one such trope of mobility will be shown to be an unambiguous pointer of irony, comedy, and to a certain extent, parody. That trope is cross-dressing. Indeed, cross-dressing lends itself exceedingly well to the questioning of categories on levels other than gender. But, since I noted above that strategies such as irony are hardly ever totalizing - one text usually combines "serious" 
with ironic bits - we are still left with the difficulty of deciding which is which; and hence, with the need to question the categories that guide our judgments.

There is a still-deeper sense in which the laughter solicited by irony cannot be totally encompassing. At stake is the nature of laughter itself, and its historical moment. In an essay from which the epigraph to this chapter was taken, Kevin Newmark discusses Walter Benjamin's essays on modernity and Charles Baudelaire's significance for understanding it. Key to these essays is the notion of shock and the depletion of experience. The structure of experience is bound up with humor, but humor, Newmark states, is not just superficial amusement. He cautions:

The structure of experience ... could not be easily subsumed under the reassuring rubrics of "humor" or the "comic" without reducing its complexity a great deal more than would be legitimate. (242)

He then goes on to explicate Baudelaire's definition of laughter as shock, as loss of balance, as fall. One of the reasons that laughter results from shock, as Newmark interprets Baudelaire, is that laughter

[...] possesses the linguistic structure of a sign: corresponding to neither pure knowledge nor simple existence, laughter can only occur on the site of their mutual impossibility to achieve the fullness of presence, as either simple being or thought. (251)

This position between being and thought is explained elsewhere in the essay as a result of laughter's nature: who laughs knows that he laughs. Baudelaire defines laughter as self-reflexive.

Baudelaire's extraordinary essay came out of the poet's obsession with a citation: "The Sage does not laugh without trembling." In this and the other thoughts on laughter discussed in Newmark's paper, a certain duality, or rather, double-edgedness is striking. Laughter is never simple, sheer amusement. That the films discussed in this chapter, to a varying degree, made me laugh, yet never entirely so, squares well with that idea. In a sense, the films' position in variety programs makes laughter almost too obvious an effect. On the other hand, perhaps the parodic quality that triggers the laughter is not only in each case, but by virtue of the nature of laughter, only partial. Entertainment and shock, or trauma, in other words, the shocking experience of modernity and the entertaining quality of the parodies, are then connected on a profound level. This may be a relevant thought to keep in mind as we imagine watching my last example.

MAKING A MAN of Her (1912, Nestor) begins with a cowboy making love to the kitchen maid. Three times he reiterates the same exaggerated gesture. The maid is sent away, and the boss decides he does not want to risk hiring another female for the job. A cross-dressed girl gets the job. The boss makes her/him 
smoke a cigar, but as soon as he turns his back, she throws it in the fire, for it makes her sick. After a while, the boss and his wife return from the city with a niece. The women like the "boy." In the kitchen the cross-dressed woman cuts herself, faints, and so, the boss's Wife and her niece discover her long hair. The cowboys come into the kitchen. The women support the brave girl, who goes off, dressed like a cowboy. The story repeats itself: she must fight a cowboy who is jealous of the sympathy she gets from the women, she loses, cries and her cap falls off. Again, but now in the outside world, among the other sex, her gender identity is unveiled. Next, three couples sit in front of a house. Then a black woman gets the vacant job. This figure, however, looks clearly like a man in drag. End of story.

Many moments in this film are hilariously funny. But not all of it. The moment that the woman about to cross-dress demonstrates how desperate she is for a job, cut in right after the girl gets fired for having been subjected to sexual harassment by a cowboy - who, of course, is not at risk - had a painful intensity about it. The reasons for the cross-dressed woman to be discovered are stereotypical, and that might bother many of us a little today, but would it pass, at the time, as something laughable about women? When going out into the world and left to her own devices, the first thing the woman is confronted with is the violence of the male world. Is that funny? Physical violence is what disqualifies her; her body, that is, disqualifies her for her job, first, and for her disguise, second. Is that funny? I have no way of knowing. Our sensibilities have changed, especially with respect to gender, but on the other hand, it seems problematic to simply assume that at the time, people would have been completely insensitive. Is it a matter of moral judgment or the history of morality then?

I feel that we would be failing in our duty as historians if that were to be the only conclusion. Looking closely at the film, I can see that there are several elements that at least make the label parody plausible, if only as a question mark to be put to the genre. The reiteration, for one. First, there are two girls who lose their jobs through their femininity. The thrice-repeated gestures of the would-be lover have a tone of exaggeration about them. In subtle contrast, the dramatic gestures of despair of the woman about to cross-dress when she realizes she won't be eligible for the job because of her sex - while kitchen maid, as opposed to cowboy, is one of the rare jobs for women anyway - sufficiently point to a seriousness that the parody then overlays with laughter, but mild laughter: both at and with the cross-dressing girl. For, she is, after all, quite brave. And the mistress takes to her, in spite of her deception. When she is then physically confronted, there is a tone of critique, perhaps in Hutcheon's sense of irony as critical distance, toward the violence in public culture.

Parody is biting itself in its tail when, at the end, the new maid is a man in drag. Just briefly, we glimpse the inevitable merry-go-round of gender and, by 
extension, other categories of identity. This closing scene evokes the paradox of parody more than any other scene in the film. Parody thrives, I have been suggesting, on the existence of, and expectations regarding, a genre, expectations which are then turned around. But by doing just that, parody also thrives on diversity. It breaks the genre up from within. Even more so, I would venture, in the cases discussed here, where the parodic is only a hint, a possibility, an incident almost; where all it says is: this is not what you think it is. Like cross-dressing.

What appears here in terms of gender - and has elsewhere been pointed out in connection with racial stereotyping - makes manifest the point of laughter. Laughter seduces us into a reflection that does not require a separation of intellectual engagement from sensual or emotional engagement. It shows, in other words, to what extent such self-reflective forms can enhance the "depth" of these funny, superficial entertainment items that the Western appears to be at first sight. Questioning categories is not a futile act of endless regressing into the abyss of relativism. If I now look back at the attempt to define the genre of the Western as loosely as possible through the concept of family resemblance, the ante can be upped considerably. The resistance to definition is important, epistemologically as well as politically.

James Clifford (1994) has argued along similar lines against rigid definitions in an important article on the concept of diaspora, currently a topic very much discussed in cultural studies. In an attempt to critically analyze the consequences of defining such a politically charged phenomenon, he probes several types of definitions. His findings can usefully illuminate the inquiry in this study of what it means to speak of the early Western without either reifying features or diluting the genre beyond recognition. The self-reflexive subgenres discussed here have implicitly demonstrated the need to suspend a unified genre definition. Clifford's types of definitions enable me to sum up what the issues are.

He distinguishes normative, polythetic, and diacritically specifying definitions. The first is the most common, but also the most insidiously restrictive one. It is comparative in procedure and exclusionary in outcome. It poses one illustrious case as the norm, and derives a number of features from its analysis. This would be the equivalent of taking, say, The Great Train Robbery, and dismissing all films from the genre that do not contain elements such as a holdup, a chase, horses, a train, travel, landscape. Alternatively, one can "accept" films that possess only some of these features, inevitably as less "pure" instances of the genre. This seemingly liberal procedure might make the corpus unmanageably large and the defining force of the genre concept, accordingly reduced. Either all the examples of self-reflexivity presented in this chapter 
would count as parodies, but then, that category would hardly have any analytical value, or only a few would, in which case, under no circumstance would Coeur ARDENT, nor, probably, Destiny is ChANGeless pass muster.

Polythetic definitions come closer to the loosely knit network of features I have derived from family resemblance. Shared elements, rather than a limited number of features, indicate rather than define the "genre." To paraphrase Clifford (307), these elements help tracking (rather than policing), the range of parodies that demonstrate that there was never a "naïve," "innocent," or "primitive" "pure" genre we can call "Western". The very notion of category is out of place here. Finally, Clifford argues that diacritical specification is a useful way of examining both what, in our case here, a parody of the Western is and what it does, in the first place to the Western, but also to itself. Such an approach examines not so much what is "inside" the category, but rather its borders. It would examine neighboring genres and specify what these do and do not have in common with the genre under scrutiny. In the course of this study, for example, travelogues and ethnographic films have been invoked in the spirit of diacritical specification. But also the pre- and post-filmic narratives, the paintings and the postcards, the illustrated lectures, the exhibitions and the World's Fairs would appear in the larger field where Westerns rub elbows with their neighbors.

Unexpectedly, however, parody and films containing elements we might construe as parodic bring the diacritic approach to a provisional halt. Parody is and is not a full member of the family; it is inside and outside what it parodies. Entirely parodic films would cast a critical light on the genre from without. COEUR ARDENT, in contrast, is firmly situated within the family, but winks at the outside as if to say that strict obedience to the normative definition of the genre blows itself up from the inside. If I have highlighted such ambiguous instances in this chapter, I aimed to follow up the earlier discussion of genre with an even more un-fixing reflection on the Western. But then, parodying and ironizing, critical as such productions may be, are also forms of allegiance. They operate through a doubling that sticks to the very gesture that distances itself from its object, its laughing stock. The one and only unambiguous rejection this analysis permits, then, is of the illusion that a simple, unsophisticated, naïve Western ever existed.

\section{Notes}

1. Newmark writes this à propos of Baudelaire's essay "The Essence of Laughter." The epigraph is preceded by "[...] laughter comes to name the fallen mode of all experience; it thus becomes another name for a radically secular, that is to say, non-teleological and indeterminate, mode of history" (1995: 244). 
2. For a lucid discussion of the properties of parody, see Dan Harries' Film Parody (2000).

3. See figure $\mathrm{Q}$ for the advertisement of a Western comedy.

4. For an historical survey of the concept, see John Vignaux Smith and Reginald McGinnis in the Encyclopedia of Aesthetics, vol. 2, edited by Michael Kelly (1998: 529534). One of the more analytically oriented of the many studies of irony is Wayne C. Booth, A Rhetoric of Irony (1974).

5. This definition of parody as intertextual spoof that creates ambiguity is put forward by, among others, Margaret A. Rose, Parody: Ancient, Modern, and Post-Modern (1992). The emphasis of post-modern parody is also pronounced in Linda Hutcheon's A Theory of Parody: The Teachings of Twentieth-Century Art Forms (1985). But since Hutcheon discusses more visual examples, her concept is not so confined to cases of literal quotation.

6. The relevant case here is the adoption of the discourse of the Western within the discourse of comedy. As a result, the film in question can be processed as comic, or even as parody.

7. See Gilles Deleuze, Difference and Repetition (1994). 


\title{
Riding the Wilderness
}

\begin{abstract}
Young as the art-science of motography is, it has already played its part in many a strange scene. The railroads, especially, can tell more than one tale

of flying bits of wild scenery, or the wilder antics of curious tribes of humanity that have been captured and every move carefully preserved on the mutable celluloid.

While the roads of the east have not neglected the use of the cinematograph in recording those features of their property and territory which require motion for their setting, it is in the west that the idea has received most attention. - Nickelodeon, $1909^{1}$
\end{abstract}

Travel was the modern practice; a railroad system the material production that made it possible; settlement the socio-political result. In between, the railroad as sign and material object became the focus of fascination. All those who remained in the East gained cultural access - through films, among other cultural activities - to the vanishing point of the perspective that the railroads opened up. That gaining, having, and using access: That, too, is a cultural practice, and visual culture thrived on the fascination with that rather suddenly emerging access. Behind the imaginary vanishing point lay the equally imaginary wilderness against which the urban population construed its sense of modernity. Thus, "the wilderness" was signified through a double articulation, of end point and of endlessness. In this chapter I will examine three filmic type scenes that based their appeal on this "sense of an ending" (Kermode 1966) consisting of a vanishing point in conjunction with the wide-open possibilities that circumscribed the space of modernity.

What more significant and beautiful image of linear perspective as the visual imagining of endpoint and endlessness, than the two parallel lines of a receding railway track that approach each other but never touch? The common feature between closure and openness is the narrative signification of the notion that modern speed - that most pervasive excitant and burden - at once opened up, and stopped at, the wilderness. Hence, the wilderness marked a temporal as well as a spatial experience of liminality, the transition between realms, phases, ages that all cultures appear to mark through special rituals, or rites of passage. The films of my corpus have their own rites of passage, consisting of recurring scenes that will become the formulaic hallmark of the Western. I will draw out 
the structure of these scenes in order to suggest the urgency with which they are called upon to inscribe the double "sense of an ending" outlined above. That urgency points to one reason why, my study contends, the emerging Western is more than just one instance of visual culture at the turn of the century of modernity; why, indeed, it may well be that era's most characteristic visual practice, at least in America.

One type of scene I have in mind is the robbery, the hold-up, of train or stagecoach. In order to foreground the deeper sense of such scenes I seek to complement this type scene with the last-minute rescue narratives. By means of such suspense machines as threats of being run over by trains, or other possible accidents, rescue narratives position the train itself as an antagonist. A third type scene is characterized by its visual makeup. This is the phantom ride, the film that is shot from the front or rear of a moving train and shows the passing landscapes from this perspective. As this description of the phantom ride PANORAMA OF Gorge RAILway (1900, Edison) makes clear, the combination of motion, speed, and scenic beauty created a spectacular visual effect:

One of the most interesting places in the vicinity of Niagara Falls is the Whirlpool Rapids, where the immense volume of water which passes from the Falls, speeds along through its rocky and tortuous passage towards the ocean. The camera in securing this picture was placed at the front end of a train ascending the grade at a very rapid rate of speed. The combined motion of the train in one direction and the water in the opposite direction, the latter impeded and interrupted in its course by the rocky path through which it flows, sending beautiful masses of spray and foam many feet in the air, makes an impression on the audience long to be remembered. ${ }^{2}$

These three type scenes can only be named in retrospect, once they have established themselves, through sheer frequency, as the leading thrill machines of cinema culture. The following quote from a Biograph advertisement suggests that as an idea, this thrill machine was present and as yet unnamed:

The American Biograph has always led in railroad scenes, and during the winter and early spring some splendid pictures were secured. Among them may be mentioned "A Race Between Two Trains on Parallel Tracks," "A Narrow Escape From Death on a Trestle in Front of an On-Coming Train," two scenes of the Putnam branch of the New York Central, showing the reverse curve going up a mountain side, a high curve on the Manhattan elevated Railroad at Harlem, and many others. ${ }^{3}$

Deducing from the titles and descriptions of the films mentioned here, I guess they are, respectively, a chase film, an "approaching train" or "passing train" film, and a city-phantom ride. They are mentioned together; this is why the present chapter, following this contemporary lead, brings the three types of scenes together as a significant knot. 
Both hold-up and rescue scenes are fictional narrativizations of speed (or the stopping of it), based on the fear of it. Whereas in the cultural imagination speed was dangerous in itself, but also productive, and hence, in this capitalist phase of industrial societies, necessary, the danger is displaced from speed to what stops it. Displacement and analogy are the twin mechanisms of a metonymically informed, or motivated, metaphor. The metaphor becomes a conveyor of the anxiety that speed is dangerous, however exciting it may be. Thus, the excitement is displaced from the traveler to the outlaws who, literally, go against the grain of modernity and are dangerous: they personify danger. The metaphor thus accommodates both the fascination with speed and the nostalgia for what went away because of it. The outlaw, therefore, had to be romanticized so that he could embody the tension between the modernity in which the viewer was caught, as well as the nostalgia that regulated his or her slower psychic rhythm of adaptation. I

Phantom rides appear in multiple forms. They can be either "autonomous" nonfictional films, or function as scenes or episodes that are inserted in longer (fictional) narratives. I wish to remind the reader here that no films in this period can be considered really "autonomous," since these short films were never seen separately but always in the context of a larger film program. What I mean to distinguish here are films that were distributed and exhibited as separate titles within a program, from scenes that were used for creative editing on the part of the exhibitor, an intervention to which these travel shots seemed to lend themselves very well. Some films sold by film companies were promoted in advertisements as scenes to be inserted in other films. For example, in the list of Hale's Tours films distributed by Biograph, the title Departure of Train From STATION is advertised as:

[a] very useful film, as it can be used as a starter for any trip, and is particularly valuable, as it shows a wedding party off on their honeymoon amid a shower of rice and old shoes. Very laughable and lively throughout. Puts the audience in good humour of the trip. ${ }^{4}$

Such bits sometimes display a reversed perspective. This happens in films that show the passing-by of the train, rather than from the train, featuring the means of travel more than the experience of travel. But in essence, these films all celebrate travel. The (literal) shots "into" space symbolize a safe and dominant form of visual access to a space that is the object of, as well as being created by, this panoramic perspective. Through the distancing camera the perspective of the traveler enables and structures a visual field that is seemingly all-encompassing. At the same time, the thrill of possible danger that is associated with this modern means of transportation provides visually exciting rides for the moviegoer, safe in her or his seat. Among the train films that we find in the archives we can 
see examples of films that play with both of these attractions, often embedded in short narratives that support this visual spectacle.

Together, these three type scenes - hold-ups, rescues, and phantom rides become, over time, important markers of the genre of the Western, even though their significance in the contemporary culture declined when the sentiment they conveyed and sustained was no longer acutely felt. This is precisely why they have such great historical importance for "the Western." They also provide an opportunity to examine the close bond, as well as the tension, between narrative and display, also vividly felt at the time. This is the tension between moving image and still spectacle. Given the anchor of each pole in a particular era, this tension symbolizes the more diffuse tension between modernity and its nostalgia - the historical discrepancy between lived time and historical time. The latter tension negotiates the different rhythms of social change and psychic adaptation. In view of these staggered embeddings one can argue without exaggeration that the three type scenes, as three different configurations of a key experience of the time, together function as a mise-en-abyme of modern (visual) culture. As a strategy of narrativizing the image of the Wild West, then, these scenes also make a claim for the cultural importance of narrative as such.

Where in $\mathbf{P}$ I discussed phantom rides as conveyors of the aesthetics of the picturesque, here I examine the other side of this filmic type. I am interested in how these sequences film train rides rather than landscapes, or more precisely, how they film the experience of travel rather than the experience of landscape. ${ }^{5}$ These films shot from trains not only display panoramic views of scenery, they also show, in the same frame, the machinery that enables these vistas. There is an inherent tension within the image between background and foreground, between steel train and the natural space it traverses. ${ }^{6}$ By shifting angles, the film thus shifts its perspective, providing an ambiguous position for the spectator to identify with. The anxiety and shock associated with this modern means of transportation are important attractions exploited through these phantom rides. The name phantom ride connotes this double meaning. On the one hand, the phantom-like perspective enables views that are magical and otherwise unattainable. On the other hand, this phantom-like experience can be frightening, or at the very least thrilling.

This double effect is noted, for example, in the following description. It is a response to the exhibition of a phantom-ride film with special effects that are added to the images to underscore the exciting roller-coaster effect of the (joy) ride, up to its climax in the form of a crash:

[Lyman Howe] also shows applied ingenuity in some of his "novelties," but it is of a kind that every exhibitor should be able to equal. His "Runaway Train," for example, is a travel film taken from a railway train traveling though the Alps. His projecting 
machine is so geared that it may be speeded up until the train (on which the spectator is supposed to be traveling) appears to be running down grades and around corners at a frightful speed. Then, at last, it hurls itself down a steep grade, straight at an obstruction on the track. There is a flash of blinding white light on the screen (from the spotlight) the effect man fires a pistol - and the show is over. Simple, but very effective. ${ }^{7}$

The down-to-earth tone of this fragment connotes the exorcizing need to understand how the fright is the product of trick, not magic. This particular exhibition plays with the possibility of creating effects at the very moment of reception, making the viewing of the film a truly live event. As I will explain later, the exhibition of train films in Hale's Tours is in many ways similar to this attempt to make viewing film a multi-sensual experience. $\mathbf{U}$

Phantom rides recreate the experience of train travel, playing out the tension between the lust for pictorial beauty and the thrill of physical danger in virtual rides that are physically safe but flirt with possible disaster. I mean the word "virtual" in both senses, referring to the physical and the imaginary: virtual as substitute for the personal, bodily experience, and as providing otherwise unattainable vistas. This is why I position them in the context of narrative trajectories followed in the many hold-up films, the chases, or the last-minute rescue films. As trains are stopped and chases start, the virtual rides of the spectator continue. The integration of the early train rides into narratives quickly moves toward narratives about hold-ups, about fatal accidents that happen or are avoided at the last minute, about chases between trains or other, older, means of transportation. This last category is especially significant because the competition between modern trains and older means of travel, such as horses, is played out. In this respect I remind the reader of films such as A DisTANT RELAtive (1912, American) or Cowboy Justice (1910, Pathé: American Kinema) discussed earlier $\mathbf{M}$, that feature chases between different modes of transportation and their historical connotation.

In this sense, we can understand why the early travel films go in several narrative directions. For example, phantom rides like the one in GoING THROUgH THE TunNel (1898, Edison), summarized in the Edison catalogue as: "On the way to Santa Monica, California, the train approaches, runs through and emerges from a tunnel. Train passes in opposite direction. Camera is at front end of train, giving a very novel view," soon developed into narratives such as the one in What HAPpened In The TunNel (1903, Edison). ${ }^{8}$ This narrative spinoff is described in the Edison catalogue as:

Interior of railroad coach. Pretty young lady and colored maid occupying seat. Young man in rear seat tries to attract young lady's attention. She drops her handkerchief. Young man picks it up and hands it to her, and then takes advantage of the opportu- 
nity and leans over the back of her seat and begins to make love to her. As the train enters a tunnel he tries to put his arms around her, and when the train emerges from the tunnel he is hugging and kissing the colored maid, the young lady in the meantime having changed seats with the maid. ${ }^{9}$

Shifting women as a way of shifting genres, the "danger" represented by the tunnel is mobilized for the sake of a classical comedy of error.

In A RAILWAy Tragedy (1904, Gaumont) the dangers of traveling by train are grave, especially for women. Where the previous film shows a comic incident, with all its heavy ideological implications for the categories of race and gender, the following "tragedy" shows the danger of physical violation particularly for women:

A woman gets out of a wagon and boards a train. In the compartment she sits next to a man and falls asleep. The man steals something from her purse. When she wakes up she asks him if he knows something about it. They fight, and he throws her off the train. Two men find her on the tracks. Just in time they pull her off the tracks before a train comes rushing by. The man is captured when the train pulls into the station. (my summary)

Up to a certain point in the film, the film can be interpreted as a comedy similar to What Happened in the Tunnel. But not after the sudden shift to a much darker mood displayed when the violent crime is being portrayed. This shock effect is caused by the instability, or better, the fluidity, of generic categories within the early film program. Train films that shift from panoramic views of the surroundings to a narrative inside the train were new in their format, and, as these two examples illustrate, they could result in either comedies or tragedies.

Phantom rides that move towards fictional narrative could also find shape in films like Hold-Up of THE Rocky Mountain Express (1906, AM\&B): ${ }^{10}$

The action shows a railroad run, an interior comedy scene, the hold-up as viewed from the inside, then on the track, finishing with a race between the train and the bandits, who first take to [a] hand car and then to a horse and wagon. The robbers are captured at the crossing for an exciting finish. ${ }^{11}$

This film, as I argued in $\mathbf{N}$ is a conglomerate of generic spin-offs of the travel genre. Following the order of the scenes, we encounter a phantom ride, a come$\mathrm{dy}$, a hold-up, a chase, and a rescue scene. It illustrates very clearly the possible plot lines that are generated by the narrative motor of the phantom ride - moving from panoramic views from the train, to scenes in the train, to obstructions on the tracks, and chases along them.

The inherent drama of being on a train is certainly due to the fact that trains are part of the public sphere within which they isolate contingent and transitory 
cells of social life. The fact that these micro-worlds are in lonely isolation as they travel through the open country, enhances their vulnerability. Clearly, trains are therefore dangerous, especially for women. ${ }^{12}$

Indeed, a special role was set aside for women in the railway-centered films of the more elaborately fictional kind. In the style of the "Serial Queen" serials, for example, there is The Runaway EngIne (1911, Kalem). This film tells about a romance between a telegrapher and the son of a railroad president. The boy's father objects to their love. But when the girl saves the father from a train wreck he gives them his consent. Here is the story:

Interior of an office (the station). The daughter of a train engineer works as a telegrapher at a railway station. She is being assaulted by two hobos. The son of the railroad's president rescues her. They fall in love. Meanwhile, the train with the boy's father in it departs without a driver. The camera standpoint is the empty driver's cab, similar to the famous shot in THe Lonedale Operator (1911, AM\&B). The effect that this point of view produces is thrilling: we can see the empty cab and the speed with which the train moves. The girl chases the train in an empty train of her own. Here, the camera is mounted on the front of the train, a device that aptly conveys the sense of speed, resulting in a heightened suspense. She causes a collision between the two trains in order to stop the wild train, and jumps off her own at the very last moment. (my description)

This film flaunts its orientation to female spectatorship. First of all, obviously, it proclaims female heroism. In addition, it references serial queens. Moreover, it offers cross-references between popular magazines and films by showing the young woman reading women's magazines. ${ }^{13}$

But not all viewers were equally thrilled. The film was quite negatively reviewed in Nickelodeon. We can learn much from this review about the still unnaturalized intertwinement of narrative and spectacle:

The girl's exploit is undoubtedly daring but loses much of its exciting effect because the audience is not made aware of her purpose. We know she intends to save the president's special, but just how is not clear, and we do not learn [it] until it is practically accomplished. We follow her wild ride sympathetically but our suspense is vague and not intense enough to be exciting. Too bad the sub-title editor did not see fit to explain matters more fully because the incident seems highly sensational in retrospect. Truly a daring and dangerous leap on the part of the leading lady. The plot is rather worn but serves well enough to introduce a sensational incident, which is all it was intended to do. ${ }^{14}$

The machinery of trains is dangerous not only on the cultural-ideological, but on the psychological and physical levels as well. Yet, since culture merges all 
these dimensions of human life in a specific setting, this is also a sociological and ideological kind of danger.

The experiences of modernity, with its shocks and the instability of control and power, are played out in these films. The cultural significance of these dangers is evident in the sheer frequency of my type scenes. Hold-ups and accidents are repeated over and over again in the films of the time. Even anecdotes about these railroad tragedies that are "faked" for the camera are published in newspapers:

Such tricks, though, sometimes miscarry. There was, for instance, a show of moving pictures showing a photographer hit by an express train. An actor, impersonating the photographer was rehearsed to select a pretty rural view from a railroad track in New Jersey. As he was focusing his camera the train was to come along and strike him. It was to be a real express train at full speed. At the critical moment the moving picture camera was to be stopped and a dummy substituted for the supposed photographer. The man sent out to tell the engineer of the express train about the play failed to reach him. The engineer, running his train at full speed, saw what he believed to be a man on the track. He blew his whistle. The man paid no attention. The engineer put on his emergency brakes. The engine came to a standstill just as it struck the photographer. Climbing out over his engine the engineer snatched up the body and found it to be a dummy.

In this anecdote the attempted realism, pursued through the use of a real train, caused confusion. ${ }^{15}$ The realism was too shocking for the innocent collaborator, the real engineer. The race for his "last-minute rescue," a notification of the staged accident by the film people, failed to achieve its goal in time. At the last moment the train managed to stop. Dummy saved: film ruined.

The striking parallel between filmmaking and real life is put forward in many anecdotes such as these that were popular in newspapers. Reports in journalistic style proliferate, describing all possible confusions, near-accidents, and exciting situations associated with filmmaking. They function not only to boost the realism of the moving images to be seen in the movie theaters, encouraging the idea that these actions are so real that they scared people in real life, but they also cash in on the exciting stories of the film plots as if they were news events, "real" accidents. The article on staged accidents continues:

While making the pictures for "The Great Train Robbery" there was another incident not in the bill. One of the "bandits" was supposed to attack the fireman of the train on the locomotive tender, beat him on the head with a piece of coal, and throw him overboard. It was another case of the moving picture camera being stopped and a dummy being substituted for a living man. To make the scene more effective the train was stopped on a bridge crossing the Passaic River. The pictures were taken on a Sunday afternoon, and just as the "assault" occurred a trolley car passed crowded with pas- 
sengers. The passengers were horrified to see what seemed to be a bandit murdering a railway fireman and casting his body from the bridge to the ground beneath. The trolley car was stopped; the excited passengers rushed back to assist the wounded man to find the dummy. ${ }^{16}$

These printed stories, whether humorous or sensational, participate in a discourse of promotion, not only of the genre but also of the sentiment that was its psychological motor. They exploit the identification of the public with victims who are subjected to sensations similar to those felt by the urban dweller on the busy streets of the metropolis or with the heroes who triumph over physical and emotional dangers. This campaign was so effective because every potentially rescuing reader knew travel was really dangerous and knew this modern culture.

The archaic adventures of earlier pioneer days, or the air of out-of-town life, are escape routes out of everyday life, but those adventure stories that involve the modern machinery of the railroads also appeal to the modern senses:

Give the Kalem a railroad story and it'll put it all over about every other firm of film producers. "The Runaway Freight," released this week by the K is so railroady that you can smell the soft coal all through its two parts and hear the click of the dispatcher's keys as a steady undercurrent of the drama. And it's a first class drama all the way through, from the first scene to the last, with a thrilling leap by a brakie from the top of one freight train on one track to a fast moving freight on a track adjoining. The multiple kept a Savoy theatre audience guessing last Monday all through its lively action. ${ }^{17}$

The realism of the film is underscored in this review, stressing how the sensual effects of smell ("smell"), of sound ("click"), and the adrenaline-raising "thrilling leap," all make this drama exciting for its audience. The sensual identification that held the audience at the Savoy in suspense, had already been taken to the extreme in the theaters of Hale's Tours (1904-1912). ${ }^{18}$ Some of the early Biograph railroad films mentioned before were re-issued and exhibited in Hale's Tours. In the train compartments that were rebuilt into movie theaters, spectators were given a position parallel to that of the characters in the films. The audience watched the film seated in train compartments that were similar to the ones in which the characters on the screen experienced their adventurous journeys.

The Kalem film mentioned here exemplifies the transition to a narrativization of the same play with visual perspective taken to the extreme that was so popular in the exhibition of phantom rides in Hale's Tours. This narrativization was effectuated by placing these vistas in combination with their counterparts in the "passing trains." This almost inverted phantom ride occurs, for example, in Fast Mail, Northern Pacific Railroad (1897, Edison). This film shows a 
train passing while the camera is set up along the tracks. People standing along the tracks wave to the train. The Edison catalogue presents the film as follows:

Here is a twelve car train dashing along at a high rate of speed. It is seen first in the distance and approaches and passes by the camera. As it takes less than 30 seconds to show this 50 foot strip on a Projecting Kinetoscope, an idea may be formed of the speed of this pet train of the Northern Pacific Railway. The waving grass along the track side, the black smoke, and the clouds of dust that follow the train, make very vivid effects. ${ }^{19}$

Obviously, the passing train ride had a much more limited visual scope than its counterpart, the phantom ride. This is clear from the following complaint about the lack of scenery in a ride that features not West, but South America:

From the Artics to the Tropics - Edison, is a scenic film which would be more interesting if it showed more scenery. The scene is laid in the picturesque Andes of Peru, but in following a gravity car in its journey down the mountains, we view little else than railroad tracks and tunnels. It is true that we are finally allowed to turn our gaze away from the gravity car and catch a glimpse of Callao and some of the sealevel country, but we have meanwhile missed all the mountain views. The car starts on a snow-capped mountain summit and winds up among tropical palm groves. This explains the title. ${ }^{20}$

Such films shift the perspective from an "on board" vision to one "in front of the train." The resulting last-minute rescue embodies narrative suspense in its essence.

In the context of cultural history, I would argue that this narrative form activates an effect similar to that of the earliest films of approaching (or just-passing) trains that supposedly scared the first movie audiences, like the oft-quoted anecdote of the very first public film screening of Lumière's L'ARRIVÉE D'UN TRAIN EN GARE DE LA CIOTAT (1896). That film supposedly terrified contemporary audiences because the train seemed to literally "hit" the spectators. The same happens here, but this time in fictionalized and narrativized form. ${ }^{21}$

The significance of such scenes surpasses that of the incident they stage. The approaching-train type of film can be understood as symbolic for the impact of the cinematic apparatus: it enters frontally the perceptual realm and travels through the visual field into the psychic experience of the spectator. ${ }^{22}$ In the self-reflexive Edison film Uncle Josh At The Moving Picture SHow (1902), this is the gist of the joke. The character Josh ducks when the film THE BLACK DiAMOND EXPRESS (Edison, 1896) is shown as movie-within-movie in the film program he is watching. This self-reference points to an understanding of this film as a "type" of film. The humor lies in the fact that the "real" audience can relate to Josh's position in the movie audience. This topos of the fiction-reality 
confusion keeps recurring in cinema up to the present. Given its persistence, one could speculate that achieving the effect is one of cinema's goals.

To complicate matters in this move towards narrativization, Hale's Tours, in turn, were similar to rides in amusement parks but in the form of narrativized rides because of their use of film as go-between medium. Today this sensual combination is exploited in theme parks such as Disney World. There, an attraction like Space Mountain provides a vicarious trip into space through combining visual effects with the physical effects of a roller-coaster. Virtual reality as an on-screen experience is only one step ahead. Compared to these rides where the public underwent the ride themselves, Hale's Tours provided instead a narrative form of this sensational amusement. The suspenseful narratives of approaching dangers and the last-minute getaway are samples, symptoms, and symbols of the successful narrativization of cinema. The quote above, about the spectacular exhibition of Lyman Howe, underscores this.

In an issue of Motography from 1911, an elaborate description is given of the Edison last-minute rescue film of that same year, THE SwITcHMAN's TowER. I offer this fragment here as representative for its long plot description in which it brings out the sensational aspects of the film. It opens thus:

This is a railroad picture and as such is bound to make a great public appeal, as railroad pictures are always popular. The exceedingly thrilling rescue of a child is shown and it is not impossible that the producer will be criticized for having allowed the child to risk any such extreme danger. As a matter of fact, the charming little girl was just as safe as though she had been working in the studio. Through a photographic trick the child was never in front of the onrushing locomotive, although to all appearances the cowcatcher nearly touches her. All who remember Edison's exciting railroad story, "The Little Station Agent," may look forward to a similar thrill in this. ${ }^{23}$

Again, the danger is put forward as the essence of the visual experience. This experience becomes the motor of narrativity, leading up to a climax that is by generic necessity an extreme moment of danger, released into rescue. The climax of the narrative, the actual last-minute rescue, is described as follows:

And then Bill realizes what he has done and covering his eyes with his hands, reverses the switch knowing the train will pass over the spot where his child is but that the trainload of passengers will be saved.

The train rushes down the track toward the child who stands with her back to it, unconscious of it, but the young mother suddenly appears at the edge of the track and snatches the child from in front of the engine, a fraction of a second before the iron monster sweeps over the spot. This is a splendidly thrilling scene and after it is over we do not wonder that all the characters are willing to forget their small personal differences in the light of such ordeal. (24) 
In this last sentence the word "spectators" can just as well replace the word "characters." The similarity in experience between the characters in the film and the filmgoers who witness the same events in their seats is what makes the last-minute rescues so "splendidly thrilling." The phrase integrates aesthetic splendidly - with psychological attraction - thrilling. Hence the title of this chapter, "Riding the Wilderness." It refers to a cinematic experience of train films that is effective in the specific way that only cinema can bring about, both on the level of visual perception and on the level of suspenseful narratives.

"Riding," of course, is what you do on horseback. At a time when the new means of transport replaces the old, and the urban one replaces the "wild" one, the two are bound to compete, if not clash directly, on the screen. The French film LE RAILWAY DE LA MORT (1912, Gaumont) includes stunts on the train with its elaborate chase that starts at a "ranch." The fact that this is a European example is significant in the light of the cultural meaning of the West as temporal frontier. It includes a typical Western shot that shows a horse and wagon ride through the open plain. This shot has particularly beautiful photography and thereby gains emphasis in the flow of images. A train enters the image. On a horse one of the two main characters chases the train. There is persistence in the chase: the two men pursue each other even on the roof of the train. The camera is always set up on the roof in order to provide a good overview of this action, but hereby it also moves along with the same speed as the machine beneath it. Again, this combination of speed and danger, and its ensuing suspense, has a strong visual impact. When the train wagon is uncoupled from the locomotive, the camera remains in the same position, and when the train pulls off and we see the image of the train moving away from the camera, the visual effect of departure is emphasized. After this visually exciting sequence the film ends rather gloomily, in tragedy, when the two protagonists are killed by the explosion of gunpowder.

On its own, this ending is a reference to and a mix of another European film, A RAILway TRAgedY, with its physical danger and its gloomy atmosphere throughout, as well as to other spectacular stunts of railroad clashes staged before the camera, such as A RAILroAd SMAshup (1904, Edison). The shift in tone foregrounds the tragic as such. For, these collisions, explosions or other accidents stop time. This arresting of time, turned spectacular and narrativized, serves a self-reflexivity of the moving image in general. This is yet another reason why my corpus, the films we tend to classify as "Westerns," constitutes a particularly representative section of early cinema in general. These films demonstrate how far the moving image can go in moving the viewers it holds in its spell. It is a strategy of the moving image to speed up and then screech to a halt. When time stops, spectacle unfolds. 


\section{Notes}

1. Wilson Mayer, "Moving Picture Work of the Railroads," Nickelodeon I, 2 (February 1909): 41-42.

2. Edison Films Catalog 105 (July 1901): 95. Quoted in the Library of Congress catalogue, Inventing Entertainment.

3. "Press Comments on the Recent Achievements of the American Biograph." Biograph Bulletins (1899).

4. "Hale Tour Runs: Attractive Railroad Pictures Which Have Been Found Highly Successful With Tour Car Schemes." Biograph Bulletins 73 (June 30, 1906).

5. Jennifer Peterson (1997: 85-86) rightly nuances the conception of the travel genre as moving from "motion oriented" views to "landscape oriented" views. She insists that motion as motif is still very important in travelogues in the late 1910s. In these films characteristics of the phantom ride are incorporated into more elaborate travel films.

6. We are reminded here of Leo Marx's famous book The Machine in the Garden (1964) about the conflict between the pastoral state and urbanization which is an often recurring theme in American culture. On the cover the painting of Lackawanna Valley (1856) by George Innes echoes this imagery of trains cutting through the natural landscape.

7. "Lessons from Lyman Howe." Motography VI, I (July, 1911): 4-5.

8. Edison Films Catalog 94 (March 1900): 21. Quoted in the Library of Congress catalogue, Inventing Entertainment.

9. Edison Films Catalog 288 (July 1906): 27. Quoted in the Library of Congress catalogue, Inventing Entertainment.

10. I wish to cite again the illuminating article by Charles Musser (1984) that deals with the integration of fictional narrative and panoramic travel film in the transition from actuality genres to story films: "The Travel Genre in 1903-04: Moving Toward Fictional Narrative."

11. Biograph Bulletin 73 (June 30, 1906).

12. In her section on "The Genders in and on Trains," Lynne Kirby points out this double motif: the woman endangered by or on the train, and the respectability that the presence of women on trains indicated. This presence thus functioned as a sign of cultural legitimacy (1997: 82-89). My examples of A RaILway Tragedy on the one hand, and the A RunAwAy ENGINE, which I discuss below, on the other, constitute two different expressions that echo this double function. About pre-cinematic fiction about the possible dangers of and on trains, see Schivelbusch (1986).

13. See Ben Singer (1993) and (2001) on serial queens, popular melodrama, tie-ins, and female audiences. Other female heroes feature in railroad films, such as the Hazards of Helen episode The Pay Train (1915, Kalem) or The Railway Mail Clerk (1910, Kalem).

14. Nickelodeon V, 2 (January 14, 1911): 57.

15. The film mentioned here could very well be The Photographer's Mishap (1901, Edison).

16. "Some Moving Picture Tricks. Amusing Incidents Often Occur in Creating "Magical" Illusions." New York Times (January 3, 1909). 
17. Variety (November 14, 1913).

18. About Hale's Tours film exhibitions, see Raymond Fielding (1970).

19. Edison Films Catalog 105 (July 1901): 9. Quoted in the Library of Congress catalogue, Inventing Entertainment.

20. Nickelodeon IV, 7 (October 1, 1910): 201.

21. For references on this topic in the history of early cinema and some excellent primary sources, see Stephen Bottomore (1990).

22. Examples of this format are: BLACK DiAMOND Express (Edison, 1896), CALIForNiA Limited, A.T\& S.F. R.R. (Edison, 1898), CANYon of THE Rio Grande (Edison, 1898), Overland Express Arriving at Helena, Montana. (Edison, 1900).

23. "Reproduction of American History" Motography VI, I (July, 1911): 23-24. 


\section{Spectacle}

Main Entry: spec $\bullet$ ta $\bullet$ cle

Pronunciation: 'spek-ti-k\&l also -"ti-k\&l

Function: noun

Etymology: Middle English, from Middle French, from Latin spectaculum, from spectare to watch, frequentative of specere to look, look at - more at

SPY

Date: 14 th century

I a : something exhibited to view as unusual, notable, or entertaining; especially : an eye-catching or dramatic public display $\mathbf{b}$ : an object of curiosity

or contempt

2 plural : GLASSES

3 : something (as natural markings on an animal) suggesting a pair of

glasses

- Merriam-Webster's Online Dictionary, 2005

Once the train stops, either held-up or crashed, the type scenes discussed so far in this cluster congeal in a suspension of movement. Narrative yields to vistas of the wilderness destroyed and mourned. Sensation is intensified in such moments, as the viewer is seduced on the two most attractive levels of filmic pleasure: suspense that makes the heart beat faster, and a natural scenery whose beauty recalls its absence in the urban setting in which the viewing takes place. Sensation is doubled at the moment that the medium is most acutely confronted with its paradoxical position between narrative movement and vision. Those are the moments when the former yields to the latter but happening so fast that the effect of the narrative climax lingers on in the sensation of viewing the vista.

At the place of this tension, the strategy that is the major counterpart of narrative - display - will be exploited to suture over the gap between the two movements. This is where, in our present perspective, we tend to speak of clumsiness. In the perspective of a synchronic and self-aware history, however, the visibility of the seams is not a sign of clumsy craft but in fact an extraordinarily successful instance of cinematic thought. For the first time, cinema accommodates the needs of both visual pleasure and the nostalgia for a vanishing wild nature, as well as the pleasure of the thrill that compensates for it. The need for narrativity, I contend, is at its most urgent when these two cultural feelings are to be served in conjunction. 
And then, there is the opposite version - and this counterpart is the subject of the present chapter. The films that rely on monstration rather than narration, films that are basically examples of the cinema of attractions, or of what Gunning later distinguished as views, give evidence not merely of the photographic achievement of producing beautiful views, but also of the performance of building up tension, high or low. A lack of narrative development of action and characters does not mean, therefore, a lack of suspense. The structuring of time and space by the cinematic apparatus implies in itself a form of suspense, that may or may not be "satisfying" according to historical conventions. One could argue that in early cinema, especially in the first ten years, the visual construction of time and space of the cinematic spectacle itself created and resolved a tension, one that could be considered a visual and - why not? - narrative suspense. When films became longer, and narratives became more elaborate and more complex, then, but only then, did the primary filmic feature of visual display become part of narrative trajectories. With a gain of integration, a loss occurred. For, the medium's self-reflectivity disappeared and would have to be reinvented later.

Strangely perhaps, at the historical moment my study is probing, it is the very strategy of display - that mode of cultural production inherited from earlier media and genres, that produces this tension and puts it to use to attract its viewers. For, at first sight at least, a primary characteristic of display, of monstration and attraction, is that the action or happening takes place within one shot or frame. This temporal and visual condensation has been characterized by film scholars such as Burch (1990) or Staiger, Thompson and Bordwell (1985) as a "primitive" mode of representation or narration, a mode that is not as sophisticated as narrative editing or montage. The latter techniques produce continuity between shots. Against this view, Gunning rightly argues that the cinema of attractions is not so much a specifically historical type of film, an historical genre if you will, but a mode of filmic showing. Although invented in the early years of cinema and typical for one-shot films, this mode will be taken up for its own sake in later styles. Therefore, I treat it as a specific mode of producing spectacle, a distinct filmic strategy, and not as an as yet imperfected groping towards something else.

Adepts of psychoanalysis might understand this by way of an analogy with Lacan's theory of the imaginary and the symbolic stages. This analogy is instructive for more than one reason. In Lacan's narrativized theory, the imaginary stage is the first moment of the life of the Lacanian infant. This creature perceives the world around it only in bits and pieces, detached body parts like the breast, to name a not-so-arbitrary example. Or the face of a parent, its own hand flying by, or a glimpse of the cradle. These bits and pieces all have the same status of objects. At the moment of the mirror stage - when the baby dis- 
covers its visual wholeness in its mirror image - this imaginary stage is largely but not wholly overruled. From then on, the child, now an emerging subject, begins its difficult journey into the symbolic order. But the symbolic order, as the tale of the mirror argues, is grounded in a visual experience that is alienating. The child recognizes itself, that is, outside of itself - in the mirror - in reversal - mirror images are reversed - and beyond reach. This makes the mirror story so convincing in spite of the impossibility of ever "proving" its empirical truth. In the wake of the sacrifice required by the symbolic, then, the imaginary "way of life," the order of seeing fragments without seeing them in terms of fragments because there is no immediate whole in view, will travel along and will never quite leave the subject.

If I now suggest an analogy with the single-frame views that constitute spectacle in early Westerns, this is not to turn early film into a babyish thing after all, but, on the contrary, to underline the cultural importance of such techniques in "later life," when film, fully involved in its symbolic order of extremely sophisticated techniques, can still hold the congealed moments of visual fascination that at one point in history constituted its primary attraction. ${ }^{1}$

Following up, also, on my chapter on narrativity, I examine here how narrativity within display, and the display of narrativity, both balancing a combination of telling and showing, create a visual spectacle. My reasons for studying this phenomenon are the following. First, I am often struck by the complexity of the very short, apparently simple films that do not tell a story but depict a situation. I believe that these films may be more influential and more persistent in the development of genres, and specifically of the Western, than one would expect. As I argued before, the history of the Western did not start with narratives such as The Great Train Robbery (1903, Edison) but with attractions such as A BuCKING BRoncho (1894, Edison), its namesake A BuCKING Broncho (1904, AM\&B), Black Diamond Express (1896, Edison), and Herd of Cattle (1901, $\mathrm{AM} \& \mathrm{~B})$.

These attractions, although often staged for the purpose of cinematic reproduction, can be considered nonfictional because of the direct recording of profilmic events involved in achieving the attraction. Far from being a case of primitive clumsiness, "not edited" is often a boast of "authenticity." As I have argued before, this quality is questionable as a basis for the distinction between fiction and nonfiction, for "authenticity" is an effect. And the word "effect" points to strategies aimed at achieving it, in other words, to rhetoric. The visual rhetoric that produces the authenticity effect of the films I just mentioned is, precisely, the single shot/single frame, whether this technique was due to limitations of cinematic know-how or not.

In addition to this complexity inherent in the single-shot view, a second reason for my interest in the relationship between telling and showing that follows 
this initial situation where display dominates, is that I wish to nuance the oppositional division between narrative coherence and the disruption of the flow that warrants this coherence, precisely, by means of a pro-filmic coherence. What I am talking about, then, is not only so much an interest in longer narrative films as opposed to short cinema-of-attraction films that show moving tableaux of something - a stunt, performance, trick, or wonder of nature - but rather an interest in the way in which and the reasons why, this production of spectacle is a feature of film that is fully integrated in narrative, even though reviewers may criticize or applaud the successfulness of these ambitions.

To make my case, let me juxtapose two seemingly different types of films, in order to analyze their common ground in the spectacle of their creation of suspense and display: two films about trains, one an exciting narrative, the other a staged stunt performed in front of an audience. The first is about the last-minute rescue of a gentleman-in-distress by a girl, THE Runaway ENGINE (1911, Kalem), discussed in the previous chapter. $\mathbf{R}$ The second is the incomplete fragment of a Vitagraph film from approximately 1911, listed as BITS \& PIECES \#319 in the FM catalogue: "Een fantastisch duel. Twee locomotieven botsen op elkaar" [A Fantastic Duel. Two trains collide], a fragment I evoked in B.

The latter film, although appearing incomplete in the sense that it lacks the framing of an opening title and a clear ending, is a perfect, self-contained narrative. It arouses tension, reaches a climax, and has a denouement. To briefly summarize the images of the film: two trains ride towards each other. A spectacular frontal collision is shown. Spectators in a kind of stadium watch the spectacle. Lots of smoke and two ruined trains are displayed at the end. ${ }^{2}$

The film is spectacular, awesome. It celebrates catastrophe rather than, or in addition to, expressing a fear of it. The ruins of the two engines are displayed in all their glory. The collision is anticipated by a festive crowd of spectators. It resolves a fear by celebration of - and thereby takes the sting out of - catastrophe rather than by showing a last-minute way out of danger as the former film does. The trains, in other words, go all the way, and that is the visual point of the fragment. This film definitely has a "catastrophic aesthetic." It appears to offer an excellent case for Michel Ribon's speculation that the flirtation with catastrophe, which he sees in all art, is bound up with novelty: It is a matter of attraction and repulsion, integrated in favor of the predominance of the former (1999). This would surely overdetermine the meaning of the disaster's incarnation in a train accident, a phenomenon that was emblematic of the new culture of modernity with its speed and unlimited expansion of world experience. In an excessively generalizing statement that is nevertheless useful for the applicability of this grandiose aesthetic to our modest little bit of film, Ribon writes: 
Always in some way tormented by the tragic sense of life... The great artists - those who make us see and feel something really new - make us inhale, at the same time, a smell of catastrophe: a touch of disaster, in the way of a warning, colors them. (20; my translation $)^{3}$

Although Ribon was unlikely to be thinking of railroad accidents in early Westerns when he wrote of great artists who make us experience something truly new, I find it helpful to think of the public - after all, represented in the film itself, in the guise of the spectators in the stadium - as being given a thrill similar to that provided to the elite by great art. It helps the historian to realize the novelty of train riding and to see the extended horizons it made available, at least in travel's filmed version, as truly new.

My second example, The Runaway Engine also plays with this novelty, and the thrill of danger and catastrophe that comes with it. $\mathbf{R}$ But here, the fear of catastrophe is used on the level of a toy - it is played with. The film offers a resolution for the tension, perhaps even instead of the tension, by showing a way out of approaching danger. You may recall the plot: a president of a railway company has boarded a train with no driver on board. His son's lover rescues him by causing another train, driven by her, to collide with his, in order to stop his out-of-control vehicle. After a wild chase by train, at the very last moment before the collision, she jumps off to save herself.... It surely sounds thrilling enough.

But if the reception of the film is an indication of contemporary experiences of suspense in terms of spectacle's troubled relationship to narrative, then the evidence disappoints. As the earlier quote from Nickelodeon suggested, RunawAY ENGINE does, precisely, fail to hold the viewer in suspense: "We follow her wild ride sympathetically but our suspense is vague and not intense enough to be exciting." 4 Here the lack of narrative motivation reduces the build-up of tension. The review gives a clue to how the creation of suspense could have benefited from the use of intertitles: "Too bad the sub-title editor did not see fit to explain matters more fully because the incident seems highly sensational in retrospect." This suggestion adds insult to injury for the film historian who takes her or his own standards for granted. For, as a remedy for the failure of suspense, it refers to a practice that would later be considered as a means of reducing suspense, namely prolepsis, or the announcement of coming events. ${ }^{5}$

This paradoxical bit of reception, then, is instructive for the topic of this chapter as well as for that of $\mathbf{R}$. For, with respect to the function of spectacle, precisely, the Vitagraph film shows the essence of the same event as the nonfiction example that serves here as its counterpart. It focuses on a collision of trains and leaves out any motivation or narrative background. There is no document of its reception, unfortunately. This would be difficult to find because of its unidenti- 
fied status. Would this fragment also have failed to pass muster with the critic? Not necessarily, for here there is an internal reception. The onlookers in the stadium are, after all, shown in their enthusiasm for the disaster. Clearly, they were thrilled. But then, they were not watching a film, but a stunt, a real occurrence of the representation - for a stunt, of course, is also a representation. This is why the comparison holds only in part, but it does help to grasp the significance of spectacle. It is therefore legitimate to see this fragment as a purely sensational film that may be considered more successful as spectacle than the narrative counterpart from Kalem, even though, as a "less" narrative film, it may seem to the anachronistic viewer or to the critic fed with sophisticated later techniques, a more primitive film.

It is the combination of narrative development, and the prominence of characters, with visual spectacle as we see it in the Kalem film, that is considered problematic in the Nickelodeon review. According to this critic, in RunAway ENGINE, recognition of the character's intentions is made impossible by the lack of clear indications: "The girl's exploit is undoubtedly daring but loses much of its exciting effect because the audience is not made aware of her purpose." This lack appears to be considered an insufficiency of the rhetoric of motivation. In terms of the dynamic of narrative and spectacle, this insufficiency can be rephrased as an incompetence of the narrative that spoils the effect of the sensational spectacle. And this would hold for the second film as well.

Not that this case can be easily generalized, however. In a review in Nickelodeon of THE BORDER RANGER (1911, Essanay), a month later, a seemingly contradictory opinion is asserted. Here, speaking clearly with the ironic tongue from after the beginning, already tired of the not-yet genre, the reviewer mounts an opposition between interest and thrill:

A Western melodrama constructed from old familiar elements, interesting enough but scarcely thrilling, even though the villains are getting ready to torture the hero with a red-hot poker. A squad of horsemen is seen galloping over the plains and everybody knows they will get there in time to save him. This squad of horsemen has become so familiar in Western dramas, particularly in Essanay Western dramas, that the instant they appear all suspense is at an end because they were never known to fail. Some terribly original producer will let them come too late some time; but such dare-devil iconoclasm need never be feared from Essanay who will uphold the orthodox traditions as long as they hold the ghost of a thrill. Essanay fathered most of the Western traditions and will doubtless be loyal to the end. ${ }^{6}$

For the jaded writer it is precisely the recognition of familiar narratives that spoils the "thrilling" display of action. Narrative, here, seems to stand in the way of visual sensation. According to this statement, a film can be either "inter- 
esting" or "thrilling" but not both at the same time. The key is recognition: whereas it is indispensable for understanding, it is deadly for thrill.

We have seen the paradoxical truth of this clash between effects before $\mathbf{N}$. Chases as familiar narratives build up expectations for an ending, and when this ending is already known beforehand, the chase loses all of its effects. Reversing the perspective, then, one can surmise that it may be for this reason that the collision of the trains in BITs \& PIEcEs \#319 is so spectacular. As an opposite of the chase - the trains are riding towards each other, rather than one pursuing and hence, following the other - with an opposite outcome - disaster happens, collision takes place instead of capture or escape - the film defies "regular," that is, narrative expectations. Instead of primitive, then, we may just as well see it as an ironic response to the allegedly more "mature" narrative integration of spectacle.

So far I have focused on the apparently significant choice for either narrative or spectacular ambitions and expectations. As a next step, I use the provisional insights gained from that inquiry to examine more closely the shifts from the one to the other within narrative films, from following a plotline - with or without predictable endings - to "zooming in" on the image for its own sake. This transition occurs when visual spectacle interrupts a flow of events that have only an "event status." With this term I mean that the events are the twists and turns of the plot but serve no other purpose than to propel the narrative. Stunts, explosions, close-ups, or long shots of wondrous sites and sights interrupt the narrative, or at least change the pace of the films in terms of narrative by either accelerating the flow of images, or slowing them down. They consequently set aside for some time the "purpose," the thrust of the plot, the logical order of goals or intentions, obstacles, a climax of events, and narrative closure.

How do we recognize this change within the films? An avowedly paradoxical method is to consider the announcements of events to come by means of intertitles. As a production of suspense, intertitles are paradoxical because, in terms of suspense, you would expect abrupt occurrences of events rather than loud proclamations of their coming. Suspense is, after all, mostly an effect of an unequal distribution of knowledge, either between characters, or between characters, on the one hand, and the viewer, on the other (Bal 1997: 160-61). Nevertheless, intertitles can be deployed to many different effects. For example, they play a significant role as an internal form of reception - in a sense that balances on the boundary of the metaphorical - in the film LosT AND WON (1911, Selig).

In this film about love lost and found, a scene is inserted that consists of nonfiction footage of an oil well in operation. Radical cuts are made between narrative fiction and nonfictional display. The intertitles framing the oil find list numbers, ostensibly to emphasize the spectacularity of the event. These titles are 
even cited in the program leaflet of the Dutch cinema the Electro Bioscoop in Middelburg where the film was programmed on 9, 10 and 11 December 1911:

The area where this film was shot is situated near the largest oil well in the world, only recently discovered. The well is of such scope and force that it projects the oil over hundred meters into the sky. It is 12 meters wide and about 800 meters deep. It yields about 50000 to 75000 barrels of oil a day. The film is important if for this reason alone. ${ }^{7}$ (my translation)

The last sentence, which appears to have been added to promote the film, suggests that this one scene makes the film interesting to see, and is more gripping than the rest of the film, the story of the narrative. The spectacle is set up to compete with the narrative.

In this film the inserted footage could be taken out without changing the flow of the narrative. But clearly, this would also spoil the film as the intertitle construes it, as (real, sensational) spectacle. Clearly, judgments about good or bad editing, successful or failed narratives are impossible to make and are not relevant. There is a more adequate way to assess this film, and others of its kind, if we balance what we see (today) with the indications of projected reception within the films. Such films had several ambitions, which were all met, without one necessarily disrupting the other.

If this interpretative use of intertitles is meaningful, then we can once more revert to the fragment about the colliding trains. Here, too, the intertitles function as a zooming device. Reversing the perspective, I would like to offer the speculation that maybe this was footage that could be inserted into a narrative film, just like the oil drilling in LOST AND WoN. In fact, as I mentioned before, a very similar film, THE RAILROAd SMASHUP (1904, Edison) that shows the collision of two trains, was released both as individual stunt film, and as inserted (final) scene in the narrative of Rounding Up of THE YEgGMEN (1904, Edison). $\mathbf{M} \mathbf{R}$ This double use provides evidence that this was common practice (Kirby 1997: 59-60).

The intertitles emphasize the spectacular character of the event, again by impressing the audience with numbers:

A fantastic duel: Two locomotives collide at a speed of hundred kilometers in the presence of the inhabitants of Indianapolis. ${ }^{8}$ (my translation)

This intertitle self-reflectively frames the stunt with the trains as spectacle by stating that the inhabitants of Indianapolis are watching - as if the entire population were sitting in the stadium. ${ }^{9}$ The speed of the trains is mentioned as if to give weight to it. To create tension and suspense, a later title describes how the people on the train barely escape the collision, again flirting with catastrophe: "A moment before the collision, engineers and stokers jump off the locomo- 
tives." ${ }^{10}$ Here, incidentally, the tension concerns not only narrative and spectacle, but also words and images. As an ultimate paradox, the words exaggerate the spectacle for more intense effect, whereas the image relativizes this, for the actual images show the men posing in a very relaxed way in front of the train. The suspense is suggested in the titles, and the images illustrate - or as the case may be - contradict it.

Taking this case as emblematic, I submit that the tension, or collaboration, between spectacle and narrative disposes of different strategies to increase sensation. But sensation is the goal, the thrust towards which the deployment of spectacle relentlessly works. The stunts which produce the spectacle may be either technological or psychological, sometimes deploying an implicit analogy between what is shown and what the viewers are invited to experience: danger, thrill, not for an Aristotelian catharsis but for its own sake, as participation in the kind of life modernity has in store for the viewers. For, it is specifically in terms of emerging modernity, the modern life that is itself thrilling and yet depriving its subjects of an already idealized past, that the spectacular spectacle is exploited. That is why, in addition to such other novelties as amusement parks, trains are so popular in our films; they offer the benefit as well as the danger of modern life in a nutshell. They also offer opportunities to stage spectacle as well as narrative. And as the condensation of modern life, with its steel and machinery, simmering heat and smoke, speed and danger, its promise of far horizons, the train is, also, an object that can be made to move - not only as machine but also as spectacle itself; not only as moving image of the possibility of the moving image, but, also, of the image that, through visual thrill, moves its spectators.

In terms of the modernities at stake, these films show and solicit what the body undergoes. They playfully draw attention to the body itself, rather than to what the body does. Sensation is shown to go hand in hand with mere perception. Transcending narrative and bodily excess here signifies the reasons why visual culture, as of this moment, becomes such a predominant force.

Spectacular stunts, whether physical or technological, emblematize this. Within narratives they "zoom in," bring the flow of the plot to a pause. Yet, it seems the Western plot, or the "Western" flavor is particularly good for spectacle. ${ }^{11}$ Variety mentions the film The Stampede (1909, Selig), that includes the Wild West Show "Miller Bros. 101."

The plot allows for many Wild West stunts that compensate for flaws in this film and are considered the main attraction by this reviewer:

"The Stampede" is a series of ranch life pictures into which is intermingled a light love story. The daughter of the ranch owner and one of the cowboys are sweethearts. A jealous rival decides on something desperate. He stampedes the animals, hoping the hated rival will be crushed, but is foiled, as the girl just arrives in the nick of time 
to save her sweetheart. The rival is summarily punished. The stampede is not as well worked out as was anticipated, but other feats of horsemanship were followed with interest. They included broncho bucking, lariat throwing and other pastimes shown in the Wild West exhibitions. The picture was posed by members of the Miller Bros. “101 Ranch" Shows. ${ }^{12}$

The reviewer of QUEEN OF THE RANCH (1909, Lubin) is even more explicit in his valorization of spectacle and stunts over generic innovation or a sophisticated narrative:

S. Lubin has here turned out a Western story which, while it has few points of startling novelty, gives a whole wild west show on the sheet, and a mighty thrilling one at that. Its rush of motion in addition to an easily understandable narrative makes it a highly entertaining subject. The story has to do with rival suitors for the hand of the Queen of the ranch. She repulses one and he seeks to have the fortunate rival murdered by paid assassins. The Queen frustrates the plot and all ends happily. There are two or three capital break-neck chases on horseback, and a scene at the round-up is nicely managed. A large company must have been engaged for the production, most of which has out-of-door settings. A score of riders are seen at once. ${ }^{13}$

Some critics praise the exploitation of spectacular possibilities of the Western theme by filmmakers, others criticize the lack of sophistication of plot, acting, or other elements of filmmaking. It is difficult to come to a conclusion in terms of failure or success of the genre, since others have demonstrated the rise of critical voices, announcing the demise of popularity of the Western in the mid1910s. Although reviews in the trade press are not unimpeachable evidence of how the films were actually appreciated, critiques like the ones quoted here demonstrate that the balance between visual spectacle and narrative sophistication can go both ways. This balancing act, not its outcome, provides evidence to the effect that the tension between narrativity and spectacle was on people's minds.

Even more explicit about the hierarchy of plot and spectacle is the following review of a film with the significant title: WHEn We Were Young (1914, Selig [?]):

Made by the Miller Bros.' "101 Ranch" outfit and released in the Warner's Features program, this three-reel drama is a stirring picture of Indian warfare in the early days of the Western plains. Dustin Farnum is credited with the work of directing. He had the Miller people to work with and used them to build a fine picture of action. There is a story, but it serves only to string together the episodes of hair-raising horsemanship and the pop-popping of firearms. There are half a dozen pitched battles between miners and Indians, U.S. troops and Indians and scouting skirmishes. The screen is never idle for a moment and the action gets something of that whoop hurrah that pulls 
the wild-west audiences from their seats when the bluejacket line sweeps into the arena to route the redskins. The placing of these scenes in the appropriate setting of the wide prairies gives them added strength. Miller's horsemen appear to accept long chances as part of the day's work. One of the cowboys did a fall that invited a broken neck and another dropped his mount in a mid-riding, which is the feature of the film under discussion. The proceedings begin with an old man and his gray-haired wife looking across a river to a spot where a granite monument rises. A dissolving view brings the husband back to his youth when he took part in the Indian fighting commemorated by the stone shaft. The wife figures incidentally in the narrative. The love story is a subordinate part of the tale, but serves nicely to give it the romantic touch. The result is first rate picture entertainment. ${ }^{14}$

The title of the film suggests a youthful liveliness. The reference to Wild West Shows activates a positioning of spectacle as dominant to narrative. The appeal of physical stunts to the audience is foregrounded in juvenile terms ("whoop hurrah that pulls the wild-west audiences from their seats"). The use of real locations is underscored. And whereas the phrases I emphasize show the wavering between narrative and spectacle, the title of this film strongly invokes the nostalgia for which the spectacularity of the image offers a compensation. When the recent past is irretrievably lost, the virtual travel afforded by the moving image allows the indulgence of traveling back in time. Beyond narrative, the spectacle offers a moving image that moves.

\section{Notes}

1. Among the works of many psychoanalytic theorists of film, Kaja Silverman's Threshold of the Visible World (1996) stands out in its clear and full elaboration of the cultural significance of the imaginary's ongoing participation in subjectivity.

2. Although this particular film, or scene, is a rather "pure" nonfictional registration of a staged collision, in the New York Times of August 20, 1911 we can read a report of the use of a "real" locomotive for the staged train wreck in Lonedale OpERATOR (1911, AM\&B). This report constitutes a clear case of the "spectacularizing press" that describes the physicality of filmmaking in order to promote a particular release.

3. “Toujours tourmentés de quelque façon par le sentiment tragique de l'existence .... Les grands artistes - ceux qui nous donnent à voir et à sentir quelque chose de vraiment neuf - nous font en même temps respirer un parfum de catastrophe: une touche désastre, comme un avertissement, les colore."

4. "Recent Films Reviewed." Nickelodeon V, 2 (January 14, 1911): 57.

5. About intertitles and their "epic" function, see Eric de Kuyper (1991).

6. "Recent Films Reviewed." Nickelodeon V, 6 (February 11, 1911): 169; emphasis added. 
7. "De omgeving in welke deze film opgenomen is, bevindt zich in nabijheid van de grootste petroleumbron te wereld, die eerst sinds kort ontdekt is geworden. De bron is van zulk een omvang en kracht, dat zij de olie meer dan 100 meters hoog in de lucht spuit. $\mathrm{Zij}$ is 12 meters breed en omstreeks 800 meters diep. Levert plm. 50000 tot 75000 vaten petroleum per dag. Deze film is hierom alleen reeds belangrijk." Programs of the Desmet Collection, FM. Box: "Programma's Diversen."

8. "Een fantastisch duel: Twee locomotieven loopen tegen elkander met een snelheid van 100 kilometer in tegenwoordigheid der bevolking van Indianapolis."

9. Kirby (1997: 60) writes about the practice of staging train wrecks at county fairs in the US in the period 1896-1920s. She uses Susan Sontag's term "Imagination of Disaster." Kirby's article on "Male Hysteria and Early Cinema" (1988) is also relevant for this topic.

10. "Machinisten en stokers springen van de locomotieven een oogenblik voor de samenstoot."

11. Some more extremely physical stunts in "Western" settings are performed in Sulla ViA Dell'oro (1913, Cines), The Last Minute (1913, Éclipse), and, last but not least, the earlier-mentioned Cowboy Millionaire (1909, Selig). Yet, I wish to point out another association for the stunts that are related to both the celebration and the anxieties of modernity, namely amusement parks. Films that feature amusement parks but also a "Western" or "rural" point of view are also part of my corpus, such as Cowboys' Day Off (1912, Broncho Films) or Rube and Mandy's visit to Coney Island (1903, Edison). The ambiguous locations of these "parks" are significant for the tensions felt at this moment in history between the modern and the premodern. Often at, or just beyond the city limits, amusement parks provide fantastic settings for rides and other physical and visual entertainment.

12. Variety (September 18, 1909).

13. Variety (April 24, 1909).

14. Variety (October 31, 1914); emphasis added. 


\title{
Time Travel
}

\begin{abstract}
"Scenes of travel and historical subjects, first and always. Both educate and at the same time afford true enjoyment. The former opens up new worlds to the forced stay-at-homes. The latter impresses upon youthful minds important facts in a forceful, interesting manner that no textbook could ever do."

- Motography, $1911^{1}$
\end{abstract}

The Acme of sublimity in natural scenery is reached in Arizona. The world is not aware that this is true, nor do I hope to prove that it is true except to those who, with an interest aroused by words that are inadequate and pictures that fall short of the reality, shall some day undertake the marvelous journey that glorified for me the summer of 1898 .

- Burton Holmes, $1908^{2}$

We are not finished yet with the thematics of travel. Central to my case here are again the films about, made from, and using trains, discussed in $\mathbf{R}$, but here they are considered as part of a larger category of films, all thematizing travel as an activity of modern life. Travel is used as a strategy to keep medium and theme integrated, to the greater enjoyment of the urban viewer who is fully aware of the possibilities beyond his armchair. In previous chapters I discussed the fine line between travelogue and fiction film, as one case out of many where genre discussions blur rather than illuminate crucial features of the corpus, whereas the suspension of such distinctions helps us to grasp the cultural meanings of both. Here, the opposite seems to be happening: a fugitive, time-bound "genre" emerges. A similar crossing between medium and narrative serves to explore the strategy deployed by this simple device: the traveling camera as a tool for virtual travel. This device became so enthralling that it became the hub of many different phenomena attached to it like spokes. Hence, my proposal to speak here of a grouping as yet not stable, not permanent, not frozen enough to pass muster as a genre, but perhaps more revealing for it.

"Time travel," a genre indicator based on plot and stunts in later Hollywood films of which BACK TO THE FUTURE (1985, Spielberg) is the paradigm, is a label I here attach to films that bind the theme of travel and the technology of the traveling camera to a provisional, always-fleeting satisfaction of the double desire of nostalgia for the past and the dream of a future. As such, this "genre" is neither an "immature" predecessor of the later genre nor an entirely different 
genre, but a Wittgensteinian "relative." It also depicts place as time and time as place, distant but reachable. But, in distinction from the later genre, it is much more removed from science fiction. In contrast, it is emphatically bound up with realist rhetoric. Indeed, whereas the later genre flaunts its transgression of realistic conventions, my group of films and other visual artifacts such as postcards, photographs, and paintings, is rather removed from the general notion of fiction. Instead, it wavers between nonfiction and fiction, using both to foreground the real possibilities the traveling camera affords the virtual traveler. Showing the landscape becomes showing off the technologies that package it. "Virtual," here, indicates the production of the illusion of presence - of the past and the remote places together, in the pastness of remoteness. ${ }^{3}$

Travel emancipates from the confinement in the slow and small world before modernity. It enables people to see things they have never seen before. These things include the mighty natural scenery that urbanization has set apart as both far and prior, almost but, thanks to travel, not quite lost. Not only does this possibility facilitate fundamental changes in cultural attitudes, so that a different relationship between the direct environment and the world at large can emerge, it also produces and promotes a visual regime in which looking itself can be an adventure. ${ }^{4}$ In the case of travelogues about the American West, the trigger of virtual travel is the wilderness that is vanishing as it is visually opened up. The look is one of a virtual reservation: looking replaces being. For this reason I call this fascination with looking at this temporally loaded geographical space, "wild looking." This type of look is more literally a "mode of looking" since it really is an operation. It is the look of the tourist, the latter's primary activity. Therefore, I flesh it out by relating it to the semiotic process of tourist travel as Jonathan Culler (1988) has called this process of meaning making. ${ }^{5}$

We have seen this look at work already in $\mathbf{P}$. There, the tourists, dangerously balancing on the edge of spectacular rock formations but depicted in restful poses, stood in for the visitors of a virtual museum of photographs or for the armchair tourists browsing through an album of postcards sent by more adventurous - or wealthier! - friends. Here, I analyze this tourist appropriation of the world through a closer look at the Westerns as tourist attractions. The "punctuated locations" are now seen less as the spectacle - a postcard even in the moving image - than as the live, visible, tangible world to be conquered, albeit peacefully, for the satisfaction of a profound desire born of anxieties inherent in modern city life. Both in the films and in the press, this conquest is emphatically presented as serving the benefit of the viewer, not in aesthetic but in existential terms.

This chapter, then, is most specifically about tourism, the figure of the tourist and the activity of tourism in relation to setting and location. This activity is a form of amateur ethnography as well as a form of self-reflection. While unmoti- 
vated by business or science, tourist travel remains quite literally a "field trip" where knowledge and experiences are gathered. While geared toward nature and its "wild" inhabitants, it also helps the continuous self-definition the modern subject needed so keenly. Hence the fact that there is an inherent temporal dimension to tourism as a mode of travel. The places visited are considered as pre-modern. As a result, going out of the modern city towards the primitive and picturesque places elsewhere in the world means going back in time, to a time still sticking to the city-dweller through the glue of emotional attachment fed by nostalgia. This return to "before" the present was the primary meaning attributed to remote places. This return to a past just lost entails visions of places that, in that affectively nourished vision, have an inherent temporal dimension based on implicit, intuitive comparison. This comparison that turns elsewhere into elsewhen is the paradoxically non-reflexive, self-reflective dimension of tourism. ${ }^{6}$ It turns the attention to the spectacular vistas into an attention to one's own needs.

There is nothing surprising in this conversion of place into time. The temporal signification of place increases the strangeness, and hence, the tourist value of the places visited. This overdetermined strangeness by semiotic conversion enhances the "travel effect" of the visualization of these places. This involves an important paradox of tourism and travel. Tourism, Culler reminded us, is a modern quest for authenticity, the sole option in a time when the historical authentic has ceased to exist - if it ever did. The quest seeks to bring about while "finding it," the infusion of geography with history, as an affective and non-reflective counterpart of the scientific-colonial endeavor of mapping. Thus, tourism and the travel that facilitates it, embody the dual sentiments of instant nostalgia and urban anxiety. This makes the combination of tourism and travel in the virtual experiences afforded by vision a profoundly satisfying form of time travel.

The notion that the category of travel films solicits a specific look implies a set of problems that cannot be glossed over in any discussion of it. These problems emerge out of the relation of cultural excitement to political agency. Here, this agency is that of the continuous need to reconfirm colonial conquest. The emerging tradition of the "travel film," continuous with ethnographic films on the one hand, and landscape travelogues on the other, trains viewers in the habit of practicing a look that has often been characterized as "colonizing" and "exoticizing," a look that has here been more specifically presented as "picturesque." It turns the near-overwhelming power of nature that solicits the experience of the sublime into manageable vistas one can safely take home. The screen - like the postcard and the print after paintings - is Renaissance perspective's portable version of offering a "window on the world." In the case of Western films the profound emotional appeal of this look, and hence, the interiorization of a 
cultural colonialism, can be understood when we compare the American viewer to the European one. For, each of these two groups of viewers had a slightly different relationship to the colonial past, a difference that had to be both accommodated and kept under wraps if the films were to serve both audiences.

For Europeans, seeing these films was a way of making a vicarious trip to America, thus virtually duplicating, and hence, stirring the buried memories of the trips their countrymen and women had made when they settled the New World. For them, the look solicited by travel films took the shape of what Marianne Hirsch called in an altogether different context, postmemory. ${ }^{7}$ It revived the culturally sedimented mixture of firsthand and hearsay accounts of experiences never lived, yet interiorized. Through the new phenomenon of travel films, those who remained behind in the Old World but whose relatives undertook the adventure of going to America were informed of the New World, its excitements, and its dangers. These trips were associated with a particular form of time travel. They were "modern" in the sense that they were made possible by modern transportation systems, such as trains and steam ships, "contemporary" because the travelers abroad were overseas at the time that the people at home were thinking about them, fantasizing about their exploits, and worrying about their well-being. Such trips were a going back in time, to a place that symbolized a remote pastness, and because they were simultaneously building a future life abroad, they were dealing with the future, transforming the previous future. In this respect, the comparison to BACK TO THE FUTURE can be illuminating, if only on a metaphorical level. ${ }^{8}$ For American viewers, prone to cultivating their European roots overlayered with heroism, this viewing experience, although equally temporalizing, must have had less worrisome and more heroic, nostalgic implications. ${ }^{9}$ Dangers were represented, and hence, of course, also addressed on behalf of the American viewer but, significantly in view of the time-place dynamic at issue in this chapter, these could easily be displaced onto contemporary dangers occurring elsewhere.

An illustrative example of a film heavily relying on the former sentiment is a Dutch film about the contemporary dangers in Mexico, and the fears of the migrant's family left behind, as told in Telegram uit Mexico (1914, Hollandia). Let me remind the reader of this film, discussed earlier, about a young Dutchman who travels to Mexico, leaving his worrying parents behind. The separation between these aging parents, on the one hand, and the adventurous son, farming and fighting in Mexico, on the other, came to stand, metaphorically, for the cultural gap between Europe and America, modern guardian of the wild. As a consequence, the remote place - Mexico - came to stand for the past - for conquest, with its fights, dangers, and uncertain futures. Both audiences were served by this film, which offers two distinct positions for identification and other forms of emotional projection. J 
I add the latter to remind my reader that identification is, of course, not the only form of engagement the moving image solicits. The mechanism of projection is at least as important. The projection of desires onto objects, such as vistas, is an object relation based on desire or fear and estrangement as much as identification. This becomes clear when desire and enjoyment of nature are metaphorically conflated in another example, the Italian film NEL VORTICE DEL DESTINo (In the Vortex of Destiny, 1913, Savoia Film). On the level of the narrative, this film foregrounds desire. It is about a man who is disillusioned in love and moves to Mexico to start a new life. Here, too, parenthood and childhood are contrasted, but not, as in the previous film, on the basis of the opposition between the Old and the New Worlds. Years later the main character saves his son's life when the boy travels to the West and is almost killed by Mexican cowboys. Here, the two generations meet in the New World. Together they return home, to Europe, and the family is reunited. These two examples both speak to the hazards of travel to the dangerous West, and offer reassurance when they end happily with a reunion of the family in the primary home, in Europe.

In these Westerns travel is transformed into adventurous stories experienced in locations - in the fabula - that have become settings for the visual narrative. ${ }^{10}$ The distinction is crucial for the understanding of a grouping of films based on place, such as the one here mentioned with the shorthand misnomer "Western." $\mathbf{L}$ Location is a place, used as setting. The 1999 edition of the MerriamWebster's Dictionary defines setting as "the time, place, and circumstances in which something occurs or develops." Locations, on the other hand, are defined as positions or sites "occupied or available for occupancy or marked by some distinguishing feature" with "situation" as its synonym. As the situational embedding of narratives, specific locations are settings of specific stories. Place thus bounds fabula to spectacle. In this way location becomes active in a semiotic process. But, more significantly for this chapter, in these stories the location becomes also a signifier for temporality. In terms of the grouping of travel films, however, this temporality cannot simply be reduced to pastness.

For through the narratives of adventures with a happy ending, location functions temporally in two distinct ways, depending on the viewer's own position. From the vantage point of the European, or Europe-identified viewer, the primary temporality evoked is future-oriented. For, according to Europe's postmemories, the "future," life in the West, the New World, is at first an exciting adventure. But "staying behind" in Europe cannot be presented as all bad; that would alienate a potentially huge audience. Hence the emphasis on danger. When it turns out to be a little too exciting, the "past," as signified by Europe, the Old World, becomes an even better future than the tempting one witnessed with shivers of fear. Both films evoked above play with this cycle. The effect of this cycle is overdetermined by the presence, in all temporalities that are cycli- 
cal, of the cycle of life itself, embodied in the family. In its psychological version, this cycle is signified by means of the return to the primal family as a return to the past as well as an alternative, safer future.

Here, again, we encounter one of the reasons why the Western, more than being just another kind of film, is a paradigm of the cultural historical significance of the coincidence of film, the closing of the frontier as the completion of settlement, and the emergence of modernity. And within this paradigmatic status of the Western, the fugitive group of "travel films" stands out as emblem of the larger genre as a whole. Travel thus becomes the overdetermined metaphor for the medium itself in its cultural embedding. By analogy, then, I contend that travel in some sense is always a form of time travel. For, as a result of modernization, travel creates its destination, which the sharp temporal awareness of modernity must define as "of other times" in relation to the moment where the self is exiled: either backward or forward, depending on where the traveler is coming from. Most often, backward then jump-starting forward. This widening of the scope of this chapter is not meant to make it impossible to probe the distinctiveness of time travel. On the contrary. In the case of going West, this time travel remains of specific significance. And it is this significance that makes the group of films visible in the first place.

This significance is both specifically real and symbolic. In $\mathbf{I}$ mention the paradox of travel, as sponsored by railroads, the tourism that results, and the preservation of nature sponsored by railroad companies, a nature that needs to be protected from traveling mankind. The circle closes when we realize that this need to preserve nature, in turn, serves the tourist industry that causes the need for preservation. It becomes necessary, first of all, in order to ensure continued touristic travel. This coincidence of interests is symbolic for the temporal dimension of travel and tourism. Hence, the specific importance of traveling West, and the resulting group of films that put this traveling at the disposal of the Eastern urban viewer in the form of virtual travel.

Again, the contemporary press shows evidence that this symbolic meaning was culturally present and recognized as such. About travel and advertisement of cities and/or other (distant) places, in other words, about the temporal significance of travel, Watterson R. Rothacker writes in Motography:

Cities, towns and even villages all over the United States are flaunting the colors of community patriotism and shouting long and loud the praises of the respective places. All this noisy evidence of civic pride must not be considered as a mere spasmodic burst of empty enthusiasm; quite the contrary, it is replete with meaning and is thrown at the public as an announcement of progress. It has an epochal significance. ${ }^{11}$

Celebrating progress, Rothacker declares the street evidence of "civic pride" of great importance, "replete with meaning," and uses a temporal metaphor to 
characterize that importance. Continuing, the author is clear about the role of film in this historical and cultural project of progress. He specifically mentions "travel films" and relates them to emotional solicitation:

Scenic and travel moving pictures create a yearning to see the original of the subject. Their graphic depictions of the beauties of scenery are decidedly effective in actuating $a$ desire. Thus they encourage travel by disclosing its pleasures, and benefit the advertisers by suggesting a trip over the road identified in the pictures. (12; emphasis added)

The goal of travel images is clear: to enhance a desire to see the places that are dispersed throughout the touristic genres of visual culture. An advertisers' ideal, they help "push" this desire and thus encourage actual travel.

In the case of American travel films, it is often stressed in the press how such promotion is necessary in light of competition with Europe. Although overtly attributed to the fact that Europe is the more prestigious travel destination, the fragment below resonates also with the apparently common discourse of yearning and desire. About the promotion of American tourism instead of European travel the same author writes a year later, in a discourse that blends commercial interests with nationalist ones:

Perhaps it is because film perfection was not attained first in America that there are now on the market more moving pictures of European scenery than there are filmed bits of picturesque America - or, perhaps, it is because European names were considered a greater box-office magnet. Anyway, the fact remains that there are now on the market moving pictures showing the wonders of our own Yellowstone National Park, the beauties of Colorado, the grandeur of the Canadian Rockies, the splendor of our Northwester territories, and other gems of our wonderlands, which when disclosed motographically cause the most phlegmatic "yes-but-in-Europe" bug to acknowledge that his own country offers him the best travel "buy" available.

The "See America first" slogan is being exploited by our enterprising American railway companies. The American railways are finding in moving pictures an advertising medium that convinces. By means of moving pictures tourists and homeseekers are being honestly attracted in a manner that guards against misrepresentation and the attendant disappointments, and enables the prospective traveler or homeseeker to choose his route or future home advisedly. ${ }^{12}$

This promotion of America as tourist object has a history before film that coincided roughly with the advent of the transcontinental railroad system around the 1860 .

Between 1872 and 1874, William Cullen Bryant edited and published an extremely popular two-volume work entitled Picturesque America. The publication of this work is evidence of a sentiment that was felt, and its popularity illustrates the success of the "campaign." The books contained both steel and wood- 
cut engravings by prominent artists of the time. As it proclaims on the title page:

Picturesque America; Or, The Land We Live In. A Delineation By Pen And Pencil Of The Mountains, Rivers, Lakes, Forests, Water-Falls, Shores. Canons. Valleys, Cities, And Other Picturesque Features Of Our Country. With Illustrations On Steel And Wood, By Eminent American Artists.

In the Introduction to the 1874 edition Bryant writes:

It is the design of the publication entitled Picturesque America to present full descriptions and elaborate pictorial delineations of the scenery characteristic of all the different parts of our country. The wealth of material for this purpose is almost boundless. [...] On the two great oceans which border our league of States, and in the vast space between them, we find a variety of scenery which no other single country can boast of. In other parts of the globe are a few mountains which attain a greater altitude than any within our limits, but the mere difference in height adds nothing to the impression made on the spectator. Among our White Mountains, our Catskills, our Alleghenies, our Rocky Mountains, and our Sierra Nevada, we have some of the wildest and most beautiful scenery in the world. On our majestic rivers - among the largest on either continent - and on our lakes - the largest and noblest in the world - the country often wears an aspect in which beauty is blended with majesty; and on our prairies and savannas the spectator, surprised at the vastness of their features, finds himself, notwithstanding the soft and gentle sweep of their outlines, overpowered with a sense of sublimity. By means of the overland communications lately opened between the Atlantic coast and that of the Pacific, we have now easy access to scenery of a most remarkable character. For those who would see Nature in her grandest forms of snow-clad mountain, deep valley, rocky pinnacle, precipice, and chasm, there is no longer any occasion to cross the ocean. A rapid journey by railway over the plains that stretch westward from the Mississippi, brings the tourist into a region of the Rocky Mountains rivaling Switzerland in its scenery of rock piled on rock, up to the region of the clouds. But Switzerland has no such groves on its Mountainsides, nor has even Libanus, with its ancient cedars, as those which raise the astonishment of the visitor to that Western region - trees of such prodigious height and enormous dimensions that, to attain their present bulk, we might imagine them to have sprouted from the seed at the time of the Trojan War.

In The Incorporation of America (1982) Alan Trachtenberg situates this work by Bryant in the American culture of the time, a post-industrial culture that can perhaps best be described as one of commodified imperialism:

The buried contradiction here between the appeal of wild grandeur and the comfort of mechanized access to the site where such an appeal can be satisfied is not merely comic in its blithe leap over wagon tracks and rotting carcasses that marked a mode 
of access only a few years past; it indicates a special kind of denial of social fact that afflicted sections of American culture in these years. Thus the railroad, the prime instrument of the large-scale industrialization which re-created American nature into "natural resources" for commodity production, appears as a chariot winging Americans on an aesthetic journey through the new empire. Tourism, already implicit in the landscape conventions, becomes yet another form of acting upon the land. (18)

This (popular) aesthetic heritage enhanced the status of the filmic version. A double mechanism is at work here: the larger project of promoting nationalistic pride in the tourist enterprise reflected its prestige onto film, and film, on the other hand, proved to be an essential instrument for the popularization and commodification of travel. In articles about travel films, writers thus emphasize this value of travel imagery because they want to prove the medium's respectability, which would then rub off on the item to be promoted. The Motography article quoted above describes that practice of advertising itself. But these images also serve the goal of armchair travel per se, as the immense and persistent popularity of travel imagery clearly demonstrates.

We can see many different forms and formats in different media, which goes to show that it was a preoccupation of visual culture, not of film alone. But of course, film's novelty and doubly moving nature was eminently suitable to produce it. I will now take a look at some of the earliest nonfiction films and analyze how the touristic gaze is part of their strategy of using travel to promote travel. Then, I will examine how this strategy operates in films that are closer to fiction.

[SANTA FE TOUR OF CALIFORNIA] (c.1905-08, Unidentified) is a prototypical early travel film. An elementary travelogue, it shows a collage of touristic imagery that is structured as an itinerary, duplicating medium with content. We see a landscape spotted with tall cactuses and in the background a vacation resort with a hotel. The camera takes us on a car trip through the desert. A variety of shots suggest, through their sheer variety, the movement of travel. Each time the opening shot opens up the landscape through which we travel.

After some time we arrive at the hotel. Children are riding donkeys. An orange tree is foregrounded by shots in which some tourists are plucking oranges. Donkeys carrying riders who could be tourists walk through snowy hills. Then a shot of a car driving through a landscape of cacti is taken from a high standpoint. The road is meandering, which gives an emphatic form to the car's movement. A man and a woman are bathing near a small waterfall. This might be a hot spring. Again, donkeys and also horses appear, near what looks like a horse rental place.

Children play in a playground with goats, a donkey, and some small dogs. They are feeding a little goat with a bottle. Then we see a golf course, a woman 
playing golf, a horse track, and a family riding on horseback. The car drives over a road through palm trees. People are picking oranges. Groups of tourists walk over a dam. A close-up of streaming water. A pan over the hills and the resort. Panoramic shots of the grounds. A Navajo girl dances, laughing at the camera. In the background some tourists, a couple dressed for rough weather, walk past, looking at what is being recorded. A tennis game in front of the hotel. Behind it, rolling hills.

You get the picture. The items shot are all touristic attractions, not particularly wild but exotic enough, yet reassuringly peaceful. Playing children certainly help in this. For my purposes, the two elements that make this film effective as a "travel film" are the images of movement and the representation of tourists. The film shows horses and donkeys, as the past way of traveling, as contrasted with the car, the means of transport of the modern tourist. Children at play, families horseback-riding, tourists calmly strolling and enjoying the fruits of nature, all these activities are continuous with one another and suggest that visiting the Wild West is safe, pleasant, and relaxing.

Tourism is both a tiny bit adventurous - urban Easterners have lost the habit of riding on horseback - and so easy a child can do it - riding donkeys is just like riding horses. The touch of the child feeding a baby goat even hints at the need for preservation. "Nature" needs human help, and the child, as young as the goat, provides it. They grow up together, in peaceful harmony.

Finally, the couple walking past the Navajo girl dancing exemplify the "wild look" when they try to get a glimpse of the greatest excitement of all: the native, dancing for their visual pleasure, laughing contently while doing so, is also, simultaneously being visually stored for further consumption. This dancing girl, too, might need preservation. Doubly objectified - by the film audience and by the couple who demonstrate that it can be done - she caters to the look that has already conquered. Looking at how she is being canned, the couple's curiosity naturalizes this taming of the West.

Tourists figure in many films, including Coaching Party and Yosemite ValLEY (1903, AM\&B). In the latter film, horses and wagons meander through a forest. This is a single-shot film that consists wholly of a journey. TouRISTs ARRIVING AT WAWONA Hotel (1903, AM\&B) is a fragment of a trip: only the arrival is represented. A few carriages and people on horseback arrive at a large building. In the background one can just glimpse a portion of a mountain. It is enough to signify both "tourism" and "Wild West." The title complementary to this film, Wawona, Big Tree (1903, AM\&B) shows a big hollow tree with a horse and carriage that ride through the tree. This unlikely disproportion, a popular image at the time, also could be found on postcards. CAscade Near WAWONA, CAL (1903, AM\&B) shows a moving postcard image of a waterfall, reminiscent of the cases I have discussed in terms of picturesque aesthetics. $\mathbf{P}$ 
These three separate titles show different tourist attractions and different stages of trips. Yet, they are profoundly similar in terms of their promotional thrust. Particularly in a cultural context where audiences were frequently treated to this kind of imagery, such films did not need to be more explicit to convey the point of the strategic use of travel as medium, subject matter, and goal. Innumerable cases display similar promotional qualities, such as COACHES Arriving at Mammoth Hot Springs (c.1899, Edison) and Coaches Going to Cinnabar From Yellowstone Park (1899, Edison), Hotel Del Monte (1897, Edison) or Tourists Going Round Yellowstone Park (c.1899, Edison).

One step further towards fiction, some films show the beginnings of the narrativization of travel. These films would be categorized as travelogues. The examples above already showed traveling figures as both characters and as attractions. The following film narrativizes the touristic gaze more emphatically. A Trip up Mount RaInier (1911, Edison) shows the following images. A waterfall, a woman and a man sitting next to it on a rock. They wave at the camera. The shot is reminiscent of the stereocards of waterfalls with tiny figures in the foreground, photographs of places named after the vistas they afford, functioning as the "punctuated locations" I discussed above. P The couple rise and climb out of the picture frame.

Here is my description of the film. A man and a woman are sitting next to a waterfall, on a rock. They wave to the camera, recognizing its importance as facilitator of the enjoyment. This shot is strongly reminiscent of the stereocards discussed earlier, where a small figure in the foreground signifies both the imposing grandeur of the scenery and the possibility to "manage" it. $\mathbf{P}$ When this job has been achieved, the figures, in a final act of service to the medium's selfreflection, climb out of the frame. Then the tourists are multiplied, in a gesture of signifying the twin notions of "mass" and "popular." A small column of men and women with backpacks and walking sticks hike down along a brook. In an homage to nature's benefits, they drink from the brook.

A new shot shows a more even terrain, still rocky and with a brook and mountains in the background, continuing the Western version of the locus amoenus. A large group of tourists continues the signification of tourism as mass culture. The very large group walks through a grassy patch. Wearing the hats and carrying the walking sticks that visualize their kind, they laugh, for of course, travel is great fun. From a rocky hill, stones roll down. They appear to have been thrown on purpose, for the effect of mitigated danger. A number of variegated shots show rocks with water streaming through them.

A snowy descent follows. In the foreground a man is playing the violin, echoing the situation in the movie theaters where live music accompanied the experience. You see people slide down, perhaps on sleds, perhaps just sitting on the sloping ground. They subsequently start that favorite game of children 
when the first snowfall marks the beginning of winter: they make snowballs and throw these at one another, in the sweetest version of fighting. A few tumble down the slope.

What makes this nonfiction film almost a fiction of time travel is the persistent allusion to travel through life's phases. First presented as adults, living in couples, the tourists become gregarious youngsters, descending not only the mountains' slopes but also into their own past. They end up as children, denoting the innocence of this pleasure, a meaning perhaps called for in the face of the commercial interest the film also clearly serves. Snowball fighting turns that typical element of the Western's idiom into innocent play. Tourism is like a fountain of youth.

Even when such emphatically temporal metaphors are absent, temporality finds its way into the travel film. The cultural encounter between urban and rural life is temporalized when another strategy becomes apparent, which is to show "old" things as implied attractions to promote tourism. The ethnographic field trip comes forward, for example, when practices such as calf branding are the object of the "wild look." The film Calf Branding (1898, Edison) makes this practice its sole focus. Again, the travel multiplies its levels when, as David Emrich (1997) mentions, the first films made in Colorado were shot in 1897 by Edison's cameraman James H. White during that man's own travel through time. "He was sent to the West: to Colorado, through New Mexico, Arizona and arriving in Pasadena, California by the end of the year" (11). The camera man, in other words, traverses the seasons, much like the tourists in A TRIP UP MOUNT RAINIER who move from summer to winter by simply moving higher up. Emrich does not mention titles that are shot on this trip, but he reproduces a picture and description of the same film that is entitled CALF BRANDING in the archive of the Library of Congress. It is clear to me that this is the same film that is catalogued by this name. The strategy here is binary opposition. These films were shot to promote a civilized state and promote progress, but they did so by showing these "old" trades such as calf branding.

Here, again, the interweaving of commercial and aesthetic interests are doubled with an interweaving of past - calf branding - and present - railroad travel. The Edison films were sponsored by the Denver and Rio Grande Railroad. Emrich cites the 1900 Edison catalogue:

The grandest scenery in the West is along the line of the Denver and Rio Grande. The capital views [...] were secured during a trip over the lines of this great scenic railway [...]. At every point we were met with the hearty co-operation and obliging courtesy of the officials. Tourists who choose this route are assured of magnificent scenery and also of the best treatment. ${ }^{13}$ 
Tourism is a form of amateur ethnography, and with it came the problems of temporality inherent in that science. As Fabian (1983) forcefully argued, ethnography has been premised on stripping its object of temporality, and hence, also, of co-temporality or coevalness with the ethnographer. Projecting, thus, an unspecified pastness - that is really an a-temporal existence much as in the notion of pre-history - on the other, the cultural others become "the world" on which the "window on the world" is premised. The result is a visual readiness for the taking - which, under capitalism, becomes outright consumption. Tourism becomes ethnographic consumption when not nature but people become the attraction. We saw this demonstrated in SANTA FE Tour of CALIFornia; we saw it in Hopi Indians DANCE fOR TR at [WALPI, ARIz.] (1913), mentioned before in $\mathbf{D}$ and $\mathbf{K}$. This is an existing, traditional tourist attraction. The Hopi Snake dance had already existed as an attraction for 30 years when this film was made.

The specific site where this dance before an audience of tourists is performed has a temporal dimension of great pastness. It is located near a famous pueblo, an ancient city. This is a "punctuated place." The film begins with several frames, cutting then to close-up. The first frame is taken from a high angle. It shows a circular dance and the tourist audience around it, looking very confined, purposefully packed together into a single frame. A lot of tourists are watching the dance, looking like cowboys with their hats. The group includes women. A close-up follows with Roosevelt looking like a cowboy, with his company, and close by also a Mexican with a large hat. The dense group of many tourists raises the question, who is the greater attraction, the dancing Indians or the famous Roosevelt and his crowd? Roosevelt's presence certainly gives respectability to traveling to the West. A camera pan shows people sitting on a rocky wall. The crowd seems to have grown. The ripples of the waves continue to increase the number of people benefiting from this massification. In the last part we see a little bit of landscape in the background, where people are standing on roofs and rocks.

Another shot from the dance follows. The camera comes very close, so that the Hopi are dancing right past the camera.

Although this film is clearly not sharply separated from nonfiction, we can see travel and mobility developed as a theme in fictional stories. As a characteristic tied to landscape depiction and the exotic gaze at "others," such as Indians, the narrative thrust of the moving images supports travel as a theme. Many films feature tourism specifically in the context of encounters with Indians and relationships of white men with Indian women. The Tourists (1912, AM\&B), An Up-to-Date-Souaw (1911, Pathé: American Kinema) or A Romance of the Western Hills (1910, AM\&B) are examples of this thematic. These films are about the contact of cultures and the question of assimilation. A RoMANCE of 
THE Western HiLls, subtitled in Biograph Bulletins "Civilization as it Appealed to the Indian Maiden," presents the double gaze between the Indian as touristic object and the tourist as exotic object to the Indian. The self-promotion, including the way it glosses over what is at stake in the events, becomes apparent once we compare the presentation in the Bulletins with the film as it presents this story visually.

The presentation has a tone critical of the situation of contact, yet uses euphemisms and outright distortion to save the film's attraction.

There is little wonder why the Indian is so stoical and misanthropic towards the white man, when we consider how he has been treated. True we have endeavored to civilize him, but this has only made more vivid his hopelessness. The Indian might have been made the white man's best friend, but the white man did little to inspire his confidence. This Biograph subject is a powerful illustration of one of the many indignities the redskin suffered. A party of tourists visit the Indian village and are charmed with the pretty little Indian girl, who offers for their consideration ornaments and beads. A book of civilization falls into her hands and naturally the girl is fascinated by the apparent mysticism of it, but her lover, a young brave, tells her "White man's book no good." This, however, does not dissuade her, as her slight association with the white people has made their sphere appear to her enthralling, hence when she has the chance of living in their world she is elated. ${ }^{14}$

My own viewing of the film reveals a more disturbing story. It begins with the image of an Indian camp against a backdrop of hills. Two white people, a man and a woman, enter the village with a donkey. They try to sell books, but no one wants them. A trapper walks by reading; he clearly knows better than the Indians what is good for him. He accidentally drops a book. A girl picks it up, but her father throws it away, hitting a young Indian. Since this youngster is in love with the girl, he gives the book back to her.

Substantiating the Bulletins' sense of the girl's "elation," the intertitle intervenes by stating: "The Indian girl adopted by tourists." True, two tourists see the girl with the book and take her along. But rather than "adopting" her, they actually pay for her. This ironic reversal of the failed sale of books to the Indians and successful sale of the Indian girl to the whites was lost to the title writer. The buyers live at the foot of the mountain on which the settlement is located. The girl is shown enthusing about the house. Meanwhile dressed in Western garb, the girl meets the couple's nephew. He flirts with her. But then he drops her for a white woman. Again, the intertitle embellishes this situation by simply attributing the failure of this interracial relationship to the girl, a naïve idolizer cast as a woman scorned: "She finds civilization a gift not yet perfect." The uncle and aunt criticize the nephew, perhaps disappointed in their plan for a civilizing mission of a different kind. But the girl returns to the Indians. She runs 
into the young man earlier shown to be smitten by her. Her beau goes down the mountain to avenge her wrong. ${ }^{15}$

Another film about tourists who visit Indians and with a love angle in the story is The Tourists (1912, AM\&B), described as follows in the LoC catalogue:

Tourists stop between trains at the Albuquerque, New Mexico, railroad depot and examine the wares for sale by Indians. One tourist goes sightseeing on her own and becomes very interested in an Indian chief who returns her interest. His wife leads a group of irate Indian women in chasing the tourists back to the train.

The linguistic equivalent of the promotion of touristic attraction in travel films can be noticed in the short stories based on film plots published in Motion Picture Story Magazine. O Poetic descriptions open the stories, setting a tone for an historicizing and almost religious poetics of primitive peoples. Stories such as "Spirit of the Gorge" and "Romance of the Cliff Dwellers," also extant as a film copy, deal with these themes. Whether or not this poetic conception of history befits the written account more than the filmic version I do not wish to evaluate here. It is clear, though, that the printed stories cash in on the time travel afforded by the scenic trips to the locations depicted in the films. Pastness, beautiful scenery, and exotic peoples go hand in hand, and sell well to the movie-going public in the cities of the time.

This transformation of travel seen to travel experienced in reading hints at another transformation, this one more broadly cultural. As a consequence of the logic of this constant promotion of the possibilities afforded by technological advance, the next step would be to make the resulting films themselves the item that can travel. This transformation brings another ambition into view, one that again substantiates the notion of a window on the world: from Travel Films to Traveling Films. For, the counterpart of the travel film is the traveling film. In the wake of the culture of travel in the late 19th and early 2oth centuries, films themselves became traveling commodities, mobilized within the framework of yet another conquest where commercial and scientific interests were integrated.

Westerns were exported, so that the American West became a coveted object all over the world. From local, historically and geographically specific, they became embodiments of the universalistic myths of the early days of the "global village" we still live in, and which becomes smaller every day. The mythified return to the wilderness, and the instant nostalgia that pertains to it, becomes a preferred entrance into the past through travel, in both directions, both geographically and time-wise: a device for cultural time-travel. 


\section{Notes}

1. “Travel Pictures Again." Motography VI, 3 (September, 1911): 106.

2. Burton Holmes, "The Grand Cañon of Arizona." Burton Holmes Travelogues (1908): 115.

3. On time travel à propos of BACK to the FUtURE, including the philosophical implications of that topos in the new Hollywood cinema, see Vojkovic (2001).

4. For the term "visual regime," see Martin Jay (1988).

5. On the "wildness" of this mode of looking, with its nostalgic, almost envious fascination for what it considered "primitive" and thus, simultaneously, used to define the urban self, see Torgovnick (1990).

6. Self-reflection can be intuitive, a narcissistic form of visually mirroring the self, as well as intellectual, taking a critical look at oneself as if one were another. See Bal (1991: chapter 7).

7. Hirsch develops this concept to explain the effect of Holocaust memories on secondgeneration survivors (1992-93: esp. 8-9) and (1997).

8. Rather, the later film turns the emotional temporality of these early films into a literalization on the level of fantasy of what it reveals about modern life.

9. The reverse may very well have been the case as well: Europeans looking at American imagery and experiencing a sense of time-travel towards the future.

10. In the case of this particular film a third dimension intervenes, in that the geographical location of shooting is in the Netherlands instead of in Mexico.

11. "Realism in Municipal Advertizing." Motography V, 4 (April, 1911): 11-13 (11); emphasis added.

12. Watterson R. Rothacker, "Yellowstone Park on the Screen." Motography VII, 4 (April, 1912): 169-170 (169).

13. Edison Films Catalog 94 (1900): 18. Quoted in the Library of Congress catalogue, Inventing Entertainment.

14. Biograph Bulletins (April 11, 1910); emphasis added.

15. For an analysis of this film, see Gregory S. Jay (2000). 



\section{Practices}

In this final cluster of chapters I will consider the cultural practices that already began to shimmer through the strategies of representation and cultural intervention discussed in cluster 3 . In cluster 1 , the background from which to make a case for the specificity of the corpus and the ensuing plea for a more adequate historical approach was introduced by way of an emphatic and self-conscious positioning of the researcher in the present. In cluster 2, the contemporary "feelings" that most profoundly explain the success of the films as well as their inevitable "strangeness" to us today, were presented as an everyday philosophical sense that belonged to the culture that produced and consumed the films. These sentiments, I contended, framed the films, as they determined the mood in which they were viewed.

In cluster 3, a few major, specific strategies of representation narrowed my inquiry down to a small-scale analysis of how it was that the effects could be produced in a manner so congenial with the larger cultural moment. Here, finally, I will widen the scope again, to study some elements of the contemporary culture - a culture of spectatorship as novelty - not as a frame for Westerns, but rather as result of them - the Western as frame. The distinction between "cause" and "effect" should not be taken to indicate a mechanistic causality principle, however. On the contrary: the directions of the movement from outside in and from inside out will turn out to be so inextricably intertwined that the practical division into clusters will, in the end, itself be argued to be no more than the genre and period concepts we cannot help but use, if only as a shorthand tricky, risky, and dangerously believed - for a much more complicated historical endeavor; as a device or tool to present a provisional order in what must be represented as a kaleidoscopic vision in which every order can be changed, suspended, turned over. This cluster, then, sums up the historiographic principles this study proposes: archive/meta-archive $\mathbf{U}$, museum with objects versus records of objects $\mathbf{V}$, self-reflexivity $\mathbf{W}$ and (self-) regulation $\mathbf{X}$, estrangement and mobility $\mathbf{Y}$, fragmentation and hypertext $\mathbf{Z}$.

To this effect, I will now consider cultural practices "surrounding" the filmic Westerns, the circular influences and the web-like networks, as well as contemporary reflections on the mutual influences of these practices. In this cluster I take the issues already discussed in the previous sections one step further and investigate the specific relationship between text and spectator. "Period World Views," "perspectives," or "viewing positions" are themes throughout this clus- 
ter. Specifically in $\mathbf{\nabla}$, where "identity" and (European) perspectives are important, but also in all the other chapters! In short, I focus on how the strategies I discussed in the previous cluster of chapters on the level of texts end up working on the level of context.

In the first three chapters $\mathbf{U} \mathbf{V} \mathbf{W}$ I consider issues of museification, of collection and display and how these play a part in the context of shaping the Westerns. These cultural practices are the cultural expressions of the kaleidoscopic collage of the world and the structural principles of touristic viewing as I analyzed in previous clusters. In $\mathbf{U}$ I will discuss more elaborately the context of the film program found in museums, collections, and archives. The universalizing function of Westerns established particular practices. By this I mean the role Westerns play in the 19th-century project of mapping the world: of exploring, sampling, collecting, categorizing, and displaying the world. As analyzed in the previous clusters, the universalizing function of Westerns establishes a conflation of past/present/future and of local/global. Here, I will focus on how this is really part of the cultural and scientific practices of the period, or rather, how this is a cultural practice. Whereas collecting is the activity under scrutiny in $\mathbf{U}$, in $\mathbf{V}$ the central cultural practice is that of exhibiting, present in world exhibitions and their inherent encyclopedic ordering. $\operatorname{In} \mathbf{W}$, the practice under scrutiny is the show culture, the more emphatically entertaining form of display.

Vision and visuality, films as educational texts or encyclopedia of the world, consumer culture, classification and organization in structures of knowledge, substantiate Gunning's discussion of the "world as object lesson." Visual "shocks," special effects, and technology become concrete in combination with ethnographic displays. I will take up the theatricality of display in $\mathbf{W}$, and I have discussed display as (narrative) strategy in $\mathbf{S}$. In $\mathbf{V}$ I will elaborate on vision/visuality in relation to display and exhibition. In this cluster the different chapters represent the multiple meanings of "practices" that are relevant for my corpus: "repetition," "performance," "exercise," "profession." 


\section{Universal Ambition}

The fundamental event of the modern age is the conquest of the world as picture... [with picture defined as] ...the structured image that is the creature of man's producing. In such producing, man contends for the position in which he can be that particular being who gives the measure and draws up the guidelines for everything that is. - Martin Heidegger, $1938^{1}$

Main Entry: ${ }^{\mathbf{T}}$ uni $\bullet$ ver•sal Pronunciation: "yü-n\&-'v\&r-s\&l Function: adjective

Etymology: Middle English, from Middle French, from Latin universalis, from universum universe Date: 14th century $\mathbf{1}$ : including or covering all or a whole collectively or distributively without limit or exception $2 \mathbf{a}$ : present or occurring everywhere $\mathbf{b}$ : existent or operative everywhere or under all conditions < universal cultural patterns $>$ 3 a : embracing a major part or the greatest portion (as of mankind) $<$ a universal state $>\mathbf{b}$ : comprehensively broad and versatile $<$ a universal Genius $>$ - Merriam-Webster's Online Dictionary, 2005

From travel films, this chapter shifts to traveling films: to the "universal ambition" implied in making films travel. This is the ambition of grasping the world by camera and collecting, then displaying in traveling programs, these moving world pictures. In a first outward movement, the camera traveled in order to document, to grasp the world "universally." In the second, inward movement, the films that were produced by that ambition were brought "home" to the collector's archive. In a third, outward movement, they traveled from there to many places to show the world what the world looked like. Together, these three travels make possible the fulfillment of an ambition to master the world, taking the measure and drawing up the guidelines for everything that is. My focus in this chapter is on the inward motion, the practice of collecting. The next chapter will be devoted to the outward movement, the practice of exhibition. 
As the Webster's dictionary entry specifies, the notion of the universal harbors the ambition of "including or covering all" - all places, countries, cultures - "or a whole" - the world as a whole. As a result, a picture emerges in which all peoples are one humanity. The second specification in this entry is as significant as the first. This including or covering is done, the entry says, "collectively or distributively." Ultimately, these two will come together when the Internet will distribute, ideally, the comprehensive images of the world to the whole world watching them collectively - the whole wealthy (and "connected") world, that is. But in the early 2oth century, the universal ambition will proceed through a more piecemeal distribution. The institution of cinema, its programming and its sales, including the travels of films, works by means of a different kind of distribution from the Internet, but in some significant way the former prefigures the latter. $\mathbf{Z}$ The next chapter will probe some of the meanings of that practice. Here, the traveling camera is at stake.

It is within the framework of the universalizing function of the Westerns, as they operate in the culture of exhibition of the films, that I would like to look at some examples from film history that indicate how this programmatic filmic practice of "exposition" is related to the formation of collections. Whereas in the next chapter I will discuss film's function as "museum," of presenting the world as a visual collection, here I focus on the films as collectors' items. In order to understand the history of cinema and of the Western in particular, these two aspects supplement the questions raised earlier regarding the ontology of the historical object, such as the fragment in its distinction from the detail. B The practices discussed here affect, and are affected by, that ontological distinction. For, within the framework of universal ambition, every film constitutes a "detail" of the universal "man." In addition, more is at stake than insights into the historical anchoring of the generic fiction, or of the typical characters figuring in it. $\mathbf{N}$ The so-called features that characterize the Western are, again, "details" of the image of the world that cinema, at this particular moment in time, set out to document. In my attempt to reposition the relationship between past and present as a form of interaction, therefore, I find it indispensable to also take into consideration the combined cultural practices of collecting and displaying, and the underlying ambition according to which knowledge and possession are continuous.

Heidegger's essay "The Age of the World Picture" provides the philosophical underpinnings of the sentiment that informs the impulse to collect the images that are thought to make up the Picture of the World. Heidegger wrote:

When we reflect on the modern age, we are questioning concerning the modern world picture [Weltbild]. We characterize the latter by throwing it into relief over against the medieval and the ancient world pictures. But why do we ask questions concerning a world picture in our interpreting of an historical age? Does every period 
of history have its world picture, and indeed in such a way as to concern itself from time to time about that world picture? Or is this, after all, only a modern kind of representing, this asking concerning a world picture? (1977: 128-129) ${ }^{2}$

This statement integrates the ambition of the period with more general historical questions we still ask today. The common thread, then, between the universal ambition of early collectors and present-day historiographic concerns, is unsettlingly sturdy. But to the question, "Does every period of history have its world picture?" the answer is not only a generalizing "yes" but also a qualifying, specifying "according to each age's specific epistemologies and media." In the age on which I am focusing, the epistemology is a triple belief in encompassing knowledge inherited from the 19th century of pervasive positivism, in the additive structure of knowledge that informs collecting, and in the reliability of the new technology of visual recording. To this we must add, a belief that such jigsaw-type pictures of the world could be assembled and performed - as a puzzle - by an individual whose signature the picture collection would carry. This squares with the word "exposition," the parasynonym of "exhibition," which means showing, arguing, and self-presentation all at once. ${ }^{3}$

If, in the 17th century, to be was to think, in the period of which our corpus' historical moment is the turning point - between the late-19th and the early2oth centuries - to be was to know and to know was to own. Reassuring ideologies like "I know, therefore I am" as well as "I own, therefore I am" subtend both positivism and, in the collapse of these two ideologies, capitalism. These integrated economic and scientific ideologies are both grounded in the reign of the individual. What we consider today primarily entertainment - going to the movies - cannot be isolated from these moments in which the individual was still the master of his own house and head; moments, also, when the possession of the house and head of others constituted a form of self-possession. Not only nations defined themselves through their territories, including those recently conquered; on a smaller scale but according to the same model, people did, too. In this sense, a film collector is a small-scale model of the nation in which he (usually) practiced his passion. As the other side of the enlightenment paradigm of ordering, classifying, and generally manifesting an encyclopedic agenda, collectors of Albert Kahn's stature are also an image of the nation that was steeped in colonialism. In addition, such collecting marks the shift from materiality to image as spectacle, as a recipient of the overview of the world as world view. The apprehension of the world that the world picture entailed in Heidegger's view easily led to the accumulation of fetishized ensembles of images. ${ }^{4}$

There is a tension here, inherent in the passion to know. I seek to understand the relationship between historical practices of collecting - which are by definition local, specific, and transient - and the universal "archival" ambition tied to this particular form of collecting of images rather than artifacts that is enabled 
by the new medium, as well as the impulse to show that archive to the world. But knowledge is never "pure," it does not stand on its own, even in the case of an individual pursuing it for its own sake. For, at the same time, in the practice of collecting there is a conflation between the thirst for knowledge, itemized according to a specific concept of collecting - facts, instances, images - and the need to bring the objects of knowledge into the realm of the individual home or business. There, the point of knowledge surfaces. Knowledge is tied up with education, so that the point of collecting is the distribution and display to the public. In this conflation the inextricable bond between private and public, individual and collective, plays itself out. From outgoing to homecoming to going out again, this movement from universal to specific, from the world to the collection, then back again, from singular possession to public display, characterizes the object of study in this chapter.

To make this clear, I wish to juxtapose three collections, each of which plays a different role, yet all come from a "universal ambition." Albert Kahn wanted to collect films. He was concerned with the making and collecting of raw, unedited footage. George Kleine was an importer - the largest importer of European films in the United States and Canada - a producer, and distributor. His collection sheds some light on the American trade in European films and on the ambitions of the distribution practice. In his effort to establish a non-theatrical distribution system, his endeavors included a 1910 catalogue of over one thousand educational films, intended to promote the use of films in schools and other institutions. ${ }^{5}$ Jean Desmet was an Amsterdam film exhibitor who collected films from Europe and the Unites States for the purpose of showing them to entertainment-seeking audiences in his movie theaters. His legacy is an archive of exhibition: a collection that shows us a history of film exhibition.

The collections of these three entrepreneurs form the bases of three archival institutions: the Library of Congress in Washington, DC, the Musée Albert Kahn in Paris, and the Nederlands Filmmuseum in Amsterdam. I take these men, or rather, these archives as exemplary in this chapter. Not that I wish to analyze their collections, although the holdings of two of them feature prominently in this study. Instead, I wish to highlight them as three cases of a universalizing operation, or ambition, of the medium film. For, globalization, such a current topic in this day and age, finds its roots in later-19th- and early-2othcentury culture. ${ }^{6}$ It is in these first decades of the medium that international trade takes on a cultural significance. Cultural imperialism, humanistic utopianism, or the positivist endeavors in the age of the collectors' craze, whatever its manifestation: films of the American West stand surrounded by, and receive their cultural meaning and significance from, all those filmic records from all over the globe. They are part of the larger world picture. 
The archive of the Musée Albert Kahn in Paris serves as a typical, and yet also a-typical example for this inquiry. Typical - as the museum is significant as a cultural practice. A-typical - because, while the endeavor fits in its time, the project of Albert Kahn was also unique in some respects. And his collection did not even include films about the American West! The geographical span included Europe, Northern Africa, and Asia. Yet, this museum offers a case for the realization, the emergence, of what we have, today, as the only means to get access to this historical material: the archive. The archive, however, is not simply a storeroom where the leftovers of the past are laid to rest - where they turn to dust, unvisited, unless some cultural archaeologist digs them up, dusts them off, and brings them to the surface of cultural activity again.

Taking Jacques Derrida's point at the beginning of his short text Archive Fever, but permitting myself to extend his remark on the word "archive" to characterize the institution, I wish to insist that the archive is a physical, historical, and ontological principle in one. Continuing the analysis of the archive from which I earlier quoted the sentences before the following $\mathbf{A}$, Derrida writes:

This name apparently coordinates two principles in one: the principle according to nature or history, there where things commence - physical, historical or ontological principle - but also the principle according to the law, there where men and gods command, there where authority, social order are exercised, in this place from which order is given - nomological principle. (1995: 1; emphasis in text)

And "principle," here, is meant as both "beginning" and "order." The latter, to continue Derridean lexical expansion, encompasses more than sequential order. The word also points to the chronology of which history is so fond because it facilitates its conflation with teleology, the tendency in opposition to which my study sets itself. It also comprises taxonomic, logical, or semantic order, the categorizations of thematic, pragmatic, or other slightly arbitrary divisions that sort out the accumulated mass. Order is not coincidentally ambiguous here: chronology is the order - in the sense of neatness - of the historian overly anxious about messiness.

In the spirit of his time, the French banker Albert Kahn (1860-1940) decided in 1909 to send cameramen all over the world. Their brief was to document the globe in its "familiarity of strangeness" for his Archives de la Planète: to "to fix once and for all the aspects, practices, and modes of human activity whose fatal disappearance is only a matter of time."7 Between 1909 and 1931 Kahn collected films, stereoscopic plates, panoramic views, and autochromes in a project whose title indicated that my chapter title applies here: his Archives de la Planète. Besides the collection of imagery, Kahn was concerned with a form of distribution of his project through various related publications and lectures. This program was very diverse, almost hypertextual avant la lettre. ${ }^{8}$ 
This endeavor resulted in an archive that included miles and miles of nonfiction footage, exemplifying what Tom Gunning calls the "view aesthetic." As Gunning put it:

While many actuality films exemplify [the] aesthetic of the "view", with travelogues and process films being perhaps the clearest examples, the desire evident in these films to provide a nearly endless and (ideally) exhaustive catalogue of views of the world reached a climax in the films shot for Albert Kahn and his utopian project of 'Les archives de la planète', in the 1910s and 1920s. (1997: 19)

This archive today, presents a "fascinating archaeology of the nonfiction films through a peerless demonstration and an encyclopedic collection of the 'view' aesthetic." Gunning brings together a number of elements that characterize the period's visual culture: the archive/collection, the view aesthetic and the element of world as showcase. He comments on the same page: "Taken collectively the films construct an exotic panorama of the planet on display, the ultimate cinematic World Exposition." The view aesthetic is thus symptomatic of the presentational side of the urge to map and collect, to create an encyclopedic world-collage. ${ }^{9}$

In spite of numerous reminders that have been voiced, in particular by critical anthropologists, it deserves reiterating that the collector was well aware of the devastation wreaked by his own endeavor. "Time" is presented as an autonomous agent here. Yet, the drive to collect was not only a consequence - the desire to preserve what was threatened with loss - but also bound up with its cause. Not that filmmaking is on a par with the actual shipping off of monuments, such as the Parthenon frieze, but as a form of tourism, it certainly partook of the economic and cultural depletion and pollution of the areas visited. ${ }^{10}$

It would be instructive to see the daunting ambition of Kahn's project as evidenced in a list of films in this archive. They were taken in about 48 countries from over the largest part of the globe. ${ }^{11}$ That list surely testifies to "universal ambition." But this allegedly geographical and ethnographic universality shows its relative status when we complement the spatial with the temporal axis. For, the picture of what the world in its totality looked like was inevitably also a picture of how it looked at a certain time, but looks no longer. And enthralled as he must have been by his universalist project, Kahn realized the irremediable loss already in process. In fact, it was this loss, the "fatal disappearance" that fuelled the project at its conception. In this sense, Heidegger's probing of what it meant to want to picture the world, rightly insists on the participation of history in the project. He continues the passage quoted above as follows:

What is a world picture? Obviously a picture of the world. But what does "world" mean here? What does "picture" mean? "World" serves here as a name for what is, in its entirety. The name is not limited to the cosmos, to nature. History also belongs to 
the world. Yet even nature and history, and both interpenetrating in their underlying and transcending of one another, do not exhaust the world. In this designation the ground of the world is meant also, no matter how its relation to the world is thought.

Kahn's phrase "the familiarity of strangeness" resonates with this awareness of history's participation in the endeavor. The word "strangeness" may well refer to a temporal discrepancy as well as to geographical distance.

Seen through Heidegger's eyes, Kahn's project lends itself to a number of illuminating comparisons. His project differed from that of the Lumière cameramen who, in a sense, were sent to film the unfamiliar strangeness on the globe. ${ }^{12}$ Or, from that of the Pathé cameramen, for that matter, whose movement over the globe was described in the article "World-Wide Activities of Pathé Frères:"

They [were] taking pictures of native life and scenes, and today [...] Pathé Frères are enabled to show the millions of moving picture lovers such rare scenes as linger long in the memory of the beholder and which do much to spread the knowledge of our distant neighbors, their ways and customs, among all mankind. ${ }^{13}$

In the oxymoron of "familiarity of strangeness" I wish to emphasize the paradoxical duality of Kahn's project. In this, Kahn was not fundamentally different from, before him, such writers as Emile Zola, who, as Kahn's literary counterpart, set out to map the social world in its entirety though a close study of his own time and place. Kahn can also properly be compared to a photographer like Edward J. Steichen, whose famous 1955 exhibition in the Museum of Modern Art in New York, also published as a book, The Family of Man has recently been brought back to the attention of cultural critics. ${ }^{14}$

The Kahn archive is characterized by a particular kind of temporality which repositions the task of historians, namely a simultaneity between the making of an institution and the invention of its principle; between the production of objects and the justification for their existence. In the case of this particular project this simultaneity defines its nature, its ontology. Kahn's archiving was a form of collecting raw material, unedited rushes, images that coincided with their making - unlike the archive we use, today, to make sense of the past. In line with this simultaneity, a feverish activity surrounded the project, as it did in other, comparable cases. Lecture tours illustrated with films or slides were a logical side effect of the eagerness to collect, to order, and to store the planet in its entirety. Such lectures were a contemporary commodity that can be considered a truly live archive. Films were selected to accompany a lecture, a live performance, and vice versa: lectures were prepared as a function of the material gathered.

But the temporal coincidence transformed the picture, compared to our common ideas about what picturing means. The picture - the collection as a whole made the world, construed it as we since then assume it was before the pictures 
were taken. Heidegger seems to understand the endeavor of world picturing in this way when he writes, still on the same page:

With the word "picture" we think first of all of a copy of something. Accordingly, the world picture would be a painting, so to speak, of what is as a whole. But "world picture" means more than this. We mean by it the world itself, the world as such, what is, in its entirety, just as it is normative and binding for us. [...] Hence world picture, when understood essentially, does not mean a picture of the world but the world conceived and grasped as picture. What is, in its entirety, is now taken in such a way that it first is in being and only is in being to the extent that is set up by man, who represents and sets forth. (1977: 129)

I wish to invoke these combined activities here because in these instances the cultural functions of the archive, the exhibition, and programming do more than coincide. They do not just happen at the same moment, independently from one another, but are mutually constitutive. In the case of the archive set up by Kahn, these practices - collection and ("illustrative") exhibition - were even willfully and specifically combined. For example, the autochromes in the collection were made not for their individual aesthetics, but to illustrate lectures by the geographer Jean Bruhnes, who directed the archive (Rohdie 1998: 29).

It is within this ambition that the cinematic representations of the West came to function; it is what made them tokens as well as the forerunners of a universal and universalizing genre. This becomes clear from other archives born of the universal ambition of their collectors. For example, in the Filmmuseum where I have done much of my research, the Desmet collection represents the bulk of the archive's collection. It consists of the legacy of films Jean Desmet distributed and exhibited in his theaters. ${ }^{15}$ In the grouping of practices here - distribution and exhibition first, archiving in the wake of these primary activities - we notice, again, a combination of two practices to whose simultaneity we are no longer accustomed. Although it is not within the scope of my project to perform a close reading of the archives mentioned here, such a detailed analysis would certainly be relevant. Instead, I would like to project such a study by asking the fundamental, if somewhat daunting, question of the character of the collections in terms of cultural practices in which the films of my corpus play a significant part. The question, then, becomes, what kind of collection is the Desmet collection, and how does it compare with the Kahn collection in terms of the cultural practices of travel as a means of collecting the world; of the ambition to appropriate a universal view of what there is, anywhere? That this question is fundamental indeed becomes clear from a third term of comparison, the George Kleine collection in Washington DC, part of which I have also studied.

Kleine, as both producer and distributor, left a collection of films that he bought, imported, and produced himself. Originally not intended as a collection 
of the type of the Kahn archive, this collection, like the Desmet collection in the Netherlands, is more than a record of the combined practices of gathering and exhibiting; in fact, it is a micro-archive of exhibition. This is why collecting and exhibiting cannot be disentangled from each other. Not only does this collection consist of films from the period that are of value in their individual form - they are, each of them, part of the visual heritage of film history. It also reflects the practice of collecting, distributing, and exhibiting films. The films are in that sense, not only part of film history, but are, embody, film history; they are film history's material existence. To put it another way: they are not just a museum but a "meta-museum" that deserves study in that respect as much as for its specific treasures. ${ }^{16}$

To analyze specific archives in terms of archives would be a challenging project. Some questions, however, are relevant for any historical study that takes place, largely, in archives. The thesis, here, is that the archive as we have and use it now, is based on another kind of archive, a live archive in the making then. This realization allows the historian today to work with the assumption of an epistemic correspondence - two archives - which necessitates an awareness of the fundamental difference between them. The archive-then was a micro-culture in the making; the archive-now a barely accessible means to get a sense of what the ambition was that informed that archival practice as such, and what the corpus "early Westerns" contributes to its specific meanings. ${ }^{17}$

Heidegger's vision of the world as picture resonates with this historiographic point. Ellen Strain explains the passage I have quoted in such terms:

In his essay "The Age of the World Picture" Martin Heidegger contends that the modern age can be discerned by its essential phenomena: science, technology, culture, the loss of the gods, and the artwork as Erlebnis (translated as subjective experience with the connotation of adventure and event). The late nineteenth century saw the blossoming of these phenomena and of the resultant metaphysics: "the world picture," i.e., the mastery through science and visual objectification of a world which comes into being through the fact that Western man first looks upon it. (1977: 130) Heidegger's concept of the world as picture involves seeing the world as a whole and as governed by a system. It is not only about reproducing the world as representation but about "getting the picture." As this colloquial expression implies, the world understood as picture "stands at man's disposal as conquered" (133); the modern individual perceives "the whole picture" and is equipped and prepared to deal with it. [...] And science was that process of measuring and drawing guidelines which established a place for the self within a secular world. (1996: 75-76)

Strain's interpretation insists on the third aspect of the French term for exhibition, exposition, which is the notion that showing the world is an argument that implicates the self. If we take this implied self-referentiality into account, it be- 
comes worthwhile to try to get a glimpse of what contemporaries thought of this collecting frenzy.

Some of the meanings attached to this phenomenon of traveling films that allow one to travel can be gleaned from the contemporary press, both literary and journalistic. The following poem, printed in Motion Picture Story Magazine, provides an entrance into this culture of enthusiasm. Note that the poem centers around a story-teller, the enthusiastic recipient of the collector's practice that made visual story-telling possible. As a good student of the collector with his universal ambition, this narrator presents himself as the collector's clone. From the vantage point of this man, the world could be experienced in an afternoon:

\section{A Motion Picture Traveler}

At Villa de Luxe there could always be found

An assemblage enraptured, admiring,

When J. Vanderbillie de Gould was around -

Entertaining was he and untiring.

$\mathrm{He}^{\prime} \mathrm{d}$ tell of the Orient, France and the Nile,

Of Great Britain and Africa, too;

$\mathrm{He}^{\prime} \mathrm{d}$ climbed up the Alps where he lingered a while

To enjoy the magnificent view.

On the various industries, customs and dress

Of the countries both near and afar,

$\mathrm{He}^{\prime} \mathrm{d}$ declaim in a manner that needs must impress -

He'd met emp'ror, King, Sultan and Czar.

But, alas! to that charming vacation resort

Came a stranger from Brooklyn one day,

Just as J.V. de G. was describing some sport

He has witnessed in far-off Bombay.

'It was really amusing to watch them," said he,

"The natives in garb so fantastic

Were jumping and tumbling, each vying to see

Who could make the most ludicrous antic.

I sat next to the King, and when luncheon was served,

On gold trays set with rare, precious stones,

We - " he broke off abruptly, completely unnerved,

As a voice called out: "Hello Bill Jones!"

With a muttered remark, sounding almost like 'jam,"

He was off of that porch in one bound.

Then the stranger observed: "He's a beautiful sham,"

While the boarders all gathered around;

"You believed in these stories Bill loved to relate, 
And he feared that the truth I'd disclose;

Why, he's never been out of his own native State -

'Twas the Pictures taught Bill all he knows!" ${ }^{18}$

The recipient and stand-in function is figured quite literally, as the narrator moves from "He'd tell" to "He'd climb," and enjoyment is mentioned as if in an advertisement for a travel agency. After stipulating that this figure is an eyewitness, he is quoted in direct discourse, boasting about royal banquets and other event straight out of fairy tales. The joke is on him, though, when in the end his secret is betrayed. It turns out he was enabled to be such a social success, so entertaining a story-teller, by the movies. Throughout the poem, a tone of didacticism prevails; Bill had been taught, and although the poem pokes fun at him, the descriptions embedded in what his boasting contains are appealing enough. This didacticism aligns the recipient of the images with the "teacher" who collected them for his benefit. Most importantly, they feature a specific element of all the cultures "visited," at least as they are summarized in the proliferating clichés that resulted from such world-picturing practices. They contain, indeed, a world-picture.

That the universal ambition of collecting the images of the world had a strong didactic purpose is evidenced in reports about exhibitions of film around the world, abundant in the trade press. This global exhibition is evidence of the spread of the medium, the ensured commercial success, and the prospects for national film markets. But also, it is the other side of the collector's ambition and its embedding in a cultural thirst he himself had first provoked, and then quenched. For example, in 1910 Nickelodeon reports:

An American has been giving moving-picture shows at Maskat during March and meeting with great success. [...] The same man has been in the Middle East for more than a year, entering Turkey at Aleppo and coming to the Persian Gulf by way of Baghdad. He has given shows at Mohammerah, Bassorah, and Bushire. He left Maskat for Aden. Success seems to have crowned his efforts everywhere, as the Arabs are very fond of such entertainments, and the wealthier sheiks quite generous.

The machine used was of French manufacture and so were most of the films. The subjects were largely Turkish, with scenes from the Arabian Nights. [...] It is a question of only a short time until every important town in the Middle East has a moving picture theater. At present France has practically a monopoly of the business of furnishing films, but there seems to be no reason why American manufacturers might not share in the business. ${ }^{19}$

Although the export of the American product and status of American film in the world seem to be the topics of articles like this one, the underlying assumption is more relevant here. 
The case for the promotion of the medium in general, for its Universal Ambition apparently can still be made fifteen years after the Lumière Brothers' first public screening. Hence, it is still a vivid, exciting prospect to imagine the world picture as marketable through accumulating its many synecdoches. In this quotation, incidentally, a funny if disturbing coincidence occurs between two moments of the exploitation of the orientalist exotic - in the films and in the exhibitions - which structurally if not factually recalls the double position of American Indians in the Westerns. $\mathbf{D}$ This global spread of the medium and the international exhibition of both local and imported footage imply a framing of each individual film that is in many ways similar to the object of the museum, or the individual who performs in an ethnographic exhibition. Where the museum centers, the traveling exhibition de-centers, but both glorify the universalist project.

This promotion of film as global, universal medium is also apparent in the feature "World Wide Activities of Pathé Frères" in Nickelodeon some months later:

[...] Pathé Frères are enabled to show the millions of moving picture lovers such rare scenes as linger long in the memory of the beholder and which do much to spread the knowledge of our distant neighbors, their ways and customs, among all mankind. On the steppes of Siberia, in the wilds of Africa, beneath the torrid sun of India, in China, Japan, Tibet, Egypt, South Africa, Australia, South and Central America, and swarming over the countries of Europe are Pathé camera men, scaling mountains, exploring caverns, brooking any danger from man, beast or climate, and all constantly on the alert for anything of interest to the stay-at-homes who travel only with the motion picture screen. $^{20}$

Here the adventure of making pictures all over the world ("scaling mountains," "brooking danger") is given a universal weight, indeed, an ethical thrust comparable to that of missionaries: "to spread the knowledge...among all mankind." The democratic medium not only enables armchair travel for the less wealthy, but also spreads knowledge, and rescues the distant inhabitants of the earth from their anonymity. Moreover, the final destination of these traveling images was spread all over the world as well, since Pathé and other companies distributed their films across Europe, America, Russia, and Asia. The quotation also displays in its own formal structure the breathlessness typical of the way cinema was processed at the time. It shows this variety of people and their customs in a form of collage characteristic of the culture in general. $\mathbf{K}$

The exalted tone of this clip demonstrates the importance of attending to the collusion between ethics and aesthetics that ruled the business then and now. The poem quoted earlier suggests a similar missionary quality, even clearer to the extent that it is mildly ridiculed. The ethical dimension of the greed for in- 
formation, thinly disguised as an educational drive, is inextricably bound up with the aesthetics that subtended the collector's project. In this respect, I cannot quite agree with critics such as Sam Rohdie who separate functions according to what I find an anachronistic aesthetic.

Writing about the Kahn archive, Rohdie claims that each photograph in the collection "lacked power as an image because it was primarily illustrative of an idea." "Because" begs the question of the relationship between ethics and aesthetics, as it neglects, also, the link between knowledge and possession. This Kantian purism ignores the larger cultural-historical context that in this case as always, does not admit such separation of functions. Instead, I would argue that the "visual power" of images is at least in part determined by the purpose for which they were made, not so much by the individual "artist" but by the project within which this individual acted, and which was in turn framed by cultural demand.

The troubling term, here, is "illustration," a notion that expressed functional (inter-)dependency and is therefore, in our current aesthetic conceptions, aesthetically pejorative. But especially in the case of films it is apparent that it is precisely their visual impact that is the purpose of the images. "Illustrations of an idea," then, is another way of saying "visualizing an idea," which is quite an acceptable and frequently used phrase in assessments of artistic production. For this reason, Rohdie's attempts to analyze the images in terms of their illustrative nature as opposed to their imaginative powers are significantly anachronistic. Moreover, that he should do so within the context-bound opposition of entertainment and aesthetics - "striking" - and education - "interesting" seems equally problematic:

This is one reason perhaps that the autochromes of the Archives, however interesting, are seldom striking. No matter how particular an autochrome was, it was never more than an illustration of an already known. The image did not surprise and thereby confound existing categories, but comforted the viewer by confirming established categories. [...] That is, the autochromes were not to be viewed aesthetically, nor even strictly speaking on their own as vues of China or Japan, but rather as material for lectures by Brunhes at the Collège de France in much the same way as geographers today might employ photographic slides. The images needed to be accompanied. Indeed, they belong within the tradition of the illustrated geographical voyage-lecture and need to be understood as such. They are images grounded therefore and explicated at every turn by the scientific word. The audience for Brunhes lectures were the educated pursuing a course of study even though the illustrated lecture of this kind was also part of popular entertainment which some have argued to be a forerunner of the early cinema with its exotic geographical vues. (28-28; emphasis in text) 
I have no quarrel with this reminder of use-specificity. I just do not see why images used as illustrations can therefore not be aesthetic. The problem stems from a contradiction within the argument itself. Based on an aesthetics of ontology, Rohdie's assessment judges the images nevertheless according to pragmatic standards.

In previous chapters I explored the programming of films in which (time) travel was facilitated, feeding cultural emotions such as instant nostalgia and a curiosity for the exotic. Here, the universal ambition of the medium is linked to ways of structuring knowledge about the world. Thus the primary function of the medium occurs within a dynamics of fragmenting and collecting. These projects of collecting, indeed, required fragmenting, in order for the bits and pieces to be manageable, not so much, or not only, by the learners in the process of acquiring knowledge, but primarily by the institutions that aim to display the world in temporally limited bits. We have seen that such acts of fragmenting are inherent in some cultural practices at the turn-of-the-century and also, that they are emblematic for modernity. Some basic if unspoken principles of the aesthetics of film, as well as some relationships between the medium and its cultural context, can mutually illuminate each other. In this sense, the use of photos, slides, and films for geography lectures is not a hindrance for the historical assessment of the material, but part of it. Hence my inclusion of the Kahn archive with its outspoken presentation program in this chapter.

In this respect, the position of a genre like the Western has a specific meaning. Not only does the Western reflect attitudes toward moments in time in specific places of the world, as I have argued before. On another level, in a culture of universal ambition its programming adds to its meaning, as it gives any Western, however fictional its plot, a connotation of learning, exploration, and the exotic; in other words, of a voyage of discovery, that companion of conquest and settlement. It provides the pleasure of entertainment, the thrill of instant nostalgia, and the obscure sense of superiority of modern life and urban society, with an epistemic justification. In the period still permeated with ideas of enlightenment, learning is, after all, the most edifying activity imaginable. This is the way this process of collecting for education structures a heritage, such as archival collections, over time. This process is extremely important for film history in general, if we wish to construe such a history as cultural.

Others have discussed the phenomenon of the 19th- and early 2oth-century World Exhibitions as an emblem of modernity. Undeniably, the World's Fairs share with a project such as Kahn's the ambition to "collect" the world, albeit in that case for a transient - if wildly spectacular - event, an ephemeral construction of unity in a temporary exhibition. It is because of their combined epistemological, educational, and also aesthetic thrust that these blockbuster shows provide a context for understanding cinema as a practice of exhibition, as well 
as a symbol for modes of display and popular ethnography that played a part in early cinema's signifying practices. But such exhibitions could not exist without the collecting that went on in order to cater to the taste for knowledge it had itself created. More explicitly perhaps than film programs, the Worlds Fairs pretended to offer global travel-on-the-spot for the non-leisure classes. But the ambition remains strikingly similar. ${ }^{21}$

The Library of Congress holds a collection of titles that were shot by Edison's cameramen at The Pan-American Exposition held in Buffalo, N.Y. in 1901. The titles show a range of interests, from technological wonders to peoples from all over the world, from panoramas showing flâneurs on the fairgrounds to staged shows: Opening, Pan-American Exposition; Pan-American Exposition by Night; Panorama of Esplanade by Night; Panoramic View of Electric Tower From a Balloon; Circular Panorama of Electric Tower; A Trip Around the Pan-American Exposition; Esquimaux Game of Snap-theWhip; Esquimaux Leap-Frog; Esquimaux Village; Japanese Village; Spanish Dancers at the Pan-American Exposition; Horse Parade at the Pan-American Exposition; President McKinley Reviewing the Troops at the Exposition; President McKinley's Speech at the Pan-American Exposition; Sham Battle at the PAm-American Exposition.

The place of Westerns and Westerners is one among many; yet, the West is also implicitly promoted in the desire to document other civilizations in the process of disappearance. We can see this in other ethnographic as well as theatrical subjects filmed by Edison in 1898: Circle Dance; Buck Dance; Eagle Dance, Pueblo Indians; Wand Dance, Pueblo Indians; or Congress of Nations (1900, Edison). The similarities reside in the integration of travel, learning, and entertainment by means of the power of visuality. This integration is effectuated in cultural practices other than ours, to make modern consumer culture ethically and aesthetically more palatable than it might otherwise be. It helps the cultural sense of righteousness, that is, if consumer culture's less edifying aspect, naked greed, is so skillfully veiled by layers of uplifting sentiment.

This ethical imperative lies at the bottom of the undeniable fact that the three endeavors of physical, intellectual, and sentimental mobility were frequently presented as each other's metaphors. This is evident even today in the way the Kahn collection presents itself on the Web:

This space is a travel in and of itself. In addition to its park with the very picturesque Japanese garden, this museum holds a precious collection of autochromes from the beginning of the century on several regions of the world. We owe it to Albert Kahn, a generous banker who decided in 1909 to fix, by means of photography and cinematography, "aspects, practices, and modes of human activity of which the fatal disappearance is but a matter of time." Under the guidance of geographer Jean Brunhes he sent professionals to fifty countries in order to make the "archives of the globe." The 
financial ruin of Albert Kahn made it impossible for him to complete the inventory of the globe. This multimedia documentary oeuvre that he created avant la lettre, is presented today thanks to a "performing" audiovisual system: the visitor can project what he or she chooses on individual consultation sets. ${ }^{22}$

Keeping in mind that this text is written and presented now, we might be astonished by the connection between the two cultures, converging on the terms of the initial project. I have emphasized expressions that partake of the ambition of the archive-then, in a blurring relationship with such historically circumscribed sentiments that the archive-now would do better to examine, instead of repeating the appeal. Kahn, clearly, understood that collecting and vanishing go hand in hand, although, like most of his contemporaries, he viewed this simultaneity as a matter of fate ("fatale") rather than cultural agency. We recognize this nuance from the instant nostalgia with which the modern city-dwellers gave themselves over to the bitter-sweet visual experience of contemplating, in the present, of the almost hallucinatory dark theater, that which no longer existed.

\section{Notes}

1. Martin Heidegger, "The Age of the World Picture." (1977 [1938]: 134).

2. The relation between Heidegger's text and visuality more in general is the subject of an in-depth exploration by Silverman (1999).

3. On the culture of exhibition as a widespread epistemological and artistic principle in the late 19th century, see Hamon (1992). On the various meanings of the word "exposition" and its implications, see Bal (1996).

4. On the image as fetish, see Debord (1970). Mitchell (1985) explains the conception of the image as fetish in Marx's sense of commodity fetishism. Here, however, I contend that the object of fetishization is not just the image (Mitchell), not even just its accumulation (Debord), but specifically its totalizing, encompassing ambition.

5. For an overview of his paper archive, see George Kleine. A Register of his Papers in the Library of Congress. (1979)

6. I mean here the modern variant of globalization, by means of (visual) mass media. This to differentiate the older traditions of travel and collection, such as the 18thcentury China trade or those that go back to the Crusades in the Middle Ages.

7. "fixer une fois pour toutes des aspects, des pratiques et des modes de l'activité humaine dont la disparition fatale n'est plus qu'une question de temps" (my translation). See for this often quoted declaration, for example, the website of the Musée Albert Kahn at: http://www.mcm.asso.fr/le_guide/structures/lieux/musee_albert_ kahn.htm. This page was downloaded on February 1, 2000, but is no longer accessible.

8. About Kahn's utopian and multimedial project, see Jeanne Beausoleil and Pascal Ory (eds.), Albert Kahn (1860-1940). Réalités d'une utopie (1995). See for an analysis of 
the Kahn archive then-and-now, Sam Rohdie's “Geography, Photography, the Cinema. Les Archives de la Planète." (1998).

9. In some cases these practices clearly work in tandem: mobility is an aspect of both collection and distribution. In her dissertation on amateur film Martina Roepke (in preparation) significantly names her chapter about this phenomenon "Bewegung und Bewahren." Bewegung and Bewahren here designate two aspects of modernity in which the rise of amateur film practice can be located: the medium's capacities to both reproduce and to manipulate reality.

10. For a discussion on a number of aspects on the culture of collecting, see Elsner and Cardinal, eds. (1994). The universal ambition discussed here is different from the fetishism that also often motivated collecting. The non-uniqueness of films as objects and the fundamentally public nature of the medium makes fetishism a less likely motivation for the archives discussed here.

11. In an interview with Peter Delpeut the museum's curator explains how the access to this footage today is structured by these same regional categories. This is an example of how the "new" archive is modeled after the beginning: the "old" archive. See NFM-Themareeks 12 "Albert Kahn. Een beeldarchief van de planeet" (1992).

12. About the traveling camera of the Lumières, see Lenk (1997). For an excellent analysis of the first Lumière films and their position in film history, see Elsaesser (1999).

13. Nickelodeon V, I (January 7, 1911): 17.

14. See for example, Marianne Hirsch, Family Frames (1997) and Marja Roholl (2000). The title for the original exhibition was "The Greatest Photographic Exhibition of All Times," indicating the universal ambition of the project. In Steichen's own words the exhibit was " a mirror of the essential oneness of mankind throughout the world. Photographs made in all parts of the world, of the gamut of life from birth to death." On the website of the Château de Clervaux where the restored photographs are exhibited after their legendary global tour in the $1950 \mathrm{os}$ and 6os, the ambition of Steichen is described: "In 1951, in the middle of the cold war, the American photographer of Luxemburgian descent, Edward J. Steichen, began with the preparations for his great plan of an exhibition making man conscious of himself through the universal language of photography. The plan, inviting professional and amateur photographers, famous authors and those yet unknown to the general public to send in their works, met with great enthusiasm. Steichen received more than two million pictures from all over the world. At first he retained 10000 photographs, then whittled these down to 503 pictures by 273 photographers from 68 countries. Together they composed 'The Family of Man' in an impressive setting of 37 themes, based on love and faith in man, depicting birth, work, family, education, children, war and peace." http://www.clervaux-city.lu/Familyofman.htm.

15. For a pioneering effort to write a history of Desmet and early film distribution in the Netherlands, see Ivo Blom's Jean Desmet and the Early Dutch Film Trade (2003).

16. On the notion of meta-museum, see chapter 1 in Bal (1996).

17. On the necessity and difficulty of using the archive critically as, also, a record of what got recorded, see Spivak's, A Critique of Postcolonial Reason (1999: chapter 3).

18. By Lizzie Pinson, printed in Motion Picture Story Magazine II, 9 (October 1911): 83.

19. "Moving Pictures in the Orient", Nickelodeon IV, I (1 July 1910): 7.

20. Nickelodeon V, I (January 7, 1911): 17-18. 
21. Robert Rydell (1984); Curtis M. Hinsley (1990); Julie K. Brown (1994). About the role of cinema in this context see for example, Emmanuelle Toulet (1991) and Tom Gunning (1994). Christopher York's argument (2001) suggests that leading anthropologists were responsible for, or at least in collusion with, the twin project of scientific collection and popular entertainment.

22. "Cet espace est un voyage à lui tout seul. Outre son parc au jardin japonais très pittoresque, ce musée détient une précieuse collection d'autochromes du début du siècle sur plusieurs régions du monde. On la doit à Albert Kahn, généreux financier qui décide en 1909 de fixer, par la photographie et la cinématographie, 'des aspects, des pratiques et des modes de l'activité humaine dont la disparition fatale n'est plus $q u$ 'une question de temps'. Sous l'égide du géographe Jean Brunhes, il envoie des professionnels dans cinquante pays pour constituer les 'archives de la planète'. La ruine d'Albert Kahn empêche de mener à terme cet inventaire du globe. Cette œuvre documentaire multimédia, qu'il crée avant la lettre, est présentée aujourd'hui grâce à un système audiovisuel performant : le visiteur peut faire la projection de son choix sur des postes de consultation individuelle" (my translation). From: http://www.mcm. asso.fr/le_guide/structures/lieux/musee_albert_kahn.htm. 


\section{Virtual Museums}

We endorse this as being the best Indian story ever made. All of the properties used are genuine, the details accurate, and the settings beautiful. The Indian canoes, blankets, garments, teepees and weapons used in this story were received from a famous collection. This film is suitable for use at the most particular Chatauquan exhibition, or a tent show, vaudeville house or Nickelodeon. - Moving Picture World, 1907

Main Entry: vir•tu・al Pronunciation: 'v\&r-ch\&-w\&l, -ch\&l; 'v\&rch-w\&l Function: adjective Etymology: Middle English, possessed of certain physical virtues, from Medieval Latin virtualis, from Latin virtus strength, virtue

Date: 1654

$\mathbf{1}$ : being such in essence or effect though not formally recognized or admitted

2 : of, relating to, or using virtual memory $3:$ of, relating to, or being a hypothetical particle whose existence is inferred from indirect evidence - Merriam-Webster's Online Dictionary, 2005

Main Entry: $\mathbf{m u} \bullet \mathbf{s e} \bullet \mathbf{u m}$ Pronunciation: myu-'zE-\&m

Function: noun Etymology: Latin Museum place for learned occupation, from Greek Mouseion, from neuter of Mouseios of the Muses, from Mousa

Date: 1672 : an institution devoted to the procurement, care, study, and display of objects of lasting interest or value; also : a place where objects are exhibited - Merriam-Webster's Online Dictionary, 2005

In Moving Picture World an advertisement appeared for Kalem's THE RED MAN's WAy (1907) on behalf of George Kleine's Optical Company. The text of this ad, quoted as epigraph here, shows the explicit promotional strategy. This strategy emphasizes the "museal" aspect of the film. It mentions that the props are "gen- 


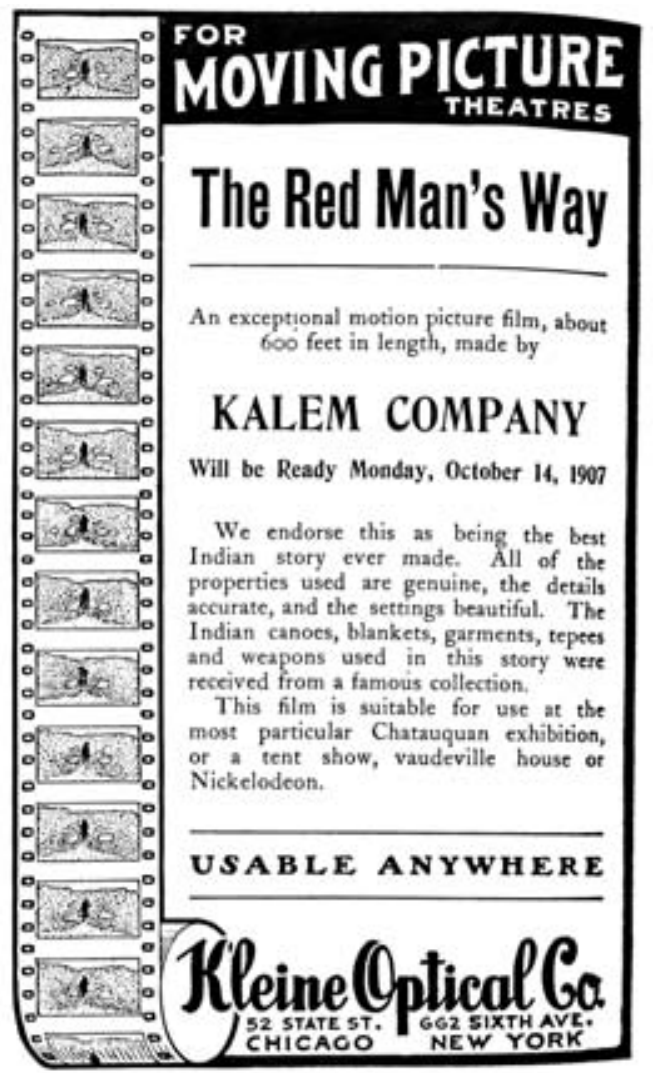

V Ad for Kleine's release of The Red MAN's WAY (Kalem), Moving Picture World I, 32 (January 12, 1907) uine," the details "accurate," and the scenery "beautiful." As if to prove the authenticity of these elements, and thereby to legitimize the production, their provenance - from a "famous collection" - is cited. This is significant for an understanding of film as cultural practice. It points to what I would call a "museal" function that is ascribed to film. The loop established here from "real life" considered ethnographically - "Indian canoes, blankets, garments, teepees and weapons" - to the collection echoes the universal ambition. From "were received from a famous collection" to representation - the best Indian story ever made - the functions are integrated in an apparently self-evident recommendation. The final sentence demonstrates that the production company was well aware of the attraction of that function. Most explicitly, the film's various possible uses are enumerated in a sequence that has nothing surprising about it: "This film is suitable for use at the most particular Chatauquan exhibition, or a tent show, vaudeville house or Nickelodeon." (see figure $\mathrm{V}$ ).

Several earlier chapters have already shown how film was considered to be an excellent instrument for education, for teaching about history, geography, or ethnography. Touristic impulses are apparent in the popular mix of curiosity and mastery in education. Education easily goes together with an "official," nationalistic thrust that museums also often serve (Duncan 1991). The journalist quoted below explicates the educational and nationalistic value of using real locations and beautiful landscapes:

William N. Selig is making pictures of Buffalo and Cleveland. These reels will form a part of the Selig program, intended to cover all the large cities of the country. It is of a piece with the splendid advice to "see America first." The educational value of these 
pictures will be undoubted. We have had scenes of foreign cities and foreign lands and have enjoyed them. Now we may have a chance to get acquainted with the great home centers.

In this connection the writer has often thought, when looking at the picture of an unusually good landscape, how much more interesting the drama would be to the beholders if on the initial screen there should be a line or two indicating the locality. For instance, "The scenes of this play are laid in the Catskill Mountains." In that way in great measure a dramatic film might also become educational. ${ }^{2}$

The author's assessment is based on the reality effect that "true" landscapes have, which is worthy of a signpost, such as "a line or two" to help the audience to "get acquainted" with the treasures of the nation, or to encourage a double or even triple - way of looking; at the narrative; at the physical reality within which the narrative is set; and the patriotic and ideological consequences of understanding that the physical reality constitutes a piece of America. The use of authentic props, as promoted in the epigraph, points to a similar effect. In a situation where people were aware of the "pastness" of the stories about Indians, such reality effects transform into a museum or, if you will, a museality effect that puts forward not so much the excitement of outdoor reality in itself, but that satisfies the curiosity and mastery that informs designation and display. It is a form of symbolic conquest. What are the ideas that underlie this aspect of our films?

First, it entails a strong awareness of the value of the films, but also the props, as material objects. The materiality of things is central in museal discourse. There, this materiality harbors a concern for preservation and display. Here, I wish to place this materiality in relation to the visibility of things. Through their materiality objects have, or represent, an embedded authenticity. This marks the principle of presentation, rather than re-presentation, through the "chain of evidence" that transcends sign systems. They do not symbolize or re-present anything, rather, they have a tactile, synecdochic relationship to the generating culture; it is the visible residue of that culture, a material link to it, a guarantor of its authenticity. This aspect is also a strong feature of museality, as distinct from other forms of representation. Emphasis on visibility shifts the focus from material culture to visual culture, from three-dimensional objects to their two-dimensional representation, a shift that the ad quoted as an epigraph seeks to mitigate. To this effect the ad foregrounds the material reality and connects it to the use value in the visual culture of museum display. A third aspect of museality is the function of museums and their holdings as treasure houses of cultural memory.

These three aspects - materiality, visibility, and memory - come together in the museum and the collections it possesses. Objects have a "social life" (Appaduraj 1991) and often this life ends in museums. In a study that usefully 
brings together the analysis of material and of visual culture, Eilean HooperGreenhill, drawing on Doxtator's book (1992) about the traveling exhibition Fluffs and Feathers: An Exhibit on the Symbols of Indianness, speaks about the ideological life of objects:

The tangibility of artifacts makes abstract notions tangible. Acting as symbols, objects link unconscious responses to real issues or relationships in society; the wigwam and feather headdress that represent "Indianness" to many people in the West render invisible the actual lived circumstances of Native Americans or Canadian First Nations. In this way, objects structure common-sense categories, some of which may be deeply destructive. Some cultures have been subjected to representative symbols chosen by outsiders unfamiliar with the beliefs and life-ways so represented. These objects serve to objectify and caricature the peoples represented through the construction of stereotypes and categories which debase or ridicule. (2000: 111)

Thus, with reference to Homi Bhabha who offered a critique of such practices in The Location of Culture (1994), she states that "[o]bjects are the inscribed signs of cultural memory" (111).

A fourth aspect of museality is education. Whereas films were also considered potentially educational, as we have seen $\mathbf{H}$, museums' educational function is much more pronounced and near-exclusive, especially when the museum is ethnographic and the aesthetic function is pushed to the background. As a representation machine and a constructor of cultural memory, cinema's usage or practice is also educational, even missionary sometimes, and these traits were deployed from the earliest manifestations of the medium. In fact, the educational value of the new medium, as stressed so often in the years in which the respectability of the medium was the object of debate, struggle, and polemics, was often seen as tied to, precisely, those characteristics that were possibly also its danger: the power to visually represent reality. $\mathbf{X}$

In its museal function, cinema can quite literally be compared with museums as institutions. The institutional definition of museums is formulated by the American Association of Museums (AAM) as follows:

A non-profit permanent, established institution, not existing primarily for the purpose of conducting temporary exhibitions, exempt from federal and state income taxes, open to the public and administered in the public interest, for the purpose of conserving and preserving, studying, interpreting, assembling, and exhibiting to the public for its instruction and enjoyment of objects and specimens of educational and cultural value, including artistic, scientific (whether animate or inanimate), historical and technological material. (emphasis added) ${ }^{3}$

Museums and films have part of this definition in common. Assembly and exhibition are crucial for filmic display as well, a property that is duplicated with- 
in the films' contents. Earlier I analyzed four modes of display of the exotic other as evidenced in a few films. D Here I wish to consider display as a powerful cultural practice that renders films much like museums.

As I announced in the previous chapter, the objects of reflection of that chapter and this one are closely connected. There it was the impulse to collect that I presented as a significant cultural practice. In this chapter it is the inevitably subsequent practice of exhibition. Of course, films may end up in museums like the ethnographic props used to make them, but they are not, at the time, destined to be museums. Nevertheless, as a cultural practice, film is a form of display quite analogous to museum display. And although they are themselves material objects and use material objects for their representations, their cultural life is more volatile, transient, and unmoored. In order to gain insight into the museal aspect of films, then, I propose to compare them to a practice that we have only recently begun to be engaged in: electronic display. In other words, I propose to make a comparison between early films and a conception of the virtual museum.

Indeed, early cinema has more in common with today's virtual museums than with the actual museums that had been founded by the turn of the century, with which they shared features and functions but not material appearance. The comparison with virtual museums clarifies why the museality effect partakes of the diffuse cultural function of film and the practices that nourished it. The "exhibitionary complex" of early cinema, to invoke Tony Bennett's terminology, (1995) is a product of the mixing, or drawing together of three ingredients. These comprise the filmic - here I mean the combination of photography and movement - the 19th century inheritance of the system of representation of the exoticized object, and a turn-of-the century appetite for the particular blend of sensationalism and popular science. These three elements determine the specific museality of our films.

As Bennett points out in his chapter on the "exhibitionary complex":

For the emergence of the art museum was closely related to that of a wider range of institutions - history and natural science, museums, dioramas and panoramas, national and, later, international exhibitions, arcades and department stores - which served as linked sites for the development and circulation of new disciplines (history, biology, art history, anthropology) and their discursive formations (the past, evolution, aesthetics, man) as well as for the development of new technologies of vision. (1995: 59)

Bennett's Foucaultian analysis of the emergence of the institution of the museum demonstrates an approach that is different from my aim here, but the synchronic rise of institutions, discourses, disciplines and media he mentions is relevant. I attempt to see how, outside of the institution, film participated in a 
popularized museal discourse. The term "virtual" is appropriate here for two reasons: because films are not really museums, and they display by means of virtual means. Not really being a museum but using virtual means, possibly a new museum paradigm, film takes the exhibitionary aspect to the extreme.

I invoke here the recent phenomenon of virtual museums consciously. These digital portals of the old institutions exhibit the collections of digitally-recorded sound, text, and image. The virtual museums avant la lettre, the virtual exhibitions of early cinema, operate technically in a different way, but are similar in the sense that they exhibit outside of the museum as building, for a broader audience, in the context of "learning while having fun." But there is more. As I have mentioned before, the practice of programming short films among other items of entertainment strengthens the similarity. While digital virtual museums can use links and different media (sound, moving image, still image, text), early films were exhibited in a program format with accompanying music, lectures, intertitles, slides, stage acts, and so on. ${ }^{4}$

There is an important similarity of museal display in exhibitions and the programming of films in their exhibitions. The heterogeneity that makes it so difficult to come up with a genre definition is also characteristic of the museum, and especially the virtual one, where the viewers - now called users - can determine their own program and itinerary. Instead of homogeneous objects, the early exhibition programs offered "assemblies." Assembling items for a show is an active construction of a new whole, even if that whole falls apart again right after the show. Bhabha calls this "seriating":

The process of making a display is a process of making a new series, of seriating. As objects are brought together new series are made, and statements are iterated and reiterated. (1994: 22)

He emphasizes not only the construction, hence, the active intervention such seriating constitutes, but also its meaning as "utterance." Series make statements, and together, many series construct the reiteration of statements that Butler discusses as the making of, not only a particular meaning, but the reality - in her case, sex - that such reiterated statements produce (1993). In the context of ethnographic representation Hooper-Greenhill asserts something similar:

Groups of objects brought together in the form of a collection generate social and cultural statements. These statements are produced through the objects combined together in such a way that each individual object confirms the statement as a whole. (2000: 49)

These statements build conceptions of histories, cultures, and identities. They construct master narratives. This is what museums do, as Hooper-Greenhill states, but the same can be said of films: 
The choice of objects collected, their placing in groups or sets, and their physical juxtaposition construct conceptual narratives and present visual pictures. Assemblages of objects produce knowledge, and this is one of the most vital functions of museums. (49)

The relevance of the museality effect of my films becomes clear when we look at the practice that most closely resembled the film exhibitions, while also containing films: the World's Fairs that flourished at the same time as film did. These Fairs presented a great number of "showcases," particular ensembles of exhibits, grouped usually according to nationality. These showcases exhibited a very successful mix of what Gunning (1994) called "grandeur and transience." "Grandeur" expresses the wonderment and enthusiasm for the technological achievements. "Transience" points to the simultaneous awareness of loss that informed the instant nostalgia so suitable to attract visitors to these exhibitions.

About World's Fairs in particular Gunning writes:

The World's Fair provides one of the richest instances of the visual and technological culture that emerged in industrialized countries from the middle of the nineteenth century into the twentieth. Cinema moves within this culture less as its culmination than as a parasite, drawing upon both its forms and its themes but initially remaining relatively neglected, seeming like a pale shadow of richer, more vivid forms. But as such it has a great deal to tell us about the visual practices which cinema sought to emulate and from which it emerged. (1994: 423)

These visual practices include forms of collecting $\mathbf{U}$, exhibition, and spectatorship. They come together and are thematized in the films about the World's Fairs. These show collections, exhibit them, but by the same token they are about exhibition and spectatorship. In effect, they duplicate the gaze.

We can see this clearly in Opening PAN-American Exposition (1901, Edison). The images show the festive parade of the opening, including, surprisingly, the audience on the scene. It starts with a rather solemn procession of official-looking men in black coats. But in the last seconds of the short film we see soldiers marching, and a line of what seem to be visitors parades diagonally through the image as well. This combination of the self-reflective representation of the act of looking with the display of the various constituencies that are involved in the Fair as institution, shows once again that filmmakers were quite aware of the aspects of their films that I am discussing.

In another film shot at the Pan-American Exposition of 1901 in Buffalo, New York, the Electric Tower is featured. Circular Panorama of Electric Tower (1901, Edison) shows a complex array of movement: the camera pans, but we see spectators on the scene moving about in different directions as well. A later film combines education with comedy, almost parodying these filmic registra- 
tions of visits to Fairs. In Mabel and Fatty Viewing the World's Fair at SAN FRANCISCO, CAL. (1915, Keystone) the title characters take the film viewer along on a trip across the fairgrounds.

In terms of my heuristic comparison between displayed films and virtual museums, Anne Friedberg (1993) offers an interesting comment. She makes a distinction between the mobilized gaze and the virtual mobilized gaze. The distinction helps her make an important point. Her argument is that representation is a virtual mobilization of the gaze:

The virtual gaze is not a direct perception but a received perception mediated through representation. I introduce this compound term in order to describe a gaze that travels in an imaginary flânerie through an imaginary elsewhere and an imaginary elsewhen.

Her study, like mine, analyzes early film as a cultural practice akin to others such as shopping and strolling. In her context - which is European and particularly French - she establishes an important analogy between these different but related practices as part of a visual culture:

The mobilized gaze has a history, which begins well before the cinema and is rooted in other cultural activities that involve walking and travel. The virtual gaze has a history rooted in all forms of visual representation (back to cave painting), but is produced most dramatically by photography. The cinema developed as an apparatus that combined the "mobile" with the "virtual." Hence, cinematic spectatorship changes, in unprecedented ways concepts of present and real. (2-3)

The filming of spectators on the fairgrounds is done through this extra layer of representation, the virtualization. Thus it offers a commentary on spectatorship as active, as opposed to the passivity of being put on display. ${ }^{5}$

To make the case for my comparison, I offer a somewhat longer quotation from which the reader can glean a good sense of the ideas and sentiments that inspired the World's Fairs, at least in their presentation to the public. The passage concerns a particular section of the Fair. In The Book of the Fair, an elaborate guidebook to the 1893 World's Columbian Exposition, Hubert Howe (1893) describes in a separate chapter the exhibits on the "Midway Plaisance." This stretch of land on the Exposition grounds was very popular with the visitors. It was the place where the "lighter" exhibitions, from a giant Ferris wheel, an American Indian Show, a Moorish palace, to a model Eiffel Tower could be found. Julie K. Brown summarizes the visual attractions of the Midway as follows: "A traditional form of popular theatrical attraction, combining color, sound, and light with visual effect, was presented in a number of entertainment concessions located on the Midway" (1994: 103). 
Hubert Howe opens with the purpose of the Midway:

If to any class of visitors the Columbian Exposition was somewhat of a disappointment, it was to those who went there merely in search of amusement. Instruction rather than amusement, but instruction conveyed in its most attractive form, was the main purpose of the Fair, and surely there were never such opportunities for a comparative study of what has and is being accomplished in every branch of industry and art. But men would not always be thus instructed; would prefer rather to take such education in homoeopathic doses, with a strong admixture of recreation, of fresh air and sunshine, of saunterings among flower-beds and waterways, and above all with plenty of good things to eat and to drink. Hence it was that in favorable weather at least half of the visitors would be found outside the buildings, on the wooded island, on the lagoons, the boulevards, or seated in shady or sheltered spots listening to the music of the bands.

But as places of recreation there were none that would compare with the Midway plaisance, an epitome and also a supplement of the Fair, with its bazaars of all nations, its manifold attractions, and yet with educational as well as pleasurable features. All day long and far into the night this spacious thoroughfare, a mile in length and 600 feet in width, was crowded with sight-seers who, whatever else they missed, would make the tour of this novel and heterogeneous exhibition. (835; emphasis added)

The passage is clear and explicit about the purpose: "Instruction rather than amusement, but instruction conveyed in its most attractive form, was the main purpose of the Fair." This would be reversed for film, where entertainment came first but instruction or moral education were criteria for acceptability, as we have seen earlier. $\mathbf{H}$ The reference to homoeopathy, however, could be applied more easily to film programs than to the Fair. There, the "small doses" of instruction would fulfill the criteria quite precisely.

It is this quasi-medical discourse that links the Fairs and cinema in an unexpected way. The reference to fresh air is an interesting detail in this respect. This preoccupation with air as a source of health was very much in the air, so to speak. It was believed that fresh air was the best way to battle tuberculosis and other diseases. Of course, film would not at all offer such healthy entertainment. But the discourse itself is relevant nevertheless. Concern for public health is part of the discourse in which preoccupation with instruction and especially with the morality of the masses circulated. And that is certainly something for which film was thought to be useful. The homeopathy metaphor can easily be translated into the notion that the masses receive a "small dose" of moral instruction along with the wildly exciting entertainment offered by representations of Western subjects. Part of that implicit instruction, sneaked in with entertainment, might well be the promotional effect of showing "fresh air" in representations of the outdoors - if not the actual experience - so characteristic of the 
Western. In other words, as a genre, the Western subtly but systematically advertises the benefits of fresh air.

Finally, that the Midway Pleasance is presented as an "epitome and also a supplement" of the Fair is relevant from a theoretical perspective. It is a formulation that comes close to my claims about the Western, one genre among many, on the one hand, but particularly characteristic of cinema of its time, on the other. The Western, I hope to have substantiated in previous chapters, condenses a very great number of features of the culture in which it emerged. As did, the passage alleges, the Midway Pleasance as a central element, a mise en abyme, of the Fair. In this respect, the word supplement, today inevitably inflected by Derrida's complication of that notion (1976), is, precisely, a useful supplement to this view. The supplement, the philosopher has convincingly argued long ago, is both "additional" and "essential," both outside and an integral part of that to which it is a supplement. The Midway Pleasance is simultaneously a supplement to the Fair, a commercial area outside of the more official, representational national pavilions, and the most attractive part of it. Since attraction is the means through which educational value is homeopathically "sold," the increased attractiveness is essential to the Fair. This, then, is how I see the films under discussion here: both just another genre and, in all the aspects previously analyzed, essential to early cinema. Boldly put, this status foregrounds the Western's position as indispensable, representative genre of early cinema culture as a whole.

If this comparison, then, offers more than incidental insight into the status of our films, it is worth looking at the specifics of the description. It foregrounds the display of heterogeneous collections. It presents the exhibits as showcases that stand as fragments for the wholes they represent (in the sense of "speaking for"). The encyclopedic collecting craze discussed earlier $\mathbf{U}$ resonates strongly with the presentation in this guide. The following description of the different "bazaars of all nations" could as well be a description of Kahn's Archives de la planète:

From the Arctic zone there are also two Exposition colonies, one of Eskimos from Labrador, and the other from the portion of Lapland near North cape in Norway. The former is likewise termed the Innuit colony, and consists of several families, each living in a cabin covered with moss or bark. There was also a house during the earlier part of the season, and in a topek or lodge are kayaks or canoes, with paddles, harpoons, nets, sleeping bags, and other articles needed for the outfit of the Innuit hunter. Within the enclosure is an arm of the lagoon, where are illustrated Eskimo methods of boating, fishing, and seal hunting; and on one side is a pen for dogs, of which many are running around the village, such as are used for draught animals, offensive to sight and smell, but strong, powerfully limbed, and with thick coating of hair. Sledges are driven by an Eskimo boy, armed with a heavy whip fifteen feet in length, 
the crack of which is heard afar in the grounds. Not a few of the inhabitants have learned to speak the English language and converse freely and intelligently about the Fair and the part they play therein. Their winter dress of seal-skin, and in summer a suit of pearl-gray color trimmed with fur - a tunic, pantaloons, moccasins, and hood. Both sexes are attired alike, except that in the garb of the women is more of an ornamentation and that their hoods are larger; for these also serve as baby holders, in which the little one rests on the mothers' shoulders. (Howe 1893: 878-879)

Let me now compare these literary impressions of the 1893 Columbian Exposition with some filmic impressions of the Pan-American Exposition of 1902 in Buffalo, New York, as filmed by the Edison company. Three titles are directly related to the description of the Inuit hunters from the guidebook: EsQUIMAUX Village, Esquimaux Game of SNap-The-Whip, and Esquimaux Leap-Frog. The first film consists of three shots showing a low building, perhaps an igloo, next to a small pond. Clearly set at the exhibition grounds, it resembles the dwellings of polar bears in a zoo. A few men run around and dogs pull a sled along the water of the pool. The Edison catalogue describes the films as follows:

One of the principal features at the Pan-American Exposition is the Alaskan or Esquimaux Village. In this most interesting exhibit, scenes are enacted just as they take place in the far away frozen North. In this subject we depict a large number of Esquimaux clothed in their native costumes and seated on their sleds, which are drawn by spans of four Esquimaux dogs. They are engaged in a race and are to be seen running over the ice and snow at a high rate of speed. There is a pond in the foreground of the picture on the shores of which the home stretch of the race takes place. ${ }^{6}$

The two other films, issued by Edison together with the title SCENE IN THE Esquimaux Village, show single-shot registrations of frontal scenes of the games of leapfrog and snap-the-whip. The backgrounds consist in both cases of dwellings, in the first a tepee, in the second an igloo-like low building resembling the one in the first film.

These films make striking use of background. Tents are used as stage sets. They invoke the "natural habitat" of the people featuring in the films. The activities, significantly games and play, reinforce this image of "everyday life among the Eskimos." The release title for the last two films is therefore meaningful because these films make clear how the larger category of "the village" is really what is on display here.

In the later fiction film [PANTERKat,De Moedige IndiaAn] Panthercat, the Brave Indian (c.1912, Kalem) the museal diorama display is invoked by the use of a fake backdrop and a staged scenery which shows the emblematic and generic domestic setting of a cooking fire in front of a cave dwelling. Also in Romance of THE Cliff Dwellers (1911, Edison) we can see staged settings of the cliff dwellings, including the emblematic diorama display of women with 
traditional headdress grinding corn on stones near the fire in front of their house. These two films are examples of the way the mode of display of museums and other forms of exhibition is taken up by film and adapted into fiction film. The combination of the ethnographically appealing otherness of the Western cultures - both Indians and cowboys - and the medium's suitability to show what they tell establishes a particularly close affiliation between the films of our corpus and the World's Fairs.

Again, the Midway - that epitome and supplement of the Fair - demonstrates just how close that affinity is. For, the feature it shares with film is the commercial aspect that is not so pronounced in the Fair as a whole. On the Midway the visitor can find more wonders, says the guide:

Located for the most part at the Western extremity of the plaisance are a number of attractions, some more or less valuable from an ethnological standpoint and others mainly of a commercial character. One of the most remarkable is the encampment of Bedouins, already briefly mentioned. It is popularly know as the Wild East show, and consists of a typical group of Arabs with their dromedaries and steeds, the men dressed in native costumes and armed with scimitars and spears. They parade along the avenue, chanting in discordant notes, and otherwise advertising themselves and their exhibits. Upon the fence of their encampment are crude paintings showing Arabian life in the desert, and within the enclosure Bedouins are living in their tents, with their wives and children, as they do at home. Here, also, the horsemen indulge in various games and contests of speed and arms, as with loud shouts they race around the course or run across it, ostensibly filled with all the emotions which possess them when ranging the desert. In close proximity to the Johore bungalow, already described, is a Brazilian concert and dance hall, in which the performers are somewhat gross looking Indian women. (880; emphasis added)

The so-called "Wild East show" puts these exhibition shows in close relation to the Wild West Show; clearly, "wild" calls for representation. The effect is that the idea of "the West" is expanded and now includes the East as well, and that the theatrical show comes to include the museal paradigm as adapted from the Exposition. We see a resemblance between these Arabian scenes and CHEz LES Tounkegs (1908, Pathé Frères), a partially identified film that we no longer know where it was shot. D But the images show us a camp-site, much like those ethnographic displays at Fairs and expositions. They show staged scenes of women in exotic clothing, a group of children playing, and a small child being examined for lice by its mother.

The ethnographic thrust spills over from the Fair into film. JAPANESE VILLAGE, shot at the Pan-American Exposition, is much like the Eskimo village films, for it shows a generic setting of a Japanese house, with a man and two boys doing gymnastic tricks in front of it. SPANISH DANCERs AT THE PAN-AMERICAN ExPOSI- 
TION shows dancers in full dress performing their dances in front of their living quarters. These various ethnographic nonfiction films are, of course, not at all "Westerns." Yet, I contend that it is for a large part the West, source of ethnographic knowledge, moral education, the representation of healthy life in the outdoors, and, perhaps most importantly, subject of instant nostalgia, that facilitated, indeed "naturalized" this generalization of the porous boundary between exhibition and film display.

A last feature of this complex of museality and film is also, specifically, derived from the World's Fairs. The ethnic "others" exhibited there were live people, asked to behave "normally," and thus show what they are. But inevitably, besides being passively on display, figuring in an exhibition acting out their own lifestyle, they also become actors. Hence, the aspect of performance is an important element of the exhibits. And performance is, of course, what actors do in films. Like the exhibits themselves, the films where such exhibits were recorded, then, are cases of "self-performance."

This self-performance is again especially intense when the subjects on display - and subsequently filmed - are precisely those inhabitants of the "Wild West" who evoke, not only their own alterity but simultaneously the recent history of the disappearance - the destruction - of what made them "other." Look at how the tour continues:

Elsewhere are several exhibits by North American natives. In the Winnebago Indian village are not a few tasteful articles of native manufacture, and within another enclosure is said to be the original log cabin of Sitting Bull. Near by are what purport to be relics from the battle field where General Custer met his death, while purely or partially commercial in character are the Ice railway and the display of French mosaics and spun glass work. There are also such special attractions as the captive balloon, and the California ostrich farm, the latter harboring some 30 birds. In this vicinity, and at the Western extremity of the plaisance are the Hungarian cafe and concert garden, and the grounds devoted to military encampments. The former contains a vaudeville stage, and on the roof are given the concerts which form a popular feature of the plaisance. (880-881; emphasis added)

In a single sentence - the one I have emphasized - we find a summary of imperialism, modernity and its commercialization of technology, and a "highbrow" artistic legitimacy

In this description the role of artifacts is evidenced in "tasteful articles of native manufacture" and "the original log cabin" puts the same emphasis on the ethnographic character of these objects as the ad for the film I quoted at the beginning of this chapter. Presented as particularly characteristic of the exotic other, when artifacts are made by "other" people, they are implicitly said to stand for "a way of life." Artifacts thus embody the other; they signify other- 
ness. And, again in the same vein as Kahn's enterprise, it is at the same time precisely the similarity that is underscored in the fact that the other has an everyday life. This ordinariness - this "family of man" aspect - is signified by the "domestic" artifacts such as clothing and pots and pans.

And this is exactly what Kalem advertised in the company's film Red CLoud (1908):

A splendid exposition of the primitive life of the Red Man, in which special attention has been paid to details of costumes, etc. ${ }^{7}$

Note the word "exposition." The last word, "etc.," is significant in that it implies not only the larger "collection" of all possible artifacts, the usual props, but also the train of effects, the synecdochical logic by which the artifact stands for the otherness and thereby defines the spectator in his own identity. As Barbara Kirschenblatt-Gimblett rightly suggests in an analysis I presented earlier, "[p]erhaps we should not speak of the ethnographic object but of the ethnographic fragment" (1998: 18). B She is discussing here two very different forms of display, the in-situ versus the in-context display, and the functioning of the rhetorical logic of the figure of metonymy and the aesthetic of mimesis in the case of the first:

The notion of in situ entails metonymy and mimesis: the object is a part that stands in a contiguous relation to an absent whole that may or may not be re-created. The art of the metonym is an art that accepts the inherently fragmentary nature. Showing it in all its partiality enhances the aura of 'realness.' [...] The art of mimesis [...] places objects (or replicas of them) in situ. In situ approaches to installation enlarge the ethnographic object by expanding its boundaries to include more of what was left behind, even if only in replica, after the object was excised from its physical, social, and cultural settings. (19-20)

In-situ is taken a step further in film. The "habitat" of what are basically fragments is extended beyond the walls of the museum or the exhibition space, and taken "on location." At the same time it is displayed in the narrow circle of the spectator watching. It is this specific representational form of metonymy-cummimesis that makes the Western such a typical document - epitome and supplement - of its culture and time.

The contemporaries were keenly aware of the continuity between exhibition and film with, especially, the West as the link. This is nowhere more explicit than in a description of RED CLOUd on the same page of the Kalem ad in Moving Picture World, where it is proclaimed:

No more fascinating theme is presented to the dramatist of to-day than the American Indian, the redskin of pioneer days. And the Indian is peculiarly adapted to the mo- 
tion picture drama. For we are able to show him in our wonderful camera, just as he is in his wild life on the plains. ${ }^{8}$

To end with a last contemporary document: the Edison catalogue gives a description of SHAm BATTLE AT THE PAN-AMERICAN Exposition in terms that pull together all the aspects of the common ground between the two media I have highlighted in this chapter:

On the closing day of the Pan-American Exposition, Saturday, November 2nd, 1901, a sham battle took place at the Stadium on the Pan-American Exhibition grounds, between the six tribes of American Indians and the United States Infantry stationed at Buffalo. The battle was most exciting and realistic, there being about 250 American Indians clad in their picturesque dress and fully decorated in their war paint. About half the Indians were mounted upon spirited horses. The attack was begun by the Infantry rushing the Indians who made a firm stand and succeeded in repulsing the soldiers. The scene is replete with charges and many hand-to-hand encounters. Most of the action took place close to our camera and the picture which we secured is excellent. The scene opens with a parade of the American Indians, which in itself is of great interest, the parade portion of the film consuming about 25 feet. $^{9}$

I have emphasized the "symptoms" of the communality. The wish to collect, in the sense of completion and ordering, extends to the wish to put on display. Display is a key operative in the construction of the master narratives that are emblematic of modern times (Hooper-Greenhill 2000: 24) with an investment in the past:

Museums create master narratives through acting both as the constructor of a present-day "reality" and through bringing into focus a memory of the past that (coincidentally) supports that present. (25)

National identity is a product of this construction. As a technology that enables this construction, film plays a similar key role and takes up where museums leave off. The kaleidoscopic discourse of the film program can help enhance as well as disguise or smoothen this effect.

The transition from record of actual museum exhibits in which actual people performed their own roles, to continuing the show on film sets and recording the performances of others, to films as virtual museums, is not difficult to imagine. The powerful camera is there to make the transition possible. But to further substantiate the Western subject as the content of the films, that camera recorded not only museum exhibits. It also went out to record Western shows as they were frequently performed in the cities. These shows are the subject of the next chapter. 


\section{Notes}

1. Ad for The Redman's Way (1912, Kalem). Moving Picture World I, 32 (October 12, 1907).

2. G.F. Blaisdell, "From the Observatory." Moving Picture News IV, 39 (September 23, 1911): 20; emphasis added.

3. For this and other definitions of museums see the website of the Department of Cultural Policy and Management of City University, London, at: http://www.city.ac. $\mathrm{uk} / \mathrm{cpm}$.

4. The digital virtual museum is a recent object of research in the field of museum studies. Particularly the new possibilities of the "docent function" of virtual museums, which makes a virtual collection a museum, are discussed by W. Boyd Rayward (1999).

5. Joost Raessens (2001) adds the "interactive mobilized virtual gaze" to the list, the same thing can apply to virtual museums.

6. Edison Film Catalogue. Quoted in the Library of Congress catalogue, Inventing Entertainment.

7. Moving Picture World III, 25 (December 19, 1908).

8. Moving Picture World III, 25 (December 19, 1908); emphasis added.

9. Edison Films Catalogue; emphasis added. Quoted in the Library of Congress catalogue, Inventing Entertainment. 


\section{Wild West Show}

[A]s the Western outfit returned, season after season, and the fame of Cody as scout, plainsman and hunter became more widely known, and the merit of his organization impressed itself more deeply upon the public mind, the patronage grew and with each succeeding year, the membership and service of the enterprise increased. For in truth, Buffalo Bill's Wild West and Congress of Rough Riders is no longer a mere entertainment. Its value as an educator, a pictorial teacher of the early history of the United States, stands today as a foremost factor in its magnetism and success. Col. Cody, himself, continues the center of interest. Although the years have whitened his locks, them [sic] seem to have had no appreciable effect upon his physique. His figure is still erect, commanding; his marksmanship is still excellent; he rides with the ease and grace of the early days; he throws the lariat with the skill of the prairie bred rider.

- Show World, $1908^{1}$

Pictures of the Buffalo Bill type will always be popular - the more so as that type of picturesque American vanishes into the past. - Nickelodeon, $1910^{2}$

As we have seen, Buffalo Bill's presence at the 1893 World's Columbian Exposition in Chicago was significant for the phenomenon that concerns us. As a show within this exhibition, it offers an emblematic example of the practice of showing that is so characteristic of the culture at the time. More specifically, his show there can be seen as a practice that mediated between two "subgenres" or variants of showing, between the longer-term museal spectacle that was the World's Exposition, but then devoted to the globe in its entirety, and the punctual spectacular show that, within that framework, represented that part of the globe referred to as the "Wild West." What better example of the exemplarity of the Western - showing the West - for the culture in which cinema came into its own, than this double-take on showing that Bill's act represented?

The historically and culturally specific viewer as inscribed in the films under discussion in this study is a cultural agent firmly anchored in her or his own time and place. The statement from Nickelodeon that serves as an epigraph for this chapter could not be more explicit in describing the viewer for which the material was shown. In a succinct manner it points out both the a-historical 


\section{Important Announcement}

Realizing that the day of the ordinary Cowboy and Indian picture has passed from public favor, a radical change has been made in the BISON COMPANY, and in the future nothing but

SENSATIONAL - SPECTACULAR - WESTERN - HISTORICAL - MILITARY PRODUCTIONS

will be released. To this end the entire stock company has been reorganized and new directors employed, the regular company now numbering sixty people. In addition we have leased from the Miller Brothers their

\section{Famous 101 Ranch Wild West Show}

Including the entire company of 350 people (riders, actors and Indians), together with their horses, equipment and paraphernalia. The BISON COMPANY is unquestionably.

\section{The Largest Stock Company IN THE WORLD}
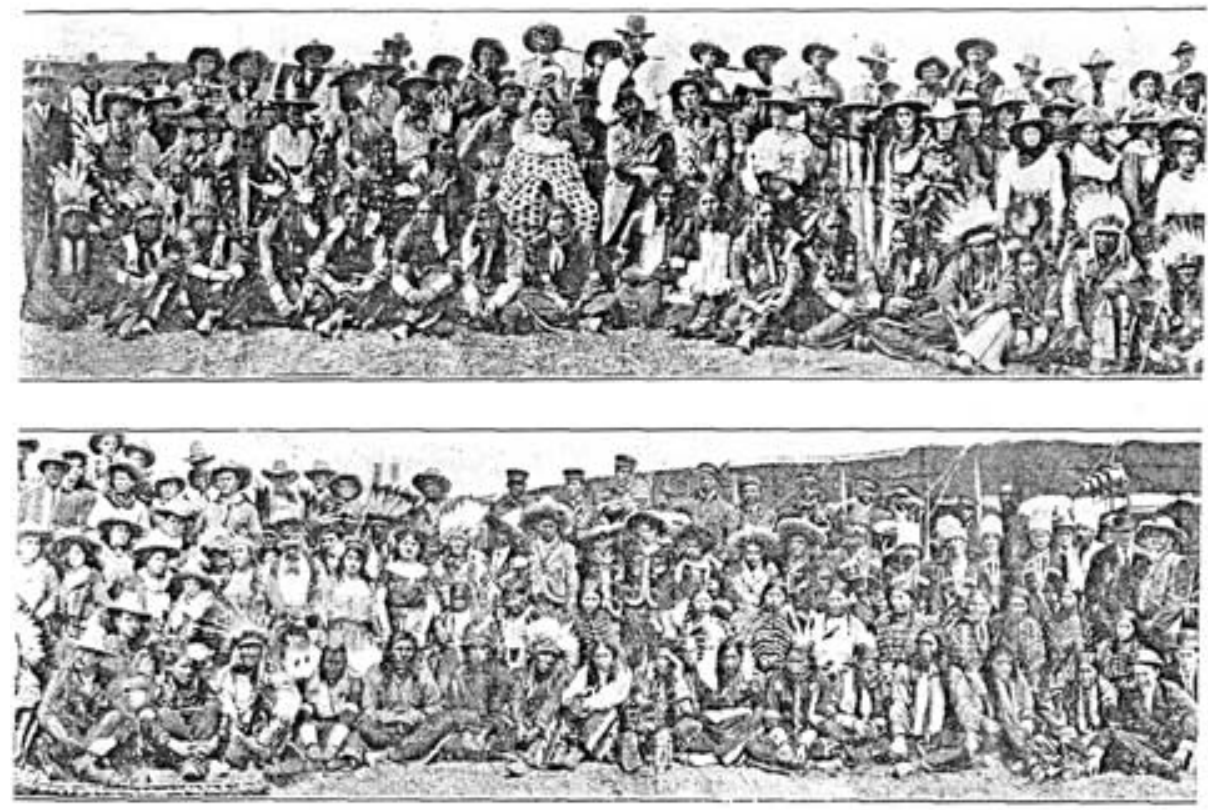

SOME OY THY ADDITIOSS TO TRY MHSOY sTOCX CONFAYY

The massive productions now being made will create a sensation wherever shown. We will begin releasing them in a few weeks.

WATCH FOR RELEASE DATES!

\section{NEW YORK MOTION PICTURE CO., 1 Union Sq., New York Gity}

W Bison's Wild West Show. Moving Picture News IV, 48 (December 2, 1911): 15 
dream of popularity characteristic of its time, and the motivation that clearly holds for the moment itself. As such, it could as well have served to usher in the previous chapter. And that is precisely the point in the present chapter. The link between these two - the ambition to collect $\mathbf{U}$ and to show $\mathbf{V}$ the world, on the one hand, and the cult of the West's wildness on the other - is one of the arguments for the emblematic status of what I must persist in calling "the early Western" in a cultural history of cinema at its earlier stages.

Lest this historical anchoring be considered a feature of our time looking back at a past "innocent" of this contingency, however, I am about to make a case for the opposite viewpoint. In order to draw a lesson from the films as such regarding the self-awareness of what they were and did, it is a different aspect I wish to foreground, in addition to, or superposed on, the construction of the chronotopically bound viewer. On the basis of material, elements of which I discuss below, I presume that the writer of this epigraph characterizes this viewer in terms of the appeal of show itself. This appeal, connected as much to education as to entertainment, turns a pseudo-ethnographic eagerness to show what life in the West was like into a key feature of the culture in which the Western could flourish, and which flourished to a greater extent thanks to, or in terms of, that Western.

Showing, so that you can see with your own eyes that which no longer exists: This miraculous experience is promised by the Wild West Show, and underlies the confident statement of the epigraph. It is also the promise of film. Hence, the filming of the Wild West Show is indeed a mise en abyme of the deep attraction of the films of my corpus for the culture in which they emerged and functioned. ${ }^{3}$ We have seen showing at work for seduction and entrapment, and for the generation of social cohesion in times of uprooting changes. But in the days of blooming positivism in philosophy of science as well as everyday life, showing also functioned as knowledge production and learning. Hence, show itself, as a medium, and experience, a cultural practice, is a particularly characteristic feature of (American) modernity. The show is such a popular form of theatrical exhibition because of the impossible fulfillment it promises. In spite of the generalizing naivety of his jubilant statement, the writer of my second epigraph appears to be self-conscious, perhaps even reflective, about the historically specific circumstances that, at this particular moment in time, conditions and creates the popularity of the Western that will be sustained throughout much of a century.

Under this assumption, I will continue in this chapter my examination of practices of exhibition. This time, however, it is not the positions themselves so much as the reflections on their construction as evidenced by the films; in other words, what I am after is a genuine "cultural philosophy" of vision in vision. I will examine this issue by probing the self-reflexivity in the films, under the 
rubric of "Wild West Show." The simple question is: what did the films look like, in terms of visual regimes of the time? ${ }^{4}$ More than that, though, my claim is a stronger one, which holds specifically for the incipient Western. As I will argue, in this respect the Western had its own specific cultural philosophy to offer, with its own, strong, and acutely felt appeal.

The reader will recall that emblematic events were the stuff of the film's narrative. $\mathbf{F} \mathbf{K}$ These events could be historically or ethnographically significant. Of a totally different order but emanating profound resonance with events of that kind, these could also be the show as such - as a phenomenon whose appeal was, at least in part, derived from its self-mirroring capacity; the show as emblematic event of the time. Such events were the likes of the rodeo show a show of a show, then, just as well as the hold-up, a paradigmatic event emerging from stagecoach and train travel. $\mathbf{R}$ Surprisingly, if one considers the spectacular nature of such events in terms of plot, the films put forward here stand out as different yet related, as commentaries on the spectacular itself. Shows showed films, but also, films filmed shows.

As it turns out, this simple observation is pregnant with significance. In the first place, self-reflexive films shot shows in a documentary mode, like journalism. But, in the second place, this journalistic presentation of shows could just as easily be faked for the purpose of, precisely, showing it. That is a small but important step that leads into a vertiginous maelstrom of possibilities. Instead of happening, shows could be staged for the sake of their recording. From faked shows to fiction is, again, a small step. Moreover, to complicate matters, films were elements in the show of which they also presented the recording. And vice versa: a "real" show was often an element, incongruously inserted, within a program of otherwise fictional films. The fundamental fragmentation of films, which we can now barely recognize as intrinsic rather than a flaw due to the limitations of beginnings, greatly facilitated this dazzling alternation of levels of documentary and realism, semi-fiction and overt fiction.

The result of this fragmentation is here considered in the mutuality, the reversibility of the cultural fact of the show and the astonishment, evidenced by this self-reflexivity, before the possibilities offered by the medium to fixate the show's inherent transience. By that capacity, the medium resolves a great dilemma, between direct perception conducive to the thrill of presence, of witnessing, and retrospective knowledge of that which derives its attraction from its state of (recent) loss. This self-reflexivity can be construed as a culturally specific attitude that, fugitive as it might appear, cannot be dismissed as just a side effect. Rather, it characterizes a crucial aspect of the cultural absorption of new experiences, including the paradoxes they contain. I offer the notion that the phenomenon of "showing the show" questions on yet another level the possibility to understand the corpus as more than just film only. Meanwhile, this phenome- 
non also further questions the evolutionist model through which the corpus has been traditionally understood. Last but not least, it provides the genre of the Western with a specific cultural mission that no other genre is able to fulfill in precisely this way.

Wild West Shows have been discussed earlier. K S In this concluding cluster, where my historiographic principles are taking the lead over the snippets of history-writing that was mixed into earlier analyses, self-reflection, often alleged to be characteristic of our postmodern times, serves as an emblem of the historiographic position this study is advocating. ${ }^{5}$ My first examples were the 1894 Edison kinetoscope films of Buffalo Bill's Wild West Show, that focus on such show performances as Buffalo Dance, Sioux Ghost Dance, A Bucking Broncho, and ANNIE OAKLEY (1894). I wish to complement these examples evoked earlier with other footage from the show, not to investigate the Wild West Show itself, but to interpret in a slightly new light those aspects that I discussed as the "spectacular" elements of Westerns.

In 1910, Nickelodeon announced a film made of Buffalo Bill's Wild West show. I quote this article in full, because it not only tells us about the content of the film, as well as the program of Buffalo Bill's show, but it also frames this film with sentimental investment. ${ }^{6}$ Instant nostalgia is evidenced when the author emphasizes the exceptionality of the film. I emphasize phrases that indicate selfreflection in their enthusiastic expression of instant nostalgia:

The motion pictures recently produced by the Buffalo Bill-Pawnee Bill Film Company have already made a tremendous hit, and the makers say there will be a great demand for the films, which are photographically excellent. Col. Cody has been known across the American continent as Buffalo Bill for little short of fifty years, and the films will perpetuate him not only in the minds but before the eyes of his myriad admirers.

At Madison Square Garden, New York, the Associated Press and prominent newspapermen tendered Col. Cody a farewell banquet, the public realizing that it was its last chance turned out en masse, filling Madison Square to the roof.

It was the last chance to see the old scout in person, but the enterprise of others have made it possible to see Buffalo Bill again - exactly as he is on the moving picture screen, surrounded by his valiant troupe of wild Westerners and Pawnee Bill's gathering of notables from the far east.

Every scene has been photographed and is as life-like as if you joined the sweltering crowd and jammed your way into the crowded tent on the road. These pictures are the only ones in existence and it is claimed no more will ever be taken of the old scout. ${ }^{7}$

Then follows the program, which I also quote for the extraordinary variety of items within which the show of the show is embedded. Here is the program as it is shown in 3,000 feet of film ${ }^{8}$ : 


\section{A Grand Review}

The World's Rough Riders, introduced and led by Buffalo Bill (Col. Wm. F. Cody).

U.S. Artillery and Cavalry Drill.

The Buffalo and the Famous Huntsman in pursuit of his native game.

The Prairie, under a scorching sun - "Oh! What a good drink; pass it around."

Mexican Joe will illustrate the use of a lasso.

Perfection of High-school Equestrianism. Mr. Ray Thompson's Mixed Blood Texas Range Horses.

Mr. Rhoda Royal's "Famed Blue Ribbon" thoroughbreds.

Rossi's Musical Elephants.

Riding Wild Bucking Horses and Mules, introducing the only lady bucking horse rider in the world.

Buffalo Bill Shooting Glass Balls.

Arabian Acrobats.

Japanese Troupe.

Devlin's Zouaves.

A Grand Military Tournament.

Football on Horseback, between Indians and Cowboys.

The Far East.

Trained Arabian Horses.

The Final Salute! Buffalo Bill Bids You Good-Bye.

Here we can see spelled out how history and representation are conflated in the Wild West Shows. Celebration and a form of re-staging of the past, which through the person of Buffalo Bill and the other "authentic" Westerners - or Easterners for that matter - maintains the vitality of actuality. It is as if the occasion of this "last" performance comes to stand for a second closure of the frontier - one that people can actually attend, in the present. The fact that this was not at all the last performance of the show is ignored here; the point of the piece is that it will hype the film more if the show were believed to be the last. Film's ability to record rare or singular events is here accentuated to invoke a nostalgic and spectacular framing of the show as well as its filmic version. The film follows the structure of the program of the show. The film is structured in scenes that correspond to the acts of the live performance.

The variety of items in such programs facilitates a realization of what we would now call interdiscursive mixture or heteroglossia. ${ }^{9}$ Where units from different genres were shown in one program, relations among genres were more evident than they would be today, when one feature film is seen in isolation. For example, in the announcement of "McMillan's Indian Show" in Nickelodeon, the strong bond between vaudeville, Wild West shows, and film is mentioned: 
Fred H. McMillan is preparing to put another Indian show upon the road. The Cherokee Blanch show met with such unbounded success that steps have been taken to duplicate the show. Moving picture managers have taken to the Indian show with great enthusiasm. It takes the place of vaudeville and is of a higher class than the usual vaudeville seen in moving picture theaters. The public seems to look on it as a welcome change, and by changing the pictures every day the show is well worth seeing more than once. The show consists of Cherokee Blanch and her shooting specialty, and other Indian dances and singers, and 2,00o feet of film showing scenes of Western and Indian life. ${ }^{10}$

Not only is this noticeable interdiscursivity part of the jubilation about the medium's unheard-of capacities, But an altogether different kind of mixture also demonstrates the wide cultural basis for this enthusiasm. Vaudeville as a genre would not have accommodated the incorporation of the Western show into it or the other way around - if the new genre hadn't had sufficient cultural recognition.

As we have seen, parody is a meta-genre that confirms the integration of a genre as cultural commonplace. $\mathbf{Q}$ The phenomenon, or genre, of the spoof is only possible - would only be deemed worth the production costs - if the primary, parodied genre is widely known and appreciated. Thus a comedy about little kids who imitate a Wild West Show, such as Buffalo JIM (1914, Vitagraph) testifies to the popularity of that which it mocks. But this popularity is not only that of Buffalo Bill nor of film or even of the Western, but of the self-conscious conflation, or superposition, of the show of the one in the show facilitated by the other.

The film is quite funny. It shows an attack on "cowboys" by "Indians," "Buffalo Bill" performing tricks, and a "parade" of Buffalo Bill on a donkey. Key ingredients of Wild West shows are used, demonstrating a keen sense of what was considered "key" enough to allow for parodic imitation. These elements are repeated, but with the comical effect of having a little boy as anti-hero play the part of Buffalo Bill. Of special relevance for this chapter, the film also comments on the practice of filming shows. It is a form of self-consciousness about genre and multimedia conventions that I observed in more films in this period. The variant of kids playing grown-up parts of famous movies was already established in 1905 when children robbed a train in The LITTLE TRAIN Robbery (1905, Edison). This example demonstrates that the widespread popularity of the object of mockery is a condition of the genre of the spoof. It is well known that the theme of The Great Train Robbery (1903, Edison) was well rehearsed by 1905 in American popular culture. ${ }^{11}$ Clearly, without common knowledge, first of trains, then of them being robbed, this film would not even be understood, let alone as a parody. One of the means of the spread of this knowledge, 
besides oral testimony, sensational popular press, and other forms of unofficial knowledge, is that other new popular invention, film. A film about children playing cowboys-and-Indians is Injuns (1913, Powers). Its title, mocking the child's way of imitating a "typically" cowboy way of pronouncing the word "Indians," already echoes its thrust and suggests self-reflexivity on more levels than one.

Let me stop at the "detail" of children. As in the case of The Little Train RоввеRY, children turn up as a device for self-reflection, first of all in the simple sense of imitation, of mirroring. But I propose to present these films also as a foil for another case, in which the self-reflection is more than just a slightly mocking mirroring of the model. For, I have been struck by the simple fact of children playing grown-ups, and that such imitation is so comical. Commonplace dismissal needs to be eliminated first. We might tend to think that children fit nicely with the medium's and the genre's "childhood." But, come to think of it, children don't just imitate grown-ups; thanks to the aesthetics of parody, they mock them, thumb their noses at them. This simple fact harbors a profound paradox that can further illuminate and specify the kinds of self-reflection at stake in this chapter. Therefore, the role of children will return, but with a twist, at the end of the following analysis.

The Library of Congress preserves part of the footage of this film in a 1960 compilation, called Buffalo Bill's Wild West Show (1960, Blackhawk Films). It consists of material from different films about the Buffalo Bill show. ${ }^{12}$ I use it to elaborate levels of self-reflexivity and their intricate interrelations for a reading of this compilation. The intertitles of the 1960 print announce: "1907 Bailey died. Pawnee Bill bought his share, merger of Buffalo Bill's Wild West and Pawnee Bill's Far East in 1910. Footage of 1910 performances, as it was presented in a movie the Wild West Show produced that year." Let me give a description of the 1910 footage of this compilation that provides enough detail to give a sense of the mixture of self-reflection and straightforward show:

The opening title, with a photograph of both characters in the middle of the frame, says: "Buffalo Bill's Wild West and Pawnee Bill's Far East. Part One. A Grand Review."

We see a camping site, a meadow with tents on it. Benches filled with people on the sides. A parade of Arabs in dark garb, including unveiled women, walks along the tribunes, from the upper right to the lower left, diagonally cutting through the frame. After turning a corner just outside of the image they ride from left to right closely in front of the camera. One of them waves to the camera. Elephants mounted by women in fitted dresses and hats follow them. ${ }^{13}$

Waving to the camera is an obvious instance of self-reflection, even if this occurrence is often a simple sign of naivety, as in ethnographically inclined films 
about Indians, albeit unclear, even there, whether the sign is a symptom or a signal - a fact of documentary or of fiction. ${ }^{14}$ But on a more subtle level, the movement of the horsemen, from a realistically convincing angle when they pass by the tribunes to the emphatic closeness to the camera later on, could be interpreted as a kind of visual "boasting," a display of daring shooting comparable to dazzling showmanship.

The next shot is also revealing:

The camera has changed position. It stands behind a rope or railing. From the background in which the tents can be seen, half-naked Indians gallop forward, spears raised. An Indian with feather headdress follows. Behind him, another row of Indians comes to the fore. Each time they wait until the next group races along. From another spot but in the same manner we see yet another group galloping by. Are they figuring a group of "Rough Riders"? Indians stand on the sideline. The camera returns to its previous standpoint. Buffalo Bill passes by. A row of Cossacks stands in position. We return to the initial standpoint, with tents and tribunes. Indians stand in rows. A man carrying a flag comes along, followed by Buffalo Bill. They ride up to the middle of the frame, while the camera pans along, a bit to the right. Intertitle: "Ladies and Gentlemen, permit me to introduce to you the Congress of Rough Riders of the World" allegedly the words of Buffalo Bill who talks solemnly to the public, taking off his hat. The words "End of Reel One" written in a different typeface, indicate the intervention of the 1960 compilers.

To be sure, the changes in camera standpoint and angles are ordinary signs of filming, more visible to our eyes accustomed to extremely sophisticated smooth techniques. But the changes coincide with figurations in the parade itself. Alternating takes of standing and riding figures form a theatrical backdrop for the self-consciously spectacular appearance of Buffalo Bill himself. And when, much in the mode of a circus master, the latter takes off his hat and takes on a subservient role by introducing his company, the build-up of the sequence represents him as the provisional climax. Precisely for this reason, I claim an aspect of self-reflection here. For the showman whose solemn presentation is the denouement of the spectacle, and as such, is very much put on show, shows his company. The crucial moment, in other words, is the moment of showing the show.

The next sequence is titled "Riding Wild Bucking Horses and Mules introducing the Champion Lady Bucking Horse Rider of the World." Again, I describe it in detail.

The camera faces the gallery of tents filled with spectators. Wild horses enter the frame, roped by cowboys on horseback. There are also some Mexicans in traditional, or rather, stereotypical garb. Some trivial things are being done here and there, the scene is visually a bit messy, some men mount wild horses. A few times someone 
climbs on a horse. Buffalo Bill on horseback is looking on at what appears to be a series of stunts. The messiness is strange. Everyone seems busy doing something. They help each other and look on. They look at each other, not at the public, but the public is shown looking at the spectacle. After a while a woman is shown, riding a pony of some sort. The camera pans along with the horses that run away. In close-up someone saddles a horse. This happens right in front of the camera. Suddenly the horse rears.

The messiness of this scene might at first sight - and from a condescending, anachronistic perspective - appear pointlessly chaotic. The events are nearly impossible to film anyway, and the sequence is too short. There is no composition; a wild wavering of attempts interspersed with takes of horses running off. The sequence appears to be lacking in point as well as in aesthetic unity.

But what if that is precisely its point? Catching wild horses is extremely difficult, the sequence shows. Hence, it shows it in all its difficulty - including the difficulty of showing such a show. If Buffalo Bill had not been looking on, the shot of the on-looking public might have passed unnoticed. But with the manager of the show shown to be watching the show, calmly, along with the public for which he is, precisely, performing, something else is expressed. The show leader is also the leader of the show we are seeing. The chaotic quality of the sequence signifies, by its messy visual aesthetic, the chaotic life of cowboys and their heroic efforts to calm the horses, civilizing the West into the bargain. Thus conceived, the sequence is highly self-reflexive.

The following sequence is titled "U.S. Artillery and Cavalry Drill" and shows the following:

Soldiers gallop along the tribune and the tents, as well as the camera. A cannon on wheels accompanies them. The cannon is detached in front of the tribune while the soldiers ride on, exiting the frame. A minuscule shot is fired in the direction of the public on the tribune. Horses transport the cannon away. The cavalry comes along. Suddenly the men collectively dismount. Their horses lay down on their sides, then stand up and storm away. They ride along again, in pairs. One out of each pair jumps off his horse and back on again. They make rounds. Each time they enter the frame at the upper right and ride past the public again, each time performing a different stunt. For example, they stand up on the back of two horses.

Shooting a film, shooting at the public: recording a showing is again made to appear in parallel, so that one becomes a metaphor of the other. The point of the cannon may well be to suggest the kind of fighting the civilizing mission entails, but why shoot at the public, if it isn't for the parallel? The public must be truly thrilled to experience even the dangers of the Wild West, albeit with the reassuring wink of miniaturization. 
In this sequence, another aspect of the self-reflexive aesthetic can be detected: Repetition. Clearly, the "real" conquest of the West offered little by way of regularity. Through the circus-like parade of the same men entering the frame time and again, just as they would enter the "real" stage in the "real" show, the reiteration of the rounds, combined with the variation of the stunts, foregrounds the aesthetic of regularity in a show whose fictional plot contrasts with its execution. This repetition, then, foregrounds the fact that the show is put together for show. The limited reach of the filmic frame, like the limited space of an arena, drives this point forcefully home.

I end my analysis with a final scene, introduced by the later compilers, acting as historians. This is the scene where the child as figure of mockery returns to illustrate how self-reflection can be considered both as a multi-layered device for genre definition, and as a source for the cultural historian willing to take out of the notion of "early" arrogance of evolutionism. Intertitles from the 1960s tell us that "Pawnee Bill and his wife celebrated their 25th wedding anniversary in 1910. It was on that occasion that this scene of the entire cast and staff of the Show was taken." As I will argue, the final event adds yet another layer to the self-reflexivity that puts the show on show:

The camera faces a large group of people. The group fills the frame entirely. The camera pans to the right as if to maximize available space. All types of people circulate in mishmash, women as well as men, Cossacks, hussars in uniforms, men in business suits, cowboys, Indians, Mexicans, everybody waving and acting busy. The camera pans in the other direction. Suddenly I spot a Japanese-looking woman, a kind of geisha with fake breasts on the outside of her dress. This figure stands out as the obscene version of the dress-up party. And while all these people do nothing but act busy in a merely chaotic gathering, in the foreground two cowboys imitate a rodeo, one riding on the back of the other.

It seems fitting, although in full awareness of the intervention of the 1960 compilers, to see in this last fragment a doubling of the theme I have foregrounded in the previous sequences. This wedding anniversary party echoes in a comic mode some of the elements of the "real" show of the "real" show. The different costumes are here no longer in the service of any of the three layers of imagination involved in the preceding sequences. They neither re-stage the real conquest - the historical event evoked - nor the stylized version of the show as it was performed by Buffalo Bill's company, nor the self-conscious filming of that show, where the requirements of the medium were turned into devices for boasting about its capacities.

I have mentioned before, on the basis of the quote with which I started, that Buffalo Bill's "lasting appeal" was attributed to his emblematic function of making the irretrievable past present. This miracle, which fulfills the culture's hun- 
ger for fodder for its instant nostalgia, is not just Buffalo Bill's achievement, but that of the medium itself. Bill's show, then, is more than an example; it is a conflation of show and the show of the show. By ending the compilation with the wedding anniversary, the 1960 compilers have foregrounded something that the 1910 sequence already demonstrates in and of itself. The entire company attending the party in their working costumes, acting out in a festive mode what it is their job to do every day - acting - make fun of any illusion that might remain that filming past events, situations, costumes and customs, is a matter of realism.

The messiness of the party, with its jumble of costumes that rupture the homogeneity of illusion, recalls the sequence we have just seen in which capturing horses became too difficult to film aesthetically. This is, in a sense, a film crew run wild - or the entire enterprise of filmmaking displayed in its "real" messiness. It shows the underside of illusion. But in order to probe the role of childhood, I would like to turn to the two men playing cowboys. Or do they?

On one level, the two cowboys, playing - show - cowboys, playing - fictional - cowboys playing real cowboys, might seem to embody our own little boys who, today, are still playing cowboys. This matches the evolutionary model. That it should be children who turn up, this time in the bodies of adults, however, draws attention to the complexity of this act. The men don't play "like" children. They play children playing adults. And while we are at it: they play children playing adult men playing cowboys. They play, like their children, and on their festive day off, they act, as they do every day, albeit it without the master-director's critical eye thrust on their performance.

Two topics for thought suggest themselves here: evolutionism and play. The scenes of men imitating children show them slipping up in their earnest everyday task of holding up adult manhood - something the Western is invested in reconfirming as well as probing. ${ }^{15}$ Acting, in this sense, can be defined as holding up culturally imposed masks, in an earnestness that fits in. But playing, they abandon themselves to the appeal of shedding that mask, and honoring, instead of mocking, the child within them. For while acting is a profession, play is a need. We know this, both on the level of culture (Huizinga, Homo Ludens) and on the level of the individual. ${ }^{16}$ I would speculatively add, here, that playing cowboys was especially gratifying as it conquered the fear of failing - manhood - and the fear of losing - the vanishing West - by allowing the dream of men being up to the task of being men. This adds another nuance to my thesis about the complex and multiple reasons for the specific cultural success of the Western. Play, then, is not what children do, but what people want to do and children, but not adults, are allowed to keep on doing, so that children "save" adults from an irretrievable loss. 
This brings me to the other topic that imposes itself whenever we tend to see, in this silly act at the wedding party, something like a mirror image of the "early" Western as "immature precursor" of the classical Western. This train of thought would focus on the two men's childishness as something our culture wrongly attributes to the past by considering early Western the predecessors of, or in a childlike state in relation to, the classical Western. At the time these events took place, primitivism was the trend in high art in Europe, and, a generation or so after Darwin, Freud became the emblematic thinker of evolutionism. He is still taken to task for his conflation of phylogenesis and ontogenesis, which lies at the root of primitivist and evolutionist thought. Attributing to children the question that grounded psychoanalysis, "where do children come from?" he was unable to see how he was mirroring that question when asking: Where does all this - the psychic makeup of man - come from? He needed to find an origin.

Origins, however, presuppose development, and are at risk of simplifying history by seeking single answers. ${ }^{17}$ For our time and its confrontation, staged here, with early modern culture, another contemporary, working at even greater distance from the culture of our films, might be a more adequate source of inspiration. Russian philologist and philosopher Mikhail Bakhtin did not search for single answers but was interested in mapping plural causalities and sources, not origins, much in the way I am seeking to establish in this study. Bakhtin's key concept is dialogism. ${ }^{18}$ From the point of view of this concept, the children playing adults playing cowboys - and, of course, as the final layer, the filmmaker filming this play - do not imitate but rather respond to cultural sentiments that are borne on the air they breathe. And the camera filming - hence, showing - the men playing children playing men playing cowboys are inevitably, albeit most likely unconsciously, involved in responding, dialogically, to a variety of ideas, ideologies, aesthetics, and needs that permeated the culture in which this messy wedding celebration took place.

Hence, if I may take this case as an allegorical enactment of my endeavor in this study, on another level than that of children growing up and becoming men who become children again, this innocent act of playing at acting, its aspect of showing off and being on show, can be seen differently, outside the paradigm of evolution and origins. I see it as a relative of unspecified generation, of the postmodern probing of fiction that explodes all realistic illusion from within, because that illusion carries with it so many others, which foreclose what the culture, then, most desired, and what our culture, now, wishes to understand. And if they are having fun at it, playing this game at the wedding anniversary of Mister Wild West Show himself, this is, just like wedding anniversaries themselves, an act of honoring the fact that everything that happens in history has a way of disappearing and of returning, in a different mode of cultural presence. 


\section{Notes}

1. From the Philadelphia bureau "Quaker City Theatricals." Show World II, 21 (May 16, 1908): 10. Found in the papers ("clippings and printed matter") of the George Kleine Collection, LoC.

2. "New Buffalo Bill Pictures." Nickelodeon IV, 7 ( October 1910): 203.

3. For a definition of this term - briefly, a summary of a text within the text - see Lucien Dällenbach's The Mirror in the Text (1989).

4. For the concept of historically specific visual regimes, I recall the publications by Martin Jay (1988) and Jonathan Crary (1990), already cited.

5. See, for example, Linda Hutcheon (1980) and (1988).

6. As before $\mathbf{N}$ the term framing is to be taken in the specific, theoretical sense as proposed by Culler (1988) in his deployment of Derrida's Truth in Painting (1987) for literary study.

7. “New Buffalo Bill Pictures." Nickelodeon IV, 7 (October 1, 1910): 203; emphasis added.

8. 3,000 feet would mean 44 minutes of viewing time at a projection speed of 18 frames per second. See Cherchi Usai (1994) for film measurement tables.

9. Heteroglossia - the mixture of different discourses coming from different social strata - is a term coined by Mikhail Bakhtin. For Bakhtin's ideas, see especially The Dialogic Imagination (1981).

10. Nickelodeon II, 4 (October 1909): 131; emphasis added.

11. See Musser's convincing argument (1984) about this. Steve Neale (1990) uses Musser's case of The GREAT TRAIN RobBERY in his argument for a new historiography of genres.

12. Included are: Parade of Buffalo Bill's Wild West Show 1 and 2, (1898 Edison); Buffalo Bill's Wild West Parade (1902, AM\&B); Buffalo Bill's Wild West and Pawnee Bill's Far East, part 1 (1910, Buffalo Bill \& Pawnee Bill Film Co.).

13. The shot does not match the intertitles: "The World's Rough Riders introduced and led by Buffalo Bill, (Col. Wm. F. Cody)." This could be an error in sequence or a later mistake. The reader may be surprised that here and elsewhere, I may present my description of the footage as if it were a quotation. I do this to drive the point home that descriptions are one of many strategies of representing the past, the object, and quotation another. Quotations, in other words, are no less cast under the spell of subjectivity than descriptions.

14. The distinction between signal and symptom comes from the American philosopher Charles S. Peirce, founder of semiotic theory. A signal is a sign voluntarily emitted by the sender - like a handwave for greeting - whereas a symptom is involuntarily emitted but interpreted by the receiver as a sign - like a meaningless gesture interpreted as a greeting - or like red spots for measles. See Peirce as quoted in Bal \& Bryson (1991).

15. About this aspect of the masculinity of the cowboy, see Peter Verstraten's Screening Cowboys: Reading Masculinities in Westerns (1999) and Peter Stanfield's Hollywood, Westerns and the 1930s: The Lost Trail (2001). 
16. This was particularly elaborated by the psychoanalysts of the so-called object-relations theory. See Winnicott's Playing and Reality (1971), particularly “Transitional Objects and Transitional Phenomena" (1-25).

17. For an analysis and critique of Freud as exemplary thinker of his time, I wish to refer again to Torgovnick's Gone Primitive (1990).

18. See Todorov (1984). For an excellent analysis of Bakhtin's relevance for cultural history, see Hirschkop and Shepherd, eds. (1989). Dick Leith and George Myerson (1989) write the following about Bakhtin's interest in the idea of "linked practices" instead of "Grand Theory or Great Virtuosity": "what makes 'dialogism' a master concept is how Bakhtin uses the idea to formulate laws of genre, including laws of historical development" (149). 


\section{X-Rated}

The first "crime picture" thrown on the screen makes it plain why children should be kept out. The police claim that several crimes in the city have been directly traceable to these pictures. It should be stated that the moving pictures, as given in these days, principally represent the following equivalents:

The travel essay or sketch. The melodrama and farce. The dime novel. The "crime films" are simply the old-fashioned dime novels in picture form.

They should be repressed by the police. The train robbers, of which there are legions of films, aren't very harmful because train wrecking isn't a tempting crime. - Moving Picture World, $1908^{1}$

Children's play is not only envied, admired, and celebrated, but also the site where culture is most vulnerable. There is always a touch of danger when children are involved: the dangers of "bad influence" of film and/or dime novels that threaten both when they show and when they tell popular fictions of the Wild West. In the previous chapter I analyzed the "play" aspect of putting on a show, playing a role, and imitating adventures and tricks. Here, the focus will be slightly different, but only a small step away from "play." The focus is now on the practice of cultural surveillance, an attitude of public vigilance when guardians of public morality prick up their ears in the face of allegedly dangerous influences of what is now copycat behavior, rather than joyful re-enactment.

Yet, the two seem to go together: Where there is play, there is protest. In 1911, Moving Picture News published the article "Wild West Pictures" in which the editors of the magazine protested against the kind of Wild West pictures that were put on the screen. They wrote in response to the many letters that had been sent to the editorial board. Claiming to speak for the public, they declared:

The public is getting utterly sick and tired, utterly disgusted with the bad photography, the illogical stories, the poor acting, the general shooting and hold-up, that is being illustrated in these Wild West pictures, and, with the exhibitors, we feel the time has come when some stay should be made in thrusting these subjects before the public. $^{2}$ 
Although the terms in which this injunction is cast sound innocent enough aesthetic, that is - what we have here is, in fact, a call for censorship. Further bolstering my claim that these early days were already after-days, details of the elements considered offensive reveal a great deal about the cultural sentiments toward the new medium's representations of Western subjects. The enumeration of aesthetic flaws thinly disguises worries about what has sneaked into it in the middle: the representation of violence. ${ }^{3}$

The fact that the Western films touched a particular sensitivity also becomes clear from exclamations of outrage before what made these films special; the way they represented "the other" of the Eastern urban public. The same article finds the Western films offensive to the people actually living in the West:

Not only are the wild west subjects absolutely incongruous, but they offend the better taste of the Western people, the settlers in Western towns, and all who are trying to uplift the industry from an educational standpoint.

Speaking here is the voice of an educational vocation, with a hint of patriotism and a touch of communitarian humanism, praising the national virtues of the settlers in the critique of their representations. Educationalist, almost missionary in tone, the editors take their own educational mission as a standard for all cultural production, and focus on film as an influential medium par excellence. Indeed, making films is implied to be a privileged opportunity to do something valuable for the nation. Unfortunately, filmmakers appear indifferent to their calling. The opportunity missed by filmmakers to make interesting, educational films about the West is a shame, according to the editors, who continue their proclamation as follows:

If it is necessary to produce Western subjects, let them be produced with an elevating, uplifting story, so that some lesson may be taught in the production.

There is a certain acute ambivalence here: violence and force function as elements that have made America great, but at the same time the uplift discourse seeks a new level of civility, particularly in regard to immigrant and young populations who have yet to be "cultivated" and civilized. This ambivalence plays out in the tensions between "realism" and "morality." These remarks on the uplifting potential of the medium and the educational task of cinema are infused with an impassioned tone of seriousness that demonstrates how great an investment was made in the cultural value of the medium. This sentiment fits right into the debate about the respectability of film of the period.

In this chapter I am interested in the conjunction of the distinctive cultural value to which the medium aspired, and the kinds of offenses - against taste, morality, and other values - that were scrutinized and potentially, as we could call it, "x-rated." In the case of Westerns, some specific objections were made, 
for example, to the violence - a predominantly moral issue - and to a lack of realism in the depiction of life in the West - primarily an aesthetic, but also an ethnographic issue - both concerns that reveal some intriguing public opinions. But beyond classifying the kinds of issues that sparked controversy, I am also interested in negotiations that spoke through the discussions in the press, regarding possibilities for improvement. In the case of violence this is obvious: not only were the dangers of violence in movies a motivation for criticism, but also these dangers enticed writers to come up with suggestions for improvement. These are instances of a kind of indirect public intervention. The diffuse, but nevertheless organized interaction between filmmakers, moviegoers, newspaper readers, and journalists was an arena for the dynamic process of public life. Hence, an examination, however succinct, of this dynamic belongs in a cultural history of film.

To stay with the first example, in the next issue of Moving Picture News, which appeared a week later, a follow-up to the November 18th piece was given in the editorial. This new installment was provoked by the many letters the paper had received in response to the article of the previous week. The authors make a point of clarifying their ideas more explicitly and taking back some of their original objections. The tone is a little apologetic in the beginning:

It was not, nor is it now, our intention to place every Wild West picture under the ban. There are a few that come up to wonderfully good power both in dramatic and photographic art. [...] While thanking our correspondents for their kind remarks, we want them to fully understand that we like a little Western drama, and have no intention of condemning all and sundry, because it is more than possible that good, remarkably good subjects can be made showing Western life as it is to-day. ${ }^{4}$

The conciliatory tone allows the writer to slip in what is, apparently, beyond questioning: the concern for realistic representation ("showing Western life as it is to-day").

But realism is surely not a mere aesthetic standard. Immediately after this initial concession, the piece continues with an injunction in which the writer clearly demonstrates what really is the primary stake in this concern for realism:

The only elimination we ask is the degrading influence that the bad cowboys have upon the younger element. If Western pictures must be given, let them be of an elevating educative trend, something that the people will look forward to and receive with delight, something that will teach a good lesson and not leave a bad taste in the mouth with so many hold-ups, murders, and shootings; then we feel sure they will be received with pleasure and all objections will be removed from these films in the future. 
Phrases such as "degrading influence," "elevating educative trend," and "teach a good lesson" are expressions that speak to moral, educational values. Realism seems to have disappeared from the agenda, unless we must assume either that the reality depicted is sufficiently educational in itself, or that good teaching requires realistic, truthful representation. These values constitute the cultural content the writer is concerned with. But this content is also subject to rhetoric in the sense of persuasion: It must be accepted. To this issue, phrases such as "receive with delight" and "not leave a bad taste in the mouth" speak emphatically. Entertainment and instruction, utile dulce, an age-old combination, are still going strong. While the Western comes up for educationalist scrutiny, the discussion the films triggered, in turn, partakes of the genre's cultural after-effect.

In previous chapters in this cluster I investigated practices that enhanced the "positive" - and also positivistic - or celebratory aspects of Westerns, aspects that may have played a part in what Abel (1998b; 1999) has called the "Americanization Project" of Early Westerns. Nationalism, universal ambitions, historical interests, collection, preservation, and display in films about the West, are all issues that take part in establishing a (relatively) positive image of American history and present that goes so well with the "spirit of the West." I already examined some contemporary criticism, and the reader will have noticed discursive elements in those fragments I quoted that point to similar issues of moral and aesthetic worry. Criticism on the varying degrees (or forms) of realism, the negative portrayal of Indians and other Westerners, the crudeness of some film plots, the wearing out of conventional stories are concerns originating from a variety of positions. However, these critics demanded an improvement in filmmaking, specifically a better portrayal of the West and its inhabitants; they did not question the Western as such in these moral and aesthetic terms. On the contrary, Westerns were generally regarded as a good American national product, the only "red-blooded," or "natural" films that fully used the vital capacities of this wonderful new medium.

There were, however, also voices that questioned the Western as such, in its own "properties," and examining such responses in the press is an indispensable supplement in our endeavor to assess the Western in its own culture. This is why criticism is at the core of my analysis here. The other voices - those of pessimism and fear of the medium - are here represented in order to be heard, for these voices also belong to the culture under examination. I attend to the warnings of people who saw a mission for the medium that was being ignored by contemporary filmmakers, opportunities missed while cheap sensationalism threatened good, honest, and morally right virtues. I will not go over the debate of actual censorship here; I am not so much interested in specific regulations, 
legislation, specific cases of censorship, industry policy, and the like. Others have done this very thoroughly already. ${ }^{5}$

My focus here is, instead, on how concerns of the time about the possible good and bad influences of film play a part in the production and reception of Westerns. As has already become clear, in the analysis of the contemporary press it is often more important to read between the lines than to foreground the explicit criticisms. For it is in the unstated assumptions that cultural values are most significantly embedded. From the sample just quoted it has already become clear how people thought Westerns were supposed to portray life in the American West (or life on other historical frontiers of civilization) and how films failed to meet these implicit, but culturally powerful goals. In previous chapters I already invoked the contemporary voices to explain the choices that were made. The corpus of analysis here is constituted by the great number of commentaries in the press about the pernicious influences of film as well as its responsibilities. The target of the concern was, predictably, the most vulnerable group of patrons: children.

X-rated is a term used in a later period of film history by boards of review and of censors in America to designate films that are not suitable for children. This American rating system was used from 1968 onwards to judge films' suitability for viewing by children. " $X$ " meant that no one under 16 was to be admitted. This rating was later changed to "NC-17" to distinguish the films with this rating from pornographic films. Rather than being mandatory for exhibitors, ratings were used as guidelines, specifically directed at parents. ${ }^{6}$ Although this term was introduced much later, it was born out of the same concerns that we hear in these early samples, and that have governed public debate throughout film history. Classical Westerns may not have been considered dangerous or immoral by definition - in the way, say, that soft pornography would have been - nevertheless early films about the West could be a cause for concern. Specifically the portrayal of outlaws and physical violence was considered an extreme form of the "sensational" qualities already found in dime novels and the stage melodrama. This resulted in a concern about copycat behavior or, perhaps even more serious, about the degradation of "good taste."7

The warning about the "degrading influence that the bad cowboys have upon the younger element" in the Moving Picture News quoted above is a concern often expressed in the press. In 1908, Moving Picture World illustrated its concern for bad influences on children with an anecdote that is explicit in its theme of copycat behavior:

A moral to exhibitors to censor their films, or at least prevent children from witnessing sensational subjects is contained in the following, which is taken from a column article in The Waterloo, IA, "Reporter": 
'With minds inflamed with scenes of robbers and the Wild West depicted by moving pictures, Charley Jepperson, Tommy Falkenstein and Myron Killerlain, the first aged ten and the other two nine, started out to emulate the lives of the heroes as they had seen them thrown on the theater screens. [...] Their capture nips in the bud a plan the three had evolved to live as desperadoes. The boys claimed they had frequently seen the moving picture machine throw out views of bold robbers to hold up people and get away safely, and their young minds were inspired with a desire to live the same kind of lives." ${ }^{\prime}$

This fear of copycat behavior, as expressed in anecdotes like these in trade journals, illustrates a kind of sensationalism rather than a real concern. In fact, the sensationalist tone is reminiscent of the stories about the hazards of filmmaking as described in previous chapters. $\mathbf{L} \mathbf{R}$ However, in more serious cases, films were actually censored or banned from the screen, as happened with the film The JAMes Boys IN Missouri (1908, Essanay). In The Bioscope Essanay advertised the film (see figure $\mathrm{X1}$ ):

James Boys In Missouri. Famous American Outlaws. An historically correct interest holding story from beginning to end. Not requiring a knowledge of the careers of those famous bandits to be understood. replete in terrific scenes, Full of dare-devil rough-riding. See it and you will order it. ${ }^{9}$

When this film, together with THE NIGHT Riders (1908, Kalem) was pulled from the film program by the Chicago police, the exhibitor who showed the films, Jake Block, appealed to the court. In his defense he claimed that the film portrayed American history and was not morally objectionable. The judge, H.M. Cartwright, however, pronounced that, even though it was true that

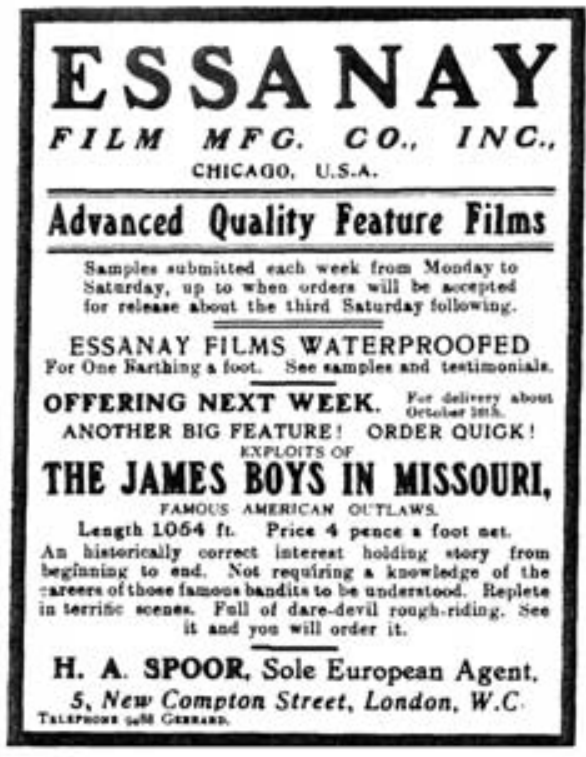

X1 Essanay ad for The James Boys From Missouri. Bioscope I, 153 (September 16, 1909): 20 images "representing the career of the James Boys illustrate experiences connected with the history of the country," this did not mean that they were "not immoral." "Pictures which attempt to exhibit that career necessarily portray exhibitions of crime, and pictures of the Night Riders can represent nothing but malicious mischief, arson, and murder." The court judged that the films were 
"immoral" and that their exhibition "would necessarily be attended with evil effects upon youthful spectators."10

While the exhibitor had also stressed in his defense that, besides telling stories that were based on historical reality, the films were also based on respectable theater plays, this was not an argument to which the judge was susceptible. ${ }^{11}$ In fact, the court expressed concern about how nickelodeon theaters

on account of the low price of admission are frequented and patronized by a large number of children, as well as by those of limited means who do not attend the productions of plays and dramas given in the regular theaters. The audiences include those classes whose age, education, and situation in life specially entitle them to protection against the evil influence of obscene and immoral representations. (Quoted in de Grazia and Newman 1982: 178)

Such condescending arguments are the mirror image of those held by educationalists who argued that the uplifting potential of the medium lies precisely in this accessibility to - and impressionability of - the lower classes and the young. ${ }^{12}$

But then a powerful medium like this could indeed have these two opposed effects. In a piece about the "moral teachings by films" the author recognizes how film

if rightly used and if handled by the right sort of people, can be made an educational instrument of great service and a source of wholesome, uplifting recreation. [...] The young will learn more with their eyes in ten minutes than in a week with their ears. The eye gate opens almost a royal road to learning. [...] Why not make a good use of the moving picture, as some ministers have already done, to give sane and sanctified recreation instead of stopping with negative denunciation of the abuse? ${ }^{13}$

The straightforward logic that seeing evil leads to new evil, or seeing good leads to good for that matter, was - and is - a persistent sentiment. There was - and often still is - a special concern for the lower classes and the young together, supposedly because both, for the first time, could freely access cultural production, but also because both supposedly lacked (as yet) the education that would protect them from negative influences. This lack of education made them at the same time the ideal target audience for the educational value of film.

The financial access argument had been heard before. Before, and coinciding with the advent of film, the cheap dime novels such as those about outlaws like Jesse James had met the same criticism. W. B. Lawson's dime novel, called Jesse James, the Outlaw: A Narrative of the James Boys, was the first issue of a series published by Street and Smith Publishers in New York, called "The Jesse James Stories: Original Narratives of the James Boys." New York: Street and Smith, 1901 (see figure X2 $)^{14}$ 


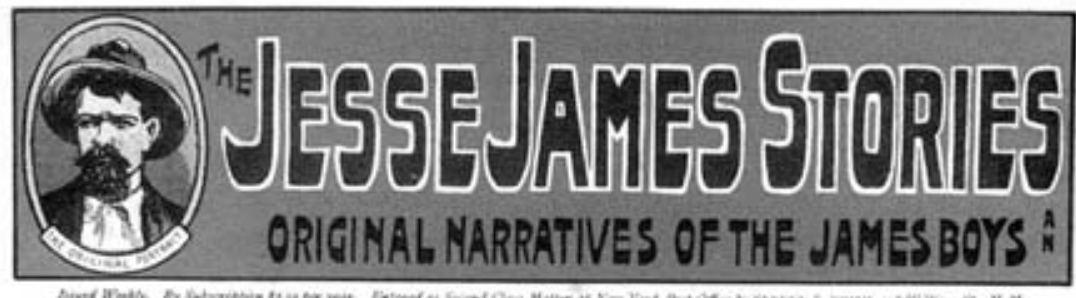

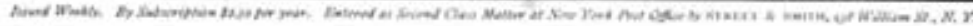

No. I. Price, Ten Cents.

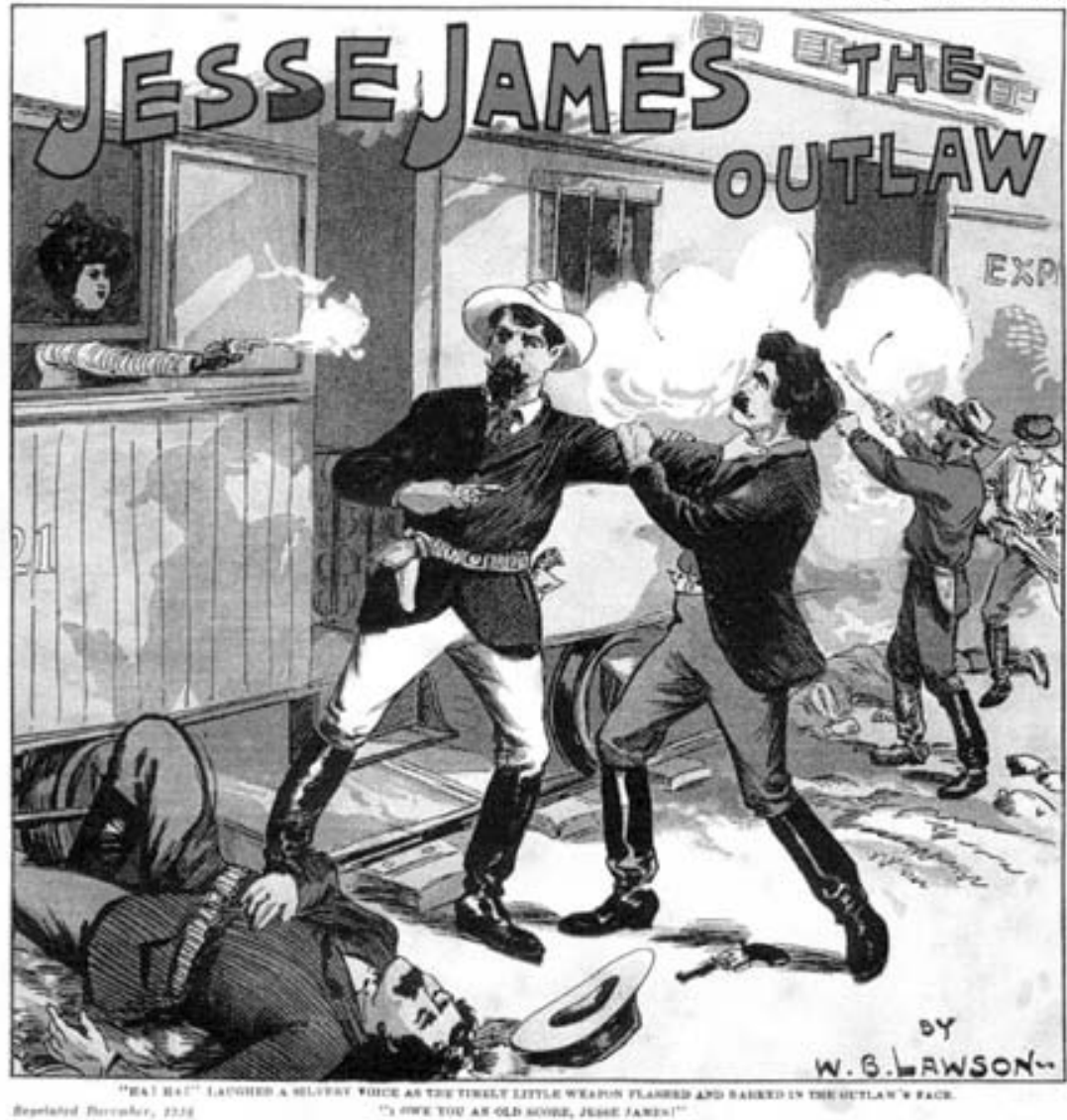

X2 Cover of the 1901 dime novel Jesse James, the Outlaw, published by Street \& Smith, New York

According to Kent Steckmesser in A Literary History of the American West (1987) "public pressure" apparently caused the publishers to cancel the Jesse James series in 1903: 
Ambivalent attitudes toward the outlaw are revealed in these stories, the clearest examples being those about the James brothers. Such publishers as Frank Tousey and Street \& Smith issued numerous "James Boys" titles, and the portrayals vary from the villainous to the heroic. Early issues frequently depict Jesse James as a murderous enemy of society, who deserved his death at the hands of turncoat Bob Ford. But then the writers transform him into a saintly do-gooder. In this role he is seen paying off farm mortgages, bouncing children on his knee just before bank robberies, and saving young women from lustful "bad" outlaws. He also becomes the traditional avenger, finishing off the cowardly Pinkerton detectives who, in bombing the James farm, had injured Jesse's revered mother. However, the moral issues involved in depicting outlaws in a favorable way are ever-present. Indeed, public pressure seems to have caused both Tousey and Street \& Smith to terminate their respective James Boys series in 1903.

In 1907, the same year that the movie about the James Boys was released, Charles M. Harvey complained about "bad" dime novels in one of the nation's leading magazines of the time, Atlantic Monthly:

Are not more crimes perpetrated these days in the name of the dime novels than Madame Roland ever imagined were committed in the name of liberty? It looks that way. Nearly every sort of misdemeanor into which the fantastic element enters, from train robbery to house-burning, is laid to them.

But these offending books must be only base counterfeits of the originals of their name. When the average American of fifty years of age or upward hears about dime novels he thinks of Beadle's. They were the first and the best of their order. Although nearly all of them bubbled over with thrills, they were not of a character to provoke breaches of the peace. For a few years they had a great run, incited many imitations, all of a lower grade; and at length, after suffering a gradual deterioration in quality, dropped out under the competition. Many of Beadle's original novels deserved the social and financial conquests which they won. ${ }^{15}$

In this and other similar commentaries - a characteristic of all times, it seems we can read a nostalgia for better days, the earlier dime novels that were "the first and the best of their order." This sounds much like the moralizing criticism of Westerns that we saw above.

But the relationship between dime novels and Western films was not one of simple analogy. My earlier comment about the need for something to be widely recognizable for it to be worth mocking holds here as well. The fears of and warnings about the destructive influences of violent dime novels were made fun of in the movies. These films seem to be based on a humorous commentary on similar types of film criticism and censorship. For example, TERRIBLE TeD (1907, AM\&B) is a comedy about a little boy's dream about being a bandit from 
the West after reading a dime novel Western. In the Biograph Bulletin the film is described (see figure X3):
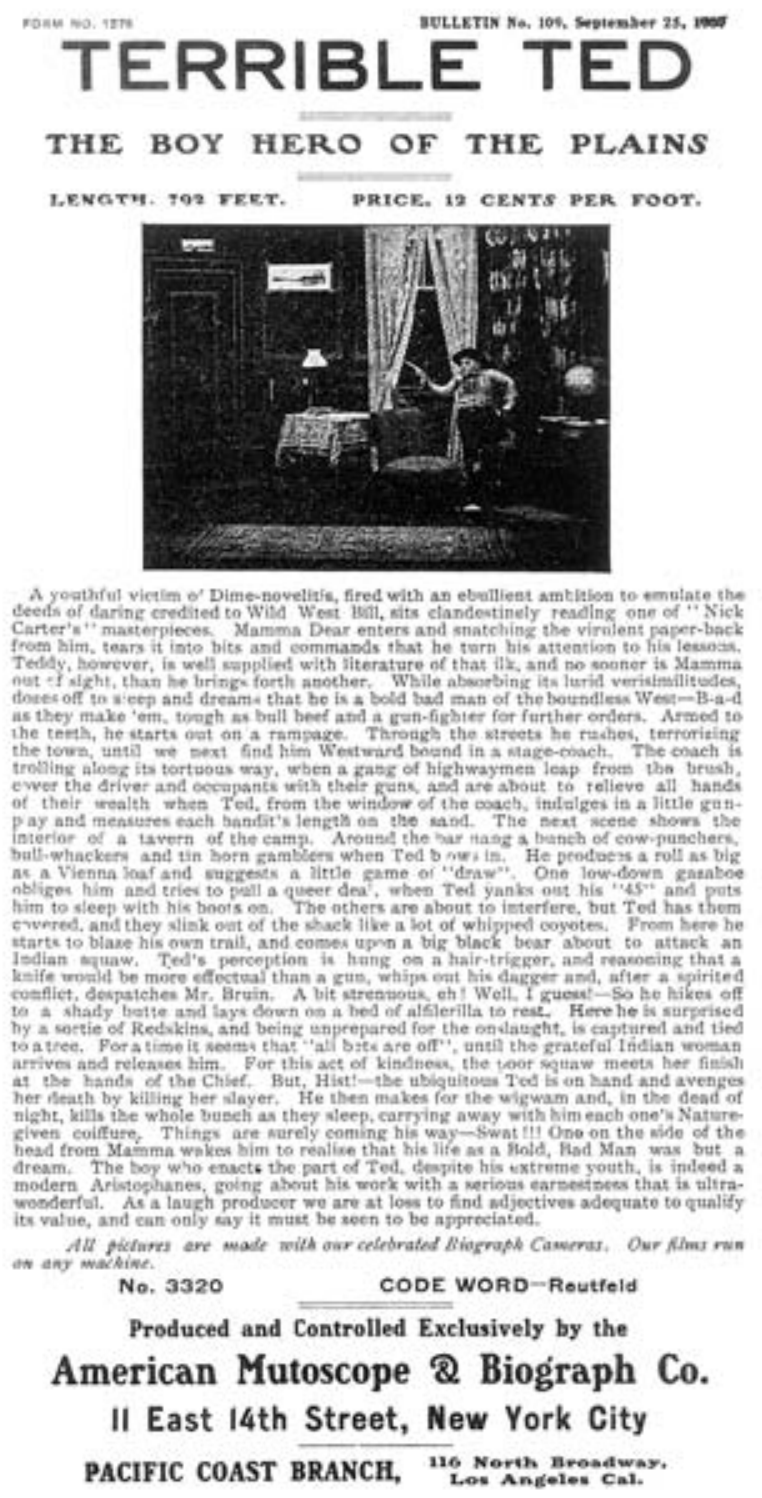
Terrible Ted: The Boy Hero of the Plains. A youthful victim of Dime-novelitis, fired with an ebullient ambition to emulate the deeds of daring credited to Wild West Bill, sits clandestinely reading one of "Nick Carter's " masterpieces. Mamma Dear enters and snatching the virulent paper-back from him, tears it into bits and commands that he turn his attention to his lessons. Teddy, however, is well supplied with literature of that ilk, and no sooner is Mamma out of sight, than he brings forth another. While absorbing its lurid verisimilitudes, dozes off to sleep and dreams that he is a bold bad man of the boundless West - B-a-d as they make 'em, tough as bull beef and a gun-fighter for further orders. Armed to the teeth, he starts out on a rampage. Through the streets he rushes, terrorizing the town, until we find him Westward bound on a stage-coach. ${ }^{16}$

If children are the primary target of the critical concerns, the published criticism, meanwhile, stages specific groups of viewers and ascribes to each of these specific representational "tasks."

Consider, for example, the clear-cut gendering of the viewers represented as performing on the cultural stage, in the following case. Audience response to The JAMes Boys IN Missouri is described as follows:

During the past week that disgraceful film, "The James Boys of Missouri," was run off at one of the city theatres. Although we were not present at the time, the news reached our ears that many in the audience had hard work sitting still throughout the ordeal. It is said that women in the audience arose with exclamations of "Oh, I can't stand this any longer!" and 'This is too much for me!' Said our informant, "You couldn't imagine anything very much worse; from murdering the landlord up to wrecking a train, it was all there; and the photography was about as bad as the picture. And then," continued the gentleman, "to cap the climax, after the killing of Jesse James, his brother seeks a pardon from the governor, and after refusing and sending the man away, the governor is shown as sending again for him and handing out his pardon with a promise from him to the effect that from then on he will live the life of an honorable citizen." it does seem rather Utopian to suppose that a man with such a long repertoire of crime could possibly be brought to look in a civilized way upon life. However we hope the picture will be permanently tabooed by the authorities. ${ }^{17}$

Firstly, the terminology that distinguishes "women" and "gentlemen" already points symptomatically to an underlying class division. The women don't speak; they "exclaim," as if on the verge of hysteria, and what they have to say is emotional and negative: “Oh, I can't stand this any longer!" and 'This is too much for me!' Clearly, this writer is not just on an educational mission for children, but wishes to save women from their own emotional vulnerability. Unless, of course, women are (like) children. The gentleman, in contrast, provides 
the reader with a clear summary of the offensive section of the plot, supplemented with a political analysis - albeit an ironic one - when he says: "it does seem rather Utopian to suppose..." and calls for social action, for censorship to be precise: "we hope the picture will be permanently tabooed by the authorities." Most importantly for an assessment of gender roles in this case, the gentleman is the spokesman who is responsible for the rendering of the women's reactions. The passive voice "it is said" yields to "said our informant" who then turns out to be "the gentleman."

The point of this division seems to be to distribute the relative weight of the arguments among people with specialized cultural authority. Women are supposedly the caregivers and custodians of children when it comes to emotional life. If they cannot stand the film, the piece appears to imply, how would our children remain balanced in the face of such violence and criminal behavior? On the other hand, the gentleman is the peer of the authorities who have the power to ban the film, for the good of the children and women alike. Hence, his quoting act has a legalistic flavor: his role in the piece is to present evidence before the imagined judge.

Censorship is not only a legal instrument for getting rid of allegedly offensive material. The presence of the institution of censorship in a given cultural milieu is an instrument for adjustment in and of itself. Censorship stands, therefore, on the same level as the press, the public who can come or refuse to come and by paying for a ticket, support the industry, and the industry itself, sensitized to the public's approval. This generalized participation in cultural life of the sheer existence of censorship is evidenced, and never more clearly than when, as sometimes happens, positive reviews by censors were used to promote the quality of films. Very similar to the defense of the exhibitor of JAMEs Boys OF MissourI, in Moving Picture News the argument for a correct depiction of history is used in the following announcement:

Something in the way of a novelty in censorship took place a few evenings ago in the projecting room of the Republic Film Co., when the management invited a number of ministers, settlement workers and educators to review the picture of Daniel Boone, recently produced by this firm [...]. After the picture has been thrown on the screen and the guests made thoroughly acquainted with the story, all with one accord made the statement that if the film companies would only put on such historical pictures and with such accuracy moving pictures would soon become the greatest actor in the education of the coming generation. [...] It behooves the other producers to sit up and take notice as this picture is not alone of value to the people who have the advantage of education, but to those who have no advantages of learning other than an evening spent at the picture houses. ${ }^{18}$ 
This self-promotion with a helping hand from the censor touches a fine sensitive note in its last words. The slightly condescending attitude toward the poorer layers of society speaks through this touching concern for those who have no opportunities for learning other than going to the movies. The suggestion, here, is that workers who had little education as children and no time at present to catch up can thus benefit from viewing uplifting films, a notion very much present around the turn of the century, and which we have already seen above. Such workers are better off, the journalist implies, at the movie house than at the drinking house. Opposite the gentleman, then, stand children, women, and workers whose well-being he charitably promotes.

Film as a tool for education of the future citizens, including the future settlers: This is the most important example of good vs. bad influence. In the case of Westerns the critiques go back and forth. Historical accuracy is regarded as good, but the depiction of criminal behavior, of outlaws, and the like as bad. Confusingly, crude and fake depictions of the "real," actual, and contemporary West are also an offense. Instead of "the truth, the whole truth, and nothing but the truth," cultural censorship seeks to limit the truth to the good truth, and nothing of the rest of it. From there to claiming that only the good is true is but a simple step.

\section{Notes}

1. "Moving Picture Shows as They Appeal to Our Critics - the Public." Moving Picture World II, I (January 4, 1908): 4-5 (5).

2. "Wild West Pictures." Moving Picture News IV, 46 (November 18, 1911): 6.

3. This kind of surveillance coming from within the culture, not from the powers that officially control it, can be considered a form of self-censuring. Foucault (1977b) would see this as a discourse of control internal to what it censors, here, the film industry. This Foucaultian view is the more apt as this is a moment of transformation within the film industry, where self-regulation becomes established through various national boards of review. These emerged in response to criticism in the press as well as explicit political pressure.

4. "Wild West Pictures." Moving Picture News IV, 47 (November 25, 1911): 5-6.

5. See Uricchio and Pearson (1993), Kevin Brownlow's Behind the Mask of Innocence (1990), and Lee Grieveson's Policing Cinema (2004).

6. See Robert Sklar (1993): 422-423.

7. These two concerns are still very much present in today's film reviews and debates about public culture. For instance, in the Netherlands the "Kijkwijzer," a recently (2001) instated classification system for the audiovisual sector, uses icons to indicate six different categories of "dangerous" or morally objectionable content that films, television shows, or computer games may contain: violence, sex, foul language, drugs, discrimination, or frightening contents. Also age recommendations are gi- 
ven: adult guidance for children under six years, no admittance under twelve or under sixteen years old.

8. "Emulate Wild West Men and Robbers Seen in Moving Pictures." Moving Picture World II, 17 (April 25, 1908): 369 .

9. The Bioscope I, 15 (September 16, 1909): 20.

10. As quoted in Edward de Grazia and Roger K. Newman (1982): 179. A full account of the court case is given there on pages $177-180$. For reference to this case and specifically the argument of the representation of historical reality, see Grieveson (1999): 295 .

11. It is relevant to bear in mind that Chicago had already censored stage versions of Shakespeare's Macbeth or Julius Caesar. See Uricchio and Pearson (1993): 93-95.

12. Specific concerns regarding children were also voiced in the articles "Children and the Picture Show" Motography VI, 6 (December, 1911): 271-272, and DeLysle F. Cass, "Higher Education and the Motion Picture." Motography VIII, 3 (August 3, 1912): 97101. Of course, this is not an exclusively American concern. In the Netherlands this debate was also active. See for example Cor Schuring "Bioscoop als kinderopvoeder (ster)" in De Bioscoop-Courant III, 71 (February 12, 1915): 16-17, a letter sent to the magazine, in response to another letter about the bad influences of the cinema (on children), in defense of the medium.

13. "Moral Teachings by Films" Motography VI, I (July 9, 1911): 5.

14. For an electronic reproduction of this dime novel and other titles, see the online version of Stanford's Dime Novel and Story Paper Collection at: http://www-sul. stanford.edu/depts/dp/pennies/home.html.

15. “The Dime Novel in American Life." Atlantic Monthly 100 (1907): 37-45 (37).

16. Biograph Bulletin 109 (September 25, 1907). Reprinted in Moving Picture World I, 30 (September 28, 1907). The title of this film may well have been a humorous reference to Terrible Teddy, the Grizzly King (1901, Edison), a political spoof about Theodore Roosevelt.

17. “The James Boys' censured by Audience." Moving Picture News IV, 38 (September 23, 1911): 19. Since this was published three years later, it is not clear if it is about the Essanay title from 1908 or about another version.

18. Moving Picture News IV, 51 (December 23, 1911): 19. 


\section{Young Wild Women}

Miss Pauline Bush, the new leading lady in our Western aggregation, is doing some of the best work, in her particular line, ever projected on the moving picture screen. On account of the peculiar class of our pictures, Miss Bush is invariably cast in the character of a Western girl - a cow-girl. This characterization is a hard one, as it is necessary that the lady impersonating the various characters used be a perfect rider, courageous, pretty, and withal an extremely good actress. - Moving Picture News, $1911^{1}$

A popular member of the Western company is Miss Betty Harte. She will be
remembered for her work in an innumerable series of pictures in which she
took the part of a boy - not a girly boy, but a real boy. Endowed by nature
with slender form, lithe limbs, a boyish face and frank, unabashed manner,
she is well equipped for such roles and plays them with great spirit.
Dressed as cowboy girl or society heroine she is equally good - a versatile
actress indeed.
- Motography, $1911^{2}$

The issues mapped out in this chapter, which is the last analytical one, serve to take or tie up one important loose end left in a number of earlier chapters. It concerns the tension between stereotyping and the inherent self-deconstruction thereof. For example, in $\mathbf{R}$ type scenes were related to the visual possibilities of the medium and its place in modernity. In $\mathbf{M}$ different meanings and manifestations of modernity were laid out. In $\mathbf{C}$ and $\mathbf{D}$ constructions of self and other were discussed in terms of representation, of space and of agents, respectively. In J the focus was on inherently unstable constructions of nation-ness in the French-American Westerns. Specifically in these last two chapters, $\mathbf{D}$ and $\mathbf{J}$, it became clear that representation is, perhaps by definition but at least in the films under discussion, self-defeating in its thrust to construct a coherent image of otherness. Yet, the deconstruction of such images of otherness presupposes that their constructions in the films, in all their inherent contradictions, are nevertheless appearances or embodiments of the cultural presence of such images - tokens of a type. It is to this cultural presence that I will now turn. I will use the theme of gender to further strengthen my case that film inherently self-deconstructs the categories it puts forward. As a consequence of this argu- 
ment, the very concept of cultural presence, so strongly and widely informed by the notion that films - as distinct from, for example, museified art - impose a coherent vision of otherness and in particular, of women as object of the male gaze, becomes untenable, yet indispensable. It becomes a theoretical fiction. ${ }^{3}$

To demonstrate this point, I will first assume a division between action and character, although the tenuous nature of that division has already been argued $\mathbf{N}$. The provisional and untenable division serves to show how film itself, as a visual producer of images and a narrative mobilizer of the images it produces, cannot help but open up a space in which rigid cultural divisions fall apart. Here, then, types of characters, type-characters, are conceived as bearers of cultural stereotypes, while simultaneously facilitating the films' undermining of those social categories. There is a narratological reason for this almost inevitable undermining. Stereotypes are reductions of individuals to a feature or a bundle of features. Narrative, in contrast, deploys individual agents in action and movement. As a result, the reduction soon arrives on shaky grounds.

The types of the cowboy and the Indian are, of course, well documented. ${ }^{4}$ But when it comes to an equally rigid social codification such as gender, we also see such types of characters as the action girl, young children, especially girls, who participate in the plot, and serial queens; tomboys, "amazons," and other women endeavoring to go outside the gendered and ethnic world assigned to them. If considered semantically and visually, that is, in their defining features and characterizing looks, these figures would appear to conform to stereotypes. If, however, their narrative mobility is taken into account, the stereotypical characterizations fall apart.

For these type characters are, I argue here, always-already mobile. The reason for this mobility is that types cannot be maintained in narrativity. Yet their typicality is culturally necessary. On the one hand, types can only function as the cultural icons they seem to be if they are recognized by the large public that the films catered to. Hence, a certain level of stereotyping is indispensable. This is how myths emerge and function. But on the other hand, the narrativization the films implement also enforces a concretization of each woman "standing for" a stereotype. This narrativization challenges the very stereotyping on which it thrives. The Indian woman sacrifices herself; the white woman saves her boyfriend. The tomboy confined to the domestic sphere teases the outdoor cowboys out of their domain and enforces their endorsement of their share of domesticity.

We can see an example of this in Tомвоy on BAR Z (1912, Essanay). The "natural," girlish stereotyping of the daughter as home-bound, and therefore curious, necessitates actions that demonstrate that the girl is anything but confined to girldom. To do that, she must leave her home. The ambiguity here is that, although she leaves home temporarily, in the end the tomboy as figure is always 
pulled back. The heroine of Bar Z, a young woman who plays pranks on the cowboys working on her father's ranch boldly goes off with a charming young man. She is both courageous and naïve. She does not know that her new lover is, in fact, a wanted thief. She is not really at fault there, because she was simply not around when the telegram arrived about the thief, so she could not have known the man's real identity. The cowboys from the ranch catch up with the pair and arrest the thief. The ambiguity of the tomboy figure is played out in this story. Her stereotypical curiosity, bred by home-boundedness, propels her outside both home and stereotype. The fact that this is unconventional and not entirely acceptable, is clear when the added naïveté enables the men to take up the role of rescuers. When we attempt to understand characters in the early Westerns under consideration, then we are bound to analyze not just isolated figures or actants, but a knot of cultural frames, actions, and characters, which I will here indicate as character-plot knots.

These character-plot knots are paradoxical. They contribute to further stereotyping, but each instance inevitably shows an individual characterological make-up that counters the centripetal force of stereotyping. Thus, not only the confused and confusing culture of early modernity, not only the specific films of the kaleidoscopic presentations of the time, but the medium of film itself both confirms and undoes the stereotyping on which such categories as gender, race, and ethnicity themselves are based. ${ }^{5}$

Annie Oakley, already mentioned, enters the stage again as the question emerges: how much space is there, in the practice of the films, for women, and what kind of space? A theatrical nexus, the arena of the Wild West Show proved to be a place where Phoebe Moses (1860-1926) could take up her job, to perform as the exhibition's sharpshooter Annie Oakley in the show. She was one example of Eastern, urban women who went West, acting out a cultural desire for liberalization of the constraints of the division of labor within the household. Western women go East, representing the urban culture through the eyes of strangers. $\mathbf{C}$

These forms of migration and mobility have a parallel in, and are symbolized by, cross-dressing. There, dressing up as a man enables a change in gender roles. In this perspective, cross-dressing - both cultural and gender-wise - is a significant cultural practice. For example, in How StATES ARE MAdE (1912, Vitagraph) the wife of a wounded pioneer takes his place in a land-rush, or in THE CRAVEn (1912, Vitagraph) the wife of the new sheriff, a coward from the East who got his new job by bragging about heroic deeds that never took place, takes her husband's place when a bandit comes to town and has to be arrested. Moreover, in some films "taking up his job" is done in female dress as well. The practice of cross-dressing is not just a ploy for comedy. Cross-dressing, the visual variant of the transgression of fixed roles in the plot, can perhaps even be 
seen as an emblem of the impossibility of stereotyping - its self-deconstructive moment, while cross-dressing depends precisely upon stereotyping, on caricature, for its effect. The mobility of film's narrative is deadly for the attempt to fix. Combined with the mobility of the American society in which the West and the rest keep displacing each other, it provides the plots that demonstrate that inherent impossibility. This constitutes the beauty of what we can no longer call Westerns "early" but should maybe call "after Westerns."

Like the tomboy, the Western girl is a category that enables women to be morally good but physically "wild" at the same time. As I pointed out, crossdressing is not always necessary to perform stunts and to save the day. In the 1910s, serial queens, for example, could be found taking part in many different adventures, facing new dangers and adversaries in each new episode. ${ }^{6}$ Some episodes of these serials could take place in different parts of the country, in either the urban East or the rural West. In the serial Hazards of Helen for example, the episode THE PAY TRAIN (1915, Kalem) of which a surviving print is held by the Filmmuseum, is a Western-type railroad action film. The same can be said of RunAwAy ENGINE (1911, Kalem), which is a story of a heroic girl who saves her prospective father-in-law by boldly racing a locomotive to prevent the crash of the train in which he is sitting. In The Lonedale Operator (1911, $A M \& B$ ), the heroine holds off the thieves who want to steal the gold from the train station. Girl detectives solve mysteries and prevent train crashes, and Western women save their spouses from lynchings or hold-ups.

Although the more classical, sexually-charged, opposition of bad girl versus virgin is not dominant, different categories of women are portrayed and put in (unstable) opposition to each other. In many films female protagonists, fighting for justice, offer contrasting images of female character types set in opposition against each other. Two Little RANGERs (1912, Solax), a film which will be described more fully below, starts by putting the good but outgoing older daughter of the postmaster next to the villain's docile wife. Although in this particular example the latter is a victim of her abusive husband and not his accomplice, the association of women with criminal boyfriends or husbands occurs often enough. Such plots establish a division between "good girl" and "bad girl" that can be complemented by the category of the good "girly" girl next to the good "boyish" girl.

In A GIRL FROM the WeSt (1912, Vitagraph) the tomboy girl Polly has a naturalness of behavior, and, unlike her older sister, has physical contact with boys. She is seen playing with a lasso with some cowboys, while her older sister criticizes her for her boyish behavior and her contact with men. When the sister's boyfriend's horse is stolen, Polly not only chases the horse thieves but also fights off Nelly, the female member of the gang. Another example of good ver- 
sus bad girl, but with an ethnic twist, is THE RED GIRL (1908, AM\&B). In this film, a physically rough Mexican woman steals gold from a white woman. When the Mexican woman is being chased by villagers, she takes refuge with a white man and his Indian lover. The rivalry between these two women leads to the downfall of the thief and the redemption of the Indian woman. She assists the posse that is chasing the Mexican woman, who is captured in the end. The Indian woman and the white woman hug each other.

Although the number of films that feature female heroines is significant, it is not merely the presence of these action-women, or the possibility of this presence that is striking. ${ }^{7}$ It is the mobility that is crucial for an understanding of how early cinema culture dealt with gender. Mobility is significant on the level of choice: choosing to do this and not that, choosing partners, choosing to be married or not. The possibility to choose, and the actual choices made determine how the plot twists and turns. But also literally, mobility is a narrative motor on the level of physical movement. Women are staged not only saving their men, but using and risking their bodies to save them. When facing the physical dangers of the Wild, of the modern (trains), or the moral dangers of the (lack of) society, or the sexual dangers of the West (rapacious Indians and outlaws), the constructions of gender are also threatened.

Examples of this shaking of gender construction are legion. Emrich (1997) mentions Girls in Overalls (1904, Selig), produced by H. Buckwalter, a film that shows the seven Vidal sisters "doing the 'masculine' work of their ranch" (14-15). This film seems to have been a type of nonfiction that was very popular at the time: the interesting or spectacular "realities" that were sensational enough for entertainment. Seven women handling a farm on their own fitted the bill. Another film that Buckwalter helped produce in Colorado was THE BANDIT KING (1907, Selig), a short-story film starring G.M. Anderson before his departure to Essanay. Much like LifE of A Cowboy (1906, Edison), this film shows a kaleidoscopic summary of outlaw life in the West with, as key ingredients, two bank robberies, a stagecoach hold-up, a horse chase, a wanted poster, and a shoot-out. According to Emrich, rather than serving as mere love-interest, the role of the female lead is that of a true heroine, played by a local horsewoman called Pansy Perry. In the original footage she is shown riding her horse and rushing to the rescue of her lover (1997: 19). Unfortunately, the fragmentary copy in the Library of Congress does not leave much material for a reconstruction of her role in the film. Some other examples of films featuring wild women of the West include The Girl Cowboy (1910, Bison) ${ }^{8}$ and The Female Bandit (1910, Bison), which was summarized in Moving Picture World as "[a] melodramatic story of suffering, heroism, a female bandit holding up a coach, rescuing a child from a burning house and several other thrilling adventures" (Moving Picture World VI, 7, February 19, 1910). In A Tenderfoot (1911) the Western 
heroine teaches an Eastern tenderfoot the ropes of living in the West (Moving Picture News IV, 27, July 8, 1911: 16-17).

The 1912 Solax film Two Little Rangers, directed by Alice Guy-Blaché, stands out as the one film in my corpus directed by a woman - according to $\mathrm{H}$. Z. Levine of Photoplay Magazine "a striking example of the modern woman in business who is doing a man's work."9 The text from which I drew this portrait is interesting in its phrasing of stereotypes and its undermining of them. In this portrait of Guy's work the author not only expresses his admiration for her ability to perform this high-pressure job, but emphasizes that her female qualities did not suffer under this "manly" lifestyle:

She quietly moves about the plant, unostentatiously and unobtrusively energetic. She carries with her an air of refinement and culture, and her dark, modest clothes bespeak and emphasize her dignity. This dignity, however, never borders on frigidity. ${ }^{10}$

The reader who shares his preconceptions of what makes a woman a woman can rest assured that she is still soft but energetic, as her domestic role prescribes. She is still a good catch, refined and all. She is dressed according to the dress code of modesty, which guarantees that the underlying threat of immodesty, continuous with "harlotry," does not get a chance. The reverse danger, then? No, really, rest assured. Neither harlotry nor frigidity threaten the stable ideal of woman as housewife. But then, the abnormal element remains, to do its undermining work: Instead of moving about the house - an activity of which this is a perfectly adequate description - she moves, unsettlingly, about the plant. The exact fit between the description of normative conduct and what the woman apparently does in this worldly place makes the change effective in its undermining of the stability of the scene as "normal." In order to understand the cultural position of a film in relation to current standards, such fragments from the contemporary press are relevant material for analysis.

The character-plot knot in Two LiTTLE RANGERs, then. The film's story nicely demonstrates the tension between action and character. Two young specimens of the female gender, a young woman and her kid sister - eligible girl-in-love and pre-pubescent tomboy - begin their young lives on the screen by being confined to their home. Although "home" is already too unambiguous a term. The home is a shop-cum-post office, a liminal space between domestic and public, and the workplace of their father, the postmaster. Soon - there is no time to waste in this 13-minute surviving print - the outside world intrudes in the shape of, first, the older sister's beau Jim, a friend of the family, and then bandit Bill. As soon as the latter enters the shop the girl distrusts him, for no reason other than his later demonstration of evil. When Bill returns home, his bad marital skills produce a scream that attracts Jim who stumbles into the domestic 
misery and, threatening Bill, takes his wife out of his hands and house. She is taken in at the post office/home. Bill is not happy.

The subsequent transportation of gold by father and beau will be intercepted by Bill, who manages to toss father from a rock to his likely death, and Jim into jail. He manages the second part of this double feat by deviously planting the latter's knife at the scene of the crime. The situation looks as hopeless as that of such traditional, age-old mythical heroes as Joseph, rotting in jail by the devious use of just such a metonymic "proof" of guilt by the rejected wife of Potiphar, in Genesis 39. Here as there, the presence of a particle of the (visual) figure is taken to prove the truth of an action in the plot, through the deployment of a rhetorical figure - metonymy - that demonstrates the bond between figure and action on which the thesis of this chapter rests. ${ }^{11}$

This particular ploy - metonymic use of objects for dubious accusations - is traditional folk tale material. It produces a character-plot knot, which is necessary for narrative logic in cases where psychology is not the binding element. Conversely, it is only with the prejudice that all narrative ought to be psychologically realistic that readers today can fault older films and stories as well as material from non-canonical traditions for being "implausible." Attention to character-plot knots, therefore, is another of my concepts intended to help overcome anachronistic projection and focus on cultural projection, instead. Here, the ploy is indispensable. For without this confusing of categories, we would have no story - not unless the girls leave their assigned place and leave home and go out into the world, to take things into their own hands.

The older daughter, devastated by the danger threatening her beau, finds the knife, and thereby notices her father half lying on, and half hanging off, a cliff. Fortunately, she has skills other than being in love: she throws her lasso, and with supernatural strength, she pulls the old man up. Meanwhile, Bill tries to reclaim his wife, who refuses to return to him. This occasion facilitates recognition, by the saved and fast-recovering father, of his attacker whose shirt lacks just the bit of fabric that the father is still clutching in his hand. This narrative device is used frequently to purge characters of their guilt, often in the form of a last-minute rescue. In A Bit of Blue Ribbon (1912, Vitagraph), the female lead of the film rescues her falsely accused boyfriend from a lynching by identifying the actual horse thief through the guilt-betraying blue ribbon of his hat.

Whereas this ploy is generally productive of narrative logic, it has a specific relevance for the positioning of women inside and outside the home respectively. Like the knife, metonymic logic binds the domestic and outside worlds, just as it binds character and action. In Two LiTTLE RANGERS, the little sister challenges Bill, who flees after being mocked by a stock comical character who challenges his honor. Being threatened by a girl and losing his wife in the bargain is, after all, more than a "real man" can bear. Both the two girls and a posse 
of cowboys pursue the escaping criminal. When Bill deploys tricks - rather than masculine strength - to shake off his pursuers, his bad luck embodied by young wild women continues to plague him. He wades through the river to cover his trail, but the girls see through his ruse and, while the posse continues to our right, they deviate to the left, and find Bill. They thus force him to seek safety in a domestic place: an abandoned cabin. In this character-plot knot, the reversal of character-space stereotyping is complete.

But the denouement will show that this confusing of the traditional identification of stereotypical characters with particular spaces is unacceptable. The question is, to whom? To the logic of the film, is my assumption. Since psychology is not a meaningful framework with which to interpret this short film, I submit that we are better off resisting the temptation to attribute the ideological position to any one figure or function. The position that is demonstrated by the quick transformation of this reversal into something more culturally commonsense is, precisely, what heals the film's narrative logic. The older girl shoots a burning arrow, sets the cabin on fire, and forces the bandit out - to the wilderness where he belongs. But only to be captured straight away by the little girl, who keeps him under fire. Stepping backward under threat of the little girl's gun, he falls off the same cliff over which he had earlier pushed the father. Mortally wounded he is taken to town by the posse, and in a long, operatic final scene that ends the film as well as his life, he begs and receives forgiveness.

This film demonstrates the close, inherent bond between the mobility of, respectively, film as a medium, narrativity, and cultural roles. The tension between domestic and outside worlds makes it necessary for the outgoing young women - both the prepubescent and the post-puberty one - to embody counterparts to the two married women, the mother and the bandit's unhappy wife who barely leave the house. But it is not just in the literal ex-cursions that the girls embody mobility. It is also - and perhaps more significantly - in their participation in the plot itself that the stereotypical roles are turned upside down, or rather, given the function of spaces, inside out. Participation in a plot requires leaving the house. Displacement, as Jurij Lotman argued in his The Structure of the Artistic Text (1977), is a condition for hero status. Either women remain inside the home, and hence, outside the plot, or they enter the plot by leaving home. Action, it appears, presupposes the undermining of roles. And roles, once activated from images into narrative agents, presuppose transgressions of spatial divisions. The film therefore, expounds the main issue this chapter probes: the mobility that the bond between action and character entails in a cinematic practice that does not allow stability.

The constitutive relationship between action and roles through mobility adds a qualifying footnote to Teresa de Lauretis's critique on Lotman's theory of narrative. ${ }^{12}$ Lotman posits a bond between narrative and mobility, in terms that 
highlight the privilege given to male heroes who, by virtue of their epic calling, travel. Women, in contrast, stay at home, which leaves little primary action open to them. De Lauretis's critique is fundamental in its demonstration of the operation of theory as, what she later calls, a "technology of gender" (1987). Theory confirms, and through its status as "scientific," naturalizes, ideological ideas that it ought, instead, to de-naturalize so that they become visible again. However important such critical revisions may be, it seems also important to suspend them for a little while, in order to make visible how the theory is always already inadequate - either false or limited.

The film under discussion here would be a good example of how the problematical theory is undermined, not by another theory but by the material it purportedly describes. If this film is any indication, the world as an exclusive male reserve is both confirmed as culturally commonplace and infirmed as untenable, unstable, ready for invasion by young wild women. Young, so that they can ride and fight; wild because they invade a territory that seems not quite appropriate to them. Or so, from the vantage point of today's theories, we think. Theories like Lotman's, then, are complicitous, not so much with the cultural productions such as the films I am looking at, but with those views, anachronistic enough - unexamined in their historical position - in their claim to universal validity. However, neither Lotman nor de Lauretis questions the theory's historical reach. This renders the films' otherness invisible when read through the exclusive lens of stereotypes that they in fact "solicit."13

The wildness of the two young women, here, is played out by their continued participation in the wildlife of action and outside world. In other cases, the transgression takes other forms, equally emblematic, such as, most powerfully perhaps, cross-dressing. ${ }^{14}$ This phenomenon is so significant because it is on the body of the gendered figure that the mobility is inscribed. For example, in the comedy MAKING A MAN OF Her (1912, Nestor) cross-dressing enables the woman to work a man's job, cooking on a ranch, an all-male society. Of course, this is cause for many jokes, which are at the same time evidence of the cultural "thinkability" of such practices. Q This comedy element can also be found in the public debate of journalism, as evidenced by a review of GIRLS WILL BE Boys (1910, Essanay) in Nickelodeon:

Considerable originality is manifested in this photoplay which is farcical in matter, but comedic in manner, in that it affords an amusing commentary on life as it is, or might be. We have seen girls dressed up as boys before, in fact it is quite a common stage expedient, but they usually do it as a matter of disguise, and not, as here, as a matter of principle. These swaggering damsels are proud of their men's togs, and seem to be quite at home in them, but presently some real male creatures appear on the premises, and our modern Amazons meet their Waterloo, succumbing to the darts of Cupid. The siege is a merry one and the final surrender proves a victory for 
all concerned. [...] Some moral precisionist will doubtless take exception to the swaggering and perverse femininity displayed by these girls, but it all seems harmless enough and makes good fun. ${ }^{15}$

But apart from the use of cross-dressing for humorous effects, the function of cross-dressing for the character-plot knot is more fundamental. Dressing up as men can enable women to perform the more serious task of saving the men who, apparently, are not able to save themselves. In THE SHERIFF's DAUghter (1911, Pathé: American Kinema) the daughter dresses up as her outlaw boyfriend to confuse his pursuers (among whom is her own father), while he makes his escape. In The Post Telegrapher (1912, Bison) Edith Black joins a group of soldiers in rescuing her fiancé who is wounded and under attack by a band of Sioux Indians. In the Civil War film A Girl Spy before Vicksburg (1910, Kalem), a general who is short of men asks his daughter to dress up as an enemy soldier in order to go undercover and blow up a transport of dynamite. Her mother is anxiously waiting for her safe return home.

In this film, as often in cross-dressing films, the opposition between the spaces of the domestic, private sphere and the outside world, the public sphere is emphasized through the opposition of gender. But by the same token, the double opposition is also made to appear unstable. For it is by transgressing the opposition that its power is made visible. And transgression, while providing evidence that the opposition is in place, also demonstrates its lack of solidity. The key effect of this film is the display of this instability and hence, of the artificiality of the stereotypical roles that narrativity by necessity unfixes. But our emerging genre more specifically necessitates such transgressions by virtue of the type scenes - chase, rescue - that embody the plot-driven mobility as speed.

If we can assume that cross-dressing is a figure - in the specific sense of a figure of visual rhetoric - that emblematizes the wildness that turns women into full participants of these representations of the "Wild West," thus undercutting the divisions that underlie the genre, then an ever denser, double figure of cross-dressing would be the cross-ethnic theatricalization of costume that we can see, for example, in An Up-To-Date Souaw (Pathé: American Kinema). As I mentioned in $\mathbf{J}$, this film is significantly titled in its French release: L'INDIENNE Ko-To-Sho sE modernise. Another example of ethnic cross-dressing is The Corporal's DAughter (1915, Edison). Here, Kate rescues the army from an Indian attack by dressing up as an Indian and fetching help. The importance of this cross-dressing for the character-plot knot in this narrative is evidently a strategy of the film, as an intertitle reads: "Kate's Indian attire, used in amateur theatricals, comes in handy."16

Let me briefly recall the plot of AN UP-TO-DATE SQuAw that I discussed for different reasons in $\mathbf{J}$. After seeing white women tourists visit her village and 
really liking what they wear, an Indian woman leaves her reservation to go to the city to go on a shopping spree for "white" clothing. Her traditional husband is furious and follows her to take her back to her village. When a drunken man becomes infatuated by the Indian woman who is wearing her new outfit, her husband attacks him and scalps him. The man is unharmed because he was wearing a wig and all ends well.

The double-edged ideological positioning of the film does not simply make it ambivalent. First of all, the discourse of comedy is not ideologically neutral. As I have argued in $\mathbf{Q}$, humor is a variegated phenomenon, and its effect is highly dependent on such questions as the inclusive versus exclusive nature of the humor. Humor is contingent upon implicit judgments. The essence of the values that serve as implicit norms for the judgments is still a potential site of identification. The viewer who feels included in the figure's position will be mild in the judgment that the ridiculing entails. This form of humor is inclusive (of the viewer). Exclusive humor, in contrast, puts the object at a distance, isolates him or her from the experiential emotional world of the viewer. Exclusive humor can be cruel.

The difference between inclusive and exclusive irony is poignantly demonstrated through the different allegiances called upon. For example, in this film the woman's husband is angry because she rejects the traditional Indian clothing and prefers the modern white fashion. The desire for upward class mobility is recognizable to an audience in a modernizing world where department stores with their display of available luxury goods are still a relatively new phenomenon. This desire is a feature that audience and figure have in common, or at least forms a basis for understanding. On that basis, the more complex deconstruction of stereotypes can take place.

One such "complex" is the gender-ethnicity knot. There appears to be a hierarchy at work here. It is through gender constructions that the ethnic positions are deconstructed. This operates through a parallelism. Oppositions of wild/domestic are parallel to male/female. This opposition is not sustained, however. The Indian woman undercuts fixed positions of gender as well as ethnicity. Her cross-dressing is not standard; she is not dressing up as a man, but as a white woman. This difference implies that migration in this film, ethnic migration, is not presented as a form of assimilation. Instead, ethnic mobility is a commentary on female freedom and restraint. As an Indian woman, this character is the object of the tourist gaze. As a wife she is held back by her husband. She is punished for leaving the house and spending money on her own desires. When she takes the freedom to move out of the reservation and goes into the white, modern city for window shopping and buying what she wants, however, the film's self-deconstruction is at its most blatant. As an Indian woman she reverses the gaze and mirrors the tourist actions of looking, and appropriating a 
private sphere as a public sphere. As a beautifully dressed woman she becomes the object of desire for the gentleman, the personification of urban decadence. But unlike depictions of urban women in cultural commentary at the time - say, from Baudelaire to Benjamin - the up-to-date squaw does not turn into the figure of the whore. ${ }^{17}$

Even though the woman is taken back to her home by her angry husband, she is not "really" punished in the film conceived as a cultural event, only in the narrative. Through ridicule, her husband himself is portrayed as a traditional husband, a category that apparently cuts across ethnic divisions. It would seem that gender is "stronger" than ethnicity. But then, what does "strong" mean? Gender establishes the link to the public, thus mediating across ethnic boundaries. On the other hand, through her ethnicity this woman's gender position is more mobile. Her domestic sphere, the conventional confinement to it, is broken open by her ethnic position, which places her already outside the white domesticity that would otherwise circumscribe the leverage granted to her.

The film is also about female vanity. Here, too, the character-plot knot requires a destabilization of the gender fixity represented in the woman's vanity. This is done by bringing it into comparison with male vanity. The gentleman is made fun of when it turns out he is wearing a wig. This surely undercuts the stereotypical savagery of scalping. Also, the shallowness of his flirting is critiqued when it turns out that he mistakes the squaw for a white woman. Female vanity, in contrast, takes on a potentially critical value when we consider it in terms of modernity. Dressing up is something for women of all backgrounds. Modern consumer culture enables women to go out and create their own personal style. Decadence is dangerous (one does not want to be laughed at!), but pleasure is permitted. The overall vision within which all these oppositions must be structurally mapped out, then, is an alluring vision of modernity as overcoming, not maintaining, classical cultural divisions and roles. ${ }^{18}$

Where does this leave the specificity of the Western when it comes to evaluating attitudes toward gender in the practice of our films? This specificity lies less in the presence of ethnic difference as a complication of gender, than in the link between these two aspects and modernity. Women of the West have some advantages over Eastern women. They are embodiments of the "New Woman," but instead of living in an urban culture they find themselves in a rural culture. Or rather, they straddle the border of culture and not-culture. Spatially, this makes for opportunities to explore multiple crossings of stereotypes so that these undermine their own condition of possibility, which is simplicity: stereotypes are first of all reductions. It is perhaps primarily the element "wild" in "Wild West," then, that, unexpectedly as this may sound, levels the ground for a reconsideration of stereotypes from within. 


\section{Notes}

1. "News Items from El Canjon Valley." Moving Picture News IV, 24 (July 27, 1911): 23.

2. "Wonders of the 'Diamond-S' Plant." Motography VI, I (July, 1911): 7-19 (11).

3. The cliché that cinema naturalizes an image of women as passive became current in the wake of Laura Mulvey's famous article (1975) that became the starting point for feminist film studies based on psychoanalysis. The term theoretical fiction refers to theoretical constructions that are indispensable to analyze our cultural objects, yet inherently untenable as understandings of those phenomena. Thus analysis and understanding part ways when analysis can only produce provisional insights that are metaphorical, comparable in that sense to conceptual or cognitive metaphors. On theoretical fictions - a concept from Freud - see Judith Butler, Bodies that Matter (1993), especially the "Introduction." On conceptual as cognitive metaphors, seeTeri Reynolds (1999).

4. Stanfield discusses the role of stock characters and types in early Westerns in "The Western, 1909-1914: A Cast of Villains" (1987). Verstraten (1999) offers deconstructive readings of potentially stereotypical male characters through a confrontational combination of psychoanalysis and narratology. Literary historians Jane Tompkins (1993) and Lee Clark Mitchell (1996) wrote studies about the constructions of masculinity in Western novels and (mainly) classical Westerns. See Karen Esders's study (1997) on women in early Westerns and the construction of sexual difference. Her main focus is on how the narrative structures of Westerns are based on the absence and/or presence of women.

5. That these diverse forms of stereotyping are neither to be conflated nor isolated from each other is the point vigorously made by Butler, Bodies that Matter (1993).

6. See Ben Singer's "Female Power in the Serial Queen Melodrama" (1990) or his chapter "Power and Peril in the Serial Queen Melodrama" in his Melodrama and Modernity (2001).

7. I consider the surviving copies in the archives an indication of the output of films at the time, not of the absolute number of films, but of the percentage of films.

8. Nickelodeon IV, 10 (November 15, 1910): 298.

9. About Alice Guy, her films, and her position in the industry, see Alison McMahan's Alice Guy: Lost Visionary of the Cinema (2002).

10. "In the Moving Picture World. Madame Alice Blache [sic.], President of the Solax Company." Photoplay Magazine II, 2 (March 1911): 37-40 (38).

11. On the paradigmatic structure of the Joseph story, see Bal's Lethal Love (1987: 95-99).

12. See her chapter 5 "Desire in Narrative:" 103-157 in Alice Doesn't (1984). The discussion of Lotman is on pages 116-121. She refers to Lotman's "The Origin of Plot in the Light of Typology" (1979).

13. The verb to solicit is used here in a sense close to Derrida's use of it in "Différance" in Writing and Difference. (1978) as "to shake as a whole."

14. Alison McMahan (2002) has studied cross-dressing films in early cinema. In her paper given at the 1997 Utrecht conference on early Westerns, Back in the Saddle Again, McMahan discussed cross-dressing in early Westerns and some examples of films by Alice Guy that are about gender role reversals without cross-dressing. An intriguing case that she discussed was the film Algie the Miner (1912, Solax). McMa- 
han quotes the plot description: "A Billy Quirck comedy. Algie is a 'sissy boy' who has as much backbone as a jelly fish. When Algie falls in love and finds that his sweetheart objects to his 'personali $\neg$ ty' he goes West and after several ludicrous experiences and hard struggles he becomes a 'man.' A comedy with strong character portrayals" (Moving Picture World V, 7, February 7, 1912). On the subversive potential of cross-dressing as cultural critique, see Marjorie Garber's Vested Interest: Cross-Dressing and Cultural Anxiety (1992).

15. Nickelodeon: V, I (January 7, 1911): 23.

16. American Kinema films with cross-ethnic-dressing by (white) men also include For the Sake of the Tribe (1911, Pathé: American Kinema), and The Souawman's Sweetheart (1912, Pathé: American Kinema).

17. On Baudelaire's figurations of the whore, see Culler (1996). Benjamin's remarks are scattered through his work, perhaps most typically in the Arcade Project (1999). On Benjamin's very complex images of women, see Weigel (1996).

18. About modernity and women as "flâneuses" see Kathy Peiss (1986), Anne Friedberg (1992), and Janet Wolf (1989). 


\title{
Zooming In, Zapping, Zooming Out
}

\begin{abstract}
If the subject of modern society was looking for refuge from the chaos of the real world in the stability and balance of the static composition of a painting, and later in cinema's image, the subject of the information society finds peace in the knowledge that she can slide over endless fields of data, locating any morsel of information with the click of a button, zooming through

file systems and networks. She is comforted not by the equilibrium of shapes and colors, but by the variety of data manipulation operations at her
\end{abstract}

control.

- Lev Manovich, 2001 ${ }^{1}$

What I have done in this study is make several moves between zapping and zooming. Zapping stands for the fragmentation, the speed, and the lack of unity in, and between, the films: in the programming, the spectacle, the panorama, the tensions between various strategies, such as display and narrative. It stands, in short, for the kaleidoscopic view that I have tried to construct of early Westerns as a cultural moment. Zooming refers to the detailed attention to concrete films whose informative interaction with more general historical and methodological problematics is the key that has opened, for me, the door to a foreign culture that projected its traces onto our present.

Zooming in on the films, I aimed to show how the films zoom in on the various aspects of the West. What I have tried to do is bridge the epistemic gap between present and past on the terms of the past, as an exercise in historical "heteropathic identification" (Silverman). The result, it is hoped, zooms out; aggrandizes our perspective on the slice of past that constituted my object, or rather, subject. This is a movement from detail to larger considerations, but not in the sense of the movement from detail to whole as in the hermeneutical circle. Instead, there is a constant shift between the object and the discourse we use to reach it. In this sense, zooming in and zooming out is much like shifting the attention from detail to fragment. B

In my attempt to foreground both parallel and difference between then and now, this project called for a self-reflection not just of the historian doing a job that poses epistemological problems, but of the viewer that every film historian also is. A persistent question was: how can we look now with the eyes of then? We cannot, definitively not, but we can use our imagination to try, in a kind of double-focus. We cannot, yet we must try, because it helps us realize that spec- 
tatorship itself is culturally and historically unstable. In this study, I have tried to bridge the unfortunate gap between the large brush strokes of cultural history and the detailed attention to the archival objects. The "bridge" is made of braiding: intricate, fragile, provisional, yet as concrete and specific as possible. This braided bridge is what I have to offer; it warrants no closing.

Instead, this concluding reflection provides a peek into the future. What is the relevance of our understanding of the first phase of cinema, for our understanding of today? "After the Beginning" is a historiographic principle of studying early cinema as a synchronic slice without origin, yet anchored in cultural space-time. A look into the future does not have to focus on the narrowing development towards classical cinema. The drawbacks of that evolutionist view have been made abundantly clear. Instead, I contend that the cultural moment in which my corpus participated, is better illuminated by looking towards the next revolutionary moment of transformation: the coming of current new media, the digital image. ${ }^{2}$

Zooming out of the subject of this study, then, I would like to end on a sketch of the new perspectives that have emerged, tentatively, and which, I hope, will inspire subsequent projects. For, as I have suggested all along, it may not be just a coincidence that we are witnessing today a remarkable surge of interest in the visual culture of the late 19th century, the early days of cinema. This interest is evidenced by a sudden increase in academic studies on early cinema, as well as by a renewed interest in the preservation and presentation activities of film archives. Temporally, this focus on "old" media coincides with the technological development of digital media and the ensuing radical transformation of the visual culture of today. I wonder if there is a specific reason for this focus on early cinema precisely at this moment of a shift in media culture that we are witnessing now, a century later. Moreover, these studies on media history are evidence of new perspectives on the past, based on non-linear and non-teleological historiographic principles. My study is intended as a contribution to that approach.

It seems that there are possible reasons for the convergence of new media and new approaches with the old ones, on two distinct levels. First, watching new media take form gives us a privileged perspective from which to reconsider the emergence and transformations of past media. Second, the non-linearity, nonhierarchic nature of post-structuralist thought has a technological and expressive counterpart in digital media such as Internet, CD-ROM, and DVD. The first fact enables a new perspective on the past, and the second offers a new set of possibilities for representing and exploring that perspective. My zooming-out question is, therefore, how is the new media's non-linear hypertextual organization of visual experience, promoted by digital technologies, related to, and relevant for, our understanding of the historicity of visual culture? 
It is the hypothesis of this final reflection that there are inherent reasons both aesthetic and semiotic - for the electronic media's facilitation and stimulation of the "archaeology" of old media, reasons whose specific nature are still to be examined. Clearly, and in general, new technologies and emerging media systems have cultural and philosophical implications, and reposition the past. This raises the epistemological question of how these moments of transformation can illuminate our understanding of the historicity of media, old as well as new. I propose to zoom out, then, to a double question: how can new media be historicized, and how can new media provide us with a fresh perspective from which to re-interrogate old media?

Of particular interest for this study was the re-positioning of old media within the practices of today's contemporary culture. Reframing the old - but once also new - media with questions raised by new media alters their historical context, but revives their complexity and embeddedness in textual and medial networks. This intervention paradoxically restores part of their historical character and thus enables new analyses of the past, as well as an historical perspective on the present. In this way it is possible to historicize the sometimes free-floating discourse regarding new media, while at the same time re-interrogating the sometimes-staid assumptions about the media past.

This hypothesis can be tested and made historically specific in order to gain insight into today's revolutionary changes in visual culture through a comparative analysis of the modalities and contextual characteristics of two bodies of significant visual objects from two moments in history. For this comparison, this book offers a starting point. This analysis is best conceived as a double case study built around the notion of mobility and travel. The first corpus is the one I have begun to lay out here: the very short films and film fragments made in Europe and the US between 1895-1915 that offered the then new and exciting possibility to "visit" remote areas of hitherto inaccessible parts of the world. In particular, this visual tourism focused on the exotics of the remote places, the "outskirts" of the Western world, but also its "backyard": the American West with its unlimited possibilities of adventures inaccessible to both the American and European urban audiences.

As we have seen, these visions of geographical distance were accompanied by visions of temporal remoteness in films with historical or futuristic themes, providing a sense of time travel as a spatial, cultural, as well as temporal displacement. These images of the world were part of a cultural discourse characterized by the mixed tropes of education and entertainment. They were presented in a variety of intertwined generic formats of nonfiction, such as actualities, ethnographic films, travelogues, historical films; and of fiction, such as science fiction films, Indian films, Westerns, or jungle films. The unifying genre concept of "Western" all but makes this diversity invisible. 
For the comparative analysis I envision as a sequel to this study, the second body of visual objects derives from today's digital media the capacity to offer visual experiences of foreign, imaginary, utopian, historical, or futuristic lands and cultures that I call virtual tourism. This form of tourism is not merely a new form of the older mode of visually traveling to places, another form of vicarious travel. Rather, it refers to a radically new mode of visual, sensual, as well as intellectual experience that is specific to today's new media. Since (physical) geographical access is easier than it was a century ago, the essence of vicarious tourism today is experience rather than presence. Moreover, in a textual sense, the centrally controlled and distributed linear text of visual travel in early cinema is replaced by a highly variable, interactive, textual network of hypertext.

This virtual form of travel demands that the "tourist" make individual choices and actively engage in the process of travel. The World Wide Web, for example, is a world to be traveled: we speak of "surfing" or "navigating" the Web. "Accessing" the Web, searching and moving from site to site resembles a journey. The places on the Web, these "sites," are structured for a reader/viewer to enter, and to choose his or her own trajectory. Webcams on the Internet show sights of a variety of sites on the globe, 24 hours a day. Similarly, the hypertextual structure of, for example, DVDs enable presentations of multiple points of view and a variety of media (sound, moving and still image, text) with the requirement that viewers make active choices. Computer games - specifically the simulation games, adventure games, and new action games - enable players to assume multiple identities, and to use these characters to interface with the digital world in an interactive manner. Other new technologies and media forms based on adaptive agents that are being developed at the present moment experiment with the limits between subjects and their environment and with different levels and modes of interactivity.

Between these two forms of mediated "tourism" there are similarities as well as differences that warrant exploring. Visual tourism of the old media can be attributed new dimensions by the comparison with virtual tourism. Indeed, the definition of what the Encyclopaedia Britannica calls "virtual museums" looks a lot like what I found in the archive $\mathbf{B}$ and what fits in the practice I discussed in $\mathbf{V}$ :

a collection of digitally recorded images, sound files, text documents, and other data of historical, scientific, or cultural interest that are accessed through electronic media. A virtual museum does not house actual objects and therefore lacks the permanence and unique qualities of a museum in the institutional definition of the term. ("Virtual Museum," Encyclopaedia Britannica Online) 
At this end of my journey through the film museum I ask questions about how we can revamp old content in new forms with the aim of "restoring" the historical actuality, or dynamics of this culture.

One example of a common preoccupation between the two moments is the archival problematic of preservation. It raises questions of selection (which films will be preserved, and thus, which films will perish?), of restoration (how should we intervene in the course of time, not only to stop decay but also to restore, what then is the "original"; should we record the restoration process?), of access (how do we make our heritage accessible?), and of presentation (how do we make our heritage visible?). In the case of visual texts such as film, the ultimate questions are, therefore, how do we incorporate new technological (as well as cultural) innovations in the course of history into the archival "life" of old films? And, more radically reframing the historical object in the face of the new context of today: How can visual "archives" (old media in an historical context, centralized, and hierarchized) be replaced by virtual "archives" (old media in a new context, networked, and de-hierarchized)?

The two moments of visual culture that I am proposing to compare for the mutual illumination of both are symbolically centered around 1900 and 2000. These moments, at both ends of the 2oth century, are characterized by the scale of the publics that make use of visual culture and by the industrial production of their texts (mass media). Both cultures can be conceived of as a web: a structured mix of parallel, overlapping, and competing representational forms (multimedia). I have argued that from the beginning of the 2oth century, cinematic representation was situated among World's Fairs, museum exhibitions, and other forms of display: postcards, popular magazines, and photographs. Similarly, today, hypertextual presentations in digital media both consist of assemblages of multimedia (photos, video clips, text, and sound) and stand surrounded by billboards and television, music videos and clips, not to mention the pace and the constant visual restlessness of city life as a whole.

Film, whether considered as a textual system or form of programming, was from the beginning a medium of explicit polysemic address. In that sense, film had a broad and variegated cultural appeal comparable to today's hypertextgenerating media (hypermedia). Particularly in its early days, film demonstrated both a generic and a medial instability. Illustrated lectures and the variety format of film shows that were, in fact, "performances," point to an instability of film as an individual medium. Something similar can be said of the digital media, which offer unheard-of mixtures of genres and styles, leaving it to the viewer to generate categories and meanings. Yet, there are some fundamental differences between "film" as individual part of a larger multimedial network of old media and "film" as component of hypertextual new media. These differences need to be explored as well. 
The terms of comparison are, again, double. For each side of such a case study a ruling metaphor can be deployed. The metaphor through which I have characterized turn-of-the-century cinematic culture is the kaleidoscope. $\mathbf{K}$ For present-day visual culture, I will deploy the term hypermedia, similarly, as a metaphor. The two metaphors can serve to bring into one conceptual network the dominant characteristic of the textual modes through which the experience of "visual tourism" became possible as "virtual tourism." The former term, kaleidoscope - etymologically "beautiful vision" - serves to characterize both the textual modalities of the films, and the forms of presentation in which they were received. But as with the optical instrument whose name it bears, the term also refers to the splintering of views to offer a fragmented ensemble, never a seamless whole, of such beautiful visions. Moreover, the hand that holds it - the filmmaker and the programmer - determines which constellation of visions the public gets to see.

The latter term, hypermedia, points from the not-yet-whole text to the other side: hypermedia have moved beyond the whole. They hand the direction over to the viewer, the user of the Internet who can select which way to turn at the crossroads, thus determining the "untrodden path" of the elite tourist. But here, too, the inevitable consequence is fragmentation. While, at least in our retrospective - and anachronistic - comparative view, early cinema did "not yet" produce full, whole texts on a par with, say, the novel, today the habits of surfing and zapping preclude any overview of what could have been "the whole." The kaleidoscope is only in part replaced by hypermedial configuration, and some characteristics are still present. Moreover, whereas spectators of early cinema viewed the fragmented visions of beautiful areas together, during an evening out, the present-day virtual tourist is free to choose both the trajectory and the time of the visit, but there she or he is irrevocably alone.

The two visual cultures have too much in common for us to neglect the unexpected, perhaps paradoxical similarities across a century of technological revolutions and cultural divides. They also differ, but in ways that are not reducible to chronological timelines. Indeed, all along I have been interested in the possibilities, implied in such a comparison, of characterizing historical difference as such in terms other than development, progress, or synchronic epistemes only. My project here, then, aimed at linking historical research, philosophical speculation, and methodological analysis as well as detailed analysis of things old.

I have tried not only to open up and present this corpus, which threatened to turn to dust because of lack of interest, funding, and tools for understanding, but also to frame it within the culture from which it emerged. This was the culture of an urbanizing, industrializing, modernizing Western world whose limits had continuously expanded in a movement of discovering, civilizing, 
conquering, and exploiting the "wild" region bordering the urban centers. Modernity and the sentiments of anxiety it elicited over the loss of what was also rejected as "old," formed the backdrop against which the exciting new medium of the moving image became popular $\mathbf{M}$. Specifically, its deployment for documenting and fictionally representing the life of cowboys and Indians of the region that was recently still "wild," but had quickly become legendary, became an extremely widely-enjoyed and -discussed cultural event. I have suggested that the Western is more than just a group of early films not only in the retrospective comparison I am proposing, and which must relinquish many tenets of earlier approaches, but also in terms of strategies and practices. Emerging from the moment of historical coincidences, the Western corpus is, I contend, emblematic for the moment of cultural history of which it gives a condensed image.

Many of these images are preserved in the Filmmuseum in Amsterdam, where I began my research during an extended internship and subsequent work as assistant curator. I used this opportunity to propose criteria for the selection of those film fragments worthy of conservation in a time of restricted finances. On the basis of these proposals, criteria of selection were put into effect, and several films were preserved. Meanwhile, in the research project I am completing with this prospective sketch, I was committed to doing justice to the corpus itself - the films, but also the fragments as well as the written sources and documents of reception, and the programs in which the films were shown and viewed. I have presented the material not as a unified series of comparable products but as a kaleidoscopically organized, variegated image of a visual practice, for which a fragmentary, alphabetically-ordered presentation seemed a suitable organizational principle. This concept has forced me to think through the implications of historical and methodological choices for the practice of cultural history more generally.

The metaphor of the kaleidoscope, while characteristic of the cultural context, turned out to be most useful when deployed as a metaphor for the conceptual process (i.e., in contrast to deployment as a metaphor for the cultural context). It was precisely by thinking through the implications of this metaphor as a tool to understand a culture different from our own, that the comparison with hypermedia occurred to me. The question that both metaphors in conjunction invite concerns the changing attitudes in present-day culture toward the processing of information. The kaleidoscopic model that I have developed for early Westerns (and by extension for early cinema as a whole), then, stands to hypermedia as "old" to "new." But just as significantly, our belated ability and willingness to notice this model at all, can be seen as the retrospective desire to highlight in the past what brings it closer to the present, and vice versa.

In terms of content, through the idea of virtual tourism, the study out of which I am zooming often touched upon a theme that was keenly absorbed 
and hotly debated then as well as now: the relation to cultural otherness. In terms of practices this relation can be characterized as, primarily, "touristic." In the face of present multicultural society and the multiplicity and differently organized strata of transnational culture, I find the analysis of the different forms, and the subsequent differences in content and vision, of virtual tourism in both periods, most relevant.

Indeed, the easy access to formerly exotic environments provided by the Internet can be instructively compared to the new tourism of a century ago, equally experienced as "virtual" although not thus named, provided by film programs. In variety programs, circuses, rodeo shows, and staged parades, films of fictive battles and suspenseful plots alternated with ethnographic films that catered to the taste for exoticism, the excitement to see in the city what can otherwise only be witnessed at great cost of time, money, and danger. C D $\mathbf{D} \mathbf{T}$ The Internet and computer games took over some of the entertainment functions of an evening out to the show circa 1900, in a culture defined by easy access to the most remote of cultural spaces.

Parallel to the programming in short bits of a variety of representational forms and other strategies of presentation and representation in place around 1900, I consider it worthwhile to examine the construction of the trajectory in the use of the intertextual structure in the digital media. To do this, I envision examining specific computer games, CD-ROM and DVD texts, and websites (specifically virtual museums, on-line archives, and phenomena like Webcams), as well as the larger "text" of the World Wide Web as a meta-hypertext. Just as After the Beginning had to be shaped according to the cultural model it has been uncovering, such a subsequent project would be conceived to examine, explain, and demonstrate the new model in its similarity to and difference from the old. The visual cultures of these two moments at the ends of the 19th and 2oth centuries in which the cultural other features as an - often exoticized - attraction, can be compared in their non-linear structure (in terms of configurations), their forms of visual/virtual tourism (in terms of perceptions), and their construction of otherness (in the discourses they constitute).

Not only is the digital turn, then, a cause for redefining and rethinking old as well as new media, but the position of the researcher, issues of preservation and archival politics, and the historiographic project must also be rethought. The question that has underlain this study is: How do we write our histories at the moment of transition, in the midst of the emergence of new models of writing and thinking? Implicitly, the objects of my study were the relationships between media, across time, and within different paradigms. Not only has this been an attempt to bring together different levels of cinema (as products, producers, and as cultural paradigm), but also to develop a new mode of analysis suitable for 
trans-historical comparison: a nonlinear, interactive, and truly analytical structuring of a dynamic network.

\section{Notes}

1. Lev Manovich, The Language of New Media (2001): 274-275.

2. For a similar perspective on historical media transformatons, see Henry Jenkins and David Thorburn's introduction to Rethinking Media Change (2003). A slightly different, more cyclical view on media change is held by Jay Bolter and David Grusin in Remediation (1999). 


\section{List of Illustrations}

B Bits \& Pieces 319, courtesy of the Filmmuseum

C1 A Cowboy Millionaire (1909, Selig), courtesy of the Filmmuseum

C2 A Cowboy Millionaire (1909, Selig), courtesy of the Filmmuseum

D1 Kalem ad for The Red Man's WaY, Moving Picture World 1, 32 (October 12, 1907): 155

D2 Rose O'SAlem-Town (1910, AM\&B), courtesy of the Fimmuseum

D3 [INDIAAN GRIJPT KIDNAPPER] Indian Seizes Kidnapper. (c.1910, Pathé Frères), courtesy of the Filmmuseum

E1 Biograph Bulletin for A TALE OF THE WILDERNESS, release date January 8, 1912

E2 Biograph Bulletin for BiLly's StRATAgEM, release date February 12, 1912

F Cartoon: "Indian Pictures as the Indians Want Them." Nickelodeon V, 9 (March 4, 1911): 246

G Cartoon: "What Would the Film Producer do Without These?" Nickelodeon V, 19 (March 11, 1911): 278

H Kalem ad for Under the Star Spangled Banner, Moving Picture News II, 4 (January 25, 1908): 61

L The shooting of Broncho Billy's Christmas Dinner (1911, Essanay)

M1 The Great Train Robbery (1903, Edison)

M2 Rescued From an Eagle's Nest (1908, Edison)

O1 Picture postcard, "Hiawatha" (1906)

O2 Minnehaha, from Hiawatha (1913, Fort Defiance Film Co.), Moving Picture News VII, 13 (March 29, 1913): 11

P1 Grand Canyon of the Yellowstone. Moran (1872)

P2 Stereocard Curtain Falls (1904)

P3 Stereocard Glacier Point (NW) Yosemite, California (1903)

P4 Stereocard Glacier Point (NE), Yosemite Valley, California (1902)

P5 Stereocard From Rowe's Point (NW) Grand Cañon of Arizona (1903)

Q Bison ad for Cowboy for A DAY, Moving Picture News IV, 15 (April 15, 1911): 29

V Ad for Kleine's release of The Red Man's Way (Kalem), Moving Picture World I, 32 (January 12, 1907)

W Bison's Wild West Show. Moving Picture News IV, 48 (December 2, 1911): 15 
X1 Essanay ad for The James Boys From Missouri. Bioscope I, 153 (September 16, 1909): 20

X2 Cover of the 1901 dime novel Jesse James, the Outlaw, published by Street \& Smith, New York

X3 Biograph Bulletin 109 (September 25, 1909) of Terrible Ted (1907, AM\&B) 


\section{Filmography}

\section{Abbreviations}

$\begin{array}{ll}\text { CF } & \text { Cinématèque française, Paris } \\ \text { LoC } & \text { Library of Congress, Washington, DC } \\ \text { FM } & \text { Filmmuseum, Amsterdam } \\ \text { NFTVA } & \begin{array}{l}\text { National Film and Television Archive, London } \\ \text { SFVuthwest Film-Video Archives, Sulphur Springs, TX }\end{array} \\ & \\ \text { BFI } & \text { BFI Early Cinema Primitives and Pioneers video series } \\ \text { GV } & \text { Grapevine Video, Phoenix, AR } \\ \text { OC } & \text { Origins of Cinema video series }\end{array}$

AM\&B American Mutoscope and Biograph

$\begin{array}{ll}\text { FR } & \text { France } \\ \text { GB } & \text { United Kingdom } \\ \text { DE } & \text { Germany } \\ \text { IT } & \text { Italy } \\ \text { NL } & \text { Netherlands } \\ \text { USA } & \text { United States of America }\end{array}$

When films are not, or partially, identified I give the title that the archive uses in brackets, if necessary followed by an English translation. Foreign release titles are given in brackets in italics. In the case of Pathé's American Kinema films, French release titles are in brackets when known. When only the French release title is known, this is marked with an [F] behind the title, followed by my English translation. The countries given designate the place of production. For Pathé's French productions I use the name Pathé Frères, for the American branch I use Pathé: American Kinema.

Most of the listed archival films I have been able to see in the film archives, a few I have watched at the Festival of Silent Cinema in Pordenone, Italy. The archives listed may not be the only archives that hold a specific film, but they indicate which archival copy of the film I have actually seen. Some of the films 
mentioned in the contemporary press may be somewhere in a film archives today, possibly not yet identified or in bits and pieces, but so far I have not been able to locate them. I list them as "films from secondary sources." When the release date is unknown, I give the date of mention in the press as an approximation (with a "c.").

\section{Archival Films}

[Aardsche Paradijs, Het] Paradise on Earth c.1919, USA, FM P Alone in the Jungle 1913, Selig, USA, FM M

American Falls from Above, American Side 1896, Edison, USA, LoC $\quad \mathbf{P}$ American Falls, Goat Island, The 1896, AM\&B, USA, FM P

American Falls, Luna Island 1896, AM\&B, USA, FM $\quad$ P

Amour D'Indienne [F] c.1910, Pathé: American Kinema, USA, CF J

ANNIE OAKLEY 1894, Edison, USA, LoC K W

ARrivéE D'UN TRAIN EN GARE DE LA CIOTAT, L' 1896, Lumière, FR, FM R

Artist's PoINT 1903, AM\&B, USA, LoC P

BANDIt KIng,The 1907, Selig, USA, LoC Y

BANk Robbery, The 1908, Oklahoma Natural Mutoscene, USA, LoC H

Battle Of The Red Men, The 1912, Bison, USA, LoC D

Bear Hunter, The 1913, Pathé: American Kinema, USA, CF D

Billy's Stratagem 1912, AM\&B, USA, FM E

Bird's-eye View of San Francisco, California, From a Balloon 1902,

Edison, USA, LoC

Bit of Blue Ribbon, A 1912, Vitagraph, USA, FM Y

Bits \& Pieces \#21, USA, FM B

Bits \& Pieces \#66 c.1910, Edison, USA, FM B

Bits \& Pieces \#104, USA, FM B

Bits \& Pieces \#319 c.1911, Vitagraph, USA, FM B S

Bits \& Pieces \#429 [De Redding; The Rescue] c.1911-1913, USA, FM B

Blade O' Grass 1915, Edison, USA, LoC E

Black DiAmond Express 1896, Edison, USA, LoC R S

Broncho Billy's Christmas Dinner 1911 Essanay, USA, FM G L

Broncho Busting Scenes, Championship of the World 1902, Edison, USA, LoC

BRother BILl 1913, Vitagraph, USA, FM G

Buck DANCE 1898, Edison, USA, LoC D

Bucking Broncho, A 1894, Edison, USA, LoC K S W

Bucking Broncho, A 1903, AM\&B, USA, LoC C S 
Bucking Broncos 1904, Edison, USA, LoC

C G

Buffalo Bill's Wild West and Pawnee Bill's Far East 1910,

Buffalo Bill \& Pawnee Bill Film Co., USA, LoC

Buffalo Bill's Wild West Parade 1902, AM\&B, USA, LoC

Buffalo Bill's Wild West Show 1960, Blackhawk Films, USA, LoC

Buffalo Dance 1894, Edison, USA, LoC

BufFalo JiM 1914, Vitagraph, USA, FM

Buffalo Police on Parade 1897, Edison, USA, LoC

Burning Brand, The 1912, Broncho, USA, LoC

CAlF BRANDING 1898, Edison, USA, LoC

CAlifornia Limited, A.T.\&S.F. R.R. 1898, Edison, USA, LoC

California Orange Groves, Panoramic View 1898, Edison, LoC

Call of The Wild, The 1908, AM\&B, USA, LoC

Canyon of the Rio Grande 1898, Edison, USA, LoC

Cascade Near Wawona, Cal. 1903, AM\&B, USA, LoC

Cattle Fording Stream 1898, Edison, USA. LoC

Cattle Leaving the Corral 1898, Edison, USA, LoC

Cheyenne's Bride, The 1911, Pathé: American Kinema, USA, FM

Chez les Touaregs 1908, Pathé Frères, FR, FM

Circular Panorama of Electric Tower 1901, Edison, USA, LoC

CoAches Arriving at Mammoth Hot Springs c.1899, Edison,

USA, LoC

K T

Coaches Going to Cinnabar From Yellowstone Park 1899,

Edsion, USA, LoC

Coaching Party, Yosemite Valley 1903, AM\&B, USA, LoC

COEUR ARdent 1912, Gaumont, FR, FM

Colonel's Escape, The 1912, Kalem, USA, FM

[ConCURrenten, De] Competitors. c.1912, USA, FM

Conspiracy of Pontiac, The 1910, Kalem, USA, FM

Convention of the Red Men c.1904, Edison, USA, LoC

Corporal's Daughter, The 1915, Edison, USA, LoC

Cowboy And the School-Marm, The 1910, Bison, USA, FM

Cowboy Justice 1910, Pathé: American Kinema, USA, LoC

Cowboy Millionaire, The 1909, Selig, USA, FM

Cowboys ANd Indians Fording River IN A Wagon 1904, Edison,

USA, LoC

K T

D L Q

G

C M

H

K

$\mathbf{Y}$

$\mathbf{N}$

J M R

C G I M S

Cowboys' Day Off 1912, Broncho Films, USA, NFTVA

Craven, The 1912, Vitagraph, USA, FM

Cripple Creek Bar-Room Scene 1899, Edison, USA, LoC

Cupid Through Padlocks 1912, Imp., USA, FM

G

Dalton Boys, The c.1914, ?, USA, LoC 
Death Mask, see The Redskin Duel

Destiny is Changeless 1912, Vitagraph, USA, FM

Dirigeable fantastique, le [INVENTOR CRAzy BRAINS AND His

Wonderful Airship] 1906, Méliès, FR, FM

Distant Relative, A 1912, American, USA, FM

F

Driving Cattle to Pasture 1904, Edison, USA, LoC

M R

Eagle Dance, Pueblo Indians 1898, Edison, USA, LoC

F K

Elevated Railroad, New York 1903, AM\&B, USA, LoC

D

Eleventh Hour, The 1914, Bison, USA, FM

Esquimaux GAME OF SNAP-THE-Whip 1901, Edison, USA, LoC

C M

Esquimaux Leap-Frog 1901, Edison, USA, LoC

D K M U V

Esquimaux Village, The 1901, Edison, USA, LoC

D M U V

Falls of Minehaha, The 1897, Edison, USA, LoC

D K M U V

Fast Mail, Northern Pacific Railroad 1897, Edison, USA, LoC

O P

Fatal Hour, The 1908, AM\&B, USA, LoC

$\mathbf{R}$

Fée Carabosse, La 1906, Méliès, FR, FM

D M

Feud ANd the TurkeY, The 1908, AM\&B, USA, LoC F

FLÊCHE EMPOISONNÉE, LA [F] 1912, Pathé: American Kinema, USA, FM

E

For the SAKe of the Tribe 1911, Pathé: American Kinema, USA, CF

D

Frontier Flirtation, A 1903, AM\&B, USA, LoC

Gap Entrance to Rocky Mountains 1902, AM\&B, USA, LoC

GIRL FROM THE WeST, A 1912, Vitagraph, USA, FM

GirL Spy before Vicksburg, A 1910, Kalem, USA, FM

GoIng Through the Tunnel 1898, Edison, USA, LoC

Grand Hotel to Big Indian 1906, AM\&B, USA, LoC

Great Train Robbery, The 1903, Edison, USA, LoC/FM

Herding Horses Across a River 1904, Edison USA, LoC

Herd of Cattle 1901, AM\&B, USA, LoC

Hero Track Walker, The 1911, Kalem, USA, FM

E G L Q W

$F$

CF S

Hiawatha 1913, Fort Defiance Film Co., USA, LoC

D O

His Last Game 1909, Imp., USA LoC

Hold-Up of the Rocky Mountain Express, The 1906, AM\&B, USA, LoC

Hopi Indians Dance for Theodore Roosevelt at [Walpi, Arizona] 1913, USA, LoC

Horse Parade at the Pan-American Exposition 1901, Edison, USA, LoC

Hotel Del Monte 1897, Edison, USA, LoC

Hotel Vendome, San Jose, California 1897, Edison, USA, LoC

M U

How States Are Made 1912, Vitagraph, USA, FM 
[INDIAAN GRIJPT KIDNAPPER] Indian Seizes Kidnapper. c.1910, Pathé Frères, FR, FM

D L N

K

Indian Day School [Isleta, New Mexico] 1898, Edison, USA, LoC [INDIANENLIEFde] Indian Love. c.1913, Pathé: American Kinema, USA, FM

Indian Runner's Romance, The 1909, Biograph, USA, LoC

INDIAN WAR COUNCIL 1894, Edison, USA

D

D

K

INDIENNE BlAnCHE, L' [F] 1911, Pathé: American Kinema, USA, FM

INJUNS 1913, Powers, USA, LoC

D J

W

E

INTERIOR New York Subway, 14TH Street to 42ND Street 1905, AM\&B, USA, LoC

In the Heart of the Catskills 1906, AM\&B, USA, LoC

Into the Haunts of Rip van WinkLE 1906, AM\&B, USA, LoC

JAPANESE Village 1901, Edison, LoC

Kentuckian, The 1908, AM\&B, USA, LoC

Kentucky Feud, A 1905, AM\&B, USA, LoC

Kiss in the Tunnel, A 1899, G.A. Smith, GB, BFI

Kit Carson, 1903, AM\&B, LoC

M U V

E

E

L

E H

LANDing of the Pilgrims, The 1915, Edison, USA, LoC Reissued in 1917 as The Story of Plymouth Rock

LAssoing Steer 1898, Edison, USA, LoC

LAst Minute, The [US distribution title] 1913, Éclipse, FR, LoC

LEATHER STOCKING 1909, AM\&B, USA, LoC

Life of A Cowboy 1906, Edison, USA, LoC

LiEUTENANT'S LAST Fight 1912, Bison, USA, FM

Little Train Robbery, The 1905, Edison, USA, LoC

Lonedale Operator, The 1911, AM\&B, FM

Los ANGELES 1912, Imp., USA, FM

H O

F

S

H O

G K

D

W

B R S Y

G M

Lost AND WoN 1911, Selig, USA, FM

C G M S

Lower Falls, Grand Canyon, Yellowstone Park c.1899, Edison, USA, LoC

Making a Man of Her 1912, Nestor, USA, FM

MARQue RÉvÉlatrice, LA [F] The Revealing Brand c.1912, Pathé:

American Kinema, USA, CF

D O

Mended Lute, The 1909, AM\&B, USA, LoC

$\mathbf{H}$

Mexican Filibusters 1911, Kalem, USA, FM

G

Midnight Fantasy, A 1899, AM\&B, USA, FM

D M

MohawK's Way, A 1910, AM\&B, USA, LoC

$\mathrm{H}$

Mong Fu Tong 1913, Éclipse, FR, LoC

Montana State FaIR 1914, Vitagraph, USA, FM
D M

G 
[NationaAl park in Amerika, Het ] The National Park in America C.1918, USA, FM

Native Daughters 1898, Edison, USA, LoC

[NEL PAESE DELL'ORo] In the Land of Gold 1914, Cines, IT, FM

D G P

K

C

[Nel vortice Del Destino] Destiny's Vortex 1913 Savoia Film, IT, FM C T

New Brooklyn to New York Via Brooklyn Bridge 1899, Edison, USA, LoC

Opening, PAN-American Exposition 1901, Edison, USA, LoC

Orphans of the Plains [Les orphelins de la Plaine] 1912, Pathé: American Kinema, USA, CF

Orphans of The Wild [Les Deux ORPhelins] 1914, Pathé: American Kinema, USA, CF

Outcast Among Outcasts, An 1912, AM\&B, LoC

Overland Express Arriving at Helena, Montana 1900, Edison, USA, LoC

Packers on the Trail 1901, Edison, USA, LoC

PAN-American Exposition by Night 1901, Edison, USA, LoC

$\mathbf{R}$

F

MU

[PANTERKAT, DE MOEDIGE IndiaAN] Panthercat, the Brave Indian c.1912, Kalem, USA, FM

Panorama of Esplanade by Night 1901, Edison, USA, LoC

Panorama of Gorge Railway 1900, Edison, USA, LoC

Panoramic View of Electric Tower From a Balloon 1901,

Edison, USA, LoC

Panoramic View of Moki-Land 1901, Edison, USA, LoC

Panoramic View of the Canadian Pacific R.R. Near Leauchoil

B.C. 1902, Edison, USA, LoC

Parade of Buffalo Bill's Wild West Show, 1 and 2 1898, Edison, USA, LoC

Parade of Chinese 1898, Edison, USA, LoC

Passaic Falls 1896, Edison, USA, LoC

Pay Train, The 1915, Kalem, USA, FM

M U

K

$\mathbf{L}$

C G K W

K

$\mathbf{P}$

R Y

Pioneers, The 1903, AM\&B, USA, LoC

D E H

PoKer at Dawson City 1899, Edison, USA, LoC

Post Telegrapher, The 1912, Bison, USA, FM

President McKinley Reviewing the Troops at the Exposition 1901,

Edison, USA, LoC

President McKinley's Speech at the PAN-American Exposition

1901, Edison, USA, LoC

M U

President Roosevelt and the Rough Riders 1898, AM\&B, USA, LoC

M U

Procession of Mounted Indians and Cowboys 1898, Edison, USA, LoC Question of Seconds, A 1912, Edison, USA, FM
K

K

$\mathbf{M}$ 
RaIlroad Smashup, A 1904, Edison, USA, LoC

M R S

Railway de la Mort, Le [Their Lives For Gold] 1912, Gaumont, FR, FM

G M O R

Railway Mail Clerk 1910, Kalem, USA, FM

RaIlway Tragedy, A 1904, (British) Gaumont, GB, OC

L R

[Rampspoedige Weddenschap van Oom Sam, De] A Fatal Bet c.1912,

Pathé: American Kinema, USA, FM

Ranchman's Vengeance, The 1911, Flying A, USA, FM

Redemption of Red Rube, The 1912, Vitagraph, USA, FM

Red Girl, The 1908, AM\&B, USA, LoC

Redman ANd the Child, The 1908, AM\&B, USA, LoC

M Y

$\mathbf{N}$

Redman's View, The 1909, AM\&B, USA, LoC

Redskin Duel, The [re-issued as The Death Mask] 1914, Kay-Bee,

USA, LoC

D

Rescued From an Eagle's Nest 1908, Edison, USA, FM

Rocking Gold IN THE KLONDIKE 1901, Edison, USA, LoC

M

$\mathbf{F}$

Romance of the Cliff Dwellers 1911, Edison, USA, LoC/FM

D V

Romance of the RaIL, A 1903, Edison, USA, LoC/FM

G L P

Romance of the Western Hills, A 1910, AM\&B, USA, LoC

D T

Rose O'SALEM-Town 1910, AM\&B, USA, LoC/FM

D E G H

Rounding Up ANd BRANDING CATTLE 1904, Edison, USA, LoC

Rounding Up of THE Yeggmen 1904, Edison, USA, GV/OC

B S

Round-up IN OKLAHOMA, A 1908, Oklahoma Natural Mutoscene Co.,

USA, LoC

Royal Gorge (Colorado) 1898, Edison, USA, LoC

C F

Rube ANd MANDy's visit to Coney IsLAND 1903, Edison, USA, LoC

Runaway Engine, The 1911, Kalem, USA, FM

R S Y

SACRIFICE, THE 1912, Vitagraph, USA, FM

G

T

Scene in the Esquimaux Village see Esquimaux Leap-Frog and

Esquimaux Game of SNAP-THe-Whip SERVing Rations to the

INDIANS 1898, Edison, USA, LoC

$\mathbf{P}$

Sham Battle at the Pan-American Exposition 1901, Edison, USA, LoC M U Sheriff's DAughter, The 1911, Pathé: American Kinema, USA, CF Sioux GHost DANCE 1894, Edison, USA, LoC

Sky-Scrapers of New York City, From the North River 1903, Edison,

USA, LoC

D K W

Song of the Wildwood Flute 1910, AM\&B, USA, LoC

SPANISH DANCERS AT THE PAN-AMERICAN Exposition 1901, Edison, USA, LoC 
Souawman's Sweetheart, The [Jalousie de Squaw] 1912, Pathé:

American Kinema, USA, CF

Stage Rustler, The 1908, AM\&B, LoC

Starlight's Necklace [La Parure de Starlight] 1911, Pathé: American

Kinema, USA, CF

Story of Plymouth Rock, The see The Landing of the Pilgrims

StrongheART 1914, Klaw and Erlanger, USA, CF

Sulla VIA DELL'ORo Cines, 1913, IT, FM

TANGLed Lives 1911, Kalem, USA, LoC

Telegram uit Mexico 1914, Hollandia, NL, FM

Terrible Teddy, The Grizzly King 1901, Edison, USA, LoC

Teufelsauge, Das [The Devil's Eye] 1914, DE, FM

TheIr Lives For Gold see LE RAILWAY DE LA MORT

Tomboy on Bar Z 1912, EssAnAY, USA, FM

Tourists, THE 1912, AM\&B, USA, LoC

Y

Tourists Arriving at WaWona Hotel 1903, AM\&B, USA, LoC

Tourists Going Round Yellowstone Park c.1899, Edison, USA, LoC

Tracked by Bloodhounds; or a Lynching at Cripple Creek 1904, Selig, USA, SFVA

Trip Around the Pan-American Exposition, A 1901, Edison, USA, LoC M U Trip Through the Yellowstone Park, A USA 1906, Edison, USA, LoC P Trip up Mount Rainier, A 1911, Edison, USA, LoC T TRIUMPH OF Right, The 1912, Vitagraph, USA, FM G

Twentieth Century Tramp, A 1902, Edison, USA, LoC M

Two Little Rangers 1912, Solax, USA, FM Y

Uncle Josh At The Moving Picture Show 1902, Edison, USA, LoC R UnCle Tom's CABIN 1903, Edison, USA, FM B

Upper Falls of the Yellowstone, The 1901, Edison, USA, LoC

Up-to-Date Souaw, An [L'Indienne Ko-To-Sho SE MOdernise] 1911,

Pathé: American Kinema, USA, CF/LoC

C D J T Y

VAlley of The Esopus, The 1906, AM\&B, USA, LoC

Vaquero's Vow, The 1908, AM\&B, USA, LoC

VOYAge À traVers L'IMPOSSIBle [Voyage Across THE IMPOSSIBLe] 1904,

Méliès, FR, FM

Voyage dans la lune, Le [A Trip to the Moon] 1902, Méliès, FR, FM F M Wand Dance, Pueblo Indians 1898, Edison, USA, LoC D K

Wash Day IN MeXico 1897, Edison, USA, LoC

$\mathrm{K}$

WATERFAll IN THE CATSKILls 1897, Edison, USA, LoC P

Wawona, Big Tree 1903, AM\&B, USA, LoC T

Western Stagecoach Hold Up, A 1904, Edison, USA, FM K

What Happened in The TunNel 1903, Edison, USA, LoC L R 
What Happened on 23Rd Street, New York City 1901, Edison, USA, LoC L White Cloud's Secret 1912, Nestor, USA, FM

White Dove's SACRIfICE 1914, Sawyer, USA, LoC

WigWAM: DE GESCHIEDENIS VAN EEN KINDERROOF IN CANADA BIJ NiJMEgEN

[Wigwam: The History of the Abduction of a Child in Canada

Near Nijmegen] 1912, C.A.P.I., NL, FM

WinNing HAND, The 1913, Vitagraph, USA, FM

Witch of THE Everglades 1911, Selig, USA, FM

Wolf Hunt, The 1908, Oklahoma Natural Mutoscene, USA, LoC C

[Yellowstone PARK] 1912, Edison, USA, FM P

Zulu's HeART, The 1908, AM\&B, USA, LoC D

\section{Films From Secondary Sources}

Acadian Elopement, An 1912, AM\&B, USA $\quad$ E

Buffalo BILl 1894, Edison, USA K

Battle of Bunker Hill, The 1912, Edison, USA H

Border RANGer, The 1911, Essanay, USA S

Call of the West, The 1912, Champion, USA C

Cowboy For a DAY, A 1911, Bison, USA $\quad$ Q

Custer's Last Fight 1912, Bison, USA $\quad$ H

Custer's Last Stand see On the Little Big Horn

Daniel Boone 1911, Republic, USA $\quad$ H X

DANIEL BoONE's BRAVERY 1911[?], Kalem, USA E H

Education of Elisabeth, The 1910, Kalem, USA C

Fatal Gold Nugget, The 1910, Bison, USA G

Female Bandit, The 1910, Bison, USA Y

Feud in the Kentucky Hills, A 1912, AM\&B, USA E

Fight For FREedoM, The 1908, AM\&B, USA H

From Peticodiac to Elgin, New Brunswick 1906 [?], AM\&B, USA P

From the Artics to the Tropics 1910, Edison, USA R

Girl Cowboy, The 1910, Bison, USA Y Y

GIRLS OF THE RANGE 1910, Selig, USA L

GIRls WILl be Boys 1910, Essanay, USA Y

HiAWATHA 1909, Imp., USA

[Hoe gloeilampen WORden GeMAAKT] How Light Bulbs are Made c.1913 F

Horse-Thief, The 1905, AM\&B, USA E G

[IN HET LAND DER APEN EN SLANGEN] In the Land of Apes and Snakes C.1913 
IN THE Wilderness, 1910, Selig, USA $\quad$ G H

INDIANS GIRL's AwAKENING, AN 1910, Essanay, USA D

JAmes Boys In Missouri, The 1908, Essanay, USA H X

Kentucky Pioneer, A 1910, Selig, USA E G

[HeT Leven Der Cowboys ] The Life of Cowboys c.1913 F

LAND of Promise, The 1912, Imp., USA $\quad$ F

Last Stand of the Dalton Boys, The 1912, ?, USA H

MOONSHINers, THE 1904, AM\&B, USA E P

Night of Terror, A 1908, AM\&B, USA $\quad$ H

Night Riders, The 1908, Kalem, USA X

On the Little Big Horn [also issued as: Custer's Last Stand] 1909, Selig, USA

[ONDERZOEKING VAN DEN MAAG DOOR RÖNTGENSTRALEN] Exploration of the Stomach by X-Ray c.1913

Outlaws, The 1911, Selig, USA

Pioneer Days 1907, Edison, USA

Red Cloud 1908, Kalem, USA

QUEEN OF THE RANCH 1909, Lubin, USA

Red Man's WaY, The 1907, Kalem, USA

Reuben IN THe Subway 1905, AM\&B, USA

Revenue MAn AND the Girl, The 1911, AM\&B, USA

[RiJSTPLANTAge In JaPAN] Rice Plantations in Japan c.1913 F

Romance of the Western Hills, A 1910, AM\&B, USA T

Rose OF KeNTUCKY, The 1911, AM\&B, USA E

Rube in the Subway, A see Reuben in the Subway

RustLER, The 1910, Selig, USA

C L

SAge Brush Girl, The 1914, ?, USA

Siege of the Alamo, The 1911, Star Film, USA H

SPOILERS, The 1914, Selig, USA E O

Souawman's Daughter, The 1908, Selig, USA L

Squaw's Love: An Indian Poem of Love in Pictures 1911, AM\&B, USA O

StAMPEDe, The 1909, Selig, USA S

SwitchMAN's Tower, THE 1911, Edison, USA R

TAle OF THE Wilderness, A 1912, AM\&B, USA E

TAMing of Wild Bill, The 1910, Lubin, USA C

TENDERFOOT, A 1911, ?, USA

Terrible Ted 1907, AM\&B, USA $\quad X$

Trapper AND the Redskin, The 1910, Kalem, USA D

Tribal LaW, The 1912, Bison, USA G

Under the Star-Spangled Banner 1908, Kalem, USA H

WeNONA 1910, Powers, USA O 
When We Were Young 1914, Selig [?], USA S

Widow's Claim, The 1912, Bison, USA G

WOMAN's WAY, A 1908, AM\&B, USA $\quad$ H

Wooing of Miles Standish, The 1907 Kalem, USA O

[ZWAVELINDUSTRIE OP SICILIË] Sulfur Industry in Sicily c.1913 F

\section{Post- I 9 I 5 films}

BACK to THE Future 1985, Steven Spielberg $\quad$ T

Ballad of Little Jo, The 1993, Maggie Greenwald A

Dances With Wolves 1990, Kevin Costner D D

DeAd Man 1995, Jim Jarmusch $\quad$ A

DeERslayer, The 1957, Kurt Neumann $\quad$ H

DesPeRAdo 1995, Robert Rodriguez A

ELISABETH 1998, Shekhar Kapur $\quad$ F

Gladiator 2000, Ridley Scott $\quad$ F

High Noon 1952, Fred Zinneman $\quad$ M

How the West Was Won 1962, Henri Hathaway, John Ford,

George Marshall F

Last of the Mohicans 1932, Ford Beebe and B. Reeves Eason H

Last of the Mohicans 1936, George B. Seitz H

LAst of THE Mohicans 1992, Michael Mann $\quad$ H

LeATHERSTOCKING 1924, George B. Seitz H

LONE STAR 1996, John Sayles $\quad$ A

Mariachi, El 1994, Robert Rodriguez A

Man Who Shot Liberty Valance, The 1963, John Ford M

Nell 1994, Michael Apted $\quad$ E

Once Upon a Time in Mexico 2003, Robert Rodriguez A

Pocahontas 1995, Walt Disney Pictures, Mike Gabriel, Eric Goldberg D

Quick AND The Dead, The 1995, Sam Raimi A

Rio Bravo 1959, Howard Hawks M

Saving Private Ryan 1998, Steven Spielberg F

SCHINDLER'S LIST 1993, Steven Spielberg F

TROY 2004, Wolfgang Petersen $\quad$ F

UnForgiven 1992, Clint Eastwood A A

Wild Wild West 1999, Barry Sonnenfeld $\quad$ A 



\section{Bibliography}

\section{Primary Sources}

Bower, B.M. [Bertha Sinclair]

1915 Jean of the Lazy A. New York: A. L. Burt Company

Bryant, William Cullen

1872-74 Picturesque America; Or, The Land We Live In. New York:

D. Appelton \& Co.

Cooper, James Fenimore

D E H O

1823 The Pioneers. New York: Charles Wiley

1826 The Last of the Mohicans. Philadelphia: Carey \& Lea

1827 The Prairie. Philadelphia: Carey \& Lea

1840 The Pathfinder. Philadelphia: Carey \& Lea

1841 The Deerslayer. Philadelphia: Carey \& Lea

Corneille, Pierre

D

1957 [1637] Le Cid. Paris: Larousse

Eckerskom, J.

c.1900 ' $n$ Prairie-film. Translated from German into Dutch

by C. Zegers. [publisher unknown]

Harriman, Mary Alice

D

1900 "The Indian in Transition." Overland Monthly and Out West

Magazine XXXV, 205 (January): 33-39

Harvey, Charles M.

1907 “The Dime Novel in American Life." Atlantic Monthly 100: 37-45

Holmes, Burton

1908 Burton Holmes Travelogues. New York: McClure Company

Howe, Hubert

1893 The Book Of The Fair. Chicago and San Francisco: Bancroft

Company. Reprinted full-text in World's Columbian Exposition of 1893

and partially in Web-Book of the Fair: A Window on the Chicago

World's Fair Of 1893, the Columbian Exposition. See electronic sources

Lawson, W. B.

$\mathbf{X}$

1901 Jesse James, the Outlaw: A Narrative of the James Boys.

The Jesse James Stories: Original Narratives of the James Boys, 1.

New York: Street and Smith, 1901

Longfellow, Henry Wadsworth

E H O

1855 The Song of Hiawatha. Boston: Ticknor and Fields

1858 The Courtship of Miles Standish. Boston: Ticknor and Fields 
May, Karl

D J

1908 Winnetou I. Freiburg, i. Br.: Friedrich Ernst Fehsenfeld.

Published in English translation: 1977 The Collected works of

Karl May. New York: The Seabury Press

Montesquieu

C

1977 [1721] Lettres persanes. Paris: Gallimard

Parkman, Francis

E H

1851 History of the Conspiracy of Pontiac, and the War of the North

American Tribes Against the English Colonies After the Conquest

of Canada.

Roosevelt, Theodore

A D K T

1912 "History as Literature." Reprinted in 1987 The Man in The Arena.

Edited with Introduction and Notes by John Allen Gable. Oyster Bay, NY:

Theodore Roosevelt Association

Rowlandson, Mary

D

1682 The Sovereignty and Goodness of God, Or The Narrative of the

Captivity and Restoration of Mrs. Mary Rowlandson. London:

Joseph Poole

Voltaire

1974 [1759] Candide. Paris: Hatier

\section{Newspapers and Periodicals}

The following newspapers and trade periodicals are used for the dates in brackets. Precise references to articles published in these papers appear in the footnotes only.

Billboard [1907]

Biograph Bulletins [1899-1912] facsimile reproductions in 1971 Kemp Niver (comp.) Biograph Bulletins 1896-1908.

Los Angeles: Locare Research Group; Eileen Bowser (comp.) 1973 Biograph Bulletins 1908-1912. New York: Farrar, Strauss and Giroux

Bioscope [1909]

Boston Post [1911]

Cinema [1913]

Edison film catalog [1900-1906]

Kinematograaf [1913] on microfilm at the Filmmuseum

original volumes held by the Filmmuseum as quoted in the Library of Congress catalog original volumes held by the Filmmuseum 
Motion Picture Story Magazine

[1911-1912]

Motography [1911-1912]

Moving Picture News [1911-1913]

Moving Picture World [1907-1914]

New York Times [1909-1914]

Nickelodeon [1909-1911]

Overland Monthly and Out West

Magazine [1900]

Photoplay Magazine [1911-1913]

Show World [1908]

Universal Weekly [1912]

Variety [1907-1914] original volumes held by the Library of Congress

original volumes held by the Library of Congress

original volumes held by the Library of Congress

original volumes held by the Library of Congress

a selection reproduced as facsimile in: 1984 The New York Times Encyclopedia of Film. New York: Times Books original volumes held by the Library of Congress scanned originals of Making of America digital library original volumes held by the Library of Congress papers in the George Kleine Collection, LoC original volumes held by the Library of Congress

reprints published in 1983 Variety Film Reviews 1907-1989 (Vol.1: 1907-1920). New York: Garland

\section{Catalogues}

Library of Congress, Manuscript Division 1979 George Kleine. A Register of his Papers in the Library of Congress. Washington, DC: Library of Congress

Horwitz, Rita, and Harriet Harrison (preps) 1980 The George Kleine Collection of Early Motion Pictures in the Library of Congress: A Catalog. Washington, DC: Library of Congress

Musser, Charles

1997 Edison Motion Pictures, 1890-1900: An Annotated Filmography. Washington, DC: Smithsonian Press

Musser, Charles (ed.) 1985 Motion Picture Catalogs by American Producers and Distributors, 18941908: A Microfilm Edition. Frederick, MD: University Publications of America 
Niver, Kemp

1985 Early Motion Pictures: The Paper Print Collection in the Library of Congress. Washington, DC: Library of Congress

\section{Electronic Sources}

Department of Cultural Policy and Management of City University, London http://www.city.ac.uk/cpm

Encyclopaedia Britannica Online http://www.britannica.com

Internet Movie Database (IMDb) http://us.imdb.com

LoC - American Indians in Silent Film, Karin C. Lund (comp.)

http://www.loc.gov/rr/mopic/indianı.html

LoC - American Memory Historical Collections for the National Digital Library http://lcweb2.loc.gov/ammem

LoC - Inventing Entertainment: The Motion Pictures and Sound Recordings of the Edison Companies

http://memory.loc.gov/ammem/edhtml/edhome.html

Maison des Cultures du Monde, Musée Albert Kahn

http://www.mcm.asso.fr/le_guide/structures/lieux/musee_albert_kahn.htm

Making of America digital library (MOA)

http://moa.umdl.umich.edu

Merriam-Webster's Online Dictionary, 2005

http://www.m-w.com

Reynolda House, Museum of American House

1990 American Originals: Selections from Reynolda House, Museum of American

Art. Co-published by The American Federation of Arts and Abbeville Press,

Inc. Reissued at:

http://www.reynoldahouse.org/andes.htm

Stanford's Dime Novel and Story Paper Collection

http://www-sul.stanford.edu/depts/dp/pennies/home.html

Ville de Clervaux, exposition of The Family of Man

http://www.clervaux-city.lu/Familyofman.htm

Web-Book of the Fair: A Window on the Chicago World's Fair Of 1893, the Columbian Exposition

http://fly.hiwaay.net/ shancock/fair/1893.html 
Western Literature Association

1987 A Literary History of the American West. Out of print, reissued at:

http://www2.tcu.edu/depts/prs/amwest

World's Columbian Exposition of 1893

http://columbus.gl.iit.edu/index.html

\section{References}

Abel, Richard

D E H J KX

1998a The Ciné Goes to Town: French Cinema, 1896-1914.

Revised and expanded edition. Berkeley: University of

California Press

1998b "'Our Country'/Whose Country?' The 'Americanization'

Project of Early Westerns" 77- 95: Back in the Saddle Again: New

Essays on the Western. Edward Buscombe and Roberta Pearson (eds.)

1999 The Red Rooster Scare: Making Cinema American, 1900-1910.

Berkeley: University of California Press

Allen, Robert C. and Douglas Gomery

1985 Film History: Theory and Practice. New York: McGraw-Hill

Alphen, Ernst van

1997 Caught by History: Holocaust Effects in Contemporary Art,

Literature and Theory. Stanford, CA: Stanford University Press

Altman, Rick

$\mathbf{G}$

1999 Film/Genre. London: BFI Publishing

Anderson, Robert

1979 "The Role of the Western Film Genre in Industry

Competition, 1907-1911." Journal of the University Film

Association XXXI, 2 (Spring): 19-28

Appadurai, Arjun, (ed.)

1986 The Social Life of Things: Commodities in Cultural Perspective.

Cambridge: Cambridge University Press

Armstrong, Tim

1998 Modernism, Technology and the Body: a Cultural Study

Cambridge: Cambridge University Press

Augé, Marc

1999 An Anthropology for Contemporaneous Worlds. Translated by Amy Jacobs. Stanford, CA: Stanford University Press 
Bakhtin, Mikhail

1981 The Dialogic Imagination: Four Essays by M.M. Bachtin.

Edited by Michael Holquist, translation Caryl Emerson and

Michael Holquist. Austin, TX: University of Texas Press

Bal, Mieke

B C S H T U W Y

1987 Lethal Love: Feminist Literary Readings of Biblical Love

Stories. Bloomington, Indiana: Indiana University Press

1996 Double Exposures: The Subject of Cultural Analysis.

New York: Routledge

1997 Narratology: Introduction to the Theory of Narrative. Toronto:

University of Toronto Press

Bal, Mieke and Norman Bryson

1991 "Semiotics and Art History." Art Bulletin LXXIII (2): 174-208

Barker, Jennifer

K

1995 "'Bodily Irruptions: The Corporeal Assault on Ethnographic

Narration." Cinema Journal 34, 3 (Spring): 57-76

Barthes, Roland

1974 S/Z. Translated by Richard Miller. New York: Hill \& Wang. 1981 Camera Lucida: Reflections on Photography. Translated by

Richard Howard. New York: Hill and Wang 1986 The Rustle of Language. Translated by Richard Howard.

Oxford: Basil Blackwell

Baudrillard, Jean

G

1987 The Evil Demon of Images. (Power Institute Publications \#3)

Translated by Paul Patton and Paul Foss. Sydney, AUS: University of Sydney Press

Bazin, André

D G

1971 "The Western, or the American Film Par Exellence." What is

Cinema? Vol. II. Berkeley: University of California Press: 140-148

Beausoleil, Jeanne and Pascal Ory (eds.)

1995 Albert Kahn (1860-1940). Réalités d'une utopie. Boulogne,

musée Albert Kahn

Belloï, Livio

1995 "Lumière and His View: the Cameraman's Eye in Early

Cinema." Historical Journal of Film, Radio and Television 15, 4: $461-474$

Benjamin, Walter

B C F M O P Q Y 1992 [1968] Illuminations. Translated by Harry Zohn.

Edited with Introduction by Hannah Arendt. London: Fontana.

1999 The Arcades Project. Translated by Howard Eiland and

Kevin McLaughlin. Cambridge, MA: Harvard University Press 
Benveniste, Émile

1970 Problems in General Linguistics. Translated by

Mary Elisabeth Meek. Coral Gables: University of Miami Press

Bergson, Henri

K

1911 Matter and Memory. Translated by Nancy Margaret Paul

and W. Scott Palmer. London: George Allen and Unwin

Bhabha, Homi

V

1994 The Location of Culture. London and New York: Routledge

Billington, Ray Allen

E

1966 America's Frontier Heritage. New York: Holt, Rinehart and

Winston

Black, Max

E

1962 Models and Metaphors: Studies in Language and Metaphors.

Ithaca, NY: Cornell University Press

Blom, Ivo

2003 Jean Desmet and the Early Dutch Film Trade. Amsterdam:

Amsterdam University Press

Bollas, Christopher

1993 Being a Character: Psychoanalysis and Self Experience.

London: Routledge

Bold, Christine

O

1987 Selling the Wild West. Popular Western Fiction, 1860 to

1960. Bloomington: Indiana University Press

Bolter, Jay and David Grusin

1999 Remediation: Understanding New Media. Cambridge, MA: MIT Press

Booth, Wayne C.

$\mathbf{Q}$

1974 A Rhetoric of Irony. Chicago: University of Chicago Press

Bordwell, David

A S N

1985 Narration in the Fiction Film. Madison: University of

Wisconsin Press

1989 Making Meaning: Inference and Rhetoric in the Interpretation

of Cinema. Cambridge, MA: Harvard University Press

Bordwell, David, Janet Staiger, and Kristin Thompson

A S

1985 The Classical Hollywood Cinema: Style and Mode of

Production to 1960. New York: Columbia University Press

Bottomore, Stephen

$\mathbf{R}$

1990 "The Panicking Audience?: Early Cinema and the 'Train

Effect'." Historical Journal of Film, Radio and Television 19,

2: $177-216$ 
Bowie, Malcolm

1987 Freud, Proust and Lacan: Theory as Fiction. Cambridge:

Cambridge University Press

Bowser, Eileen

D

1990 The Transformation of Cinema: 1907-1915 (Vol. II in History

of the American Cinema). New York: Scribner's Sons

Brewster, Ben and Lea Jacobs

D

1998 Theater to Cinema: Stage Pictorialism and the Early Feature

Film. Oxford: Oxford University Press

Brown, Julie K.

1994 Contesting Images: Photography at the World's Columbian

Exposition. Tucson, AR: University of Arizona Press

Brownlow, Kevin

D H X

1979 The War, the West, and the Wilderness. New York:

Alfred A. Knopf

1990 Behind the Mask of Innocence: Sex, Violence, Prejudice,Crime:

Films of Social Conscience in the Silent Era. London: Jonathan Cape

Bryson, Norman

G

1989 Looking at the Overlooked: Four Essays on Still Life

Cambridge, MA: Harvard University Press

Buck-Morse, Susan

C P

1991 The Dialectics of Seeing: Walter Benjamin and the Arcades

Project. Cambridge, MA: MIT Press

Burch, Noëll

1990 Life to Those Shadows. Berkeley: University of California Press

Buscombe, Edward

1984 "Painting the Legend: Frederic Remington and the Western."

Cinema Journal XXIII, 4: 12-27

Buscombe, Edward (ed.)

D

1988 The Bfi Companion to the Western. London: BFI Publishing

Buscombe, Edward and Roberta Pearson (eds.)

1998 Back in the Saddle Again: New Essays on the Western.

London: BFI Publishing

Butler, Judith

1993 Bodies that Matter: On the Discursive Limits of "Sex."

New York: Routledge

Cahn, Iris

1996 "The Changing Landscape of Modernity: Early Film and

America's 'Great Picture' Tradition." Wide Angle 18, 3 (July):

$85-100$ 
Catapano, Peter

1994 "Creating 'Reel' Value: The Establishment of MOMA's Film Library, 1935-37." Film History 24, 3-5: 28-46

Cawelti, John G.

1971 The Six-Gun Mystique. Bowling Green, OH: Bowling Green

State University Popular Press

1976 Adventure, Mystery, and Romance: Formula Stories as Art

and Popular Culture. Chicago: The University of Chicago Press

1999 The Six-Gun Mystique Sequel. Bowling Green, OH: Bowling

Green State University Popular Press

Charney, Leo

1995 "In a Moment: Film and the Philosophy of Modernity."

Leo Charney and Vanessa R. Schwartz (eds.) Cinema and the

Invention of Modern Life: 279-294

Charney, Leo and Vanessa R. Schwartz (eds.)

1995 Cinema and the Invention of Modern Life. Berkeley:

University of California Press

Chase, Malcolm and Christopher Shaw

1989 "The Dimensions of Nostalgia." Christopher Shaw and Malcolm Chase (eds.) The Imagined Past: History and Nostalgia.

Manchester and New York: Manchester University Press: 1-17

Cherchi Usai, Paolo

1994 Burning Passions: An Introduction to the Study of Silent

Cinema. London: BFI Publishing

Clifford, James

1994 "Diasporas." Cultural Anthropology 9, 3: 302-338

Crary, Jonathan

1990 Techniques of the Observer: On Vision and Modernity in the

Nineteenth Century. Cambridge, MA: MIT Press

Cronon, William

E

1991 Nature's Metropolis: Chicago and the Great West. New York:

W.W. Norton

Crowther, Paul

$\mathbf{P}$

1989 The Kantian Sublime: From Morality to Art. Oxford:

Clarendon Press

Culler, Jonathan

D I L N T Y

1976 Saussure. London: Fontana

1983 On Deconstruction: Theory and Criticism After Structuralism.

Ithaca, NY: Cornell University Press

1988 Framing the Sign: Criticism and Its Institutions. Norman:

University of Oklahoma Press 
1996 "Prostitution and Les Fleurs du Mal." ASCA BRIEF: Issues in

Cultural Analysis. Amsterdam: ASCA Press: 11-26

Dällenbach, Lucien

1989 The Mirror in the Text. Translated by Jeremy Whiteley with

Emma Hughes. Chicago: The University of Chicago Press

Davey, Nicholas

A

1999 "The Hermeneutics of Seeing." Ian Heywood and Barry

Sandwell (eds.) Interpreting Visual Culture: Explorations in the

Hermeneutics of the Visual. London and New York: Routledge: 3-29

Debord, Guy

1970 The Society of the Spectacle. Translated by Fredy Perlman and John Supak. Detroit: Black \& Red.

De Grazia, Edward and Roger K. Newman

$\mathbf{X}$

1982 Banned films: Movies, Censors and the First Amendment.

New York: R.R. Bowker Company

De Lauretis, Teresa

1984 Alice Doesn't: Feminism, Semiotics, Cinema. Bloomington,

IN: Indiana University Press

1987 Technologies of Gender: Essays on Theory, Film, and Fiction.

Bloomington, IN: Indiana University Press

Deleuze, Gilles

G Q

1990 "Plato and the Simulacrum." Logic of Sense. Minneapolis:

University of Minnesota Press: 253-276

1994 Difference and Repetition. Translated by Paul Patton.

London: Athlone Press

De Los Reyes, Aurelio

1995 “Quand l'Histoire se met en scène: Pancho Villa et la

Mutual Film Corp." Génériques I (Winter): 2-13

Delpeut, Peter

B

1997 Cinema Perdu. De eerste dertig jaar van de film, 1895-1925.

Epe: Bas Lubberhuizen

Delpeut, Peter, Daan Hertogs, Eric de Kuyper, Mark-Paul Meyer, and René Wolf (eds.)

1992 NFM-Themareeks 12 "Albert Kahn. Een beeldarchief van

de planeet." Amsterdam: Stichting Nederlands Filmmuseum

Denning, Michael

1987 Mechanic Accents: Dime Novels and Working-Class Culture in America. London, New York: Verso

Derrida, Jacques

1976 Of Grammatology. Translated and with an Introduction by

A U V W Y

Gayatri Spivak. Baltimore: Johns Hopkins University Press 
1978 Writing and Difference. Translated by Alan Bass. Chicago: The University of Chicago Press

1987 The Truth in Painting. Translated by Geoff Bennington and Ian McLeod. Chicago: The University of Chicago Press 1995 Archive Fever: A Freudian Imrpession. Translated by Eric Prenowitz. Chicago: The University of Chicago Press

Doane, Mary Ann

K M 1996 "Temporality, Storage, Legibility: Freud, Marey, and the Cinema." Critical Inquiry 22, 2 (Winter): 313-343

Doxtator, Deborah 1992 Fluffs and Feathers: An Exhibit on the Symbols of Indianness: A Resource Guide. Brantford, ON: Woodland Cultural Centre

Duncan, Carol 1991 "Art Museums and the Ritual of Citizenship." Ivan Karp and Steven D. Lavine (eds.) Exhibiting Cultures: 88-103

Dupond-Roc, Roselyne and Jean Lallot 1980 Aristote, La Poétique. Texte, traduction, notes. Paris: Édition du Seuil

Dupré la Tour, Claire, André Gaudreault and Roberta Pearson (eds.) 1999 Le cinema au tournant du siècle / Cinema at the Turn of the Century. Lausanne: Éditions Payot

Durham, Scott 1998 Phantom Communities: The Simulacrum and the Limits of Postmodernism. Stanford, CA: Stanford University Press

Dyer, Richard 1997 White. London and New York: Routledge

Elsaesser, Thomas 1996 "Subject Positions, Speaking Positions; From Holocaust, Our Hitler, and Heimat to Shoah and Schindler's List." Vivian Sobchack (ed.) The Persistence of History: Cinema, Television, and the Modern Event. New York: Routledge, 1996: 145-83 1999 "'Le cinema d'après Lumière': Rereading the 'Origins' of the Filmic Image." Mieke Bal (ed.) The Practice of Cultural Analysis; Exposing Interdisciplinary Interpretation. Stanford, CA: Stanford University Press: 60-74

Elsaesser, Thomas (ed.)

1990 Early Cinema: Space, Frame, Narrative. London: BFI Publishing Elsner, John and Roger Cardinal (eds.) 1994 The Cultures of Collecting. London: Reaktion Books 
Emrich, David

C I T Y

1997 Hollywood, Colorado: The Selig Polyscope Company and

the Colorado Motion Picture Company. Denver, CO:

Post Modern Company

Esders-Angermund, Karin

N Y

1997 Weiblichkeit und sexuelle Differenz in amerikanischen

Genrekino: funktionen der Frauin frühen Westernfilm. Trier:

WVT Wissenschaftlicher Verlag Trier

Fabian, Johannes

D T

1983 Time and the Other: How Anthropology Makes Its Object.

New York: Columbia University Press

Fernett, Gene

C

1988 American Film Studios: An Historical Encyclopedia.

Jefferson, NC: McFarland \& Company

Fielding, Raymond

$\mathbf{R}$

1970 "Hale's Tours: Ultra Realism in the Pre-1910 Motion Picture."

Cinema Journal 10, 1 (Fall): 34-47

Fossati, Giovanna

B

1996 "Coloured Images Today: How to Live With Simulated

Colours (And be Happy)." Daan Hertogs and Nico de Klerk (eds.)

'Disorderly Order': Colours in Silent Film. Amsterdam: Stichting

Nederlands Filmmuseum: 83-89

Foucault, Michel

A B G X

1972 Archeology of Knowledge. London: Tavistock Publications Ltd.

Translated by A.M. Sheridan Smith

1977a "Nietzsche, Geneology, History." Language,

Counter-Memories, Practice: Selected Essays and Interviews.

Translated by D.F. Bouchard and S. Simon. Edited with

Introduction by D.F. Bouchard. Ithaca, NY: Cornell University

Press: 139-164

1977b Discipline and Punish: The Birth of the Prison. Translated by

Alan Sheridan. New York: Vintage

Friedberg, Anne

C P V Y

1993 Window Shopping: Cinema and the Postmodern. Berkeley:

University of California Press

Frisby, David

C

1985 Fragments of Modernity: Theories of Modernity in the Work

of Simmel, Kracauer and Benjamin. Cambridge: Polity Press

Gallagher, Tag

C G 1986 "Shoot-Out at the Genre Corral: Problems in the 'Evolution' 
of the Western." Barry Grant (ed.) Film Genre Reader. Austin, TX:

University of Texas Press: 202-215

Garber, Marjorie

1992 Vested Interest: Cross-Dressing and Cultural Anxiety.

New York: Harper Perrenial

Gaudreault, André

K N

1987 "Narration and Monstration in the Cinema." Journal on Film and Video 39, 2: 29-36

1988 Du littéraire au filmique: Système du récit. Paris:

Méridiens Klincksieck

2004 Cinema delle origini. O della "cinematografia-attrazione". Milano:

Il Castoro

Geertz, Clifford

A E

1973 The Interpretation of Cultures. New York: Basic books, Inc.

Gennep, Arnold van

D

1960 The Rites of Passage. Chicago: The University of Chicago Press

Genette, Gérard

D E

1982 Figures. Vols. 1-3. English Selections. Translated by

Alan Sheridan. New York: Columbia University Press

Ginzburg, Carlo

A E

1980 The Cheese and the Worms. The Cosmos of a

Sixteenth-Century Miller. Translated by John and Anne Tedeschi.

Baltimore: Johns Hopkins University Press

Göktürk, Deniz

C M

1997 "Euro-Westerns: the West as the hinterland of the modern metropolis." Lecture presented at the conference Back in the

Saddle Again: Critical Approaches to the Early Western Film

(Utrecht University)

Grieveson, Lee

H X

2004 Policing Cinema: Movies and Censorship in Early Twentieh-

Century America Berkeley: University of California Press

1999 “The Birth of Fiction, 1907-1915." Leonardo Quaresima,

Alssandra Raengo, Laura Vichi (eds.) La nascita dei generi

cinematographici /The Birth of Film Genres: 293-306

Griffiths, Alison

D

1996a "'Journeys for Those Who Can Not Travel': Promenade

Cinema and the Museum Life Group." Wide Angle 18, 3: 53-84

1996b "Science and Spectacle: Native American Representation in

Early Cinema." S. Elizabeth Bird (ed.) Dressing In Feathers: 79-95

2002 Wonderous Difference: Cinema, Anthropology, and Turn-of-

the-Century Visual Culture. New York: Columbia University Press 
Gunning, Tom

A D G K L M N S 4 U V

1986 "The Cinema of Attractions: Early Film, Its Spectator and the Avant-Garde." Wide Angle 8, 3/4: 63-70

1991a D.W. Griffith and the Origins of the American Narrative Film:

The Early Years at Biograph. Urbana and Chicago: University of

Illinois Press

1991b "Enigmas, Understanding, and Further Questions: Early

Cinema Research in Its Second Decade Since Brighton." Persistence of Vision 9: 4-9

1994 "The World as Object Lesson: Cinema and Audiences, Visual

Culture and the St. Louis World's Fair, 1904." Film History VI:

422-444

1995a "Tracing the Individual Body: Photography, Detectives, and

Early Cinema." Leo Charney and Vanessa R. Schwartz (eds.)

Cinema and the Invention of Modern Life: 15-45

1995b "'Those Drawn with a Very Fine Camel's Hair Brush':

The Origins of Film Genres." iris 19: 49-61

1997 "Before Documentary: Early Non-Fiction Films and the

'View' Aesthetic." Daan Hertogs and Nico de Klerk (eds.)

Uncharted Territory: 9-24

Haber, John

2000 "Forward into the Past. Frederic Edwin Church: In Search of

the Promised Land." Postmodernism and Art History: Gallery

Reviews from Around New York

http://www.haberarts.com/xroads.htm

Hamon, Philippe

1992 Expositions: Literature and Architecture in Nineteenth-Century

France. Trans. Katia Sainson-Frank and Lisa Maquire; Introduction

by Richard Sieburth. Berkeley: University of California Press

Hansen, Miriam

F G K

1991a Babel and Babylon: Spectatorship in American Silent Film.

Cambridge, MA: Harvard University Press

1991b “Decentric Perspectives: Kracauer's Early Writings on Film

and Mass Culture." New German Critique 54: 49

1996 "Schindlers List Is Not Shoah, The Second Commandment,

Popular Modernism, And Public Memory." Critical Inquiry 22, 2

(Winter):292-312

Harries, Dan

2000 Film Parody. London: BFI Publishing

Heidegger, Martin

1977[1938] “The Age of the World Picture." The Question 
Concerning Technology and Other Essays. Translated by

William Lovitt. New York: Harper and Row

Hengeveld, Kees

1997 Shifters. Amsterdam: IFOTT. Inaugural lecture, University

of Amsterdam

Hertogs, Daan and Nico de Klerk (eds.)

1997 Uncharted Territory: Essays on Early Nonfiction Film.

Amsterdam: Stichting Nederlands Filmmuseum

Hinsley, Curtis M.

1991 "The World as Marketplace: Commodificaton of the Exotic at the World's Columbian Exposition, Chicago, 1893." Ivan Karp, Steven D. Lavine (eds.) Exhibiting Cultures: 344-365

Hipple, Walter J.

1957 The Beautiful, the Sublime, and the Picturesque in Eighteenth-

Century British Aesthetic Theory. Carbondale: The Southern Illinois

University Press

Hirsch, Marianne

1992-93 "Family Pictures: Maus, Mourning, and Postmemory."

Discourse 15, 2 (Winter): 3-29

1997 Family Frames: Photography, Narrative, and Postmemory.

Cambridge: Harvard University Press

Hirschkop, Ken and David Shepherd, (eds.)

1989 Bakhtin and Cultural Theory. Manchester and New York:

Manchester University Press.

Hutcheon, Linda

1980 Narcissistic Narrative: The Metafictional Paradox. New York:

Methuen

1985 A Theory of Parody: The Teachings of Twentieth-Century Art

Forms. New York and London: Methuen

1988 A Poetics of Postmodernism: History, Theory, Fiction. London:

Routledge

Huyssey, Christopher

1967 [1927] The Picturesque: Studies in a Point of View. London: Archon Books

Huyssen, Andreas

1995 Twilight Memory: Marking Time in a Culture of Amnesia.

New York: Routledge

Jameson, Frederic

1981 The Political Unconscious. Narrative as a Socially Symbolic Act. Ithaca: Cornell University Press 
Jay, Gregory S.

2000 "White Man's Book No Good": D.W. Griffith and the American Indian." Cinema Journal 39, 4: 3-26

Jay, Martin

N T W

1988 "Scopic Regimes of Modernity." Hal Foster (ed.) Vision and Visuality. New York: The New Press: 3-28

Jenks, Chris (ed.)

1995 Visual Culture. London and New York: Routledge

Jenkins, Henry and David Thorburn (eds.)

2003 Rethinking Media Change: The Aesthetics of Transition.

Cambridge, MA: MIT Press

Johnson, Barbara

G

1987 A World of Difference. Baltimore: Johns Hopkins University

Press

Karp, Ivan and Steven D. Lavine (eds.)

1991 Exhibiting Cultures: The Poetics and Politics of Museum

Display. Washington, DC: Smithsonian Institution

Kaufmann, Claudine

1997 "Le silence sied á l'Indien. Journal de la restauration (2)."

Cinémathèque 12 (Fall): 121-132

Kelly, Michael (ed.)

1998 Encyclopedia of Aesthetics, vol. 2. Oxford, Oxford University Press

Kermode, Frank 1966 The Sense of an Ending: Studies in the Theory of Fiction.

Oxford: Oxford University Press

Kessler, Frank

1997 "Brieven uit de verte. Een analyse van de film Een Telegram

Uit Mexico." Jaarboek Mediageschiedenis 8: Honderd jaar film in

Nederland. Amsterdam: Stichting beheer IISG/Stichting

Mediageschiedenis: 201-213

1999 "La féerie - un genre des origines." Leonardo Quaresima,

Alssandra Raengo, Laura Vichi (eds.) La nascita dei generi

cinematographici /The Birth of Film Genres: 229-238

2000 "On Fairies and Technologies." John Fullerton and Astrid Söderbergh Widding (eds.) Moving Images: From Edison to the Webcam. Sidney, AUS: John Libbey: 39-46 2001 "Événements et images: histoire, representation, fiction." J.-P. Bertin-Maghit et B. Fleury-Vilatte (eds.) Les institutions de l'image. Paris: Éditions de l'École des Hautes Études en Sciences Sociales: $67-74$ 
Kirby, Lynne

N R S

1988 "Male Hysteria and Early Cinema." Camera Obscura 17

(December): 113-131.

1997 Parallel Tracks: The Railroad and Silent Cinema. Durham,

London: Duke University Press

Kirshenblatt-Gimblett, Barbara

1998 Destination Culture: Tourism, Museums, and Heritage.

Berkeley: University of California Press

Kitses, Jim

1969 Horizons West. London: Thames and Hudson

Kitses, Jim and Gregg Rickman (eds.)

G

1998 The Western Reader. New York: Limelight Editions. With an Introduction by Jim Kitses

Klerk, Nico de

2000 "'Pictures to be Shewn': Programming the American

Biograph." Simon Popple and Vanessa Toulmin (eds.) Visual

Delights: Essays on the Popular and Projected Image in the

19th Century. Throwbridge: Flicks Books

Kracauer, Siegfried

K

1995 [1963] The Mass Ornament: Weimar Essays. Translated,

Edited, and with Introduction by Thomas Y. Levin. Cambridge,

MA: Harvard University Press

Kuyper, Erik de

1991 "De vreemde taal van de stomme film. Film in de periode

1910-1915." NFM Themareeks 4. Amsterdam: Stichting

Nederlands Filmmuseum

Lahue, Kalton C.

$\mathrm{O}$

1973 Motion Picture Pioneer: The Selig Polyscope Company.

South Brunswick, NJ: A.S. Barnes

Landow, George P.

B

1997 Hypertext 2.o.: The Convergence of Contemporary Critical

Theory and Technology. Baltimore: Johns Hopkins University Press

Langman, Larry

E

1992 A Guide to Silent Westerns. Westerport, CT: Greenwood Press

Laplanche, Jean and Jean-Baptiste Pontalis

A

1973 The Language of Psychoanalysis. Translated by Donald

Nicholson-Smith. New York: W.W. Norton

Leith, Dick and George Myerson

1989 The Power of Address: Explorations in Rhetoric. London and

New York: Routledge 
Lenk, Sabine

1997 "Der Aktualitätenfilm vor dem Ersten Weltkrieg in

Frankreich." KINtop. Jahrbuch zur Erforschung des frühen Films 6: 51-66

Leutrat, Jean-Louis

1987 Le Western. Archéologie d'un genre. Lyon: Presses

Universitaires de Lyon

Limerick, Patricia Nelson

1987 The Legacy of Conquest: The Unbroken Past of the American

West. New York: W.W. Norton

Loshitzky, Yosefa (ed.)

1997 Spielberg's Holocaust: Critical Perspectives on Schindler's List.

Bloomington: Indiana University Press

Lotman, Jurij

1977 The Structure of the Artistic Text. Translation by Gail Lenhoff

and Ronald Varson. Ann Arbor: University of Michigan Press

1979 "The Origin of Plot in the Light of Typology." Poetics Today 1,

1-2 (Autumn): 161-184

Lowenthal, David

1985 The Past is a Foreign Country. Cambridge: Cambridge

University Press

1989 "Nostalgia Tells it Like it Wasn't" Christopher Shaw and

Malcolm Chase (eds.) The Imagined Past: History and Nostalgia.

Manchester, New York: Manchester University Press: 18-32

Mackintosh, Barry

2000 [1985] "Before the National Park Service." The National Parks:

Shaping the System. 3rd (electronic) edition issued at:

http://www.cr.nps.gov/history/online_books/mackintosh1/index.htm

Manovich, Lev

2001 The Language of New Media. Cambridge, MA: MIT Press

Marx, Leo

1964 The Machine in the Garden: Technology and the Pastoral

Ideal in America. New York: Oxford University Press

McMahan, Alison

D Y

2002 Alice Guy Blaché: Lost Visionary of the Cinema. London:

Continuum

McHale, Brian

1987 Postmodern Fiction. London: Routledge

Milner, Clyde A., Carol A. O'Connor, Matha A. Sandweiss (eds.) 1994 The Oxford History of the American West. New York, London:

Oxford University Press 
Mitchel, Lee Clark

1996 Westerns: Making the Man in Fiction and Film. Chicago:

The University of Chicago Press

Mitchell, W.J.T.

1985 Iconology: Image, Text, Ideology. Chicago: The University of

Chicago Press

Moser, Walter

G

1988 “intertextualité et interdiscursivité chez R. Musil."

T.F. Carvalhal (ed.) Avaís do I' congresso nacional de ABRALIC,

Vol. I. Porto Alegre, Brasil: Universidade Federal do Rio Grande do Sul: 121-139

Mulvey, Laura

1975 “Visual Pleasure and Narrative Cinema." Screen 16, 3

(Autumn) : 6-18

Murray, Janet $\mathrm{H}$.

B

1997 Hamlet on the Holodeck: The Future of Narrative in Cyberspace.

Cambridge, MA: MIT Press

Musser, Charles

A C G K L R W

1984 "The Travel Genre in 1903-04: Moving Toward Fictional

Narrative." iris II, 1: 47-59

1990 The Emergence of Cinema: The American Screen to 1907

(Vol. I in History of the American Cinema). New York:

Scribner's Sons

1991 Before the Nickelodeon: Edwin S. Porter and the Edison

Manufacturing Company. Berkeley: University of California Press

1997 "Respektabilität und Aktualität: Gedanken zum kulturellen

Stellenwert von Edisons Filmen in der Kinetokop-Ära." KINtop.

Jahrbuch zur Erforschung des frühen Films 6: 67- 79

Nash, Gerald D.

E

1991 Creating the West: Historical Interpretations, 1890-1990.

Albuquerque: University of New Mexico Press

Neale, Steve

G W

1980 Genre. London: BFI Publishing

1990 "Questions on Genre." Screen 31, 1: 45-66

Nemerov, Alexander

1995 Frederic Remington \& Turn-of-the-Century America.

New Haven: Yale University Press

Newmark, Kevin

1995 "Traumatic Poetry: Charles Baudelaire and the Shock of Laughter." Cathy Caruth (ed) Psychoanalysis, Culture, and Trauma. Baltimore: Johns Hopkins University Press: 236-55 
Nora, Pierre

1989 "Between Memory and History: Les Lieux de Memoire."

Representations 26 Special Issue: Memory and Counter-Memory

(Spring): 7-24

Novak, Barbara

1995 Nature and Culture: American Landscape Painting, 1825-1875.

Revised Edition. New York: Oxford University Press

Pearson, Roberta E.

A D H

1992 Eloquent Gestures: The Transformation of performance style

in the Griffith Biograph Films. Berkeley: University of

California Press

1995 "Custer's Still the Hero: Textual Stability and Transformation."

Journal of Film and Video 47, 1-3 (Spring-Fall): 82-97

1996 "Early Cinema" and "Transitional Cinema." Geoffrey

Nowell-Smith (ed.) The Oxford History of World Cinema. London:

Oxford University Press: 13-42

1998 “The Twelve Custers, or Video History" Edward Buscombe

and Roberta E. Pearson (eds.) Back in the Saddle Again: New

Writings on the Western: 197-213

Peirce, Charles S.

E G W

1984 "Logic as Semiotic." Semiotics: An Introductory Anthology.

Edited with Introductions by Robert E. Innis. Bloomington:

Indiana University Press: 4-23

Peiss, Kathy

1986 Cheap Amusements: Working Women and Leisure in Turn-of-

the-Century New York. Philadelphia: Temple University Press

Peterson, Jennifer

D L R

1997 "'Truth is Stranger Than Fiction': Travelogues from the

1910s at the Nederlands Filmmuseum." Daan Hertogs and

Nico de Klerk (eds.) Uncharted Territory: 75-90

1999 World Pictures: Travelogues and the Lure of the Exotic

1896-1920. Ph.D. Dissertation, University of Chicago,

Department of English

Plantinga, Carl

G

1987 "Defining Documentary: Fiction, Non-Fiction, and Projected

Worlds." Persistence of Vision 5: 44-54

Popper, Karl

K

1959 The Logic of Scientific Discovery. London: Hutchinson

Quaresima, Leonardo, Alssandra Raengo, Laura Vichi (eds.)

1999 La nascita dei generi cinematographici /The Birth of Film

Genres. Udine: Forum 
Raessens, Joost

2001 "De virtuele ruimte. Computergames: interface van de eenentwintigste eeuw." De ruimte, collection of symposium Studium Generale, Universiteit Utrecht, May 2000

Rayward, W. Boyd 1999 "From Docent to Cyberdocent: Education and Guidance in the Virtual Museum." Archives and Museum Informatics 13: 23-53

Reed, Toby and R.J. Thompson 1996 "The Six-Gun Simulacrum: New Metaphors for and Old Genre." Film Criticism XX, 2 (Spring): 52-69

Reynolds, Teri 2000 Case Studies in Cognitive Metaphor and Interdisciplinary Analysis: Physics, Biology, Narrative. Ph.D. Dissertation, New York: Columbia University, Department of English and Comparative Literature

Ribon, Michel 1999 Esthétique de la catastrophe. Essai sur l'art et la catastrophe. Paris: Éditions Kimé

Rohdie, Sam 1998 "Geography, Photography, the Cinema. Les Archives de la Planète." Screening the Past: 4 (uploaded: September 15) http://www.latrobe.edu.au/www/screeningthepast/reruns/rr998/ SRrr3a.html

Roholl, Marja 2000 "De fototentoonstelling Wij Mensen - The Family of Man in het Stedelijk Museum in Amsterdam: een Amerikaans familiealbum als wapen in de Koude Oorlog." E.O.G.Haitsma Mulier (ed.) Het beeld in de geschiedenis. Historiografische verkenningen. Hilversum:

Verloren: 133-153

Rosa, Joseph G. and Robin May 1989 Buffalo Bill and His Wild West: A Pictorial Biography.

Lawrence, KS: University Press of Kansas

Rosaldo, Renato 1989 "Imperialist Nostalgia." Culture and Truth: The Remaking of Social Analysis. Boston: Beacon Hill: $68-87$

Rose, Margaret A. 1992 Parody: Ancient, Modern, and Post-Modern. Cambridge and New York: Cambridge University Press

Roth, Michael S.

1993 "Returning to Nostalgia." Suzanne Nash (ed.) Home and its 
dislocations in Nineteenth Century France. New York: State

University of New York Press: 25-43

Routt, William D.

1997 “The Australian Bushranger Genre, 1906-1912." Lecture

presented at the conference Back in the Saddle Again: Critical

Approaches to the Early Western Film (Utrecht University)

Russell, Don

K

1960 The Lives and Legends of Buffalo Bill. Oklahoma City, OK:

University of Oklahoma Press

Rydell, Robert

1984 All the World's a Fair: Visions of Empire at American

International Expositions, 1876-1916. Chicago: The University of

Chicago Press

Sadoul, Georges

1951 Histoire générale du cinéma. Vol. 3: Le cinéma devient un art

1909-1920. Paris: Denoël

Sandberg, Marc

1995 "Effigy and Narrative: Looking into the Nineteenth-Century

Folk Museum." Leo Charney and Vanessa R. Schwartz (eds.)

Cinema and the Invention of Modern Life: 320-361

Schaeffer, Jean-Marie

1997 Les célibataires de l'art. Pour une esthétique sans mythes.

Paris: Seuil

Schatz, Thomas

1981 Hollywood Genres, Formulas, Filmmaking, and the Studio

System. Philadephia: Temple University Press

Schivelbusch, Wolfgang

$\mathbf{R}$

1986 The Railway Journey: The Industrialization of Time and Space

in the 19th Century. Berkeley: University of California Press

Schor, Naomi

B P

1987 Reading in Detail: Aesthetics and the Feminine. London:

Methuen

1992 “Cartes Postales: Representing Paris 1900." Critical Inquiry

18, 2 (Winter): 188-241

Shaw, Christopher and Malcolm Chase (eds.)

1989 The Imagined Past: History and Nostalgia. Manchester,

New York: Manchester University Press

Silverman, Kaja

B S U Z

1996 The Threshold of the Visible World. New York: Routledge

1999 World Spectators. Stanford, CA: Stanford University Press 
Singer, Ben

C O R Y

1990 "Female Power in the Serial-Queen Melodrama: The Etiology

of an Anomaly." Camera Obscura 22: 90-129

1993 "Fiction Tie-ins and Narrative Intelligibility 1911-18." Film

History V: 489-504.

2001 Melodrama and Modernity: Early Sensational Cinema and Its

Contexts. New York: Columbia University Press

Sklar, Robert

$\mathbf{X}$

1993 Film: An International History of the Medium. New York:

Harry N. Abrams

Slotkin, Richard

F K I 1992 Gunfighter Nation: The Myth of the Frontier in 2oth-Century America. New York: Atheneum

Solnit, Rebecca

2003 River of Shadows: Eadweard Muybridge and the Technological Wild West. New York: Viking Penguin

Spivak, Gayatri

1993 A Critique of Postcolonial Reason. Cambridge, MA: Harvard

University Press

Staiger, Janet

Q

1992 Interpreting Films: Studies in the Historical Reception of American

Cinema. Princeton: Princeton University Press

Stallybrass, Peter and Allon White

C

1986 The Politics and Poetics of Transgression. Ithaca, NY: Cornell

University Press

Stanfield, Peter

C OXY

1987 “The Western 1909-14: A Cast of Villains." Film History I, 2:

97-112

1997 "Cowboy's Day Off: a story of labour and leisure." Lecture

presented at the conference Back in the Saddle Again: Critical

Approaches to the Early; Western Film (Utrecht University)

2001 Hollywood, Westerns, and the 1930s: The Lost Trail. Exeter: University

of Exeter Press

Steckmesser, Kent L

1987 "Lawman and Outlaws." 119-134: A Literary History of the American

West. The Western Literature Association. See electronic sources

Steuer, Jonathan

1992 “Defining Virtual Reality: Dimensions Determining Telepresence."

Journal of Communication 42 (Autum): 73-93

Strain, Ellen

1996 “Exotic Bodies, Distant Landscapes: Touristic Viewing and 
Popularized Anthropology in the Nineteenth Century." Wide Angle 18, 2 (April): 70-100

Sturken, Marita

1997 Tangled Memories: The Vietnam War, the Aids Epidemic, and the

Politics of Remembering. Berkeley: University of California Press

Tagg, John

D

1988 The Burden of Representation: Essays on Photographies and

Histories. Minneapolis: University of Minnesota Press

Thiher, Allen

G

1984 Words in Reflection: Modern Language Theory and

Postmodern Fiction. Chicago: The University of Chicago Press

Thomas, Brook

$\mathbf{H}$

1991 The New Historicism. Princeton: Princeton University Press

Thompson, Kristin

1985 Exporting Entertainment: America in the World Film Market,

1907-34. London: BFI Publishing

Thompson, Kristin and Bordwell David

A

1983 "Linearity, Materialism and the Study of the Early American

Cinema." Wide Angle 5, 3: 4-15

Tilley, Christopher

1991 Material Culture and Text: the Art of Ambiguity. New York

and London: Routledge

1993 "Interpretation and a Poetics of the Past." Christopher Tilley

(ed.) Interpretative Archaeology. Providence, RI and Oxford:

Berg: 1-27

Todorov, Tsvetan

1984 Bakhtin: The Dialogic Principle. Translated by Wlad Godzich.

Minneapolis: University of Minnesota Press

Torgovnick, Marianna

1990 Gone Primitive: Savage Intellectuals, Modern Lives. Chicago:

The University of Chicago Press

Toulet, Emmanuelle

1991 "Cinema at the Universal Exposition, Paris, 1900."

Persistence of Vision 9: 10-36

Trachtenberg, Alan

1982 The Incorporation of America: Culture and Society in the

Gilded Age. New York: Hill \& Wang

Tsivian, Yuri

1998 Early Cinema in Russia and its Cultural Reception. Translated by Alan Bodger, edited by Richard Taylor. Chicago: The University of Chicago Press 
Turner, Frederick Jackson

1921 "The Significance of the Frontier in American History."

The Frontier in American History. New York: Henry Holt

Turner, Victor W.

1967 The Forest of Symbols: Aspects of Ndembu Ritual. Ithaca, NY:

Cornell University Press

1969 The Ritual Process: Structure and Anti-Structure. Ithaca, NY:

Cornell University Press

Uricchio, William

F P I K

1994 "“Cinema als omweg. Een nieuwe kijk op de geschiedenis van het bewegend beeld." Skrien 199: 54-57

1997a Media, Simultaneity, Convergence: Culture and Technology

in an Age of Intermediality. Inaugural Lecture. Utrecht:

Universiteit Utrecht

1997b "Aktualitäten als Bilder der Zeit." KINtop. Jahrbuch zur

Erforschung des frühen Films, 6: 43-50

1998a "The Trouble with Television." Screening the Past 4

(uploaded: September 15) http://www.latrobe.edu.au/

screeningthepast/firstrelease/firg98/WUfr4b.htm

$1998 b$ "Grensgebieden: feit, fictie en het 'picturesque' in de vroege

Western." Tijdschrift voor Literatuurwetenschap 2: 99-109

forthcoming "Storage, Simultaneity and the Media Technologies of Modernity." Jan Olsson (ed.) Allegories of Communication.

Intermedial Concerns from Cinema to the Digital Age. Berkeley:

University of California Press

Uricchio, William and Roberta E. Pearson

H OX

1993 Reframing Culture: the Case of the Vitagraph Quality Films.

Princeton: Princeton University Press

Veeser, H. Aram (ed.)

H

1989 The New Historicism. New York: Routledge

Venuti, Lawrence

$\mathbf{O}$

1995 The Translator's Invisibility: A History of Translation. London:

Routledge

1998 The Scandals of Translation: Towards an Ethics of Difference.

London: Routledge

Verhoeff, Han

1982 Les grandes tragédies de Corneille, une psycholecture. Paris:

Lettres Modernes

Verhoeff, Nanna

D L J

1999 “'Where the Real Thing Runs Rampant': Landscapes in Early Westerns." Leonardo Quaresima, Alessandra Raengo, Laura Vichi 
(eds.) La nascita dei generi cinematographici /The Birth of Film Genres: 215-227

2001a "Het Kaleidoscopische Westen." Tijdschrift voor

Mediageschiedenis (TMG) 4, I (June): 129-148

2001b "Die Bedeutung des Nationalen in den amerikanischen

Pathé-Western 1910-1914." KINtop: Jahrbuch zur Erforschungs

des frühen Films 10: 39-59

2002 "Archival Poetics." Screening the Past 14 (to be uploaded in

the Fall) http://www.latrobe.edu.au/screeningthepast/

firstrelease/firstrelease.html

Verhoeff, Nanna and Eva Warth

L P

2002 "Rhetoric of Space: Cityscape/Landscape." Historical Journal

of Film, Radio and Televison 22, 3: 245-251

Verstraten, Peter

X Y

1999 Screening Cowboys: Reading Masculinities in Westerns.

Ph.D. Dissertation, University of Amsterdam, ASCA

Vojkovic, Sasha

2001 Subjectivity in the new Hollywood cinema: fathers, sons and

other ghosts. Ph.D. Dissertation, University of Amsterdam, ASCA

Warth, Eva

K M

1999 "Moving Bodies." Tijdschrift voor Mediageschiedenis (TMG) 2, 1 (June): 142-151

Weigel, Sigrid

1996 Body-and Image-Space: Re-reading Walter Benjamin.

Translation by Georgina Paul, with Rachel McNicholl and Jeremy Gaines. New York and London: Routledge

Western Literature Association

1987 A Literary History of the American West. Out of print, see electronic sources

Whissel, Kristen

1999 "Uncle Tom, Goldilocks and the Rough Riders: Early

Cinema's Encounter With Empire." Screen 40, 4 (Winter): 384-404

White, Hayden

1973 Metahistory: The Historical Imagination in Nineteenth-Century

Europe. Baltimore: Johns Hopkins University Press

White, Richard

1991 "It's Your Misfortune and None of My Own": A New History of

the American West. Norman: University of Oklahoma Press

Williams, Alan

K

1992 Republic of Images: A History of French Filmmaking.

Cambridge, MA: Harvard University Press 
Winnicott, D.W.

1971. "Transitional Objects and Transitional Phenomena." 1-25:

Playing and Reality. New York: Basic Books

Wittgenstein, Ludwig

B E G

1963 [1953] Philosophical Investigations. Translated by G.E.M.

Anscombe. Oxford: Basil Blackwell

Wolf, Janet

1989 "The Invisible Flâneuse: Women and the Literature of Modernity." Andrew Benjamin (ed.) The Problems of Modernity: Adorno and Benjamin. New York, London: Routledge: 141-156

Worster, David

E

1992 Under Western Skies: Nature and History in the American

West. New York, Oxford: Oxford University Press

Wright, Will

C G

1975 Sixguns \& Society: A Structural Study of the Western.

Berkeley: University of California Press

York, Christopher

$\mathbf{U}$

2001 Anthropology of Nostalgia: Primitivism and the Antimodern

Vision in the American Southwest, 1880-1930. MA Thesis, MIT, Comparative Media Studies

Zielinski, Siegfried

B

1999 Audiovisions: Cinema and Television as Entr'actes in History.

Amsterdam: Amsterdam University Press 



\section{Index}

acting (style) 67-68, 75, 100, 137-138, $165,273,305,372-373$

adaptation 80, 138-139, 147, 221, $238-248,284-285$

after-effect $17,24,47,129,199,267$, 379

Nachträglichkeit 17,50

amnesia 42

anachronism, anachronistic 18-19,

23-24, 30, 43, 85, 110, 114-115, 234, $339,396,398,409$

analogy $27,119,253,284,313$

archaeology, archaeological 28-29,

$32-35,43-44,331-332,406$

archive, archival 9-19, 23-43, 111,

114, 119, 122-123, 161, 325-344, 354,

402, 405-411

archival poetics $12,26,29-42$

attractions $48,53,92,170,183-184$,

225-226, 285, 298, 309, 317-319, 352 cinema of - 183, 187, 223-226, 297

authenticity, authentic 28, 45, 58-64,

74, 91, 96-104, 111, 130-137, 150-

151, 162-166, 169, 173-174, 188-206,

210, 252, 254, 298, 310, 346-347, 366

inauthentic 23, 199

bits and pieces 14, 25-43, 106, 207, $218,297,340,416$

bricolage $32,120-121,184-185,187$

captivity (narrative) 67-69, 74-76, 80,

$83,121,142,163,167,169$

catalogue, cataloguing $25,29-30,33-$ $38,111,115,123$ censorship $377,379-381,384,387-$ 389

character-plot knot 171, 174, 392, $395-397,399,401$

chase $29-31,53,70,76,194-196,215^{-}$ $217,220-235,286-288,293,300,302$, 305, 393-394, 399

Christianity, Christian $66,69,83,87$, 109, 169, 210-211

chronology, chronological 18, 34, 73, 116, 270, 331, 409; see also religion

chronotopos 12, 363

civilized, civilization $56,68,79,123$, 127, 189-190, 319, 377

class $23,48,143,172,267,341,382$, 386,400

collection, collecting $\quad 25-26,28-29,35^{-}$ $36,43,73,263,267,326-344,346-$ $347,350-351,354,358,360,379$ colonialism, colonial $279,80,87,93$, 140, 310, 311, 329

comedy, comic, comical 47-51, 53, 57, 70, 76, 114-115, 168, 184, 201203, 226-227, 258, 270, 276-277, 281, $287,351,367-368,371,384,392,396$, 398,400

commodity, commodification 158 , 160, 191, 211, 252-253, 255-256, 259$260,267,315-316,322,333,342$ costume $61,63,68,73,79,97,99$, 109, 137-138, 167-169, 181-182, 371372,399

cross-dressing $72,170,276-279,392-$ $393,398-400,402-403$; see also transvestitism 
deconstruction, self- $23,55-58,60$, 69, 71, 79, 89, 106, 142, 190, 205, $390,393,400,402$

diachronic 42,117

dialogism 373,375

digital 12, 43-44, 98, 269, 350, 360, $405,407-408,411$

dime novel 46, 63, 97, 118, 151-153, $168,196,236-237,376,380,382-385$, 389

display 56-57, 71-73, 121-123, 225234, 252, 296-302, 326-330, 347-359 documentary, 40-41, 53, 55, 58-61, 101102, 110, 126, 141-142, 146, 186-187, $196,341,364,369$

Eastern 23, 45-52, 70, 77-95, 104, 106, 109, 215-216

education, educational 131-134, 143145, 177, 241, 326, 330, 338-340, $346-348,353-354,377,379,382,386-$ 388

elsewhen 13, 16, 191, 207, 234, 239, 310,352

elsewhere $13,16,19,97,148,191$ 192, 207, 234, 239, 251, 263-264, 310-311, 352

embody, embodiment $46-48,52,85$ $86,141-142,210-211,263,401$ entertainment $64,143,176-183,238$, 277, 329-330, 337, 339-341, 352-353, 406, 411

epistemology, epistemological 36-37, $76,85,120,192,279,329,340,342$, 404,406

ethnicity $62,99,140,161,170-171$, 400-401; see also race ethnography, ethnographic 17,27 , 55-56, 59-61, 63-64, 68, 71-74, 99, 130, 140-141, 168-169, 191, 230, 239-
240, 309-310, 319-320, 332, 340-341, $346,348-350,356-358,363-364$

Europe, European $47,53,65,71,74$, 79, 91, 94, 107, 111, 159-164, 168, 172-173, 190, 217-218, 248, 293, 311$312,314,323,326,330-301,338,352$, 373,406

exhibition $14-15,26,37,56,72,116$, $118-120,123,126,155,162,182-183$, 226, 229, 240, 280, 285-286, 290, 292, $295,326-330,334-363,408$

exotic, exoticism $48,53,61,63-65,68$, 71-73, 99, 113, 118, 151, 161, 166, 169, 183, 198, 239-241, 247, 257, 261, $263,310,317,320-322,332,338-340$, $349,356-357,406,411$

family resemblance $37-38,58,106$, 108, 120-126, 216-217, 258, 279-280 focalization $52,54,93,226,260$ fragment, fragmentation $15,23,25-$ $44,61,63,72,128,130,179,189$, 207-214, 218-219, 229, 252, 298-299, $301,303,314,317,325,328,340$, $354,358,364,371,384-395,404,406$, 409-410

frontier $15-16,19,23,57,67,76-96$, $108-114,123,125,127,134,137,142$, 144, 148, 152, 154, 180, 189-190, 241, $269,293,313,366,380$

gender $23,66,68,72,131,168,170-$ $171,234,266,276,278-279,287$, 386-387, 390-403

gender-ethnicity knot 400 genealogy $18,32-33,37,80,108,110$ global, globalization 131, 160, 322, $326,330,337-338,341-343$

Hale's Tours 226, 234, 284, 286, 290, 292, 295 
heterogeneity, heterogeneous 18,28 , $41,117,119-120,122,178,184,350$, 354

heteroglossia 366,374

historical imagination 87

historiography, historiographic 16$17,24,34,36,44,81-82,116,126$, 127-128, 129-130, 134-135, 137, 158, $164,167,173,186,190,268,325$, $329,335,365,374,405$

humor $50,51,70,72,76,171,273$, 277, 290-291, 384, 389, 399-400; see also comedy and parody

hyperconscious(ness) 50-51 self-conscious(ness) 26-27, 50, 52, $111,270,325,363,367,369,371$ hypertext, hypertextuality 9, 12, 29, $31,31,34,42-44,123,325,331,405$, 407-408, 411

hypermedia $29,43,408-410$

ideology, ideological $46,48,56,58$, $67,69-70,83,87,90,113,118,128$, 133, 144, 146, 210, 232-233, 260, 287-289, 329, 347-348, 373, 397-398, 400

ideologeme 255, 268

imperialism, imperialist $29,80,87$,

$113,118,155,315,330,357$

imperialist nostalgia 80,155

international, internationalization

15, 158-164, 169, 208, 218, 330, 338, 349

intertext, intertextuality $15,18,116-$ $121,126,137-139,185,230,234,240$, 247-248, 261, 266, 273, 275, 281, 411

kaleidoscope, kaleidoscopic 9, 19-20, 34, 178-179, 183-185, 188-189, 227, $247,258,267,247,258,267,325-326$, $359,392,394,404,409,410$ live, liveliness $15,73,105,183,242-$ $243,280,306,309,318,333,335,366$

marker $70,82,108,111,113,120$, $123,206,285$

melodrama 53,67, 96, 108, 114-115, $125,141,165,220,294,380$

metaphor, metaphorical 25-26, 2829, 32-34, 37, 42-43, 56, 59, 72, 77, 79, 81-82, 120-121, 178-179, 192, 224, 234, 263, 284, 311-313, 319, 341, $353,370,409-410$ conceptual metaphor 12, 36-37, $120,178-179,184,186,402$

methodology, methodological 25, $33,37,85,102,116-117,126,161$, $163,185,189,205,209,404,409-410$ mobility 149, 164, 167, 170-173, 263, 276, 320, 325, 341, 343, 391-394, 397-400, 406 museum, museification $55,57,68$, 71-73, 118, 148, 263, 267, 269, 309, $325-326,328,331,335,338,343$, $345-352,355-361,391,407-408,411$; see also display

music 5, 74, 183, 240, 318, 350, 353, 408

myth, mythography $13,16,25,45$, 47-48, 52-53, 79, 94, 96-97, 113, 127, 129-130, 135-136, 141-142, 145-146, 149, 151, 154-155, 179-181, 207, 239, $241,322,391,396$

Nachträglichkeit see after-effect nationalism 20, 131-136, 140-142, 146, 158, 160-162, 165, 169-173, 187, $314,316,346$

nation-ness 161-166, 169-173, 390 new media $12,31,42,218,405-412$ film as new medium $13,71,93$, 98, 105-106, 123, 132, 145, 178, 
180, 188, 229, 236-238, 242, 246, 250, 330, 348, 377, 379, 410

nonfiction $19,40,60-65,71-73,97,99$, 102, 106, 110, 122-123, 126, 178, 181-186, 190-192, 199-205, 213, 224, 228-229, 252-254, 258, 260, 262, 268, 284, 298, 300, 302, 306, 309, 316, $319-320,332,357,394,406$ nostalgia $47-48,52,80,92,118,122$, 127-128, 133, 149-150, 153-156, 181, 207, 210-211, 214, 221, 237, 241, 251, 284-285, 296, 306, 308, 310, 384 imperialist nostalgia 80,155 instant nostalgia $149-155,158$, 176, 178, 180-181, 192, 322, 340, $342,351,357,365,372$

ontology, ontological 19, 71, 76, 192, 204, 328, 331, 333 other(ness) 16, 23, 25, 48, 52, 56-59, $65,68,71,79,85-86,116,161,164$, 167, 191, 194, 205, 237, 256, 258, $356,358,377,390-391,398,411$

painting $13,18,49-50,56,68,118$, 124, 137-138, 153-154, 194, 205, 224, 251, 254-258, 261, 264, 267, 275, 280, 294, 309-310, 334, 352, 356, 404 panorama, panoramic $61,189,200$, 202-203, 212-213, 250, 256, 264, 284$285,287,294,331-332,341,349,404$ parody, parodic $49-51,99,221,229$, 270, 272-281, 351, 367-368 performance, performing $15,39,49-$ 50, 59, 61-63, 67, 101, 102, 154, 180, $182,187,196,297,299,326,333$,

$357,359,365-368,370,372,386,408$ periodization $14,21,81,83,116-117$ phantom ride 40,61, 99, 199-203, 206, 226-227, 229-230, 233, 258-259, $283,285-287,290-291,294$ photography, photographic 56, 59, $61,68,72-73,96-100,127,156,169$, $178,213,224,241,251,256,260-261$, 264-266, 309, 318, 333, 339, 341, $343-344,352,368,408$ chronophotography 178,186 picturesque 19,61,72, 90-92, 121, 150, 152, 166, 168, 187, 191-192, 198, 250-26o, 262, 264, 267-268, 310 pioneer $67,70,75,84,86-87,144$, 169, 191, 290, 392

poetry, poem $46,137,139,150,153$, $155,211,239-242,247-248,336-338$ point of view, vantage point 52,54 , $183,200,203,212,221,226,258$, 263-264, 288

postcard 59, 90-91, 160, 169, 239, 254, 256, 260-269, 280, 309-310, 317, 408

postmodern, postmodernism 11,20 , $70,76,365,373$

primitivism $76,79,90,92,94,373$ program, programming 109-123, 155, 179, 183-185, 202-203, 248, 284, $327-328,340,350,408-411$ punctual (event) 132-135, 138-142, 146

punctuated places 264, 269, 309, 318, 320

race, racial $57-58,63,68-71,87,99$, $164,168-169,287,392$

reality effect 104-105, 132-133, 198, 347 religion, religious $76,84,141,198$, 210, 257, 322; see also Christianity restoration, restoring 28-29, 111, 408 rhetoric, rhetorical 56-68, 133, 172173, 188-192, 198-206, 225, 252-253, 268,358 
self-deconstruction see deconstruction self-conscious(ness) see hyperconscious(ness)

self-reflexivity, self-reflexive 170-172, $279,363-364,368,370-371$

shifter 161, 191, 205, 253-254, 268

simulacrum 113, 125

simultaneity, simultaneous(ly) 105106, 109, 127, 148-150, 180, 237, 317, $333-334,342$

spectacle, spectacular $39-40,50-51$, 102-103, 122-123, 138, 176, 180-181, 192-193, 195, 198-200, 244-245, 293, 296-306, 309-310, 364-366

stereograph, stereoscope 261, 263, 267-269, 331

stereotype, stereotyping 168,171 , 278-279, 390-402

sublime 191, 250-258, 267-268, 310 suspense 30-31, 38-39, 225-226, 291293, 296-304

synchronicity, synchronic $13,17,20$, 114, 116-118, 129, 296, 349, 405, 409 synecdoche $37,198-199,202-204$, $252-253,258,347,358$ theater, theatrical $49-50,70,118,168$, $182,202,213,220-221,232,236,238$, $326,341,352,356,363,369,382,392$ tourist, tourism $60,90,92,150,170-$ 171, 206, 260-269, 309-322, 399-400, 406-411

transvestitism, racial or ethnic 55, 57, 167, 170; see also cross-dressing travelogue, travel film 48, 60-61, 72, 110, 122, 151, 189, 191-193, 202, 256, 258-260, 294, 308-322, 332

view aesthetic $183,206,332$ virtual travel, armchair travel 251, $257,264,306,308-309,313,316,338$ visual culture $12-15,19-20,185,191$, $263,282-283,304,347-348,405-411$

whiteness 57, 87, 172, 174

Wild West Show 50, 61, 63, 73, 118123, 356, 361-375

wilderness 78-79, 83-84, 109, 282, 309, 322

World Fair, Exhibition, Exposition $56,118,267,326,332,341-42,351-$ 358 



\section{Film Culture in Transition}

General Editor: Thomas Elsaesser

Double Trouble: Chiem van Houweninge on Writing and Filming

Thomas Elsaesser, Robert Kievit and Jan Simons (eds.)

Writing for the Medium: Television in Transition

Thomas Elsaesser, Jan Simons and Lucette Bronk (eds.)

Between Stage and Screen: Ingmar Bergman Directs

Egil Törnqvist

The Film Spectator: From Sign to Mind

Warren Buckland (ed.)

Film and the First World War

Karel Dibbets and Bert Hogenkamp (eds.)

A Second Life: German Cinema's First Decades

Thomas Elsaesser (ed.)

Fassbinder's Germany: History Identity Subject

Thomas Elsaesser

Cinema Futures: Cain, Abel or Cable? The Screen Arts in the Digital Age Thomas Elsaesser and Kay Hoffmann (eds.)

Audiovisions: Cinema and Television as Entr'Actes in History

Siegfried Zielinski

Joris Ivens and the Documentary Context

Kees Bakker (ed.)

Ibsen, Strindberg and the Intimate Theatre: Studies in TV Presentation Egil Törnqvist

The Cinema Alone: Essays on the Work of Jean-Luc Godard 1985-2000 Michael Temple and James S. Williams (eds.)

Micropolitics of Media Culture: Reading the Rhizomes of Deleuze and Guattari Patricia Pisters and Catherine M. Lord (eds.)

Malaysian Cinema, Asian Film: Border Crossings and National Cultures William van der Heide 
Film Front Weimar: Representations of the First World War in German Films of the Weimar Period (1919-1933)

Bernadette Kester

Camera Obscura, Camera Lucida: Essays in Honor of Annette Michelson Richard Allen and Malcolm Turvey (eds.)

Jean Desmet and the Early Dutch Film Trade

Ivo Blom

City of Darkness, City of Light: Émigré Filmmakers in Paris 1929-1939

Alastair Phillips

The Last Great American Picture Show: New Hollywood Cinema in the 1970s

Thomas Elsaesser, Alexander Horwath and Noel King (eds.)

Harun Farocki: Working on the Sight-Lines

Thomas Elsaesser (ed.)

Herr Lubitsch Goes to Hollywood: German and American Film after World War I

Kristin Thompson

Cinephilia: Movies, Love and Memory

Marijke de Valck and Malte Hagener (eds.)

European Cinema: Face to Face with Hollywood

Thomas Elsaesser

Hitchcock's Motifs

Michael Walker 